\title{
State and Economy in Ancient Egypt: Fiscal Vocabulary of the New Kingdom
}

\author{
Warburton, David A
}

\begin{abstract}
Combining philological investigation and theoretical reasoning, this book offers a completely new interpretation of the economic role of the state in ancient Egypt. The first part provides background outlining the relevance of Keyne's General Theory to the ancient Egyptian economy. The central part uses ancient Egyptian texts as the foundation of an analysis of words commonly assumed to relate to taxation during the New Kingdom (c. 1540-1070 B.C.E.). The conclusions summarize the philological results and explore the role of the temples in the ancient Egyptian state during the new Kingdom. The result places ancient Egyptian taxation and state economic activity in an Egyptian economy based on an analysis of primary sources. The book is thus directed at a broad audience including Egyptologists and all scholars interested in economic history in general and the political development of early antiquity in particular.
\end{abstract}

Posted at the Zurich Open Repository and Archive, University of Zurich

ZORA URL: https://doi.org/10.5167/uzh-153588

Monograph

Published Version

Originally published at:

Warburton, David A (1997). State and Economy in Ancient Egypt: Fiscal Vocabulary of the New Kingdom. Fribourg, Switzerland / Göttingen, Germany: University Press / Vandenhoeck Ruprecht. 
D. Warburton State and Economy in Ancient Egypt 


\section{ORBIS BIBLICUS ET ORIENTALIS}

Published by Othmar Keel and Christoph Uehlinger on behalf of the Biblical Institute of the University of Fribourg Switzerland, the Egyptological Seminar of the University of Basel, the Institute for Ancient Near Eastern Archaeology and Languages of the University of Berne, and the Swiss Society

for Ancient Near Eastern Studies

The author:

D. Warburton is an Egyptologist and Near Eastern Archaeologist. His numerous publications include the translation of Erik Hornung's Valley of the Kings. He has done field work in Egypt, Syria, Iraq and Yemen, and lectured on the ancient world in Europe, America, the Middle East and Africa. Since 1995 he has been instructing at the institute of Ancient Near Eastern Archaeology and Languages at the University of Berne, Switzerland. 


\section{Orbis Biblicus et Orientalis 151}

David A. Warburton

\section{State and Economy \\ in Ancient Egypt}

Fiscal Vocabulary of the New Kingdom

University Press Fribourg Switzerland Vandenhoeck \& Ruprecht Göttingen 


\section{Die Deutsche Bibliothek - CIP-Einheitsaufnahme}

\section{Warburton, David A.:}

State and economy in ancient Egypt: fiscal vocabulary of the New Kingdom / David A. Warburton. - Fribourg, Switzerland:

Univ. Press; Göttingen: Vandenhoeck und Ruprecht, 1997.

(Orbis biblicus et orientalis; bd.151)

ISBN 3-525-53787-5 (Vandenhoeck \& Ruprecht) Gb.

ISBN 3-7278-1080-7 (Ed. Univ.) Gb.

NE: GT

Publication subsidized by the Swiss Academy

of Humanities and Social Sciences

Camera-ready text

submitted by the author

(C) 1997 by University Press Fribourg Switzerland

Vandenhoeck \& Ruprecht Göttingen

Paulusdruckerei Freiburg Schweiz

ISBN 3-7278-1080-7 (University Press)

ISBN 3-525-53787-5 (Vandenhoeck \& Ruprecht)

Digitalisat erstellt durch Florina Tischhauser,

Religionswissenschaftliches Seminar, Universität Zürich 


\title{
State and Economy in Ancient Egypt
}

Fiscal Vocabulary of the New Kingdom

\author{
INAUGURALDISSERTATION \\ der PhILOSOPhISCh-HISTRORISChen FakULtät \\ DER UNIVERSITÄT BERN \\ ZUR ERLANGUNG DER DOKTORWÜRDE \\ VORGEIEGT VON \\ DAVID A. WARBURTON \\ VON TEXAS (USA)
}

University Press Fribourg SWitzerLand

VANDENHOECK \& RUPRECHT GÖTINGEN 
Von der Philosophisch-historischen Fakultät auf Antrag des Herrn Professor Dr. M. und der Herren Professoren Dr. E. Hornung und Dr. F. Junge angenommen.

Bern, den 9.2.1996

Der Dekan: Prof. Dr. J. C 


\title{
Curriculum vitae
}

\author{
Name: $\quad$ Warburton, David Alan \\ Birth El Paso Texas, USA, 18.3.1956 \\ Nationality American \\ Marriage 20.3.1986 \\ with Rahel Catherine née Ackermann
}

\section{Education}

1997 Professor at the North-Eastern University of Chang Chung, Peoples Republic of China

$1996 \quad$ PhD at the University of Bern

1981-1991 Study and Research. Egyptology, Near Eastern Archaeology, Classical Archaeology, European Pre-and Protohistory, University of Basle, Switzerland 1981 MA, Archaeology, American University of Beirut, Lebanon

1979 BA, Political Studies and Public Administration, American University of Beirut, Lebanon

1974 High School Diploma, Henry M. Gunn Senior High School, Palo Alto, California, USA

Languages (aside from English in descending order of proficiency)

Modern German; French; Arabic (various colloquial dialects)

Ancient Egyptian, Greek

\section{Professional}

1995-1996 Lecturer, Institute of Ancient Near Eastern Archaeology and languages, University of Bern, Switzerland

1995 Guest Lecturer, Carsten Niebuhr Insitute, University of Copenhagen, Denmark

1991-1994 Resident Director, American Institute for Yemeni Studies, Sana'a, Yemen

1992-1994 Bibliographic Representative in Yemen, Library of Congress, Sana'a, Yemen

1994 Special Advisor to the General Organization for Antiquities, Museums and Manuscripts, Ministry of Culture, Republic of Yemen, Sana'a, Yemen

1993 Advisor, Swiss Mission in the Old City of Sana'a, Yemen

1986-1988 Researcher, Biblical Institute, University of Fribourg, Switzerland

since 1982 Freelance Translator 

To my teachers,

Bill Ward and Erik Hornung 

What I have tried to say in this book has been so frequently misunderstood that I would like to restate my aims.

Mark Blaug, 1968

Economic Theory in Retrospect, p. xi

Taxes are a portion of the produce of the land and labour of a country, placed at the disposal of the government; and are always ultimately paid, either from the capital, or from the revenue of the country.

If the consumption of the government, when increased by the levy of additional taxes, be met either by an increased production, or by a diminished consumption on the part of the people, the taxes will fall upon revenue, and the material capital will remain unimpaired; but if there be no increased production or diminished consumption on the part of the people, the taxes will necessarily fall on capital.

In proportion as the capital of a country is diminished, its production will necessarily be diminished; and therefore, if the same expenditure on the part of the people and of the government continue, with a constantly diminishing annual reproduction, the resources of the people and the state will fall away with increasing rapidity, and diștress and ruin will follow.

David Ricardo, 1817

On the Principles of Political Economy and Taxation, pp. 186-188

Speaking broadly therefore, although it is a man's wants in the earliest stages of his development that give rise to his activities, yet afterwards each new step upwards is to be regarded as the development of new activities giving rise to new wants, rather than of new wants giving rise to new activities.

It is not true therefore that "the Theory of Consumption is the scientific basis of economics." For much that is of chief interest in the science of wants, is borrowed from the science of efforts and activities. These two supplement one another; either is incomplete without the other.

Alfred Marshall, 1920

Principles of Economics, pp. $89-90$

When involuntary unemployment exists, the marginal disutility of labour is necessarily less than the utility of the marginal product. [...] Pyramid-building, earthquakes, even wars may serve to increase wealth, if the education of our statesmen on the principles of the classical economics stands in the way of anything belter. [...] Just as wars have been the only form of large-scale loan expenditure which statesmen have thought justifiable, so gold-mining is the only pretext for digging holes in the ground which has recommended itself to bankers as sound finance; and each of these activities has played its part in progress - failing something better.

Ancient Egypt was doubly fortunate, and doubtless owed to this its fabled wealth, in that it possessed two activities, namely pyramid-building as well as the search for precious metals, the fruits of which, since they could not serve the needs of man by being consumed, did not stale with abundance.

John Maynard Keynes, 1936

General Theory of Employment, Interest and Money, pp. 129-131 



\section{TABIE OF CONTENTS}

TABLE OF CONTENTS 9

LIST OF FIGURES

PREFACE 15

A Parenthetical Note 18

PART 1

THEORETICAL Considerations

INTRODUCTION

$\begin{array}{ll}\text { Method of Presentation } & 27\end{array}$

APPROACH 30

The State 32

Concept of the State

Marx, Wittfogel and Egypt 39

State Origins and Development: Beyond Marx 44

A Near Eastern Perspective 48

A Wider Perspective: the General Theory of War, Custom and Technology 51

LEGITIMACY 57

Early Evolution of the Egyptian State

$\begin{array}{ll}\text { THE ECONOMY } & 71\end{array}$

CONSUMPTION VS. PRODUCTION

APPROACHES TO ECONOMIC HISTORY

VAlue of ECONOMIC THEORY 76

PREVIOUS USE OF THEORY

POLANYI

Price Theory and Polanyi $\quad 88$

$\begin{array}{ll}\text { Redistribution } & 92\end{array}$

Polanyi and Theory 96

Peasant Societies, Taxation, Private Property and Transactions 100

The "Theory of Comparative Advantage" 104

EgYptian ECONOMICS AND ECONOMIC CONCEPTS 100

KEYNES

$\begin{array}{lr}\text { Elaboration of Value of the Use of Keynesian Theory } & 120\end{array}$

$\begin{array}{ll}\text { Sumulary OF SAlleNt POINTS } & 128\end{array}$ 
A DISCUSSION OF THE SOURCES

INTERNal Revenue 133

Administrative texts, including School Texts or Miscellanies and letters $\quad 133$

$\begin{array}{ll}\text { Privale Propaganda } & 137\end{array}$

$\begin{array}{ll}\text { Excursus on Land Ownership } & 139\end{array}$

$\begin{array}{ll}\text { Royal Propaganda } & 140\end{array}$

FOREIGN REVENUE

$\begin{array}{ll}\text { Administralive Texts } & 141\end{array}$

$\begin{array}{ll}\text { Private Propaganda } & 141\end{array}$

$\begin{array}{ll}\text { Royal Propaganda } & 142\end{array}$

O. GARDINER 86

$\begin{array}{ll}\text { PAPYRI FraGmentS From GurOB } & 146\end{array}$

$\begin{array}{ll}\text { P. GUROB } & 140\end{array}$

P. Gurob Fragment G 149

REMARKS $\quad 150$

$\begin{array}{lr}\text { P. GREG } & 152\end{array}$

$\begin{array}{ll}\text { TRANSLATION } & 152 \\ \text { REMARKS } & 157\end{array}$

$\begin{array}{ll}\text { REMARKS } & 157\end{array}$

$\begin{array}{lr}\text { The Tax lists of the Royal Canon of Turin } & 159\end{array}$

TRANSLATION 159

$\begin{array}{ll}\text { REMARKS } & 163\end{array}$

$\begin{array}{ll}\text { ThE P. WIBBOUR } & 165\end{array}$

$\begin{array}{ll}\text { REMARKS } & 105\end{array}$

$\begin{array}{ll}\text { Text A } & 165\end{array}$

$\begin{array}{ll}\text { Text B } & 168\end{array}$

$\begin{array}{lr}\text { The Turin Taxation Papyrus } & 170\end{array}$

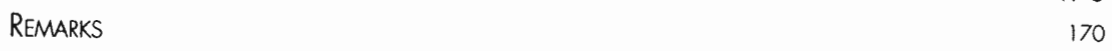

GIORNALE: P. TURIN $2009+1999 \quad 175$

$\begin{array}{ll}\text { TRANSLATION } & 175\end{array}$

$\begin{array}{ll}\text { REMARKS } & 177\end{array}$

$\begin{array}{ll}\text { INSTRUCTIONS FOR THE VIZIER } & 178\end{array}$

TRANSLATION OF EXCERPTS

REMARKS 181

$\begin{array}{lr}\text { The Bllgai Stele } & 182\end{array}$

TRANSLATION

$\begin{array}{ll}\text { REMARKS } & 184\end{array}$ 
The Rewards of the High Priest of Amun, Imn-hip

TRANSLATION

REMARKS

The Horemhab Decree

TRANSLATION OF EXCERPTS

COMMENTS

The Nauri DeCree

Translation of Excerpts

COMMENT

\section{P. HARRIS 1}

Summary of the Complete Text

TRANSLATION OF EXCERPTS

inyt

THE WORD inyt

INTERNAl ReVEnue

Administrative Texts

CONCIUSIONS

inw

THE WORD inW

INTERNAL REVENUE

Administrative Texts

Royal Propaganda

Foreign REVENUE

Administrative Texts

PREVIOUS DISCUSSIONS OF THE WORD inW

CONCLUSIONS

THE WORD bikw 
ForeIgN REVENUE 249

$\begin{array}{ll}\text { Private Propaganda } & 249\end{array}$

$\begin{array}{ll}\text { Royal Propaganda } & 249\end{array}$

PREVIOUS DISCUSSIONS OF THE WORD bikw 251

CONCIUSIONS 253

$\begin{array}{ll}\text { bikw-rmt } & 258\end{array}$

THE TERM bikw-rm! $\quad 258$

INTERNAL REVENUE

Administrative Texts 258

$\begin{array}{ll}\text { Private Propaganda } & 258\end{array}$

Royal Propaganda 259

$\begin{array}{ll}\text { CONCIUSIONS } & 259\end{array}$

$\begin{array}{ll}\text { hizat } & 261\end{array}$

$\begin{array}{ll}\text { THE WORD hiqh } & 261\end{array}$

FOREIGN REVENUE 261

$\begin{array}{ll}\text { Private Propaganda } & 261\end{array}$

Royal Proaganda 201

$\begin{array}{lr}\text { REMARKS } & 262\end{array}$

htri 263

THE WORD htri 203

INTERNAL REVENUE

Miscellanies 263

Excursus on htri and diw in the Deir el-Medineh Texts 264

$\begin{array}{ll}\text { Administrative Texts } & 268\end{array}$

$\begin{array}{ll}\text { Private Propaganda } & 269\end{array}$

$\begin{array}{ll}\text { Royal Propaganda } & 271\end{array}$

ForEIGN REVENUE

$\begin{array}{ll}\text { Private Propaganda } & 273\end{array}$

Royal Propaganda $\quad 274$

PREVIOUS DISCUSSIONS OF THE WORD htri 275

CONCIUSIONS 270

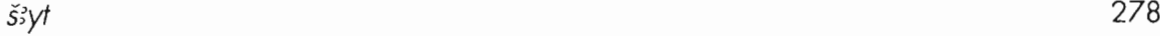

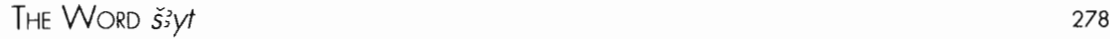

$\begin{array}{ll}\text { INTERNAL REVENUE } & 278\end{array}$

$\begin{array}{ll}\text { Administrative Texts } & 278\end{array}$

$\begin{array}{lr}\text { Private Transactions } & 279\end{array}$

$\begin{array}{ll}\text { Privale Propaganda } & 279\end{array}$

Royal Propaganda $\quad 280$

FOREIGN REVENUE

Administrative Texts 281

$\begin{array}{ll}\text { Private Propaganda } & 281\end{array}$

CONCIUSIONS 281 
šmW

THE WORD šmW 282

INTERNAL REVENUE

Administrative Texts $\quad 282$

$\begin{array}{ll}\text { Private Propaganda } & 285\end{array}$

FOREIGN REVENUE 285

$\begin{array}{ll}\text { Administrative Texts } & 285\end{array}$

Royal Propaganda 286

CONCIUSIONS 280

$\begin{array}{ll}\text { tp- } \underline{d r t} & 287\end{array}$

THE WORD tp- $\underline{d} r t \quad 287$

$\begin{array}{ll}\text { INTERNAL REVENUE } & 287\end{array}$

Administrative Texts $\quad 287$

Private Propaganda $\quad 289$

Previous Discussions of the Word 290

CONCLUSIONS 290

PART IV

CONCLUSIONS

$\begin{array}{ll}\text { PHILOLOGICAL SuMMARY } & 295\end{array}$

ECONOMIC AND INSTITUTIONAL RELATIONSHIPS 300

SUMMARY $\quad 300$

Legitimacy: State and Temple in the New Kingdom 300

REVIEW OF THE EVIDENCE 303

Construction, Administration and Prospertiy 309

TEMPLES AND GOVERNMENT $\quad 312$

$\begin{array}{lr}\text { The Egrptian State } & 314\end{array}$

$\begin{array}{ll}\text { State Income } & 319\end{array}$

Temples and Taxes 321

The Temples as Recipients of Income and as Participants in Exchange 323

Larger and Smaller Temples $\quad 325$

The Ancient Egrptian Market Economy. 326

CONCIUSIONS 335

PART V

BIBHIOGRAPHY

Bibliographical Abbreviations

$\begin{array}{ll}\text { Biblography of Articles Cited } & 355\end{array}$ 


$$
\text { Part }
$$

VI INDICES

Textual References

EGYPTIAN WORDS

Proper Names

CONVENTIONAL

TRANSCRIBED

TOPONYMS

CONVENTIONAL

TRANSCRIBED

Tombs Cited

FOREIGN WORDS

EGYPTIAN

ACCADIAN

379

Aramaic

GreEK

379

Hebrew

\section{LIST OF FIGURES}

Figure 1 The General Theory of War, Custom and Technology

Figure 2 The Keynesian Model

Figure 3 Unstimulated Low Investment in Subsistence Economy

Figure 4 The Simplified Keynesian Theory Applied to Ancient Egypt

Figure 5 The General Theory of War, Custom and Technology 
This book was originally conceived as a philological investigation of words translated as "tax" (or the like), to be accompanied by some remarks about my Keynesian interpretation of the economy. Instead, it has become a small treatise on the nature of the Egyptian economy. Realizing that the interaction of Social Science and Egyptology decisively influenced many views of the world, both ancient and modern, it was necessary to investigate the origins of some of the speculation. Thus, aside from considerations related to the philological investigation, it seemed that issues relating to the development of theoretical and historical thought also required attention. The result is that the book necessarily contains numerous arguments and discussions relating to the nature of the state and economic thought and history that reflect the development of the field, quite aside from the historical and philological details. Some of these arguments may appear dated to some. In general the discussion has been guided by an attempt to include material relevant to the understanding of the argument within the book.

Writing this book has therefore been difficult, and I have had to set limits corresponding to what I regarded as germane to the argument. Thus, some will think that I am belaboring perfectly obvious points made long ago, while others will be shocked at the brevity. I am particularly conscious that the discussion of Polanyi is long in comparison with that of Marx, yet the central role of Polanyi in the Egyptological debate dictated an imbalance, for otherwise the book would have been even longer, and the theoretical discussions would have outweighed the philological discussions to an even greater degree. Assmann's Sinngeschichte only appeared when the text of this book was complete, and both Grandet, Papyrus Harris and Römer, Priesterherrschaft after it was virtually complete. Thus the discussion of these books and the results of several unpublished dissertations from the Humboldt University have likewise not received the treatment they deserve, but this would have considerably increased the bulk of the text without having aided the argument in a significant fasion.

The selection of Egyptian texts discussed and mentioned was limited by the same criteria. I endeavoured to discuss the essential, while selecting a minimum of controversial material, and a maximum of clearly comprehensible references on which to base the argument. Although some of the texts may appear to be open to diverse interpretations, I need hardly mention that I completely omitted dozens of other references which I regarded as even less sufficiently grounded for use in an argument. Even so, in revising the text I am conscious that the translations provide fertile ground for criticism. I realized however that further struggle with my limited abilities would probably leave roughly the same scope for criticism, and that it would be wiser to recognize that regardless of my efforts, the grammatical experts would have something "to tilt at" as Sir Alan put it. I hope that better renderings will result, but also that some critics will realise that the book is not merely a peculiar collection of quotes and translations but actually a single long argument. 
Although this book betrays my iconoclastic inclinations, I am very conscious that it owes more to others than can be imagined. It is inconceivable that anyone could even begin to try to understand the economics of ancient Egypt and attempt a work of this type without the fundamental basis built up by Sir Alan Gardiner and Prof. Jaroslav Černý in countless smaller and larger works. The author has been conscious on a daily basis of his complete dependence upon these two giants, especially as Dr. J. Málek at the Griffith Institute generously helped me to browse through Černý's Notebooks and had a number of photocopies of various texts made.

While Gardiner and Černý accomplished the groundwork that serves as a basis, I invariably found wherever I went, Prof. Dr. Wolfgang Helck had already been there, usually with a clever analysis, and usually accompanied by Prof. Dr. J. J. Janssen with a divergent interpretation. Drs. E. Bleiberg and R. Müller-Wollermann likewise covered the same ground, and thus paved my way. On the other hand, I frequently encountered conclusions that had been reached by others before I had arrived at a similar point without being aware of their efforts. Among these latter, the most important were undoubtedly the works of Drs. M. Römer and C. Eyre. The substantial contributions of many others have likewise contributed to my understanding or provoked unexpected trains of thought. Without all of these major contributions I would not be in a position to even begin to organize the data or grasp the tasks.

On a completely different level, the works of Fernand Braudel have gone uncited, but readers will sense the role that the law of the "Extension of the Existing" (Erweiterung des Bestehenden) played in prolonging the longue durée of incipient capitalism.

Quite apart from the written sources, a number of people heard me out patiently while I tried to explain this interpretation, and their disbelief or dogged questioning led me to repeatedly revise my logic as well as the theoretical presentation of the form of the economy, and I should thank all those beginning with Prof. Dr. E. Blumenthal and the people at the SÄK in 1989. I am also particularly grateful to Prof. Dr. J. Assmann for having arranged for my lecture at the Seminar at Heidelberg, and equally appreciative of Prof. Dr. W. Schenkel's agreement to provide myself and Dr. Müller-Wollermann with an ideal platform at the University of Tübingen. Aside from my students at the University of Berne, I would thus also like to thank all those students and scholars at the Institutes in Tübingen, Basle and Heidelberg, as well as those at the Dept. of Near Eastern Studies in Berkeley, the Oriental Institute in Chicago, and the Carsten Niebuhr Institute in Copenhagen for having been interested enough to have expressed their criticism, as it has doubtless improved the presentation, even if many of the critical readers will not be satisfied with the new improved version.

In Berlin and Șanä'a Fr. A. Würth was not only tolerant and generous with advice, but also made herself outrageously indispensable. 
Likewise outside of the Egyptological world, Prof. Dr. J. Bæck Simonsen, Dr. J. Eidem, Prof. Dr. M. Larsen and Prof. Dr. I. Thuesen generously opened up the doors of the Carsten Niebuhr Institute at the University of Copenhagen. They provided a luxurious intellectual environment for a retired "Yemen-xpert", permitting both the use of their facilities to complete this work, and the chance to dismay and mystify them and their students with my theories. The Librarian Fr. A. Zeeberg accomplished wonders. It was in the wonderful atmosphere of that institution that this text was conjured up.

Prof. Dr. J. J. Janssen read parts of the philological study at one of the draught stages and made extensive noles, being generous with references and advice.

For many years Prof. Dr. E. Hornung and Dr. E. Staehelin made the Egyptological Seminar at the University of Basle my scholarly home, and I cannot possibly express my appreciation for the fashion in which they welcomed me and broadened my horizons. Although the subject matter was never close to his heart, Prof. Hornung's support never wavered.

Markus Wäller generously welcomed me at the Institute of Ancient Near Eastern Archaeology and languages at the University of Berne, and I cannot thank him enough for finding ways where I thought that all was barred. The willingness of Prof. Dr. F. Junge to take up the task of critically and carefully reading - at short notice - one of the more exotic things that will have crossed his desk was decisive. I owe him my thanks for his consent to do so, and if the revised version is comprehensible, this can be traced back to Prof. Junge's critical observations. This text is basically a slightly revised version of that dissertation submitted to the Philosophical-Historical Faculty of the University of Berne in 1995, and accepted by the facully on the recommendation of Profs. Hornung, Junge and Wäfler.

The Institute of Ancient Near Eastern Archaeology and Languages at the University of Berne is responsible for the final form of the text. The actual workload fell upon the shoulders of Mr. D. Dall'Agnolo. I doubt that any author has ever received such indulgent treatment in the production of his first book.

In the course of all this work, one fundamental truth has been repeatedly demonstrated: "Seek and ye shall find!". If you look for taxes, you find them everywhere. I hope that I have distinguished the wheat from the chaff to some extent. If so, the inspiration of my grandfathers Clark Warburton, the economist, and Walter Dorn, the historian, may have played a useful role in the creation of this essay in economic history. Bill Ward pushed me critically and relentlessly onwards, and, with Erik Hornung, made it possible.

The unfortunate failings are all mine.

May 1995

April 1996

Carsten Niebuhr Institute Staatsbibliothek

Copenhagen

Berlin 


\section{A Parenthetical Note}

According to the Shorter Oxford English Dictionary, FISCAL means "of or pertaining to the treasury of a state or prince".

The Egyptian NeW KInGDom (Dynasties XVIII to XX), dates to c. 1550 B.C. - 1070 B.C. Regardless of the calendar years when the New Kingdom began and ended, the conquests which marked its beginning inadvertently led to the beginning of the Late Bronze Age in Palestine, but the Iron Age had already begun before its decline was complete. Because of the conquests in Western Asia and Africa the Period can also be termed the EMPiRE. Part of the Syrian coast which they conquered is now known as Palestine, but parts of it were called Canaan when they visited (and only became Palestine because of their failure to ward off the Philistines), and other inland areas they called RINW. Their northern military expansion was brought to a halt, first by Mitanni, which they called Nahrain, and then by the Anatolian Hittites, which they called HATTI. They learnt to respect both Hatti and Mitanni, having made both love and war with them, before both disappeared from the face of the earth, leaving Egypt the only surviving Mediterranean power. The Egyptians called various parts of Nubia in southern Egypt and the present day Sudan whence they acquired gold and other desirables CUSH and W3 $W_{3}^{3}$. They established their rule there during the early part of Dynasty XVIII and retained control almost until the end of Dynasty XX. They also maintained trade relations with another distant land on the Red Sea, which they called PUNT, and which has never since been found.

The empire was lost by the latest of the many kings of Dynasties XIX and XX named Ramesses who gave their name to the Late New Kingdom or the Ramesside Period. Despite disagreement over some chronological details, the longest ruling Pharaoh of the period is the one whose dates are firm: Ramesses II began his glorious rule in 1279 B.C., praised himself endlessly for having suffered a humiliating defeat at the hands of Hatti in 1274 B.C., made peace with Hatti C. 1258, got married to a Hatti Princess in C. 1245 B.C., and disappeared into his tomb in 1213 or 1212 B.C. Due to illicit activities in the necropolis his burial was renewed in 1075 B.C., at the very close of the period.

Under the circumstances, where necessary, dates are thus expressed in terms of reigns, dynasties and kingdoms because the actual calendar year dates are by no means generally agreed upon, so that even if it is now (relatively) certain that the battle of Kadesh took place in 1274 B.C., one can also read that it happened in 1285 , or in another context another date, from sources dating to periods before our understanding of the chronology had reached its present level. But it took place in the Regnal Year 5 of the Reign of Ramesses II, the third king of the Dynasty XIX, of the New Kingdom.

Ramesses II was not the only king of that name, and the reburial initiated by the High Priest of AMONRASONTHER Herihor in 1075 B.C. actually took place during the reign of the last Ramesside Pharaoh, Ramesses XI. In the course of the following work we will constantly be referring to the Papyrus Wilbour (P. WIIBOUR) which dates to the reign of Ramesses V, and to the Papyrus Harris (P. HARRIS I) which dates to the reign of Ramesses III. Both documients 
are mentioned and discussed in the text, but is not superfluous to note that $P$. Wilbour is a cadaster survey of lands in Middle Egypt, and P. Harris a list of gifts to the temples during the reign of Ramesses III. The death of Ramesses III took place roughly a decade or so before that of Ramesses $V$, which can be dated to just after the middle of the 12th century B.C. The rulers of the Late New Kingdom followed a tradition going back more than two millennia, for the earliest kings of Egypt must have been leaders of clans during the fourth or fifth millennia, terminating the Pre-Dynastic Period with Dynasty $O$ or Negada III, and leading into the EARLY DYNASTIC or ARChaIC PERIOD (Dynasties III) at the beginning of the third millennium B.C. With Dynasty III, the OID KINGDOM (Dynasties III-VIII) is said to appear, and the structures are generally agreed to be those which can be equated with a powerful centralized state, whatever may be said of what preceded.

The MIDdie KINGDOM (Dynasties XI-XIII) is sandwiched between the FIRST (Dynasties IX-X) and Second INTermediate Periods (Dynasties XIV-XVII) which followed the fall of the Old Kingdom and preceded the appearance of the New Kingdom. It is generally agreed that state and government responsibility were divided during both periods, but it is less clear whether the First Intermediate Period witnessed a higher degree of prosperity than the Second, although both were clearly less glorious than the periods denoted as Kingdoms, which are usually characterized by periods of strong central state control.

Returning to the New Kingdom, a great deal of the material from the village of DEIR ELMEDINEH has a bearing on this work. The members of the GANG that excavated and decorated the New Kingdom Royal Tombs (in the Valley of the Kings) lived in the village. The place where they worked is called the $\mathrm{hr}$ and this has been translated as TOMB or NECROPOIIS. When the term "tomb" appears in the text of this volume with reference to income, employment, etc. in Deir el-Medineh, it can generally be stated that this is shorthand for The Great and Noble Tomb of Millions of Years of Pharaoh (LIP!H!) on the West of Thebes which means something like "The Organization Responsible for the Royal Tomb" or "The Organization of the Necropolis". Whether the Egyptians actually used the term with the same meaning at all times has not been demonstrated. ("Deir el-Medineh" is an anglicized spelling of the French transliteration of the Arabic term for the place, and has nothing to do with the Pharaonic name).

Another important institution of the Ramesside Period was the "House of Amun-Rec, King of the Gods". The Greek rendering of the Egyptian for the name of this god and his epithet (Imn-R', nsw ntrw) was Amonrasonther. The Egyptian word "House" also meant "Temple", but in this particular context, it is translated here as "Estate", and the "EstATE OF AMUN" was one of the most important central official fiscal institutions during the Late New Kingdom. His temple is, of course, the one called Karnak today.

While the temples were each under the direct control of a High Priest, of Amun at Thebes (HPA), and of Ptah at Memphis, they had armies of bureaucrats (translated as "SCRIBE" in this work) at their command; a great deal of the actual work was delegated to authorities called $r w \underline{d} w$, translated as "agents" or "CONTROLIERS". The actual work in the fields must have been supervised by ihwly's, translated "CUITIVATORS", and the work carried out by the peasants, occasionally referred to as "cultivators" as well, but generally termed men, meaning "men 
without a title", the most despicable situation known to the ancient Egyptian. These are not the same as the nmhw or "private people", but the relationship is not clear, although the $n m h w$ seemed to have owed obligations to the Pharaoh and the temples. It is probable that the temple apparatus benefited from the smdt ("SERFS"), a social designation identifying people obliged to fulfill obligations of various kinds, and that they were awarded titles as a result of their specific misfortune, e.g. "Water Carrier" or "Wood Cutter". The extent to which they were attached to individuals or the king is less clear.

The Egyptians harvested fields measured in st? 3 t. The sț ${ }^{3} t$ is usually rendered with the Greek AROURA, and is $2,735 \mathrm{~m}^{2}$. The harvest was measured in KHAR, meaning literally "sack", a measure equivalent to roughly 75 litres. In the New Kingdom, the khar consisted of four quadruple hq3t, each quadruple hq3t also being termed an OIPE (ipt). (In the GraecoRoman world, the aroura remained the same but the standard measure was an artaba, of slightly more than $1 / 2$ khar, or c. 40 litres.)

Having been harvested, and turned over to the central authorities, and issued to the recipients, a KHAR became a unit of value, and thus a measure of income and exchange. Not having currency, the Egyptians used several units of value, another being a DEBEN. The khar as a unit of value usually referred to a khar of barley, and was generally worth 2 deben. The deben was however not a currency, but a weight of c. 91 grammes. Copper deben are usually measured in wholes or halves, but silver and gold deben were measured in fractions equal to the tenth part of a deben, called KITE. There was a more or less stable ratio between the value of gold:silver:copper, set at 1:2:200 during the first part of the New Kingdom and towards the beginning of Dynasty $X X$ at 1:2:120. A four metre roll of papyrus could be purchased for 2 copper deben, equivalent to about 10-20 per cent. of a workman's monthly wage, or about the same price as a pair of sandals.

To the maximum extent possible, I tried to keep the main text in English. In the notes, I have been less consistent, occasionally translating and occasionally citing the original language. In rendering Egyptian names and toponyms, I have tried to follow a system enabling the reader to recognize the individual referred to, by remaining as close to the Egyptian as possible (e.g., Imn-htp, Mr-wr) or using a familiar form (e.g., Amenophis III, Memphis) whichever seemed most suitable.

The correct transcription of Arabic place names is a constant source of exasperation, and I do not believe that the problem can be solved in a manner at once satisfactory to all scholars and user-friendly. Familiar place names are left recognizable.

The Bibliographical Abbreviations at the close of this volume is an alphabetical list of all the monographs, collective works, serials, encyclopedias, and all relevant bibliographical abbreviations, etc. cited in abbreviated form in the text of the book.

The Bibliography of Articles is a list of the articles cited in the book, listed alphabetically according to author. Articles cited from the Reallexikon der Assyriologie (RLA), Lexikon der Ägyptologie $(L \ddot{A})$ and the Cambridge Ancient History $(C A H)$ have not been listed there.

Neither bibliography lays claim to being a comprehensive survey of Egyptological or Economic thought as only those works cited in this book are listed, and many other articles and books influenced my thinking but did not find their way into the footnotes. 


\section{Conventions}
A.D.
Common Era dates
B.C.
Before Common Era
c.
cf.
e.g.
f.; ff.
roughly
i.e.
infra
I.; II.
$\mathrm{mc}$
see
for example
following, singular and plural
in other words
below (this book)
line; lines
measure of corn, where units uncertain foipe or khan

LIP!H!

n.; nn.

N.B.

p.; pp.

p.a.

pl.; pls.

"Life! Prosperity! Health!", phrase following names of revered individuals

note; notes

rto.

don't forget

page; pages

annually

plate; plates

recto: for papyrus, the technical meaning; for ostraca the beginning of the text

supra

above (this book)

s.v.

look under

vs.

against

vso.

verso: complementary to above for recto

KRI I: 47,5

text on line 5 of page 47 of volume 1 of $K R I$.

$(2,1)$ or 2,1

line 1 of page 2 of text in original

(river)

[Osiris]

logical clarification of text which may have been understood

clarification which is not in text

textual loss

textual ornission

$[\ldots]$

substantial portion of text omitted

[...Textual Omission...]

[...Guarantees...]

clarification or summary accompanied by textual omission

[<khar oipe $>]$

suggested restoration, based on signs visible in text or external criteria, usually uncertain

[khar/oipe]

restoration, uncertain

[(khar oipe? $)]$

speculative restoration

(2)

doubt about lext or meaning of word

$\underline{20}$

written in red, used to designate important information (e.g. dates, totals, etc.), and emmer in economic texts 

PART 1

Theoretical Considerations 



\section{INTRODUCTION}

The explicit object of this study is an analysis of lexical aspects of the input-side of the Egyptian fiscal system in the New Kingdom. Fiscal activity is basically state involvement in the economy and thus such a study must be accompanied by an attempt to identify the political and economic context of the words, while pursuing the purely philological object of identifying semantic meanings. Although the world of the ancient Near East did not use concepts like "economy" and "state", modern scholars do, with the result that unconscious interpretation clouds our understanding of objectively philological questions. This required a theoretical discussion which is intended to be no more than an elaborate description of the processes involved, which are among the most interesting in human history. This work is thus an endeavour to break down the barriers to modern economic and political analysis as applied to an early human civilization, while keeping to the philological evidence.

One of the signal accomplishments of the ancient Middle East was the creation of the state, a political entity that had never before existed. The pre-conditions for the emergence of states were created as a result of the economic effects of the Neolithic, as - according to current political understanding - hunters and gatherers did not form states. The effect of sedentarization was the ability to store wealth, and the evolution of social relationships reflecting the distribution of wealth, rather than, e.g., fertility or hunting prowess. This is one of the least well understood developments in human history, and yet one of the most important. There can however be no question but that the emergence of states in the ancient Near East led immediately to the creation of additional wealth, and of an order of magnitude completely incomparable to what had existed prior to their appearance. Obviously the state played a role in the creation of wealth, and an examination of this issue is imperative, if one is to come closer to appreciating the evolution of human society, which is the ultimate goal of the social sciences. The goal of understanding this can only be achieved by the examination of texts relating to economic policies in the ancient world. While it would be desirable in the long term to grasp the economic policies of the earliest periods of state formation, this goal is at present virtually unattainable, as despite the great deal of data available, it is difficult to understand and analyze. Therefore, the more readily comprehensible world of the second millennium B.C. must serve as the initial vehicle of approach, in order to establish a theoretical framework for the understanding of the role of the state in the economy of the ancient Near East.

In an endeavour to approach the fiscal policies of the world of the second millennium B.C., material from both Egypt and Mesopotamia is available, and the data from Mesopotamia more complete than that of Egypt. Yet the sheer abundance of the material makes it difficult to achieve an overview of potential changes within the system - and there were many contrasts, as Mesopotamian civilization was not a continuum. 'It was thus decided that the

1 Cf., e.g., Gibson/Biggs, Power, Schneider, Kulturwirtschaft, Postgate, Taxation and Ellis, Agriculture, for attempts at various aspects of the problem. 
attempt to study fiscal policy begin with ancient Egypt and proceed to Mesopotamia at another stage. This will allow comparisons to be made not only between the evolving and disparate systems of Mesopotamia, but also between those systems and Egypt.

There have been several attempts to deal with various features of the Egyptian economy and its overall organization but we still continue to stumble over numerous problems because this economy is so very different not only from our own, but from the contemporary economies of western Asia, and those economists who have approached the economy have been obliged to use the completely inadequate textual material offered by Egyptologists in order to aid us in developing a theory of the economy. This remark is not intended as criticism of Egyptological endeavors in making the textual material accessible, as some of the greatest have made significant efforts.

One major problem is the evidence itself. The Egyptians were not particularly fascinated by economic systems, and thus explicit references to economic problems are not a feature to be encountered frequently in the literature as it is preserved. ${ }^{2}$ Their main concern was that the economy functioned properly, and they waxed eloquent when it did not (cf. Ipw-wr), ${ }^{3}$ or praised their efforts in a general fashion when it did, or at least when they could get away with claiming it did (cf., e.g., the inscription of the High Priest of Amun, Imn-h.p). ${ }^{4}$ The modern student is more concerned with the routine functioning of an economy which produced some of the greatest architectural, artistic, literary and religious creations known to mankind. While admitting that the Egyptians may not have had a concept of economy as such, their economic system did function.

Not only did the Egyptians not write economic discourses, but they also erased the records from account papyri when the figures were no longer important. Thus, much information was already lost three or four millennia ago. Much of what may have survived was lost in the intervening centuries, and a good deal of what remains has been read and understood by only a handful of scholars, the foremost of whom were Sir Alan Gardiner and Prof. Jaroslav Cerný, who were unfortunately not particularly interested in the workings of the Egyptian economy. Our understanding of the documents is considerably impaired as the Egyptians used the terms and figures being fully conscious of their significance, without finding it necessary to make them comprehensible to third parties who were not involved. Original documents and economically oriented translations are thus in short supply. ${ }^{5}$

Another major problem is that debate about the nature of the ancient Egyptian economy began rather late in the history of Egyptology, but long after Egyptologists began to make unconscious assumptions and to borrow from other fields without considering the premises upon which they were unconsciously speculating. Recent decades have seen the emergence of a secondary literature concerning the economy, but our understanding of the economy is still dogged by several serious problems.

\footnotetext{
In contrast, e.g., to the Greeks and the Romans.

Gardiner, Admonitions.

Cf. e.g., infra, pp. $186 f$.

W. Helck's Materialien are the major exception, but the material is offered more in the form of a collection of elements from texts, which is neither philological nor economic in orientation.
} 
One aspect of these problems is a failure to understand the texts, not merely for philological, but also for theoretical and statistical reasons. Were it possible to make a rough estimate of per capita GNP for, e.g., Regnal Year 5 of Seti I, it might have proved valuable to study every single document relating to the economy during, e.g., Dynasty XIX, placing the emphasis on the actual figures used, working with statistics rather than vocabulary. As however we are unable to estimate the population of ancient Egypt, or even the relative importance of the various types of economic activity, working with inadequate statistics would not serve a useful purpose at the moment. As the point of departure, the principal elements of the system were thus sought by traditional philological means: the examination of texts, with a view to grasping their significance.

Another aspect of this discussion is the fact that a series of questions have been posed, and yet the solutions proposed have frequently been erected on the basis of assumptions which were insufficiently examined. In this particular study, the goal is to clear up the understanding, by making explicit statements about economic and political theory, as well as interpreting the texts. Previous discussions about the economy of ancient Egypt have been dominated by conscious and unconscious assumptions about features such as price formation, grain production, private property, redistribution, temple taxation, temple economies, and economic theory, without giving equal attention to both the evidence and the entire train of thought implied by the question and the answer.

The principal element of the approach here is the attempt to define the objects of study, and to identify where interpretation begins. The object of this project is not to force categories on the Egyptians, nor to mold the categories according to the Egyptian context, but to identify the features which enable an interpretation which is at once appropriate and illuminating. Throughout, an effort has been made to identify and explicitly state the basis upon which assumptions are made and conclusions drawn.

\section{Method of Presentation}

Although the goal was primarily political and economic, this study commenced with the intention of reviewing the vocabulary of the fiscal system of the New Kingdom, and its final form corresponds to the original intent. A search through the literature, (Urk. IV, KRI, published ostraca, the Černý Notebooks, etc.) revealed that a couple of hundred texts used one

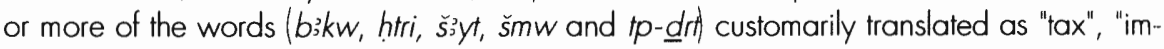
post", "duties", "deliveries", "obligations", "tribute", "booty", etc. ${ }^{6}$ There were also some texts referring to transactions of some kind, which appeared to be official in nature, but failed to employ one of the words in question. Most were simple texts of a couple of lines which did not produce very much information, and could only be understood by inference, drawing on

- Identified and discussed by, e.g., W. Helck, "Abgaben und Steuern," LÄl: 3-12; \}. J. Janssen, "Prolegomena to the Study of Egypt's Economic History during the New Kingdom," SAK 3 (1975): 173-177; Römer, Priesterherrschaft, pp. 372-411. 
information gleaned from longer texts. Of the longer texts, excerpts of some 80 were translated anew, with a view to understanding the workings of the economy.

Originally the choice of words was restricted to b3kw, htri, šmw, šsyt and tp- $\underline{d} r t$. It rapidly transpired however that other words such as inw, inyt, hist, hrp and hrt appeared in the same contexts as these, with parallel, but not identical meanings. Of these hisqt, hrp and hrt were frequent in public texts but not administrative documents, and the latter two did not appear frequently in the Ramesside material, so that they have basically been disregarded here, hrit being translated loosely as "obligation(s)" or "requirement(s)" where it was encountered in texts using one of the other terms. As one reason for excluding inw was that it had been treated extensively before I began this project, ${ }^{7}$ but $b 3{ }^{3} k w$ was thoroughly discussed while doing the project, and it nevertheless remains, it was concluded that it was logical to make a few observations about inw in a general fashion as well. hiat has been treated briefly, as it would appear that the word changed its meaning slightly, and the discourse on $t p-\underline{d} t$ was destined to be equally brief in any case. The selection thus covers most of the relevant terminology for the understanding of the fiscal process, as far as this is preserved.

This point of departure is based on the assumption that it would be impossible to make a philological and economic investigation of fiscal activity without setting specific limits. The inclusion of iconographical material from tombs, and general discussions about the potential meaning of some significant texts might well have added considerably to the general perspective of the study, but any conclusions drawn would necessarily be based upon assumptions which would inevitably render the logic circular in nature, and therefore have ultimately defeated the purpose of the study. It is difficult enough to understand the texts, without making speculative hypotheses the very basis of the study.

Presenting this material with the express goal of studying the Egyptian economy was not simple. It would have been possible to select one of the longer texts, e.g., the Bilgai Stele, the Nauri Decree or the Papyrus Harris, and used this as the basis for a lengthy commentary. This would however have involved a great deal of extraneous material, and not necessarily have achieved the object. ${ }^{8}$ It would also have been possible to simply have chapters on "Income Tax," "Wealth Tax", "Corvée Labour", "Tariffs", etc. Even if this were possible, it would have given the conclusions an unwarranted aura of certainty, and conveyed the misleading impression that the ancient Egyptian economy was somehow comparable to that of mediaeval or modern Europe, while rendering it less accessible to the Egyptological audience. ${ }^{9}$

7 Gordon, inw

8 At the time that these words were written the author was unaware of Grandet, Papyrus Harris, but this work illustrates the problem, for even in a study as monumental as Grandet's, there was room for little more than the most parenthetical notes about tax vocabulary.

- I have nevertheless maintained the goal throughout of at least identifying words in English which correspond to the Egyptian words discussed. The intention is thus not to deliberately obfuscate by asserting that the Egyptian world was so foreign from our own that we should always find some meaningless word which matches the potential significance of the word, or not even try to find one, but to identify several words to correspond to an Egyptian one, if this is necessary. The goal is understanding, not to force the Egyptian into the mold of our categories, but to try to get the nuances while being able to improve our translations. 
It was thus deemed appropriate to organize the material according to the words themselves, rather than concepts or documents. The words appear however in documents and treating each documentary source under each lexical heading would inevitably involve a considerable amount of repetition, as the same text occasionally uses several of the terms. Although a certain amount of repetition is inevitable, this is marginally reduced by adducing excerpts or summaries of the salient points of certain texts which would otherwise have to be cited constantly, and this part of the work precedes the discussions of the words. Some of this translation is new, some follows in the tracks of others, but as Sir Alan Gardiner and his memory admonish us: we must translate texts, if only to give "the critics something to tilt at". Due to the nature of the project, the words which are the object of this study have been left untranslated in these translations. The core of the work is intended however to be the chapters on the words themselves, as the documents are only a tool for studying the words. The listing of references in each chapter is not comprehensive, as there are many cases where the interpretation of the data is either doubiful or particularly open to debate. Only those cases where the word appeared to have been used in a fiscal sense which was potentially elucidating have been used. ${ }^{10}$ As the documents themselves are not all of the same nature, they have been classified into several broad categories, and each chapter is divided roughly as follows:

\section{INTERNAL REVENUE}

Texts referring to sources of income generated from within Egypt.

\section{- Administrative texts.}

This category includes account papyri and letters and judicial records, but also the school texts. The school texts will have used the words in the conventional manner and thus be philologically relevant if statistically unreliable. It is also not invariably possible to identify a school text as such with certainty. "I

- Private Transactions

Occasionally private commercial transactions will use words with a technical meaning which may or may not be the same as the technical meaning of the administrative documents. Oracles do not figure very frequently, but for the Ramesside Period, the texts will have used the terms as they were used in daily life, and thus reflect their use in the administrative domain, but concern private affairs.

- Private Propaganda ${ }^{12}$

In this category are inscriptions by private persons in their tombs, or on statues or stelae, or on ostraca or papyri. If the text appears to have been written such that the information

10 And the astute reader will be disappointed at the lack of certainty in many instances.

"W. Helck and K. A. Kitchen regard, e.g., H.O.81-82 (O. Gard. 86, infra, pp. 143-145) as an historical text, while Sir Alan Gardiner and the present writer assume it to have been a school text.

12 The word "propaganda" is used cautiously, due to the absence of a truly suitable term, merely to emphasize the "public" nature of the texts, although using the latter word would suggest conclusions which are unwarranted and misleading. R. Müller-Wollermann ("Ein Tribut an die Methode," GM 77 [1984]: 52-53) tried to define categories using "religion", "politics" and "art". Since these are obviously subjective and not mutually exclusive, they are not very useful. It is an extremely complicated problem to identify useful textual categories which can be termed both objective and mutually exclusive. 
contained in it was preserved not as a matter of convenience - such as letters, notes, commercial records - but to provide information to a broader public, it was included in this category. That the concepts of "truth in advertising" or "honesty in politics" were not within the domains of the goddess Maat should be clear to the Egyptological reader.

- Royal Propaganda

This category uses royal inscriptions of virtually any kind which appear to have served to publicize the content of the text, and the aggrandizement of the benefactor of the Egyptian people and their gods.

\section{FOREIGN REVENUE}

Texts from within Egypt or outside the country, referring to sources of income from outside the borders of Egypt proper, with the same internal categories (administration and propaganda) where applicable.

The same order is maintained both for the presentation of the documentation, and the interpretation of the texts, but the less complicated texts are merely inserted into the discussions of the words, so that these texts do not appear in the presentation of the documentary sources, as this part of the work is intended only to facilitate understanding of the discussion of the various words. This means that certain categories are not present in every chapter as the evidence has not been deemed sufficient to include it, but it was considered completely inappropriate to add a note that any given calegory was not relevant, for a given word, as this would lend the appearance of certainty to a very uncertain matter. Within each category, the texts are organized more or less in chronological order, but where it was deemed useful to present the material from several texts which enhance the understanding of the text in question, these break the chronological framework. The implicit assumption throughout is that the terms used retained more or less the same meaning during the New Kingdom. Paucity of evidence is the main basis for this assumption. It should be borne in mind that some nuances of meaning discussed could potentially be ascribed to a chronological or administrative change in the meaning. This could equally easily reflect the disparate unrepresentative nature of the sources, and thus an attempt to draw ambitious chronological conclusions would be bold. It should be clear that seemingly objective interpretations frequently implicitly draw chronological conclusions based on comparisons of e.g., Dynasty XVIII inscriptions and Ramesside administrative texts. Since Dynasty XVIII administrative texts are scarce and Ramesside tombs were primarily decorated with religious texts, comparing the two means using completely different and incompatible textual categories as the basis of chronological conclusions, which is methodologically unsound. ${ }^{13}$

\section{APPROACH}

It will be argued in this work that economics is concerned equally with the production and allocation of wealth rather than merely its distribution, and that state fiscal policy - primarily

13 Those familiar with the material can naturally read the relative chronological position of the various texts from the citations, as KRI and Urk. IV have been cited wherever possible. 
in the form of "taxation" - was the major generator of wealth in ancient Egypt. The earliest fiscal policy was necessarily based on skimming off the cream produced by a minimal level of private economic participation, and this minimal level was subsequently raised by the very state investment which stimulated surplus production in a fashion similar to taxation. In order to study the philological and economic aspects of fiscal policy it is thus necessary to cursorily review discussions about economic theory and the nature of the state.

Before turning to the evidence it has therefore been deemed suitable to establish just what we can understand of the Egyptian state and the economy, so that after reviewing the evidence, conclusions are drawn concerning the interpretation of the material. The introductory chapters altempt to discuss the meaning of the state in Egypt and Egyptology, and to discuss prevailing assumptions about the economy. Efforts to study and understand the state have revealed that there is no general agreement about what is meant by the term "state". While political scientists seemingly dismiss the possibility of using the modern term state to describe the ancient phenomenon, those dealing with the ancient world do not share this attitude. On the other hand, there is a growing consensus that the economy of ancient Egypt can be understood by neglecting modern economic theory, and this is disputed in this work. It is argued that the fiscal system as a whole was the expression of extensive state involvement in the economy, and that this was generally beneficial. The presentation of the philological evidence follows, and the conclusions attempt to resume that argument in so far the evidence allows. The conclusions are thus not merely philological but also institutional in character and the details permit us to recognize that the institutional position of the temples by the end of the New Kingdom was a structural anomaly, and it is argued that purely administrative problems were exacerbated by the monetarization of the fiscal system, and that this was detrimental. The evidence of fiscal activity does however also indicate that ancient Egypt cannot be understood as either a redistribution or a command economy, and that it has features characteristic of a market economy. The point of departure must then be the state, as fiscal policy represents state intervention in the economy. 


\section{The State}

W. Helck concluded that the ancient Egyptian language did not have a word for "state", and went on to remark that even as late as the New Kingdom, the Crown lands were the state lands. ${ }^{14} \mathrm{~J}$. J. Janssen suggests that on occasion, the words "Pharaoh" ( $p r^{-}{ }^{5}$, $)$ and "King" or "Kingship" (nswt) should be rendered as "state". ${ }^{15}$ Yet Janssen also suggests that the temples were part of the state, and agreeing with $\mathrm{O}^{\prime} \mathrm{Connor},{ }^{16}$ even advocates that the temples should actually be aligned as part of the government, ${ }_{17}$ not just part of the state. E. Bleiberg has endeavoured to demonstrate a clear distinction between royal income associated with the person of the $\mathrm{king}^{18}$ as opposed to a "wider redistributive system"19 of a "temple-centered economy", ${ }^{20}$ assuming that "Goods were collected by the temple for eventual redistribution to the people," expressing this as a fact which did not require a reference. ${ }^{21}$ D. Lorton draws conclusions which differ from these, and again suggests a completely different approach from one widely taken for granted. ${ }^{22}$

While one of these approaches may be correct, they are collectively mutually incompatible. It is therefore impossible that they can all be correct, and it is more likely that none of them reflects an examination of both the facts and the concepts. This suggests that it is essential to move beyond general assumptions and specific discussions of the texts in an attempt to understand the Egyptian state. On the most general level, even were one to assume that the state was only the government and that the government included only the secular authorities, merely identifying the Crown lands as the state lands would be a vast oversimplification as the Crown lands were not all of the "state" properties in the country, regardless of how one defines the state (and it is not entirely clear that all the so-called Crown lands even belonged to the Crown). ${ }^{23}$ It is clear that the fields of the temples were definitely not Crown lands, but it would be difficult to suggest that the temples were not part of the state apparatus in ancient Egypt, even if one were to contend that they were not part of the government. There is likewise little evidence that the temples stood at the center of a redistribution economy.

On a different level, J. Assmann maintains that all art was rigorously organized, ${ }^{24}$ and E. Hornung that there were no free peasanis before the end of the Old Kingdom. ${ }^{25}$ Such statements are probably based on the same assumptions that led B. Menu and W. Helck to suggest that at the beginning, everything in Egypt belonged to the king, and that the king assigned specific products, people and lands to individuals by virtue of his sole title to

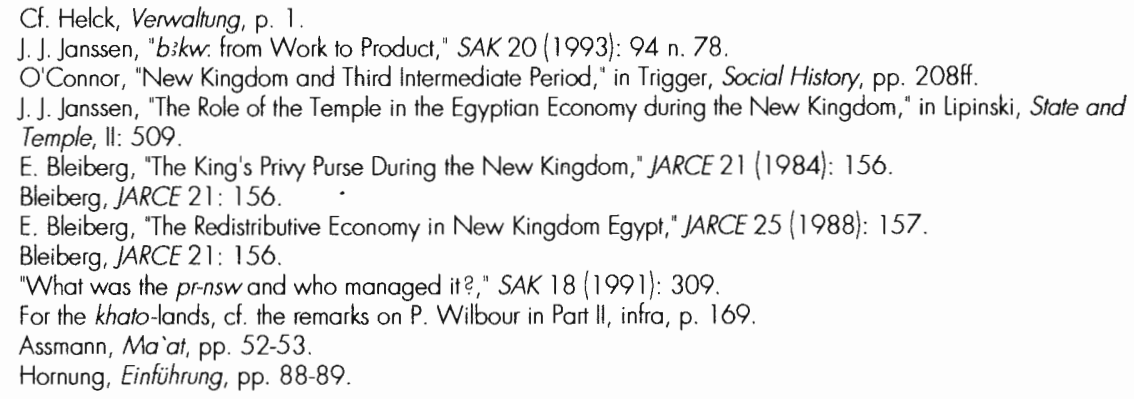


everything in the country, ${ }^{26}$ the corollary being that there were no free craftsmen before the First Intermediate Period. ${ }^{27}$ Following assertions of this type, a recent introduction to economic history characterized the ancient Egyptian economy as a "command economy". ${ }^{28}$ These radical assessments can however be traced back to analytical premises concerning ownership and labour that may not reflect either the original situation or the Egyptians' understanding of it. ${ }^{29}$

Even in the Old Kingdom it is documented that wage labourers and craftsmen were paid for the construction of tombs and that land changed hands in commercial transactions. ${ }^{30}$ It has been alleged that this is part of a long term development which led to the emergence of private property and free wage labourers, but the origins have not been investigated. While the earliest inscriptions do record that land was sold and labourers paid, ${ }^{31}$ the earliest inscriptions do not offer evidence of vast royal patronage or temple-centered redistribution taking precedence, although precisely the opposite is widely assumed. The evidence from the inscriptions demands that the tomb owners had their own income and likewise that there were free workers. It can thus be argued that private property, personal income and wage labour existed independent of the king from the beginning, and that the evidence can support this interpretation, while the opposite contention remains unproven. ${ }^{32}$

26 Helck, Verwaltung, p. I; Menu, Recherches, pp. 1-4.

27 Helck, Wirtschaftsgeschichte, p. 106

28 Rider, Economic History, pp. 3-4.

29 The assumption of state-sponsered support for the arts and industry has frequently been consciously or unconsciously based on the development of the Prussian state which was the most successful of the small German states to have emerged out of the Peace of Westphalia at the end of the Thirty Years War. The logic is the same as that applied to the possession of land being modeled on the European feudal model. Both assumptions rest on the existence of earlier states which can provide economic, bureaucratic, military and artistic models. Such states did not exist at the time that Egypt established the first major territorial nation state in world history.

30 It must be admitted that transactions are more important evidence than the use of the domains to illustrate private property. Theoretically there is no reason to assume that the domains actually existed. Merely by virtue of their being named and depicted, they could "magically" fulfill the role of provision, without any material existence. This would explain the fact that domains of the temple of $\mathrm{Nfr}-\mathrm{ir}-\mathrm{k}_{3}-\mathrm{R}^{\mathrm{c}}$ are recorded in contemporary private inscriptions (contra, e.g., W. Helck, "Tempelwirtschaft," $L \ddot{A} V:$ : 416), but that the temple received its actual provisions from elsewhere, a fact which drew the acute attention of P. Posener-Kriéger ("Les Papyrus d'Abousir et l'économie des temples funéraires de l'ancien empire," in Lipinski, State and Temple, p. 139): "aucun de ces domaines ne figure dans les papyrus d'Abousir comme source directe ou indirect des vivres utilisés dans le temple." She concluded that another institution organized the supply through the solar temple (p. 142), "sans pouvoir en apporter une preuve décisive". The hypothesis that the domains were fictional is underlined by the actual sources of the victuals: the residence and the solar temple. Temples and the Residence will have been able to maintain themselves, but the domains probably ceased to do so at a very early point in time, at which time, "magic" replaced "legal authority" (as with Min), and the records changed

31 E.g., Roccati, Littérature, p. 158.

32 For the uninitiated, the point of W. Helck's contribution "Wege zum Eigentum an Grund und Boden im alten Reich," in Allam, Grund und Boden, pp. 9-13 is unclear, until one realizes that Helck himself had posited that private property did not exist before the end of the Old Kingdom, and that in this final essay he confronted the fact that the evidence contradicted this. One part of his argument is based on the assumption that Mtn's property reflects a situation "kurz vor der absoluten Durchorganisierung des Landes" (p. 10), which allows him to postulate that the state somehow swallowed up the private property shorlly thereafter, so that it could then reappear in the First Intermediate Period. His hypothetical speculations about the nature of private property can not be treated, for they go far beyond the essential statements that the evidence indicates that the inscription of Mtn reveals that several different types of private property existed from the beginning of the Old Kingdom, and that the later texts indicale that this continued to be the case.

It need be underlined that all of the available evidence indicates that private property existed from the earliest period until the latest, and that the only reason to postulate its repeated emergence and disappearance is on the 
The contentions upon which the present work is based are that it can be argued that (a) the interpretation advocated by $W$. Helck and followers that the king owned everything is not based on the evidence, and (b) that the interpretation by Bleiberg and Janssen that templecentered redistribution was a central element of the economy is likewise based on assumptions rather than evidence, and that ( $c$ ) on the contrary, it can be assumed with equal validity that the first acts of the emerging state were to requisition or confiscate labour and objects from the population, on the assumption that (d) the private sector with individual land owners and craftsmen was already producing a minimal quantity and quality of material, and that (e) this subsequent demand led to tax or demand-generated state supported growth of the economy as a whole, $(f)$ without the regimentation generally assumed, because the state was initially primarily engaged in collecting, not producing, so that $(\mathrm{g})$ the private sector continued to prosper, until (h) state demand plummeted, when (i) the economy suffered across the board, falling to near the pre-state low level of activity. Reunification of political and economic power led to an economic revival, and subsequent disintegration to a corresponding drop.

One of the principle corollaries of this argumentation is that economic and political thinking has been dominated to a considerable extent by the European model, and has blinded scholars to the meaning of the evidence before them. This has meant that modern European states emerging out of feudalism, and modern capitalist economics emerging out of mediaeval trade fairs have been widely assumed to have been the only cases of the development of the state and the market economy. ${ }^{33}$ Recent archaeological research indicates that the concept of the state must be extended far beyond the birth of the modern world. It has also become clear that the European trade fairs were just a faint reflection of the economic rhythms dominating the Indian Ocean a thousand years before the economic awakening which preceded the Renaissance. ${ }^{34}$ The failure to understand this has been accompanied by a tendency to take many records at face value without investigating the context from which they came. With the vast quantities of data and theoretical models available today it is entirely comprehensible that the barriers to understanding were not recognized and lifted before. The following work is an attempt to identify some of the barriers and to explore the data, and to suggest a new approach.

\section{CONCEPT OF THE StATE}

While Egyptologists, Assyriologists and archaeologists have discovered the principle of the state in the ancient Near East, political scientists have tended to move away from the

\footnotetext{
assumption that whenever the state appeared it swallowed up private property. This is based on the win assumptions ( $a$ ) of the European feudal experience, and (b) that the situation described in the texts is a true reflection of sociely. The approach employed here assumes that a careful examination of the texts reveals that they can be understood in exactly the opposite sense and that a coherent picture emerges as a result.

Helck indicates his bias by stating explicitly that "all possible variations were tried, just as in the West" (p. 9, my translation), without realizing that his whole line of reasoning was unconsciously based on the Western experience, which was not only the exception rather than the rule, but also completely irrelevant.

33 Cf. Hicks, Economic History.

34 Cf. Chaudhuri, Asia before Europe.
} 
concept of the state, preferring instead to identify the birth of the term as the genesis of the concept, and thus generally date the birth of the state to the 16 th century A.D., or later, when the term "state" began to be used with its modern meaning. ${ }^{35}$ Superficially, the political scientists' principal contention would appear to be that the Greek city states were not states in the modern sense of the word, which is hardly an adequate approach in view of the antiquity of the state in the ancient Near East. ${ }^{36}$

Being unconcerned about what preceded the Greek city states, the feudal system poses a problem for political scientists: the major obstacle inevitably facing them is the lack of a relationship between the modern European states of the 19th and 20th centuries A.D. and the feudal states from which they emerged. Simultaneously, they unconsciously tend to assume that politics and the state emerged with the Greek polis, and that no serious political entities preceded the polis. It is clear that the polis did not contribute to the political developments of the feudal period in Europe. Since the polis therefore had neither predecessors nor successors - according to their logic - the polis did not have a significant role in historical developments, and can be conveniently forgotten, as a means of denying that political history preceded the Renaissance.

The narrow view that modern European states are the only real states, and that modern European states emerged out of the feudal system tends to be emphasized at the expense of a wider perspective. This obscures the fact that the scholars and politicians of these early European states sought Greek and Roman vocabulary to describe the political entities and concepts evolving during the Renaissance, Reformation, and Enlightenment. They clearly identified these with Antiquity rather than the Middle Ages. ${ }^{37}$ This line of reasoning permits political scientists to neglect the fact that the European Middle Ages were not typical in terms of human political developments, and provides a justification for maintaining that modern states are somehow exceptional.

At the basis of the assumption that states are exceptional is the logical corollary that states are actually somehow alien to social life, which is again an assumption based-consciously and unconsciously - on the mediaeval example. ${ }^{38}$ This emphasis on the mediaeval example

35 Cf. e.g. Vincent, State, pp. $5 \mathrm{ff}$.; Barry, Theory, p. 62; In a volume devoted to Political innovation and conceptual change, $Q$. Skinner points out that Milton was familiar with the concept of originality, but not the word ( $Q$. Skinner, "Language and Political Change," in Ball, et al., Political Innovation, pp. 7-8), yet allows himself to identify the emergence of the state to be associated with the appearance of the word (Q. Skinner, "The State," in Ball, et al., Political Innovation, pp. 90-131). In this fashion he follows precisely the logic to which he objected.

36 Aside from works cited in this discussion, from the wide spectrum of the literature dealing with the issue, the reader is referred to two recent works based on the assumption that states emerged long before the Greek polis: G. Stein, Early States; Gledhill, State and Society. The term is one of the select few discussed in Mignon, Concepts, pp. 307-313. (The literature cited there is useful; in the attempt at a definition the author juggled with complex problems in a couple of pages).

37 For the altitudes of the early modern historians, cf., e.g., U. Muhlack, "Von der philologischen zur historischen Methode," in Meier, Methode, pp. $161 \mathrm{ff}$.

Ball (Theory, pp. 65-82) vitually makes Machiavelli a kind of pivot by suggesting that Machiavelli was using the word vitu with an antiquated meaning, and thus became a kind of Don Quixote of political theory. What matters is that nevertheless all the thinkers immediately turned their backs on the Middle Ages and sought the forms of antiquity: by using the Middle Ages as their point of departure modern political scientists have erected an artificial barrier.

38 Cf. Barry, Theory, p. 63. 
places far too much emphasis on the political backwardness of that peninsula of Asia that gave birth to the Renaissance, Reformation and Enlightenment. Although Europe came to play a central role in world history, it was politically an insignificant region once briefly included within the Roman Empire before relapsing into political irrelevance. Because of the role of Europeans in political science, this period of political irrelevance - the feudal or mediaeval period - has accidentally come to dominate modern political thought.

There were state structures in Asia and the Mediterranean area long before the political awakening accompanying the Reformation in Western Europe, but these are consistently neglected because of the modern Western political bias of those examining the evidence. With the exception of Europe, most parts of the civilized world have been incorporated into states, so that the European feudal experience is an extremely misleading example. The role of the European model with its classical origins followed by feudal developments and the emergence of modern European nation states has blinded many modern political scientists to the development of the concept of the state beyond Europe.

Among politically oriented social scientists Eisenstadt is an exception who has made a serious effort to bridge the gap. By concentrating on the aspects of the bureaucratic empires, he succeeds in linking the Habsburgs and the Pharaohs. ${ }^{39}$ By emphasizing the similar characteristics, Eisenstadt showed that these modern anachronisms shared common traits with ancient entities. While dissenting in detail, most students of the ancient world would assent to his idea in principle. There were however many kinds of states in antiquity, although only the empires seem to receive attention. It thus remains to demonstrate a reasonable fashion in which to compare the incomparable, bridging the mediaeval gap, and moving well beyond the Roman Empire and the Greek polis. The degree to which European patterns have influenced virtually all speculation concerning the state deserves examination: the European experience was ultimately exceptional in terms of human political history, and should thus not be permitted to dominate political analysis.

The only way to approach these problems is to turn to the primary concepts. Although positivism has suffered setbacks in political philosophy, ${ }^{40}$ a state can be defined quite generally as a geographical unit with a population and a recognized legal authority. There are numerous other precepts which are generally employed to identify a state, such as internationally recognized boundaries, a government with a monopoly on the use of force, etc., but some of these have been thrown into doubt. ${ }^{41}$ Beyond territory and population, the most minimal level demands the presence of either a legitimate government or a body of law as the minimum prerequisites for the existence of a state. The existence of a state is not however established by the presence of territory, population, laws or government, for these are not necessarily interrelated. ${ }^{42}$

Cf. e.g. Ball, Theory, p. 84; Barry, Theory, pp. 61-62

${ }^{41}$ Cf. e.g. Barry, Theory, pp. $61 \mathrm{ff}$.

42 This is based on the twin facts that $(a)$ there are governments in exile which do not claim to be separate states, but rather assert that they are the legitimate government of a certain geographical and demographical entity, which may or may not correspond to an existing state; while (b) conversely, today there are no populated geographical territories which do not either belong to a state, form a state, or claim the right to become one by separating from 
Although it predates the supposed birth of the state by almost three millennia, the Ramesside State did not emerge out of nowhere: it was built on traditions going back to at least the fourth millennium B.C. Thus, not only was the ancient Egyptian state one of the oldest and first pristine states in the world, but the New Kingdom state was an evolutionary novelty older than any existing modern European states, with the possible exception of the Vatican, assuming that the Vatican is the successor of the Roman Empire. Only feudal China had a similar pedigree, but the history of the political unity of the geographic area known as China today cannot possibly be compared to the continuity exemplified by Ramesside Egypt, which may have already been an ancient territorial nation state even five millennia ago. It is thus clear that no matter how vague Egyptian ideas about the concept of the state may have been, the basic preconditions for the existence of a territorial nation state were at hand, and in the form of an extraordinary exception without any parallels, for no other state of equal stature and age was based on a pristine state. It is therefore necessary to review our theoretical models and our conceptions very carefully.

The mainstream approach to the concept of the state has been to emphasize the diversity of concepts associated with the word state, and to emphasize that in the modern world the word is used loosely in contexts where the state "acts or even thinks". 43 The modern meaning of the word "economy" is slightly younger than the modern concept of "state", which does not date back to before the 16 th century A.D. ${ }^{44}$ The modern political concept of the state can be reduced to several specific meanings, with "state" signifying "government" in the most restricted definition. ${ }^{45}$ The term can also refer to all instances of official and social authority collectively, but there are two other specific uses of the term "state" which are not semantically the same: one identifies a specific legal entity and the other the general social concept of an organism. Students of modern politics object to confusing "state" and "society" in this fashion, yet it is extremely difficult to draw a dividing line between the two, except by defining the state as a specific legal entity, which inevitably clashes with both popular and scholarly usage. ${ }^{46}$ At the same time that it is difficult to draw a distinction between the "state" and

an existing state. It need hardly be pointed out that in antiquity this was by no means universal: before the fourth millennium B.C., there was probably not one single state in existence in the entire world. By the beginning of the third millennium A.D., virtually every populated territory on the globe will have been assigned to - or be contested by - some state entity. The obligatory nature of state structures is new.

43 C.-E. Bärsch, ("Staat," in Holimann, Politik-Lexikon, p. 617, my translation) notes that the 1988 edition of the standard German dictionary indicated that the German language possessed more than 100 words including the word Staat, remarking that the Theologians "even" refer to "Gottesstaat", which is characteristically one of the few main word entries in the Lexikon der Agyptologie using the word state.

44 Cf. the very important notes to this effect in Finley, Ancient Economy, pp. 17ff. But also here, Bärsch (in Holtmann, Politik-Lexikon, p. 618): "Ob polis, res publica, populus regnum, civitas oder Reich in Antike und Mittelalter jeweils mit dem Begriff S[taat] adäquat übersetzt werden können, erscheint äußerst zweifelhaft." Q. Skinner ("The State," in Ball, et al., Political Innovation, pp. 90-131) argues in favour of an evolution of the concept, identifying Hobbes as the First real theoretician of the state, placing its origins in the 17th century A.D. rather than the 18th as contended by Bärsch. Skinner emphasizes the use of the word in the context of European history, but not the concept of the state in the context of universal history.

It is worth noting that Bärsch dates the state to the 18th century, Skinner to the 17 th and Vincent to the 16 th century A.D.

45 Bärsch, in Holtmann, Politik-Lexikon, p. 618

40 Cf. Vincent, State, pp. 22-26. 
"society" on the one hand, it is equally difficult to distinguish between the "state" and the "government" on the other. Thus, even if it is maintained that the ancients had states in the modern sense of the word, there remain several levels of difficulty.

At one time - based on the European feudal model - it was widely believed that a simple developmental sequence could be posited, with the local community being subsumed within a tribal community which became a national government, and this occasionally became an imperial government. ${ }^{47}$ The rights to private ownership, and the obligations of the members of the community were assumed to have risen from a simple level of direct community or state possession which was transformed into the tribally based feudal system. A central problem with the European feudal model was the absence of a specifically designated body which could make law, as it was assumed that the ability to define laws was elemental to the state: it was necessarily the absolutist European states which initiated state legislation, which ironically led to the development of the concept of rights, as opposed to obligations. The interrelationship between the role of the state, the rulers, the ruled and the rights of the individual was thus understood to be a clear evolutionary development, with a decreasing role for the state in the sense of oppressive government, and a more significant role for the state as a social organism with a responsible government.

This latter concept dominates when Egyptologists consciously refer to the ideology of the state referring to the literature of the "Instructions" or discussing the concept $m_{3}{ }^{c} t$, assuming that the term state refers exclusively to the wide-ranging social and political concept of an organism, the way that Hobbes, Rousseau, Kant and Hegel use the term, rather than to a specific legal entity. Assmann writes that "the concept of $M a$ 'at is fundamental to the state. "48 Assmann posits that man cannot live without $m_{3}^{2} t$ or the state. The state is all:

The institution of Pharaonic divine kingship is the geometric convergence of the human and cosmic spheres. ${ }^{49}$

Legitimacy through justice, and justice through absolute rule is the creed of the state. The same broad meaning is implied when the stale ceases to exist. ${ }^{50}$

Egyptologists discussing the economy use the meaning associated with the legal authority of sovereignty and government associated with one of the other meanings, and thus it is not entirely clear what significance one can generally assign to the concept of "state" in Egyptology. It is however clear that the ancient Near Eastern states had all of the essential features of statehood, including legal legislation. It should also be clear that although the ancient world

47 Cf., e.g., M. H. Fried, "On the Concepts of 'Tribe' and 'Tribal Society'," in Helm, Essays, p. 10.

It is worth noting that at least one Marxist scholar has gone so far as to state that Marx's paradigm is demonstrably correct for the explanation of all state developments within the context of the "Asiatic Mode of Production," equally valid for Egypt in the fourth millennium B.C. and Africa in the second millennium A.D. (cf. M. Goldelier, "La notion de 'mode de production asiatique' et les schémas marxisles d'évolution des socièés," in Suret-Canale, Production. p. 86). It need hardly be pointed out that establishing facts of this type is quite easy if the popular literature is read in the correct fashion.

48 Assmann (Ma`at, p. 200): "Ma'at ist eine im höchsten Maße staatstragende ldee". [My translation].

49 Assmann, Ma'at, p. 219. [My translation].

50 Ct. e.g. Müller-Wollermann, Krisentaktoren. Although the word "state" figures in the title of her book, she unfortunately failed to define it. Assmann (Ma ai, pp. 219-22) is more poetical about the collapse of the state. 
did not use and was not familiar with concepts like "economy" and "state", modern scholars will not only use these concepts (with the result that their use influences our understanding), but will actually try to study them, and therefore definitions are necessary.

\section{Marx, WittFogel and Egypt}

The Soviet Egyptologist M. Korostovtsev pointed out that it was characteristic of Western Egyptology to pursue the feudal model, while the Soviet V. V. Struve had followed the Historical Materialist model and was completely convinced that he had demonstrated that the basis of Egyptian sociely was slavery. ${ }^{51}$ It is an unhappy coincidence that in each case the role of private property was excluded for theoretical reasons, and that the resulting interpretations of the texts merely seemed to emphasize different aspects of the same phenomena. Ancient Egypt had a centralized government, and slavery did exist, and feudal structures could be recognized if sought, so that unconsciously influenced by Marxist theory, three different steps of social development (feudalism, slavery, and the Asiatic Mode of Production) were perceived to be characteristic of ancient Egypt, and the categories unconsciously or consciously applied. It is now possible to perceive that Marx's categories were not only not universally applicable, but that they were erected without a complete understanding of the evidence in each case. And this means escaping from the unconscious application of his theories, but not by simply disregarding all his observations and reflections. Marx's category of the Asiatic Mode of Production was an early approach aimed at studying both state formation and economics. Marx himself did not do more than place the Asiatic Mode of Production as the first step after primitive communism, and define it with two characteristics: (1) the village structure, and (2) the powerful central government. ${ }^{52}$ It was only at a relatively late point in time that Marx realized the significance of private property in India and China and he never formally incorporated it into his model. In the earlier form, he assigned the central state a major role, and assigned the government three main departments,

that of Finance, or the plunder of the interior; that of War, or the plunder of the exterior; and finally, the department of Public Works. Climate and territorial conditions $[\ldots]$ constituted artificial irrigation by canals and waterworks the basis of Oriental agriculture... This prime necessity of an economical and common use of water, which, in the Occident, drove private enterprise to voluntary association, as in Flanders and ltaly, necessitated in the Orient where civilization was too low and the territorial extent too vast to call to life voluntary association, the interference of the centralizing power of Government...53

51 M. A. Korostovcev, "Das alte Ägypten," in Heinen, Sowjetische Forschung, pp. 19-45. It is probably thus not accidental that the Germans Heick and Assmann tend to see a state organized along Prussian lines.

52 Encausse/Schram, Marxism and Asia, pp. 8ff. It will be noted that Marx's preliminary notes are very general about the nature of the state and the government, so that we will gloss over the lack of distinction, without admitting its validily.

53 K. Marx, quoted in Encausse/Schram, Manxism and Asia, p. 115. The suggestion that Egyplian and Chinese civilization were necessarily lower than the levels of medieval Europe must likewise be noted and neglected. 
This is the origin of the concept of Oriental Despotism and contributed to Wittfogel's hydraulic civilizations. ${ }^{54}$ It has however been shown that the irrigation system actually emerged after the central government in Ceylon, and therefore that in the only case where the development can be followed, that government was not a response to the problem. ${ }^{55}$

The evidence $[. .$.$] runs counter to Wittogel's assumption that the organizational$ requirements of irrigation provided the main stimulus for the evolution of political organization in irrigation society. ${ }^{56}$

The emergence of a political system which brought the petty regional polities under the sway of Anurädhapura was not the response to the organizational demands of irrigation society. ${ }^{57}$

For ancient Egypt, W. Schenkel has advanced the hypothesis that the irrigation system organized by the state emerged during the First Intermediate Period, and was therefore likewise not related to the emergence of the state. ${ }^{58} \mathrm{He}$ addressed himself specifically to the technological innovation of the irrigation revolution. While Butzer had postulated the existence of irrigation for the earliest phases of Egyptian social development, Schenkel pointed out that Butzer neglected the technological aspect, and the use of texts as a source.

Schenkel employs only non-royal texts from the First Intermediate Period and the Middle Kingdom to demonstrate that a technology associated with irrigation was introduced around the period of Dynasties IX $X$, and that irrigation was practiced thereafter. He correspondingly concludes that this chronological situation demonstrates that state involvement in the irrigation system could not possibly have contributed to the early development of the state, and thus clearly contradicts Witffogel, for the bureaucracy could not have emerged as a result of the challenge of organizing the irrigation systems which they were not organizing. ${ }^{59}$

It must however be conceded that transport canals existed during the Old Kingdom, and that even if - which is not certain - there are no references to irrigation canals during the Old Kingdom, irrigation canals are not mentioned later either. This makes it difficult to assert that there was either a "technological innovation", or an administrative revolution, for the technology and the mobilization of manpower required for an irrigation canal will have been virtually identical to that required for a transport canal. The use may have been different (although this can hardly be proven), but socially they are identical, if private people are

Wittfogel, Oriental Despotism.

R. A. L. H. Gunawardana, "Social Function and Political:Power: A Case Study of State Formation in Irrigation Society," in Claessen/Skalnik, Study of the State, pp. 133-154.

Gunawardana, in Claessen/Skalnik, Study of the State, pp. 142-143.

Gunawardana, in Claessen/Skalnik, Study of the State, p. 148.

Schenkel, Bewässerungsrevolution.

Schenkel (Bewässerungsrevolution, p. 72) states that the agricultural basis of the Nile Valley did not differ from that of Mesopotamia, but this is only true at the most superticial level, cf. D. Oates and J.Oates, "Early Irrigation Agriculture in Mesopotamia," in Sieveking, Problems, pp. 121-122. The fundamental differences are greater than superficial similarity. 
obliged to contribute their labour to construct them. The distinction is therefore spurious, from a political standpoint, even if it can be maintained that there are no specific textual references to irrigation canals in the Old Kingdom.

Schenkel thus dates the development of the state sponsored irrigation canals to the First Intermediate Period, but admits that there is no contemporary royal evidence, nor any evidence from any textual source during the rest of the Pharaonic period - either before or after the First Intermediate Period/Middle Kingdom - for state sponsored irrigation. This merely suggests that the state did not regard its irrigation responsibilities as significant, and thus debunks Wittfogel's relevance for ancient Egypt quite clearly, but leaves the significance of Schenkel's discovery unclear.

The logic behind Schenkel's conclusions is however worthy of further attention, for the suggestion that irrigation canals can only be associated with textual references would at least logically suggest that they did not exist when they are not mentioned, and thus that for the subsequent period during which canals are not mentioned they will have been abandoned. Following Schenkel's logic, the fact that irrigation canals and titles do not appear in later texts would conclusively demonstrate their disappearance, yet this can hardly be his object.

It is useful to recall something about the character of Egyptian texts. The ancient Egyptians did not hesitate to document having accomplished something for the first time, even if they knew that this was not strictly true according to our modern standards of truth and falsehood. This is best illustrated by the repeated claims that any particular expedition to Punt was the first. It is also useful to recall that obscure provincial land owners may pursue projects which greater kings do not regard as their responsibility, so that state centered royal activity is not conclusively demonstrated with provincial evidence. It is also significant that lesser kings will record lesser events that greater ones do not bother to. Schenkel's assertions about the value of textual sources are considerably reduced by the meager quality of his evidence, and of his wide ranging use of it. ${ }^{\circ}$

The fact that it is not specifically stated in the text at hand that the canal was the first built would suggest - at least according to Egyptian historiographical trends - that the person responsible for this text was conscious that this was by no means the first irrigation canal ever built. The fact that the author was not a major king cannot be used to extrapolate about responsibilities of major kings. This suggests that the use of this text is an insufficient basis

It need hardly be pointed out that, e.g., if $n h\left(b_{i}^{\prime}\right.$-land is related to the verb thi $(b)$ - arguably "irrigated" - then logical use of the philological evidence of the canals in Urk. 1:220, $14 \mathrm{ff}$. could be used to negate Schenkel's whole hypothesis of irrigation being a late development and would give it a royal background in the Old Kingdom.

Schenkel's evidence for the contention that the king was responsible for irrigation comes from Herodotus (cf. "Beund Entwässerung," $L \ddot{A} \mid: 780,782 \mathrm{nn} .46 ; 47)$. The absence of any contemporary Dynasty XII inscriptional evidence for the transformation of the Fayum is significant given Schenkel's emphasis on the importance of textual data.

The shabti-spells - which seem to date from the Middle Kingdom - do hint at some kind of obligatory labour, but neiter the nor the texts cited by Schenkel hint at a royal - or state - organized system of irrigation. For this Schenkel provides no evidence, and what evidence there is (Urk. 1: 220: $14 \mathrm{ff}$.) is earlier than Schenkel's revolution, and thus Schienkel's argument is confuted twice over. 
upon which to base a theory of the emergence of irrigation systems in ancient Egypt. And it cannot be used to demonstrate the emergence of state-sponsored irrigation systems either, for not only does it not document state involvement, but state involvement in irrigation is not subsequently documented. The text in question therefore does not demonstrate either the time of the invention of irrigation or identify those responsible for irrigation before or after its construction.

Schenkel's conclusions are (1) thus not only oblivious to the fact that the difference between a transport canal and an irrigation canal was not very great, but they also (2) fail to demonstrate the value of textual sources to prove his point. The logical conclusion to be drawn from Schenkel's evidence is that if irrigation was the responsibility of the state at all, then it was primarily the responsibility of officials so low in the bureaucracy that they are not mentioned (which suggests that they did not exist), and certainly underlines that neither the king nor the Vizier were concerned with it. Butzer's argument placing irrigation at the dawn of Egyptian civilization is neither proven nor disproven, but it is clear that the introduction of the irrigation system cannot be used to illustrate the development of strong government. There is therefore no reason to suppose that irrigation does not predate Pharaonic civilization, and no reason to assume that the government was seriously concerned with it, contra Schenkel, Marx and Wittfogel.

In a very general fashion, it can however be suggested that Wittfogel's Oriental Despotism describes the final ultimate situation of a state which is permitted to develop in this direction without interruption, and thus Wittfogel's error is the premise that this was also the point of departure. Marx assumed that what has since been termed "the genius of Europe" was behind the development of private agricultural projects, and that this tendency was lacking in the Orient. It would appear that Marx's conclusions were likewise based on the final development rather than the origins, and that Marx merely assumed that public management of canals accompanied public or state ownership of land. ${ }^{61}$

While Schenkel has clearly demonstrated that Wittfogel's model was mistaken, the principle of private ownership of land in ancient Egypt has not yet been yanked completely out of this Marxist model. It is generally agreed that private ownership of land in ancient Egypt emerged after the emergence of the state rather than preceding it. Even the most revolutionary observation in this respect failed to completely grasp the situation: M. Gutgesell correctly writes that "at the latest, cultivable land could be purchased since early Dynasty IV. "62 The meaning

or The degree to which the assumption has been absorbed without reflection in Egyptology can be read in J. v. Lapp's remark ("Evidence for Artificial Irrigation in Amratian Egypt," JARCE 32 [1995]: 208), to the effect that the Amratian irrigation systern was "probably by corvée labour in much the same manner as was practiced in Pharaonic Egypt until recent times". While Witffogel does use the Egyptian Khedive Muhammad Ali as an example of an Oriental Despot (Wittogel, Oriental Despotism, p. 25) it is difficult to understand how Muhammad Ali could be understood as a Pharaoh, although that seems to be the sense of the phrase. Evidence supporting the early implementation of corvée labour for irrigation remains to be presented, and thus the logic of the contention is unclear.

62 M. Gutgesell, "Die Entstehung des Privateigentums an Produktionsmittel im alten Ägypten," GM 66 (1983): 76. [My translation]. There is a very significant theoretical problem which Gutgesell neglects when he asserts that the theoretical conditions for the emergence of private property include a king who rewards people with land (GM 66: 68). This is based on the European feudal model, which followed the Egyptian development, and therefore need not be relevant, because the European feudal model was based on tribes, and it is now considered more 
of the Min inscription - the text in question - is however that as far back as the inscriptions go, land could be purchased and sold, and that there were legal arrangements to assure that this was possible, which has a significantly different ring to it. The fact that the mere phrase "Law of Pharaoh" sufficed to refer to guarantees surrounding property rights underlines that property rights were important in ancient Egypt. ${ }^{63}$ States collect information about land holdings, but this does not mean that they assert the right to possession of that land. The state needs to organize information $(a)$ in order to establish government revenues, and $(b)$ to assure that property rights are recognized. In general, the government - as the highest authority in the land - will have been the ultimate adjudicator in private property disputes. It may also have acquired revenue from holdings, but this does not demonstrate possession, any more than that irrigation demonstrates oriental despotism. ${ }^{64}$

These conclusions would thus suggest that there is nothing to counter the argument that the situation in Flanders and northern Italy was not that different to the ancient Orient, except that agriculture in both European areas emerged out of a feudal model which itself emerged out of the remains of the Roman Empire. Although perfectly obvious, it is apparently necessary to emphasize that the political and economic developments which led to the emergence of the earliest civilization on the banks of the Nile did not emerge on the margins of any other economically prosperous or politically successful civilization: they emerged from utter and absolute poverty. Nor were the political and economic developments along the Nile accompanied by the explosion of world trade and industry which decisively influenced developments in Flanders and ltaly. At the very close of this study we will return to the issue of trade relations, for the moment however it need merely be repeated that every single speculative thought requires re-examination.

Aside from the detailed criticism disproving Witffogel's theories in the case of Egypt and Ceylon, recent general work on Witffogel has also tended to criticize his approach, because

probable that tribes followed the emergence of states as a specific peripheral social organization, and that they were preceded by clans, so that the whole logical underpinning of Gutgesell's argument depends upon the premise of identical social organizations preceding and following the emergence of the state /cf. Fried, Political Society, pp. 170-174; and M. H. Fried, "On the Concepts of 'Tribe' and 'Tribal Society'," in Helm, Essays, p. 15). In fact, the Egyptian experience seems to suggest that the old aristocracy maintained their rights and then the officiais began to purchase land as well. The legal framework of Min's inscription suggests that such transactions were an important part of life. Gutgesell's assumption (GM 66: 71) is that the peasants began to sell their collective land, but this is not necessarily the case.

Gutgesell's other points (priestly class and independent traders) indicate mere circular logic based on Mesopotamian and Egyptian material as interpreted by the philosophers of anthropological history. This is a classic example of our own inadequate presentation of the material returning to haunt us. Fortunately, B. Kemp (Egypt) has now provided a solid base for a theory of the state which anthropologists and philosophers can use.

It is worth noting that the same confusion has arisen in the case of the emergence of the state in China. There, the European feudai model has been taken, but the situation is not that reflecting the very earliest state, so much as what Confucius speculated about developments during the early Shang Dynasty, more than a thousand years before his birth. Since the earliest Chinese states are not incorporated into this model, the logical connections with feudalism can be justified, but the method is not exactly rigorously scientific, and a comparison with Egypt inappropriate. Cf. T. Pokara, "China," in Claessen/Skalnik, Early State, pp. 191-212.

03 CF. J. J. Janssen and P. W. Pestman, "Burial and Inheritance in Ancient Egypt," JESHO 11 (1968): 140.

o4 It will be noted that this paragraph contradicts the entire argument of North, Economic History. His interpretation was influenced by those writing about the economy. 
In his blind political crusade, Witflogel found hydraulic ghosts in every despot's closet. He was not capable of distinguishing between different forms of restrictive governments. All oppressive states became expressions of the same forces that gave rise to the hydraulically based ancient states of the Middle and Far East. ${ }^{55}$

D. Price was however able to refute a large part of the scholarly criticism by demonstrating that there was considerable confusion due to the failure to distinguish his hydraulic civilizations from his hydroagricultural societies, which primarily means that Oriental Despotism is not inevitable. Although this does not aid in understanding the Egyptian evidence, it emphasizes that even Wittfogel realized that the development was not an evolutionary necessity.

It must have been an axiom of Egyptian fiscal economics that the irrigation system had to function faultlessly in order to achieve the maximum grain harvest. The Vizier had to be notified of the approaching inundation, ${ }^{\infty 6}$ partially because of major land holdings, but also because of the necessity of passing on information. There is however an enormous difference between recognizing the necessity of collecting and distributing information and in asserting responsibility for irrigation, or demonstrating state ownership of land.

\section{State Origins and Development: Beyond Marx}

One tendency of modern Marxist political analysis was specifically designed to overcome the complexities of comprehensive theories by dividing the concept of the early state from that of the industrial state. ${ }^{67}$ However, merely by virtue of selecting a set of early states by using suitable criteria, early states could come to share one set of characteristics, and industrial states another. While defensible, this is not necessarily more than a tautology, for the very exclusion of certain groups from the field of analysis tends to limit the number of possible variations on the theme. Trying to identify the early state, Khazanov came to the conclusion that the level of economic and technological development; continuity with the pre-existing system; forms of dependence and exploitation; political organization; and civilization were all factors that determined the early state. Superficially, this amounts to a mere listing of the characteristics of any state, and does not inform us about the nature of the state, either early or industrial. The "Study of the State Conferences" (which resulted in the publication of the volumes edited by Claessen and Skalnikj did not tackle Mesopotamia or Greece so that a great deal of relevant material was not drawn upon.

D. Price, "Wittfogel's Neglected Hydraulic/Hydroagricultural Distinction," JAR 50 (1994): 192-193. This article summarizes distinctions that Witffogel obscured in the course of his later work.

so Urk. N: 1113,4

or CF. Claessen/Skalnik, Early State, passim, esp. the theoretical models, by the editors ("The Early State: Theories and Hypotheses," pp. 3-29), R. Cohen ("State Origins: A Reappraisal," pp. 31-75) and A. Khazanov ("Some Theoretical Problems of the Study of the Early State," pp. 77-92).

This endeavour was intended to facilitate the ability of defining the decisive features of the early state without getting entangled in conceptually irrelevant discussions. It is however a common element of this approach that recently documented early states (in, e.g., 19th century A.D. Africa) thus share a chronological position with developing European industrial states, and to compare one of the most advanced states of Antiquity with the miserable rernnants of a failing political unit in modern Africa does not necessarily aid us in understanding the processes which led to the emergence of the most powerful political units that mankind had ever experienced some four or five thousand years ago. 
Political scientists have attempted to define the "formal features of the modern European state". 68 Vincent's minimal formal features suggest that a state assert legal primacy over all other organizations within an identifiable territory with a population. The state's legitimacy allows it to determine what is lawful, so that in essence "it is a continuous public power". 69 Barry emphasized that the power must be public and centralized and have "the monopoly of coercive power". ${ }^{70}$ Khazanov's listing is more detailed, but fails to distinguish any specific features of early states not associated with modern European states, while Vincent's "features" certainly do not exclude non-modern non-European states. The modern European state may differ from other states in the degree to which it actively makes law, but in general these criteria could be applied to the ancient Near Eastern empires, the Greek city-states, and modern non-European states without exception. There is thus little or no justification for classifying states along the arbitrary division separating modern industrial states and early states, for the common features in either list inevitably apply to members of both groups. ${ }^{71}$

The search for the first states can thus begin with the search for the first cities (which long predated the Greek polis). ${ }^{72}$ For the case of Mesopotamia, R. C. Hunt has created a theoretical model summarizing the significance of the emergence of small-scale urban civilization to illustrate the formative process which ulimately creates a city-type state. ${ }^{73}$ Imposed upon a village level subsistence pattern is an hypothetical class which does not produce, and therefore must acquire what it consumes from the productive farmers. The result would appear to be a labour shortage, which is entirely logical, as it is precisely labour that has been withheld from production, while maintaining the same level of consumption. His assumption that 90 per cent. of the population must produce 10 per cent. more is debatable, but in principle, his model is based on a single small city and simulates the emerging scheme for Mesopotamia during the third millennium B.C. with a pattern of miniature city states, lying cheek by jowl across the Jazira. Although developed for the irrigation cultures of southern Mesopotamia, it has been claimed to be equally relevant for the rain-fed cultures of the north.

Hunt's model does not however simulate fourth and third millennium Egypt where a single political unit was able to impose its rule, and to thereby acquire a right to a proportion of the

o8 Vincent, State, pp. 19-21.

69 Vincent, State, p. 21.

70 Barry, Theory, p. 69. It is very curious that Barry is hesitant about whether a state can be justified in terms of rendering life public (p. 67). Barry has evidently not had the dubious pleasure of enjoying life in a society where the state is weak. Anyone who has lived in a society such as that which Hobbes and louis XIV experienced in their childhoods can only yearn for the security of a state - regardless of the justification, as is clear from Hobbes.

71 The most extreme example would perhaps be those modern Islamic states which seemingly deprive themselves of the right to legislate by declaring Islamic law to be the source of all legislation, but the mere act of constitutionally or legally binding themselves to this provision demonstrates that these states are also enacting positive law, and thus compiying with the definition of being modern states.

It is clear that the ancient Mesopotamian and Egyptian states would fit into the mold of "modern European states" better than many other members of the United Nations.

72 Cf. e.g. Roaf (Mesopotamia, p. 58) who points out that one can argue either way, defining the developments in the Near East in the fourth millennium B.C. as relating to urban growth or state formation: the social and economic structures changed decisively, and clearly cities played a significant role in Mesopotamia.

73 R. C. Hunt, "The Role of Burecucracy in the Provisioning of Cities: a Framework for Analysis of the Ancient Near East," in Gibson/Biggs, Power, pp. $161-192$. 
surplus production and surprisingly the surplus labour from numerous villages and towns throughout Egypt. The fact that the hypothetical constraint in Hunt's model is labour indicates that Egypt's Old Kingdom part-time bureaucrats and craftsmen were part of an economic and political anomaly in economic history. There can however be little doubt that it was the ideology of the state with its determination to create enormous funerary monuments that created the demand. With different religious motives, but similar economic constraints, the same development also ultimately took place in the latter part of the third millennium in Mesopotamia. Ideology would appear to be stronger than the elasticity of labour, but more probably this can be attributed to economies of scale. ${ }^{74}$

An expressly non-Marxist approach ${ }^{75}$ attempts to combine the emergence of the state and government with the appearance of civilization, and uses Egypt as an example. Based on the premise that "chiefdoms" served as an intermediate stage between segmentary egalitarian society and the state, Service views the Badarian as the formative period, with "a growing population and increasing craft specialization. "70 He assumes that the nomes were not urban centres in this early period, but that they were religious centres with temples and divinities, which however failed to inspire local resistance to external domination and unification.

In certain respects the new united Egypt was ruled by the simple addition of a kind of Sumerian temple chiefdom on top of the scattered smallish nomes. It could even be argued that as a government Pharaoh's temple was no more than an elaborate chiefdom that somehow, for peculiarly local reasons, was able to hold in thrall a hinterland that was tremendous in size for a chiefdom. ${ }^{77}$

He perceives Old Kingdom Egypt as a theocracy, with "no clear separation of powers of the theocracy until the Fourth Dynasty, when a grand vizier was introduced as a kind of chief justice and prime minister. "78 The bureaucracy dominated by the royal family ruled up to that point, and he follows Woolley, Childe and Frankfort in assuming that the Pharaoh was responsible for all distribution, and all trading missions to acquire the necessary products. Service concludes that there was no real social stratification or classes in the Marxist sense of the word, and is unable to decide whether the state was repressive or merely bureaucratic, while realizing that evidence for a standing army does not exist. He identified the political stability with the monolithic bureaucracy, and its ideology, based on a monumental obsession with death, which required the organization of labour, and led to the emergence of hereditary guilds of craftsmen. ${ }^{79}$

74 Individual impressive monuments can be overwhelmingly awesome, and yet the labour involved need not require more than an insignificant percentage of the tolal available: the problem is management. Clearly, the geometrical mathematics involved in pyramid construction were far more intricate than that of organizing labour on this scale, and therefore not an obstacle.

75 Service, Origins, pp. xii-xiii; xvi.

70 Service, Origins, p. 228.

7 Service, Origins, p. 229.

78 Service, Origins, p. 230.

79 It will be noted that Witfogel (Orientol Despotism, pp. 250-251) drew completely different, but equally erroneous conclusions, based primarily upon work by Kees. Wittfogel's discussion of the importance of taxation and the monumentality of the architecture bears repetition (e.g., Oriental Despotism, pp. 39-44; 71), while his emphasis 
It is clear that the employment of such data as Service had at his disposal would impel him to provide an internally contradictory interpretation (e.g., the existence of guilds, a division of labour, and a bureaucracy, but the absence of social stratification), and one at variance with the emerging understanding of events. Given the available data, he could not avoid failing to recognize not only that $\langle a|$ there were many early cemeteries indicating social hierarchies and private wealth, but also failed to understand $(b)$ the social significance of the massive tomb structures in Saqqara, Abydos and elsewhere which do not have sociological parallels in the Sumerian city states. He did however identify two unique features of the Egyptian state in its formative period: the lack of a military machine, and the seeming irrelevance of any potential aspirations for local independence in any of the cities, if there were any. ${ }^{80}$ Although it is clear that his interpretation of the nomes as religious centres was exaggerated at best, and erroneous at worst - given the architectural and textual evidence that rural divine temples prior to Dynasty XII were not demonstrably significant - it is interesting to observe that any potential urban character seemingly did not give rise to aspirations for independence, comparable to those frequently experienced in Mesopotamia and early Greece.

Regardless of the errors of differing magnitude, it should be evident that when nonEgyptologists turn to the existing literature and develop views of state development based on their readings, these theories rise to prominence in discussions about the emergence of states and civilization. Not only do implicit and unconscious Egyptological assumptions influence global interpretations of political and economic development, but it is these theories which return to us as "received truth". This places the fundamental basis upon which the discourse takes place at risk of being amateur at best, for our own theories return to us in an unrecognizable form, having been developed in comparison with the European feudal experience and anthropological examples from modern Africa, combined with a superficial review of popular Egyptological literature. The theoretical models available to Egyptologists for use in explaining state structures are thus derived from a faulty understanding of the data published in popular form where Egyptologists have been unconsciously evolving interpretations since the birth of the science. These interpretations - conscious and unconscious have been given prominence and credibility by popularization, and these popular works are the only basis with which political scientists, anthropologists, historians and philosophers

on the fundamental injustice of the system would appear to be exaggerated if applied to Egypt, (e.g., Oriental Despotism, pp. 71-74), and the importance of the army centainly contrasts greatly with his other examples (e.g., Oriental Despotism, pp. 59-67), drawing the carpet from beneath his categorization of Egypt as fundamentally misruled by an enormous military machine. For the later periods of Egyptian history these tendencies do become stronger, and this may be an essential part of grasping the argument.

80 R. Müller-Wollermann ("Präliminierungen zur ägyptischen Stadt," ZÄS 118 [1991]: 48-54) suggests that the problem is one of definition, but also of purpose. She asserts that Amarna can only be used with reference to itself, but it is self-evident that Akhenaten cannot have simply invented and founded a cily in Egypt without some models in view, demonstrating that for Akhenaten a capital city had to have temples, tombs, residential areas, and workmen's' villages, as well as offices. The very concept suggests that such were the typical essential elements of a city in ancient Egypt, otherwise Akhenaten could hardly have had the idea to build something that resembles a city, not only to a city planner, but to any urban-dweller without recourse to lengthy discussions about definitions. 
can work. And their theories are thus based on their interpretation of what they have read. This can only lead to faulty circular logic.

\section{A Near Eastern Perspective}

In southern Mesopotamia early large territorial states were centered on major cities with large populations and requirements far exceeding the limited radius of the agricultural land surrounding them. This was the principal feature of developments commenicing in the fifth millennium, leading through a transformation and increase in the number and size of settlements, followed by a decrease in the size of the individual settlements at the end of the third millennium. These early south Mesopotamian states decisively influenced political and economic developments far beyond their own borders, with direct economic influence reaching well into Anatolia and the Susiana, as well as Egypt. Although developments in northern Mesopotamia are subject to debate, virtually every model would postulate that the earliest states there were first city-states. These were necessarily peripheral to the southern states, and a multi-polar world can be postulated for Mesopotamia at the start of the third millennium B.C. Although large territorial states and empires followed thereon, during the middle of the third millennium B.C. small city states dominating a limited circle of agricultural land about them were typical of the political structures at the time. ${ }^{81}$

The "state" thus experienced several interrelated forms in Mesopotamia while at virtually the same time, a relatively stable form was established and maintained in Egypt, where evolution rather than revolution became the rule. The case of Greece suggests that the polis was the basis of the political order from some time in the second millennium and that individual citystates voluntarily joined confederations, or were militarily defeated by other states, but that the political community was formed by numerous independent city-states, and that most of the city-states remained independent, at least nominally, until making the decision to join or remain with one of the larger confederations in the fifth century B.C. In each case, however, the striking feature is the extent to which urban centres are associated with state formation. Egyptologists have frequently attempted to deny an urban basis for Egyptian civilization, and this has been derided, and yet the institutionalized dynamic behavior of political development in Greece and Mesopotamia does not appear to have been a characteristic of Egyptian history where unification was the rule rather than the exception. ${ }^{82}$

81 For northern Mesopotamia, most recently, cf. T. J. Wilkinson, "The Structure and Dynamics of Dry-Farming States in Upper Mesopotamia," CA 35 (1994): 483-520. For the South: of Nissen, Grundzüge. Given the circular logic employed - observing c ceiling in site size for the third millennium and then examining the possibilities of the agricultural surplus for the same period - Wilkinson's analysis primarily confirms the validity of Central Place Theory for the northern Jazira given political equilibrium, and the logic can be extended into the second millennium. His analysis does not however account for the decline of Titrish Hüyük at the end of the third millennium, nor the enormous size of sites in the Khabur plains during the fourth millennium, so that the relevance of political data must be drawn upon.

82 Cf., e.g. J. Wilson, "Egypt through the New Kingdom: Civilization without Cities," in Kraeling, City Invincible, pp. 124-136. The reasons for this may be sought in the ethnic diversity of West Asian culture, or in the importance of cities, on in a thousand other potential criteria, including inferest rates and access to the sea. Before endeavoring to compare, the quantifiable facts should be established. (Hammond, Cily, repeats much of what Wilson said, and indicates the dangers inherent in failing to investigate). 
Assyriologists have made several serious attempts to organize their immense quantities of data $^{83}$ in terms which can be grasped by students of state formation. In one case, the origins of bureaucracy in the ancient world are contrasted with those of the modern world, which employed bureaucracy to overcome feudal structures, while the Sumerians allegedly employed it to "organize economic activity" and the Egyptians to assure "territorial unification and the mobilization of resources", while Neo-Assyrian bureaucratization essayed to "enhance centralized power at the expense of local authority". ${ }^{84}$

In each case, the goal is the concentration of power in terms of economic resources, but the alleged contrast is missing as these efficient bureaucracies all arose long after the emergence of the state, while the development of writing as an administrative tool testifies to the existence of the bureaucracy before or accompanying the emergence of the state. It is difficult to judge the extent to which the half-urban half-agricultural world of early Egypt or Sumer was feudally governed, although the logical extension of the primitive accumulation of wealth during the Neolithic would virtually demand this supposition, and thus the origins of bureaucracy in the modern world would be identical to the origins of bureaucracy in the ancient world, and the development in fact parallel, with the burgeoning bureaucracy following the state. The implications of the above quoted example reveal that even among the experts, there is a tendency to lump centuries or even millennia of early history together, condensing developments, without separating the importance of the formation from the perfected form. The result is that purely circular reasoning is subjected to criticism, and then a seemingly contrasting position established, without even establishing exactly what is being argued. In this case a feudal model is unconsciously postulated and contrasted at the same time.

In contrast to this diachronic analysis, Michalowski points out that the "administrative reforms were not brought about by the founders but by the consolidators. ${ }^{85} \mathrm{He}$ also points at, and edges around, but does not highlight a virtually insurmountable problem in the history of Mesopotamia: are the various ruling powers to be regarded as dynasties founding new states, or are the various dynasties which succeed one another in territorial units of differing size to be regarded as mere changes of government? To what extent is it justifiable to speak of the emergence of a new state when significant members of the bureaucracy are the same people who served the previous government? 80 In Egypt, there is little contention about the role of the state and the government, but there are nevertheless potential problems. Amenemhat I moved from bureaucracy to royalty, changing the government, but not the

83 One estimate put the number of published administrative documents from the Ur III Period in 1983 at more than 25'000 items: M. Civil, "Ur III Bureaucracy: Quantitative Aspects," in Gibson/Biggs, Power, pp. 43-53.

84 M. Morony, "In a City without Watchdogs, the Fox is the Overseer': Issues and Problems in the Study of Bureaucracy," in Gibson/Biggs, Power, p. 10

85 P. Michalowski, "Charisma and Control," in Gibson/Biggs, Power, p. 60.

86 Cf. Michalowski, in Gibson/Biggs, Power, pp. 59-60. He also suggests, e.g., that "there is even a possibility that the cult of the deceased rulers of Ur was continued under the Isin kings." Michalowski, in Gibson/Biggs, Power, p. 57.

The distinction between state and government is not always clear cut. Political scientists would doubtless agree that the United States of America is a distinct state from the United Kingdom, despite the fact that many civil servants served both governments in the 18 th century A.D. The independent Rhodesia was also a separate state. from the United Kingdom, but describing Zimbabwe as a different state from Rhodesia merely because of a change of government and name is a less persuasive argument. 
state. The power of government to rule in Egypt was divided, e.g., during the First Intermediate Period, but did the state remain ? $^{87}$

N. Postgate has attempted to approach the problem distinguishing between the early forms of empire which "could be as different from later ones as a pristine from a secondary state. "88 Assuming that each stage of the development in Mesopotamia during the formative millennia is characterized by a different form of successor state, and that there is a vast difference between the borders of cultural regions and political entities, he demonstrates the disparity of civilization and polity, identifying a key problem facing prehistorians endeavoring to grasp an intangible in the material detritus of culture. His logic suggests positing a similarity between tribal structures of the first millennium B.C. and the third millennium B.C., which fails to address his own recognition that pristine and secondary states need not be similar, and runs counter to Fried's logic that tribal structures are precisely a feature dependent upon the previous existence of states in order to come into their own. ${ }^{89}$ His emphasis on urban architecture as an expression of domination or political presence probably strikes at the key feature of the earliest ancient Near Eastern states developing towards, from or around urban centres, i.e., city states. The primary difficulty with this specific level of analysis is the contradiction concerning the primary nature of a cily as being far more than a mere expanded version of a village, for cities tend to be associated not only with the extraction of surplus and services and the division of labour, but specifically with trade, being located at nodal points. ${ }^{90}$ It is thus clear that assumptions about the significance of tribes and the nature of cities can cloud the logical path leading to a clear understanding of developments.

I. G. Gelb stood at the forefront of another approach, emphasizing the role of the family and private property rather than the administration. His studies did not advance to the stage of providing a global picture of the Mesopotamian state, at least partially because the discontinuity inherent in the history of Mesopotamia suggests that the state underwent numerous variations. Mesopotamia cannot be conceived globally and the relevant data are still not completely understood. Gelb's object was primarily however to discredit the concept of the temple-economy as the basis of civilization and economy in ancient Sumer, and although his view has not yet been clearly understood and adopted, the goal is significant, for the Sumerian temple economy has widely been postulated as a model for understanding the Egyptian economy, as was clear from the quote from Service, supra, p. 46.

The danger is that inadequate, inappropriate or disproven models - such as the feudal system, redistribution, or the Sumerian Temple State - are assumed to be facts. The

87 Assmann (Ma'at, pp. 219-22) finds $m^{\prime}{ }^{\prime} f$ in the First Intermediate Period (Ma'at, p. 228) while the sage finds that the lawless "have despoiled the land of kingship" (Gardiner, Admonitions, p. 54). This seems to be a fundamental paradox: $m$ " $t$ should be fundamental to the state and kingship, and yel the lowless exercise $m 3^{c} t$ when the divine state has ceased to exist?

88 J. N. Postgate, "In Search of the First Empires, "BASOR 293 (1994): 1.

89 Cf. Fried, Political Society, pp. 170-174; and M. H. Fried, "On the Concepts of 'Tribe' and 'Tribal Society'," in Helm, Essays, p. 15.

90 The earliest large Mesopotamian cities may have been trade centres as much as administrative centres. This particular development may distinguish the Egyptian and Mesopotamian civilizations, and requires extensive investigation. 
"evidence" from Egypt is then understood as conforming to the invalid model. This logic is sufficient to create a standard model for the emergence of the state in the ancient Near East which is based on the model itself and does not correspond to any known facts.

\section{A Wider Perspective: The General Theory of War, Custom and Technology}

These theoretical and historical problems suggest that it is necessary to at least attempt to define and elaborate a general explanation for state behavior which avoids excluding some states, while allowing the potential identification of individual groups of states. Rather than seeking to label these as "early" or "industrial", it may be more useful to identify specific groups within the community of states according to criteria which leap from the resulting compilation. ${ }^{91}$

The simplest fashion to approach the problem is to assert that the concept of the state does evolve, and that sovereignty and the division of powers tend to become more differentiated over time, but to assume that there is in fact a set of all states as members of the group which must fit into a definition, rather than to exclude certain societies as "merely tribal", and others as "industrial" and therefore ineligible, as this inevitably reduces the subset of eligible states to the point that the definition, typology and shared characteristics are identical. The state is a political entity seated in a geographically specific location with a human population with its own social structures, and therefore any theoretical discussion must accept the premise that it must explain why any particular state is the way it is. The issue of sovereignty does not necessarily have to have precedence, but it must be assumed that sovereign but not equal entities are being compared. ${ }^{92}$ As a rule a military conquest precedes the creation of a state, so that the emergence of the state is dictated by the military environment, and not the reverse. ${ }^{93}$ Custom, as observed by the local population prior to the conquest, in law, religion, tradition, social hierarchy and other common features of human life decides the social level which prevails following the military conquest. The level of technological efficiency is to a certain extent affected by the role of custom, but the level of technology is decisive for the

91 As our intention here is merely to identity some criteria that will aid us identifying what might be meant by the ancient Egyptian state, it is not the goal here to discuss the definitions of states, but ultimately it may be possible to distinguish such forms as "military empires", "commercial states", "ideological states" and to associate specific criteria with each unit, and then ultimately to conclude whether the primary features of the "city-states" of ancient northern Mesopotamia and Greece suggest that this become a specific category, or whether, e.g., the Greek cily states should be aligned with the commercial states of the Levantine coast, and the city states of northern Mesopolamia be simply classified as a dwart category of the southern Mesopotamian territorial states.

92 It is a very curious thing that there were no "summit conferences" of the greatest powers in the Bronze Age world, while encounters between kings of the second and third rank were a frequent event in many periods, the implication being that sovereignty was not among equals, and therefore that not all states were equal, as in the modern world as well. The suggestion that Thutmosis II met a Babylonian King (E. Cassin, "Babylonien unter den Kassiten," in Fischer Weltgeschichre 3: 19) is merely due to a misunderstanding of the source material. Although it is improbable that the Hittite king traveled to Egypt, the evidence is slightly more substantial (cf. Kitchen, Pharaoh Triumphant, pp. 90-91), and - should it have occurred - this would have been symptomatic of the changing world at the end of the Bronze Age.

93 Egypt again illustrates this simple and yet improbable principle, as military people were not in evidence in high positions during the Old Kingdom, even though the King was ideologically forever smiting his enemies. 
fundamental characteristics of a state. Taking this approach one can conclude that all political development can be explained in terms of the interaction of these three features: War, Custom and Technology.

At any given point in time, the state thus reflects a dominant military, normative and technological constellation. It has frequently been averred that the military role appears after the emergence of the state, or that the state is the endeavour of a wealthy ruling class to maintain their rule, but in fact, the military decision precedes the emergence of the state, and the wealth only really begins to accumulate after primitive state formation is established, so that while a social hierarchy reflecting previously existing relations might determine the direction in which the state develops, it is more probable that a new hierarchy emerges with the formation of a state, rather than preceding it (although the individual members of the highest level of the hierarchy may be the same people, their social role changes subtly). The technological level of any given state is determined by general factors, but these factors play a decisive role in the ability of the state to function. Although conscious and unconscious normative decisions have a decisive impact on the degree to which technology is permitted to affect the social structure, technology nevertheless plays a significant role of its own, as witnessed by the very fact that all early states are primarily dependent upon agriculture and only secondarily on industrial production, hunting or trade.

It will be noted that the interrelationship of these factors has always been historically decisive regardless of the level of civilization, economic sophistication, or indeed geographical position, and thus that the key to understanding political developments, both ancient and modern, can be found in what we will term the General Theory of War, Custom and Technology, which endeavors to classity every political entity or system as resulting from the combination of these three factors. All political evolution is dependent upon variations in the relationship between the factors. ${ }^{94}$ The interplay between these factors will permit us to grasp the ancient Egyptian state. ${ }^{95}$

This approach allows a more generalized approach to the analysis of historical political evolution, so that states need not be assigned to pre-conceived categories, such as early, modern, industrialist, slave-holding, feudal, capitalist or socialist. It is clear that the states of

94 It is well known, e.g., that when the Manchus conquered China, they themselves adopted Chinese culture, such that the Chinese civilization enveloped the invader, and the same inverse cultural developments took place in Mesopotamia whenever the nomads from the steppe and the desert were able to seize political power: their subsequent behavior corresponded to the political norms of the pre-existing civilization. Social norms of ancient Rome failed to encourage the application of industrial inventiveness to production for economic purposes, although the state made considerable expenditures to improve its military and trade positions. On the other hand, when the Portuguese, Dutch and British traders appeared in the Indian Ocean with their unique religious and intellectual attitudes combined with their advanced military technology, they were not only able to completely transform the world of the Indian Ocean without the necessity of conquest and comprehensive military viciory, but also may have introduced production-oriented economic models to the West transforming the political and economic face of the world, merely through interaction. The field fell gradually into their hands, and they modeled the local states according to their liking - not necessarily adapting local tradition, and therefore substantially marginalizing the ability of these early anthropological examples to serve as reliable sources for data on the stale.

95 This principle was developed before reading Fried, Political Society, pp. 226 ff. The primary difference in the approach offered here is the altempt to highlight what a state is in the widest sense and what a government is in the widest sense, and to not confuse the two concepts, but to explore the role of the government within the state. It is evident that Fried's path and mine diverge only on this track. 
the ancient world evolved in many different directions, and that the states of the modern world are very diverse, although all are classified as modern states today. Thus, the elements of each state at a particular point in history can be plotted onto the diagram of the General Theory of War, Custom and Technology, and then the various categories can be identified, rather than being assigned. It can be assumed that different types of state configurations existed simultaneously at different points around the globe, and that similar states existed at different times in different places.

It is clear that this interpretation appears to represent a synthesis of the approach developed by J. Haas, in contrasting the "conflict" and "integrative" approaches. ${ }^{96}$ One of his primary postulates concerning conflict is however that the conflict took place as social conflict within a single "political" entily, rather than between two different political entities:

In a situation of unequal access to basic resources, the relationship between unequal social groups is predicted to be one of conflict, expressed in some degree of sustained hostility and antagonism within the society. ${ }^{97}$

While reflecting the Leninist and Marxist assumption that the state was an instrument of class oppression, this fails to take account of the basic assumption that states emerge in geographical territories with homogeneous ethnic populations, and assumes that the social antagonism within sociely outweighs ethnic competition between two neighboring societies, a postulate which was disproved by the behavior of the working class at the outbreak of the First World War, and for which there is no more evidence in prehistoric times.

Haas states clearly that the collection of revenues depends upon the implicit use of force within the society, and correctly observes that the actual resort to force need not take place frequently, if the implicit capacity of the ruler to carry out the threat is widely recognized. ${ }^{98}$ This naturally implies co-operation among the elite, and the ability to enforce their collective will, and thus an inherent instability in the hierarchy of social relations, but is hardly indicative of more than the use of military force to carry out ordinary primate social behavior. This same typical behavior which Haas ascribes as a seemingly unique aspect of human behavior in

\footnotetext{
Marx introduced an artificial division between a superstructure and an infrastructure. The border between the two cannot be found because it does not exist: legal culture or religious thought cannot be separated from economics or technology in any of the ancient Near Eastern societies. Without the legal guarantees surrounding land ownership, ancient Egyptian sociely would be inconceivable, and without the pyramids it would not be ancient Egypt. Viewed in Marxist terms, the superstructure must be sought in a dozen discrete places identified by the General Theory of War, Custom and Technology, dependent upon the coefficients of the infrastructure: society is a vast web of relationships, and cannot be split neatly into two.

Chaudhuri (Asia before Europe, p. 5) quoles Braudel as remarking that 'structure' corresponded to the "social, economic and cultural reality, as part of the "longue durée'". The General Theory of War, Custom and Technot ogy provides a type of Braudelian structure for the State.

96 Haas, Evolution, passim.

97 Haas, Evolution, p. 107

98 Haas, Evolution, p. 115. It is interesting that Sir John Hicks (Hicks, Economic History, p. 17) developed a theory likewise based on an initial military occupation, followed by exactions, but that he expressly stated that it was not necessarily necessary to resort to force, and that the impositions could be made voluntarily.
} 
the context of the state also takes place among baboons without reference to the possession of wealth:

The baboon group is organized around the dominance hierarchy of adult males. The nature of this hierarchy varies between groups according to the constitution of each group. The simplest form of organization is probably that of groups in which one, and only one, adult male is conspicuously dominant. ${ }^{99}$

Thus a male's dominance status was a combination of his individual fighting ability $[\ldots]$ and his ability to enlist the support of other males $[\ldots]^{100}$

This evidence contradicts the whole train of thought employed in studying the distribution of wealth as the key factor in state development. ${ }^{101}$ It is logical that the emergence of wealth combined with the presence of force and the ability to employ that force to express superiority can result in the acquisition of wealth through coercion, but this does not indicate that the social inequalities are due to the existence of an unequal distribution of wealth or that this identifies the role of the state as an element of human society. ${ }^{102}$ The state thus becomes merely the ultimate human expression of ordinary primate behavior, which is a tautology, and therefore not the explanation of the phenomenon. The use of force within the community merely corresponds to the prevailing cultural norms, and expectations (custom and tradition), and therefore integration and conflict always play a role in human society, but the ultimate conflict of any significance will always take place between two societies or states rather than within any given society.

The same criticism can be applied to the warfare and trade theories of the origin of the state, as these again depend upon the logic of economics - scarcity of land and resources - as the overriding motivation for expansion or consolidation. It is the variables in combination that contribute to the nature of the state. Just as mere economic compulsion cannot explain heroic initiative, the high social appreciation of glory is an insufficient explanation for the conquest of neighboring regions. Conquest may be a catalyst, but it is not necessarily the determinant factor of events either prior to or following the emergence of the state. ${ }^{103} \mathrm{~A}$ specific level of economic and social development combined with certain norms and technological innovations following a conquest determine the course of events. Thus, seeking the explanation of the state as either the unequal distribution of wealth or the evolution of a

99 K. R. L. Hall and I. DeVore, "Baboon Social Behavior," in DeVore, Primate Behavior, p. 54

100 K. R. L. Hall and I. DeVore, "Baboon Social Behavior," in DeVore, Primate Behavior, pp. 62-63.

101 Cf., e.g., M. H. Fried for social stratification preceding the state: "The State and the Chicken and the Egg; or What Came First?", in Cohen/Service, Origins of the State, pp. 35-47.

102 C. W. Gailey ("Culture Wars: Resistance to State Formation," in Patterson/Gailey, Power Relations, p. 35) unconsciously recognizes this feature, but pursues an argument centered on the assumption that rejection of exploitative relations and repression after reconquest are primarily motivated by economic relations and that these are structurally relevant to the formation and evolution of the state. It should be evident that the appropriation of wealth by the rulers of the state reflects their acquisitive instincts, but that the behavior is not dictated by the desire for acquisition so much as an expression of superiority and power once attained.

103 Khazonov, "Problems," in Claessen/Skalnik, Early State, p. 83: "The conquest theory of the origin of the state [... is unable to convince us. Conquest could mark the origin of the early states [... But the relevant internal conditions, i.e., a sufficient level of development [...] also had to be present for this." 

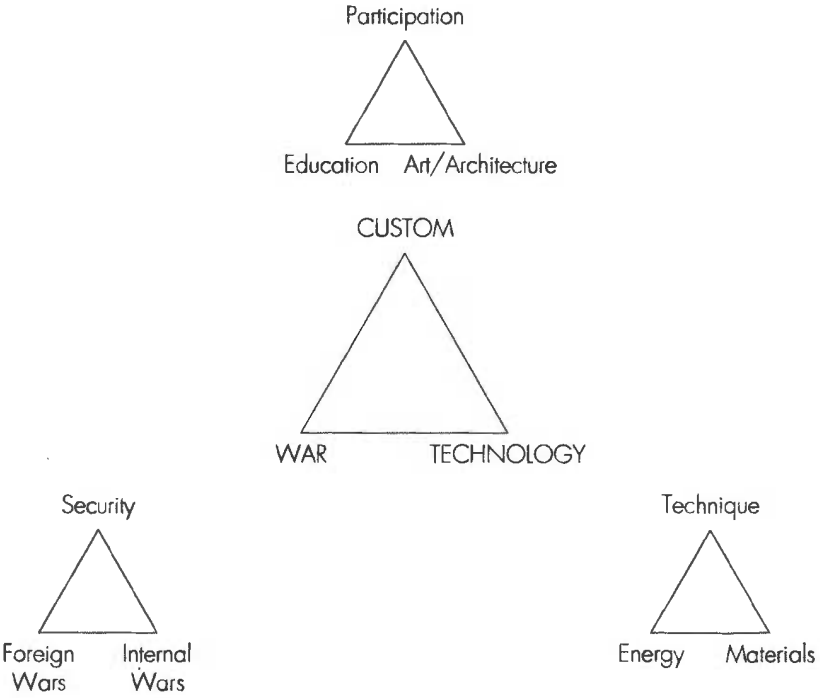

Figure 1. The General Theory of War, Custom and Technology

Following the catalyst of a military event of any kind - a defensive war, a coalition forced by neighboring powers, a conquest, etc. - a new political and social configuration emerges, which is necessarily different from what preceded, and yet emerges from it. Both external and internal influences can play a role, but the decisive feature is the ability of the new government to dictate its terms, the constraints being dictared by the technological level, and customary expectations. Its choice of methods for improving its economic position depends upon the technological and cultural configurations.

Each subsidiary triangle is linked to a potentially infinite set of subsidiary triangles.

The Participation triangles will, e.g., identify the level of political and economic participation, etc. The Education triangles will devolve to law, philosophy, literature, ideology, etc. The Art and Architecture triangles will devolve to various types of art, architecture, and ritual, etc.

Security can devolve to police, guardians, etc., but need not, for security is sufficient to identify the instrument of repression employed by the government to mobilize the resources necessary to realize its acquisitive goals. The Foreign Wars triangle devolves to defense, imperialism and offensive war. The Internal Wars triangle devolves to rebellion, civil war and unification.

The Technique triangles indicate the level of technology available. The Energy triangle necessarily leads to the use of manpower, water, traction, etc. The Materials triangle leads to trade, quarrying and production.

To establish monuments of a corresponding degree of sophistication, a ruler mobilizes the educated classes to devise both plans and a suitable ideology and organize by coercive force the manpower required at the technological level to achieve his desires. The monumentality of the architecture may correspond to the level of political participation, and legitimacy: fewer larger monuments with low levels of participation requiring justification for legitimacy, and more smaller monuments where participation is more open and legitimacy in less need of justification (ct. Wittfogel, Oriental Despotism, pp. 44-45).

The role of the government, the official legal arm of the state, is determined by the balance of achieving basic goals, by exploiting the possibilities of participation and force while observing custom, and maintaining legitimacy. 
social hierarchy are inadequate, since these preceded the emergence of wealth and the state by millions of years.

Although unable to define a state, Egyptologists wax eloquent about the ideology of the Egyptian state. During the Middle Kingdom the "Instructions" were one of the forms in which the ideology of rule and the governing of the state were defined, in the context of the obligations of a ruler to his people. During the New Kingdom, $\mathrm{m}^{2} \mathrm{c}$ became one of pillars of state ideology. The King would smite the enemies of order in a chariot ${ }^{104}$ in order to be able to institute $\mathrm{m}^{3} \mathrm{t}$. This royal ideology was the expression of the principle of the General Theory of War, Custom and Technology. There were in fact at least two ideologies: one was the application of $m^{\prime c} t$ within the borders of Egypt, but the other was the assumption that Egypt had the right to govern the rest of the world, insofar as this was worth attempting. It is clear that this ideology goes far beyond that of the baboons, as far as the latter has been grasped, and therefore some concept of "justice" as opposed to "dominance" must play a role in the concept of the state, being subsumed under the rubric "custom", as the concept evolves through time.

An attempt has been made to illustrate the principles of the theory in Figure 1. Any given state will have a balance between War, Custom, Technology and individual features contributing to each of these rubrics are each determined by an infinite series of subsidiary triangles. In terms of absolute relevance, it is probable that the technologically low early states will have had proportionately fewer germane subsidiary triangles concerning war and technology than those pertaining to custom, which is the expression of human culture, and therefore the key element. Under Custom appear not only literature, art, architecture, philosophy and other purely cultural traits, but also the level of participation, measured in political and economic terms. The role of War in society can be reduced to its primary features of internal relations and external relations, whereby a distinction is required dividing the ordinary use of force within the state, "repression", from the military use of force to quell rebellions, incite civil war, or merely to unify. The most important aspects of technology are the sources of energy and the provision of resources.

The most important feature of the system is however to grasp the message that the ability to mobilize resources for the execution of specific monumental projects does not demonstrate that the authorities control the entire society in a "command economy": it merely demonstrates that they are able to take possession of a certain proportion of the fruits of economic success, and that they can oblige subjects or citizens to work on projects of their choice.

For what is so characteristic of empirical states is political inequality; the existence of a public set of rules that authorize some individuals to perform actions not permitted

104 Using a composite bow to fire arrows with armor-piercing tips from a chariot was the highest of high-tech at the time. Cf. the representation of Pharaoh shooting from a chariot through the copper ingots. Decker (Leistung, pp. 101-102) asserts that the ingots of three fingers thickness were not used, but rather wooden targets. Mcleod (Composite Bows, p. 37) recognizes that the Cypriote ingots were the targets actually employed, but fails to accept the veracily of the representations (p. $37 \mathrm{n}, 3$ ). Later Mcleod (Self Bows, pp. 21-24) discussed the arrowheads, but did not elaborate on performance. Trials indicated that while these arrow-heads may not have pierced the ingot, they will have penetraled into it. The shaft will naturally have broken as a result of the shock, and therefore it must be conceded that the representations cannot be taken at face value. [C. Bergman, pers. comm.] 
to others, the authority to tax, conscript individuals into an army, and perhaps more significantly, to make law. ${ }^{105}$

The key element is thus the legitimacy - and not the power - of those in a position to make law and to coerce those who are subject to their will.

\section{LEGITIMACY}

The entire collection of attributes amounts to the state as a whole in the sense of a living organism. The role of the government appears as an interface, employing war or repression to mobilize resources (energy as manpower and actual materials) corresponding to the level of economic and political participation, in order to carry out its program. This program can include dominance of cultural activities (e.g., literature, art and architecture) through law, justified in terms of ideology, but it need not. One implication of this could be the suggestion that there is an inverse relationship between the level of political participation and monumental architecture as a significant feature of all known architecture, i.e., the more restricted the level of participation, the more monumental the architecture, the more open the level of participation, the less monumental the architecture (or the less the contrast between the proportions of public and private architecture). Such developments have clearly occurred throughout human history, and this has an impact on the reading of the level of economic participation, which is ultimately the source of government wealth for the achievement of its projects, for only the restrictions on private wealth enable the government to increase its resources, and thus, an increase in private participation must lead to a proportionate decrease in monumental public architecture. The same logic applies to literature (e.g., development from Pyramid Texts to Coffin Texts), statuary, etc. until a completely different level of participation is realized. These parameters are decisive for altering the role of government within the state, by increasing political and economic participation.

It is clear that legitimacy emerges from a constellation of variables, based upon the ability to threaten repression and buttressed by ideology. Ideology can be expressed in terms of philosophy, law, architecture, etc. The general tendency of ideology as an expression of justice has only recently (18th century A.D.) been extended to include popular participation in the formation of policy as a source of legitimacy. ${ }^{106}$ If divine right is the source of legitimacy, as expressed through the will of the gods and the worship of the gods, the religious apparatus is a key element of the right of the ruler to govern. Insofar as the gods are drawn into

Barry, Theory, p. 63

100 J. Habermas ("Some Questions Concerning the Theory of Power: Foucault Again," in Kelly, Critique and Power, pp. 83-84) opposes Foucault in his interpretation of punishment: "The actual task of the absolutist theory of the state is not so much to legitimize human rights as to ground the concentration of all violence in the hands of the sovereign." The point is significant, but it is curious that the problems of popular legitimacy are even conceived to have arisen in the context of the European absolutist state. Habermas has likewise revealed the internally inconsistent logic of legitimacy in the context of the democratic capitalist state (cf. Vincent, State, pp. 38-39). Surprisingly, legitimacy does not play a significant role in modern political theory (cf. e.g. the indices of Ball, Theory; Barry, Theory; Bellamy, Theories; Vincent, State). 
questions of legitimacy and government, parts of the religious apparatus must be associated with the government. There are however two caveats which must not be forgotten. (1) Popular cultural activity also pays heed to the gods, and plays a role in ideological activity, but does not necessarily express the same sentiments of legitimacy as understood by the rulers. (2) Insofar as the gods are a source of legitimacy, they cannot be assumed to be part of the government. Correspondingly the religious apparatus reflects popular tradition and political power, but need not be assigned to the government as such.

The concepts of legitimacy and economic participation are inextricably joined, as the legitimate right of the government to levy taxes or to oblige individuals to corvée labour are related to the level of economic participation, and the requirements of legitimacy can also significantly influence trade relations, even more than mere economic requirements might imply. If contact with foreign states is regarded as recognizing their legitimacy, there may be ideological obstacles to popular participation in trade relations, while the actual articles acquired through trade may ultimately be destined for the religious apparatus or monuments related to the expression of legitimacy. Thus, the level of economic participation is determined by the variables of custom, rather than technological development, and the role of government is influenced by the requirements of assuring legitimacy, and carrying out ideological functions. Political and economic participation can differ widely. While including some groups in,

Every state known to history has had a physical apparatus for removing or otherwise dealing with those who failed to get the message. ${ }^{107}$

Thus, the authorities need to include as many groups as possible into those that recognize their legitimacy, and they need to have abilities to put pressure on those who fail to recognize their legitimacy. Divine support can best be exploited in favour of authority if separate from the system of government, while reflecting state interests.

It is frequently assumed that state and government are one, but it thus transpires that the government is one of the official organs of the state. In the early states, the distinctions between the significance of "official" and "informal" elements within the state may have been more diffuse than at other times, and thus it may be futile to explore this issue profoundly, while recognizing its existence. On the simplest level, it is clear that the government of the state is that body which is regarded as the legitimate representative of authority throughout the geographical extent of the state. Even if its source is ultimately divine right, legitimacy implies that the government functions with the consent or support of the people. The key feature of legitimacy is that it guarantees that the question of succession is resolved before the expiration of the term of office of that person or group who represent the leadership of the state. 108

It is possible that questions of legitimacy in most early states were resolved by recourse to the gods, through divine right. Divine support was necessary, but it is useful to recall Napoleon

107 Fried, Political Evolution, p. 231.

108 In his review of Müller-Wollermann, Krisenfaktoren, N. Strudwick (BiOr 48 [1991]: 94) agreed that legitimacy in Egypt "comes down to the acceptance of kingship and the royal succession." This is one of the few points 
who said, "Remember that the god of war and the god of success are marching alongside me, "109 and remarked that he would depose the pope if he did not behave. ${ }^{110}$ Innovative political leaders will have bent the rules, transforming themselves from leaders to rulers and the gods will have allowed themselves to be swayed rather than face irrelevance, so that a government in clear military control of its entire territory is more likely to be able to resolve questions of succession without consulting parties they do not desire to include within the decision-making process, but there is invariably a decision-making process whenever the innovative leader's term of office expires, either due to temporal limits or death. If the gods desire to participate in this process, they must compromise. ${ }^{\prime \prime}$ In New Kingdom Egypt, the Pharaoh was the High Priest of all the Gods, and his chief minister, the Vizier, was responsible for the priests of all the gods. This would imply that the gods were not only the ultimate source of the legitimacy of the ruling pharaoh's right to rule, and to guarantee that he was able to influence or indeed decide upon the choice of his successor, but also that he was ultimately responsible for appointing and arranging that the salaries of the leading religious officers be paid, if not all of the priests in the land.

\section{Eariy Evolution of the Egyptian State}

The relationship between the king and the gods has far reaching implications for our understanding of the concept of the state according to the normative view of the ancient Egyptians, but these theocratic features are evident at an advanced stage, not the primary stage. The earliest political organization which preceded the Egyptian state must have emerged out of the chaos of clan disputes in the Nile Valley or Delta during the fifth or fourth millennium B.C. ${ }^{112}$ Whatever this organization was or did, it created a military vehicle which eventually enabled a single person to assert that he did not have to share the prerogatives of kingship with another mortal within the territory of the Two Lands: this person was the "King of Upper and Lower

where Egyptology and political science see eye-to-eye; cf. the quote used by Müller-Wollermann, Krisenfaktoren, pp. 21-22.

Legitimacy, religion and government have not been established as particular items on the char because they combine various attributes from disparate sectors, and the emphasis at the present moment is on identifying the breadth of the state and the role of the government.

109 Herold, Mind of Napoleon, p. 269

110 Herold, Mind of Napoleon, p. 109

111 Napoleon noted that the popes opposed both him and the Bourbons (Herold, Mind of Napoleon, p. 11 10). Philip II of Spain faced the sagacious opposition of an obstinate pope in his endeavors to subdue England. Despite their success, these efforts reveal that a marginalized religious institution is reduced to obstruction rather than decisive influence.

112 For this development, cf. e.g., Andrassy, Staat and Endesfelder, Staat. The subject is very complex.

Using words like "feudal" and "ribal" is unwarranted, as the evidence indicates that "tribal" structures emerged on the fringe, and after the establishment, of states, and therefore that they could not - by definition - precede the emergence of states (cf. Fried, Political Sociely, pp. 170-174; and M. H. Fried, "On the Concepts of 'Tribe' and 'Tribal Society'," in Helm, Essays, p. 15). On the one hand, this completely marginalizes the relevance of the evidence of the feudal development in Europe where the tribes contributing to the origins of the feudal order in medieval Europe moved into the vacuum of diminishing and weak Roman control (in the same way that the Aramaean kingdoms of the first millennium cannot reflect an earlier development), but it also obliges speculation to be couched in terms of "chiefdoms" the meaning of which is vague, so that the terms should not be understood with their modern significance, but merely as indicators of what was possibly part of the emerging social structure, which we cannot define. 
Egypt". "13 This person clearly owed enormous debts to those who supported him, more than to the divine powers, for it was the recognition by the people of his right to govern legitimately that decided his position, not the divine support. ${ }^{114}$ Eventually the divine powers were obliged to sanction his right to sole rule. This person or his successors thus eventually evolved a mythical origin of kingship which implied that this person was the successor of the very gods themselves as the King of Upper and Lower Egypt. However,

\section{It takes time for a king to become a god. ${ }^{115}$}

This closed the circle, making it clear that kingship was divine, and that authority was derived from the legitimacy awarded by being the successor of the gods. So much is undisputed, regardless of the extent to which the king was a divinity or a mere human being performing a divine mission. That the king was the high priest of the gods suggests that during the New Kingdom at least, the king was responsible to the gods.

The emergence of a single militarily powerful legitimate ruler of the Two Lands does not however imply that previously existing social structures disintegrated, or that they were overthrown by the pre-eminence of a single player in the political spectrum. ${ }^{116}$ The economic potential of the land would be increased as a result of the new king levying obligatory tribute payments, but this does not mean that the new king regarded himself as the sole owner of

Cf. T. Schneider, "Zur Etymologie der Bezeichnung 'König von Ober- und Unterägypten'," ZÄS 120 (1993): 166-181. The conclusion that the title refers to a leader is at least logically compelling.

114 It will be noted that this interpretation diverges from Frankfort (Kingship and the Gods, p. 18) at this point. Frankfort recognized the key political event, but gave it spiritual overtones that are ex post facto correct, but do not necessarily correspond to the actual understanding. Part of the reasoning is based on his dating of the Memphite theology, for which a later date has been suggested, cf., e.g., Schlögl, Tatenen, pp. 110-117.

Not only does Frankfort ascribe particular significance to the theological aspects of kingship, but he also extrapolated the divine essence of a monotheistic god to divinity in Egypt: "But there seems no doubt that Pharaoh's predicate 'god' found its correlate in his absolute power over the land of Egypt and its inhabitants." (Kingship and the Gods, p. 51). There is no evidence that Frankfort was justified in regarding any ancient Egyptian divinity as possessing a priori "absolute power", let alone the king. He cites Kees for claims that the king could revoke property rights, but the inscription of $\mathrm{Mtn}$, e.g., does not indicate any particular recourse to the king for his purchases or sanction thereof.

115 Fried, Political Sociely, p. 231

116 J. J. Janssen ("The Early State in Ancient Egypt," in Claessen/Skalnik, Early State, pp. 215-216) points out the military victory may not even have been among the sedentary people of the Nile Valley but in defense against marauding Bedouin, making the idea of "conquest" and expropriation very improbable. This point is of signal import however because of the use of symbols denoting conquest in the royal ideology of ancient Egypt, and thus underlines that even if it is not the key to defining the territorial extent, social make-up or population ultimately included within the boundaries of a state, the appearance of overwhelming military power is essential for the ideology of a state.

Helck (Wirtschaftsgeschichte, p. 104) writes that at the beginning of Egyptian History, "das ganze Volk als 'Hörige' organisiert und wahrscheinlich im pr-md?'.t an der Residenz registriert [war...]". One wonders not only whether this was possible, but how the new rulers could possibly have developed such an idea, and how they could possibly have accomplished this in the face of opposition, without having developed an extremely effective well armed constabulary and military machine. Such an effort was reputedly attempted by the Incas, as the culmination of nearly three millennia of political and economic development, but not at the start, and the Inca state was destroyed within a century from without, just prior to its crumbling from within, revealing that the stress factors on this form of domination are phenomenal and fail to promise longevity. Such a phenomenal transformation was also accomplished in China in the 20th century A.D. where it was the result of a civil war with the social reformers armed with both Marxist philosophy and machine guns, but even so its duration can be subject to serious doubt, and it was built on the basis of an existing bureaucratic state. 
everything in the country, it merely means that he had the right to rule the country. This is the crux to understanding developments in the following millennia, for modern thinking has tended to assume that divine right and military conquest automatically rendered the material wealth of a country the property of the king who had won the victory. This is in fact a very modern thought. When the British Empire was expanding, one commentator wrote:

Their gain shall be the knowledge of our faith,

And ours such riches as the country hath. ${ }^{117}$

The victory of the new sovereign was however merely a political event which determined the right to rule, and the right to determine a successor. We cannot even estimate the degree to which his "rule" actually infringed on the people at all, and it did not necessarily entail the title to possession. 118

Unless it can be demonstrated that the newly formed Egyptian state actually deliberately confiscated private property at unification in order to re-create it three Dynasties later, and then abolish it again, to let it emerge a couple of Dynasties later, it is more logical to

117 Cited without attribution by Walker, British Empire, p. 8. The fact is however that the British Empire did more for the expansion of Indian Ocean trade than any political development in the preceding three millennia. Stability is good for trade.

118 B. Menu ("Le régime juridique des terres," in Menu, Recherches, pp. 1-2; n. 5) cites Yoyotte, Moret, Seidl, Erman, Revillot and Kees to demonstrate the absolute right of the king to the possession of all the lands in ancient Egypt at all times, but not one single Pharaonic text. Her translation of the Min-texts dealing with the land transactions (B. Menu, "La notion de propriété privée des biens fonciers dans l'Ancien Empire égyplien, "in Menu, Recherches, pp. 56) is at variance with several of the alternative translations (e.g., Gödecken, Meten, p. 11 ; Roccati, Litterature, p. 86), and seems to be more influenced by her assumptions than by the text. R. Müller-Wollermann's remarks ("Warenaustausch im Ägypten des aiten Reiches," JESHO 28 [1985]: 147-148) indicate that the only other alternative for translating is $w$ in the sense implied by Menu would imply that Min was being paid by the nswtyw, and if one were to assume that the king assigned the field to him by virtue of being an office holder, he would probably indicate that the king ordered the payment, and not that some nswtyw were paying him. Therefore, the initial impression that her interpreiation preceded the translation appears to be confirmed, as the general impression that he purchased the fields from private people who were in possession, and then registered them at the royal offices seems compelling.

D. Kessler ("Tempelbesitz," L̈̈ VI: 369) states that the fields not listed in P. Wilbour "must be state lands". As these missing fields make up some 96 per cent. of the cultivable land in the region, it is slightly more realistic to state that the temples had full possession of perhaps 2 per cent. of the land in the area in question, and that another 2 per cent. was occupied by tenants using the land on generous terms, and this statement is quite different to demonstrating that the state owned all the land in Egypt. Whatever limitations there may have been on the right to "own" land, as either "possession" or "property", most of Menu's evidence is derived from P. Wilbour, which covers only a small proportion of the land in question, and her assumption that the $n m h w$ are the holders of the apportioning paragraphs (Menu, Recherches, p. 30) is illogical and self-contradictory as she says that the nmhw are those without titles /"dépourvue de resources propres provenant notament de l'exercice d'une charge, "Menu, Recherches, p. 29), while the holders mentioned in P. Wilbour include priests, stable-masters, scribes and soldiers, etc, and are therefore beneficiaries of the state system. In any case, Wilbour seems to be a temple document, and payments associated with nmhw are to Pharaoh, not the temples, in the Horemhab Decree (I. 31, cf. Kruchten, Horemheb, p. 1 18) as in P. Valençay I Gardiner, RAD, p. 73, 1-2) so that Menu's whole train of ihought on this issue is ungrounded and inconsistent. The evidence that the nmtiw would own land seems to emerge from the evidence (cf. infra, pp. 139f; and the "Stèle d'apanage", G. Legrain, "Deux stèles trouvés à Karnak," ZÄS 35 [1897]: 13-16] but it is equally unwarranted speculation to suggest that the nmhw owned the remaining 96 per cent. of the land not listed in P. Wilbour, and certainly not my contention. 
interpret the evidence of the extensive legal guarantees surrounding private property - as evident in the inscriptions of $M \underline{n}$ - to suggest that the existence of private properly was one of the first things guaranteed by the state, and that personal royal, state, government and official property had to come from the holdings available at unification, and that the initial victory was thus followed by concessions, guarantees and agreements. This suggests the logical conclusion that the very existence of the state was conceived by compromise, the population awarding sovereignty to a single individual in return for, e.g., security. Security of person and security of wealth and property are two of the fundamental requirements which would attract the individual to abandon his own sovereignty, and therefore the concept of abandoning wealth to the ruler as a result of his victory would in fact effectively negate the value of voluntarily participating in the new state structure. ${ }^{119}$ This logic would indicate why military activity need not be associated with rule after unification, and why urban resistance was minimal, which are two of the most distinctive features of postunification Egypt. ${ }^{120}$

In terms of social relationships, the most significant result of the Neolithic was the accumulation of wealth, ${ }^{121}$ but this was a slow process, and not notably successful in comparison with the creation of wealth that followed the appearance of the first states. Regardless of how wealth was distributed - and the available genres of data make it impossible to judge the matter in an intelligent fashion - the fact of distribution is evident, for a failure to distribute the wealth created would have resulted in the death of the system. It is impossible to judge in a sincere fashion whether the earliest farmers decided to render their wealth directly to the gods or to an emerging ruler, and it is unlikely that we will ever know. The next step is virtually impossible to follow for it can be equally logically contended that either (1) private property was

119 It is curious that Min (Cf. e.g., Roccati, Litterature, pp. 83-98) assents that he purchased land from nswtyw, for the concept has been associated with the idea that these were the "king's men", and it is of course precisely the "king's men" who would gain the most from such a hypothetical compromise, as they might acquire large parcels of land where security had previously prevented cultivation. K. Gödecken's thought (Helck, Witschaftsgeschichte, p. 70) is quite close to this, but this is pure speculation, on my part and on hers. R. Müller-Wollermann's ("sw. ijw Bavern als Kolonisatoren," VA 3 [1987]: 263-267) interpretation is only marginally different, as presumably the state will have made colonization or homesteading possible.

M. Gutgesell's ("Die Entstehung des Privateigentums," GM 60 [1983]: 72) note that these nswtyw were the last "Freibauern" makes little sense. He states that cultivable land could be purchased since Dynasty IV at the latest (GM 66: 76) when what he means is that as far back as our inscriptional material goes, land could be bought and sold. He then ascribes the development of the aristocracy to the possession of land acquired by purchase, rather than the opposite, which is what the evidence would imply, i.e., that through the sale of land to officials, the aristocracy contributed to its own downfall. This is however all speculation.

120 It bears repeating that a great deal of the theoretical thought about private property arises because of the Marxist model which omits an early stage of wide-spread private ownership of land, and this is the origin of belief that the emergence of land ownership must follow the European feudal model. This logic is not relevant in view of the facts of ancient Egypt.

121 M. Atzler (Herrschaftsformen, pp. 123ff.) reads the evidence such that a complex economy with a social hierarchy and a division of labour was a feature of the Gerzean period which resulted initially in co-operation, and subsequently in a central government, and even assumes predynastic scarcity of labour (pp. 141-145). His assumptions seem however to be based on irrigation systems controlled by "state" authorities, for which we have no evidence, cf. supra, p. $40 \mathrm{ff}$.

Atzler carefully avoids using the word "state" for any of the Pre-Dynastic or Early Dynastic entities, seemingly reserving the term for the fully fledged developed state of later times (p. 217). 
the inevitable consequence of the Neolithic or (2) that wealth belonged exclusively to the legitimate ruler (s) of the community, by virtue of his (their) political role. ${ }^{122}$

The evidence from the tombs of Neolithic Egypt and Early Dynastic Egypt suggests the existence not only of private property but also the slow development of social stratification. ${ }^{123}$ Although this cannot be argued very far, B. G. Trigger is doubtless correct in asserting that before the end of the Gerzean, "the need to integrate and manage this new economy probably contributed to the breakdown of the relatively egalitarian tribal structures". ${ }^{124}$ The evidence from Abydos certainly confirms that there were differences in the social and economic positions of the rulers and the ruled, and suggests that wealth and political rule went hand in hand, but the differences were not yet vast. The evidence from Saqqara and Helwan can be understood as underlining this fact, or it can be used to suggest that political power and wealth were in fact divided, that there were extremely wealthy members of the communily who were integral parts of the state system, and yet independently wealthy. The tombs can also be understood as expressions of power which was not necessarily reflected in the political process: private property on a vast scale. ${ }^{125}$ Assuming that the first King of Upper and Lower Egypt had won a series of military victories which placed temporal power in his hands without destroying the privately wealthy, the disparity between the various cemeteries is precisely what one would expect, and does not confirm that the new ruling king claimed the right to the possession of all of the properly in the land of Egypt, either in theory or in practice, but it does suggest that the Egyptian state had its origins at the close of the late Pre-dynastic Period.

Assmann's concept of $m^{3}{ }^{c t}$ as "vertical solidarity" 126 underlines the fact that part of the legitimization to rule was the obligation to respect other peoples' rights to life, limb and property. It is typical that one well known legal case from the New Kingdom citing a precedent refers to the so-called "Law of Pharaoh" guaranteeing the right to inherit properly. ${ }^{127}$ The fact that the mere phrase "Law of Pharaoh" suffices to describe this underlines that Pharaoh was able to make law, and that one of Pharaoh's primary responsibilities was to guarantee the possession of private property. This did not mean that he did not tax his

122. It may be extremely important for speculation to recall that the initial shortage will have been seed-corn rather than land at the beginning of the Neolithic, and thus that access to grain rather than land may have been decisive for the first two thousand years of the Neolithic, but this is purely speculative.

123 Cf. Atzler, Herrschaftsformen, passim; B. G. Trigger, "The Rise of Egyptian Civilization," in Trigger, Social History, pp. 33-36, cf. e.g., the assertion of the centralized manufacture of poltery during the Gerzean culture. This would have been big business of the time. The evidence from Ma'adi likewise supports the hypothesis of independent commercial activity (Trigger, Social History, pp. 25-26).

124 Trigger, in Trigger, Social History, p. 48.

125 This is precisely what would lead to the relations of Figures 3.4. and 3.5 in E. Cruz-Uribe, "A Model for the Political Structure of Ancient Egypt," in Sitverman, For His Ka, p. 48. As the families switch from an independent position to one of contributing to the ideological and administrative build-up of the state, their position coalesces around that of the king.

126 Assmann, Ma at, passim.

127 CF.J.J. Janssen and P. W. Pestman, "Burial and Inheritance in Ancient Egypt," JESHO 11 (1968): 137-170. This particular case is particularly interesting because it is specifically stated that the one who buries has the right to inherit the property of the deceased. As both Egyptologists and non-Egyptologists are constantly amazed at the quantities of material goods that were placed into, or spent on, tombs and burials, it is extremely significant that despite the costs, there was enough to inherit to justify the expenses. 
subjects, but it suggests that the basis of his power was the right to "taxation" which in turn implies that people had their private property, and their "free labour power" and that this was exploited, rather than going to the trouble of creating a "command economy".

The immense armies of labourers required for the construction of the tombs of the kings and the leading members of sociely may have been obliged to serve as corvée labour, or they may have received rations in exchange for work, or they may actually have been paid for the effort. It is unfortunately a mere matter of speculation, but it is not inappropriate to assume that some form of obligations may have prevailed, whereby the people of any given "leader" will have owed that leader obligatory services, and that leader may have owed the king services, so that the king could benefit from corvée obligations on a vast scale. ${ }^{128}$ This does not however necessitate central registration of all individuals across the country.

W. Helck suspects that the Dynasty III transtormation changed the political landscape of Egypt completely. Whereas during Dynasty I the royal court was badly understaffed and the supply system not well organized, ${ }^{129}$ Helck suspects that the Egyptian state really emerged when Dioser began to assure regular supplies for the royal court, etc. ${ }^{130} \mathrm{It}$ is precisely in attempting to distinguish a particular date when a "chiefdom" is transformed into a "state" that one faces a serious problem of definitions. J. J. Janssen points out that the quantities of copper implements increased during Dynasty I, and suggests that "it may have been rather the result than the cause of Egyptian civilization" going on to remark that the use of writing indicates the development of an incipient administration, underlining the argument that the origins of the Egyptian state lie in the Pre-Dynastic period, and that the increasing wealth was the consequence of the emergence of the state. ${ }^{131}$ B. G. Trigger notes that "by the end of the Early Dynastic Period most of the principal elements of the court culture of the Old Kingdom were already well established, "132 suggesting that the Egyptian state of Dynasty I which emerged out of the Neolithic is the logical beginning for the study of the Egyptian state - as the Egyptians themselves maintained. ${ }^{133}$

The tombs of the Old Kingdom are decorated with the personified domains delivering their goods to the owner of the tomb, ${ }^{134}$ and in some of the tombs inscriptions specifically state

128 It is difficult to judge the political and economic significance of the Phyles, but certainly Roth, Phyles has identified the most important properties of the system centered around the king.

129 "In der Tat kann man Ägypten in dieser Zeit noch eher als ein Häuptlingstum als ein wirkliches Reich ansprechen." W. Helck, Wirtschaftsgeschichte, p. 30.

130 Helck, Wirtschaftsgeschichte, pp. 30-31

131 Janssen, in Claessen/Skalnik, Early State, p. 217.

132 Trigger, in Trigger, Social History, p. 66.

133 It is evident that - if the logic expressed here is correct - the primary importance of expropriation and acquisition of wealth ascribed to the coercive structures of early states does not apply to Egypt, and thus suggests that the creation and appropriation of wealth followed the emergence of the state, and that the state was not an instrument of crass class oppression, although it must have been dominated by a dominant social stratum which apprecialed wealth and power, as reflected in the construction and equipping of their tombs. The state thus provided the opportunity for acquisition, but not the motivation.

134 Jacquet-Gordon, Noms, passim. 
that the owner paid the workers, ${ }^{135}$ or that he has, e.g., been given a sarcophagus or false door by the king, ${ }^{136}$ which necessarily implies that $(1)$ the king had some authority over the granite and limestone quarries, and (2) that the owner paid for the remainder of the tomb, which again supports the concept of the maintenance of private property on a vast scale, ${ }^{137}$ and the existence of a labour market. B. J. Kemp has however noted that despite his own impression that private commerce and manufacturing were widespread during the Old and Middle Kingdoms, ${ }^{138}$ one of the principal concerns of the state administration was the transfer of produce to the court, and that the explosive growth of state employment could potentially have produced "serious pressures on the agricultural surplus." 39

Royal decrees of the Old Kingdom partially exempted temple land from royal interference, 140 but we have no idea of the quantities of land which came into the possession of the temples. It is this protection from royal interference that provides us with the earliest references to fiscal activity in a developed sense. ${ }^{141}$ These decrees are also among the most significant sources concerning divine temples during the Old Kingdom, for most of the temples preserved as ruins date from the following Middle and New Kingdoms, or are dedicated to the funerary cults of the kings of the Old Kingdom. ${ }^{142}$ It is certain that the kings founded, built, expanded and provided for the divine temples and for the gods during the Early Dynastic Period and

137 Helck (Wirtschaftsgeschichte, pp. 73ff.) suggests a change from a period when the King supplied officials with tombs during Dynasty IV to a reversal in Dynasty $V$ when the official had to provide for the tomb himself, but it is possible that this can be traced back to the limited quantity of data available. Even where tombs are allegedly assigned, this does not mean that the construction was paid for by the king, as specific sites can be awarded as an honor, upon which the official would have to erect a tomb at his own cost. All this is however highly speculative, and it is simply fair to conclude from the documentation that most of the recorded cases indicate that the owner paid for the tomb, where the malter is recorded. It is equally logical to contend that tomb owners were always as a rule obliged to pay for their tombs, and that only exceptionally did the King provide entire tombs, although he may have provided a number of high-quality items as a matter of course.

138 B. J. Kemp, "Old Kingdom, Middle Kingdom and Second Intermediate Period," in Trigger, Social History, p. 81. "Furthermore, the archaeological record suggests a complex and extensive marketing system, $[\ldots]$ and makes it hard to accept that this was entirely, or even largely, the responsibility of a closed government redistributive system."

139 Kemp, in Trigger, Social History, p. 176. This is - of course - not logically consistent, for consumption will have only risen gradually with slow demographic growth: the labour necessary to produce sufficient corn therefore remained the same, but the size of the labour force was diminished, as the division of labour removed workers from subsistence production. The constraints will have been the surface area of cultivable well watered land and the work force.

140 Goedicke, Königliche Dokumente, p. 2, item 1.

141 The earliest references to census-type activifies combined with exactions belong to a very early stage of social and economic development, and it is purely speculative to assume that we can draw reliable conclusions concerning ancient Egyptian perceptions of the existing social relationships using modern vocabulary

142 This is one of several logical conclusions to be drawn from the Abu Sir papyri. P. Posener-Krieger (in Lipinski, State and Temple, pp. 139-140) has been cited supra (p. $33 \mathrm{n} .30)$ for her interpretation of the logic, but it is equally plausible to argue that the kings set up divine temples to supply their funerary temples (as would be the logical conclusion following Winter (apud Posener-Krieger), because they knew the supplies would be more reliable. That the kings of the New Kingdom incorporated their funerary temples into the domains of the wealthy Amun - rather than the penurious Osiris - is probably not an accident of geography. 
the Old Kingdom, ${ }^{143}$ but it is not certain to what extent support for the divine temples was an important aspect of economic activity as a whole, or in terms of royal expenses, or in terms of temple support. ${ }^{144}$ It is not certain that the temples had their own means enabling them to pursue major construction works, and it is possible that our evidence is representative in indicating that the traditional deities of Abydos and Coptos were still among the most important outside the domain of the royal monuments, but this is difficult to judge.

According to Helck's understanding, it was the event of liberating certain parts of the temple bureaucracy and above all the employees of the royal mortuary temples during the final part of the Old Kingdom that eventually led to the existence of a class of skilled craftsmen in search of work, for which they could receive remuneration in the private economy. ${ }^{145}$ This is based on the supposition that a bureaucratic development had dominated the market for most of the Old Kingdom. It would however be far more "logical" to assume that quality craftsmen were only beginning to appear on the market in large numbers at this point, and that it was the very existence of this group that led to the creation of the finely decorated tombs of Dynasties $V$ and $V I$ (both private and royal), as well as to the construction of temples, which were themselves only beginning to get a firm footing in the economy at this point.

143 Cf. Helck's notes (Wirtschaftsgeschichte, pp. 54-55) on the limited data concerning temples, and above all his observation that before Dynasty $V$, the temples probably did not have much land (Wirtschaftsgeschichte, p. 54). While probably valid, his deduction is merely based on the fact that the kings did not donate very much land to the temples before then. This may be related to the amount of land that the kings had at their disposal, the extent to which they supported temiple independence, and the (unknown) holdings of the temples themselves. It merely underlines the point that royal support for the temples was limited during the Early Dynastic period and the early part of the Old Kingdom. The same conclusion emerges from D. Kessler's notes ("Tempelbesitz," LÄ V: 366-367). H. Goedicke ("Cult-temple and 'State' during the Old Kingdom in Egypt," in Lipinski, State and Temple, pp. 113131) likewise draws attention to the paucity of information about temples during the earlier period, but makes an important distinction between full-time and part-time temple employees, and associates part of the growth of temples with official cults associated with the state and kingship. He also suggests that the systematic exemptions of temples became a substantial financial burden by the end of the Old Kingdom and contributed to its fall. A. M. Roth ("The Organization and Functioning of the Royal Mortuary Cults of the Old Kingdom in Egypt," in Gibson/Biggs, Power, pp. 138-139| indicates that the part-ime staff and lack of competition among the mortuary temples during the Old Kingdom left the field free for the provincial officials when the power of the central government of the Old Kingdom began to decline. This would tend to contradict Goedicke's assumptions as the temples should have become independently politically important if resources were increasingly available to them. As both the temples and the government were eclipsed in the subsequent phase, it would appear superficially that the precarious hold on power maintained by the provincial authorities was based on a lack of power at the center, and not a diffusion.

144 Aside from the Solar temples of Dynasty $V$, indications of royal construction on a large scale are rare. Reused blocks naming earlier kings and occasional statues are found (e.g. Pepi | at Hierakonpolis), but this does not demonstrate that major construction projects were carried out exclusively by the king.

145 Helck, Wirtschaftsgeschichte, pp. 103-106. Helck ("Tempelwirtschaft," L̈̈ VI: 417) perhaps unconsciously contradicted this position in suggesting that the temples were assuming a progressively more important economic role in the economy towards the end of the Old Kingdom, but neither interpretation corresponds to the evidence. The evidence presented by R. Müller-Wollermann ("Warenaustausch im Agypten des alten Reiches," JESHO 28 [1985]: 121-168) can be used to demonstrate the opposite of her hypothesis of the non-existence of a labour market. The reason prices were not inscribed on tombs could be merely that one did not want to contest with the gods the value of the work. If the craftsmen were content, that sufficed. Mentioning precise prices would complicate the religious aspect. For this tricky matter, cf. D. A. Warburton, "Some Remarks on the Manufacture and Sale of Shabtis," BSEG 9-10 (1984-85): 345-355. It is very probable that the failure of the expense to match the expectations meant that people were wary of recording specific figures in such contexts in the event that they be regarded as insufficient in the eyes of some responsible official in the Netherworld or the Beyond. 
R. Drenkhahn has approached the problem from a different angle, assuming that the craftsmen were merely a professional group which found employment in various different branches. She concluded that the majority of the craftsmen must belong to some kind of establishment:

Their various affiliations can be expressed in the captions, by adding a $p r-\underline{d} . t$ or $p r-$ '3, nswt, w'b.t. There are also numerous references to craftsmen who only have a professional title, without additional details, which renders a precise identification difficult or impossible. For it appears inadmissible in advance to recognize their identity as an independent group, which is not obliged to either a private person or the state. ${ }^{140}$

Thus, the data is understood to indicate that a large group of independent craftsmen may have existed, but to recognize this fact is impermissible. She then proceeds to postulate that the presence of the royal specification should be understood as indicating a rise in stature, without assuming that it would be equally possible to interpret this as meaning that a private craftsmen had merely performed in the royal service, and adopted the corresponding title (cf. e.g., "By appointment to Her Majesty", a claim found on products of private enterprise). Drenkhahn's section entitled "Craftsmen in the Service of the State (King)" speaks for itself. Under this heading however, she writes:

This involves the title extensions $p^{2}{ }^{c}{ }^{3}, p r-n s w t, n s w t, w^{c} b . t$ as well as the indication of belonging to a temple. ${ }^{147}$

An-accidental - peculiarity of the sources is that craftsmen working in the temple workshops are not mentioned in the Old or Middle Kingdoms, but appear in the New Kingdom. ${ }^{148}$

Not only does she seemingly assume that royal and temple service is identical in being that of the state, but she also assumes that the specification implies constant employment, and uses this argument to dispute $\mathrm{H}$. Junker's interpretation in one case, where it is in fact merely the juxtaposition of two interpretations of the significance of the specification, ${ }^{149}$ neither of which is compellingly correct, given the nature of the sources. C. Eyre suggests that $\mathrm{Hmwt}$ $\mathrm{pr}^{2} ;$ are to be understood as "state craftsmen" in the Old Kingdom, and should be distinguished from others. ${ }^{150}$

It is clear that thinking along the lines of Drenkhahn's arbitrary conclusions contributed at least indirectly to Assmann's absolute conclusion:

The role of art and craftsmanship is therefore even more significant. In Egypt art and craftsmanship were state monopolies and virtually militarily organized. ${ }^{151}$

140 Drenkhahn, Handwerker, p. 134. [My translation]

147 Drenkhahn, Handwerker, p. 142. My translation.

148 Drenkhahn, Handwerker, p. 154. My translation.

149 Drenkhahn, Handwerker, p. 146. [My translation].

150 C. Eyre, "Work and the organization of Work in the Old Kingdom," in Powell, Labor, p. 13.

151 Assmann, Ma'at, pp. 52-53. [My translation]. According to Sir John Hicks's theory of economic development. (Hicks, Economic History, p. 23), these craftsmen must have belonged to the royal entourage, and thus we see the influence of Egyplology directly affecting economic history. 
Assmann constructs his vision of the Egyptian state on the assumption that even Drenkhahn's assumption that some craftsmen were attached to privale people was bold. Both Assmann and Drenkhahn fail to accept the ultimate implications of the evidence for private enterprise within the state: even for the Late New Kingdom, when temple craftsmen are recorded, both those of the temple of Amun and the craftsmen at Deir el-Medineh sold their wares on the private market, despite their "state" affiliations. ${ }^{152}$ Both Drenkhahn and Assmann also disregard the evidence of the individual tomb proprietors in the Old Kingdom who specifically stated that they paid the workers who built their tombs.

R. Müller-Wollermann has shown that independent craftsmen building private tombs probably voluntarily negotiated their remuneration in advance, and that they were paid in bread and beer which they then used to exchange for other products at local markets. ${ }^{153} \mathrm{~A}$. M. Roth has tied the phyles into the social and construction system of early Egypt, both private and royal. ${ }^{154}$ She has also plausibly suggested that not only the value of bread and beer, but also that of cloth was used "as compensation for labor" "with well-known values". ${ }^{155}$

It would thus seem that there are no indications of temple craftsmen during the Old Kingdom - and contra Drenkhahn, by no means accidentally - but that craftsmen are associated with (1) the royal sphere, and (2) private foundations, and that (3) alongside these is a pool of craftsmen and manpower altached neither to the king nor private people, accompanied by (4) the phyles as the vestige of the ancient clan system, representing a social net, including both private and royal leaders. The basic significance of this is to underline the appearance that $(a)$ royal projects and (b) tombs and mortuary cults were the primary sectors of the nonsubsistence construction and service parts of the economy, and that their existence contributed to the stimulation of both service and article exchange markets.

We thus perceive that the Old Kingdom experienced the emergence of a differentiated economic structure, positing (1) royal and (2) crown lands; along with (3) temple lands; (4) private funerary domains; (5) private land holdings; combined with (6) a labour market; probably including (7) private commercial trade; ${ }^{150}$ and (8) the sale of land, as well as (9) the assertion of the royal right to a proportion of the non-royal holdings, i.e. income, use, and wealth taxes, probably supplemented with corvée labour, which is a kind of tax in kind.

152 Cf. e.g., D. A. Warburton, "Some Remarks on the Manufacture and Sale of Shabtis," BSÉG 9-10 (1984-85): 345-355; e.g., Giomale, Verso 8 (Botti/Peet, Giornale, pl. 40; KRI VI: 590ff; Allam, HOP, pp. 331-335)

153 R. Müller-Wollermann, "Warenausiausch im Ägypten des alten Reiches," JESHO 28 (1985): 145-146.

154 Roth, Phyles, passim. For the labour force, composition and context, cf. C, Eyre, "Work and the Organization of Work in the Old Kingdom," in Powell, Labor, pp. 5-47. Although excellent, his interpretation is marred by attempting to weave contradictory evidence together, while the approach used here is to follow a more logical line.

155 A. M. Roth, "The Practical Economics of Tomb-Building in the Old Kingdom," in Silverman, For His Ka, p. 236.

150 While the Old Kingdom kings were definitely intimately involved in trade with foreign countries, it is curious that the direct connections across the Sinai came to an end with Dynasty ll at the latest. This can be interpreted in a number of ways, one of them being the severance of private trade with the strengthening of the Egyptian state, and thus the possibility of the invocation of royal prerogatives in international trade from the beginning of the Old Kingdom, or the simple result of the development of economic muscle, which made the private trade cease to be lucrative. It is however clear that whatever international trade existed during the Proto-Dynastic and Early Dynastic periods may have been private: whether this continued on a large scale after Dynasty III is probably impossible to answer decisively. 
Thus, while some scholars of the ancient Near East have pursued a definition of the state far beyond that consciously employed by political scientists, other scholars have been unable to break the bonds of political theory, and consequently assume that the Egyptian state with its public and private property, legal guarantees, legitimate ruling bodies, etc., must have emerged out of a feudal past. These conclusions must be lined up with the assumptions of those political scientists who contend that the state did not exist before the 16th century A.D. Very few Egyptologists would consciously agree that there was no concept of the state before the Greek polis. The result is that some elements of modern Egyptological theory are based on self-contradictory circular logic: logic based on conscious and unconscious assumptions. The fact that there was a state structure can hardly be used as evidence for feudal relationships having preceded it and molded it. The degree of private enterprise demonstrated by the records stands in clear contrast to the absence of any recorded "redistribution" on a large scale. The state was collecting and constructing, but it does not seem to have been redistributing, primarily because the population had their own sources of income in the private sector.

Regardless of what preceded it, by the end of the Old Kingdom, the Egyptians most assuredly had a form of state which political scientists would have difficulties in discounting. The Egyptian state recognized several categories of participant in the process of law: the king, his princes and officials, clans and clan leaders - potentially as local officials, the population at large, the gods, their temples and their priests all had their proper place in society. The rights of each were defined by virtue of the relations between them. The strength of the King vis-à-vis god and man during Dynasties III and IV is clear, and the growth of that power during the preceding period is as clear as its decline during the following period, but for the situation of the Old Kingdom, much of our speculation in detail is purely guesswork based on hypothetical analyses of fragmentary sources of uncertain and debatable significance.

The state was however clearly decisive for the social and economic development of the land. The number of important structures increased explosively, and the cemeteries of the private people are grouped around the tombs of the most important kings. The kings had enormous temple complexes constructed, for themselves and to a lesser extent, the gods. It was their officials who constructed huge tombs /although these need not have been funded out of their professional income). It was clearly the advent of the Old Kingdom state which emerged out of the nascent late Pre-Dynastic and Early Dynastic State that created this wealth, transforming a largely clan dominated sedentary Neolithic culture, albeit with long distance trade connections with Palestine and Mesopotamia. ${ }^{157}$ The security derived from legitimate government contributed to economic growth, and the legitimacy derived from ruling and recognizing individual property rights also authorized the legitimate rulers to "expropriate" goods and "conscript" services.

157 For a reviews of evidence and references, cf. r. E. Levy, et al. "New Light on King Narmer and the Protodynastic Egyptian Presence in Canaan," BA 58/1 (1995): 26-35. and A. P. Largacha, "Relations Between Egypt and Mesopotamia at the end of the Fourth Millennium," GM 137 (1993): 59-76. 
During the Late New Kingdom, a thousand years after the end of the Old Kingdom, the state was still probably the single most important economic player in the Two Lands, and thus it was the activity of the state that assured that demand would increase, and therefore production, wealth and prosperity. During the New Kingdom, we are not however obliged to turn to speculation about the relationships between the institutions and the people. legal specifications delineated the rights and obligations of the state and also both directly and indirectly, the rights and obligations of the subjects, and the rights and obligations of the officials. Assuming that the state existed and that it was an evolving organism, we can furn to the actual documentation in order to return to our theoretical considerations about the role of the state in ancient Egypt. One of the most decisive points is however the emergence of powerful divine temples in the thousand years separating the Old Kingdom from the New.

On the one hand, the architectural remains testify to the extent of divine construction during the New Kingdom, but the absence of temple workshops and craftsmen during the Old Kingdom suggests that the interpretation of the architectural remains need not be ascribed merely to accidents of preservation and reemployment. The temples played a different role during the New Kingdom than during the Old, but it is difficult to quantify a difference based upon the hazards of preservation. The material permits certain observations to be made about the New Kingdom which contrast with the impressions of the Old Kingdom. Documents relating to land ownership are in short supply, but it is possible to demonstrate that the agricultural land of New Kingdom Egypt was in the hands of the King, the temples, officials and private people. The exact rights under which officials and private people could "own" land are however the crux of the problem.

The Egyptian Pharaoh of the New Kingdom was personally wealthy, and responsible for Crown lands, and the ultimate High Priest of all the gods and head of state. ${ }^{158}$ The primary difference between the Old and New Kingdoms was in the development of politically and economically apparently independent temple organizations and we will return to this point in the final chapter, after having examined the economic structure of the United Kingdom of Upper and Lower Egypt, and the evidence of the texts relevant to state involvement in the economy.

158 This makes his position analogous to that of the Queen of England who is one of the richest people in the world, but receives an allowance from the government to carry out official functions, and the head of the Church of England when in England, and the Church of Scotland when in Scolland, and also head of state of the United Kingdom and many states of the Commonwealth. Just as the New Kingdom Pharaoh had viziers to manage government affairs, the Queen has prime ministers to head the various governments of the states, and thus in Britain, there is no question that the Church of England is part of the state, and that it is less arguably part of the government, as the apex of the state hierarchy is one level above the apex of the government structures. 


\section{THE ECONOMY}

Yvan Koenig explained that the papyrus he published was a palimpsest because demand far outstripped supply during the Ramesside Period, ${ }^{159}$ citing Sir Alan Gardiner, who noted:

There is good reason for thinking that, in the Ramesside period, the demand for papyrus as a writing material far outran the supply. To this state of affairs the very frequent employment of potsherds and fragments of limestone bears witness $[. . .]^{160}$

Viewing the same evidence, J. Černy concluded

These frequent palimpsests can best be explained if we assume that papyrus was a relatively expensive material. ${ }^{161}$

After going over the evidence and concluding that ready made papyrus rolls were not expensive, J. J. Janssen cites Černý, indicating that in fact,

papyrus appears to have been far from scarce in the Village [...] Though of course ostraca, being quite without value, were cheaper still, one can hardly say that papyrus was expensive. ${ }^{162}$

R. Caminos took issue with this assertion. His reasoning was that because they re-used papyrus, it must have been expensive, asserting that Janssen's

view that papyrus was not expensive rests on weak arguments that no court of law would admit as evidence. ${ }^{163}$

It should be clear that the logical sequence linking the use of ostraca and palimpsests with scarcity and high demand led to the assumption that papyrus was expensive, based on the assumption that the Egyptians viewed things through a functional competitive market-type mentality. That even Janssen associated the facts that papyrus was cheap and abundant indicates that he implicitly assumed that prices were formed as a result of demand and supply, although he explicitly denies that this assumption has been demonstrated. ${ }^{164}$ When Janssen defended the evidence of the prices, he withdrew the argument for abundance, but like Caminos, he did not do so with strong support of the evidence, and primarily because he had perceived the logical inconsistency in his stance, and sought to correct the error of making the association. ${ }^{165}$ A roll cost about the same as a pair of sandals, but rolls do not appear to have been as abundant as sandals. This makes it uncertain whether sandals were

105 J. J. Janssen, "The Price of Papyrus," DE 9 (1987): 33-35. p. 190.

Gardiner, P. Chester Beathy I, p. 2.

Černy, Paper and Books, p. 23.

Janssen, Prices, pp. 447-448.

Janssen, Prices, pp. 560-61.

Y. Koenig, "Livraisons d'Or el de Galène au trésor du temple d'Amon sous la XXe Dynastie," Hommages Sauneron,

"Some Comments on the Reuse of Papyrus," in Bierbrier, Papyrus, p. 52 n. 23. 
comparatively expensive or papyrus comparatively cheap, but confirms that abundance and demand and supply do not seem to have been as relevant to price formation as some scholars would be inclined to conclude. ${ }^{160}$

We should hesitate before drawing perfectly "logical" conclusions about "economic" behavior. The tendency to make economic assumptions which contradict the evidence remains with us, as there is a lot of similar involuntary economic reflection in the Egyptological literature. The following notes may appear to be slightly longer - and more tedious - than required, but it is useful to review the discussion before embarking on a study which is avowedly economic in orientation.

\section{CONSUMPTION vS. ProduCtion}

While an unconscious misunderstanding of the relevance of market rules has dominated much of the peripheral discussion of the economy, the term "redistribution" has dominated much of the conscious discussion of the economy. It should be emphasized that not only is there room for doubt about the relevance of the laws of supply and demand, but that there is also room for doubt about the relevance of the term redistribution. Regardless of how important the term is, fundamentally "redistribution" does not by itself account for production, for the origins and development of wealth. The wealth acquired - in order to be "redistributed" - was acquired by taxation: the surplus is produced by the farmers. And insofar as this surplus was "redistributed", it was given to a different class: the dependents of the state. It is therefore a question of circulation.

The father of modern neoclassical economic theory,

[...Alfred] Marshall maintained that the theory of supply and demand was not the scientific basis of economics. The central problem of economics, according to him, is not the allocation of given resources, but rather how the resources became what they are. ${ }^{167}$

Exploration of the significance of the demand which created resources in ancient Egypt is the central point of the present work. The object of this work is thus not to demonstrate either the existence of unemployment or surplus production, but to examine the economic implications of those elements of the economy which we can grasp.

100 I cannot follow J. Baines's logic, for he states bluntly "that it was never very cheap" but cites Janssen, whose data apply only to the New Kingdom and thought that he had demonstrated the opposite (cf. J. Baines, "Literacy, social organization, and the archaeological record: the case of early Egypt," in Gledhill, State and Society, p. 196).

167 Screpanti/Zamagni, Economic Thought, p. 180. 
Our object is alien to the Egyptian way of thought, since the Egyptians very probably never tried to understand their economy in the way that they consciously created at least one state ideology. Understanding the economy is however of fundamental interest not only for its own intrinsic attractions, but also because it influences us in interpreting the evidence (cf. supra, p. 71). Enthusiasm has however been restrained and the level of debate limited, at least partly because the sources are elusive, and the terrain unfamiliar.

During this century, the interpretation of the economic history of the classical world has undergone a revolution. The Graeco-Roman world had a passionate love for stories, biographies, inscriptions but also figures and data, and Rostovtzeff employed this data effectively to create an economic and social history of the ancient world. ${ }^{168} \mathrm{His}$ interpretation was not consciously biased, and concentrated on social history in the light of economic and technological improvements, all in the context of a clear understanding of the basic historical trends of the ancient world. Following the publication of his works and numerous similar studies, Sir Moses Finley postulated that the ancients could not possibly have understood economics in the current sense of the word. Thus he sought to find illuminating sources in classical texts with no apparent bearing on the economy, and developed a theoretical model for the Graeco-Roman world corresponding to our own image, and yet at variance with it. ${ }^{169} \mathrm{His}$ view has since been assailed as slightly paternalistic, and current work suggests that the economy of the Graeco-Roman world was much more in accord with Rostovtzeff's view than was widely thought as a result of Finley's work, so that for the world of classical antiquity there is an increasing tendency to return to standard methods and approaches. 170

The entire history of classical Egyptian civilization stood however on the other side of the chronological and psychological divides separating the Bronze Age from the Iron, the monetary economy from the non-monetary, and therefore no theoretical assumptions can be taken for granted, no concept unexamined. The ancient Egyptians stand magnificently apart. It is a challenge to approach an unfathomable aspect of a distant society of whose very existence the ancients were not conscious.

It is important to face the obstacles and study the economy as our interpretation of a society depends upon our prejudices, and it is obviously imperative to identify the parameters by which we view any society: either consciously or unconsciously, virtually every scholar has

108 Rostovtzeff, Hellenistic World and Roman Empire.

109 Finley, Ancient Economy.

170 Cf. e. g., Kloft, Wirtschaft, Rathbone, Economic Rationalism. It is worth noting that Finley's selective exploitation of sources allowed him to distort the interpretation of basic economic data. Finley cited the case of Trimalchio to demonstrate that the ancient world thought exclusively in terms of self-sufficiency (Ancient Economy, p. 36), and concluded: "he was openly delighted with his wealth and boastful about it, and he was equally pleased with his self-sufficiency". It should however be noted that Andrew Carnegie boasted "that he could fish in his own lochs, drink milk from his own cows, eat grapes from his own greenhouses, [... and allow his guests to shoot over his own moors" (W. Newlands, "Rich Treats await at Carnegie's old home," W FT [5/6 August 1995]: |XX). That Carnegie was the greatest industrial capitalist of his age underlines that such boasting can be directly associated with the acquisition of wealth for its own sake, and cannot be used to argue about entrepreneurial motivation. 
an interpretation of the Egyptian economy. It is however dangerous to theorize about the economy and then conclude that the economy was the most important thing in the world, as it was only part of the basis of the civilization, not the civilization. Realizing this however does not negate the obligation to examine the issue, but to enhance our understanding we must define many institutions, as economics is about social relations, and human society is made up of customs and institutions. And we cannot be certain about the appropriate weight to assign to any given method of approaching the subject.

Traditionally, and practically, the most significant approach is and will remain the study of texts in and of themselves. This must however be supplemented with other methods. One is the employment of advanced statistical analysis. ${ }^{171}$ Another is the use of ethnographic material. The methods of economic history should also be drawn upon. And economic theory must also be included, and interpretations and conclusions examined in the cold light of theoretical observation.

Using ethnoarchaeological methods anthropologists, archaeologists and other scholars draw on information gained from existing primitive economies to understand conditions in the ancient world. While valuable for providing insights about the use of technology and about the quality of life in Palaeolithic times, and informative about the nature of village and rural life, it does not prove anything: it merely illustrates. Anthropologists deliberately seek out the poorest parts of the world and study the habits of the natives there, but even there, technologically, many of these peoples are actually above levels achieved in the ancient world, and yet they reflect a different type of society. We must be wary of employing such data as economics represents the study of aspects of social relationships and not the level of technological achievement, so that the mere use of identical technology cannot permit conclusions about economic relationships. The ancient Egyptian economy and state were created by social and political innovators, and even if the methods that they used were technologically primitive, their social and political accomplishments were not. Their state was millennia ahead of many of the African and Asian societies sought out by anthropologists in search of ethnoarchaeological parallels, and therefore such parallels must be used with caution, and only in a context where they can throw light on a specific type of social constellation. ${ }^{172}$

The study of economic history and the study of economics are two different fields, using different methods. Vastly oversimplified, economics is a new science dominated by the study of the laws governing the functioning of modern capitalist economies, for the science of economics grew up with the industrial revolution, and has been primarily concerned with the development of the capitalist world, with its system of production for markets and trade

171 S. Katary applied statistical methods to the study of the Wilbour Papyrus, and achieved results which would have been inconceivable without computer-aided analysis (Katary, Land Tenure). It is clear that we must increasingly think in terms that enable our data to be fed into computers, but computers do not enable us to infer and draw conclusions: they can only aid in data management, and statistics are in short supply given the existing structure of our science. It is only by flexible approaches and original thoughts that computers can be used effectively: the approaches must be identified and attempted. In this domain the study of the ancient Egyptian economy is still in its infancy.

172 Janssen (Prices, p. 540) notes that the very items still traded today in Africa are those recorded in his volume: "Clearly not much has changed in Africa over three millennia." 
based on profit and comparative advantage. Economic history is a field which uses traditional historical methods and approaches to pose questions from an historical viewpoint, and is generally more closely allied with history and social history than with economics.

One reason for the divergence of economic history from economics is the fact that originally the primary concern of economics was the distribution of goods in an economy dominated by scarcity. Needless to say, industrial economics today are no longer dominated by the scarcity of goods (for industry can apparently produce in virtually unlimited quantities), but by the twin scarcities of consumer credit and employment. Scarcity of goods was however the primary feature of human experience since the emergence of the first hominids, and therefore economic history is dominated by the fashion in which goods were distributed among the various social groups which made up any given sociery. Economic history and social history are thus mutually related, but only in a more distant fashion to the science of economics, which is today dominated by financial problems.

It is important to grasp the extent to which our models of ancient Egypt have contributed to a slightly imbalanced understanding of economic history in the larger context. It is very rare that economic history and theory are combined in a single work.

The distinguished economist Sir John Hicks did however mention Egypt several times in his A Theory of Economic History, leading to the conclusion that Egypt could be no more than a Revenue Economy. ${ }^{173}$ His assumption is that the specialization of labour preceded the emergence of the market. Although he does indicate in one reference that a market may have existed at a very early date, he then logically excludes it, by suggesting that the bureaucracy was predominant. It is however difficult to understand how a revenue economy with craft specialization can emerge without being globally primarily either a redistribution, market, or command-economy. The revenues must be levied on some group, and therefore the assumption that a revenue economy can function well in a pre-market environment is difficult to integrate into a comprehensive theoretical model. ${ }^{174}$

Sir John was doubtless conscious of these problems, but the data available to him did not reveal that the evidence for an early form of market economy existed. In defining the emergence of the market, Sir John identifies two significant features. One is the existence of craftsmen who produce for a market. The second is the existence of contracts dealing with commercial transactions. Since both of these items clearly existed in ancient Egypt, a market economy existed according to his own definitions. He failed to recognize it however, because the data was not clearly presented.

A far more sophisticated presentation of the Egyptian economy is presented by North in his Structure and Change in Economic History. ${ }^{175}$ His analysis is however based on the as-

173 Hicks, Economic History, pp. 18-24

174 One of the primary difficulties is that people tend automatically to assume that the mere possession of a title meant that the person holding the title was exclusively an office holder, and that this was his primary source of income, as in the case for bureaucrats today. This was not necessarily the case in ancient Egypt where the members of the Gang worked on free lance projects, and in Roman Egypt it is clear that entrepreneurial gentlemen farmers bore official titles (cf. Rathbone, Economic Rationalism, passim).

175 North, Economic History, pp. 97-99. 
sumption that property rights were limited, and that the centrally organized command-economy apparent from the texts and presented in the conventional histories is the only economy. His entire argument is based on the redistributive model for Ancient Egypt. The assumption that problems related to property rights were the principle barrier to economic development in antiquity is derived from the interpretations of the economy currently available. Since it can be argued that the guarantees were specifically stated by Mtn at an early stage of historical development, and that these guarantees were so widely taken for granted that they never appear again - except implicitly in economic activity and explicitly in the "law of Pharaoh" then the entire basis of his argument rests on an interpretation of the evidence which is certainly not comprehensive.

It should thus be clear that presentation of the data mixed with interpretation can lead scholars from other disciplines to fail to recognize the difference between interpretation and presentation. The use of the theory should thus be clearly marked, and the actual sources clearly identified. The assumption that it is possible to work without theoretical models is difficult to accept, for preconceptions always influence one's conclusions, as we saw in the case of the price of papyrus mentioned at the beginning of this chapter.

\section{VALUE OF ECONOMIC THEORY}

Economic theory can be applied to pose questions concerning factors potentially influencing relationships between social groups to throw light on ancient economic activity. The use of modern economic theory to elucidate long term economic trends does not imply the assumption of economically "rational" behavior - it is merely a tool used to enhance understanding. There is however no agreement on the value of theory. J. J. Janssen writes that familiarity with modern economic thought can actually be an obstacle:

$[\ldots]$ odd as it may seem to be, profound knowledge of the modern market-directed economy proves to be of little value to the egyptologist and may even be obnoxious since it tends to blind him to the fundamental difference between the modern Western world and ancient Egypt. ${ }^{170}$

This objection to the use of market-oriented thought would appear on the surface to be entirely justified, but there are three reasons which suggest that the judgment is premature. On the one hand, (1) modern economic thought is not the solid mass of logically coherent and consistent theory it is often perceived to be, and (2) scholars of the ancient world are generally unaware of theoretical developments, but even more serious is the difficulty posed by $(3)$ those selecting alternative theories.

One of Janssen's main contentions is that anthropological material can contribute to understanding ancient Egyptian sociely. This point is important and well taken. But it need not be relevant to the use of modern methods of economic analysis. In his study of Commodity Prices, Janssen indicates that he has avoided theoretical discussions because he regards this 
as premature (p. 1), and yet proceeds to discuss the theory of prices in anthropological terms (pp. 556ff.), because:

these prices do not have the precise meaning that prices are supposed to have in our society. ${ }^{177}$

With this statement Janssen draws two conclusions: (1) that the word price has a "precise meaning [...] in our society", and (2) that the prices in Deir el-Medineh were somehow not normal, according to this standard. This was however accomplished without discussing any standards defining what a price is "in our society". Having avoided modern theoretical discussions of price formation by asserting that his approach was not theoretical, Janssen was justified in declining to discuss modern economic theory. His preference for the use of anthropological examples is likewise methodologically consistent, as the use of anthropological examples is not theoretical, and they can illustrate behavior patterns. In themselves however, anthropological parallels do not constitute a proof of the validity of an alternative theory, nor can they disprove a theory against which they are not measured. There are two different categories involved. One is modern theory, and the other is anthropology.

Merely claiming that modern theory is insufficient to understand Egyptian prices does not alone demonstrate the inadequacy of modern theory. Nor does it provide a methodological justification for using anthropology as an alternative to modern economic theory. There should be no doubt whatsoever that in studying a society such as ancient Egypt anthropology can - and should - supplement economic theory. Janssen himself was and is conscious that the two are not the same, and has frequently avoided theoretical discussions, as he regards this as premature. Janssen understands the logic of his procedure, and is aware that the path he chose was that followed by anthropologists like Dalton and not necessarily that of Polanyi. This has not widely been recognized however:

Following the scholarship of J. J. Janssen, for ancient Egypt, most scholars have tried to build on the models of pre-market economies devised by Karl Polanyi. ${ }^{178}$

The basis of this approach is the assumption that modern theory cannot be used, rather than the demonstration that it is either unsuitable or incorrect. Eichler has argued that the mere relevance of Polanyi renders the use of modern theory inadmissible, and thus reveals that the methodological system employed by Polanyi's adherents does not share traditional scientific attitudes towards investigation and demonstration. ${ }^{179}$

It is contended here that modern economic theory can provide aid, if properly employed. Modern theory has several different price theories, so that the problem is not that the theory is inadequate for the ancient world. There is no complete agreement on the issue. Nor has modern theory managed to provide a comprehensive theory of profit. ${ }^{180}$ This is an obstacle

177 Janssen, Prices, p. 515.

178 E. Bleiberg, "The Economy of Ancient Egypt," in Sasson, Civilizations, p. 1375.

179 E. Eichler, "Polanyi - Keynes - Warburton," GM 131 (1992): 25-31.

$180 \mathrm{Cl}$. Obrinsky, Profit Theory, passim, and Screpanti/Zamagni, Economic Thought, pp. 255-256. 
to the assumption - widely held among Egyptologists - that understanding of ancient economics demands that one emphasize the lack of understanding of profits in the ancient world. As modern theory has no comprehensive theory of profit, it is not justified to assert that modern theory is based upon profit. Profit may be a significant aspect of the modern economy, and it may have been a feature of the ancient economy, but the significance of this is not certain, and profit theory is certainly not an essential aspect of modern theory. Thus, the problem is that economic theory is difficult to grasp, but this alone does not demonstrate that it is an obstacle to understanding.

Related to this is the third problem: that of the use of "alternative theories". The primary bastion here is that built around Polanyi's opposition to theories based on exploitation. This has led several scholars to model their conclusions according to that theory, rather than either modern theory or the evidence, without realizing that Polanyi did not produce any economic theories. ${ }^{181}$ It is however not clear that Polanyi's message has been widely grasped. Despite the seeming assertion that Polanyi provided "adequate tools of analysis" 182 there is some confusion about how Egyptologists should understand this. Although allegedly an adherent of the Polanyi approach, E. Eichler specifically argued in favour of redistribution, stating at the same time that the possession of land was a source of prestige in ancient Egypt, and maintaining simultaneously that the state ruthlessly abused its citizens. Polanyi maintained however that private property was one of the basic features of an exchange economy, and that justice played a central role in the redistribution economy. Eichler's lack of familiarity with the principles of Polanyi's system thus led him to make statements implicitly and unwittingly discrediting the entire "theory", and is thus an unusually valuable illustration of the dangers of the failure to grasp theory. ${ }^{183} \mathrm{E}$. Bleiberg has attempted to deny the profitmotive in ancient Egypt, asserting this as a fact, based on Polanyi. Polanyi made no such claims however.

R. Müller-Wollermann has attempted to disavow the evidence of a market in favour of reciprocal trading, influenced by Polanyi's categories, and this has led her to theoretically far reaching conclusions. ${ }^{184}$ Among her conclusions is the claim that in view of Polanyi's theory, market exchange is excluded by evidence of the presence of reciprocity and redistribution. She has also speculated that redistribution is a kind of reciprocity. These are clearly theoretical possibilities with great potential, and suggest a system which can serve to understand economic and social patterns.

181 Cf. D. A. Warburton, "The Economy of ancient Egypt Revisited Yet Again," GM 146 (1995): 103-111

182 J. Renger, "On Economic Structures in Ancient Mesopotamia," Or. 63 (1994): 165.

183 E. Eichler, "Polanyi - Keynes - Warburton," GM 131 (1992): 25-31

$M$. Gutgesell has also endeavoured to use economic theory at a high level. In contrast to some other participants he suggests that the use of theory be recognized, on the assumption that market economic assumptions be avoided (cf. "Wirtschaff," LÄ VI: 1277 n. 3). His familiarity with theory is however unfortunately incomplete. CF. D. A. Warburton, "Keynes'sche Überlegungen zur altägyptischen Wirtschaft," ZÄS 118(1991): $78 \mathrm{n}$. 12. In the example cited there he refers to the failure of prices to fall as a demonstration that the economy was determined. In fact however, one aspect of Post-Keynesian economic analysis is the recognition that prices do nol necessarily fall, although they do rise, so that his demonstration reveals only his own distance from the theoretical base.

184 R. Müller-Wollermann, "Warenaustausch im Ägypten des alten Reiches," JESHO 28 (1985): 121-168. 
It is not clear however that Polanyi contended that one could argue by using evidence of redistribution to eliminate the possibility of market exchange (and Janssen certainly does not claim this). Equally, according to Polanyi, redistribution was determined by asymmetrical social relations and reciprocity by symmetrical relations. Ultimately, therefore, MüllerWollermann's conclusions defy integration into Polanyi's system, although the assumption of the validity of his system was her point of departure.

Grandet interpreted P. Harris I in terms of Polanyi's theories, and thus permitted his philological conclusions to be influenced by his economic assumptions. More seriously however, he ultimately placed the implementation of the concept of "redistribution" into question, and thus implicitly undermined the "theory" that he thought he was applying. ${ }^{185} \mathrm{~J}$. J. Janssen repeatedly found evidence confirming the market, yet denies the validity of the evidence by asserting the primary nature of the redistribution system. Janssen has also suggested that the tools issued to the Gang were given to them in the context of the redistribution economy, although this is not really part of redistribution in an economic sense. ${ }^{180}$

It would seem thus that Polanyi's system (1) has been insufficiently well understood, so that those applying it failed to agree upon the meaning, or that it (2) is inadequate. This alone indicates that Polanyi's system has certainly not been demonstrated to be the "best available tool of analysis". ${ }^{187}$ These cases demonstrate that premising any kind of conclusions with theoretical presuppositions is not a problem limited to the unconscious application of market economics. They throw doubt on the scientific value of Polanyi's "theory" and certainly show that it is not very well understood. They clearly demonstrate that the use of any theory is in and of itself dangerous, if used without undue caution. These cases certainly cannot be used to justify the suggestion that modern theory is unsuitable: they merely advise caution.

Objection to the use of modern theory also neglects the fact that there are major debates in the field of modern economic theory and policy concerning state-interventionism vs. laissezfaire, protectionism vs. free trade, and about the various theories of the origin of value and price. Several alternatives are available with theory wrestling with the very problems concerning the role of the state in the economy, and the role of the market, and the origin of value, that are extremely relevant to ancient Egypt. The objections to spurning the choice of subtle theory in favour of Polanyi, merely because he disputed the relevance of the market exchange system do not warrant repetition. ${ }^{188}$ By renouncing the use of modern economic analysis - even as a simple means of verification or testing - Egyptologists are distancing themselves from mainstream thought, and actually hindering communication with economic historians who might be interested in the data, which can only lead to a greater gap separating Egyptologists from economics. Interpreting data without theoretical analyses and presenting this material as "uninterpreted data" to the social and economic historians does

Grandet, Papyrus Harris.

Cf. Janssen, Markt op de Oever, J. J. Janssen, "An Exceptional Event at Deir el-Medina (P. Turin 1879, Verso II)," JARCE 31 (1994): 93: "[..] the workmen, being at the receiving end of the redistribution system, were provided with copper for the tools they needed for their work in the royal tomb."

Renger, "Economic Structures," Or. 63: 165, quoting Silver.

Cf. D. A. Warburton, "The Economy of ancient Egypt Revisited Yet Again," GM 146 (1995): 103-1 11 
not render a service. It is essential to separate the material from the methods and the interpretations, so that historians can judge for themselves. ${ }^{189}$

Another objection to theory is the interpretation of the role of the market in modern economics, particularly capitalist economics. Dobb has suggested that capitalism requires not only production for the market, but middlemen acting on the profit motive. ${ }^{190}$ Marx maintained that the relevant criterion was merely the existence of wage-labor. Weber suggested industrial production associated with rational accounting. Polanyi maintained that the crucial step to the exchange economy occurred with the emergence of markets for land and wage labor. ${ }^{191}$ Wallerstein has characterized capitalism as being intimately associated with the state, with the state bearing the losses, and private entrepreneurs making the gains. ${ }^{192}$

We noted above that the ancient Egyptian economy had the basic criteria to be a market economy according to Sir John Hicks. These other sources suggest that the ancient Egyptian economy could even be classified as a kind of nascent capitalism, for we have wagelabour, a market for land, production for the market, and state involvement. There is no evidence of rational accounting in the earliest periods or of an organized credit system, but peculiarly, banking does not appear to be regarded as an essential feature of capitalism. It would thus appear that ultimately the only objection to the use of theory is the mere intention of a separatist approach. It is however difficult to justify on any sound economic or epistemological basis.

Even if modern theory was directly applicable however, one great obstacle to a thorough economic analysis of the ancient Egyptian economy is the fact that we are inevitably interpreting when discussing the most basic data. The Egyptian economy was based on the use of grain. Grain was collected as "taxes" or "rent" and paid out as "wages" or "rations", and used as a medium of exchange. It was harvested on both (a) large plots which belonged to king, the temples, the government and - possibly - powerful individuals and (b) small holdings, yet we have no idea about the proportion of GNP ${ }^{193}$ consumed by government expenditures and income, not to mention the total GNP, so that a sectoral breakdown is virtually impossible. Thus we have no way of judging things on a micro level, and this would ordinarily prevent further speculation, but the field of macro economics exists to aid in this gap: we do not need to grasp the way an individual firm or government department operated in order to be able to provide an outline suggesting the conditions under which they made their decisions.

This does not discredit the use of theory, but does advise caution in making assumptions about what theory is. Economic theory is a far more subtle tool than is apparent at first sight.

189 As J. J. Janssen and R. Müller-Wollermann did in exemplary fashion in their studies of commodity exchange.

190 Dobb, Capitalism, pp. 4-11

101 Polanyi, Livelihood, p. 10

192 Wallerstein, World-System, I: 348

193 Gross National Product (GNP) is equal to the financial value of the total quantity of goods and services involved in transactions in a given country annually. 
Economics defines relations within a system, with the emphasis on social relations, rather than technological arrangements. It is not the intention here to suggest that Rh-mi- $R^{c}$ and Thutmosis III discussed, e.g., monetary policy or unemployment as such, but they will have discussed arrangements for income, and improvements in organization to increase the yield. Obviously their ability to run an economy working in concrete terms is a worthy object of study, as it was enormously successful. Prosperity was not only the basis of their success, it was also the result. Theory may help us to understand how, although it can not help us to understand why.

When Wolfgang Helck published his Wirtschaftsgeschichte, in 1975, he explicitly stated that it was nearly impossible to produce such a book as he himself had written, ${ }^{194}$ and abstained from an attempt at economic analysis. Yet six years before, Siegfried Morenz had bravely produced a pioneering comprehensive interpretation of the ancient Egyptian Economy using Thorstein Veblen's Theory of the Leisure Class. ${ }^{195}$ Prestige-Wirtschaft im alten Ägypten effectively explained the entire economy of ancient Egypt in a convincing fashion, based on the principle of consumption. From the purely economic viewpoint Morenz's approach was ill-founded, as Veblen's approach emphasized (1) that society was being transformed through technological development and (2) that rentiers were social parasites making money off industry and consumers. There is no evidence to substantiate the provision that technological development was the cause of Egyptian economic activity / rather than the result), and there is no evidence of a rentier class, because the administrators who organized the economy can certainly not be termed primarily parasitic (at least until the final developments) and traders are not conspicuous enough to indicate the particular subspecies of rentier postulated by Veblen. An historian of the ancient Egyptian religion, Morenz had however captured the spirit of economic activity, and identified the most crucial and central feature of the ancient Egyptian economy: the circulation of goods. ${ }^{196}$

It sounds like a mere tautology, for economics is about the study of the circulation of goods, but Morenz successfully demonstrated that the central administration played an important part in this circulation, which was dominated by the royal and temple economy, the temples being the "repositories for the revenues from the empire". 197 This feature of circulation or

194 Helck, Wirtschaftsgeschichie, pp. vii.

195 Although Helck did state that his work was not theoretical, he took an extreme position on Morenz's book: "Die letzlich von Morenz ins Spiel gebrachte Vorstellung von der Prestige-Wirtschaft kann als unanwendbar außer Ansatz bleiben, schon weil die grundlegende Vorstellung von einer ägyptischen Primitivkultur nichı paßt - genausowenig wie die Vorstellung einer leisure class in alı̈gyptischer Zeit, da eine solche in einer Wirtschaft ohne Geld und einer Gesellschaft, in der Vererbung mit der Ausführung des gleichen Amtes verbunden war, unmöglich ist." (Helck, Wirtschaftsgeschichte, p. 203). The simplicity with which these thoughts are expressed is admirable.

196 Morenz, Prestige-Wirtschatt, pp. $36 \mathrm{ff}$.

197 J. J. Janssen ("The role of the Temple in the Egyptian Economy during the New Kingdom," in Lipinski, State and Temple, II: 509) quotes D. Redford. Morenz (Prestige-Wirtschaft, pp. 34-35): "Es muß die Feststellung genügen, daß die Tempel faktische Verfügungsgewalt über Arbeitskräfte, Ländereien und auch Produktionsmittel gehabt haben. [...] Im Ganzen kann man davon ausgehen, daß die Tempelwitschaft allermeist auf Dotationen der Könige beruht $[\ldots]^{\prime \prime}$ 
"redistribution" through a central administration had previously been allegedly identified as a key feature of the contemporary economies of Western Asia, where it was emphasized that the market did not fulfill the function of accelerating circulation of basic goods, although commercial trade was significant for a number of strategically significant articles, such as copper and tin.

The other significant element of the economy that he effectively identified was the vast wastefulness involved in manufacture and construction for the Beyond, which he characterized - after Veblen - as "conspicuous consumption". Klaus Baer made the same point about the ultimate destination of the money - going into tombs - but conspicuous consumption was not a mode of production, as it only accounts for one part of the equation: consumption. ${ }^{198}$ And one should not be misled by the quantities of objects in the tombs, for the "law of Pharaoh" implies that it was well worth going to the trouble of providing for a proper burial for another person, merely in order to acquire that person's property, which means that the greater part of it must have remained above ground. ${ }^{199}$

Strongly influenced by the assumption that price fluctuations are a significant indicator of any economic system, M. Gutgesell has endeavoured to provide several mutually contradictory explanations of the Egyptian economy, including the suggestion that the principal element was its determined nature. ${ }^{200}$ By employing a single variable to justify the choice of an explanation for the economy, he undermines the potential relevance of his conclusions. There is an enormous difference from understanding why a particular variable behaves the way it does, as opposed to employing a single variable to understand a system. ${ }^{201}$ The resilience of economic and ideological continuity - at a reduced level - during the so-called Intermediate Periods when political power was fragmented suggests a priori that a determined economy could not survive such an event. ${ }^{202}$ It has been pointed out elsewhere that the use of the Keynesian theory using the variable of infinitely elastic demand can account for the continuity of activity on a reduced level, but we will return to this infra (pp. 122ff.). ${ }^{203}$

198 K. Baer, "An Eleventh Dynasty Farmer's Letters", JAOS 83 (1963): 17.

199 CF. J. J. Janssen and P. W. Pestman, "Burial and Inheritance in Ancient Egypt," JESHO 11 (1968): 137-170.

200 M. Gutgesell, "Wirtschaft," $L \ddot{A}$ VI: 1275. Gutgesell fails to note that not one single planned economy survived for anywhere near as long as the Egyptian cult-oriented system. To take but a few examples, the Inca Empire, the Spanish and Portuguese overseas imperial systems, the French mercantilist state, both the Dutch and English East India companies, the Soviet Union, and the Ur III centralized system were all (respectively) eclipsed within some two and half centuries, some in considerably less time.

201 This point in particularly important as Gutgesell used price stability to demonstrate that the ancient Egyptian system could not have been a market economy, while we will ultimately establish that this price stability can be explained in market terms, and therefore one must clearly distinguish the methods of reasoning (cf. infra, pp. $329 \mathrm{ff}$ )

202 It has been shown that certain provincial areas were actually capable of improving their situation when freed from central administration, through an intensification of social relationships centered on individuals just below the apex of the political structure: cf. S. Seidlmayer, "Wirtschaftliche und gesellschaftliche Entwicklung im Übergang von Alten zum Mittleren Reich," in Assmann, Problems, pp. 175-217.

203 Cf. D. A. Warburton, "Überlegungen," ZÄS 118 (1991): cf. pp. 78 n. 12; 79-85. One principal problem of modern economic developments is the absence of a tendency for prices to fall, while they do rise, so that M. Gutgesell's position is untenable, cf. p. 78 n. 183 supra. 
Several serious attempts have since been made to analyze the Egyptian economy and to understand its basic features, and these are also supplemented by a great number of marginal remarks about the economy, that suggest that the authors have an interpretation in mind, but do not express that interpretation clearly. One of the most important of the theories consciously employed was based on the work of the Hungarian economist Karl Polanyi. ${ }^{204}$

\section{POLANYI}

The term "redistribution" appears as one of four types of interchange identified by Polanyi whose argument was that modern capitalist mechanisms were not available in antiquity. According to him, an important element of historical understanding was the assumption of the lack of a market which created demand which led to production, and therefore that the greater part of economic activity consisted of demand being heavily influenced by supply, and that supply did not necessarily react to potential demand in the market. And that therefore, the existing financial arrangements encouraged acquisition by trade rather than production, and that trade was likewise primarily dominated by demand rather than supply, and promised greater profits than production in any case. And that trading profits were made without taking risks. Based on these assumptions, Polanyi developed an approach which posited the existence of four different types of economic category, as opposed to the single - market - category which had been uncritically and unconsciously applied before Polanyi approached the issue. ${ }^{205}$

Polanyi therefore distinguishes "household", "reciprocity", "redistribution" and "exchange" as primary forms of economic integration. Not only did he never provide an economic analysis of the mechanisms by which the ancient Near Eastern redistribution economies functioned, but his very postulate for the importance of the term redistribution was based on controversial evidence and conclusions. Based on preliminary interpretations of the evidence from Kültepe (which have since been contradicted), 200 Polanyi argued that the appearance of an individual who could participate in market behavior on several levels was a recent phenomenon, and therefore that market behavior was a recent development.

This argument led to two other related contentions. One was that one of the significant events in economic and social history was the moment when wage labour appeared, and land became an asset which could be bought and sold, for his logic interpreted this as

204 Polanyi himself was familiar with the Graeco-Roman material (as demonstrated in the posthumously published volume, Livelihood), but he also endeavoured to co-operate with others more familiar with the ancient material, cf. Polanyi, Trade and Market.

205 This paragraph has been used virtually verbatim in D. A. Warburton, "The Economy of Ancient Egypt Revisited Yet Again," GM 146 (1995): 105.

206 K. Veenhof (Trade, pp. 356ff.) demonstrated the erroneous basis of Polanyi's use of this data (K. Polanyi, "Marketless Trading in Hammurabi's Time," in Polanyi, Trade and Market, p. 19). Polanyi's posthumous volume (Polanyi, Livelihood) repeated the arguments as if they had gone unchallenged (pp. xl-xli); cf. Polanyi, Livelihood, p. $x x$; Polanyi, Trade and Market, p. viii. J. Gledhill and M. Larsen ("The Polanyi Paradigm and a Dynamic Analysis of Archaic States" in Renfrew, Theory, pp. 197-229) effectively demolished the relevance of Polanyi's. theory as presented in the final work (Polanyi, Livelihood) to Mesopotamia and Mesoamerica, so that a great part of the evidence upon which the theory was buil has now vanished. 
meaning that man and nature became mere objects in the market-place, and that this was the decisive event transforming the world from reciprocal exchange arrangements to the market dominating life. ${ }^{207}$ The other was that the "distinctive feature" of redistribution is the pattern of "rights and obligations", 208 asserting that the system was based on reciprocal obligations, and that the cynical market-oriented interpretation did not take the propaganda seriousiy. ${ }^{209}$

The assumption of the validity of Polanyi's "theory" has however not been accompanied by either a complete grasp of it nor general agreement about it. Bleiberg has stated that redistribution in Polanyi's model is the most suitable system for understanding Egypt, and that the profit-making motive was absent in ancient Egypt.

The absence of money as a means of obtaining wealth was paralleled by an absence of a profit motive and price-making markets in the Egyptian world view. ${ }^{210}$

Janssen stated however that

nobody as far as I know ever made the unlikely statement that in ancient Egypt people were not interested in accumulating wealth. ${ }^{211}$

Polanyi himself did not dispute the profit motive. His claim was not that the profit motive did not exist, but rather that trading was risk-free:

In effect, participation in business is participation in profits. ${ }^{2.12}$

The mere fact that the tombs were robbed for their precious materials makes it clear that the ancient Egyptians were conscious of the fact that in their economy silver and gold were money equivalents, and confirms that they were interested in accumulating wealth. The teaching of Ani specifically admonishes investing wisely. ${ }^{213}$ While correct in asserting that according to Polanyi price-making markets were absent, Bleiberg's short sentence thus still contains three fundamental errors concerning: (1) Polanyi, (2) the Egyptian economy, and (3) the Egyptian mind.

Similarly, Bleiberg assumed a division in the economy of ancient Egypt, trying to fit inw and bikw into categories. ${ }^{214} \mathrm{He}$ concluded that the inw were the king's personal "income", and that this consisted of "gifts". R. Müller-Wollermann also discussed inw and likewise concluded

207 Polanyi, Livelihood, p. 10

208 Pearson, in Polanyi, Livelihood, p. xxxiv.

209 Polanyi, Livelihood, p. 15.

210 Bleiberg, "Economy", in Sasson, Civilizations, p. 1382.

211 1. J. Janssen, "Debts and Credit in the New Kingdom," JEA 80 (1994): 136, n. 35.

212 K. Polanyi, "Marketless Trading in Hammurabi's Time," in Polanyi, Trade and Market, p. 21.

213 Cf. Lichtheim, Literature II: 138 "If wealth is placed where it bears interest, It comes back to you redoubled"; II: 139: "Do not be a mindless person, Then your god will give you wealth." Quack, Ani, p. 101: "Besitz soll zinstragend angelegt werden, Damit er vermehrt zu dir (zurück) kommt"; p. 105: "Stell dich nicht töricht an, Wenn dein Gott Vermögen gegeben hat."

214 E. Bleiberg, "The Redistributive Economy in New Kingdom Egypt: An Examination of Bskw(t)," JARCE 25 (1988): 157-168. 
that it meant "gifts". 215 Although they agree about the meaning, both inadvertently neglected texts which might have suggested other conclusions, and thus both reached conclusions suggested by Polanyi, but failed to take account of additional evidence which might not have led them to the same conclusions. This certainly does not demonstrate the theoretical value of Polanyi's method.

The Assyriologist J. Renger has rushed to the defense of Polanyi's arguments, which were assailed by the economist M. Silver. ${ }^{210}$ It is to Renger's credit that he dealt with this, for Silver's book is not only a serious challenge, but filled with errors revealing that its author was not at home in the ancient Near East. Renger confirmed that Silver amassed an extraordinary amount of data concerning ancient Near Eastern economics in the endeavour to disprove Polanyi, but Renger demonstrates that Silver's command of the data is itself wanting. Silver alleges that Polanyi made 14 critical points against the market economy, and Silver assumes that he has demonstrated that Polanyi is in error. While demonstrating that Silver's claims are exaggerated and methodologically questionable, Renger's own arguments in favour of Polanyi remain unconvincing.

Renger dismisses the Old Assyrian trading colonies by remarking that "they clearly represent an exceptional case". 217 He then states:

Scholars of several disciplines have thus recognized the principle of redistribution as a major economic, social and political determinant in the Inca state and have claimed that it played a decisive role in parts of the history of ancient Egypt, and could also be observed in ancient Cyprus, Crete, and the Mycenean states on the Greek mainland. ${ }^{218}$

In the Inca state, there does not seem to have been much "redistribution": primarily, it was a system based upon the appropriation of labour, but included both private properly and collective ownership. While it may have been what Hicks termed a Revenue Economy, or a "command-economy", "redistribution" was not its fundamental feature. ${ }^{219}$

In the Aegean, it is probable that exchange played a very important role. In view of the increasing evidence that the Aegean was not really comparable to the supposed redistribution "data" from Egypt and Western Asia, one group of scholars recently withdrew the contention that the Aegean evidence corresponded to a "redistribution" economy :

215 R. Müller-Wollermann, "Bemerkungen zu den sogenannten Tributen," GM 66 (1983): 81-93.

216 J. Renger, "On Economic Structures in Ancient Mesopotamia," Or. 63 (1994): 157-208

217 Renger, Or. 63: 164, n. 12.

218 Renger, Or. 63: 177.

219 Cf. Mason, Peru, pp. 180ff. Mason notes that "Heavy kribute in the form of labour was demanded from the peasants, who profited very little from it" $(p .180)$. It is significant that although grain production was not collectivized to the same extent as wool production, private ownership of llamas existed, so that even the redistribution of wool was not exclusively "redistributive" in character. Since the redistribution of wool was not based on need but by family size, there was no justice (because those in possession of llamas received just as much wool as those who had none), which reduces the relevance about Polanyi's claims concerning "rights and obligations" to a superficial meaningless phrase.

Being preliterate, Inca sociely is an ideal candidate for circular argumentation confirming theoretical reasoning, so that other authorities can doubtless be found with different arguments. 
In this paper it is suggested that the best source for analogies is anthropology, and not Mesopotamia, the Levant or Egypt which reached a higher level of centralization than societies in the prehistoric Aegean ever did. 220

Aside from the mere assumption of its relevance, the argument in favour of applying the "redistribution" system to ancient Egypt is partially based on the "evidence" from Mesopotamia. Needless to say, this evidence from ancient Egypt is being contested in this book, and the evidence for Mesopotamia is rapidly being reduced to the period of the Third Dynasty of Ur, to which Renger repeatedly refers. It may ultimately prove to be the case that the Ur III period is the only known case illustrating "redistribution", and it remains to be seen whether this characterized the entire economy. ${ }^{221}$

The logic in adducing additional examples is thus demonstrated to rest on a circular basis of repeated repetition demonstrating the claims. A different kind of circular argumentation was employed by Dalton two decades earlier, based on the claim that Polanyi's critics had failed to provide a convincing alternative structure. The "alternative structure" is the "imperfect market" which is the basic assumption of all economic analysis.

The request that an alternative structure must be sought lies therefore upon the assumption that the validity of the "imperfect market" has somehow been thrown into doubt. The doubts themselves have however only been created by Polanyi's proposed alternative system. Dalton pointed out that

Polanyi argued forcefully against the use of market theory to analyze nonmarket economies. ${ }^{222}$

and claimed that Polanyi's

paradigm also comprises a special set of real-world processes, special concepts, and analytical conclusions reached by using the concepts to analyze the process. ${ }^{223}$

The first line of reasoning thus places critics who reject the categories in the position of being in error merely by virtue of rejecting the categories, which is a very simple device, but irrelevant, if the very relevance of the categories is in doubt. ${ }^{224}$ This is especially significant since traditional economic historians can contend that the "imperfect market" is a valid category, which can incorporate all of Polanyi's fundamental points into modern theoretical thinking without difficully.

S. Voutsaki, "Value," in Gillis, Trade and Production, p. 14. Cf. also B. Sjöberg, "The Mycenaean Economy: Theoretical Frameworks," in Gillis, et al., Trade and Production, pp. 19-32.

221 It should be noted that the size of the Ur III empire is also being progressively reduced: the "evidence" from Tell Brak in northern Syria has been shown to have been the result of hasty conclusions, which were in error; cf. D. Oales and J. Oales, "Tell Brak: A Stratigraphic Summary, 1976-1993," Iraq 56 (1994): 167.

222 G. Dalton, "Karl Polanyi's Analysis of long-Distance Trade and His Wider Paradigm," in Sabloff, Trade, p. 68.

223 G. Dalton, "Karl Polanyi's Paradigm," in Sabloff, Trade, p. 71.

224 This seems to have been at the heart of $E$. Eichler's argument in "Polanyi - Keynes - Warburton," GM 131 (1992): 25-31, and was certainly part of my response, D. A. Warburton, "The Economy of ancient Egypt Revisited Yet Again," GM 146 (1995): 103-111. 
The second contention seemingly raises Polanyi's arguments to a higher sphere, since it asserts that there is "real-world" evidence and that the tools are of demonstrated value. Polanyi's theory was however based on assumptions which were later demonstrated to be erroneous, so that the "real-world process" is lacking - but has nevertheless since been assumed to exist. As clearly stated above, the concepts - as used by Polanyi's adherents with regard to the Egyptian economy - have not been understood, and they have not aided the development of understanding. The value of the analytical tools has thus not been demonstrated, so that both the actual application and the whole theoretical framework require reexamination.

At the same time, the role of the market has unfortunately been pushed out of the discussions, since Polanyi assumed that it did not exist, while Silver seems to be persuaded that a market operating under conditions of demand and supply did exist in the ancient world, and that there was no "unsuperable barrier to price-making markets". 225

The evidence from the Near East does not suggest that price-making markets comparable with today's global market existed at any point in time until quite recently. 226 Renger is therefore justified in rejecting Silver's approach on that level, but the potential lack of a price-making market does not eliminate the possibility of market level exchange activity. If the market system was capable of allocating goods, then the market performed its modern role, regardless of the extent to which price formation was influenced by potentially irrational features. Such a market determined by requirements and wants (including not only the desire to acquire, but the desire to increase wealth) would serve to distribute goods in an economy, and therefore the factors influencing the regulation of transfers may not have been prices. Thus one argument against the application of market laws is removed.

There is however evidence of markets related to profit and price fluctuations in ancient Mesopotamia 227 to which Renger does not assign signal importance, but this view is not widely shared:

Study of Old Assyrian trade has refuted notions of the economic historian Karl Polanyi, who thought that markets and entrepreneurial activity did not exist in the ancient Near East. [...] Neither the venerable model of the progressive stages from redistributive to market economies nor the world-system theory of Emmanuel [sic] Wallerstein can account for the nature of the Old Assyrian System. ${ }^{228}$

It was precisely with this data that Polanyi developed his system, so that Dalton's "real world" evidence has been conclusively rejected. These markets may not establish the universality of the principle of price-making markets. There can however be no doubt whatsoever that

225 I quote Renger (Or. 63: 160), quoting Silver refuting North.

226 Cf., e.g., Chaudhuri, Asia before Europe, pp. 76-77. The types of profits possibie in the pre-modern world virtually preclude modern price calculations.

227 It is obvious that the evidence from Mesopotamia does demonstrate that price-making markets existed as well: cf. J. Gledhill and M. Larsen, "The Polanyi Paradigm," in Rentrew, Theory, p. 204ff. It is quite interesting that Renger prefers not to approach Larsen's arguments directly.

228 N. Yoffee, "The Economy of Ancient Western Asia," in Sasson, Civilizations III: 1393-1394. 
market mechanisms played a significant role in ancient Mesopotamia, potentially along with redistribution (but this has not been demonstrated). The evidence available from Egypt is insufficient to establish that market mechanisms functioned as effectively as in Mesopotamia, where price fluctuations could be exploited to make profits. ${ }^{229}$ The existence of imperfect markets can however be postulated.

\section{Price Theory and Polanyi}

Examining prices in Deir el-Medineh, Janssen questions whether they were determined by supply and demand. ${ }^{230}$ Taking comparative data from modern Africa, he cites examples of prices determined neither by market value nor production costs to illustrate possible sources of apparently irrational price formation and incompatible expectations. ${ }^{231}$ While this approach does not correspond to the labour or production theory of value and pricing, it is entirely compatible with the principle that prices ultimately represent the disutility of labour and can be understood using marginal utility analysis, i.e., that a price is whatever a person is willing to sacrifice in order to acquire the good in question, or whatever he is willing to receive to part with it.

The labour theory of value belongs to the Marxist school, and can hardly be assumed to be a modern economic tool. J. Schumpeter was generally correct in asserting that Marx's real mentor was David Ricardo, 232 and Schumpeter pointed out that Marx's labour theory of value was lifted from Ricardo, and that, "Everybody knows that this theory of value is unsatisfactory", 233 and that the labour theory of value "does not work at all outside of the case of perfect competition". ${ }^{234}$ Needless to say, perfect competition can hardly be assumed for ancient Egypt or any other country, and thus the labour theory of value has been discarded, in favour of its predecessor. ${ }^{235}$

Cf. Veenhof, Trade, pp. 356ff, or my quotes in "The Economy of ancient Egypt Revisited Yet Again," GM 146 (1995): 104 n. 2

230 Janssen, Prices, p. 559. Janssen (Prices, p. 515) notes that "these prices do not have the precise meaning that prices are supposed to have in our society", but does not specily what this "precise meaning" is. There is no "precise meaning" for price in modern economic thought, and this betrays that Janssen was nol familiar with economic theory before dismissing it.

231 Janssen, Prices, pp. 540-542.

232 While Schumpeter emphasizes Marx's theoretical abilities in a chapter entitled "Marx The Economist," (Capitalism, etc., pp. 2 lff.), A. Brewer has nothing but contempt for Marx's economics ("A Minor Post-Ricardian? Marx as an Economist," HPE 27 [1995]: 111-145). Both are agreed on the Ricardian influence.

233 Schumpeter, Capitalism, etc., p. 23.

234 Schumpeter, Copitalism, etc., p. 24, cf. pp. $22 \mathrm{ff}$

235. It is worth pointing out that Carl Menger described the labour theory as an "error" as early as 1871 (ct. Menger, Grundsätze, pp. $119 \mathrm{ff}$.). Menger's own theory - based on an equilibrium position with imperfect competition is completely compatible with the prices in Deir el-Medineh (cf. A. M. Endres, "Carl Menger's Theory of Price Formation Reconsidered," HPE 27 [1995]: 261-287).

For some reason archaeologists continue to believe that economics relies on unsophisticated theories of labour or demand and supply, as, e.g., S. Voutsaki, "Value and Exchange in Pre-Monetary Societies: Anthropological Debates and Aegean Archaeology," in Gillis, et al., Trade and Production, p. 7. It is even maintained that "labour in pre-capitalist economies is not a commodity" (p. 9), although this is not only irrelevant, but also mistaken. She terminates her argument asserting that: "In this paper it is suggested that the best source for analogies is anthropology, and not Mesopotamia, the Levant or Egypt' (p. 14). It would seem that insufficient familiarity with theory appears to be a motive for selecting anthropological parallels. One should compare janssen's remark in 1961: "the 
Ricardo's predecessor, the founder of the science of economics, Adam Smith observed:

The real price of every thing, what every thing really costs to the man who wants to acquire it, is the toil and trouble of acquiring it. What every thing is really worth to the man who has acquired it, and who wants to dispose of it or exchange it for something else, is the toil and trouble which it can save to himself, and which it can impose upon other people. ${ }^{236}$

While the labour theory of price has been discarded for more than a century, ${ }^{237}$ marginal utility analysis is not only one of the current notions, but can also be traced back to the origins of economics.

It could be maintained that the prices recorded in Deir el-Medineh might not be compatible with Walras's general equilibrium analysis, or even with Marshall's partial equilibrium analysis. They can however be understood in terms of Jevons's marginal utility analysis, and are readily comprehensible in view of the "marginal disutility of labour" and Jevons's "law of indifference". ${ }^{238}$ This means that Janssen's statement - that the prices in Deir el-Medineh are not normal in modern terms - refers only to his own personal interpretation of the role of prices in our society, and that his statement is invalid when confronted with modern economic theory. Having stated that knowledge of modern economic theory is "obnoxious" he has absolved himself of the necessity of studying it. This does not however demonstrate that the prices in Deir el-Medineh cannot be accounted for using modern theory. ${ }^{239}$

Janssen's endeavour relies on the claim that the workmen of Deir el-Medineh were "target traders" and that one can find anthropological parallels in modern Africa. This however fails to take account of the fact that virtually all modern consumers - in the western world and the third world and the socialist block - are also "target-traders", with the difference that they use "money" instead of articles to acquire other articles. A "target-trader" is basically someone who seeks to acquire specific articles through trade, and must be opposed to the entrepreneur who only uses the acquisition or production of articles as a means of acquiring wealth, as opposed to the articles. ${ }^{240}$ The fact that retail prices differ widely in the modern world, and bear little relation to wholesale prices suggests that the behavior of traders, manufacturers

Egyptologist may find it useful to turn his attention for a moment to the so-called 'primitive' peoples, who form the subject of cultural anthropology' (Ship's Logs, p. 98). Plus ça change..

236 Smith, Wealth of Nations, p. 47 (Book One, Chapter Five). It is significant that Kemp (Egypt, pp. 250ff.) confuses the issue of price formation with the premises of a subsistence labour price coupled with supply and demand, neither of which can be shown to have had a decisive impact on price formation. The prices are precisely those anticipated in any economy without a market mechanism.

237 Screpanti/Zamagni, Economic Thought, pp. 152-153.

238 Cf. Pribram, Reasoning, p. 284. For the "law of indifference", cf. Jevons, Political Economy, pp. 136-139. It is worth noting that Jevons's theory of the origin of value is disappointing, cf. p. 184.

239 It will be noted that at the close of this study we will conclude that Walras's "general equilibrium analysis" does account for the prices, cf. infra, pp. 329ff. There is naturally no contradiction between Jevons's prices and Walras's prices, because the two reflect different aspects of the same system.

240 It is very curious that $M$. Römer whose insights are otherwise very valuable fails to understand that Wen-Amun cannot be understood to be an entrepreneur: he was an emissary dispatched with the object of purchasing very specific articles, and thus a "target-trader" if one will, but definitely not an entrepreneur; cf. M. Römer, "Der Handel und die Kaufleute im alten Ägypten," SAK 19 (1992): 284. 
and consumers cannot be categorized in the same fashion, and that prices mean different things to different people in the modern world.

Modern economic theory has failed to produce a comprehensive theory of prices significantly different from that advocated by Adam Smith two centuries ago. Smith's theory can certainly be applied to modern anthropological conditions without alterations. Janssen's contention concerning prices is therefore economically speaking incorrect, as the prices from Deir el-Medineh can be understood using modern concepts of price theory.

Modern economic theory in striving to account for a comprehensive concept of economic behavior, applicable to the modern world, has stumbled upon the key to understanding the ancient world as well, and it is hardly accidental. ${ }^{241}$ Janssen's methodological approach does not suggest that it will enhance understanding to reject economic theory out of hand. Rather than withdrawing certain economies from discussion, theory should be expanded to include them, and they should be permitted to contribute to theory. ${ }^{242}$

In a modern economy, supply, demand and production costs as well as marketing strategies influence prices far more than they did - or could have - in Deir el-Medineh. With marginal utility analysis, however, modern economic thought has incorporated a tool which can explain price behavior in Deir el-Medineh and in the modern world. This suggests that theory can serve a useful role, and that knowledge of it is not superfluous, especially before condemning it. The issue is not that facts should be obliged to correspond to the model, but rather that using the theory should lead to improved understanding. That the economy of the village at Deir el-Medineh can be understood by viewing behavior in peasant societies is not in dispute. It should be clear however that peasant societies can also be seen to observe economic laws, and - far more importantly - the Egyptian state was neither a mere village writ large nor a mere consumer and it is advisable to have recourse to every available tool to understand this.

Among the basic points of the Polanyi school is to emphasize that minor factual errors in Polanyi's model should not deter one from grasping the purpose of the system.

It seems - and this certainly applies to the discussion among Assyriologists - that the critique of these [factual] errors [in Polanyi's work] has distracted attention from Polanyi's basic concern, namely that ancient economies operated under rules other

241 M. Blaug points out (Economic History, p. 132) that Smith's theory of value was ultimately behind the system employed to compare the economies of the US and the Soviet Union (before the demise of Communism), underlining the fact that it is ultimately the only reliable means of making economic data comparable.

The implications of the theory of the disutility of labour are necessarily that prices are whatever the market will hold, and that fluctuations only occur under conditions of competition, which responds to demand. Thus demand and supply are decisive, with the critical feature of competition, rather than the object of profit-making being the missing element, in contrast to Janssen's assumption (Prices, p. 561). It is worth noting that under Walras's system, the profit-seeking entrepreneurs failed to win because their competition evened out prices so that, according to Walras, the consumer won. Thus profit-seeking and competition are not necessarily compatible, and they should be distinguished in studying the economy, but since neither was an all pervasive element in ancient Egypt - in contrast to China and Mesopotamia - the point does not require elaboration.

For a theoretical discussion about prices, cf. P. C. Dooley, "Value," in Creedy, Foundations, pp. 124-158.

242 The analogy to the situation of withdrawing the early states from comparison with modern states in order to account for differences, and thus lump together quite different entities should be evident. 
than those of our modern market-oriented economy, and therefore require a set of analytical tools different from those derived from the analysis of a modern economy. ${ }^{243}$

The argument is thus that the ancient economies were different and that different tools are necessary. Prices are extremely important in this argument because the pivotal feature of Polanyi's system is the assumption that

the fundamental difference between our modern economies, governed by pricefixing markets, and those economies - traditional and non-industrial, ancient as well as mediaeval - [was] the social embeddedness of the economy determined economic activities and behavior. ${ }^{244}$

The debate between Renger and Silver seems thus to have become fixed on the issue of price-fixing markets. Renger states that "Silver's premise is the applicability of the economic laws of the price-fixing market and neo-classical economics". ${ }^{245}$

Economists say however that "the principal mechanism used by the market system is a set of prices". ${ }^{246}$ This confirms that prices are a result of market activity, but not that the purpose of markets is to establish prices. It also confirms that current theory holds that there are "sets of prices". Above all however, it underlines the fact that prices are a mechanism of exchange: the purpose of markets is not to not fix prices, it is to allocate goods. If ancient markets allocated goods, then ancient markets will have been markets in the modern sense. Polanyi's contention is that the redistribution system outweighed the market system in exchange, and thus Polanyi's market related contentions are ultimately based on Iwin assumplions: that the market did not function and that one can recognize this failure to function in the absence of price selting markets. These are however two separate assumptions. The role of the market is a matter of macro-economics, prices belong to micro-economics. Polanyi has confused two separate economic categories (and his adherents have added to the confusion by confusing the problems of money and profits).

leftwich states that price theory is part of micro-economics, and not part of macroeconomics. Price theory according to leftwich is about behavior:

Price theory is somewhat abstract. We may as well face this point at the outset. Difficulties will be encountered in this respect, but if we recognize the nature of the difficulties they will seem less formidable. Primarily, we shall find that price theory does not give a description of the real world. [...]

Price theory is abstract because it does not and cannot encompass all the economic data of the real world. [...] Consequently, the function of the theory is to single out what appear to be the most relevant data and build an overall conceptual framework of the price system in operation from these. We concentrate on the data and principles that seem to be the most important in motivating most economic units. [...] We should make theory our tool and not our master. ${ }^{247}$

243 Renger, Or. 63: 184-185.

244 Renger, Or. 63: 164.

245 Renger, Or. 63: 166.

246 McKenno, Price Theory, p. 1.

247 Leftwich, Price System, p. 10. 
We thus note that price theory is a domain of micro-economics relating to one particular mechanism used by the market, and that this particular mechanism is very theoretical. It is however clearly stated that price theory must be based on "what appear to be the most relevant data". This makes it clear that there is no such thing as a "precise meaning" of price "in our society", as Janssen put it. This counters the whole logic of both Janssen's and Polanyi's arguments, since it is evident that there is no reason why price theory cannot accommodate any particular behavior or motivation. Polanyi's contentions about embeddedness can be incorporated into modern theory as "non-production related variables influencing price", and simply be considered one of many factors influencing price formation. Thus, Polanyi's approach to price formation need not be regarded as a barrier to the use of modern economic theory. ${ }^{248}$

It is evident that price-fixing markets are not at the core of modern economic theory, and that Janssen's alleged anormal prices are completely compatible with modern theory. The mere absence of price-fixing markets does not however demonstrate that people did not seek profits or to accumulate wealth, which counters contentions expressly raised by several of Polanyi's adherents, although Polanyi himself did not dispute this. Thus price theory can be Polanyi compatible, and thus the emphasis of the Polanyi model as an alternative to modern theory cannot be built on the issue of price formation.

At the same time, Polanyi specifically stated that the advent of the market exchange economy appeared when land and labour could be sold. Therefore, the presence of wage labour and transactions involving the sale of land defy integration into Polanyi's model if a post market redistribution model is selected, so that even without the additional details concerning the role of markets, the very basis of Polanyi's contentions has disappeared.

In sum, Polanyi's assumptions about irrational behavior can be incorporated into modern price theory, and the formation of prices does not effect the role of the market in society. Price mechanisms are micro-economic and markets are macro-economic. Therefore, price mechanisms cannot be used to argue against the validity of market theories. At the same time, the presence of markets in ancient Egypt is demonstrated according to Polanyi's own definition.

\section{Redistribution}

Redistribution is a way to reallocate to the producers the products of the labour of a society which are collectively produced, centrally collected and stored. ${ }^{249}$

This is Renger's summary of what Polanyi meant with "redistribution". Within Polanyi's system, the implications of "redistribution" are (1) that it is a label which is part of a larger model and not a theory in itself; (2) the basic premise of which was that the market did not function; 
(3) that it represents a reciprocal relationship between the ruler and the ruled, (4) permitting producers to receive the products of their production back again; $(5)$ in a society where land could not be bought and sold, $(6)$ before the emergence of wage labour.

Renger notes that it is difficult to convince the peasants to over-produce, and asserts that redistribution can "occur in a variety of political systems". 250 Speaking in the name of Polanyi, E. Eichler maintained that "no ancient government ever attempted to persuade the peasants of the necessity" to over-produce grain, stating that repressive measures were the only manner of compelling the peasants to comply with the wishes of the state. ${ }^{251}$ Polanyi however stated that the basis of the redistribution system had to be the rights and obligations of the participants in the state apparatus. ${ }^{252}$ Therefore Renger's statements imply - and Eichler's assume - that this basic element of Polanyi's model was faulty, and that Polanyi was in error, and yet nevertheless proclaim the validity of the system as a whole.

Applying Polanyi's approach to the economy of ancient Egypt thus involves not only assuming that Polanyi's fundamental assumption was invalid, yet also that the evidence should nevertheless be understood in terms of the theory. The application of the Polanyi system demands that (1) things were collectively produced and redistributed in an economy (2) without private property (3) before the development of wage labour because this type of activity is incompatible with Polanyi's paradigm. The evidence confirms that as far back as the inscriptions go, land could be bought and sold, and that there was wage labour. The evidence for redistribution on a massive scale - demonstrating that the greater part of the economy depended upon collective production - remains to be produced. The assumption of the relevance of the Polanyi paradigm thus denies the relevance of that data which is available, and assumes that the data confirming the theory exists. This is bad methodology, effectively preventing the examination of evidence of inefficient market behavior, what economists call "imperfect markets". This alone signifies that the unexamined use of Polanyi's theory is methodologically unsound. The fundamental political element of Polanyi's system is rejected by the adherents, and thus in principle, the evidence indicates that both the economic and political basis of Polanyi's system cannot be assumed for ancient Egypt, given repression and private property.

Describing the ancient Egyptian economy, Grandet writes:

It is thus probably advisable when analyzing an economy conforming to this type of integrative model to employ terms like "requisition", etc. rather than to use terms like "imposition", since - on the theoretical level at least - the entire productive apparatus

250 Renger, Or. 63: 177.

Renger claims that the exislence of real estate trading does not demonstrate the wide spread sale of land, and therefore that the scarcity of Old Babylonian documents documenting the sale of land deserves emphasis. This is a blatant misuse of the evidence, for the sale of factories and fields in the modern world is far less common than the sale of goods and real estate, so that his comparison fails to achieve the goal (cf. Or. 63: pp. 180-188).

251 E. Eichler, "Polanyi-Keynes-Warburton," GM 131 (1992): 26. [My translation].

252 Cf. quotes in D. A. Warburton, "The Economy of Ancient Egypl Revisited Yet Again," GM 146 (1995): 106107. 
legally belonged to the powers-that-be or their representatives, and that everything that had to be redistributed (or left at the disposition of the producers) can be assimilated to wages.

It is however necessary to remark (and we will return to this) that in practice, the double movement of collecting and redistributing which is characteristic of such an economy was frequently impractical (given geographic distances, economic actors, problems of rations, etc.) and that simple administrative measures could be employed instead. The powers-that-be could thus, by arrangements of várious kinds, directly assign the goods produced by one producer to a specific consumer, authorizing its direct acquisition by the latter. ${ }^{253}$

The indication that administrative expediency could substitute "redistribution" with a measure simply leaving a proportion of the produce in the hands of the producer denies the existence of "redistribution". Ultimately, it assigns the economy to a type of "commandeconomy". Renger indicates that in the Old Babylonian Period that the entire production was not actually collected and circulated through the system, but rather that merely a part of the surplus collected. 254 This implies that "taxation" or "rent" is a far more appropriate fashion of describing the situation, and that "redistribution" is misleading, if not erroneous. A similar situation can be argued for Egypt.

Extremely relevant for the understanding of the Egyptian economy is that there is in fact little evidence of "redistribution" as such. It is contended that the king or the temples redistributed the income which was collected, but there is a great deal evidence of collection, yet precious little of wide-spread redistribution. The workers of the Gang responsible for the construction of the Royal Tombs must have been one of the smallest, most compact, best established, most state-dependent groups in the entire country, yet even they did not get paid regularly. ${ }^{255}$ J. J. Janssen has even advanced the thesis that the Late Ramesside state was actually obliged to turn to the free market in order to purchase the grain in order to pay the Gang. ${ }^{256}$ If the state could not even provide for some of its most important direct employees, it is clear that the redistribution system was not a significant feature of the economic system in the Late Ramesside period.

It is probably symptomatic of the argument that even if one could demonstrate that the workers of the Gang were regularly paid before the Late Ramesside period, it would not confirm the existence of "redistribution" according to Renger's definition as given above.

253 Grandet, Papyrus Harris II: 56-60. [My translation]. It is interesting to note that in Sir John Hicks's theory of economic development, precisely this type of maneuver is the precursor of feudalism (cf. Hicks, Economic History, p. 18). I would propose that one of the reasons for which the system proposed by Grandet did not lead to feudalism was market distribution, which subverts administrative power.

254 Renger, Or. 63: 179-180.

255 Cf. e.g. J. J. Janssen, "The Year of the Strikes," BSEGG 16 (1992):41-49, where he concludes that strikes were frequent.

256 This is the only possible conclusion following from Janssen's contention that the personal copper of the workman was being collected in order to purchase grain in order to pay their (undeserved) wages, cf. J. J. Janssen, "An Exceptional Event at Deir El-Medina," JARCE 21 (1994): 91-97. His interpretation of the text is however open to doubt. 
Renger's definition implies that the goods must be collected and returned to those who gave them - literally "redistribution". Since the Gang were not farmers, but mere civil servants and thus not producing anything of value to anyone - demonstrating that they were paid regularly would only demonstrate that civil servants were paid, which is characteristic of modern society (except when the US Federal Government runs out of funds occasionally).

Janssen's conclusion that the Late Ramesside authorities actually had recourse to the market in order to pay the workers is thus particularly striking because the greatest part of the wages of the gang were paid in grain, and the one commodity which the state should have had in surplus was grain. If Megally's interpretation of P. Louvre E 3226 is correct, during Dynasty XVIII, the state was exchanging surplus grain for other articles which it did not have. ${ }^{257}$ If Janssen's interpretation is correct, by the end of Dynasty XX, the state had no income whatsoever, while the market was functioning far more effectively than the redistribution system /and Janssen seems convinced that metal was the active ingredient of this economic activity). This certainly discredits the argument that redistribution emerged to meet needs which the market could not, which is the basis of Polanyi's argument for the significance of the term. To take an outside observer's interpretation:

Joseph collected all the food produced in those seven years of abundance in Egypt and stored it in the cities. [...] When famine had spread over the whole country, Joseph opened the storehouses and sold corn to the Egyptians, for the famine was severe throughout Egypt. (Gen. 41: 48-57).

The text states that Joseph "collected" the grain and then "sold" it back: he did not purchase it and sell it, or collect it and distribute it. He collected it and he sold it. Since this would correspond to the evidence of $\mathrm{P}$. Louvre $E 3226$, Renger is completely correct to state that this "story has an added value for us since it conveys the notion the authors of Genesis had about a storage economy." 258

Even more importantly, however, Janssen has also demonstrated that the texts can be understood as implying that even under ordinary circumstances, the products of the temples were physically taken to the villages, and sold at market, and not transferred by administrative decree (as suggested by Grandet). Observing the character of this market, he states however that

It is not really probable that in a redistribution-economy like the Egyptian one that the market played more than an insignificant role. ${ }^{259}$

Thus, the relevance of a market to allocate goods is explicitly denied, while the existence of the market is openly recognized. The assumption of the validity of Polanyi's theory is the only reason to belittle its importance. The formal denial is curiously based upon a theoretical interpretation, but the details upon which the theoretical interpretation are built are also 
rejected by both Janssen and Grandet. Omitting the repetitive use of the word "redistribution", it can be argued equally easily that the economically significant expenses of the "redistribution" economy hitherto demonstrated can be accounted for in terms of market exchange and wages. And that the state employed the market successfully, for its own purposes, based upon data published by scholars who allege the relevance of Polanyi's models.

Assuming the absence of private ownership of land maintains precisely that fragment of Polanyi's theory which defies that evidence which virtually everyone tacitly recognizes. In adapting the evidence to the theory, the role of the market as a means of allocating goods is denied, although clearly present. Assuming repression refutes Polanyi's political argument. Rejecting the evidence of the market in favour of redistribution, while conceding its existence, involves repeatedly denying the relevance of those market elements which have been established. The use of Polanyi's methods has thus not eliminated confusion or contributed to understanding. Ultimately, in combination with Janssen's claims, Grandet's statement effectively eliminates the value of Polanyi's theory for the study of ancient Egypt.

As in the case of price theory, we find that there is confusion about the potential value of the redistributively relevant "analytical tools" offered by Polanyi's theory, especially when this theory is accompanied by assumptions which fail to take account of the evidence, and therefore imply that the evidence is less valuable than the theory.

\section{Polanyi and Theory}

In the absence of proof that Pharaoh actually tried to apply or failed to apply justice in the form of $m 3^{\prime c} t$ across the board, we must respect Polanyi's assertion for the reciprocal nature of the relationships between the ruler and the ruled. As Polanyi's use of prices does not have any effect on the interpretation of the market as an exchange regulator, the relevance of his reflections on pre-market activity lose their value. As Polanyi's system of redistribution has been denied by Grandet, the only remaining elements of his fundamental theory depend upon the assumption of the absence of private property, which defies the evidence.

As the evidence indicates that materials were in fact not redistributed as understood by Renger and Polanyi, but rather transferred through the market as indicated by Janssen, the problem comes down to the theoretical implications of the label, and discussions concentrating on the evidence itself. The contradictions and inadequacies brought to light reveal that the theoretical role of his model is virtually useless, as it has been shown to have been employed in a mutually contradictory fashion by his adherents, most of whom neglect the evidence. If the theory had any value for the specific understanding of particular phases or aspects of economic development, it could still be considered to offer a broader perspective, and it might be maintained that its real value has been neglected in this respect.

Even though Polanyi emphasized repeatedly that this basic conceptual scheme involving three modes of integration - reciprocity, redistribution, and exchange must not be seen as representing an evolutionary pattern, there is a clear tendency in 
some of his writings to link these modes with specific stages of societal development. ${ }^{260}$

Although Polanyi and Janssen indicated that the various types of economic activity could subsist simultaneously, ${ }^{261}$ it has also been contended that while the categories of reciprocity and redistribution were compatible and existed simultaneously, they are not compatible with the market economy. After reviewing the evidence of the transactions recorded in tombs of the Old Kingdom, etc. R. Müller-Wollermann concluded:

"Supply and demand appear" indeed, but only in the general sense, and not in the sense of an economic system, as there was no clearly perceived labour market where these factors and the wage rates could be widely disseminated. ${ }^{262}$

There is no evidence for this contention either way, but the mere fact that wages were not recorded on the walls of tombs cannot be taken as prima facie evidence that the rates were not known. The evidence contradicts the assertion that there was no labour market, as the mere increase in the number and size of private tombs in the course of the Old Kingdom suggests that the market was expanding. Her parallel conclusion that there is no evidence for the development of trading markets is likewise contradicted by her evidence, as she herself concludes that the workers were paid in bread and beer, and therefore forced to go to the market to acquire by exchange the other articles they desired. ${ }^{263}$ Based on this interpretation of the evidence, she concludes theoretically,

A market economic system cannot be demonstrated for the Old Kingdom, but its absence cannot be proven either. The evidence of the economic categories of reciprocity and redistribution render its existence improbable however. ${ }^{264}$

Thus, the simultaneous parallel existence of all the three modes is hypothetically excluded, although the evidence from Mesopotamia has effectively demonstrated that redistribution and market economy may have existed in parallel, and although J. J. Janssen had already stated that all three forms could coexist simultaneously:

Of course in every developed sociely all three systems are present, but it is their relative importance which may widely differ. Just as market exchange is the dominant factor in the western world, so redistribution was in Egypt, a relatively large part of the production of the country being collected by the state through its various organs

J. Gledhill and M. Larsen, "The Polanyi Paradigm," in Renfrew, Theory, p. 203. They cite three rypes because general presentations of the theory do not usually mention "householding" because it was not fundamental to the system, but to neglect it would be unjust to Polanyi, and to omit it fails to account for one type of interchange which exists in modern market economies to this day, where, e.g., household labour is widely taken for granted and not measured or remunerated at market rates.

261 Janssen, Prices, pp. 558-562.

262 R. Müller-Wollermann, "Warenaustausch im Ägypten des alten Reiches," JESHO 28 (1985): 146 . Her quote is from Helck, Wirtschaffsgeschichre, p. 106, cf. infra, p. 125. [My translation].

263 Müller-Wollermann, "Warenaustausch," JESHO 28: 146-147.

264 Müller-Wollermann, "Warenaustausch," JESHO 28: 165. The evidence she employs is slender. [My translation]. 
in order to be redistributed among a fairly large number of categories of its servants.

It is from this sphere that most of our documents come $[\ldots]^{265}$

It is important to note not only that our documentation skews our impression of the relationships, but also that this evidence only indicales that some proportion of that part of the surplus - and not production - documented in official records was redistributed. Our evidence does not touch upon production in general, or upon the nature and distribution of that part of the surplus which did not move through the state sphere.

Using her own data, Müller-Wollermann could have argued that the existence of a market effectively rendered the existence of a redistribution economy improbable, for Polanyi's basic criteria for a market economy were presented by her. According to Polanyi's system the redistribution system emerges because the market does not function, and therefore the existence of a market could refute redistribution just as easily as the reverse. Therefore it is more logical to accept Janssen's judgment that all three exist in parallel, and the categories are not mutually exclusive, which does not make them analytically fruifful.

Müller-Wollermann also cites Polanyi to the effect that reciprocity is based upon symmetrical social relations, while redistribution is based on asymmetrical social relations. The social imbalance existing in a system with both reciprocity and redistribution is greater than that necessary to accommodate redistribution and market exchange since both are compatible with asymmetrical social relations. ${ }^{200}$

The logical conclusion is that this merely raises Polanyi's categories to types of interchange which exist in parallel in any economy, and therefore negates the analytical value of his categories for economic analysis, which probably explains why economic laws were never established according to the various categories. It should also be clear that any relationship between a tomb-owner and the workers making it must be per definitionem asymmetrical, that of employer and employee, and it can not be described as redistributive if the satisfaction is expressed in terms of payment for services rendered. It is therefore evident that these transactions do not correspond to Polanyi's categories, even if other transactions (such as those in Deir el-Medineh) might.

It has thus been established (1) that Polanyi's social behavior can be included within modern price theory and that the prices from ancient Egypt can be analyzed using modern theory without Polanyi and (2) that the characteristic feature of the modern economic system is not "price-fixing markets", but that prices are merely mechanisms regulating exchange, and that even modern price theory is so abstract that it has nothing to do with the real world. it has

260 Cf. Müller-Wollermann, "Warenaustausch," JESHO 28: 125. Despite the necessary dialectical contradiction, she even suggests that redistribution be classified as a special type of reciprocity (JESHO 28: 130). For an approach based on asymmetry as the principle element of Egyptian society, cf. J. Baines, "Restricted Knowledge, Hierarchy and Decorum," JARCE 27 (1990): 1-23. This would reinforce the logic suggesting that asymmetrical relations - redistribution and market - were the primary aspects of macro-economic activity, and that reciprocal relations dominated only in the villages 
also been established that $(3)$ redistribution as defined by the Polanyi system need not be assumed for ancient Egypt, and (4) that the market appears to have been far more effective than generally consciously recognized. It has likewise been established (5) that not even Polanyi's adherents maintain that the political basis of the redistribution system was in evidence.

It has also been established that Polanyi's analytical tools do not aid in understanding the facts. The system has not contributed to understanding ancient economics because there is so much disagreement among his adherents about what they actually mean. The system also has no overarching value, for its individual categories are not mutually exclusive, and cannot enhance understanding of the significance of any particular piece of evidence. At no level of micro- or macro-economic analysis can Polanyi's system be regarded as a useful analytical tool.

This is however only one half of the argument.

Even if there was any justification for maintaining the economic significance of either redistribution or reciprocity in ancient Egypt, there is also a priori no reason why any theoretical approach cannot be compatible with Polanyi's labels because the one describes the external features of a system, while the other examines the internal mechanisms; especially as Polanyi himself did not provide the theory. ${ }^{267}$ Polanyi's theory is not an economic theory so much as a social model describing relationships. In studying economic questions, the object is to identify and isolate the variables, and to study the potential effect of the interaction of the variables. "Redistribution" merely accounts for part of consumption, for the re-circulation of previously existing wealth, and not production, so that the economics of redistribution cannot be accounted for simply in terms of "reciprocity" with the workers of the land rendering services unto Pharaoh in return for which they receive grain and fish from him.

Those products must be acquired by Pharaoh, in order for him to deliver them to the workers, and it is conventional wisdom to assume that these were acquired through "taxation". And the evidence indicates that the articles acquired are maintained by that sphere of society which does not produce, and not "circulated" through the sociely on a vast basis. In the previous chapter, it was shown that when examining the emergence of a city state with a division of labour, Hunt established that the first constraint in the system was not land or grain, but labour, and that increasing the labour supply was the weak link in the economic and political chain. ${ }^{268}$ It is evident that his model assumed that part of the production was rendered up to the ciry, and that most of the production stayed in the rural areas, i.e., a form of taxation to support the non-productive part of the population, and not a system of redistribution to return produce back to the producers. Nevertheless, his chief contention was that a labour shortage was the major problem. Yet, both ancient Egypt and Mesopotamia were able to overcome this constraint to a considerable degree and create civilizations which were unique and still command our admiration today. Investigating this is thus the primary priority.

${ }^{267}$ CF. Pearson's note (in Polanyi, Livelihood, p. xxavy) to the effect that only the framework was erected.

268 R. C. Hunt, "The Role of Bureaucracy in the Provisioning of Cities: a Framework for Analysis of the Ancient Near East," in Gibson/Biggs, Power, pp. 161-192. 
It is relatively logical that even if Polanyi's economic and political system is rejected, Egyptologists would nevertheless contend that Egypt was not merely an example of Oriental Despotism. As noted before, the available economic theories come from either the socialist or the capitalist world. Some socialist approaches to the ancient world emphasized the dogmatic application of Marxist theories developed for application based on the European model. It was observed however in the preceding chapter that this type of circular logic was not restricted to Marxist circles.

Although Marx did begin to develop another theory concerning the Asiatic Mode of Production, Egyptologists might also take issue with Marx's basic orientation, as he naturally discounted the importance of the various features of the state, basically lumping all of the financial roles into one "government" department, while virtually all states had financial arrangements on several levels, parallel in the relations of government and temple, and hierarchical in the distribution of responsibility down to the villages. The most significant of the "government" financial departments requiring further examination is that of the temples, but equally relevant is the picture of the countryside, with its hierarchical distribution of responsibility based upon financial exactions from the villages.

Initially Marx was unaware of the extent of private property prevalent in village societies, and he was obliged to adjust his theoretical constructs to account for this. ${ }^{269}$ On the theoretical plane, although Marx eventually realized this, Polanyi did not. Polanyi's system was based on the assumption of a development similar to slave or feudal society, so that the existence of private property undercuts the very basis of the principle of redistribution, as it is rendered irrelevant as the primary feature of the economy. Marx's basic system proceeded from tribal property to common property to feudal property to bourgeois sociely, without an intervening phase of widespread private ownership of land prior to the societies of classical antiquity. Since he maintained that the principal feature of land ownership in feudal society is that possession is transferred not sold, a phase of development during which private ownership of land was a principal element of agricultural society does not figure in the models developed by Marx or Polanyi. It is equally probable that neither Marx or Polanyi ever grasped the significance of the introduction of metallic money, as they had no means of assessing what preceded what was familiar to them.

Nevertheless, Marx's view that the Asiatic Mode of Production was distinct from the European experience and based on village society is not without interest. A glance at the economy of "feudal" China might aid in grasping the implications of what Marx thought. At the time of the revolution, the Chinese economy was based on a system of land tenure, with a concentration of wealth through large land holdings (in an unusually egalitarian village, 7 per cent. of the population controlled 31 per cent. of the land; and 53 per cent. owned 24 per cent.). "The only thing left to invest in was land. Land was safe, but the returns were small when defining the beginning of the market economy with the emergence of the sale of land, and the sale of labour. 
compared with those from usury because scarcity drove land prices ever upward. "270 Prevailing interest rates were denominated in metal (silver at 50 per cent. a month), but metal, grain and salt could be hoarded as commodities or stores of value, and both metal and grain were used as units for calculating value. Confucian teaching kept the peasants in thrall. A wealthy landlord had easy access to unpaid but lucrative positions in the religious world and the local government.

As far as the higher authorities were concerned, the main purpose of the village government was the collection of taxes, the supply of manpower for public works, and the conscription of soldiers. As long as the extremely heavy quotas in these three spheres were met, no one cared how they were distributed. ${ }^{271}$

Assigned the obligation to collect taxes, a landlord could conceal part of his own holdings and squeeze peasants to produce the balance, aside from having the opportunity to alter the records. Obliged to organize public works, a landlord could ease the load on his own tenants, and place it on others. ${ }^{272}$ Given public commissions he could sell the government his own products. To a considerable extent, this appears to be compatible with a view of ancient Egypt.

Although apparently insignificant in itself, as metal accompanied grain and salt as monetary units, the mere use of coins and the influence of the use of money can be related to artificially exaggerated fluctuations in prices, potentially contributing to the price of land being driven up, combined with usurious interest rates, neither of which is in evidence in Egypt. K. N. Chaudhuri cites a curious case of dissidence against a policy of taxation in money at the Chinese court some thousand years ago.

The critical document pointed out that human labour combined with the natural fertility of the soil produced such useful things as grain and silk, while money in the form of coins was an artificial index of value and an official monopoly. A wealthy merchant may possess stocks of money but farmers normally organize their activities in a different way. Even a rich farmer normally evaluates his welfare in terms of enlarging his land-holdings in order to harvest more crops, repairing or building

Hinton, Fanshen, p. 35. This thumbnail portrait is derived from the summary in the first part of this volume.

It will be noted that Wittfogel (Oriental Despotism, pp. 80-81) implies that large landholdings were decimated. According to Hinton (Fonshen, p. 27) the Communist Party figures indicaled that 10 per cent. of the population owned 70-80 per cent. of the land, as well as most of the draught animals.

271 Hinton, Fanshen, p. 49

272 This feature could be very relevant to understanding ancient Egypt. It is generally assumed that the people we know with titles carried out tasks associated with those titles and thus figured as part of the "redistribution" system, but it is entirely possible that an independently wealthy individual could carry out a function which would be mentioned prominently in his tomb, which function he had received because of his wealth, rather than the other way around. And it is assumed that water carriers always carried water, but why could they not simply be ordinary people detailed to carry out specific tasks on a regular basis?

That the water-carriers in Deir el-Medineh frequently remain anonymous (S. Eichler, "Untersuchungen zu den Wasserträgern," SAK 17 [1990]: 146) would correspond to the idea that the work is the important activity, rather than just who carried it out - while officials at the higher level will necessarily have perceived things in exactly the opposite fashion where their own "responsibilities" were concerned. 
houses, or owning his own oxen so that he need not borrow from others. As for the poor farmer, he has barely enough to eat and wear. He may even be a sharecropper, toiling hard just to fend off starvation. Such people have little opportunity of seeing any copper coins, let alone of owning them. The enlightened governments in the past had taken into account the reality of agricultural production in the Celestial Empire and collected taxes in grain, silk and labour services. [...When the Sung emperors succeeded in obliging peasants to pay in coins, the commentator noted '.... After a bumper harvest when the price of grain is low, they have to sell their crops at one-third of the normal price in order to raise enough cash to pay the government. ${ }^{273}$

Thus, the effects of this policy may have economically transformed the Chinese landscape. The collection of taxes in kind, corvée obligations, the ideological situation, and the fact that landlords appear as officials, ${ }^{274}$ etc. remain as parallels with ancient Egypt. The documentation is insufficient to demonstrate that the introduction of taxation in coins created the vast economic discrepancies which left the social structure intact, but led to a concentration of wealth and ownership, reflected in urban exploitation of rural areas, which seems to have been the rule in both Mesopotamia and China, so that vast differences are perceived driving wedges between the various elements of the ancient oriental systems of government, rendering Egypt seemingly unique as a member of this class. As the economic role of exchange, silver and interest rates were greater in ancient Mesopotamia, and the economic value of land and money-lending greater in China, quite different economic structures emerge when reviewing the evidence.

In terms of Marx's Asiatic Mode of Production, he misjudged the role of irrigation, was slow to grasp the significance of private property, and probably failed to realise the effects of the introduction of metal currency so that his system cannot be applied without extensive revisions, which can only be undertaken after establishing the facts of the ancient world of Egypt, Mesopotamia, India and China.

273 Chaudhuri, Asia before Europe, p. 82. It is probably significant that price fluctuations not only follow the introduction of the obligatory use of symbolic metal money, but that both fluctuations and prosperity followed the introduction of the first paper money. However much it may facilitate exchange, the influence of coins is not a precondition for market exchange, but it clearly can serve to change the social distribution of the ownership of property by undermining poor peasants, as noted by the implications of purchasing coins after a bumper harvest, as mentioned in the quote.

A curious parallel can be found in the Americas shortly after the conquest, when peasants deliberately selected to pay their obligations in metals rather than goods, cf. Frank, Capitalism, p. 127.

274 It is important to note here that the analysis of the Heroninos archive by Rathbone (Economic Rationalism) has not only demonstrated that the estates concerned were operated with the express objective of making a profit, but also that the owners of those estates were councillors at Alexandria, and would thus appear in the official records under that title, rather than the profit-minded gentlemen farmers that they were. The evidence certainly demonstrates that Sir Moses Finely was in error concerning Graeco-Roman economic motivation, but it is rash to suggest that it be used to suggest that the economy of ancient Egypt was similar. It would be mistaken to neglect this emerging evidence, and to exclude the possibility that many of the officials whose titles are preserved may in fact have been pursuing "economic rationalization" on their estates in a ruthless fashion, and that this was their primary business concern, rather than administration. The improbability of private individuals participating in the international grain trade of the second millennium B.C. Would however suggest that it was not in the interest of private individuals to compete with the state in grain production, which had decisive financial, economic and social implications. 
Marx's comprehension of the relevance of village structures should however not be neglected, for the related characteristics of the peasants' way of life is very relevant to ancient Egypt.

The materials from Deir el-Medineh indicate a kind of village mentality, even though the workers were civil servants. The system of reciprocity and the market system common among peasant societies are not the same. The conventional system used in ancient Egypt was based on general prevailing price levels, which is typical of peasant societies, where there is little room for real discussion. In modern Middle America, activity at the markets (and not in the villages) follows set rules:

The price prevails until there is some change in the supply and demand factors. Bargaining in any single transaction reflects the state of the market place as a whole, and the market place as a whole reflects the operation of the entire regional and national markets. [...] What makes these economies different from a modern, dynamic economy [...] is thus clear. They do not lack economic rationality $[. .$. What is lacking is the social organization [...] dedicated to and organized for economic activity. ${ }^{275}$

The principle of prevailing prices is occasionally violated in the texts from Deir el-Medineh, but by and large, the same basic rules apply. It could be that other social obligations linked the two participants in the transaction of, e.g., O. Petrie 14, or that the price simply corresponded to the number of items lying on the ground at the end of the transaction, but the generation of the price in certain documents is not at all clear. ${ }^{276}$ On the whole, however, prices were generally defined by the conventional rules of the market mechanism, either capitalist or pre-capitalist. The behavior is to all intents and purposes economically rational. On the micro-level, the village mentality of the ancient Egyptians was far more influenced by the world of peasant societies than that of market dominated economics, but economically the distinction belween the wwo worlds is one of scale rather than intent. The market always decides the prices, on whatever basis, based on the principles which can be accounted for with Jevons's "law of indifference" and marginal utility analysis. The workmen of Deir elMedineh were an unusual group - full-time life-time employees with (more or less) regular income, but their origins lay in the villages of Upper Egypt which surrounded them, and their activity reflected their origins. possible explanation. The price is not only not round, but also was not altached to a specific donkey, and therefore the specification of the price - and a low one - is peculiar, especially as the purchaser expects a good donkey. 
In order to understand the basic principles of ancient Near Eastern markets, it may be useful to refurn to the Aegean. In defending the use of Polanyi's paradigm, Renger referred to the potential evidence for redistribution, and S. Voutsaki was cited as suggesting that parallels be sought in anthropology instead (supra, p. 86). While anthropological examples might be useful for illustrating the fashion in which transactions take place, to understand the transactions themselves it would be advisable to turn to David Ricardo. ${ }^{277}$ The "Theory of Comparative Advantage" governs markets, and indicates that in a modern economy it is always in a nation's interest to produce that good in which it has the greatest market superiority, regardless of whether it can produce other goods more cheaply than other countries. In Antiquity, Anatolia possessed both tin and silver, but tin mining was given up during the second millennium while silver production continued. At the same time, Anatolia was importing tin, and tin was being exported around the Mediterranean. ${ }^{278}$ This clearly demonstrates that the ancient Anatolians completely grasped the "Theory of Comparative Advantage". They could have produced tin, but selected instead to import it, to put their energy into silver mining. At the same time, this also effectively tied the entire ancient Near East into a market economy, because the Anatolian silver was being used in transactions throughout the ancient Near East.

This influenced the kind of market dynamics that we should expect in the ancient world. When supplies were limited, price fluctuations may have been wild, but in general, the tendency was for Babylonian textiles to flow North and Anatolian silver to flow South. Obviously the price-setting competition took place between Cypriote copper and Omani copper, or Cornish tin and tin from Central Asia. Since prices were denominated in metals throughout the East, it is difficult to establish when the price of metal was fluctuating, and when there was inflation or deflation. This means that prices cannot be used as a gauge of economic activity on their own, but that the market decided the prices, in two completely separate ways. The value of silver decreased in Egypt after peace was made with the Hittites, who controlled the silver supplies, suggesting that more silver was flowing in the relaxed political climate.

The evidence from Anatolia thus indicates that the "Theory of Comparative Advantage" was actually grasped, and applied by the Anatolians, with consequences for the whole ancient Near East. It has not yet been appreciated that the same phenomenon may have dominated Egyptian mining activity as well. Keynesian theory would suggest that the search for precious metals was important in ancient Egypt, and that gold-mining led to an increase in production. It is known that tin was in the Eastern desert yet not exploited. It could be argued that the Egyptians were technologically unable to exploit this tin. The copper in Sinai was definitely exploited, but it is unclear that it was exploited by the Egyptians.

277 Ricardo, Principles, pp. 527-537; Samuelson, Economics, pp. 834-835.

278 For the evidence of the tin trade, cf., e.g., Veenhof, Trade or J. Gledhill, and M. Larsen, "The Polanyi Paradigm and a Dynamic Analysis of Archaic States" in Renfrew, Theory, pp. 197-229. For the evidence of third millennium tin mining, and second millennium trade, cf. M.H. Gates, "Archaeology in Turkey," AJA 99 (1 1995): 223-225. 
J. J. Janssen noted that "the economic aspects the gold production are still largely obscure,"279 but went on to state that "so far as we know the Egyptians themselves did not mine copper in the Sinai during the NK", 280 citing the note familiar from the Inscriptions of Sinai:

In the face of all this evidence [of copper slag in Sinai] it would be idle to attempt to deny that copper was mined and smelted in the Sinai peninsula probably at an early period. At the same time there is not a scrap of evidence for believing that the miners were Egyptians. Had this been the case we should confidently have expected to find in the vicinity of the workings some monumental evidence of these visitors who left such complete records of their enterprise in mining the turquoise. ${ }^{281}$

Since then, a building has been found, which has been called the "Egyptian Mining Temple at Timna", and should thus be the monument which Černy was seeking. ${ }^{282}$ The evidence supporting the contention that this was an official Ramesside copper mining temple consists of a number of fragments of Egyptian pottery, some objects naming Ramesside pharaohs, several heavily damaged pillars, some fragmentary Sphinxes, and a graffito of Ramesses III smiting the foes of Egypt. ${ }^{283}$ Together this evidence definitely implies that the presence of the Egyptians in the area of the temple was more than accidental, and that a shrine to Hathor the Lady of Turquoise was built under the auspices of one of the Ramesside pharaohs, but the actual context of the discoveries suggests that it is impossible to reconstruct the temple as it originally stood and the association of the temple with official Egyptian copper mining is simply lacking. ${ }^{284}$ In other words, an Egyptian copper mining temple has not yet been discovered. Although copper-related activities associated with a temple of The Lady of Turquoise have been discovered, the Egyptian context of this copper working is completely lacking. Although Ramesses III does mention Hathor, the Lady of Turquoise, in P. Harris just after the references to copper missions, it would be difficult to interpret the passage in the manner advocated by Rothenberg. ${ }^{285}$ There seems to be no reason to revise Černý's appraisal. 286

279 Janssen, "Prolegomena to the Study of Egypt's Economic History during the New Kingdom," SAK 3 (1975): 153.

280 Janssen, SAK 3: 156.

281 Inscriptions of Sinai ll: 7

282 Rothenberg, Temple.

283 A. R. Schulman, "Catalogue of the Egyptian Finds," in: Rothenberg, Temple, pp. 114-147, with figures and plates.

284 There are several problems involved. (1) The architectural remains do not suggest the dimensions of an official Egyptian temple: 10x15 metres is more like a shrine than a temple (ct. Schulman in Rothenberg, Temple, p. 114). The actual architecture as preserved does not resemble any Ramesside Hathor temple. The Hathorheads preserved on the pillars do not necessarily match those of an Egyptian Hathor more than her levantine analogues. The sphinx however does bear a much closer resemblance to levantine styles than Egyptian, and Hathor is not associated with sphinxes. (2) The stratigraphy as published indicates that fragments of an Egyptian faience jar were found in the layers otherwise dated to the Chalcolithic, so that the absolutely ravaged state of the temple suggests that it is unwise to conclude that the smelting equipment arrangements were actually in use during the Ramesside period. (3) Nothing in any way indicates that this building was an official Ramesside structure: there are no lengthy texts or large stele. (4) Nothing indicates that were it to have been officially recognized that it was related to Egyptian participation in the copper mining industry, and in fact the expected reference to turquoise is not missing: Eg. Cat. 21, p. 118.

285 Cf. infra, p. 216 n. 691

280 Grandet (Papyrus Harris II: 261-263) assumes the validity of the archaeological reports which are thrown in doubt here, and thus understands developments in an alternative fashion. 
On the basis of the archaeological evidence hitherto produced, it is entirely reasonable to suggest that the Pharaohs did not deliberately engage in copper mining in Sinai. It is not clear that they established a monopoly on copper imports, and therefore, copper from Sinai may have been acquired from entrepreneurs. Given the logic of the "Theory of Comparative Advantage" it could be argued that the Egyptians did not exploit the tin in the eastern desert or the copper in Sinai because their comparative advantage was in the production of gold, which was worth far more than copper or tin or silver.

In Mari and Assur, the gold:silver ratio was roughly 1:4, while on the Levantine coast 1:3 was known. In Egypt, a ratio of gold:silver:copper of 1:2:200 demonstrated that even when the ratio fell to $1: 2: 120$, Egypt was still in a favorable position purchasing silver (which it did not have) with gold (which was in demand and which it did have), in order to purchase copper. ${ }^{287}$ Ricardo drew the logical conclusions from such a situation at the beginning of the 19th century A.D.:

All that I contend for is, that it is the natural price of commodities in the exporting country, which ultimately regulates the price at which they shall be sold, if they are not the objects of monopoly, in the importing country. ${ }^{288}$

This would suggest that every single price from ancient Egypt was itself a reflection of the "Theory of Comparative Advantage" because they were all denominated in either silver or copper and there was a competitive market for copper with producers in Cyprus, Anatolia and Oman competing with the Sinai producers. The evidence for both tin and copper thus corresponds to an economic incentive - and not a technological barrier - dictating the priorities. This can only imply that all prices were ultimately the result of market forces. ${ }^{289}$

\section{EgYPTIAN ECONOMICS AND ECONOMIC CONCEPTS}

In ancient Egypt it was absolutely essential to have your name inscribed in a Book of the Dead in order for it to be of any value. It is therefore evident that Books of the Dead in which the names were accidentally not filled out suggest that the book was written first, and that the names would be filled out when the sale was consummated. The shabti funerary figurines placed in the tombs likewise required the name of the deceased in order to be able to aid him or her in the Netherworld, and therefore the missing names on such figurines must be

287 Cf. D. A. Warburton, "Keynes'sche Überlegungen zur altägyptischen Wirtschaff," ZÄS 118 (1991): $81-82$ n. 21. It would appear that a ratio of $1: 8$ or $1: 9$ for Anatolia rests on dubious references, and this should be disregarded.

288 Ricardo, Principles, p. 530. It need hardly be pointed out that this would throw some doubt on North's contention that price-making markeis could not have existed in Antiquity (North, Economic History, p. 42).

289 Cf. the remark by E. M. Brumfiel ("The Economic Anthropology of the State: An Introduction," in Brumfiel, State, p. 2): "The logic of state economic policy is the logic of power rather than the logic of the market." If will be noted that the political power of Egypt extended to the Nubian gold fields, which rendered the economic comparative advantage of mining copper in the Sinai marginal. Since the Canaanites did not have access to gold, but did have access to copper, they mined it and sold it to the Egyptians. Both observed the laws of power - but their actions were determined by the market. All too frequently it is assumed that power can avoid the market, but ultimately the market decides, or least it has since the third millennium B.C. 
sought in negligent commercial activity. These phenomena demand that there was production which was not intended for specific customers and clients, i.e., production for the market. ${ }^{290}$ In the same way, it could be contended that those who manufactured small bronzes and figurines likewise produced without orders. It is equally fair to assume that tool-makers and basket-makers and potters were likewise in the position of being guaranteed customers, and could therefore produce without orders from specific clients. But the low level of general economic activity would imply that it is more probable that builders, furniture-makers and other craftsmen made goods or carried out commissions to order. The implication being that the producers sold their own goods, and that others carried out commissions so that merchants or traders were relegated to a role in carrying out exchange transactions of a marginal character, and this would suggest that traders are not merely lacking in the documentation because it is skewed in favour of the bureaucracy, but also because of the structure of the economy: the bureaucracy and the state were significant.

The market thus determined the general underlying tendency, but when Morenz sought to define the economy in ideal terms, he hit upon the key to understanding the system: the circulation system. While there may be some doubt about the interpretation of the significance of specific elements of the Egyptian economy, there can be no doubt about the role of circulation: it is a key, as Polanyi and Morenz indicated. Although proposed models cannot be tested against the data, let alone confirmed, the certainty of circulation remains paramount. The economic historians J. J. Janssen and R. Müller-Wollermann preferred Polanyi's approach, based on redistribution and reciprocity: the national economy of Upper and Lower Egypt operating as a reflection of the village or small city-state economy writ large.

B. Kemp suggests that the Egyptians had a basically acquisitive mentality, and this is undisputed: the issue is the means available to realise the goal, and state employment will have been among the most altractive possibilities. Avarice in acquiring a surplus in order to create monuments, etc. generated the income which was redistributed, and thus the surplus was created by taxation, not redistribution. Polanyi's objections to the concept of surplus prevented the school from examining the theoretical implications of the surplus. It must be noted that there is a fundamental economic difference between the economic production of goods for the market with a view to making profits, and merely making trading profits, and most are agreed that the second was a common feature of ancient civilization, while there is disagreement about the relevance of the first. ${ }^{291}$

The significance of the economically rational behavior has been interpreted in vastly different ways. Some contend that the evidence from Deir el-Medineh suggests that the economy was embedded in social life, and that understanding can only be achieved through comparison

290 Cf. e.g., the evidence for shabtis, where there is no middleman: D. A. Warbuton, "Some Remarks on the Manufacture and Sale of Shabtis," BSEG 9-10 (1984-85): 345-355.

291 This point becomes even more significant in the absence of a generally recognized comprehensive modern theory of profit, as this fact merely underlines that both ancient and modern societies were complex, and that identifying the key features of modern economics is more difficult than is generally assumed. Cf. Obrinsky, Profit Theory, passim. 
with peasant societies, ${ }^{292}$ while others contend that this is the "birth of economic man". 293 Janssen has recently pointed out that the two are not contradictory, but merely underline the rule that the social organism adapted to the market is missing, which is quite evidently the case. $^{294}$

The Gang was not only joined to upper Egyptian villages through sociological and psychological links, they also received "rations" or "wages" from the Egyptian state, through the redistribution system identified by Morenz, and discussed by Janssen. This redistribution system collected revenues from fields and marshes across Egypt, and turned them over to the employees of the state: grain, fish, dates, fire-wood, and many other items were ultimately delivered to the employees of the state, and it is this aspect of the economy that is the central subject of this work.

The following interpretation of the Egyptian economy is based on the premise that despite the paucity of data, a macro-economic model for the economy can be proposed, reflecting a pre-capitalist market economy. A very imperfect market - as familiar from the world of the "peasant economies" - allocated goods, but the role of the state in economic activity was so great that it had an effect on the laws of supply and demand to the extent that we are unable to recognize all the principles in every case. In general, however the basic principle will have been the tendency to even out economic behavior, but there will have been tendencies in various directions.

In The Ancient Economy, Sir Moses Finley suggested that the basic terms in Marshall's Principles of Economics, "such as labour, production, capital, investment, income, circulation, demand, entrepreneur, utility" "cannot be translated into Greek or Latin".295 Although one could quibble, the basic idea is correct. Taken word for word, one might not doubt Sir Moses's opinion, but examined differently, "work" was known, if not labour, "money" but not capital, "hoarding" but not investment, "profit" and possibly "income", "scarcity of coinage" but not circulation, "supply" but not demand, "trader" but not entrepreneur, "value" but not utility. It would seem that their analytical faculties were not very well advanced but they did understand their problems: how to build a bigger tomb, raise a bigger obelisk, conquer a larger country. These problems were the ones they faced and solved.

The differences between the two vocabularies testify to the role of exchange in society, and social attitudes towards exchange and those who carry it out. In the absence of a clearly defined market in which objects could be manufactured on the assumption that they would be purchased, entrepreneurial activity would be primarily oriented toward trade rather than production. If traders acted on the principle of making a profit through the acquisition and

292 J. J. Janssen, Prices, pp. $556 \mathrm{ff}$.

293 B. Kemp, Egypt, pp. 232-260, esp., pp. 241-248.

294 J. J. Janssen, "Debts and Credit in the New Kingdom," JEA 80 (1994): 136 n. 35

This line of thought neglects a supremely important aspect of modern economic behavior, where a state of equilibrium can arise with high underemployment, and an economic imbalance dominated by a tendency to increase supply for a market which is already saturated, implying that the modern economy has economically significant irrational elements, cf. Drèze, Underemployment Equilibria, passim, esp. pp. 15-27.

295 Finley, Ancient Economy, p. 21. 
sale of objects, or through hoarding in order to release products onto the market when they were scarce, this implies that they implicitly understood the effects of supply and demand, but that they would necessarily attract the universal hatred or contempt of mankind as a result. Finley emphasizes that this was the case in classical antiquity, and the evidence from ancient Egypt is similar. 296

The position of trade and manufacturing as respected professions only emerged in more recent times, ${ }^{297}$ but this does not mean that wealth could not be acquired in this fashion: it was just not respectable, landed, wealth. Through history, landed wealth has frequently tended to pay serious attention to social responsibilities and activities. The sense of responsibility resulting from having several families dependent upon the estate must have induced many an ancient subject or citizen to feel a similar responsibility for the general welfare of his homeland, and to contribute to its political destiny. A well managed estate also guaranteed that they were free of cares and had the time to do so, and that they could make profits effortlessly, and therefore not be obliged to pursue the creation of wealth as a goal in itself. Therefore, those who merely pursued wealth were worthy of contempt, and endeavoured to make themselves respectable as quickly as possible, by marrying into the right families and taking over the necessary social obligations. Prestige did not derive from wealth, but wealth could lead to the acquisition of prestige through participation. This ability of society to gather in the capable meant that there was a constant renewal of the human resources at the service of the state throughout history. This gave the role of the state an added importance in light of the fact that the administration of the agricultural resources was the sine qua non for the ability of the economy to leap beyond subsistence.

Returning to the economic sphere, and the role of redistribution in light of these social and political givens it is perhaps useful to return to the fundamental issue raised by Hunt, that it is the job of the bureaucrat to assure the surplus production necessary to maintain the level of overall employment based on the division of labour, which by definition however effectively reduces the level of agricultural employment, while endeavoring to maintain output. It is the peasants who must produce the difference, and this has resulted in widespread distrust: "The peasant looks upon outsiders (including officials) as his enemies." 298 Resenting interference, the individual independent peasant land-holder strives to seek his own economic balance:

Thorough empirical studies on peasant farms in Russia and other countries have enabled us to substantiate the following thesis: the degree of self exploitation is determined by a peculiar equilibrium between family demand satisfaction and the drudgery of the labour itself. ${ }^{299}$

296 Cf., e.g., M. Römer, "Der Handel und die Kaufleute im alten Ägypten," SAK 19 (1992): 282-284.

297 At the beginning of the 20th century A.D., "[...S he considered herself very broadminded because she had allowed her son to marry into 'trade'. 'As Sir Hugh was a multi-millionaire I was not very impressed,' observed Bertrand Russell in laler years." (From Winstone, Bell, p. 21).

298 F. G. Baily, "The Peasant View of the Bad Life," in Shanin, Peasants, p. 308.

299 A. Chayanov, quoted by B. Kerblay, "Chayanov and the Theory of Peasantry as a Specific Type of Economy," in Shanin, Peasants, p. 153. 
While independent peasants can afford to make these decisions for themselves, those who are part of a vast feudal economy dominated by temples, landlords and exploitative middle peasants view things in a different way:

Unused resources, wasted manpower, declining production - these were the fruits of a system that in the long run could only bring disaster on its victims and beneficiaries alike. ${ }^{300}$

This landscape was the result of deliberate but inefficient exploitation, and varies significantly from that represented by Hunt, where labour shortages rather than "wasted manpower" were the problem. Hobbes described the situation preceding the emergence of the state:

In such a condition there is no place for industry because the fruit thereof is uncertain, and consequently no cultivation of the earth, no navigation and the life of man nasty, poor, solitary, brutish and short. ${ }^{301}$

In many modern states of the Third World, a different situation prevails as prices for local products are kept low so as to permit an impoverished under-employed urban population to purchase foodstuffs. Low prices necessarily reduce the production incentives in agricultural areas, and production stagnates. Underemployment in both urban and rural areas rises, and foreign imports rise, so that the essential elements for stagnation are there. If demand for production is reduced to the minimum level, savings are reduced to nil, and investment fails to take place.

In each case, the assumption is different: (1) a free choice against over-indulgent selfexploitation, (2) the consequences of multi-faceted feudal exploitation, (3) the absence of a central authority guaranteeing security, and (4) a mere neglect of the politically amorphous rural population, but in each case the result is the same agricultural inefficiency and poverty on a vast scale.

On the one hand, Hobbes assumed that a government guaranteeing security was the lacking element, while in feudal China, it was not the lack of authority, but the inefficiency of the system of myopic exploitation that prevented development. ${ }^{302}$ On the other hand, Hunt suggests that the labour shortage was the problem, which was no where in evidence. ${ }^{303}$ Certainly, one key to understanding the system is demand: the great English economist John Maynard Keynes pointed out that in a pure laissez-faire economy, in the event of a decline in demand, investment and production would sink to a level of poverty where savings would

300 Hinton, Fanshen, p. 36.

301 T. Hobbes, Leviathon, Chapter 13, p. 62 (original edition).

302 Despite all the horrors, if would appear that the formative Egyptian state bore a strong resemblance to the Chinese feudal system based on a small group of land-lords controlling not only most of the draught animals and land, but also the unpaid official and semi-official posts.

303 Cf. Chaudhuri, Asio before Europe, pp. 84-85: "A great many people, members of the different civilisations of Asia, were not engaged in growing their own food or raising their own livestock. Farmers [...] who [...] had no wish or incentive to feed any one else other than their own families and extended kinship groups, nonetheless provided food to classes without direct involvement in its production." 
be reduced to zero, which is precisely the situation described by Hobbes, so that the state is one theoretical actor in the equation, but demand must be another. If the market alone is unable to correct the situation, intervention is necessary, and only the state has the power to intervene, transcending the individual micro-economic problems of the economy as a whole. Despite these theoretical constraints, ancient Egypt, a technologically primitive sociely, developed an economy sufficiently sophisticated to produce literary, philosophical, artistic and architectural wonders which still command the attention of the world. Assuming that the temples and the government were the primary factors in increasing demand in ancient Egypt, these powers will have exercised an extraordinary influence on the economy. The theoretical aspect of state intervention in an economy in order to stimulate, and thus increase, demand was carefully studied by Keynes, who showed that state intervention could call into existence demand which was hitherto not present, in order to shift the economy to a new level of equilibrium, with a higher level of prosperity than that previously prevailing. ${ }^{304}$

\section{KEYNES}

These facts suggest that many aspects of the Egyptian economy can be elucidated using the Keynesian approach, so that the value of the model exceeds the mere imposition of an unwieldy construction upon the flexible administrative methods of the ancient Egyptians, but actually contributes to the understanding, as well as the explanation of the Egyptian economy. This approach has been selected as the fiscal system can serve to define the essence of an economy as a whole, especially if that economy is defined in terms of "redistribution". The Keynesian interpretation of the Egyptian economy is merely a refinement of the redistributive model, designed to enhance understanding, by joining the principle of demand with the market and "redistribution". 305

Much of the theoretical background to the study of the economy does not and cannot contradict other interpretations, it merely emphasizes certain distinct points. The key element is that the employment of Polanyi's categories has not improved the level of discussion, as the prescribed social relationships are violated by applying all elements of his approach to ancient Egypt, and the data has been wisted to match his model rather than the reverse. The lack of theoretical mechanisms accompanying his model likewise makes it inappropriate to reject analytical approaches to the mechanisms of the economy which can only aid compre hension. In a very general way "redistribution" is certainly a key element in the fiscal system of any state, and therefore the employment of Keynesian theory to illuminate "redistribution" cannot be dismissed, unless the interpretation of the variables is erroneous. Keynes himself put it quite simply: 
Ancient Egypt was doubly fortunate, and doubtless owed to this its fabled wealth, in that it possessed two activities, namely pyramid building as well as the search for precious metals, the fruits of which, since they could not serve the needs of man by being consumed, did not stale with abundance.[...] Two pyramids [...] are twice as good as one $[\ldots]$ ] $]^{306}$

This passage terminates the chapter on the "Marginal Propensity to Consume", where Keynes discusses the difficulties of increasing demand, as there are very few products for which the demand curve is infinitely elastic. Consumption is dependent upon abstaining from investment, and thus requires liquidity, in order to acquire. Increased consumption increases demand, which increases aggregate demand in an expanding economy, but creates competition between sectors in a stable or diminishing economy. Aggregate demand can only be increased inelastically if both liquidity and consumption are permitted to increase with competition for scarce resources excluded. On the one hand, liquidity is usually unable to sustain indefinite demand stimulation, and demand itself is usually insufficient because it flags. According to Keynes this unusual constellation was the key to growth, rather than investment as such. Put simply, an infinitely elastic demand curve is one where demand is unlimited. Normally, any product that can be consumed reaches a saturation point on the market, and demand flags, with the result that the price falls, and production and employment stagnate. Keynes thus drew upon the example of pyramid construction to illustrate the principle that if something is absolutely useless, and yet infinitely desirable, demand for it will not slacken, meaning that investment and employment will continue to increase.

In the modern capitalistic world however, those investing in such products would inevitably distort the interest rate structure such that their production would continue to flourish, while other sectors declined, until a new equilibrium was reached. Keynes's theory of price formation was based not only on supply and demand, but also interest rates, so that price stability would be virtually unattainable with fluctuating interest and wage rates, which are the necessary repercussions of the massive concentration of investment and demand in one part of the market. In the modern world, state intervention would have the same - or even worse - consequences as the state is responsible for the currency as well as fiscal policy, so that state financed demand would either result in (a) inflation, (b) distortion of the interest rate structure, ${ }^{307}$ or $(c)$ excessive taxation. Each of these would necessarily have a negative impact on the overall economic structure, so that driving away the unemployment problem would merely create other acute difficulties. In the General Theory, Keynes was particularly concerned that interest can suppress demand for investment and thus the whole series of demand curves, and thus threatens to maintain an economic equilibrium at a low level of prosperity indefinitely, unless the demand can be stimulated in another way, for demand is the key to increasing prosperity and employment. "Aggregate effective demand",

306 Keynes, General Theory, p. 131. Superficially the reference to mining might not appear compelling, but in terms of providing an additional motive for expeditions into the desert and the conquest of Nubia, mining had an enormous impact on prosperity and employment in ancient Egypt.

307 Government bonds are the most certain type and thus preferred by investors wanting to avoid risk. 
the "propensity to consume", and the "marginal efficiency of capital" are the decisive factors which could potentially leave an economy at an equilibrium of absolute poverly. The primary difficulty as Keynes perceived it, was to stimulate demand, while balancing off the various evils, in order to achieve an equilibrium at a higher level of prosperity. In the modern world there is virtually no way to avoid the choice of the lesser evil, but the ancient world was governed by a different situation, as the understanding of the details of currency fluctuations and market mechanisms had not yet penetrated into every aspect of the economy.

Keynes himself was interested in the ancient world, and wrote some papers (which remained unpublished during his life time) about the economies of Greece and Mesopotamia which

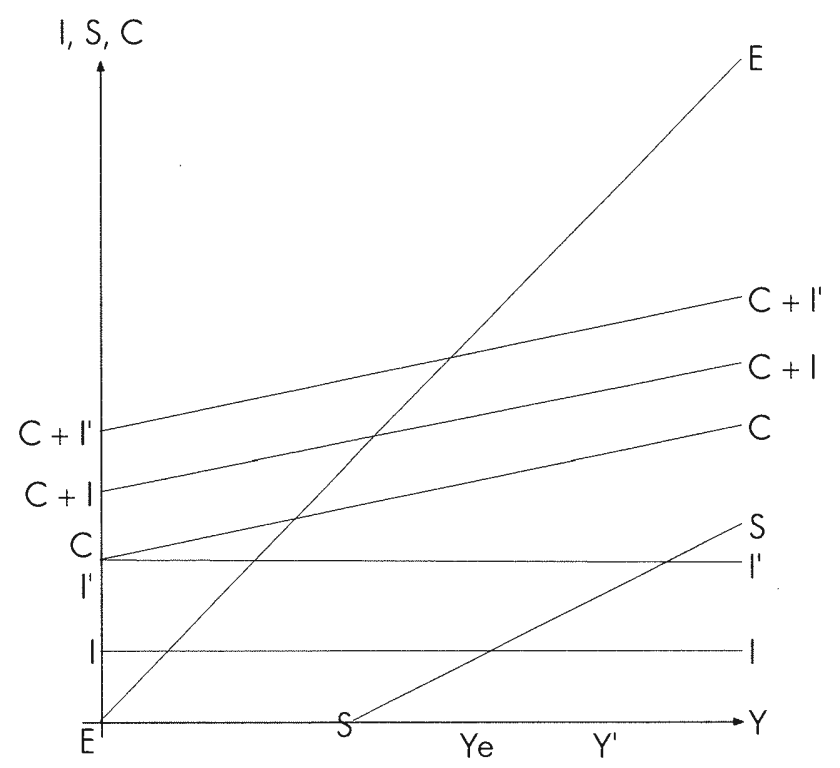

Fig. 2. The Keynesian Modele08

The left vertical scale represents investments, savings and consumption (I, S, C); the bottom horizontal scale is the income level $(Y)$. In the classic Keynesian paradigm, investment is stable at a low level of equilibrium (I), with a stable growth of consumption (C) but minimal savings $(S)$ as people only save when income grows, as from $Y e$ (income at first equilibrium) to $Y^{\prime}$ (income at increased equilibrium) after new investment (I') demand stimulates the economy, with increased Consumption and Investment $\left(C+I^{\prime}\right)$. The ideal equilibrium line $(E)$ is the ideal situation where income equals investment, savings and consumption, so that all available means are re-circulated within the economy. Only in the ancient agrarian world where government income and expenditures could be measured in grain and usefully employed without the danger of debt was this a realistic possibility.

This was taken from Screpanti/Zamagni, Economic Thought, Fig. 7, p. 233. 
were dominated by interest rate structures, ${ }^{309}$ in contrast to ancient Egypt, although this was not known at the time. The critical role of interest rates was thus assumed to have been a prevalent problem in the ancient world, and so it is not surprising that Keynes did not direct any further energies to the study of ancient Egypt, and did not realize that ancient Egypt was an ideal case for illustrating his theory. Keynes's primary concern was however the modern world in any case. ${ }^{310}$

Keynes was confronted with the situation of the depression and the inability of the capitalist system to rescue itself, as it must have according to the premises of the laissez-faire economists who assumed that equilibrium with lower unemployment would be achieved by lowering wage rates. ${ }^{311}$ Keynes pointed out that aggregate demand would not increase by lowering wages, as effective demand had more or less peaked in any case. Thus, knocking down wage rates would not increase employment if demand was flagging, for liquidity would not be increased, and therefore effective demand would stagnate. ${ }^{312}$ If effective demand did not rise, investment would not rise, and the economic situation would continue to be bleak (as it had been for millennia). It was thus only by external stimulation that the economy could be spurred on to a higher level. It is the "marginal efficiency of capital" (by which the interest rate structure is meant) which thus determines the level of prosperity. If interest rates sink to zero,

the position of equilibrium, under conditions of laissez-faire, will be one in which employment is low enough and the standard of living sufficiently miserable to bring savings to zero. ${ }^{313}$

It should be eminently clear that the construction of pyramids, tombs and temples was an absolutely ideal method of increasing demand, and thus that the reference to Keynes' General Theory can be largely justified on this basis alone, but many of the basic problems of modern capitalist production as perceived by Keynes were already surmounted in ancient Egypt several millennia ago. These problems concern demand, consumption, savings and investment, as each of these has an influence on the other, with the result that the equilibrium between these factors determines the state of any economy at any given moment in time.

When he died, he was working on the creation of the post-war economic system symbolized by Bretton-Woods, which led to one of the most successful economic transformations in world history, and thus it was probably more valuable for humanity that he did not devote himself to scholarly pursuits. Cf. Gardner, Sterling-Dollar Diplomacy. In passing we might note that the interpretations of economic development in the second half of the 19th century A.D. offered by Keynes (Consequences) and Polanyi (Transformation) do not differ widely. It was only their interpretation about what should be done in future that did.

311 They did not realize that mankind had lived for millennia with a high proportion of involuntary unemployment, and that there was no reason why this had to change, cf. Fig. 3, p. 119 infra.

312 Say's law dictated that demand would rise to meet any supply, and therefore that equilibrium was inevitable. The general assumption of the economic community was that equilibrium would inevitably be reached, and thus the failure to realise that the realization of Say's law required placing financial power in the hands of those seeking to acquire, and that it would only then therefore be possible to establish a new equilibrium at a higher level

313 Keynes, General Theory, pp. 217-218. 
In an agricultural economy, without external stimulus, production will equal consumption, with a high level of unemployment or underemployment, as over-production would not result in an increase in consumption, and thus there is no incentive to produce above the necessary minimum. The price structure and investment possibilities virtually assure this. In ancient Egypt, the land itself could practically guarantee that a minimum of labour input would produce the maximum consumption level, so that demand would not increase without artificial stimulus.

The state provided the artificial stimulus by (1) obliging the farmers to over-produce, by means of fiscal measures, (2) creating a class of craftsmen employed full time on temple and tomb construction and maintenance, thus withdrawing this class from significant agricultural production, (3) paying for the major construction projects with the surplus withdrawn from the farmers, and ( 4 ) creating a bureaucracy which also required maintenance. These measures alone guaranteed that demand was stimulated beyond the subsistence minimum.

Demand stimulus as the explanation for the success of the Egyptian economy as the fundamental element enabling the redistribution system to function superficially contradicts Hunt's analysis. It is generally agreed that the state redistribution system collected grain (and other products) from one part of the community, turning them over to another part of the community. This was possible as corn production promised incredible yields. ${ }^{314}$ Since the labour input was the weak variable here, the only way to increase secondary and tertiary employment was to drastically reduce agricultural underemployment, increase the overall level of employment for individuals, taking people off the land, employing them in the construction and service sectors, maximizing agricultural production with heavy rent and taxes. Removing people from agricultural production forced those who were left to produce more than was being produced per capita before, in order to pay the recipients who were employed in the other sectors. Increasing the demand stimulated production, so that the two variables were related. The fact that the Roman empire was able to produce sufficient quantities from Egypt, to maintain not only the population of Egypt, but the plebs at Rome as well, suggests that Pharaonic pragmatism overweighs Hunt's theoretical scheme, and that the real problem in agricultural economies around the world is under-employment, rather than a shortage of labour, i.e., that the system is closer to that suggested by Chayanov and described by Hinton than to Hunt's postulated restrictions. ${ }^{315}$ The investment increases employment producing temples, tombs, boats, etc.

The fact that the measures employed for increasing production were fiscal in nature guaranteed that state investment would not have a negative impact on private investment, because the

314 Cf. Gardiner, Wilbour II: 71; Rathbone, Economic Rationalism, pp. 242-244. Modern records indicate yields of 5-15 khar/aroura.

315 It should be evident that references to the finite limits of the agricultural surplus are inappropriate, as the increased workload was spread over a diminished workforce, but demographic growth proceeded slowly, meaning that overall demand for grain remained constant until the population began to change, which was a much more long term development, and even here the evidence indicates that the limit was demand rather than supply, so that neither the workforce nor the actual quantity of grain which they could produce are relevant variables. 
interest rate structure was not affected, signifying that there was no competition between the state and private sectors for scarce means. The private sector was thus left untouched by the fiscal (as opposed to) monetary solution of the problem.

In fact however, the monetary solution (using inflation or interest rates) was excluded from the outset by the fact that Egypt neither had a currency, nor an all-pervasive system of interest rates. ${ }^{310}$ Money is assumed to possess three basic attributes, as (1) a unit of value, (2) a store of value, and (3) an exchange value. In ancient Egypt, the copper deben was a unit of value and evidently a store of value, but it was not normally employed in transactions, and thus fails to meet all three criteria. ${ }^{317}$ The khar of grain was used both as a unit of value and a unit of exchange, but storing grain is not a realistic method of keeping one's savings, so that it likewise fails to meet all three criteria. ${ }^{318}$ Beds and other articles could be used for exchange purposes, and perhaps as a store of value, but they could not be regarded as a unit of value. In any case, there was no government controlled money or currency, which could be used as a tool of monetary policy, ${ }^{319}$ and thus the monetary inflationary alternative was not available. ${ }^{320}$

Increasing grain production was inflationary, but so long as (1) the excess production could be absorbed by diverting state employment into non-agricultural sectors and (2) the resulting "inflation" did not damage private sector entrepreneurial investment, the situation was one in which inflation played a positive rather than negative role. This is crucial for the Keynesian

316 Cf. J. J. Janssen, "Debts and Credit," JEA 80: 129-136. The evidence adduced certainly corresponds to that of the famous purchase of the slave-girl (cf. A. H. Gardiner, "A Lawsuit Arising from the Purchase of two Slaves," JEA 21 [1935]: 140-146), and suggests that among themselves, the workmen had access to a credit system which was not injurious to their wealth, in great contrast to, e.g., feudal China.

317 Cf. Warburton, "Überlegungen," ZÄS 1 18: 81, n. 21; p. 82; Janssen, "Prolegomena, "SAK 3 (1975): 177.

318 It could be contended that grain was the equivalent of money, for the wealthy could afford to maintain large well insulated silos, and the poor had few resources anyway so that the rodent problem in Egypt should not be taken so seriously. (It was however the situation after the inundation that was used as an illustration for spontaneous generation, where mice supposedly appeared spontaneously once the water began to subside). Grain is listed among the things lent to others in Janssen, "Debts and Credit," JEA 80: 129.

It should be noted that for the purposes of the Keynesian interpretation of the economy setting grain as a true equivalent to money is not an obstacle, but actually a corollary of the argument, so that the contention that money did not exist in Egypt is intended more as a realistic appraisal of the situation than a dogmatic statement of position. Inflation through the grain standard is impossible, and increased production will only lead to economic growth and prosperity.

319 The supply of precious metals cannot have fulfilled the same investment and income roles as grain which was the essential component of public investment, being primarily determined by access to grain. Thus, precious metals may have performed all of the utility roles demanded of money, but they could not be employed to alter grain production, which was the basic source of wealth. Cf. Warburton, "Überlegungen," ZÄS $118: 81$, n. 21 ; p. 83 , n. 24 for remarks concerning the purist Keynesian approach to the role of precious metals. It must however be noted that the production of gold did have at least a marginally significant influence on employment - by diverting labour from the market place (and thus decreasing unemployment), and increasing the necessary grain production to pay the workers involved.

320 This whole paragraph appears to force the Egyptian economy into the theoretical framework, but the purpose is exclusively to identify and analyze any possible implications of the roles served by the articles in question, and not to create the impression that the Egyptians thought of pots and pans as their savings.

If Janssen's ("Debts and Credit," JEA 80: 129-136) understanding of the evidence of the references to materials belonging to one person but in another person's possession is correct, and this is a form of credit, it will be noted that precisely the items assigned a partial monetary role here appear in these texts, including a bed as an article which could be loaned. 
theory as inflation in capitalist economies can have an extremely detrimental impact on both employment and investment, by rendering certain industrial undertakings uneconomic. It is extremely advantageous for a growing economy to have sticky wages, i.e., wages which remain stable or rising while prices rise or fall. If wages were not in money they might not remain stable in money terms, but if grain demand stays high and constant, and wages are paid in grain, and taxes collected in grain, and grain a medium of exchange the threat of negative economic repercussions is avoided. It is only through increasing effective demand through high wages or income that the private sector can contribute to the economic growth stimulated by the government program, as the income can be absorbed through production leading to transactions and the generation and accumulation of wealth.

That the state was collecting grain meant that increasing demand was a more or less automatic process, and that demand here had a positive effect on employment. The same was true on the investment side, as the employment in the temples, etc. increased both aggregate employment, and aggregate income, without taxing the capital markets. And without inflation. Without a currency, the danger of inflation was avoided, since inflation occurs when the government consumption exceeds government income - and the whole basis of the program was to maximize state income. Thus many of the basic elements of the Egyptian economy are logically ideal forms of implementing a cyclical development which would spur demand and employment, underlining the relevance of the Keynesian theory for understanding the process. Keynes himself has come under attack for various faults of the theory, some of which arose from conscious application of the theory, such as the shift of the Phillips curve. Since the Egyptians were doing this unconsciously, they did not face this danger either.

It is quite clear that the Phillips curve was pushed to the right in the 1970's and 1980's, to the extent that people doubted its relevance, but the curve only claims to establish a statistical relationship between inflation and unemployment, not to explain the entire economy. ${ }^{321}$ Not only does the interest rate have an influence on investment, and the investment curve effect consumption, so that even with income and prices steady, a change in the consumption curve will have an effect on the demand for labour, and thus unemployment, but consciousness of the assumed relations encourages people to change their expectations. Such a change will naturally effect the Phillips curve as the increased demand in consumption will drive up prices, especially if it had a negative impact on investment, and this will seemingly influence unemployment. In the end the problem is demand, as an increase in demand can lead to an increase in supply, one of the major constraints being money, and another labour. The lack of a money or currency also eliminated the possibility of the impact of the interest rate structure from having a detrimental impact on investment and thus production. Investment curves in the capitalist world are determined by interest, as the expectation of profit must

321 The Phillips curve offers two challenges: (1) that in statistically identifying the relationship between intlation and unemployment, investors can anticipate inflation, and act accordingly, which creates a self fulfilling prophecy; and (2) no one knows why the relationship exists, for it is a mere statistical reality, and therefore the relationship need not be based upon direct connections, increasing the danger that (I) threatens to make a statistical relationship into a real one. Cf., e.g., Holler, Arbeitsmarktes, p. 32. 
exceed the anticipated interest rate, otherwise investment subsides until the interest rate has fallen. If the interest rate is zero, investment will also be zero unless stimulated. ${ }^{322}$ The fact that there may have been agriculturally related interest rates had the opposite effect, and was precisely the same as the state's role in skimming off agricultural production, as the exaction of interest for grain resulted in the incentive to produce more grain than was necessary for consumption. ${ }^{323}$ These private sector interest rates will thus (1) not have had a negative impact on the economy, actually spurring it on, and (2) the conflict between the state and the private sectors for scarce resources will have been reduced to a minimum. ${ }^{324}$

Aside from industrial investment, land ownership is one of the most enticing means of investing excess capital in the modern world, and in most of the Mediterranean world throughout history. The state may have been one of the major land owners in ancient Egypt, but this did not seem to have increased demand for private land to the extent that the price was driven upwards, as K. Baer has shown that the price of land in ancient Egypt was comparatively low. ${ }^{325}$ This meant that capital investment would not be directed to the mere possession of land, but to using the land for productive purposes, i.e., increasing the grain supply, and thus being able to maintain a large household.

322 Since no one will lend funds to another for entrepreneurial purposes without an incentive.

323 There would appear to be very little evidence on interest rates in ancient Egypt, and it is anticipated that another study must be devoted to the subject. The interpretation of the $\mathrm{Hq}^{3}$-nht papers permits the conclusion that interest existed, supported by other sources, but interest could not have played an important role in the economy as we understand it. This is one of the greatest points of contrast belween contemporary Egypt and Mesopolamia. For ancient Egypt, we have no firm data on interest rates of any kind, but repayment of grain related loans, at e.g. 100 per cent. p.a. for seed corn would equal 20 per cent. of the crop, with a tenfold harvest. There is no evidence of metal-related interest. In ancient Mesopotamia interest rates of c. 33 per cent. in grain and 20 per cent. in silver were usual.

It is perhaps interesting to note that rates of $321 / 2$ per cent. were usual in 16 th century Holland. In feudal China 50 per cent. a month in silver was not unknown. This would indicate that in early and feudal agricultural and trading communities relatively high interest rates were the rule. In the ancient world there is no evidence for decisive falls in interest rates, as opposed to the simple cancellation of debts.

Interest rates fell decisively in Holland so that by the end of the 17 th century they were at $21 / 2$ per cent. The value of silver fell decisively during the same century, as the Chinese market was saturated (cf. D. O. Flynn and A. Giráldez, "Born with a 'Silver Spoon': the Origin of World Trade in 1571, "JWH6 [1995]: 201-221), but the drop in interest rates is the opposite of what would be normally anticipaled with a drop in value, and was certainly far greater than the drop in the value of silver. It thus appears reasonable to suggest that interest rates were the decisive factor enabling the industrial revolution, as low rates permit profits to be made with manufacturing, whereas high rates not only result in high debts and ultimately the concentration of agricultural lands in the hands of a small elite, but they also encourage entrepreneurs to pursue profits through trade rather than production. It is unclear why interest rates fell.

That the rates fell at precisely the moment when Europe began to overtake the Indian Ocean - and not when silver from the Americas began to flood the European market - is however clear, and that the economy of Europe was industrially transformed immediately thereafter is equally clear. This would suggest that low interest rates and banking are significant criteria for modern capitalism, and that technology and precious metals play less of a role than would be expected.

324 Aside from the fact that most of the wealthier land holders will probably have been state officials, but this is irrelevant at the moment.

325 Cf. Warburton "Überlegungen," ZÄS 118: 84, n. 26; K. Baer, "The Low Price of Land in Ancient Egypt," JARCE I (1962): 25-45. 


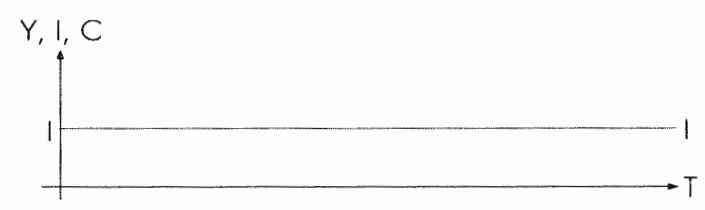

Fig. 3. Unstimulated Low Investment in Subsistence Economy

The left scale is the level of income, investment and consumption, against the bottom scale of time Without growth, investment stagnates at a minimum level: an equilibrium at the poverty line. It is possible to have economic activity and even the production of luxury goods in such an economy, but prosperity is not wide-spread.

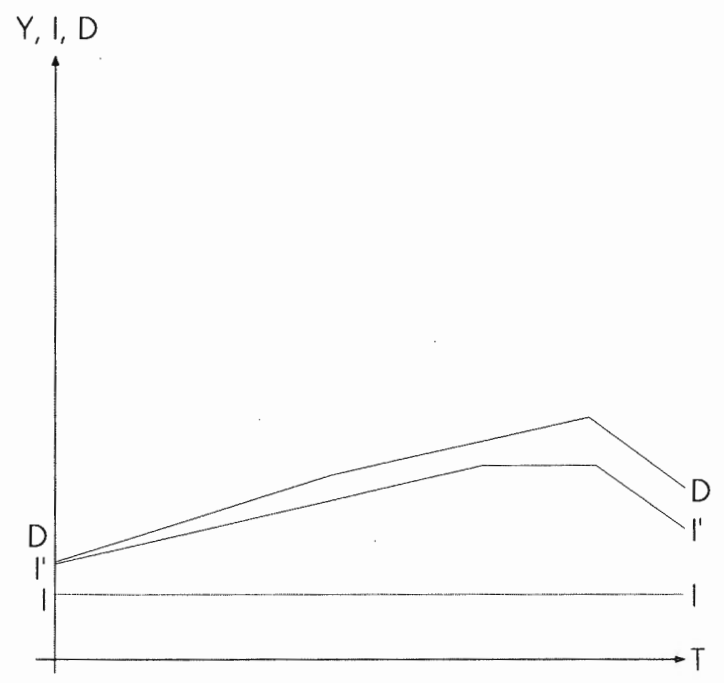

Fig. 4. The Simplified Keynesian Theory Applied to Ancient Egypt

Investment (I) is stagnant at subsistence level, with income (left scale) stable over Time (bottom scale, T). The level of investment is such that no significant changes can be achieved without substantial changes in the demand structure, i.e., antificial stimulation. This is accomplished by the government artificially raising demand for grain (taxes), which is immediately paid out in wages and rations, i.e., Demand $(D)=$ Investment $\left(I^{\prime}\right)$, until private demand likewise increases as a result of stimulation (through new government investment ['] , creating new stimulated Demand curve [D']). It is noted that with private investment, demand has risen considerably, but it is dependent upon the state investment ( $\left({ }^{\prime}\right)$ without which it falls, to a little way above previously existing level, because it is dependent upon the increased level of state demand. (This graph presumes that during the First Intermediate Period - right end of graph - general prosperity dropped across the country, which does not suggest that the new equilibrium eliminated wealth or the distribution of prestige goods). 
Egypt was thus basically on the grain standard, and this particular commodity was the basis on which the entire economy flourished. It was the grain which was used to pay the workers who built the monuments of the land, and by withdrawing labour from the agricultural sector, demand was actually increased, along with employment.

It will be observed that this whole study is devoted to the fiscal system, or the means by which the government increased demand for numerous products, and that it was thus primarily concerned with the role of the state. The private tombs may well have been built with private means, for the most part, as during the Old Kingdom, which renders it probable that a private sector flourished along side the state sector. It is also possible that the temples were actually purchasing part of their necessities from the private sector. The workers in Deir el-Medineh spent part of their spare time engaging in outside work, making funerary equipment for the wealthier segment of Theban society. ${ }^{326}$ The private sector did thus exist, and thus the economy will have been a mixed economy, with the state potentially taking the lion's share of the surplus economy, but obviously not impinging on the private sector, as otherwise there will not have been so many private stele and tombs made on private contract by private craftsmen for private people. The entire economic system was thus oriented towards consumption and investment, as the potentially negative influence of interest rates and savings were effectively negated, and the "propensity to consume" given free rein. It was merely the state fiscal system which guaranteed an equilibrium at a high level of prosperity for all.

The ideal feature of temple and tomb construction is that the demand is infinitely elastic: the law of the "Extension of the Existing" (Erweiterung des Bestehenden) indicates that one can always make a large tomb or temple, one can always employ more priests, encourage additional services, and all this without negatively effecting the rest of the economy. The state did not hamper individuals in their own investments.

\section{Elaboration of Value of the Use of Keynesian Theory}

This analysis has been disputed on several levels. One approach contends that the Egyptians did not do it deliberately and that the relevance of Polanyi's redistribution system is clear, but that of Keynesian theory less so. Another objection has been the assertion that the logic is purely circular. The intellectual validity of using Keynes to analyze a non-monetary economy has likewise been thrown in doubt. ${ }^{327}$

The only purpose of the theory is to provide parameters for comprehending the variables, and therefore the relevance of the theory can only be used to analyze situations, and to compare its value relative to other theoretical frameworks. Viewing Mesopotamia, ziqqurats appear to be comparable to pyramids, and thus it is tempting to equate the two systems, but interest rates and trade played significant roles in Mesopotamia, so that when the economy

Cf. e.g., E. Eichler, "Polanyi-Keynes-Warburton," GM 131 (1992): 25-31; D. A. Warburton, "The Economy of ancient Egypt Revisited Yet Again," GM 146 (1995): 103-111. 
faltered, not only tax exemptions were proposed, but also the cancellation of debts. In Egypt, tax exemptions lead to a decline in the economy, as demand is reduced. It is difficult to understand the significance of this gesture, as it is automatically assumed that if the institutional obligations to pay are reduced that the income will automatically fall into the private sector, or that it fails to make a difference. In fact, once an administrative construction project came to a halt, it was normal for the fields responsible for the grain supplies for the workers involved either to cease production, or to be transferred to another project. The mortuary temples of the new Kingdom pharaohs are a case in point. It is assumed that the reigning pharaoh was wrongfully misappropriating the goods of his predecessors when he transferred certain of their fields to those of his own funerary temple. In fact, according to the theory that one continued to build as long as one was alive, one also stopped when one died, and the mortuary temple ceased to be a construction site and became a divine temple, with the result that the construction workers previously engaged at the temple were no longer employed for construction at that temple, and thus that they no longer received wages. The newly ascended pharaoh promptly re-organized things, sought out a site for his new tomb, and transferred the workers from the former royal tomb to the new royal tomb. The same event also applied to the mortuary temples, but here the administrative machinery had to be slightly revised, as the function of the temple changed, whereas the construction in the royal tomb came to a halt and was stopped, and it was a mere detail to re-assign the Gang to continue work at the new tomb. The mortuary temple was transformed, and therefore administrative measures were called for. If however, in other cases, land was withdrawn from the domains at the disposal of the private or public sectors in order to guarantee a given project, then that land and its production was no longer at the disposal of the state. If the temple construction project came to a halt, and the workers were laid off, and the grain continued to be collected by private individuals, the demand situation would remain stable. If however, the workers were cut off from the economy, and the grain no longer collected, demand had slackened, and the state system had suffered a set back.

The assertion that the logic is circular fails to understand the basic purpose of the theory. The theory is merely an elaborate detailed description, and therefore the description should match the situation it endeavors to describe. If the theoretical description is correct, then it not only describes the economic situation, but allows conclusions to be drawn from the premises, permitting inferences concerning things which are not known. Thus the theory must be "circular" insofar as it depends upon describing a situation, but its value lies in the next step, which involves inferences, such as conclusions concerning price behavior or the role of grain which relate variables which have hitherto been unrelated.

A more sophisticated objection is that Keynes's system was designed for monetary economies and that it therefore cannot be applied to the non-monetary Egyptian economy. If however it serves the purpose of a model, then it is worth using. But the fundamental features distinguishing monetary from non-monetary economies have not yet been identified, and the nature and importance of money is not clearly defined. Economists are agreed that money is an absolutely essential part of the modern economy and that a money economy can be either perfect or catastrophic, which is as much as saying that money is simply another 
variable in a complex series of equations. Economists are also not in agreement about what money is. ${ }^{328}$ Economists are accustomed to assert that money is a difficult problem, and that the total money supply is very important, and then to use either $M 1$ or $M 3$ because they can measure it, and they are unable to measure the real quantities, let alone velocity. Money is a part of any major equation, but money is just one element, with investment, employment, consumption, demand etc. ${ }^{329}$

From a Keynesian standpoint, money has several features. On the one hand, anything that can act as a bridge between the present and the future can serve as money, but Keynes did point out that money has two other fundamental features unrelated to paper: zero elasticity of supply (as far as the entrepreneurs are concerned) and zero elasticity of substitution. Thus, although most people interested in Egyptian economics would not claim that Egypt had money, many economists could be persuaded to believe that emmer and barley were in fact money, because they would match the definition of being a link between the present and the past, have zero elasticity of substitution, and could only minimally have their supply altered by the private sector. ${ }^{330}$ It is futile to dispute whether Egypt had money or not, and therefore the key features is that the effects of the use of the articles that did serve as money was such that the main dangers implied by Keynesian theory could be avoided.

In economic terms, the ultimate effect of artificially stimulating an increase in grain production was the equivalent of deficit spending, insofar as it increased prosperity. As it did not hamper overall production by distorting demand and interest rate schedules, it did not have the negative effects commonly associated with deficit spending, such as inflation. This merely underlines that it is necessary to grasp the basic principles of the economy and economics rather than to become overly attached to concepts or words.

The best counter to objections to the use of the theory is however to point out that many modern economic textbooks bear traces of Keynesianism, yet Keynesian theory can be applied only to closed economies while most modern economies are not closed, so that this would be a seeming misuse of the theory, yet the authors find it useful. The key question is thus whether the theory can be shown to be of value for ancient Egypt. B. Kemp suggests that

Any economic system that we propose for ancient Egypt has to be able to account for the apparently successful adjustments which local communities made to changes of different magnitudes within a relatively crude state system of economic direction. ${ }^{331}$

328 As can be seen from the different measures of money used by economists, $M 1, M 2, M 3$, etc.

329 For our purposes, the case of China is extremely relevant, for the mere effect of introducing metal coins may have transformed ownership patterns in the course of a millennium, while leaving the social relations and much of the political and economic system intact. But it is atso possible that the economy adjusted to the introduction of money and reached a slightly different equilibrium and that the influence of trade as a major factor had a decisive impoct.

330 Certainly far less than private banks can alter the money supply today, so that this definition is no longer relevant to the modern economy, if it ever was.

331 Kemp, Egypt, p. 240. 
Assuming the relevance of this statement, and leaving Polanyi behind, we can turn to examples of unconscious economic interpretations which have been offered, such as that mentioned at the beginning of the chapter. Another case concerns the tomb robberies:

Viewed economically the frequently regretted tomb robberies are desirable, as unproductive capital is brought into circulation. ${ }^{332}$

It is clear that this thought is inspired by an economy in which gold and silver can be exchanged for products in such a fashion as to stimulate economic activity. The main value of gold according to the Keynesian economic model is to (1) increase employment through prospecting and mining, and (2) withdrawing it from circulation. Virtually any economic model would suggest that it should not leave the tombs, and that it should be followed by more, as this increases production. In detail, following the interpretation of Keynes offered above, it can be concluded that $(1)$ the employment effort in exploiting the tombs was negligible in comparison to that of occupying Nubia and prospecting for gold there, and (2) that increases in the gold supply would not have the magnitude of economic significance of increases in demand in the agricultural sector. Therefore increased military activity and gold production and agricultural taxation were vastly more valuable than the increase in gold in circulation, and thus it is not surprising that the decline of the economy at the end of the New Kingdom was not inhibited by increases in the supply of gold/due to removal from the royal tombs), as the administration failed to increase grain production and this led to a decline in the economy, as posited. ${ }^{333}$ Therefore the economic argument in the passage

332 L. Stöck, "Gold," LÄII: 728. [My translation].

333 K. Jansen-Winkeln ("Die Plünderung der Königsgräber des Neuen Reiches," ZÄS 122 [1995]: 62-78) has argued that the royal tombs were deliberately exploited as an easily accessible mine during Dynasties XXI and XXII. On a purely hypothetical level of Keynesian analysis, it must be pointed out that the economic effects will have been limited because of ( $a$ ) the role of grain in the economy, and because of (b) the ease with which it was accomplished, which did not increase employment. Insofar as the exploitation of the Valley of the Kings was not a ringing economic success, the scenario confirms the Keynesian theory presented here, as the economy did not grow as a result.

While agreeing in principle with the suggestion that the Royal Tombs were officially emptied, it must be noted that Jansen-Winkeln's interpretation involves two separate internally contradictory arguments.

(1) It is asserted that the Valley of the Kings was well protected ("Wir wissen zwar nicht allzuviel über die Geschichte der 21 . Dynastie, aber allem Anschein nach hat es sich um ein recht straffes Militärregime gehandelt, derartige Zustände [gemeint sind Plünderungen] sind sicher nicht anzunehmen", p. 65), while simultaneously maintaining that security problems were the reason for moving the mummies around. Although the logic behind moving the mummies disappears, this does not effect either the logic of the argument as a whole or the Keynesian significance of events.

(2) The reference in IRL 47, 3-5 is translated as signifying that the workers should accomplish a task "zu der ihr noch nie ausgezogen seid", rather than "a task to which you haven't gone yet", with the suggestion that this is the beginning of the exploitation of the Valley of the Kings. The letter in question is however addressed to P'y- 'nh as High Priest of Amun, and thus contrary to the prevalant assumption that he inherited the job from Herihor, and Herihor reburied Ramesses II and Seti I in Year 6 of the Renaissance-era (= Regnal Year 25 of Ramesses XI, approximately 1075 B.C.; cf. Kitchen, Third Intermediale, p. 252), so that the richest tombs in the Valley must already have been exploited before this letter was written, so that Jansen-Winkeln's translation cannot be used to illustrate thefts beginning at the end Dynasty $X X$. 
cited is based on reasoning which can be seen to be unsound in Keynesian terms, and historical developments bear out the Keynesian interpretation. ${ }^{334}$

On the other hand, W. Wolf partially attributes the decline at the end of Dynasty XX to construction projects:

If during Dynasty XX a continuous decline in the economy began, which eventually led to the catastrophe, a whole catalogue of reasons can be given. There were the bloody wars against the Libyans and the Peoples of the Sea, which were carried out almost exclusively by mercenaries; there were the monstrous state construction projects in the entire land, including Nubia, which exhausted the state finances; there were the inestimable donations to the temples $[\ldots]^{335}$

In view of the Keynesian theory, it was not the costs to the state that resulted in the decline in the economy, but the fact that major construction projects were no longer attempted, that the massive projects of Seti I and Ramesses II at Abydos, Heliopolis, Avaris, Karnak, etc. were given up, and instead of massive temples across the land, minor constructions were maintained, and efforts concentrated on Medinet Habu, and useless reserves turned over to the temples, which were not employed to expand construction. It was precisely the administrative laxitude that led to the decline of the economy, and not the projects. All the projects of Ramesses III cannot begin to be compared with the glorious stimulation to demand that Cheops and Snofru made, which led to one of the golden ages of Egyptian history.

$\mathrm{J}$. Baines lists the contemporary major cemeteries of the officials and the royal monuments, but points out that

Against this, not a single provincial tomb of consequence is dated to the 4 th dynasty, and virtually no cemeteries of simple graves have been assigned to the period. In the mortuary record, which is almost all that is available, provincial Egypt is a blank for the period. Vast amounts of labour were brought to the capital to construct a rigidly defined and regimented setting for the aftermath of a small group of people [...]. Those who provided that labour were so impoverished that they could not bury themselves appropriately for an afterlife of their own, while those who supervised

334 The claim that it was returned to the tombs is patently erroneous, as Jansen-Winkeln (ZÄS 122: 62-78) points out, for the gold definitely came into circulation - but had no positive economic effects because of the Keynesian economy.

The necessary logical corollary of this contention is that the development of a grain market would necessarily have adverse effects on the economy, as it would become a kind of capital market and indicate that the state was not carrying out its obligation to create, collect and redistribute the surplus, and thus unable to guarantee prosperity. This likewise evidently took place towards the end of the New Kingdom, and the economy only recovered with the emergence of the Mediterranean grain market in the middle of the first millennium.

335 Wolf, Kulturgeschichte, p. 345. [My translation]. This financial exhaustion is occasionally expressed in terms of bankruptcy and this is financially and economically incorrect, as the lack of a credit system rendered this impossible. The purpose of demand is to remove items from circulation so that more can be acquired, and thus this is not a form of exhaustion. It is bizarre that mercenaries should be an indication of expensive waste, as their initial appearance seems to have been during the First Intermediate Period, and therefore-according to conventional logic - they cannot have been that expensive. 
their labors either belonged to the group buried in the monuments in which case their values were centred on the capital, or they were themselves impoverished. ${ }^{336}$

It is evident that the complete absence of simple cemeteries could be used to demonstrate that life-expectancy increased such that mortality was eliminated during Dynasty IV, but to assert that there are no cemeteries at all cannot be used to claim that people were impoverished. ${ }^{337}$ Dynasty IV was a period of consolidation, involving religious, political, administrative and economic transformations, but developments during Dynasty $\mathrm{V}$ certainly suggest that impoverishment was not the principal problem.

Demand stimulation, and not financial burdens was the problem.

[A] though monumental tomb construction and burial of riches is an obvious feature of ancient Egypt, its effects are still not properly understood. Explanation for the First Intermediate Period has sometimes been sought in the idea that continued pyramidbuilding exhausted the country. However, this may have been true only in so far as it stood in the way of growing demand amongst the official class, bearing in mind the finite limits of the agricultural surplus. [...] The role of strong central government in raising the general level of prosperity is shown by the way in which during the First Intermediate Period, and even probably during the late Old Kingdom, the level of consumption of men of power, as indexed by their tomb sizes, seems to have declined.

Yet they were now no longer in competition with a lavishly endowed court. ${ }^{338}$

B. Kemp has identified the key indicators here, in relating the fact that the decline in royal construction projects accompanied by the decline in private undertakings revealed that state economic activity had not been able to increase the level of economic activity such that private sector demand was sufficient to release the capacities of the private sector to take responsibility for demand stimulation. W. Helck has indicated that precisely this development took place:

This led to a completely new development in Egypt, as the bureaucratic regimentation of the population dissolves.[...] Free craftsmen appear who [...] sell their labour. Supply and demand appear in place of the planned system of labour. The power of the bureaucracy is broken [...] The planned economy is replaced by the market economy in a few areas by certain very limited groups. ${ }^{339}$

336 J. Baines, "Literacy, social organization, and the archaeological record: the case of early Egypi," in Gledhill, State and Society, p. 201

337 The logic is purely circular, as is Baines's equally bizarre contention that writing on papyrus for administrative purposes was not widespread, while simultaneously conceding that urban Memphis - which is where one would expect to find administrative records - has not been found. This is quite aside from the fact that administrative records on papyrus do not survive as well as cuneiform tablets, so that his comparison with Ur III is completely spurious: Baines himself completely relativizes his conclusions in the final paragraphs by pointing out that administrative documents were written on perishable material and the admission that the proportion of the population affected by the obligatory labour "cannot be known" /cf. J. Baines, "Literacy, social organization, and the archaeological record: the case of early Egypt," in Gledhill, State and Sociely, pp. 196; 207-208).

338 B. Kemp, "Old Kingdom, Middle Kingdom and Second Intermediate Period," in Trigger, Social History, pp. 176177.

339 Helck, Wirtschaftsgeschichte, p. 106. [My translation]. 
Helck was misled from understanding that the collapse of the economy led to the craftsmen seeking work. The private craftsmen had been active since before the advent of history, and the state sector had merely contributed to an increase in quality and numbers, so that when the economy began to suffer as the state reduced demand, the craftsmen had merely become more numerous, but their private sector activity had been expanding since the end of Dynasty IV. The dissolution of the state affected the aggregate demand structure: the key factor in the major state projects of Dynasty IV was not the employment of craftsmen, but mere labourers, and it was here that the economic repercussions of the demand crisis became manifest. Kemp may exaggerate the wealth of small communities during the First Intermediate Period, but the principle of infinitely elastic demand can explain the entire system: whether expanding or contracting, government expenditures did not impinge on the private economy because it had a completely different base, meaning that the stimulation did not have a negative impact, as implied by Kemp's remark about the competition between private and royal tomb construction. Despite a certain limited private prosperity, and potentially production, there can be little doubt that the private economy was not up to the task of replacing royal demand, when this declined. The craftsmen continued to find employment: it was the toiling masses who reverted to underemployment as investment declined: the return to Keynes' equilibrium at the level of poverty (cf. supra, Figs. 3 and 4, p. 119 ).

This reveals the role of demand - as opposed to redistribution - in economic stimulation, and Kemp only errs in suggesting that the finite nature of the agricultural surplus was the obstacle, as this was not the problem, if one examines the millions of cubic metres of stone involved in construction projects initiated by Cheops and Snofru, indicating beyond doubt that the grain which fed Rome almost three millennia later was equivalent to the resources available, and thus that only demand was lacking. ${ }^{340}$ And, the possibility of erecting tombs in provincial areas, from Aswan to Dakhla at the end of the Old Kingdom meant that demand was present, and that the transport of grain to the center would not have been necessary, and yet the economy faltered because of declining state economic activity, as the private sector could not collect the revenues, i.e. stimulate demand on the same scale.

Of the properties of money enumerated by Keynes, the only significant aspect which did not necessarily correspond to the Egyptian reality was the condition of zero elasticity of supply as far as the private sector was concerned, in so far as private farming could conceivably have increased the supply, and yet the failure of the state to maintain its construction projects, with the consequent decline in the collection of revenues led to an overall decline in the economy, because the private sector was unable to actually make up for the lack in demand. This implies that grain could arguably be held to be money, and unfortunately confirms that the high level of equilibrium was dependent on state intervention.

Another feature of money that has attracted a great deal of attention is the price stability of ancient Egypt, where prices changed very little over hundreds or perhaps even a thousand years. ${ }^{341}$ If the price of an object is considered to be merely an expression of Jevons's "law 
of indifference", and traditional prices are the ones to which one is accustomed, in a market with a limited degree of latitude in supply and demand, then price changes need not be expected, but Keynes made not only wage rates, but also interest rates a key feature in his price theory, and therefore the lack of interest plays a key role in the economy, and could likewise explain the lack of price fluctuations.

Another key feature that arises from the entire train of logic is the fact that prices did not fluctuate despite enormous changes in the supply of precious metals, not just enormous variations between the quantities available during the Old Kingdom and the New Kingdom, but there were also enormous variations through the course of the New Kingdom, which failed to be reflected in prices, which indicate that the grain standard was again the true measure of economic activity, and that this economic activity can best be understood in terms of Keynesian theory.

These theoretical considerations appear to be speculative, but one of the purposes of the use of the theory is explain the workings of the economy, and another is to identify the distinctive differences between the Egyptian economy and other economies, and here, the Mesopotamian economic structures led to price fluctuations, which were influenced by both interest rates and supply and demand. It could be maintained that this is part of the explanation.

It was noted that Polanyi's classifications of transactions in terms of reciprocity and redistribution did not lead to theories of price formation or demand, so that the implication that prices determined by tradition (Jevons's "law of indifference"), which can be analyzed in terms of marginal utility, provides a theoretical underpinning not present in Polanyi's analysis. The additional evidence that price fluctuations did occur in Mesopotamia, and that interest played a significant role in the economy there, while it did not in ancient Egypt (but that it did in feudal Chinal suggests that the Keynesian model in combination with modern theory can be used analytically to gain a greater understanding of the Egyptian economy, as a unique case. The same applies to the economic implications of the demand for grain indicated above. It is thus possible to assign Polanyi's system of categories a role as indicators of social, but not economic, significance.

According to Helck, the entire population was registered at an early point in Egyptian history in order to serve as corvée labour. It is likewise widely believed that the king had sole title to all the land in ancient Egypt, and that private individuals could not therefore own land. ${ }^{342}$ These widely accepted assumptions led to the presupposition that ancient Egypt was a hydraulic civilization and therefore a case of Oriental Despotism. Polanyi likewise accepted the premise, but drew the opposite conclusion, that the redistribution system in ancient Egypt represented a just system without private ownership of land, and the rule of justice on the basis of rights and reciprocal obligations linking the king and his subjects. The assumption of wide-spread state involvement in irrigation (relating to the corvée labour presumably) led Schenkel to conclude that its absence in the documentation prior to the

342 I have not been able to establish a Pharaonic source for this wide-spread belief, cf. supra, p. 61 n. $118 ;$ pp. 3334 n. $32 ;$ p. 60 ก. 114 and pp. $42-43$ n. 62. 
Middle Kingdom - because, being sponsored by the state, it must be reflected in our records - meant that it was in fact absent, and therefore that it appeared after the emergence of the state, and used a single unreliable text to align himself against Butzer's interpretations based on archaeological evidence and environmental analysis.

One of the great ironies of placing Polanyi and Wittfogel as potentially providing explanations for Egyptian society and economy is that Polanyi's tendency is to emphasize that the Pharaohs must have been just rulers, while Wittfogel's whole argument is based on the assumption that the hydraulic civilizations inevitably led to despotism, so that although both assume asymmetrical social relations, Wittfogel's reading of the is quite at variance with that of Polanyi. Along the same lines, Müller-Wollermann's affirmation of the veracity of Polanyi's unfounded and unelaborated theoretical reasoning led her to neglect the fact that part of her evidence actually contradicted her conclusions, rendering non-existent theory more powerful than fact. $M$. Gutgesell has taken the opposite approach, attempting to induce general principles from isolated and doubtful facts, without aligning them within the framework of a theory.

Thus, involuntary and well thought-out interpretations supplemented with a tendency to merely posit facts, and repeating them, have created several different - mutually incompatible interpretations based upon the same nonexistent evidence. The quotations concerning papyrus cited at the beginning of this chapter implied that economic debate has been widely ignored by those scholars not explicitly interested in economic activity, and that it is necessary not only to develop a liaison with the economic theories of the other states of early antiquity, but also to make the relevance of economic theory to the understanding of ancient Egyptian civilization evident to all scholars, as our own involuntary assumptions cloud our interpretation of material which is quite foreign, and represents a form of economy which cannot be grasped with pre-conceptions. If this lengthy introduction can be justified, it is certainly in terms of expressing the hope that laying explicit theories and interpretations before the reader enables a dialogue with general agreement on what exactly is fact, theory, extrapolation or interpretation.

\section{Summary of Sailent POINTS}

It was shown that Polanyi's theory has seriously influenced the interpretation of the material, but that the use of the theory did not demonstrate its value, and that the categories of "redistribution", "reciprocity", etc. are not mutually exclusive, and therefore cannot be used to demonstrate the absence or presence of market activity. We have also seen that Polanyi's principles are not incompatible with market analysis, and that we can understand the data from the ancient world in terms of market analysis.

It was shown that the principle feature of economic activity in ancient Egypt was a market functioning with a low level of activity, and that the state may have contributed to an increase in overall economic activity by pursuing a policy similar to taxation, based on the premise that this taxation was a kind of demand stimulus. Thus, the economy was not interpreted as a "command-economy" in which all economic activity was commanded by the state, 
because the evidence does not support this. At the same time the term "Revenue Economy" seemed inappropriate, because the revenues ultimately came from private production, implying that a type of pre-capitalist market economy existed. The role of the state in this economy was to increase demand through the collection of revenues.

Regardless of whether the payments made to the temples were "taxes" or "rents", the net effect was to take surplus production and place it at the disposal of a powerful bureaucracy which used it for investment projects, such as temple, tomb and palace construction. This led to an artificial increase in demand, and removed workers from the agricultural sector, increasing overall employment, and itself spurred demand, by increasing aggregate income, and thus aggregate expenditure and investment.

These seemingly simple Keynesian measures were combined in a setting which corresponded to Keynesian theory, in so far as

(1) inflation was avoided by the absence of a currency which could be debased;

(2) the grain standard meant that income resulted in immediate expenditure, which inevitably involved employment, and the marginalization of non-subsistence related employment; so that

(3) demand was restricted only by the capacity of the state to limit it, and thus contributed to secondary and tertiary employment; while

(4) interest rates failed to impede investment because of their irrelevance to the overall economy, and increasing investment and income did not negatively affect the interest rate structure; since

(5) the possession of agricultural properties did not signify unproductive investment for prestige reasons, but actually increased income directly by

(6) generating private sector employment, which benefited from state aid to training; and

(7) guaranteed that the private sector could take up some slack when state demand slackened.

The most important element of the construction of temples and palaces and tombs was that demand was effectively "infinitely elastic", implying that this demand stimulation measure did not have an adverse effect on other economic sectors, the construction could contract, although, if state contraction was related to demand contraction, the economy suffered.

The effect was thus equivalent to "national debt" in the modern world, but far superior because (a) the demand curve could not exceed the available resources, while (b) guaranteeing that resources were not wasted, and the economy stimulated. Thus the effects could only be positive, and could not be negative, because there was no system of credit to which the rulers could turn.

The whole system worked because Egypt was basically a closed economy, but the increased income did permit the stimulation of imports, and generated considerable wealth as far away as South Arabia, without hindering the development of local industry, as the greatest part of the local demand stimulation was spent on temples and palaces, which cannot easily be imported, although minor items of temple services such as incense can be. The result was that jobs were not exported, although it was possible to spend surplus income abroad, which increased local agricultural employment, and prosperity. That the state 
investment policy failed to have a negative impact on the distribution of resources meant that the private sector could flourish, as far as demand would allow, which was generally at a higher level than that of any other country until well into the second millennium A.D.

This would explain the tendency for expensive tombs and temples during periods of decline, and the presence of wealth in cemeteries of the intermediate periods, and provide the model requested by Kemp, accounting for the economy in a comprehensive fashion. 
PART II

SOURCE DOCuments 



\section{A DISCUSSION OF THE SOURCES}

Although the objects of this study are particular words, these come from a textual context, and many different categories of text contributed sources for this work. The vast majority of these texts have little immediate economic relevance, and have been adequately published in the literature, so that mere remarks about the reading of specific details are required, while others deserve longer treatment, primarily to provide a perspective on the sources, but also to emphasize certain points and draw attention to details, or to provide a suitable context for discussion. ${ }^{343}$ The selection of the translations and/or commentaries (which follow this introductory chapter) is intended to provide insights into this source material, discussing or presenting selections from the school texts $(\mathrm{O}$. Gardiner 86$)$, administrative texts (the Turin Canon Tax Lists, the P. Wilbour, the Turin Taxation Papyrus, P. Greg and the Giornale), private propaganda texts (the Instructions for the Vizier, the Bilgai Stele and the Rewards of Imn-hip) and royal propaganda texts (the Horemhab Decree, the Nauri Decree and P. Harris I), prefaced by these short remarks about some of the other texts and genres consulted. With the exception of the selection from the Giornale, all of these texts have been selected because of the use of the words which are the core of this study, but other texts provide germane information without the actual employment of the words, and therefore the following remarks are intended to provide a general background to the context of the source material.

\section{Internal Revenue}

\section{Administrative texts, including School Texts or Miscellanies and Letters}

Although many of the original administrative texts are extremely fragmentary, certain of the texts called school texts or miscellanies are better preserved, and may use the terminology in a representative fashion, although the figures should be used with caution if at all.

Probably the most widely known ${ }^{344}$ Egyptological fiscal text is the miscellany extolling the privileged position of the scribe, preserved in P. Anast. V and P. Sall. I, etc.

Lo, dost thou not recall the plight of the cultivator at the time of registering the šmw, when the snake has seized half the corn, and the hippopotami have eaten the rest? The mice abound in the fields, the locusts descend, and the herds devour. The sparrows take lack to the cultivators. The remains which are upon the threshing floor, they are seized. Its hoof-in-ore is gone and the team dead from threshing and ploughing. The scribe moors at the riverbank, and goes to register the šmw, the porters bearing sticks and the Nubians palm branches. They say, "Give (us) the

It was only at the very final stage of the preparation of this text that $K$. Kitchen's own translations of his $K R /$ began to appear, and thus there will be a certain amount of seemingly unnecessary overlap by the time the published text of this work appears.

344 The text will even be found cited by Chaudhuri (Asia before Europe, pp. 90-99), where it is both chronologically and culturatly outside the scope of the work. (But curiously appropriate as an illustration of a popular view of Oriental Despotism and the Asiatic Mode of Production). 
grain!" But, there is none. They strike with fury. He is bound and thrown into the well, where he gets a good walering. His wife has been bound in his presence, and his children are in fetters. His neighbours have abandoned them and fled. Their corn departs. But only the scribe who controls the everyone's bikw has no htri, (for) his $b 3 k w$ is counted in writing. He has no šsyt. Take note of this. ${ }^{345}$

This text is unusual in that several of the words with which this study is concerned appear

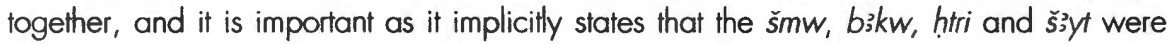
various kinds of dues of a comparable nature, at least insofar as the "victims" were concerned, and that these could conceivably all be different designations for exactly the same thing-the grain from the peasant to be collected by the scribe - the difference being exclusively administrative.

It is however typical of the texts serving as sources for this work that the text fails to state what the $b 3 k w$ or the šs $y t$ were, or to whom they were paid or why. That it implies that the šmw was a grain impost is also typical, as this is one of the few things that is rather well known in any case. Equally typical is that $b_{3}$ k w figures twice in $P$. Sallier $I$, which fails to mention the htri used in P. Anast. V, where bikw appears once, while bikw and htri would not otherwise appear to be synonymous, but rather complementary, so that an elaborate logical structure cannot be built on this text.

Also typical is the fact that a single phrase in this text which does not use any of the words involved in our study has been interpreted with diametrically opposing implications for the significance of the text and Egyptian Economy. $p$ ' ' $g w$. $f$ n bi' ' $q w^{346}$ means literally "his hoof-of-ore has perished." Texts ${ }^{347}$ using the phrase have been interpreted as referring to a "hoof tax", 348 but other authorities have asserted that this is impossible, and that it must refer to the "hire" of cattle, ${ }^{349}$ although it is only used explicitly of donkeys and swine. ${ }^{350}$ As the term appears virtually only in administrative texts, it is thus at least more likely to be administrative than private, but the evidence is insufficient for any firm conclusions. There is however clearly a great gap separating the implication that the text can be understood as suggesting either (1) that the ordinary peasants mentioned rented cattle in order to carry out "taxable"

345 IEM, pp. 64-65; Caminos, LEM, pp. 247-250. This translation is slightly freer than usual, as the author has doubtless taken some poetic license, and this should be reflected in the translation, but also because the two important parallel texts diverge in central points.

346 LEM 64: 15; 83:10. P. Anast. V uses "his hoof'; P. Sall. I, "her hoof" / "their hoof".

347 P. Cairo 58071, I (= P. Bulaq XII, W. Spiegelberg, "Varia," RT 15 [1893]: 141-145, esp. 142-143); P. Cairo (G. Maspero, "Notes sur quelques points de Grammaire et d'Hisloire," ZAS 19 [1881]: |16-131, esp. 119): P. Cairo 58057 (Wente, letters, pp. 112-1 13; Möller, lesestücke, 3: 8).

348 W. Müller, "Ein Terminus des Verwaltungswesens," ZÄS 32 (1894): 131; W. Müller, "Viehstever," ZÄS 34 (1896): $167-168$.

349 Sir Alan Gardiner, "Ramesside Texts Relating to the Taxation and Transport of Corn," JEA 27 (194 1): 19, n. 3; Caminos, LEM, pp. 247-248.

350 This excludes the apparently logical interpretation that it would refer to some kind of metal "cow-shoe" put on cows when threshing. The references to "teams" of callle follow the reference to the "hoof-in-ore", so that it is impossible to be certain that the cattle are in fact meant, whereas the references to donkeys and swine are clearly linked to the use of the phrase. There is also the grammatical element of identifying just who or what is meant by the suffix, cf. n. 346 supra. 
activities, or (2) advancing the conclusion that the cattle were privately owned by small time farmers, and taxable in themselves, from (3) the clear evidence that it is used specifically only in administrative texts relating to donkeys and swine, and that it is associated with the b3kw as an obligatory state administered payment. As in many other cases, this study cannot propose a definitive solution to this very relevant question, and thus we will try to throw light on the various questions from as many sides as possible (but, cf. infra, p. 240 n. 823).

$P$. Sallier $\left.\right|^{351}$ is a letter purportedly from a chief archivist of the treasury of Pharaoh to a scribe relating that a stable master was given 30 arouras of land for official purposes, but that it was appropriated by the steward of a mortuary temple, and the recipient of the letter is instructed to return the land to the stable master. The letter goes on to specify various properties of pharaoh: estates (pryw), places, "h?; mint fields, šmw, domains (rmnyt), instructing the recipient to make the re-allotment separate from these various properties.

There are thousands of administrative notes from Deir el-Medineh (DeM), the town in which the Gang ("The Crew of the Great and Noble Necropolis of Millions of Years of Pharaoh") who made the royal tombs lived. ${ }^{352}$ These notes inform us that they received pay in grain and in various commodities. Their grain income should have been $51 / 2 \mathrm{khar} / \mathrm{month}$ of grain for the foremen, and $4 \mathrm{khar} /$ month for the ordinary workers. ${ }^{353}$ They also provide information about their working week, and private transactions. P. Greg has been included below as an example of the type of text Deir el-Medineh has yielded up.

Many of the remaining published administrative texts of New Kingdom date are so fragmentary that it is impossible to judge their value, and others leave considerable leeway for interpretation, so that they must be used judiciously. Papyri from the Turin Museum and Gurob in Egypt are employed to illustrate the types of administrative material available. Letters are among the useful sources, in that they can be taken at face value, and occasionally include information that is otherwise not at all clear. Typical is however $P$. Anast. VIII referring to silver, fish and wool, but in a context that does not permit any logical interpretation which is compelling. ${ }^{354}$ In P. Bologna 1086, ${ }^{355}$ a Scribe of the offering Table writes to a Prophet confirming that "three men and one youth makes 700 khar" (1. 21), noting that he told the archivists in the granary that the three cultivators were "to soldier in this year" (1. 23). The obligation of two hundred khar from each worker (and one hundred from the youth) is defined as Isw-prt (1. 21). It is not at all certain what obligations are implied by this - sowing or harvesting,

351 LEM, pp. 87-88; Caminos, LEM, pp. 326ff.

352 Cf. e.g., Allam, HOP; Cerný, Community, Demarée/Janssen, Gleanings; Gutgesell, Datierung; Janssen, Prices; McDowell, Jurisdiction; Valbelle, Ouvriers; Ventura, City.

353 Helck, Wirtschaftsgeschichte, p. 232. That regular and complete deliveries of their goods was the exception rather than the rule should be clear to those familiar with the literature. As the basic measuring unit for corn during the New Kingdom, the khar was roughly 75 litres; as a unil of value, it was equal to roughly 2 deben. For these and other details, cf. Janssen, Prices, pp. 109-111; $455 \mathrm{ff}$.

354 Cf. KRI III: 499-504; Wente, letters, pp. 120-122.

355 KRIIV: 78-81; W. Wolf, "Papyrus Bologna 1086," ZÄS 65 (1930): 89-97; G. Möller, lesestücke III: 9-11; A. Gardiner, Wilbour Il: 115. 
field-work or responsibility, but the figure or 200 khar is identical to that in 0 . Gardiner 86 (cf. infra, pp. 144 n. 408).

$P$. Berlin $3047^{356}$ relates a case potentially concerning the failure of tenants to pay their rent to a human owner, assigned the land to assure income for himself, and his brothers and sisters (1. 9). ${ }^{357}$ In Regnal Year 46 of Ramesses II, the Chief of the Granary of Amun Ni3 and the Royal Scribe of the Offering Table Nfr- '3bt had a civil suit concerning income from land before the highest officials of the Estate of Amun, the High Priest of Amun, B3k-n-Hnsw, some prophets of the temples of Amun, Mut and Khonsu, the Steward of the Estate of Amun, and Hwy the Municipal Court Accountant. ${ }^{358} \mathrm{Nfr}-{ }^{\circ}$ abt claimed that $\mathrm{Ni}$ ? and his brothers and sisters had managed a piece of land assigned to him and his siblings, "without giving me my apportionment" (1. 10). Nis confirmed this, but protested that they were turned over to the temple of Mut. A lacuna interrupts the statement, but it seems that at one time he received goods from the plot, while at another he did not. ${ }^{359}$ The Prophet of Mut then confirmed that he had received and ploughed the land (II. 18-19). More than 100 arouras are then divided up among the brothers and sisters, following which is the concluding statement of the Court:

Statement of the Court Auditors, by the prophet of the Temple of Mut, Wnn-nfr (32): "As for these three years which the Chi[ <ef of the $\mathrm{Gra}$ >] nary $\mathrm{Ni}_{3}$ w was eating the fields together with his sisters, the (33) Royal Scribe of the Offering Table Nfr' 'sbt ploughed them not, his servants ploughed them! [...] Statement of the Royal Scribe of the Offering Table (34) Nfr-'3bt, to the Prophet of the House of Mut, Wnn-nfr, "Look to my fields! You shall plough them, and you (35) will give to me a fraction of their harvest in corn and greens." Statement of the Prophet of the Temple of Mut, Wnn-nir, "I will do it! Behold, I shall indeed do it, and more than its like!"

This text makes it clear that there were lands managed by individuals associated with the temples which "belonged" to private individuals by virtue of assignment, and not inheritance, which could however be inherited.

Another rare example is an extremely valuable text which fails to employ the vocabulary of this study, but does provide some insight into fiscal behavior: P. Valençayl, "a letter addressed by the Mayor of Elephantine to no less a personage than the Chief-Taxing-master:"

[... To this effect: Ptunteamun, the scribe of the House of the Adoratress of Amün, has come, he has arrived in Elephantine to demand the corn which has been fixed for the House of the Adoratress of Amün, and he said, "Let 100 sacks of barley be given"; so he said to me, but there are no fields bearing that amount. And he said to

350 KRi II: 803-806; W. Helck, "Der Papyrus Berlin P. 3047,"JARCE 2(1963): 65-73; A. Erman, ZÄS 17(1879): $71-76$.

357 It is important to note that even in court, the plaintiff did not hesitaie to point out that income which might theoretically be due to him by virtue of his official function (a quasi salary) was destined for his family.

358 Clearly hisb and not khar

359 Or epigraphically, it could be that he received goods from one part of the plot, but not from another. This reading is contradicted prima facie by the Nis's agreement that it was true that Nfr-'sbt did not receive anything. And there is no reason to suspect it.

360 A. H. Gardiner, "A Protest Against Unjustified Tax-Demands," RdÉ O (1951): 1 15; Gardiner, RAD, pp. 72-73. 
me, "They are being demanded from you on account of a holding of Kha(n)to-land in the gezirah of Ombi", so he said to me, though, I had not cultivated (any) holding of Kha(n)to-land in the gezirah of Ombi. [...] It is a holding of some private persons who pay gold into the treasury of Pharaoh which those private persons have cultivated, and they regularly (?) hand over its gold to the treasury of Pharaoh, and I have never touched (any) holding there. ${ }^{361}$

The significance of this text is multi-fold, for it (1) suggests that these private persons (nmhw are not the types of individuals associated with the apportioning domains of P. Wilbour, i.e., the beneficiaries of the state apparatus; ${ }^{362}$ (2) that these nmh w paid their "taxes" (gold) directly to Pharaoh as the tax on their land (and not via the Mayor of Elephantine - a key point in considering EK 3, the tomb of P3-hry, infra, p. 138); and that (3) the income of a piece of khato-land managed by the Mayor of Elephantine can be claimed by a scribe of the Adoratress of Amun. This clearly means that the nmhw were the primary titular holders of the land, and clearly not Pharaoh; and that income from khato-land could be indisputably assigned as temple income.

\section{Private Propaganda}

Of the two lengthy texts of particular relevance which belong in this category, excerpts of both the Bilgai stele and the record referring to the rewards of the High Priest of Amun, Imnhip, are presented below.

On the walls of many private Theban Tombs are depictions of scenes involving the collection of tribute or taxes, but for the most part the space provided for the captions does not compare favourably to the generous surface awarded the visual image, so that epigraphic evidence is more of an anecdotal quality.

The tomb of the Vizier Rh-mi- $\mathrm{R}^{\mathrm{C}}(\pi \mathrm{r} 100)$ contains not only one of the most complete versions of the "Instructions of the Vizier"363, but also depicts the payment of various forms of dues to the Vizier, as the head of government, both from internal sources and external sources. There can be little or no doubt that as the representative of the government, the Vizier received income, and that this is depicted in the tomb. The mayors and district heads assembled on the walls of his tomb delivered objects of wood, animals, metal, beads and similar exotic or valuable articles. ${ }^{364}$ Corn appears seldom in the lists from the districts South of Thebes, ${ }^{365}$ and more frequently for those to the North. ${ }^{306}$ While the Vizier "receives" the offerings of the foreign people, he merely "counts" those of Egypt.

Gardiner, "Tax Demands," RdÉ 6: 117

Contra B. Menu ("Le Régime juridique des terres," in Menu, Recherches, pp. 29-30). Cf. infra, pp. $165 \mathrm{ff}$. for relations between khatolands and apportioning paragraphs.

Treated in a separate chapter, infra, pp. $178 \mathrm{ff}$.

Urk. IV: $1119 f f$.

E.g., Urk. IV: 1124,$5 ; 1127,3 ; 1128,3$

Cf. e.g., Urk. IV: 1130,$9 ; 1131,10-12 ; 1132,6 ; 1133,1 ; 6 ; 1134,15-17$, etc. 
Among the tombs outside Thebes, scenes from daily life are well preserved on the west wall of the tomb of $P_{3}-h r^{367}$ (EK 3). One set of scenes shows the preparation of the fields, sowing, harvesting, threshing, winnowing, counting, collecting and storing grain, with an inscription noting that $P_{3}$-hry stood viewing work in the fields of the Southern District. Another set of scenes shows scribes carefully counting livestock, and the inscription suggests that $P_{3}$ hry was responsible for doing the sums, as other scribes are involved in detail work. Another set of scenes shows ships being laden with grain, and scribes counting gold rings, and the inscription relates that he was receiving the gold.

The scenes relating to the fields specify that P:-hry was not only Mayor of el-Kab, but also a "scribe of counting of grain", but the authority with which he was associated in this profession is not defined. ${ }^{368}$ The scene with the counting of animals suggests that this was done in his capacity as overseer of the fields of the Southern district. ${ }^{369}$ The inscription accompanying the export of grain and the receipt of gold rings may have recorded the place where the viewing took place (it is defaced), but does not indicate more than the generic title of mayor, without naming the city of el-Kab, or any other. ${ }^{370}$ Another inscription indicates that he was - probably ex officio - also an Overseer of Prophets, ${ }^{371}$ but we have no reason to believe that $P$;-hry was part of the temple administration. Several references emphasize his relationship to the king. ${ }^{372}$

It would be difficult to assert that the activities represented in this tomb were not administrative and fiscal, but the only reference to a fiscal term in the scene is the use of the word bikw by a worker who allegedly desires to "make an excess of bikw for the official". ${ }^{373}$ The reader should be conscious that the philological and iconographic material are complementary, but not intimately linked, and therefore the fiscal argument cannot be based on iconographic evidence, which should be borne in mind.

Jo8

8 The inscriptions (Urk. N: 124,5-10) merely relate that Ps-hry viewed the activities in the fields according to their various seasons. W. Helck (Verwaltung, p. 235) remarks that "der Abtransport des Stevergetreides [...] stellt z.B. Ps-hri in seinem Grab als seine wichtigste Sorge hin" citing this reference. However, the main inscriptions do not refer to the transport of the grain - only the labels - and the word šmw does not appear in any of the main texts, except in a mere phrase of a primarily religious rext (Urk IV: 116,15$)$. It should be noted that the implications of the references in $P$. Valençay and the Mes Inscriptions are that the provincial officials were not involved in the collection of income for the King. Far more important to P3-hry than the transport of the grain was the counting of gold in the relevant scene. The suggestion that this is a trade transaction - grain for gold - should not be excluded, but it is by no means the only interpretation.

369 W. Helck (Venwaltung, p. 172) understood this such that the counting of the herds was for tax purposes, and yet concluded, "hier handelt es sich also um die 'staatlichen' Herden." Either the herds belong to the state or they are being taxed, but the probability that the state would tax its own herds taxes the imagination excessively. It is by no means clear whom the herds belonged to, or why the counting was done.

370 W. Helck (Verwaltung, p. 81) asserts that Ps-hry "von sich behauptet, er 'erfreue das Herz des Schatzmeisters bei der Südfahrt," but - in contrast to Helck, P3-hry does not relate this to the grain (or the gold for that matter). Even if the translation is correct, it would be peculiar for the official in question to see the grain in el-Kab, as it is transported away from el-Kab, but this is another matter.

371 Cf. Helck, Verwaltung, p. 220.

372 E.g., Urk. IV: 118,$10 ; 119,2$. We have little reason to speculate that his "lord" was other than the king

373 Tylor, Paheri, pl. Ili, middle register. This passion with "excessive" payment of "taxes' was not restricted to field workers. It appears in the Bilgai stele (infra, pp. 182 ff.) and is even attributed to an overly zealous Roman governor of Egypt (cf. Wallace, Taxation in Egypt, p. 3 il) 
The inscriptions in the tomb of Mes appear to reproduce court records concerning the transfer, transmission and inheritance of property. One detail which arises from the court proceedings is a reference to records:

The lands of Neshi, although originally a gift of Pharaoh, were not exempted from all taxation: they had to contribute grain to the royal Granary, and other products to the royal treasury. $[\ldots]$ The register of the Treasury was preserved in the Treasury itself, while that of the Granary was preserved in the "office" of the Granary [...] We might have expected to find that the census-lists dealing with the lands of Neshi were preserved in the local Treasury and Granary of Memphis: on the contrary, they were kept at Per-Ramessu. ${ }^{374}$

This indicates that the lands awarded to Neshi and inherited by Mes were obliged to make regular payments to the Crown, and not the temples, with a curious confirmation of the reference to the payments to the Royal Treasury, explicitly mentioned in P. Valençay I, although the produce of land would presumably have been grain.

\section{Excursus on Land Ownership}

Having cited several relevant sources on land ownership, it is worth summarizing some additional evidence as well. Although it does not all come under the private propaganda heading, it is logical to slip it in here. What can be termed private land is known from a number of sources. ${ }^{375}$ The Inscription of Min-msw indicates that he was rewarded for his efforts on behalf of Pharaoh with land and serfs to work it. ${ }^{376}$ The inscription of the sailor I'h$\mathrm{ms}$ in El-Kab indicates that he too was rewarded - in a far more modest way - with land and serfs or slaves. ${ }^{377}$ The Inscription of Mes indicates that such officially ordained awards could be inherited, and that records of "ownership" were maintained at the treasury, so that it may be assumed that they owed payments to the treasury. ${ }^{378}$ The Instructions of the Vizier indicate that boundary lines of šdwplots were officially recognized. ${ }^{379}$

In P. Valençay I, the scribe notes that a piece of land "belongs to some nmhw who carry gold to the treasury". In the Horemhab Decree, the nmhw are specifically identified as being obliged to render up the hitri and bikw payments, but that they are to make the payments themselves, and that Pharaoh's officials do not have the right to confiscate these payments for their own credit. In the stele d'apenage, land is purchased from the nmhw-n'. Thus, part of the population enjoyed the use of the produce of pieces of land awarded them, and they could inherit and sell this land, along with the obligations set upon it, while another part

CF. W. A. Ward, "Some Aspects of Private land Ownership and Inheritance in Ancient Egypt, ca. 25001000 B.C.", in Khalidi, Land Tenure, pp. 63-77; W. Helck, Wirtschaffsgeschichte, pp. 235-236; K. Baer, "The Low Price of land in Ancient Egypt", JARCE I (1962): 25-45.

376 Urk. IV: 1441-1445, II. 25-26.

37 Urk. IV: 11,1

378 Gardiner, Mes, p. 39

379 Urk. IV: 1111,8 ff. Cf. infra pp. 179-180, with nn. 537, 543. 
seemed to have had rights of ownership, likewise associated with payments. This indicates that these payments were either a type of "rent" - if actual possession remained with Pharaoh or the temples - or a tax - if the actual possession of the land was transferred from Pharaoh or the temple to the individual.

One reference ${ }^{380}$ starts stating that the King Ramesses III was on a visit to the temple "Wsr$M_{3}^{c} t-R^{c}$, beloved of Amun (L!P!H!) illuminating Heliopolis", 381 and goes on to list various military professions (I:A 4, soldiers, weapons bearers, sailors), before referring to "ploughing the great khato-lands of Pharaoh", which appear to have been managed by military scribes but within the administration of a mortuary temple. In the following section, there is a reference to an otherwise unidentified treasury, if Kitchen has reconstructed the text correctly. Part of the population did not however enjoy direct access to land, and they were provided for by the state, to some extent at least. The workers at Deir el-Medineh presumably lived off their income as state employees, but they also earned money by manufacturing grave goods on the side, and may have owned small plots of land, which provided a supplement to their income. There were however people who were less well off, and a badly preserved letter of Ramesside date ${ }^{382}$ records a statement terminating with

"the bread which is given to me from the Granary, (5) I live from it, since I do not have a field in Egypt." Take note of this.

Give it to him, bread $5[\ldots] 2$.

The state of the letter discourages further speculation, but this confirms that at least for the person in question, it was worth stating that he did not possess a field, implying that others - possibly including those of his class - did.

(End of Excursus)

\section{Royal Propaganda}

The inscriptions of the kings of Dynasties XVIII to XX constantly refer to inw and $b 3 k w$ taken from foreign countries and Egypt, but three royal texts are slightly more generous in the use of terminology, and these are treated at the close of Part II.

381 This is similar to the beginning of $P$. Gurob, $2,11-2,13(R A D, 14-18)$, where the presence of the King is signaled, followed by the htri. It is evidently an official record, and not the joltings on a slip. 


\section{Administrative Texts}

The excavations at lachish in Palestine brought to light a fragmentary bowl with two hieratic inscriptions (one inside, one outside) dealing with šmw from a regnal year $4 .{ }^{383}$ The object has been dated to the reign of Merneptah, and it has been asserted that the name Lachish was written on the bowl. ${ }^{384}$ The toponym is definitely not lachish $\left(r-r y-s 3\right.$, not $\left.r-k y-s^{3}\right)$, while the reign is probably correct. The payment was definitely expected in wheat, but the units and quantities and the time frame are not specified.

The excavations at Tell Sera' in southern Palestine have produced several additional fragmentary hieratic ostraca of a similar nature. One refers to $460 \mathrm{khar}$ of grain, and is dated to regnal year 22. $\bigcirc$. Goldwasser correctly refrained from even considering reading the first sign as part of $b_{3} k w$, and so no term is attached to the context. Another inscription mentions 2000 khar of grain, but likewise without context.

The import of these texts is clearly not equal to their lamentable state of preservation and the information contained, for the proof that Egyptian administrators were actively maintaining records of fiscal activities relating to the transfer of grain in Palestine is invaluable in indicating the degree to which Palestine was incorporated within the empire. It is not however clear whether the grain was transferred to Egypt, or whether it was intended for local consumption by the local Egyptian authorities.

Goldwasser likewise emphasizes that these administrative notes may have been written on complete bowis, which substantially increases their intrinsic interest, as it is not at all clear why this would be done. His conclusion that they were votive in character must not be dismissed out of hand, but the motivation is not at all clear.

\section{Private Propaganda}

Many New Kingdom private tombs - at Memphis, Thebes and Amarna - are adorned with scenes in which foreign "tribute" is collected, both with and without the royal personage. These scenes show the products of foreign countries, and provide stereotype depictions of the foreign peoples. According to the Egyptian view of the world, even if "trade" or "exchange" was involved, this was not necessarily emphasized, and the "foreign trade delegations" were regarded as rendering tribute, iconographically.

In the Tomb of the Vizier Rh-mi-Rc (TT 100), the introductory text accompanying the depictions of the foreigners from Punt, Syria, and Crete, identifies the objects as inw and higt. ${ }^{385} \mathrm{~A}$

KRI IV: 39, 10-12.; J. Černý, "Report on Inscriptions," in: Tufnell, Lachish IV: 133; pls. 44, 47. Cf. O. Goldwasser, "The lachish Hieratic Bowl Once Again," Tel Aviv 9 (1982): 137-138; O. Goldwasser, "Hieratic Inscriptions from Tel Sera' in Southern Canoan," Tel Aviv 11 (1984): 77-93.

384 Ahituv, Toponyms, p. 130: "a reading of the name as Lachish is not improbable". Cf. M. Weippert, "Lachis," RLA V: 412 for doubt.

385 Urk. IV: 1094,6-10. 
distinction is made in that the countries which are named deliver inw, in contrast to the "hiqut of every foreign country" presented by the undelineated others. ${ }^{380}$ The text makes it clear that even though termed inw and not hiqt, the deliveries from Punt are made because "of the power of his victorious majesty". 387 Their offerings are lapis lazuli, silver, gold, ${ }^{388}$ myrrh and electrum, etc. ${ }^{389}$ The tribute of Punt ends with a note that the Vizier is delighting himself and his master in "receiving the inw of every foreign land, brought because of the power of his majesty. "390 This juxtaposition seems to suggest that inw and hiqut are used interchangeably and loosely in this context, and without any particular significance. That said, it is stated that the hiq is dedicated to Amun, in a context indicating that the conquered territories of Nubia are meant, ${ }^{391}$ potentially suggesting that certain objects of the inw were retained by the king, as opposed to some of the real hizt which is rendered unto Amun.

\section{Royal Propaganda}

The Kings of the New Kingdom acquired various products from the defeated peoples of the empire. At Beth Shan in Palestine, Seti I set up several stele commemorating military activity. The smaller one of those preserved relates the reaction to an incursion, which brought the immediate delivery of $b_{3} k^{k} w$, prisoners and hiqt because of the strength of the royal father, Amun-Re'. ${ }^{392}$

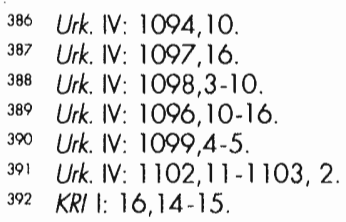




\section{O. Gardiner $86^{393}$}

81,1 The Royal Scribe and Superintendent of the Treasury [<of the Lord of the Two Lands

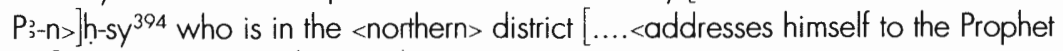

81,2 of $>$ ] Amun in Thebes (nwt rsyt), Hri: in L!P!H! This sending is to inform you about $t[$ <he > ..... (situation?) $]]^{395}$ of the

81,3 Estate of Amun ${ }^{396}$ which is here under my authority in the northern district, which extends from the Porte of [Imhotep? ${ }^{397}$.....(to the?)]

81,4 $\mathrm{Ends}^{398}$ of Lower Egypt, with the three streams, namely the Great River, [lnamely the Western Arm and) ${ }^{399}$

81,5 namely the Stream of Avaris, ${ }^{400}$ with the documentation (šmyt) ${ }^{401}$ of all the people of the Estate of Amun in [?...]

393 KRI III: 138-140; H.O. pls. 81-82; Helck, Materialien, pp. 467-468; Wente, Letters, pp. 118-119.

394 CF. KRI III: 136-140; and W. Helck, Verwaltung, p. 408 for the personal data concerning P;-nhsy who is assumed to have flourished during the reign of Ramesses II. While the present writer follows Sir Alan Gardiner ("The Geography of the Exodus," JEA 10 [1924]: 92) in assuming that this text is a model letter, neither K. A. Kitchen nor $W$. Heick have cast serious doubts on the value of the letter and its relation to $P_{3}$-nhsy. There is no reason why a fictitious letter could not have been attributed to a living person. It is even possible that the content of the letter reflects a real situation, but this should not be assumed.

395 W. Helck has restored "den [Besitz des] Amuntempels" (Materialien, p. 467), following Sir Alan Gardiner (JEA 10: 92), who was however less sure of the restoration.

396 The fact that $I m n$ precedes $p r$ in 81,3 while the usual order appears in 81,6 would suggest an inexperienced hand, but the characters belie this.

397 Cf. Urk. 1: 102, 17 (A. Roccati, Litterature, p. 194), where Wnni assembles his troops by the Sb;-n-ly-m-htp. This must be located in the northeastern extremity of the Delta, cf. Helck, Beziehungen, p. 18. Although the evidence is admittedly temporally somewhat removed, it is perhaps spatially admissible to restore the text thus.

398 It is difficult to judge whether phwy ("the Ends of Lower Egypl", as written) or phw ("the drainage systems of Lower Egypt") are meant. Sir Alan (AEO II: $154^{*}-155^{*}$ ) points out that each nome had its own phw, and that these were perhaps stretches of the Nile which flowed through the respective nomes. M. Bietak (Tell ed-Dab'a ll: 137) identifies them as "wohl Entwässerungssysteme und Seebecken [...], die sozusagen das von Flußarmen gespeiste, an der Obertläche bei Depressionen auftretende Grundwasser abziehen". It is perhaps best to understand the word here with its literal meaning, "end", following A. H. Gardiner (JEA 10: 92), supporting the interpretation that the preceding restoration is indeed justified.

399 The size of the lacuna is not large, but as Sir Alan Gardiner (JEA 10: 92) has pointed out, the "name of the second of the three Nile-branches" is missing. This would be "le fleuve de l'ouest" according to P. Barguet ("Tod: Rapport des Fouilles de la saison févier-avril 1950," BIFAO 51 (1952): 101, n. 4) and M. Bielak (Tell edDab'a H: 1 18): "Der Westliche Fluß war vielleicht der unleserliche Name auf dem GARDiNER-Ostrakon."

400 This is possibly otherwise known as the Stream of P; $R^{c}$, which flowed by Avaris/Tell el-Daba'a, cf. M. Bietak (Tell edDab'a II: 1 19-120): "Man muß sich also offenbar damit zufrieden geben, daß hinter jedem dieser [sechs] Namen ein eigener Flussarm anzunehmen ist, ausgenornmen vielleicht die mögliche Identität des Wassers von Auaris mit dem Wasser des Re', was aber noch näher zu prüfen wäre." If our restoration is correct, the area under discussion would thus have been virtually the entire Delta. If however, the second Nile-branch was not the "Wesiern River", but rather the "River of Amun" (cf. M. Bietak's maps, Tell ed-Dab'a II: 120 and Abb. 23), then the author would perhaps have been responsible for only the eastern Delta. This interpretation does not however fit his reference to "the three branches" $(81,4)$, which seems generally to imply the entire Delia.

401 Although unclear in H.O. 81 a, 5 (where KRI III: 138, 11 has correctly added the second - quite superfluous papyrus roll determinative), the word is also clear - although damaged - on the verso, H.O. 82a,2. Our ability to recognize its meaning is however not enhanced by this second appearance. W. Helck (Materialien, p. 467) has "die Gesamtheit aller leute". And E. Wente (Letters, p. 118 ) suggesis "occupations(?)". Neither appear however to be philologically satisfying. The context suggests a kind of "list". Prof. Janssen has drawn my attention

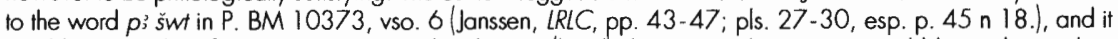
would appear that if $p$; $\breve{s} w t$ can be translated as a "(legal) document", then $t ;$ šmyt could be understood as "(official) documentation". 
81,6 consisting of herdsmen of all the animals in the fields belonging to the Estate of Amun in the Southern City, with [here under my authority? ..... ]

81,7 namely: cattle herdsmen, goat herds, shepherds, swine-keepers, $[$.

81,8 donkey grooms, ptrw-anima ${ }^{402}$ tenders, bird-keepers, fishermen,

81,9 fowlers, vintners, salt-workers (2), ${ }^{403}$ natron workers, papyrus

$81,10[\ldots .$.$] gatherers cutting in the thicket, rope makers, mat-makers (?) [.... ]$

$81,11[\ldots]$ I have brought their name list, each of them $[\ldots .$. with their wives? $]$

81,12 , and together with their child $[$ ren $] .404$ This name list was $[\ldots .$.

$81,13<$ in the bureau of $>]$ the Estate of $\mathrm{Ti}(L !)$ in the Estate of Amun [...]. 405 I ha[ $[<\mathrm{ve}$ found them and $>($ ? $) \ldots . .$.

81,14 I have htri as šsw.t, ${ }^{406}$ and fou $[<\mathrm{nd}>\ldots . .$.

$81,15[\ldots .$.$] people [\ldots .$.

82,1 [..... in Regnal Year 24, I šmw 21 under the Majesty of the King of Upper and Lo[<wer Egypt, Ramesses $\left.\|_{>} \ldots . . ..\right]$

82,2 [<to $>$ let the Prophet Hri know them, each man according to its documentation ${ }^{407}$ the summary $[. . .$.

82,3 [Cultiv>] ators, 8'760 men, each one of them under the obligation of 200 khar, ${ }^{408}$ cattle herdsmen, men being $[. . .$.

82,4 [<cat>] tle, and pasture cattle, each man of them having 500 animals; goatherdsmen, being 13'080. E[<ach man> .....

82,5 [<bird->] keepers, being $22^{\prime} 530$, each of them having $34^{\prime} 230$ birds; fishermen $[. . .$.

402 This word is quite difficult, cf. A. Nibbi, "Some Remarks on Ass and Horse in Ancient Egypt and the Absence of the Mule," ZAS 106 (1979): 166-168; K. Kitchen, "Prd > Pir = 'Mule' in New Kingdom Egypt?," GM 13 (1974): 17-20; Helck, Beziehungen, p. 512, No. 83;. Lesko (DLEI: 186) provides only "(domesticated animal)" which is probably the best provisional solution. Regardless of the philology, it seems rational to maintain herds of reproductive cattle, and to employ herdsman to watch after them, but mules would presumably be put to work, and therefore need not appear in herds with herdsmen.

403 Helck (Beziehungen, p. 513, No. 99) has related this apparent hapax (?) to the Semitic m/h, based on its appearance beside hsmnyw. So also Materialien, p. 467

404 Cf. Helck, Materialien, p. 467, where he has restored their wives as the logical complement to "their children" which itself is however not certain, although the traces certainly speak in favour of pay.sn msw (sic!). S. Allam ("msw = Kinder/Volksgruppe/Produkte/Abgaben," SAK 19 [1992]: 1-13) has suggested another alternative explanation, which can be argued either way, should the traces actually be present. Either "products" or "children" can be argued.

405 This passage has baffled J. Cerny, A. H. Gardiner, W. Helck, E. Wente and K. A. Kitchen as an intelligible version of the hieratic or a plausible translation has not been established.

400 This is the crux of the matter, and - as usual - it is not clear.

407 Cf. supra, p. 143 n. 401.

408 This figure can be used to make comparisons on the level of the reliability of the text and the meaning of this statement. E. Wente (Letters, p. 119 ) translates that they produce 200 khar each, and this statement seemingly corroborates the identical one in P. Bol. 1086, 21-26 |KRI IV: 81, 2-5; W. Wolf, "Papyrus Bologna 1086," ZÄS 65 [1930]: 95-96), where each adult field worker is expected to account for 200 khar. In that reference, it is however a tsw-pht - which can be understood as "sowing order" - and it could be suggested that the sowing and not the harvest is meant. If one extrapolates and concludes that sowing orders were issued in units of 700 khar (for which peculiar figure, of. P. Berlin 3040a vso. 7; KRI Ill: 160, 11) then this refers merely to sowing orders and not harvests.

According to v. Beckerath's table (Chronologie, p. 122), Ramesses II 24 | šmw 21 would be near the end of March 1255 B.C. of the Julian calendar, and Krauss ("Deiailfragen der altägyptischen Getreidewirtschaft," in 
82,6 them at three silver deben annually; the donkey grooms being $3^{\prime} 920[+\ldots$. with $]$ 82,7 [animals 20?'] 870 ; the pwtrw tenders, being 13'227, each man having 551 animals; peo $\left[<\right.$ ple $\left.{ }^{409} \ldots ..\right]$

82,8 plans which I made for them, to the effect that I re-assigned a number of their people, and let them build [.....

82,9 a great barn for the $\breve{s}^{c}$ of Memphis (Mn-nfr), ten arouras (of land) belonging to it $[\ldots . .$.

82,10 [<the grs] anary in it about its four sides: total 160 silos [there being 40 on each side $\left.^{410} \ldots ..\right]$

82,11 many items of the treasury in silver and gold, bronze and clothing [....

Fs Fecht, p. 267) maintains that the harvest should have been completed by the end of May, so that if the letter - and thus the date - is to be taken seriously, then this can refer only to the harvest preparations.

W. Helck (Wirtschaftsgeschichte, p. 246) and W. Schenkel ("Landwirtschaft," LÄ III: 932-933), have examined the estimates of the yields per surface area, seeming to imply that cultivators "employed" by temples each had to harvest twenty to forty arouras. The figures for Graeco-Roman Egypt confirm that 5 khar/aroura $=14$ hectolitre/ hectare) is a reasonable rate, and thus 40 arouras are implied in an assessment of $200 \mathrm{khar}$. With a harvest season lasting several weeks, this implies a total area of 2 arouras/day, or slightly more than $5000 \mathrm{~m}^{2} /$ daily, or some 800 litres/day.

Assuming that these cultivators are employed to do this work, and that the entire harvest was rendered to the temple, and then redistributed, this is a great deal of work. Assuming that the usual assessments were merely what had to be delivered to the temples, and the income was what went beyond this, then the amount of work involved is almost inconceivable. It is far more probable that these are merely the lower level administrators, who have field-workers in their employ. But, this would not explain the special case of the "stripling" with the 100 khar responsibility in $\mathrm{P}$. Bologna 1086

409 These figures are quite remarkable, for the total must have exceeded the preserved one of 61 '517 which amounts to some wo-thirds of the tolal number mentioned in P. Harris I 1 1,4:86'486 as the dependents of the Estate of Amun. If this is a list of all the temple dependents in the Delta - as suggested in the translation here - it would support the contention that the majority of the dependents were in the Delta. The idea is appealing, but the evidence slim.

410 I am obliged to Prof. J. J. Janssen who has provided the most logical and simplest solution to reading this passage. 


\section{Papyrus Fragments from Gurob}

Sir Alan Gardiner retrieved a number of administrative papyri from the material brought to light by Sir Flinders Petrie at Kom Medinet Ghurab, generally known as Gurob. ${ }^{411}$ Several potentially interrelated texts are drawn together here. P. Gurob, an account papyrus attached to a letter, is one of the well published fragmentary administrative papyri. Dating to Regnal Year 2 of Setill, a htri of fish is associated with a Mayor $(I .2,12)$. The letter of the first text is in the same handwriting and of approximately the same date as the following notes concerning servants and payments. ${ }^{412}$ The papyrus seems to have been written and stored in Gurob.

\section{P. GUROB 413}

$1 . x+10[\ldots<w h i c h>] \mid$ did

2,1 like that which was done for P3-R', absolutely perfectly. ${ }^{414}$ I will cause myself ${ }^{415}$ to be praised on account of this.

2,2 I will not allow fault to be found for me. 416 That which my Lord (LIP!H!) caused to be done benefited $\mathrm{me}^{417}$, letting people be brought to me

2,3 to instruct them (and) to educate them to accomplish this great task. Fortunate is the finding of my lord

411 For the identification of Mr-wr(t) as Kom Medinet Gharab ("Gurob"), cf. D. Arnold, LÄll: 87-88; 922-923; AEO If: $115^{\star}-116^{\star} ;$ A. H. Gardiner and H. I. Bell, "The Name of Lake Moeris,"JEA 29(1943): 37-50; A. H. Gardiner, Wilbour II: $29-30$.

412 Cf. Sir Alan Gardiner's remarks, RAD, p. ix.

413 RAD, pp. 14-18; Griffith, Kahun Papyri, pp. 94-98; pls. 39-40; A. H. Gardiner, "The Harem at Miwēr," JNES 12 (1953): 145-149; W. Helck, Maferialien, e.g., pp. 150, 481, 650, 666, 675, 683; Wente, Letters, p. 36. The first page is represented by the tail ends of the lines, the second is the conclusion of the text begun there. Athough only a short note at the end of this page is directly concerned with "taxation", the preceding text is presented as well, as this is relevant to the interpretation of all the texts relating to Mr-wr, which follow. As will be noted, the text is clearly to be dated to the second year of the reign of Seti II.

414 "q3y sp sn. Sir Alan (JNES 12: 146) translates as "they being exactly exactly alike".

415 With W. Spiegelberg (apud Griffith, Kahun Papyri, p. 106) and Sir Alan (JNES 12: 146-147), it is assumed that the scribe has placed a superfluous there. The assumption is of course decisive, in determining that the letter was written by a lady to Setill.

416 As discovered by W. Spiegelberg, and confirmed by Sir Alan, this represents an idiomatic expression.

${ }_{417}$ W. Spiegelberg read F. LI. Griffith's sh as an adjectival noun ("a fine thing") moditying the following sentence (Kahun Papyri, p. 106; pl. 39/hieratic, 2; pl. 39 hieroglyphic, 25), while F. Ll. Griffith himself had understood this as the object of the preceding sentence (Kahun Papyri, p. 95). Sir Alan corrected the reading of the hieroglyphs but generously attributed the identification of the form as an "adiectival predicate" to Spiegelberg $(R A D, p p$. 14 ; 14a and JNES 12: 146-148), while curiously adopting Spiegelberg's translation, although obviously reading the seated figure as the 1st. pers. sing. dependent pronoun (cf. Černy-Groll, p. 22) improves the sense. The following infinitive construction ( $\rho$; r dif) would then be the subject of a preceding verb (sh), with the 1 st. pers. sing. fem. pronoun wi as an object. The dot of the seated female figure can be almost invisibly written when part of this pronoun (cf., e.g., Kahun Papyri, pl. 39/hieratic, 3; or the hieratic text of Nwt-Nhti's testament-J. Černý, "The Will of Naunakhte and the Related Documents,"JEA 31 [1945]: pl. 8, col. 3, line 3), but it can conceivably have been omitted. (Sir Alan assumed that precisely this error was made in 2,6: cf. JNES 12: 146; $148 \mathrm{n}$. g). Sir Alan (JNES 12: 146) notes that "we shall find that this short text contains at least two other miswritings", and therefore the suggested readings are not that farfetched. If a male scribe unaccustomed to such activily was actually taking dictation from a lady, this would explain at least one of the faults, where the seated female figure is inexplicably preceded by a $i($ JNES 12: 146) 
2,4 that they $y^{418}$ should be made to perform that which the like thereof has not been done for $P_{3}-R^{c}$ since those who are here are large children,

2,5 people who are like those people whom my Lord (LIP!H!) sent. Those who

2,6 are able to, perform, and those who understand take instruction. They are foreigners 419 like those brought

2,7 to us in the days of Ramesses II (LIP!H!), the great god, your good father. They tell us, "We were as ' $h$ i $w^{420}$

2,8 in the houses of the officials." They take to learning and they are able to do all that has been explained to them.

2,9 This is an information dispatch (for Pharaoh). ${ }^{421}$ Year 2 III 3 iht 20.

2,10 Copy for every servant active in the house of ps-hnty of Mr-wrt since year 2 III sht 14 . [A deliberate space of two lines, followed by:]

2,11 Year 2 III 3 h $h t 1<7>$. (The Royal) One was in the temple of [Seti II] in Memphis.

2,12 Received as hitri of fish which was on the Mayor [.... of [...<the>] Southern City.

2,13 'd-fish: gutted, 300; whole 700, Total 1000.

vso.

$1,0[<\ldots .1>] 00$

$1,1[\ldots .<$ The usual wa> $]$ ges ${ }^{422}$ making Moringa Oil 130 hin; sesame oil 130 hin

$1,2[\ldots<$ sesame oi $]$ I 2155 hin.

1,3 [<moringa oil hin 130 sesame oil hims] 2286: details of it

418 Sir Alan (JNES 12: 146-147) translates st as "her" and "one", while this could also represent the 3rd. pers. pl. pronoun, and thus logically could refer to the people who are sent. For the text correction, cf. RAD, pp. 14-14a n. 8a and JNES 12: 147). The st at the end of the sentence underlines the thought.

419 The reference to foreigners being residents - even traditional residents ("like those sent" a decade earlier; II. 2,5-2,7) is interesting as it can be confirmed by archaeological data. Although there seems to be a hiatus following the early Hyksos period followed by a moderate settlement in early Dynasty XVIII, there was also sufficient imitation Mycaenean pottery to support the assumption of the presence of foreigners in Mr-wrt/Kom Medinet Ghurab at the period at the close of the New Kingdom; cf. Kemp/Merrillees, Minoan Pottery, p. 248 land cf. index, p. 336, s.v. "Medinet el Ghurab").

420 As Sir Alan (JNES 12: 146) suggests: "mere numbers" perhaps?

421 Sir Alan (JNES 12: 147; 149 n. k.) suggests a restoration, which is however not essential, and thus transiated neutrally.

422 This follows Griffith's proposal to some extent. Sir Alan correctly noted (RAD, p. 15a, 10a) however that Griffith's (Kahun Papyri, p. 96) suggested reading, "hnt hrw (2)", "is quite impossible", but himself provides two equally unsuitable readings. The group given in facsimile $\langle R A D, p .15 a, 1.10 \mathrm{a}$ ) and in Griffith's photograph (Kahun Papyri, pl. 40,1. 1.) can be read as $m n$, perhaps with a solar disk as determinative. Thus, one could translate - with Griffith - "daily". D. Mueller ("Some Remarks on Wage Rates in the Middle Kingdom," JNES 34 [1975]: 249-263) has however shown that there would appear to have been a term meaning "basic wage" written $\mathrm{mn}$. in the Middle Kingdom. This unit might be meant here, with an understandable confusion arising from the similarly written term for "daily". 


\begin{tabular}{|c|c|c|c|c|c|c|c|c|}
\hline & $\begin{array}{l}\text { moringa } \\
\text { oil } \\
\text { hin }\end{array}$ & $\begin{array}{c}\text { makes } \\
\text { hin }\end{array}$ & $\begin{array}{l}\text { Sesame } \\
\text { oil } \\
\text { hin }\end{array}$ & makes & employees & $\begin{array}{l}\text { each } \\
\text { hin }\end{array}$ & $\begin{array}{l}\text { Sesame } \\
\text { oil } \\
\text { hin }\end{array}$ & $\begin{array}{c}\text { Total Sesame } \\
\text { oil } \\
\text { hin }\end{array}$ \\
\hline 1,4 & 5 & 10 & 2 & 10 & 89 & 2.5 & 222.5 & 232.5 \\
\hline 1,5 & 5 & 10 & 2 & 10 & 70 & 2.5 & 175 & 185 \\
\hline 16 & $<5>$ & 10 & $<2>$ & 10 & 70 & 2.5 & 175 & 185 \\
\hline 1,7 & & 10 & $<2>$ & 10 & 69 & 2.5 & 172.5 & 182.5 \\
\hline 1,8 & & 10 & $<2>$ & 10 & 78 & 2.5 & 195 & 205 \\
\hline 1,9 & & 10 & $<2>$ & 10 & 68 & 2.5 & 170 & 180 \\
\hline 1,10 & & 10 & 2 & 10 & $<6>7$ & 2.5 & $167<.5>$ & $177<.5>$ \\
\hline 1,11 & & 10 & 2 & 10 & $<7>7$ & 2.5 & 192.5 & $202<.5>$ \\
\hline 1,12 & & 10 & 2 & 10 & $<b>4$ & 2.5 & 160 & $\langle 170\rangle$ \\
\hline 1,13 & & 10 & 2 & 10 & $6<3>$ & 2.5 & 157.5 & $167<.5>$ \\
\hline 1,14 & & 10 & $\begin{array}{c}1 \\
\star \\
{[5]}\end{array}$ & 10 & 40.5 & $2<.5>$ & 101.25 & 106.25 \\
\hline 1,15 & & 10 & 2 & 10 & 34 & 2.5 & 85 & 95 \\
\hline 1,16 & {$[<5>]$} & 10 & $\begin{array}{c}1 \\
\star \\
{[5]}\end{array}$ & 10 & 33 & 2.5 & 82.5 & 87.5 \\
\hline $\begin{array}{l}1,17 \\
1,18\end{array}$ & & 10 & 2 & 10 & $\begin{array}{r}38 \\
2\end{array}$ & $\begin{array}{l}2.5 \\
2.5\end{array}$ & $\begin{array}{r}95 \\
5\end{array}$ & $\begin{array}{r}105 \\
5\end{array}$ \\
\hline & & & & [130] & & & {$\left[\begin{array}{ll}2^{\prime} & 156.25]\end{array}\right.$} & ${ }^{\star}\left[2^{\prime} 826.25\right]$ \\
\hline
\end{tabular}

vso. a

la, $1[<$ Regnal Year 2 ....(The Royal) $>]$ One was in the House of [Ramesses II], the great $k$; of $P<a r>$ aharakhte.

la, $2[<\ldots \text { the Mayor } \mathrm{P}>]_{3}-\mathrm{Sr}_{r}$ of $\mathrm{Mr}$-wrt [<received $]$ instead of fish, alfalfa mats 50 .

la,3 $[<\ldots .0>] \mathrm{f}$ the fisherman P3-hrw, son of Imn-ms, tpyw fish, $[\ldots ..] \mathrm{mc} h q^{3}{ }^{3}$ 1520. Details of it:

la,4 [.....] 3145445332222

$1 a, 5[\ldots]<21100100>412212012<8>132<.+>11311157683$

la,6 [.... loaves isbt-bread: $20 ; \breve{s}^{c} y$ t-cakes: oipe 8

$1 a, 7[\ldots<l>] 2$

vso. $b$

1b, 1 Regnal Year $<2>, 1$ prt 10 (The Royal) One was in the temple of [Ramesses II], the great $k^{\prime}$ of Paraharakhte.

Ib,2 Receiving the htri of fish which is upon the Mayor $\mathrm{P}_{3}$-sr of Mr-wrt: dried tpyw fish, mc $[\ldots .$.

16,3 making fish 1600. Details of it: $159127127125141 \quad 123 \quad 12[<0+>\ldots$.

$1 b, 4116114736560702$.

1b,5 inw of the royal superintendent of the Throne: given towards material support of this house, good bread: large 'qw-loaves: 10; Syrian beer [....

16,6 Regnal Year 21 prt 11 (The Royal) One was in the Temple of [Ramesses II], the great $k$; of Paraharakhte.

$1 b, 7$ Withdrawn from the magazine of this House, given to the Porter Sš-sisw-nb-nht for $t[$ he $>$.... 


\section{P. Gurob Fragment $G^{423}$}

$1,1[\ldots]$ hrr $<5>$, tunic $424[\ldots](1,2)[\ldots$.$] papyrus 39[\ldots].(1,3)$ Withdrawn from the storeroom of this house for $(1,4)$ the $t p-\underline{d} t^{425}$ of the Opening of the Year Festival:

1,5 royal linen, as covering hrr 1

1,6 royal linen, tunic, ?

1,7 mk-cloth, s;-p;, 5

1,8 mk-linen, $n f^{c}, 10$

1,9 double fine thin dress ${ }^{426}, 6$

1,10 double fine thin tunics, 3

1,11 thin dress, 15

1,12 thin tunics, 15

1,13 thin loincloths $(?),{ }^{427}$ papyrus $[\ldots$.

1,14 given towards in $[<w>$... $]$

$1,15$ from the hands of the Scribe Se[<ti of this House $>. .$.

1,16 Thin dresses, $[<9>\ldots]$

$2, x+1 \quad[\ldots .$.$] making as cov [<$ ering $>\ldots]$

$2, x+2[\ldots .$.$] all <$ fay $>$ ence (?) for coverings [(?)...]

$2, x+3[\ldots$.$] decorated with m$ m of lapi $[<s$ lazuli $>. .$.

vso.

$1,2[<$ Regnal Year.... day 10... (The Royal) One was in> $]$ the House of [Ramesses III], the great $k$; of Paraharakhte,

$1,3[\ldots]$ clothing given towards the One who is there from the journey, from the hand

$1,4[\ldots .$.$] the pi-hnty which is in Mr-wrt.$

$1,5[\ldots]$ royal scribe of the Harim, Seti of this house.

$1,6[\ldots<$ in the time of the (?) King $>$ ship (of) the King of Upper and Lower Egypt [Ramesses II].

vso

$2,1[\ldots$.$] diw cloth 24$, making silver deben $[. .$.

2,2 lapis lazuli, extra fine quality, ${ }^{428}$ deben 6 , (making) silver deben [....

423 RAD, pp. 20-21; W. Helck, Materialien, pp. 932-933.

${ }^{424}$ For hrr cf. perhaps H.O. 65, 2 vs. 2. That the $m s$ is a tunic or galabia is supported by Janssen, Prices, pp. 259-264.

425 Prof. J. J. Janssen was so kind as to confirm my suspicion that this was indeed tp- $d r t$, as Sir Alan Gardiner (RAD, p. 20a, I. 7a) at least indicated was possible. Cf. J. J. Janssen, "Requisitions from Upper Egyptian temples P. BM 10401)," JEA 77 (1991): 88

426 For the idg, ct. Müller, Liebespoesie, p. 43; pl. 17, 15; J. J. Janssen, Commodity Prices, pp. 282-284; J. J. Janssen, "A Twentieth-Dynasty Account Papyrus," JEA 52 (1966): 85 n. j. For the idg as a mantle, cf. E. Edel ("GAD.TuG maklalu

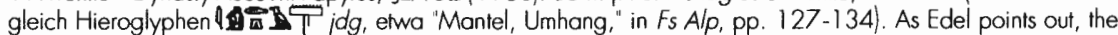
implications of dripping oil as suggested in Müller, Liebespoesie, pl 17, 15 do not support the reading as a kerchief, and the prices and quality are quile high, but it is clear that this must be one of those festive dresses worn at parties.

427 Adding with W. Helck (Materialien, p. 932) - another variation to Janssen's (Prices, p. 272) list of possible writings of this word, for the meaning of which, s.v. pp. 272-277. 
2,3 lapis lazuli deben 40 (making) [ <silver debers....]

2,4 green stones ${ }^{429}$ deben 10 (making) [<silver debens....]

2,5 safflower ${ }^{430}$ blossoms mc. [....

\section{REMARKS}

As Sir Alan has arranged the material, there are several more pages with lists of various kinds of clothing, ${ }^{431}$ sand then indistinct remarks about comings and goings and some figures ${ }^{432}$ before some notes about deliveries of fish to the Harim at Mr-wrt. ${ }^{433}$ The letter seems to have been written by a lady to the reigning Pharaoh Setill, and the other notes on the same papyrus were written in the same hand, so that the additional fragment translated here has been related to the first text due to the repetition of the phrase referring to the presence of the Pharaoh. Each statement referring to the receipt of htri fish from a given Mayor is preceded by a neutral statement to the effect that the King is in a particular temple. What seems to unite all of these documents is the Harim at Mr-wrt, and the fact that there is a strict accounting for fish where on the one hand Pharaoh seemingly receives them from $\mathrm{P}_{3}-\mathrm{Sr}_{\text {, }}$ the Mayor of Mr-wit as a hitri payment ${ }^{434}$ but then Hri, the Mayor of Mr-wrt gives fish - without any other identification - to the Harim. ${ }^{435}$

The relationship of the text in the letter to the accounts may be clear in that both concern temple employees or dependents, but a careful examination of the letter did not allow any deductions concerning the significance of the transfers. It is merely clear that (a) considerable quantities of sesame and moringa oil were expended for the employees of the establishment; (b) that the fish being collected from the Mayor of Mr-wrt were probably collected from people unrelated to those being "instructed" in the letter; and $(c)$ that the people being given instruction were foreigners. It is possible that these latter were the ultimate recipients of the fish, but it is not clear that the two delivery types of fish were identical.

Associating the term htri with the term $m n$, i.e. the assumption of a reciprocal obligation, the htrican be interpreted as the Moyor's obligation to the Pharaoh, and the $m n$ as the obligatory wages to the employees and overseers. But, the htri is not the same as the $m n$, as the htri is fish (and a few loaves and mats) while the "wages" are moringa and sesame oil, so that the products are not the same.

It can merely be suggested that the Mayor's htri is for the pi-hnty of Mr-wrt, and the fact that a civilian was responsible for the deliveries to the pi-hnnty. The pi-hnty was at least partly staffed by foreigners (clear from the references in the letter of the recto, pp. 146-147), and responsible in some way for some activity beneficial to the god $P_{3}-R^{c}$. The documents show that this institution received fish, sesame oil, and moringa oil (and probably also the loaves)

429 Cf. Harris, Lexicographical Studies, pp. 102-104.

430 For kt as Canthamus tinctorius, "safflower", cf. R. Germer, Flora, pp. 173-175.

431 RAD, pp. 22-23; 25

432 RAD, pp. $24-26$.

$433 R A D, p p .26-28$. These are followed by some badly preserved texts relating to the šmw and inyt as grain deliveries.

$434 \quad R A D, \mathrm{pp} .15,6-8 ; 17,14-16$.

$435 R A D$, pp. $26,18-27,1-2$. Some additional fragments also related to fish, but in their present stale do not specify whether they were collected from or delivered to the temples listed. 
to be redistributed to the dependents, and that htri designated some of this. Additional references suggest that the manufacture of cloth or garments be associated with the pi-hnty. The Royal Superintendent of the Throne's inw is for the temple. Whether it is justifiable to explain the use of the term inw by the foreign origin of the Syrian beer is extremely speculative. The first page of the verso of $P$. Gurob Fragment $G$ appears to be the same type of entry as found in P. Gurob, mentioning "(The Royal) One's" presence in the shrine of Ramesses II the great $k$; of Paraharakhte. The second page mentions lapis lazuli, but the list is quite similar to that on the recto, where valuable clothing materials are listed under a heading which indicates that they are "withdrawn" from the temple. This text bears a very close resemblance to P. B.M. 10401, 436 which is however from Thebes and not Gurob.

Col. I of P. B.M. 10401 lists metals, garments, fruits, and animals, etc. as having been the

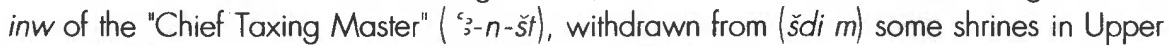
Egypt. ${ }^{437}$ The Prophet of the temple of Khnum at Elephantine delivered gold, cloth, stones and fruit. ${ }^{438}$ Cloth and fruit follow in another entry related to Khnum. ${ }^{439}$ A Prophet at Kom Ombo delivered some fruit and mats. ${ }^{440}$ The temple of Horus Behdely provided cloth and an ox. ${ }^{441}$

Col. Il appears to bear another heading, beginning with " $(2,1)$ tp- $\underline{d}$ tr of the Prophet Nb-Ntrw" as col. I began with "the inw of the Chief Master". Although there is no reason to believe that a new text began with the top of col. II, it is curious that only the affiliations of this Prophet and the chief Taxing master are missing, but this is doubtless a mere oversight, the Prophet being the same as that mentioned in connection with the Behdety, and the items being likewise assigned to the Chief Taxing Master, merely under a different heading. The chief problem being whether to interpret the $t p-\underline{d} r t$ as an ex-officio obligation on the Prophet himself, or as a particular designation for a payment rendered up by the temple. The items listed in cols. II and III from the temples of Horus of Nekhen, the house of Nekhbet, and the Khnum temple at Esna repeat the same items: gold, cloth, animals and bread.

436 J. J. Janssen, "Requisitions from Upper Egyptian Temples (P. BM 10401)," JEA 77 (1991): 79-94. My own approach is a mere shadow of that produced by Janssen's masterly abilities, so that for the text and translation, one is referred to his article, and the treatment here is intended to touch the salient points.

$437 \mathrm{~J}$. J. Janssen (JEA 77: $84 \mathrm{n}$. (c)) rejecis the possibility that this is the substantive, as the genitive $n$ is absent. Were this a conventional verbal construction, then one would expect a multitude of objects to be referred to as $n$ ? inw rather than $p^{3}$ in w. As he interprets the first phrase of the sentence as being formed with a direct genitive (snny n? iht, translating "List of the objects," JEA 77: 81) this appears to be a secondary issue. The use of the genitive $n$ usually suggests that the previously designated inw came from that source (e.g., "the inw of every land", KRI I: 197,8), while the dative $n$ defines the ultimate recipient (e.g., "for his father," KRI I: 23, 3). An $n$ could thus conceivably have been misconstrued by an Egyptian, who understood it as a dative, suggesting that it was "for" him "rather than "his" - whatever this may be interpreted as signifying. Taking the construction as a direct genitive also explains why the abstract determinative rather than that of a verb of motion is used, etc. I thus read: " $(1,1)$ List of the items, the inw of the Chief Taxing Master $(1,2)$ which were withdrawn from the shrines." This does not imply that I understand anything except a direct relationship belween the "Chief Taxing Master" and the inw, and most certainly not the implication that the "Chief Taxing Master" was fulfilling his obligations by recourse to the temples to make up an unexpected deficit. It should be noted that hitherto it has not been established that the official we call the "Chief-taxing Master" was part of the government rather than the temple bureaucracy, so that "requisitioning is perhaps exaggerated, if the transfers are within the temple system.

438 Janssen, JEA 77: 80, II. 1,3-12.

439 Janssen, JEA 77: 80, II. 1,13-16.

440 Janssen, JEA 77: 80, II. 1, 17-21.

441 Janssen, JEA 77: 80, II. 1,22-25. 


\section{P. GREG ${ }^{42}$}

TRANSLATION

A 1 [....(wood?) <750>] [Left Blank] plaster khar $11 / 4[$ [...(rest?) $<k$ har $>] 5 / 8$

A 2 [.... through 443 the scribe P3-sr: wood, 500, rest, 1000; plaster, khar 1, rest, khar $7 / 8$.

A $3[\ldots<10 \ldots<1>$ he workmen worked at the site $444[\ldots] 25$

A $4[\ldots<$ gi $>$ ven to the site on this day $5<6,>20$, total 76

A 5 [.... day 11 for the left side, through the scribe $\mathrm{P}_{3}$-sr, the foreman, $11 / 4$; khar 3.

A 6 [....work]men, men, 14, each one, khar $12 / 4$, making khar 21 , men 9, each one, khar 2, making khar 1<8>.

A 7 [...<khar $] 1 / 2$ brought later khar $33 / 4$. Details of it: the foreman, khar $12 / 4$

A 8 [.... khar $1<1 / 4>$ surplus (from?) before of III sht khar $1 / 4$

A $9[\ldots .$.$] this <$ day $>$ khar $473 / 4$

A $10[\ldots<$ received as the inyt from the r-prw-chapels of the> We $]$ st of Thebes, beer, $d s$-jars 5

A $11[\ldots$ [.. potter $>$ Pth-m-wis of the right to the scribe P3-n-t3-wrt, b3:kw 2

A 12 [....] of the right; workman $\mathrm{Hwy}$, son of $\mathrm{Hwy}$-nfr of the left

A 13 [....] [??? ] diw for the right side, made from Regnal Year 51 sht 1

A $14[\ldots<$ khar $>] 52 / 4$, their five days, khar $2 / 4 ; 1+1 / 4+1 / 8[\ldots$.

A $15[\ldots . .<k$ < $>$ ar $1 ; 2+3 / 4$ [Left Blank] 1/8 khar 1/4;2/4 +1/8+1/16 [???]

A $16[\ldots .$.$] each one khar 1[<2 / 4>\ldots .]$.88 , each one for their five days, khar $3 / 4+1 / 8$ $+1 / 16$ making khar $11 / 4[\ldots$.

A $17[\ldots . .$.

A $18[\ldots .$.$] khar 1[<2 / 4>]$; 4 ; their five days khar $1 / 4 ; 1 / 16[+$ ? $] 1 / 8$

[Loss?]

B $1\left[\ldots .(\right.$ Received from the $?)<$ Temples $^{445}>$ of West Thebes... $]$

442 KRI V: 437-448. This fragmentary papyrus has unfortunately been losi (Cf. JEA 65 [1979]: 3), and thus hazarding a translation based on an imperfect transcription is perhaps rash, but this is one of the most important papyri from Deir el-Medineh specifying institutional relations. A similar one $(O$. Edgerton 13) is unfortunately not published either. J. J. Janssen (pers. comm.) suggests that the text be dated to the reign of Siptah/Tawasert, and not Ramesses III, as listed by K. Kitchen; Kitchen himself indicated his uncertainty in the matter of the date (KRI V: 437). Centainly the workman named Pth-m-wi? was not listed under Ramesses III in Valbelle, Ouvriers, Annex, IV, but is listed for Siptah, even though D. Valbelle used P. Greg as a source for the composition of the Gang dated to Ramesses III (Ouvriers, p. 344).

443 Prof. J. J. Janssen (pers. comm.) suggests the reading of. "through" rather than "from" for $m$ - $\underline{d} r$. Logically this is correct in this case, as the scribe was not a wood-culter, but it not invariably logically and thus semantically correct.

$444 \mathrm{~J}$. Cerny (Communily, pp. 81-84) proposed "work in progress" as a rendering for the place of work as related to the royal tomb, $p^{3} r^{-}-b 3 k w$. It would seem that the most appropriate rendering in this and many other cases would be "site".

445 r-prw. Spencer (Temple, pp. 37-42; 54-55) has shown convincingly that in the absence of a context, this should not be understood narrowly, and can refer to the temples, and in this case must refer to the mortuary temples. 
B 2 [(By the workmen of the? $)]$ right side of the Gang [land the workmen of the left side of the Gang?)]

B 3 [(Regnal Year 5 I sht 16: the Gang was working on this day $\left.{ }^{446} \ldots ..\right]$

B $\left.4[\text {.... (given to the site? })^{447}\right]<$ this day> [... $]$

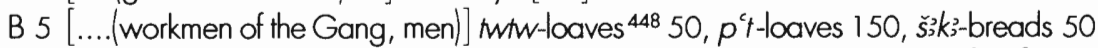

$B 6$ [By the workman] '3-phty of the right side, workman $\mathrm{Hr}$-m-wis of the le[<tl $\rangle]$

B $7[<$ Regnal year $5 \underline{\mid \text { iht } 17>}>$, the workman worked at the site.

B 8 [<lamps is $>$ sued to the site, on this day, 42, 16 tot $[<\mathrm{al}>\ldots .$.

B $9[<$ Received as inyt from the chief of $>$ the royal provisions of Pharaoh (LIP!H!) in the city ${ }^{449}$ biz-cakes, 7 and $p(r) s$ cakes $[. . .$.

B $10[<$ Received as the inys]t from the temples of West Thebes, beer, $d s$-jars, [Left Blank] 5

B 11 [<By the workman>] of the Gang Ki-s; of the right side, and S;-Widyt for the left $[\ldots . .$.

B 12 Regnal year $5 \leq$ iht 18 . The workmen of the Gang were working at the site $[\ldots$.

B 13 lamps issued to the site on this day, 42 , total $5<2>$

B 14 Received through plaster-maker Bik-n-wrnr of left, plaster, sacks, $1[\ldots$.

B 15 By the workman Mry-Rc of right and the workman Nht-sw of lef $[<t>\ldots .$.

B 16 Regnal year $5 \underline{\text { s ht } 19}$, the workers of the Gang were not engaged ${ }^{450}$ on this day. $[\ldots .$.

B 17 By the workman of the Gang, Ps-n-Imn, of right, and workman of the Gang, Hwynfr of lef $[<t>\ldots$.

B 18 Regnal year $5 \underline{3 h t 20}$, the workmen of the Gang were not engaged on this day.

B 19 Received as the inyt from the temples of West Thebes, beer $d s$-jars [Left Blank] 5

B 20 Received ${ }^{451}$ through the fisherman $P_{3}-t w-i$; of right, fish, deben [....

B 21 Received through the wood cutter $\mathrm{Nb}-\mathrm{R}^{\mathrm{c}}$ of right, wood, 500,452 bikw [....]

B 22 By the workman of the Gang Qn-hrr-hpš.f on rig [<ht, the work>]man of the Gang, $\operatorname{Im}[<n->\ldots$.

B 23 Total from I sht 11 to 20 making 10 days [...]

B 24 Wood, 1,750; plaster khar $11 / 4$, bikw 2 of the potter [....

B 25 left, through the scribe P3-sr [Left Blank] wood [Left Blank]; plaster khar $11 / 4[\ldots .$.

B 26 Regnal year 5, 1, ht 21, the workman of the Gang worked at the $\operatorname{sit}[<\mathrm{e}>\ldots .$.

This restoration is merely a deduction based on the comparable entries and the traces in the following lines.

Prof. Janssen (pers. comm.) points out that the quote using "this day" never immediately precedes "receiving" so that the published version must be correspondingly emended, and this restoration removed. Usually the Gang was working or absent "on this day", or it referred to the place where they were in the preceding word. The "man of action" determinative indicates that they were not at rest, or that it refers to "the site". The logic of the text indicates the order. Thus the restoration.

This must be a loaf and not an $r$ and they were not "absent from work", but merely from the site.

45) I have no confirmation that this was written in red.

452. The units of wood are never specified, so we cannot estimate the volume. 
B 27 lamps issued to the site, this day, 56 [Left Blank] 20 Total [ $\langle>6\rangle]$

B 28 Received as the inyt from the chief of the royal provisions of Pharaoh (L!P!H!) in the city, bis-breads $8<p[(r)$ s-breads $>\ldots .$.

B $29 \mathrm{~d}[<\mathrm{at}>] \mathrm{es,} \mathrm{mht}$-vessels 4, brought to him (from the) West of Thebes for beer, dates, g3y-vessels $[\ldots$.

B 30 Received through the wood cutter, Bik-n-Mwt of $r[<i g h t$, wood, $2>] 50$

$B$ 31 Received through the wood culter $H^{c}$-m-tri $[<$ of the ....<wood $>. .$. .

B 32 Received through the wood [<cut>]ter $P_{3}$-iwd (of the leff) ${ }^{453}$ wo $[<$ od $>$.... $]$

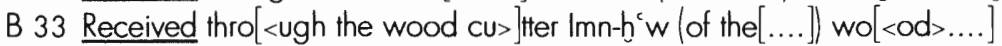

B 34 By the workman P3-bhnw of the right, (and) the workman $[\ldots<$ of the $>$... $]$

B 35 [ <Regnal Year 5 l $>$ ] 3 ht 22, the workmen are work[<ing at the site $>$ ]

B $36[<$ Lamps (?) is $>$ sued to the si $[<$ te this day $>$.... $]$

C 1 Received as inyt from the [....

C 2 Regnal Year $51 ;[<h t 27$. The Gang was working at the site $>\ldots]$

$[x$ lines lost $]$

$\mathrm{C} x+3[\ldots]$

$\mathrm{C} x+4$ [Received throu $>$ gh the fisherman $B 3 k-[<n-l m n$ of left $>$....]

$C x+5[<$ Regnal $]$ year $5[<1>]$ hht 28 . The men of the Gang we $[<r e$ working at the site this day $>$ ]

$\mathrm{C} x+6$ lamps issued to the site [<on this day ....]

$\mathrm{C} x+7$ Received as inyt from the temples of the West of [<Thebes: beer $d s$-jars 5>]

$\mathrm{C} x+8$ By the workman $\mathrm{Rm}^{c}$ of the right, $[\ldots .$.

$\mathrm{C} x+9$ Regnal year $5 \underline{1}$ sht 29. The men were not engaged this day.

$\mathrm{C} x+10$ the remainder of the diw corn of $\|$ sht for the right side $[. .$.

$C x+118$ men, each one, khar 4, making khar 32 [....]

$\mathrm{C} x+12[<\operatorname{men} 7>]$ each one khar 2, making khar 14, porters $[. .$.

C $x+13$ [<8 men, each one, khar 4, making khar $>] 32$

$\mathrm{C} x+14$ the issuing of the diw corn [<ll sht to] the foreman, khar $[. .$.

$C x+15$ men 22, each one, khar 1 making khar 22, porters, men, $2[\ldots$.

C $x+16$ stripling Wnn-nfr khar 1, $P_{3}$-ym khar 1 [....

$\mathrm{C} x+17[\ldots .$.$] each, totaling on this day, khar 80[\ldots$.

$[x$ lines and $x$ columns lost $]$

vso. A

A $1[\ldots .$.$] for l e[<t$, wo $>$ ]od, $500,[\ldots<$ total $1>] 500$

A $2[<$ Received as the inyt of the chief of the royal provisions of Pharaoh> $](L ! P ! H !)$ bi ${ }^{3}-$ breads, $p(r)$ s-breads, 8 , dates, 1, 10

$[x$ lines lost $]$

453 Restored using (vso. B 9). 
vso. $A x$

A $x+3$ [<lamps issued to the site on this day $>$ ] 50

$A x+4[\ldots]$

$A x+15[\ldots]$

A $x+16[\ldots$.. Textual Loss... <dates $>$ mht $2[\ldots .]$.

$A x+17[<$ Regnal year $6 \underline{\mathrm{N} \text { sht } 15}$, the $>]$ men of the Gang were working $[<a$ the site $>]$

$A x+18$ [<lamps issue $>$ d to the site on this day $60[+? \ldots .$.

$A x+19[<$ Received as the inyt from th $>]$ e temples of the West of Thebes: beer $d s$-jars $<5$ ? $>$

$A x+20[<$ Regnal year $6 \underline{\mathrm{N}}$ sht $6>]$ the men of the Gang were working at the s<ite $>$

$A x+21$ [<lamps issue $>$ ] to the site on this day, 60

$A x+22$ Received as inyt from the temples of the West of Thebes: beer, $d s$-jars 4

$A x+23[<$ Regnal year $6, \underline{N} 3 h+1>] 5$, the men of the Gang were working at the site

$A x+24$ [<lamps iss $>$ ued to the site on this day, 50

$A x+25[<$ Received as iny $>]$ t from the chief of the royal provisions of Pharaoh $[\langle\lfloor! P !>] H !)$

bi [<3-breads, $p(r) s$-breads.... $]$

$A x+26[<$ Regnal year $6 \underline{\underline{N}}\rangle]$ 3ht 18 , the men of the [Gang....]

$A x+27[<$ The issuing of the diw cor $>$ n of I prt to right, [<the fore $>$ man of the [<Gang $>]$ khar 2, the scribe khar $[\ldots .$.

A x+28 [<men 9, each ones] khar 1 1/2, making khar $131 / 2$, men 13, each one khar 2 , making $k h[<a r 26>]$

$A x+29[\langle\mid w-p\rangle] 3 y$, khar 1 of remainder, it is for $N$ sht, khar $1 / 2$, porters [....

$\mathrm{A} x+30[\ldots$.$] of \mathrm{IV}$; ht khar $1 / 8$, total $[\ldots]$

$[x$ lines lost $]$

vso. B

B O [<Regnal year 6 IV iht 19, the Gang worked at the site this day $>]$

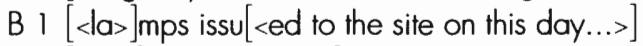

B $2[<R e>]$ ceived as inyt [<from the chief of the royal provisions of Pharaoh $(L ! P ! H !)$ in the city $>$ ]

B $3[\ldots .$.$] da [<t e s . . .>]$

B $4[<$ Received through $>$.... $]$

B 5 Received from the wood cutter $P[<3$-iwd of left $>\ldots]$

B 6 Received from the wood cutter Imn-h $h^{c} w$ of $[\ldots .$.

B 7 Received from the wood cutter $B 3 k-n-\left[\left\langle M w t\right.\right.$ of right $\left.>{ }^{454} \ldots.\right]$

B 8 Received bikw of potter Pth-m- $[<w i 3\rangle$ ? ... Textual Loss... $]$

B 9 P3-iwd of left, wood, 500 Bik-n-Mwt of the rig[ $<h t$, wood $>. .$.

${ }_{454} K R I V: 443,12$ suggests than the remaining signs suggest another reading, but this is restored taking (vso. B 9) as a guide. 
B 10 P:-n-Rnnt of right, wood, 500, in day $20[\ldots$.

B 11 total from $N$; $h t 11$ until 20 , making days $[<10>\ldots .$.

B 12 bikw of the potter

B 13 left, wood, 2000, bikw of the potter [....

B 14 inyt from th[ $[<\mathrm{e}>]$ chief of royal provisions of Pharaoh $(L ! P ! H !)[<$ in the city bisbreads>....]

B $15 \mathrm{p}(r) \mathrm{s}$ breads 23, remainder 17, dates 14, remainder 46 , beer, $[\ldots$.

B 16 Regnal year 6, IV sht 21, the men of the Gang were working at the [<site $>$ ]

B 17 lamps issued to the site on this day $[. .$. .

B 18 Received as inyt from the temples of the West of Thebes: beer, $d s$-jars [....

B 19 Regnal year 6 IV sht 22, the men of the gang were working at $t<$ he site $>$

B 20 lamps, issued to the site on this day, $22[\ldots$.

B 21 received as inyt from the temples of the West of Thebes, beer, ds-jars [....]

B 22 Regnal Year 6 IV sht 23, the men of the Gang were working at the <site>

B 23 lamps, issued to the site on this day [....]

B 24 Received as inyt from the temples of the West of Thebes, beer, $d s-[<j a r s>\ldots .$.

B $25 \operatorname{Re}\left[<\right.$ ceived through>] fisherman, $\mathrm{H}^{c}$-m-tri (and) Hwy by [....

B $26[<$ Received $>]$ through fisherman B3k-n-Imn of left, fish, deben $400[+? . .$.

B $27[<$ Regnal $]$ year 6 IV 3 , $h t 24$, the men of the Gang were working at the <site>

B 28 lamps, issued to the site on this day $10[\ldots$.

B 29 day of completing with the left awnings in cloth (?and?), lamps [....

B 30 lw-piy of right issued lamps on this day, 6, left [....

B 31 Receiving through the fisherman Hry of the right, fish deben $500[(2) \ldots$.

B 32 Regnal Year 6 IV sht 25 Receiving as inyt from the temples of the West [<of Thebes, beer, $d s$-jars $>. . .$.

B 33 Regnal year 6 IV $3, h t[<2>] 6$, day of the festival of Sokar-Osiris $[\ldots .$.

B $34[<$ Receiving $>]$ as inyt from the [<chief of $>$ ] royal provisions of Pharaoh (L!P!H!) bi $[<$;-loaves $>\ldots .$.

B $35 \mathrm{p}(\mathrm{r}) \mathrm{s}$ breads 4 , dates $m h t 5$, beer, ds-jars, $3[\ldots .$.

B 36 Regnal Year 6 IV ; ht 27, the $m[<e n$ of the Gang> $]$ were working at the si $[<$ te this day>....]

B 37 lamps issued to the site this day, $1[<8>\ldots .$.

B 38 Received as inyt from the temples of the West of Thebes, beer, $d s-[<j a r s>\ldots .$.

B 39 [<Received $>]$ through the plaster maker $\mathrm{H} 3 \mathrm{~d}$-nht $[\ldots .$.

B $40[<$ Regnal Year $6 \mathrm{~N}$; ht 28>] The $\mathrm{m}[<$ en of the Gang were working at the site this day>....]

[...Textual Omission...]

[There is a column $\times$ which has some elements which may be interpreted, but this is omitted here] 
vso. C

C 1 [Regnal year $7 . . .$.

C 2 Regnal year $7[<\mid$ prt $>] 12$ the men of the Gang worked at $[<t$ the site this day $>\ldots]$

C 3 lamps issued to the site this day [....

C 4 Received as inyt from the chief of royal provisions of Pharaoh (LIP!H!) $\left[<b i_{3}-\right.$ breads $>. .$. <and $p(r) s$-cakes $>. . .$.

C 5 the remainder of the diw corn of $\|$ iht of right, men 22 , each one, $3 / 4[<$ making khar $162 / 4>$ ]

C 6 the hmwt-slaves khar $12 / 4$, for IV sht khar 1 1/4, total khar $201 / 4[+? . .$. . $]$

$C 7$ the foreman of the Gang khar 2, the scribe khar 1, men, 22, each one $[<k$ har $3 / 4$ making khar $162 / 4>$ ]

C 8 the guardians, khar 1 , the porter It-(?), khar $1 / 21 / 8$, stripling $[\ldots$.

C 9 total 24. Time, all which was made from this day [...]

C 10 Day of arrival made by workman of the Gang Qn-hr-hps.f. on the way [....

C 11 Regnal year 71 prt 13

C 12 Regnal year 7 I prt 4, receiving as inyt from the ch[<ief of royal provisions of Pharaoh $(\lfloor! P ! \mid H !)>]$

C 13 bi-breads 7, plr $)$ s-cakes 7, dates 2

C 14 Regnal year 7, I prt 15, Regnal year 71 prt $16[\ldots$.

C $15[<$ Regnal year $7 \mid$ prt 17> $]$ the $[<$ work $>]$ men of the Gang were working $[<$ at site this day $>$....]

C 16 lamps issu[<ed $\rangle]$ to the site on this $d a[\langle y\rangle \ldots$.

C $17[<$ Received $>]$ as inyt [<from the $>]$ temple $[<s$ of the West of The $>$ bes, beer $[<d s$-jars $>$.... $]$

C 18 Regnal year 7 I prt 18 [<The workmen of the Gang were working at the site this day>....

C 19 lamps [<issued to the site this day $>$....

C $20[<$ Received as inyt from the temples of the West of Thebes, beer, $d s$-jars $>$.... $]$ [...Textual Omission...]

[There is a column $x$ and some unplaced fragments which have some elements which could be interpreted but are omitted here].

\section{REMARKS}

This text gives an impression of the financial entanglements of the administration at Deir elMedineh. The bikw appears associated only with wood-cutters and potters. The source of the diw corn is never indicated. Two categories of item are listed as inyt: the small quantities of breads and dates coming from the "Chief of the Royal Provisions of Pharaoh", and the quantities of beer and loaves from the mortuary temples of the West Bank. 
The Chief of the Royal Provisions of Pharaoh recalls the reference in the text of the High Priest of Amun Imn-htp, 455 to the income destined for the "provisions" which ultimately went to Pharaoh, and therefore there seems to be circulation of goods between the crown and temple domains.

Dates, beer and precisely the loaves mentioned appear in the lists of offering for the festivals in P. Harris I (e.g., 17a, 13; 17b, 5; 6; 21b, 2; 3), donated tot he temples by Ramesses III. While this obviously suggests that the supplies were of a specific kind (and not generic), the vast quantities offered to the temples (totaling almost 170'000 loaves for Thebes alone in 31 years) reveal that the types might be special, but that they were not unusual. It is not clear that the very same loaves are in fact meant.

This text does not detail the htri income of the Gang, but other texts show that this includes many different kinds of supplies. ${ }^{456}$ 


\section{The Tax Lists of the Royal Canon of TURIN457}

\section{TRANSIATION}

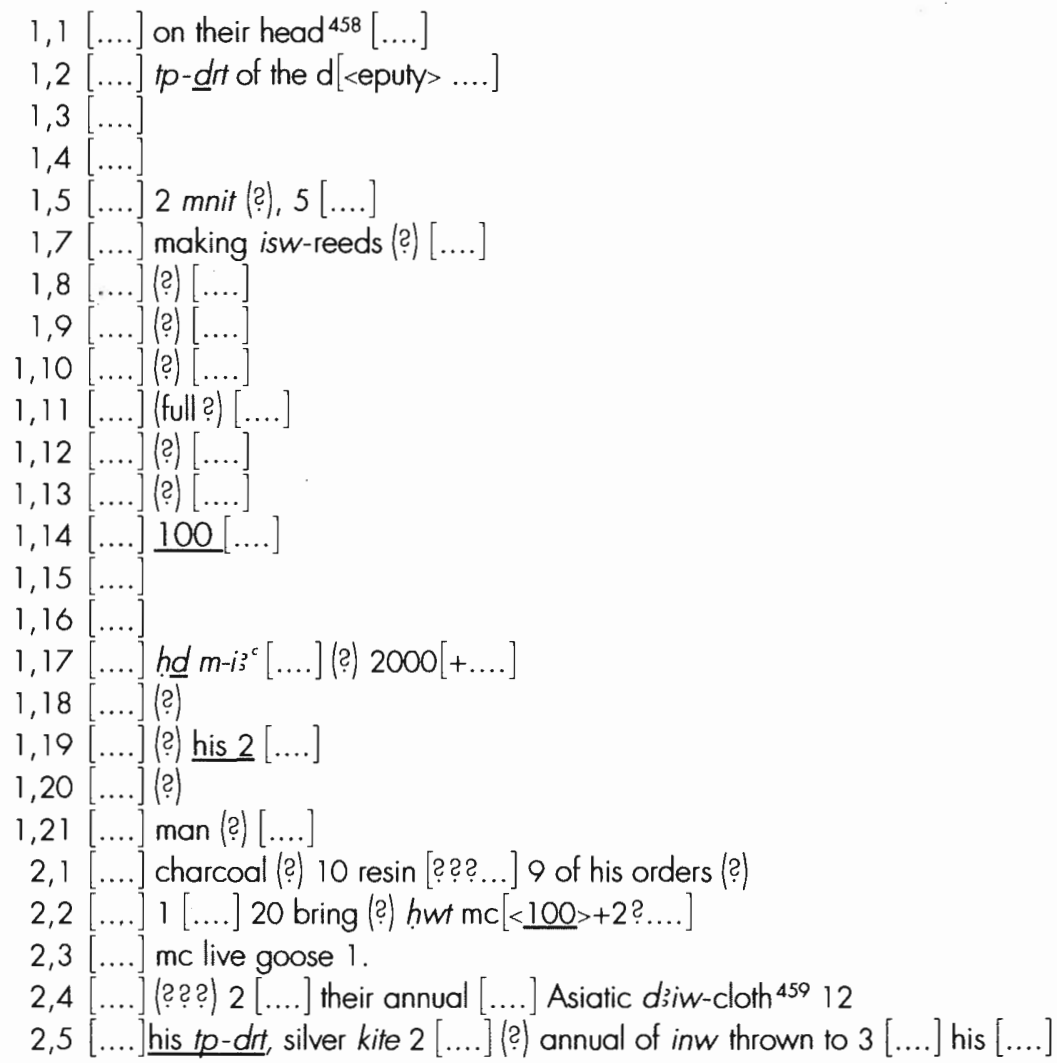

457 On the recto of the Turin Canon (P. Turin 1874; Gardiner Royal Canon) are some detailed notes which repeatedly use the words with which this study is concerned. Helck translated them as well (Materialien, pp. 468-472; W. Helck, "Anmerkungen zum Turiner Königspapyrus," SAK 19 [1992]: 151-216, esp. 194-205]. The papyrus is very fragmentary, and thus a translation does not necessarily throw much light on the subject, but some parts are well enough preserved to justify presentation here, and some of the references may be fragmentary and of no value in the context of this papyrus, but can be used to elucidate other references.

It is of course amusing to try and fit some of the missing fragments into positions, but this has been tried many times, and does not necessarily demonstrate the hypothesis. As the interpretation of fragmentary texts is highly speculative in any case, the temptation to philological discussion has thus been suppressed. A serious altempt at commentary of this particular text would unfortunately lead one immediately into the realm of insubstantial fantasy.

458 As this can mean anything from obligation to authority or "on behalf of", etc. it would serve no purpose to suggest a transiation.

459 Not foreign or imported, but merely a designation of type, cf. Janssen, Prices, p. 265 n. 70. W. Helck/Materialien, p. 930) suggests that they were foreign, but his alternative suggestion that they were manufactured in Egypt corresponds quite well to the interpretation of P. Gurob, ct. supra pp. $146 \mathrm{ff}$. 
$2,6[\ldots .]$.1 Asiatic diw-garments $6[\ldots .$.$] thrown to them 4$ years 460 as $[. .$.

$2,7[\ldots$.$] of [\ldots .$.$] to deben of silver [\ldots$.

$2,8[\ldots .$.$] stripling [\ldots .$.

$2,9[\ldots]$

$2,10[\ldots .<$ hun $>]$ dred

$2,15[\ldots<$ hun $>]$ dred

$2,12[\ldots<$ hun $>]$ dred 30

$2,13[\ldots] .7[<00\rangle]$ waterfowl. 400

$2,14[\ldots] 85$

$2,15[\ldots .] .400 \mathrm{mc}^{461}[\ldots$.

$2,16[\ldots .$.$] in fish (10,000$ ? $)[\ldots$.$] mnt-jars, 1$

$2,17[\ldots<$ go $>]$ ld deben $[\ldots .$.

$2,18[\ldots<\mathrm{fi}>] \mathrm{sh}\left(20^{\prime} 000[\ldots]\right.$.

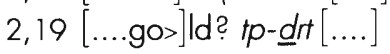

3,1 Guardian of the ${ }^{c} h w$ which is in $M w-h_{3} r_{-}{ }^{-} 3$, men 1, his annual $\underline{b_{3} k w}$ : fish $5^{\prime} 000$

3,2 Guardian of natron who is in $R_{3}^{3}-m^{c}-n_{3}$, (ditto) [ $\left.=1 \mathrm{man}\right]$ (ditto) [= his bikw] ditto [=annual] gold deben 1 [....] $1000^{462}$

3,3 Mat weavers who are in $M r-w r\left(\right.$ ditto) [=1 man] (ditto) [= his $\left.b_{3}^{3} k w\right]$ [<ditto $>$ ] [=annual] [<textiles $\langle$ ? $|>] 6[<0 \mid$ ? $\rangle)]$

3,4 Proper $\underline{\underline{s}_{3} y}<\underline{w}$ s of the [....] Guide of the Two Lands silver 1 (ditto) $[=\text { his b3kw? }]^{463}$ near (?) $[\ldots]$ it $[. .$.$] town [\ldots .$.

3,5 Proper šdy wh[<ich $]$ it [<i>]s exacted from the fishers, fish, (from the) lake of Sobek fish $200^{\prime} 000$ remainder $[\ldots .$.

$3,6 \underline{t p-d r t}$ of the mayor of Lake of Sobek. [...] gold [...] 2 wnd $w^{464}$ bulls [....] live

3,7 tp-drt of the deputy of $[\ldots ..] \perp[\ldots$.

$3,8[\ldots .]^{465}$ the scribe of $[\ldots .<$ hun $>]$ dred

$3,8 \mathrm{a}[\ldots .<$ hun $>]$ dred $[\ldots ..] \perp[\ldots$.

$3,8 b^{46 \infty}[\ldots](2 ? ?)$ silver kite 40 on $[\ldots .$.

$3,9[\ldots .$.$] fish 20^{\prime} 000<+?>$, fowl $\underline{30}$

$3,10[\ldots<$ pro $>$ per htri $[\ldots .]$.

$3,11[\ldots .<$ hun $>]$ dred $[\ldots .$.

$3,12[\ldots .$. (???) $[\ldots .]<$. hun>dred

3,13 tp-drt $[<\mathrm{of}>]$ the ma[<yor> ....] donkey 1

400 This expression (and the same in the preceding line) refers to back obligations "thrown" together.

401 This is almost assuredly to be read differently, but cannot be resolved.

462 W. Helck (Materialien, p. 958) understood this as meaning "Natronwächter in Ramun liefert $1000 \mathrm{dbn}$ Gold ab." Considering the condition of the papyrus this reading is certainly a bit courageous, but even comparing it to other sources indicates that the lacuna here must cover something to the effect that so-and-so-much-of-somethingelse equals the gold-obligation.

463 Dot in black, not red.

464 Sir Alan discards the possibility that this is to be read, but proposes nothing else.

405 Sir Alan does nol make any distinction indicating that there may have been a red "ditto" here, so that the line cannot be used to suggest that scribes paid $t p-\underline{d} r t$.

4 se Although Sir Alan has numbered this line as $[3,8)$, the appearance of the fragments does not support this numbering, and thus the deviation. 
3,14 which is upon him for Pharaoh $[\ldots]$.1 sht $1[\ldots$.$] which is on [\ldots]$.10 donkey 1 ox 1

3,15 gold $(?)[\ldots$.$] fish [\ldots$.$] on t p-\underline{d} r t[\ldots]$

$3,16[\ldots .].(? ? ?)$

3,17 wrr $[\ldots .$.$] b; [\ldots .] q m ;.[\ldots$.

$3,18[\ldots .$.$] y 10[\ldots .] .3[\ldots$.$] khar (2) 100$

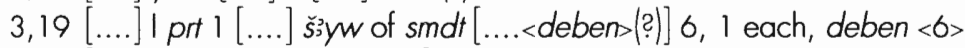

$3,20[\ldots<$ templ>]e Abydos $[\ldots .].(? ? ?)$

$3,21[\ldots$.$] in villa [<\mathrm{ge}>\ldots .$.

$3,22[\ldots$.$] all, from southern district [...] all smdt of the mni [...] Memphis deben 1$

$3,23[\ldots . .$.$] nat [<$ ron $>\ldots . .$.$] the s[<i l v e r>\ldots .$.

$3,24[\ldots<$ deben>(?) $]$ scribe, 50, making deben

$3,25[\ldots<$ smdts $(?)]$ scribe, 10 making deben $[\ldots .$.

$3,26[\ldots .]$.5 black leather sacks 5

$3,27[\ldots<5>? \ldots .$.$] ore, handfuls (?), each one, 20$, making 100 . Wooden (?) whips 5 $4 / 5, x-1467[\ldots]$.

$4 / 5,1$ inw (?) man 1 [.... bank, all, of the Estate of Amun in the Southern district [....] as ore, ore $[\ldots .$.

$4,2[\ldots .$.$] charcoal [\ldots$.

$4,3 / 5,4[\ldots$.$] controllers of the (e) [\ldots .$.$] his [<t p\rangle] \underline{d} r t$, silver deben 2

$4,4[\ldots .$.$] gold (? ? ?)[$ blank $](?)[\ldots .$.

4,5 steward $[. .].(?)[\ldots .$.

$4,6 \underline{\mathrm{tp}-\mathrm{drt}}$ of the overseer $[. .$.

$4,7[\ldots<\mathrm{gu}>] \mathrm{m}[\ldots]$

4,8

4,9

$4,10[\ldots] 10$

$4,11[\ldots$.$] fat. (?) [\ldots$.

4,12 annual $[. .$.$] . I of man 1$

$4,13 \mathrm{tp}$ - $\mathrm{d} r \mathrm{t}$ of each of them, they [....]

4,14 hunters (?) man, 1, half of stripling

$4 / 5,15$ hunters (2) of [...] 2 making [....

$4 / 5,16(?)[\ldots].(?)[\ldots .$.$] overseer of fortress of [<8(?) \ldots .$.

$4 / 5,17$ (?) $[\ldots .$.$] tpyw-fish mc 2, [<his >$ tp-drt (?) $[\ldots$.

4,18 [<Annual>...] fisherman, fish which are from the water of $[\ldots .$.

$4,19[\ldots].(?)$ ps-loaves $10[$ blank $]$ made (?) [...] 8 their annual šmw $\mathrm{f}[<$ ish.... $]$

467 The scribe was forming columns for his own purposes, and these seem at times to have made one column of coherent data in lines extending from column $\mathrm{V}$ to column $\mathrm{V}$. Although this was not done consistently, and therefore the interpretation is bound to be limited by speculation, the reading has been taken in that fashion. Cf. Sir Alan's note to the effect that the columns in the published text are only indicated as a reference (Royal Canon, p. 17.) 
$4,20[\ldots .]$.550 total $400[+\ldots$. blank $]$ proper $\underline{s_{3}^{3} w w}[\ldots$.$] overseer of fortress of [\ldots .]$. making 3 in place $[<0 f>. .$.

$4,21 \mathrm{tp}-\underline{d} \mathrm{~d} t$ of each of $\mathrm{t}[<h e m>\ldots .$.$] granary delivered silver k$ ite $[<2>\ldots .$.

4,22

$4 / 5,23[\cdots]$

$4 / 5,24[\ldots .$.$] making the list of the remainder from them [\ldots .$.$] total 3000[\ldots$.

$4 / 5,25[\ldots .$.$] his \left[<\check{S}_{3} 3 w s\right]$ of Regnal Year 1 bull/ox $1332[\ldots](?) 10^{\prime} 101$

$4 / 5,26[\ldots<50>($ l. $)] \underline{2}[=$ bull/ox $] 75952$

$4 / 5,27[\ldots .] .1[$ lbull/ox $] \begin{array}{llll}3 & 30 & 27 & 5^{\prime}[<2>] 30\end{array}$

$4 / 5,28[\ldots .] .1\left[=\right.$ bull/ox $4 \begin{array}{lll}4 & 36 & 3[<3>\end{array} 6^{\prime} 400$

$4 / 5,29[\ldots],[$ l. bull/ox $][<3>] 27[\ldots ..] 4^{\prime} 800$

$6, x+1[\ldots].(?)[\ldots$.

$6, x+2$

$6, x+3$

$6, x+4$

$6, x+5$

$6, x+6$

$6, x+7$

$6, x+8[\ldots .$.$] gold (2)[\ldots$.

$6, x+9[\ldots . .(?)[\ldots]$

$6, x+10[\ldots](?)[\ldots$.

$6, x+11\left[\ldots<m \underline{d}^{3}>\right] \operatorname{iw}(?)[\ldots$.

$6, x+12[\ldots .$.$] Overseer, Mayor [(?) \ldots .$.

$6, x+13[\ldots$.$] of each of the mayors of [\ldots]$

$6, x+14[\ldots$.$] tp-d n$ tr of the deputy

$6, x+15[\ldots .$.$] mdiw from [. .$.

$6, x+16\left[\ldots .<\underline{d}^{\prime} ; i>\right] w f[<\mathrm{rom}>\ldots$

$6, x+17[\ldots<m \underline{d}>]$;iw $f[<$ rom $>$

$6, x+18[\ldots<m>$ diw $\mathrm{f}[<\mathrm{rom}>\ldots .$.

$6, x+19[\ldots . . t p-d r t[<0 f>]$ the controllers $[\ldots .]$.

$6, x+20[\ldots$.$] of Wsr-Mict -R^{c}[\ldots]$

$7,1[\ldots$.$] his \check{s}_{3} y w$ of Regnal Year 1, bull/ox $1[\ldots$.

$7,2[\ldots .$.$] ditto$

$7,3[\ldots .$.$] ditto [\ldots .$.

$7,4[\ldots]$ ditto 1

$7,5[\ldots]$ ditto 1

$7,6[\ldots .$.$] ditto 14$

7,7 [....] ditto 16

$7,8[\ldots$.$] ditto 12$

$7,9[\ldots .$.$] ditto 16$

$7,10[\ldots$.$] ditto 15$

$7,11[$....] ditto 13 


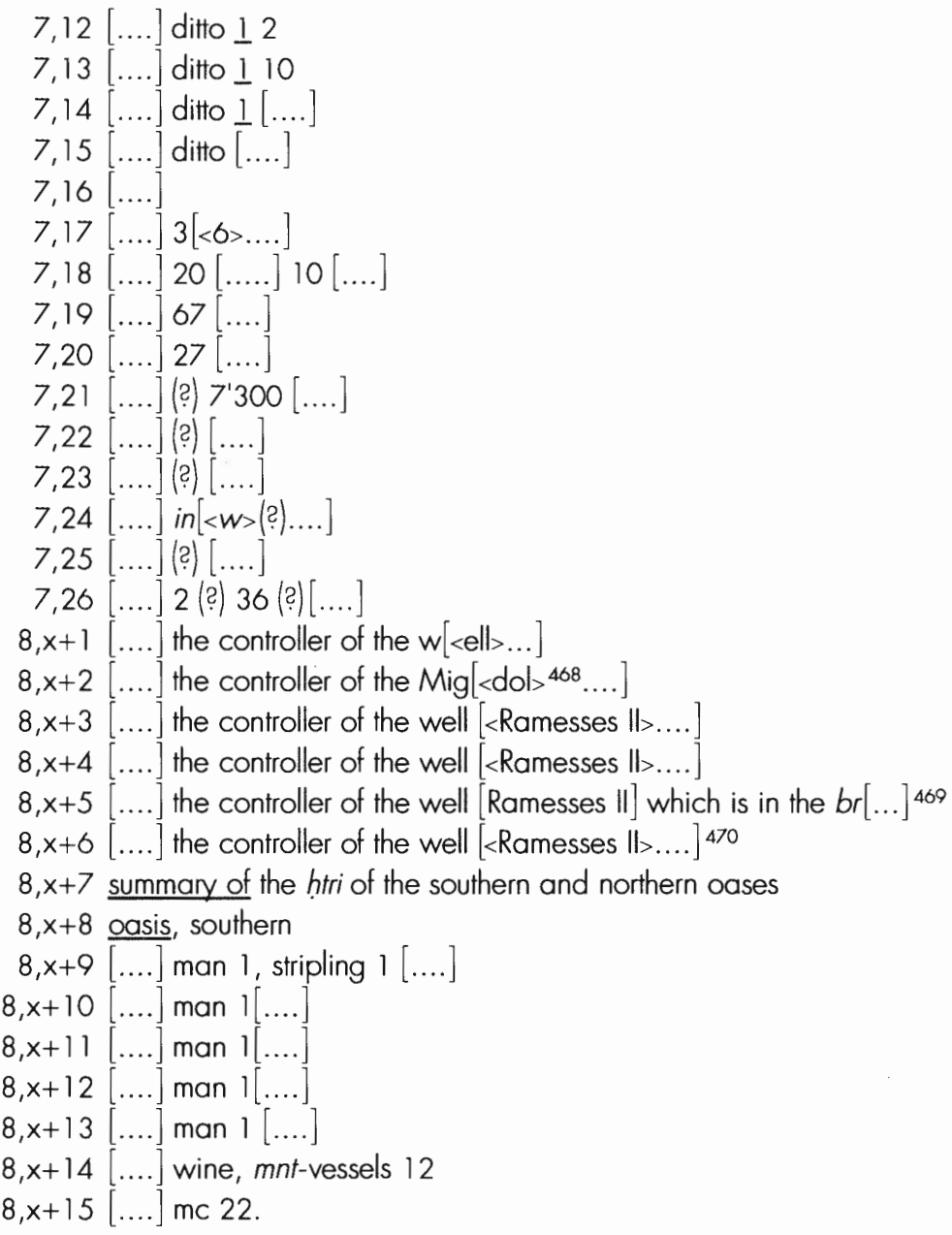

\section{REMARKS}

This execrably preserved papyrus once recorded a series of records concerning various fiscal activities, naming the term employed along with the person upon whom the obligation was put, and the precise objects which were turned over to the administration as a result of this. It must be emphasized that it does not appear from the fragmentary remains visible today that the lists recorded to whom the payments were made (with the exception of "which is upon him for Pharaoh", 3, 14). Geographically, it certainly referred to oases and the

408 Following Sir Alan (Royai Canon, p. 17).

469 This is probably related to the toponym, but alternatively, cf. infra, p. $192 \mathrm{n} .584$.

470 W. Helck (Materialien, p. 250) points out that these forifications and wells were on the desert route between Sile and Raphia, but goes on to suggest that it is not preserved whether they delivered grain. This last note is rather 
Fayum, administratively, it seems to have covered many different types of profession, and the diversity of the objects rendered up includes wine, charcoal, fish, cattle, gold, etc. The value of the papyrus being considerably impaired as a result of its fragmentary state, the following conclusions resemble the above "translation" in being restrained rather than exuberant, and attempt to summarize the conclusions which can be justifiably drawn from the text, without undue exaggeration.

It would seem that the words written in red ink had some particular significance, and these include tp-drt, šs $y w, b 3 k w$, but also šdyt. This necessarily implies that these terms were in some way significant, and it is evident that the term $b 3 k w$ and the term šsyt

are employed in a very similar fashion, not only being written in red, but serving as the basis for a series of assessments ( $b_{3} k w$ in fish and silver; $\breve{s}^{3} y w$ in cattle), underlining that the scribe concerned here was using $b^{3} k w$ in a fiscal sense.

Aside from the word for annual, certain of the rates of assessment, and the word for summary, only one title is written is red (if "hunter" is the correct rendering), and this only once (and it is assumed here that this is an oversight), so it is assumed that no particular importance was associated with the officials, but that these terms of reference (rates of assessment, etc.) were significant.

It is pointless to attempt to use the text statistically, so that the categories alone are worthy of attention. Where preserved, b3kw is never associated with officials, as opposed to workers, while the opposite is true of $t p-\underline{d} n t$. šsyw seems to be employed with regard to both classes of people (cf. 3, 19) and institutions (cf. 3, 4), as well as officials and individuals (cf. 4/5, 20ff.; col. 7).

Conversely, professional administrators (mayors, overseers, deputies, scribes, controllers) outnumber workers (fishermen, fowlers, guardians, mat weavers), but they all figure alongside one another, but wherever possible, it would appear that the types of obligations that they owe are clearly distinguished, although the jottings physically mix the categories, they are clearly differentiated).

In the preserved text, fish and cattle are the most important items listed, but gold and silver figure to a striking extent. It is striking that successive lines list alternatively mats, whips, fowl, fish and silver (or gold), and that - seemingly - only cattle were deliberately grouped together and kept apart. Although an entire deben of gold is explicitly collected from the natron guardian $(3,2),{ }^{471}$ it would appear that there is otherwise no evidence of the employment of financial substitutions or equivalencies for exactions intended to be delivered in fish, mats, wine, reeds, gum, or geese, etc., and thus it seems fair to conclude that the actual articles listed were assessed, assembled, and acquired.

curious, because there are very few -if any - references to grain in the entire recto of the Turin Canon. E.g. $(4,19)$ refers to $\check{s} m w$, but the final traces suggest that "fish" may be read instead of grain as the form of payment.

J.-M. Kruchten ("L'Evolution de la gestion dominiale sous le nouvel empire Égyptien," in Lipinski, State and Temple, pp. 517-522) points out that there are two types of $n w d w$-controllers, and that the ones responsible for grain need not be associated with "responsibility", so that the "controllers" in this text, should be understood as officials responsible, but not as "agents" of the domains.

${ }_{471} \mathrm{Not} 1000$ as in Helck, Materialien, 958. The "1000" must be associaled with an item in the lacuna, but the 1 does clearly refer to a deben of gold, no matter how improbable this may seem. 


\section{The WilBour Papyrus}

\section{REMARKS}

The administrative text par excellence for fiscal materials of the Ramesside Period is the Wilbour Papyrus. ${ }^{472}$ The 10 metres of this enormous papyrus are covered with over 5200 lines of inked entries in two texts ( $A$ and $B$ ) listing primarily temple holdings (Text $A$ ) and khato lands (Text B) in a small part of central Egypt. The larger of the two texts, the 4500 lines of Text $A$, lists only 4 per cent. of the surface area of the cultivable land in its part of modern Egypt, but indicates that its authors were concerned primarily with temple land. it was prepared for the office of the ' $3-n-n_{-}$, a title which has been translated "Chief-TaxingMaster". This title is not known with fiscal responsibilities outside the temple sector. The object and intended use of the text have however never been resolved.

\section{Text $\mathrm{A}^{473}$}

The entries of Text A follow a pattern. Divided into four sections, the text of each section lists a series of holdings identified directly with (1) the Estate of Amun, followed by a series of entries related to (2) the funerary temples of the Pharaohs in the Estate of Amun, followed by the holdings related to (3) Heliopolis, and then by (4) Memphis, and then by (5) the smaller temples. Each section ends with (6) miscellaneous holdings related to "Landing Places of Pharaoh", "white goats", "the treasury of Pharaoh", Harems, so-called mint-land of Pharaoh, and khato-lands of Pharaoh. Each section was defined by the area surveyed in several days, the whole text being an office copy relating to a survey carried out in less than four weeks in July and August of perhaps 1140 B.C. ${ }^{474}$

The main individual entries follow a similar pattern. A group of fields "under the authority" of a given figure are listed. Each individual plot is listed, followed by a figure giving its size in arouras $\left(2735 \mathrm{~m}^{2}\right)$, a rate of assessment of either $5,7.5$ or 10 - most probably in khar (c. 75 litres) ${ }^{475}$ - and the total assessment. Occasionally such entries are followed by a note

472 The complete text has been translated in absolutely exemplary fashion by Sir Alan Gardiner (Wilbour III) and provided with an incomparable Commentary (Wilbour II). An excellent summary of the solient points of the text will be found in the first pages of Katary, land Tenure. A summary of the problems can be found in J. J. Janssen "Prolegomena to the Study of Egypt's Economic History During the New Kingdom," SAK 3 (1975): 139-147, and these are also briefly mentioned by Janssen in Lipinski, State and Temple, II: 505-515. Menu, Régime Juridique should also be consulted.

473 Katary, Land Tenure, pp. Iff. provides a very competent up-to-date summary of the text, and thus this summary strives for even more brevity.

474 v. Beckerath (Chronologie, p. 124) places the ascension of Ramesses $V$ at the end of December 1145 B.C., and the text dates to his fifth year. The last day of the survey (ill sht I) would fall in the first days of August according to his correlation.

475 The actual written form signifies that the units are to be read as oipe (or one-quarter of a khar, 20 litres), but to be understood as khar, and thus the widely used "mc' for "measure of corn", which relieves the editor of deciding how this semantic problem is to be solved. 
that 7.5 per cent. of the total assessment is to be turned over to another institution, the posh entries. ${ }^{476}$

Following the paragraphs dealing with these relatively large fields is another form of entry relating to smaller plots and parcels, termed "apportioning domains" in English, and these appear to be individual land holdings, as the plots are associated with individuals (and not "under the authority" of officials as in the "non-apportioning" paragraphs), and are generally small, being normally of 3 to 5 arouras, and the assessments would appear to be made at a much lower rate of assessment. Among these "apportioning paragraphs" the tenants or beneficiaries are private citizens (soldiers, priests, widows, citizenesses, etc.) who presumably received the right to till the plot in exchange for services. It would appear however that the right to the plot was not undisputed, as they were obliged to pay the assessments to the temples. Among the paragraphs dealing with these types of holdings are references to plots of land having changed hands, with the occasional note indicating that they were "bought" or "carried off" (inw) as it is put in Egyptian. ${ }^{477}$ The entries in the P. Wilbour indicate however that along with whatever rights of ownership were transferred, an obligation to render up a portion of the grain produced on the plot was also transferred to the new owner. ${ }^{478}$

Certain of these paragraphs begin with an entry referring to the šmw pš (translated as "apportioned harvest-taxes") rather than beginning with a designation of an institution, although the institution then follows. The entries under this heading are invariably small holdings identified with individuals, related to small temples. Sir Alan emphatically drew attention to an important element of this in his original commentary:

One cannot well escape the impression that the apportioning domain paragraphs perform for the larger and more distant temples the same function that the harvest-tax paragraphs perform for the smaller temples, that in fact the two kinds of paragraph are merely different forms of one and the same kind. ${ }^{479}$

In discussing P. Harris I, we will encounter exactly the opposite phenomenon, that namely the equivalent paragraph dealing with the smaller temples omits the sentences using the usual fiscal terms, while those terms dominate the texts of the relevant portion of the para-

476 These transfers have been interpreted as referring to leases for land or personnel, by one institution to another.

477 Since it is not usually possible to bear away a plot of land, it must be assumed that the colloquial expression literally meant that the participants understood that the plots had been purchased in the same way as a donkey or bed, i.e., the title to the land had been transferred, but the new "owner" (or his employees) came to the piece of land, rather than the piece of land coming to the owner as in the case of a donkey.

478 A general note of caution should be adduced, as it has been suggested in the literature dealing Graeco-roman economic history that the Ptolemaic and Roman administration of Egypt followed ancient Egyptian - rather than modern Macedonian - ownership and administrative patterns. In Graeco-Roman Egypt, similar pieces of land to those of the "apportioning paragraphs" of P. Wilbour are the klhroucikh gh, i.e., "allolted" or "apportioned" land. This was re-classified as private land under the Romans. On the assumption that the Ptolemies simply continued with existing arrangements, and that the prevailing system of the New Kingdom continued until the middle of the first millennium, there is evidence that these Graeco-Roman terms reflect the New Kingdom terminology. Cf. Wallace, Taxation in Egypt, pp. 1-3 and Rathbone, Economic Rationalism.

479 Gardiner, Wilbour Il: 25 (italics in original). 
graphs for the larger temple complexes. This re-inforces the conviction that the Egyptian state had a very clear fiscal organization and that the significance of the terms used was taken seriously by the bureaucrats in the administration. This does not however mean that the terms were used in other contexts as precisely.

The one point upon which all commentators agree is that the 17'324 arouras $(4730 \mathrm{ha})$ of surface area ${ }^{480}$ surveyed is only a small part of the cultivable land in this part of Middle Egypt. By way of comparison it may be recalled that Ramesses III claimed to have given the temples some 1'071'780 arouras (292'595 ha) in all of Egypt during his reign, ${ }^{481}$ or that Fairman estimates that in the middle of the 19th century A.D., cultivable land in the same area will have been the equivalent of some 590'000 arouras (or roughly 160'000 ha). 482 It has been suggested that this is due to the fact that the lists concern only summer cultivation, or that it is only a list of state lands, or only temple lands. Given the nature of the text, the suggestion that it be understood as a list of lands which the temples were managing for one reason or another is not particularly impossible. It is extremely hypothetical, but the Nauri Decree has a reference to ipw of temple holdings, and it is possible that the Wilbour Papyrus itself is the ipw-cadaster of Amun. 483

Regardless of the interpretation, this document is the most important source for information about land holdings. But the fiscal significance of the text is less clear. The most logical assumption is to conclude that the assessments refer to the income of the temples in question, but the matter is open to dispute.

480 Estimate by A. Fairman, Review of the Wilbour Papyrus, JEA 39 (1953): 119

481 P. Harris 167,8 .

482 I have taken the liberty of rounding these figures as the actual numbers are completely irrelevant. Fairman quotes Willcocks for 453,329 feddan, and I have based my calculations on this.

483 This document or the people responsible for it are mentioned in few texts. A sailor of the ipw of $\mathrm{mm}$ is known from the Abbot (Abbot dockets, col. A. 7; Peet, Tomb-Robberies, I: 132; 134, II: pl. 23, A 7). A foreigner or dragoman is in P. Mayer A (P. Mayer A 9, 20; Peet, Mayer Papyri, p. 15, and pl. page 9/20); (for translation of dragoman, cf. note in Turin Taxation Papyrus, infra, p. 174 n. 508). A document of uncentain character in P. Sallier II 8, 9 (Helck, Dw:-Htij II: 1 17-120), but the implication of P. Sallier 1, 8 (LEM p. 87, 16; Caminos, LEM, pp. 326-328 and Gardiner, Wilbour II: 78, n. 5) is that an ipw must be some form of document relating to a land survey. It is explicitly stated that an ipw was a land cadaster in the Inscription dedicatoire at Abydos (KRI II: 333,2$)$, and in the Nauri decree $\{K R I \mid: 50,1)$. It is specifically associated with temple bikw in P. Munich 809 (=P. Mook, Allam, HOP Tafelteil, pl. 102: 1, 5; W. Spiegelberg, "Ein Gerichtsprotokoll aus der Zeit Thutmosis' IV.", ZÄS 63 [1928]: 106). J. Assmann's translation of P. Leiden I 350 3, 9 (ÄHG, p. 314, "ihm gehört jede Akte seines Katasters") merely reproduces Zandee's rendering (De Hymnen aan Amon van Papyrus Leiden / 350 = OMRO 28 [1947]: 46). While representing a stylistic improvement on G. Fecht's attempt ("Die Form der aliägyptischen Literatur: Metrische und stilistische Analyse", ZÄS 91 [1964]: 47, "sein-ist-jeglichesInventar seines-Katasters") this begs the question (cf. also A. Gardiner, "Hymns to Amon from a Leiden Papyrus", ZÄS 42 [1905]: 27). It is identified as both a file and a document in P. BM 10373, vso. 2 (cf. Janssen, LRLC pp. 42-47, esp. p. 45 n 13; pls. 27-30

The only reference indicating that an ipw was not a mere file in a comprehensive document, but rather such a document itself is $P$. Sallier I, where the use is rather ambiguous. But it is clear that the ipw of Amun was a text related to surveying (measuring cords are mentioned in P. Leiden I 350) of agricultural land ( $P$. Leiden I 350, as well as Nauri and the Inscription Dédicaloire) for fiscal purposes (cf. P. Munich 809; P. BM 10373), and that it had low level employees (P. Mayer A) as well as scribes. If one takes the renderings of Fecht, Assmann and Zandee literally, it could be contended that the ipw of Amun was responsible for all the cadasters - and the text certainly seems to indicate this. 
B. Menu contends that the "apportioning domain" paragraphs refer to the holdings of the $n m h w$, assuming that the nmhw ware those without a role in the official state, while the holders of the parcels in the "apportioning domain" paragraphs are beneficiaries of the state apparatus (cf. supra, p. $61 \mathrm{n} .118$ ), as must be the conclusion drawn from their titles The assessments are low. She also contends that the sums refer only to the revenues which are to be assessed, rather than the assessments. ${ }^{484}$ It may be worth comparing the administrative figures in P. Wilbour with the actual quantities collected from people with similar titles in P. Amiens:

\begin{tabular}{|c|c|c|c|c|}
\hline Title & $\begin{array}{c}\text { P. WilBOuR } \\
\text { ("normal domains") } \\
\mathrm{mc} \text { (=khar?) }\end{array}$ & $\begin{array}{l}\text { line } \\
\text { khar }\end{array}$ & P. AMIENS & $\begin{array}{l}\text { line } \\
\text { (recto) }\end{array}$ \\
\hline $\begin{array}{l}\text { cultivator } \\
\text { controller }\end{array}$ & 200 & 17,3 & $\begin{array}{l}232 \\
260\end{array}$ & $\begin{array}{l}3,1 \\
3,5\end{array}$ \\
\hline $\begin{array}{l}w^{c} b \text {-priest } \\
\text { scribe }\end{array}$ & $\begin{array}{c}300 \\
25 \\
\text { ("apportioning") }\end{array}$ & $\begin{array}{r}9,20 \\
49,20\end{array}$ & $\frac{228}{10}$ & $\begin{array}{r}1,11 \\
2,7 \\
\text { (verso) }\end{array}$ \\
\hline $\begin{array}{l}\text { w'b-priest } \\
\text { scribe } \\
\text { controller } \\
\text { controller }\end{array}$ & $\begin{array}{r}12 / 4 \\
12 / 4 \\
222 / 4 \\
-\end{array}$ & $\begin{array}{l}54,23 \\
54,24 \\
34,20 / 26,5 \\
82,10\end{array}$ & $\begin{array}{l}3 / 4 \\
92 / 4 \\
6 \\
12 / 4\end{array}$ & $\begin{array}{l}6, x+4 \\
4, x+4 \\
5, x+4 \\
5, x+9\end{array}$ \\
\hline sherden & $3 / 4$ & 54,28 & $31 / 41 / 8$ & $4, x+1$ \\
\hline
\end{tabular}

These figures suggest that two different types of assessments are being made, and that the figures in Wilbour A are - more or less - the intended revenue, with the "normal domains" being productive fields intended to provide the temples with their main income, and the "apportioning domains" basically the fields at the disposal of the servants of the state with nominal assessments. ${ }^{485}$

\section{Text B}

While Text A has attracted a great deal of attention, Text B of the Wilbour papyrus is one of the most neglected texts in Egyptology. It is a list of khato lands of Pharaoh only, merely grouping those under a single authority together. Fairman estimated that Text B covered perhaps 14'420 arouras. ${ }^{486}$ Sir Alan Gardiner concluded that the Egyptian designation referred to plots of 10 arouras, literally meaning "thousand (land cubit) of land of Pharaoh". ${ }^{487}$ The term is sometimes used without "of pharaoh", and it is difficult to judge whether there were khato-lands which were not Pharaoh's, or whether, the specification was simply omitted las happens frequently in titles where the organization to which the person is attached is omitted). It is known that khato-lands of pharaoh were managed by temple officials (as in

484 Menu, Recherches, p. 11.

485 The figures were drawn from Gardiner, Wilbour III; and A. H. Gardiner, "Ramesside Texts Relating to the Taxation and Transport of Corn," JEA 27 (1941): 37-56.

480 Fairman, JEA 39:120.

487 Gardiner, Wilbour H: 161 ff., esp. $165 f$. 
P. Wilbour Text B and the Turin Taxation Papyrus ${ }^{488}$ ), and that unspecified khato-lands were managed by secular officials (as in P. Valençay I). Regardless of the relevant authority, income was put at the disposal of temples, as in P. Valencay I a scribe of the Divine Adoratress of Amun expects to be able to collect the income from some khato-land managed by the Mayor of Elephantine. ${ }^{489}$ The only khato-lands of $P$. Harris $1(27,12)$ are not identified as associated with Pharaoh, having been "made" for Heliopolis. ${ }^{490}$ The Turin Taxation Papyrus records corn being collected from khato-lands of Pharaoh. ${ }^{491}$

It does not throw more light on the situation to realise that Text B explicitly states that the khato-lands lay upon fields belonging to other institutions. Sir Alan pointed to the significance of this:

There can be no doubt that what follows 'on the fields' names the titular possessor of the fields upon which the khato-land of Pharaoh lay, and this unexpected revelation that Pharaoh was not unconditional lord of land to which his name was attached calls for explanations that are not obvious at the present juncture. ${ }^{492}$

The instifutions were mostly temples, but "in Text B we find 'on the fields of Pharaoh' well over 50 times. " ${ }^{493}$ Sir Alan originally speculated that this might have referred to the mortuary temple of either Ramesses IV or Ramesses V, but pointed out that this expression "was found in Text A in certain paragraphs closely associated with the Landing-places of Pharaoh". ${ }^{494}$ If could be concluded that they were lands which changed hands and were temporarily designated before assuming a new identity. ${ }^{495}$

Gardiner, RAD, p. $36,3$.

Gardiner, RAD, p. 72, 10. Not khato-land of Pharaoh however.

Other temples are "given" fields (e.g., 59, 6) or Fields are "made" for them (e.g., 9, 4-5), bui only Heliopolis received khato-lands.

Gardiner, RAD, p. 36, 3; 14. The following chapter of this work.

Gardiner, Wilbour II: 167.

Gardiner, Wilbour II: 168.

Gardiner, Wilbour II: 169.

For the fact that the areas were constantly changing, cf. Gardiner, Wilbour II: 189-190. 


\section{The Turin TAXation Papyrus}

\section{REMARKS}

One of the most familiar documents relating to taxation is P. Turin 1896+2006, generally known as the "Turin Taxation Papyrus". As Sir Alan Gardiner has edited and translated the document with his (un)usual ability, ${ }^{496}$ a new translation is not offered here, but rather a commentary on the value of the text. Although only the word šmw appears marginally, it cannot be disputed that the text is directly associated with fiscal activities of some genre.

The first page of the text as preserved has the appearance of a title page ${ }^{497}$ explicitly stating that the Nubian War Lord $P_{3}$-nhsy authorized the collection of grain from the khato-lands of Pharaoh, under the responsibility of P;-hni, Prophet of Sobek, by the Necropolis Scribe Dhwty-ms and the two porters. ${ }^{498}$ Just why the honourable Dhwty-ms, Scribe of the Great and Noble Necropolis of Millions of Years of Pharaoh (L!P!H!), was delegated to collect grain is not entirely clear, as it will be noted that the grain collected was not brought directly to the Gang at the Necropolis, as might be expected were the Gang suffering from their traditional lack of payment. Such a situation is mentioned in a letter of this period:

Se[nd] Nsy-Sbk your scribe, let $(9)$ the porter Dhwwy-ms and the scribe Iw.f-n-Imn go together with him. Let them bring the grain. [... vs. 4...] Send (vs. 5) your scribe together with the Necropolis scribe Iw.f-n-[Imn] and the porter Dhwity-ms (vs. 6) or the porter Hnsw-ms. L[et] them hurry to bring the grain (vs. 7) that the Gang not starve. ${ }^{499}$

While the unknown correspondent can hardly have meant this literally, the Turin Strike Papyrus indicates what might occur if things got out of hand. 500 It is possible that the workers required payment. It is however less clear why they would have expected to be paid at all,

(1941): 22-37.

As Sir Alan pointed out, this fits perfectly with the vivid portrait from the miscellany where "the scribe moors at the river-bank and registers the $\breve{s m w}$, the porters behind him bearing clubs". Cf., e.g. P. Lansing (LEM, p. 105 and Caminos, LEM, p. 390| here, but also supra, pp. $133 \mathrm{f}$

The translation of iry "', as "porter" has certain advantages over that of "janitor" or "door-keeper", as the Norman English term can refer either to the guardian of a gate (porte) or to one who carries (porter) things, and it is apparent that these burley fellows were employed for both these (and other) purposes. R. Caminos (LEM, p. 249) prefers "aparitor" based on the study by E. Jelinková-Reymond ("Recherches sur le role des guardiens des portes iry-'3:| dans l'administration générale des temples égyptiens, " CdÉ 28 [1953]: 39-59. It is however not necessary that they performed the same functions in the Theben Necropolis of the Late New Kingdom and in the llemples of the late Period.

499 LRL, pp. 69-70; Wente, LRL, pp. 81-82

500 RAD, pp. 45-58; W. F. Edgerton, "The Strikes in Ramesses III's Twenty-ninth Year, "INES 10 (1951): $137-145$. J. J. Janssen's study of the grain deliveries at Deir el-Medineh (Prices, pp. 464-465) has shown that these were anything but regular anyway. The statement that they lacked grain, fish and greens might carry conviction in the 
for the tomb of Ramesses XI (KV 4) is in a lamentable state..$^{501}$ They could not have been active in the Valley of the Kings, for the tomb is quite incomplete, despite a reign of 29 years. It is therefore logical to assume that they were in fact working on the still to be discovered tomb of Herihor. ${ }^{502}$ Would the Gang then have been responsible to a different set of authorities, with Dhwity-ms responsible to the High Priest of Amun, and not acting in his capacity of Necropolis Scribe responsible to the Vizier. Or does Herihor obscure background make such distinctions impossible?

Starting out at the town of $\mathrm{lw}$ - $\mathrm{m}$-itrw, ${ }^{503}$ they collect some grain from khato-lands of Pharaoh, and then deliver it to the Mayor of Western Thebes. For the first part of the papyrus we can follow the collection and delivery of the grain in detail, while the grain collected later is not accounted for:

mouth of a striking workers, but the insistence on the delivery - in the same breath - of such essential commodities as clothing and ointment, does not assure us that their plight was as bad as all that.

The statement that the Gang had "no clothes" (RAD, p. 53, 16) would be quite without interest were it not for the temptation to compare this with the equally bizarre statement in P. Berlin 9784, 4, where an individual who wishes to be paid (and who is probably not in dire straights) says, "I am naked, pay me[...]" (A. H. Gardiner, "Four Papyri of the 18th Dynasty from Kahun," ZÄS 43 [1906]: 27-47). It would nol appear improbable that this represents the textual preservation of an idiomatic expression (the words diverging either because it was "an expression", or because of the way it was written down) in support of a demand to be paid.

M. Gutgesell (Datierung, p. 554) has used this as evidence of the failure of the economy to function properly. This has been rebutted elsewhere by the present author (cf. D. A. Warburton, "Keynes'sche Überlegungen zur altägyptischen Wirtschaft," ZÄS 118 (1991): 78, n. 12) and Gutgesell himsell, who later transformed the Gang at Deir el-Medineh from being the exploited victims of royal whims to revolutionary entrepreneurs ("Die Struktur der pharaonischen Wirtschaft - eine Erwiderung," GM 56 [1982]: 104, an explanation which is closer to the truth in practice, but of minimal economic impontance (but, cf. Warbutton, ZÄS 118: 78, n. 12).

501 That the workers were not rewarded for the quality of their work is clear from the fact that they were (eventually) paid for decorating the tomb of Ramesses III, as the artwork there borders on the criminal. But the tomb of Ramesses XI suffers not merely from bad workmanship and negligence, but also from a virtual failure to exist.

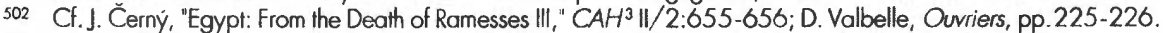

503 At a small village some $4.5 \mathrm{~km}$ south of Armant today. Sir Alan retracted his earlier position that iw-m-itrw lay at Jebelein $\left\{A E O\right.$ II: $274^{*}$ contra JEA 27: 24\}, accepting the view that it was a trifle north of Al-Rizeikat, some $10 \mathrm{~km}$ further north. P. Monter (Géographie ll: 52) retained the traditional view, associating it specifically with the large island lying below Jebelein today. M. Megally (Recherches, p. 88) does not regard the distinction as significant. The discovery of a statue of the Mayor Mys referring to the excavaled sanctuary of Sobek at lw- $m$-itrw near the village of al-Mahmoud Qibly (4.5 km south of Armant) would appear to have resolved the identification in favour of this village.

This would appear to eliminate the necessity of seeking the island, despite the name. Cf. H. S. K. Bakry, "The discovery of a temple of Sobk in upper Egypt," MDAIK 27 (1971): 131-146. The statue is in the luxor Museum (cf. Bothmer, Luxor Museum, p. 141).

Sir Alan (JEA 27: 24) found it "strange that what is virtually the title-page to the entire document should have mentioned [ $\mathrm{P}_{3}$-hnni, the Prophet of Sobek] alone." This would have been justified if all (or most) of the payments were in some way connected with the obligations of lands belonging to - or in some way financially responsible to - this temple or the prophet himself.

This toponym appears in two separate chronologically and administratively unrelated documents recording grain income - in the Turin Taxation Papyrus of the Theban Necropolis dating to the end of Dynasty XX, and in P. Louvre E 3226 (cf. M. Megally, Recherches, pp. 87-88) of the Theban administration, dating to mid Dynasty XVIII and although grain income does not figure in $\Pi 100$ (Rh-mi-Rc, Urk. IV: 1126$)$ precious metals and cattle do. A Landsat photograph of the region clearly shows that the extent of the cultivable land visible on maps produced today is considerably exaggerated, making the area a particularly unexpected source of important supplies of locally cultivated grain. 
The Turin Taxalion Papyrus

\begin{tabular}{|c|c|c|c|c|c|c|}
\hline lines & $\begin{array}{l}\text { grain collected } \\
\text { from }\end{array}$ & dale & khar & delivered to & date & khar \\
\hline $2,1-2,7$ & $\begin{array}{l}\text { Iw-m-itnw } \\
\text { khato-lands } \\
\text { šmw of mud flats }\end{array}$ & III 3 ht 16 & $\begin{array}{r}\frac{1342 / 4[=]}{\frac{542 / 4}{+80}}\end{array}$ & $\begin{array}{l}\text { Mayor } \\
\text { of West Thebes }\end{array}$ & $\frac{113 h+21}{s}$ & $1362 / 4 ?$ \\
\hline $2,8-2,11$ & 'gny & III $3 h t 19$ & $\frac{332 / 4}{32 / 4}$ & $\begin{array}{l}\text { Scribe } \\
\text { and Chantress } \\
\text { fisherman }\end{array}$ & III $3 h t 23$ & $\begin{array}{r}31 / 41 / 8, \frac{33}{1 / 32} \\
2 / 41 / 161 / 32\end{array}$ \\
\hline $2,12-2,15$ & $\begin{array}{l}\text { Iw-m-itrw } \\
\text { Foreigner }\end{array}$ & $\underline{113 h t 26}$ & $1832 / 4$ & $\begin{array}{l}\text { Mayor } \\
\text { Cultivator }\end{array}$ & III $3 h+29$ & 10 \\
\hline $3,1-3,3$ & Mont temple & IV $3 h t 12$ & $\underline{0}$ & $\begin{array}{l}\text { (Appear } \\
\text { again in 3,8) }\end{array}$ & & \\
\hline $3,4-3,7$ & $\begin{array}{l}\text { Shrine } \\
\text { of Ramesses III }\end{array}$ & IV $3 h t 13$ & $\underline{30}$ & $\begin{array}{l}\text { Scribe and } \\
\text { Chantress }\end{array}$ & IV $3 h t 14$ & $\underline{30}$ \\
\hline 3,8 & Mont Temple & This day & $\frac{14[=]}{\frac{8}{6}}$ & (2) & & \\
\hline $3,10-4,5$ & $\begin{array}{l}\text { Esna } \\
\text { Khnum and Nebu }\end{array}$ & IV $3 h+20$ & $\underline{402}[=]$ & Expenses & 24 & $33 \frac{6}{7}$ \\
\hline & $\begin{array}{l}\text { Deputy's šmw } \\
\text { (Account of scribe }\end{array}$ & & $\begin{array}{r}+220 \\
+1231 / 4 \\
\underline{651}\end{array}$ & = Mayor & $3 n \pi<4$ & \\
\hline $4,6-4,8$ & sundry souls & I prt 5 & $\frac{8 \sqrt{2 / 4}}{21 / 4}$ & Chantress & & $103 / 4$ \\
\hline $4,9-5,4$ & $\begin{array}{l}\text { Ni-pr-imw \& } \\
\text { Iw-m-itrw } \\
\text { sundry souls }\end{array}$ & & $\begin{array}{r}62 / 4 \\
132 / 4 \\
132 / 4 \\
\end{array}$ & Chantress & $1 \check{s m m} 9$ & $\frac{182 / 4}{6 \frac{12}{2 / 4}}$ \\
\hline $5,5-5,6$ & 'hiw of Pharaoh & $\underline{1}$ pn 13 & $\begin{array}{r}5\left[\frac{72}{53}\left[\begin{array}{l}5 \\
=\end{array}\right]\right. \\
\left.+\frac{161 / 4}{(\text { deficit }}\right]\end{array}$ & & & \\
\hline $\begin{array}{l}5,7-5,9 \\
5,10-5,11\end{array}$ & $\begin{array}{l}\text { Scribe of Sobek } \\
\text { "hiw of Pharaoh } \\
\text { Amun Temple }\end{array}$ & Nprt 13 & $\frac{20}{3}$ & & & \\
\hline
\end{tabular}

vso.

\begin{tabular}{|c|c|c|c|}
\hline $2,1-2,11$ & $\begin{array}{l}\text { Prophet of Hathor } \\
\text { sundry souls }\end{array}$ & $\begin{array}{l}\text { Year } 14 \\
1 \text { sht } 10 \\
\end{array}$ & $\underline{30}$ \\
\hline & $\begin{array}{l}\text { Smnt } \\
\text { sundry souls }\end{array}$ & & [uncertai \\
\hline $3,7-3,15$ & $\begin{array}{l}\text { lw-m-itrw } \\
\text { sundry souls }\end{array}$ & & $\underline{20} ?$ \\
\hline $4,1-4,4$ & $\begin{array}{l}\text { Khnum and Nebu } \\
\text { Temple }\end{array}$ & $\frac{\frac{1 s h t 25}{11 s h t 7}}{11 \text { sht? }}$ & $\frac{1}{0}$ \\
\hline
\end{tabular}

RAD 44,

14-16

sundry persons

$\begin{array}{r}4 \\ 12 / 4 \\ \hline 132 / 4\end{array}$ 
There are certain difficulties of detail in the text, foremost among which is that the dates given by Sir Alan and those recognizable in $P / R$ are not compatible: those of the facsimile of the papyrus seem to differ by one month from those logically necessary for the comprehension of the document, as in the case of the first grain collected, delivered in Thebes on $\|$ sht 21 , a month before it was collected in Iw-m-itrw on $\underline{\text { II }}$ iht 16 . Assuming that the $P / R$ transcriptions are correct, the only admissible conclusion is that the papyrus was prepared at a later date in a hasty manner, as a result of which some dates were mistakenly transferred from the notes to the papyrus as preserved. ${ }^{504}$ It is widely assumed that the Wilbour Papyrus was likewise compiled in an office from field notes. A record of such changes will be found in an older document:

11 Regnal Year 2 II sht 15

12 Spent (a number of) day(s) measuring with the scribes of fields in the southern district

13 Regnal Year 2 II sht 20

14 Spent the day writing for him the adjustment of the inw in the office of fields of the northern district. ${ }^{505}$

Of great apparent interest is the fact that payments "for Pharaoh" were taken from temple officials and delivered to the secular mayor, $P_{3}-w_{r}-{ }^{c} 3\langle 3,11 ; 3,16 ; 4,2)$. As however Sir Alan rescued the enticing words from the midst of a lacuna, it is difficult to justify drawing any conclusions.

In terms of content, the papyrus appears to be remarkably straight forward, detailing exactly who paid what, and where it went. This is virtually the only case where the entire process is recorded.

1,7 Given to the Necropolis [from] the grain of the khato-tands of Pharaoh (LIP!H!) from the hand of the Prophet of So[bek Ps-hni]

The grain from I $w$-m-itrw, from the khato-lands went to the Mayor's granary, 506 along with some šmw grain from the "northern mud-flats". 507 There can be no doubt that both were under responsibility of temple officials.

This is based on the rather presumptuous assumption that Sir Alan noted the discrepancy during his stay in Turin, and lost the notes on the matter in the course of preparing the text of $R A D$, and thus fails to refer to the matter, as it must have attracted his attention.

sos P. C. Smither, "A Tax-Assessor's Journal of the Middle Kingdom," JEA 27 (1941): 74-76.

The text is abbreviated as it is chronologically outside the scope of the present study, and otherwise not very relevant. The revised rendering of hbi inw ("reducing" or "adjusting", in place of "assessing" the inw) is based on the contention that the scribe's activity in both the southern and northern districts was due to some bureaucratic mix-up, obliging him to "adjust" the obligations of the parties involved.

506 For the final sum in I. 2,7, Sir Alan transcribed and translated $1312 / 4$ and $1362 / 4$, restoring 5 (RAD p. 37,$5 ;$ JEA 27:24), while $P / R($ pl. $C, 7$ ) have clearly $1032 / 4$ and $1012 / 4$. Sir Alan has taken the sum given in $I .2,4$. It is not easy to solve this problem.

507 'm 'm.t.tand. R. Caminos (Tale of Woe, p. 62) suspects that W. Helck's (Materialien, p. 292) assumption that this land was not of particularly notable quality can be upheld, while failing to demonstrate why a particular type of grain would be named after such land. The sequence in the onomastica $\left.(A E O): 10^{\star}-13^{\star}\right)$ indicates either (as pointed out by Helck) very poor quality agricultural land or the commencement of a new category, whereby "mud-flats" is not the worst rendering until its true meaning is identified. Personal experience at the temple of Armant in this century supports it. 
The grain from the town of 'gny was received by the Scribe and the Chantress of Amun, while the following entry refers to grain from Iw-m-itrw again, and again it is received by the Mayor, although it is grain of a foreigner ${ }^{508}$ and not further identified.

The 30 khar of grain of the Shrine of King Wsr-Mict-Rc stp-n-Imn (LIP!H!) collected by Dhwwy-ms and duly turned over to the Chantress of Amun and the Scribe (II. 3,4-7) are preceded by 6 khar which are not accounted for $(3,1-3)$. They appear again in conjunction with a second collection from the temple of Mont, but again the destination of this grain is not listed, although a blank in the papyrus indicates that space was reserved for the note. It does not appear to have gone to the Chantress and the Scribe who received the grain immediately prior to it. As the Mayor is the only other official who definitely received grain from Dhwhy-ms, it is perhaps warranted to suggest that he was in fact the recipient, but as it was not recorded it could have been someone entirely different. The only tenable and logical conclusion would be that this grain was deliberately distinguished from the grain given to the Scribe and Chantress, and that it was not delivered to them. Yet, the Mayor receives grain at the Granary, "The Granary Overflows" (II. 2, 6-7), which is the same first silo into which the grain accepted by the Chantress and Scribe is poured (II. 3,7; 5,4). Drawing any conclusions from the failure to note the receipt of the grain on the copy preserved is thus devoid of purpose, unless we assume that very careful records were kept at the silo according to which certain grain would be credited to one party, and other grain to another. We are thus obliged to conclude that it is not necessarily unwarranted to suspect that the grain did in fact go to the Necropolis as stated in the text, and that the Moyor and the Chantress and the Scribe were all part of the same team.

The source of the grain is less clear. The opening reference indicates that the papyrus should record grain from khato-lands under the responsibility of the Prophet of Sobek. References to grain of the temple of Sobek appear in the text (II. 1,$7 ; 2,2 ; 5,9)$, but other temples figure: that of Khnum and Nebu at Esna (II. 3, 11 ; vs. 4, 1), Month-Lord-of-Thebes (I. 3,1), and the Portable Shrine of Wsr-M: ${ }^{2}$ t$R^{c}(1.3,7)$. To assert that all of this was under the supervision the Prophet of the Temple of SobekLord-of-lw-m-itw would be over bold. Pharaoh's "h 'holdings ${ }^{509}$ appear (II. 5,5; 5,8), under the authority of the scribe of Reckoning of the temple of Amun, and were we to give the title page complete precedence, Pharaoh's ' $h$ '-holdings would be a division of Pharaoh's khato-lands.

When subjected to a detailed examination, we find that the apparent clarity is of limited value, and that grain from temple holdings (e.g., the Khnum temple at Esna) winds up in a granary which is operated by both the Mayor of the West, and a Chantress of Amun, ${ }^{510}$ most probably with the object of arriving at the Necropolis, to pay workers who were no longer working.

508, ;" "is customarily translated as "foreigner", but Sir Alan remarked (JEA 27: 25 n. 4), actually referred to someone speaking a foreign language. Neither E. Hornung (Amduat II: 75, 5) nor $\mathrm{H}$. Goedicke ("The Title [imy-r'] in the Old Kingdom," JEA 46 [1960]: 60-64) have sought to dispute the identification of this word with the Greek $\beta \alpha \dot{\alpha} \beta \alpha \rho \sigma_{5}$, but this is entirely indefensible. The lonian graffito at Abu Simbel refers to "those of foreign speech" in

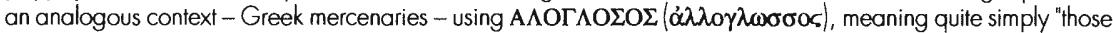
speaking a different tongue". This is clearly the Greek word to be used. Cf. T. F. R. G. Braun, "The Greeks in the Near East," CAHP III/3:50. I have not located the thesis of Prof. L. Bell who evidently drew similar conclusions.

509 Gasse, Nouvelles Données, p. $37 \mathrm{n}$. (80) suggests that this is a magazine.

510 It is logical to assume that the references to $(1)$ the Scribe $N_{s y}$-Imn-m-ipt (lines 2, 10;3,6); $(2)$ the Scribe of Reckoning of the Temple of Amonrasonther Nsy-Imn (lines 3,2; 5,8); (3) the Scribe of Reckoning of the Temple of Amun Nsy-Imn (lines 4,6; 5,5); (4) the Scribe of Reckoning Nsy-Imn (line 4, 11 ); and (5) Nsy-Imn-m-ipt (line 4,4) occasionally refer to the same person, but is immaterial here. 


\section{GIORNALE: P. TURIN $2009+1999511$}

\section{TrANSLATION}

1,1 irt-fish, ${ }^{512}$ small, 300: making silver kite 1

$1,2[\ldots]$ large, fish, 800, making silver kite 1

$1,3 \check{s ̆ n}^{c}$-fish, ${ }^{513} 100$, making silver kite 1

1,4 palm ropes, ${ }^{514}$ very great, ${ }^{515}$ AA quality ${ }^{516}$ for the royal barques, of cubits 1,200 $[+x], 517$ making silver deben 14

1,5 palm ropes, very great, AA quality for the royal barques, of cubits 1,200 making silver deben 12

1,6 palm ropes, very great, AA quality for the royal barques $[<$ of cubits $>] 1,000\left(+x^{2}\right),{ }^{518}$ making silver deben 10

1,7 palm ropes, cubits, 500, making silver deben 5

1,8 palm ropes of cubits (?) biry 1, making silver kite 1

1,9 palm rope, cubits 300 , making silver kite 1

1,10 palm rope, cubits 200 (?), making silver kite 1

1,11 palm ropes, cubits 7 , making silver kite 1 .

1,12 cedar, trunk, ${ }^{519}$ good, of cubits 50,1 , making silver deben $10[+x$ <against si> $]$ lver in objects

1,13 cedar trun[ $[k$, good $>]$, of cubits 50,1 , making silver deben $[x$ <against si $>$ lver in silver

1,14 cedar, trunk, good, of cubits 45, 1, making silver deben $[x]$ against silver in objects

1,15 cedar, trunk, good, of cubits 45,1 , making silver deben $[x$ kite $] 5$ against silver in silver

1,16 cedar trunk, AA quality, of cubits 40,1 , making silver deben $[x$ <against $>]$ silver in objects

1,17 cedar, trunk $[<(?)$ quality, of cubits $>] 40,1$, making silver deben [x against] silver in silver

$1,18$ cedar, tr[unk, of cubits $x], 1$, making silver $[\ldots . .]^{520}$

511 KRI VI: 560-566; Botti/Peet, Giornale, pp. 10-13/pls. 1-3; Helck, Materialien, 893-895.

512 Unknown type, not mentioned in Gamer-Wallert, Fische.

513 Unknown type, cf. Gamer-Wallent, Fische, p. 44. She remarks that the type must be unusually small, but the price mentioned here indicates a higher quality - at least - than the preceding examples. The reading is Kitchen's, as Botti/Peet were unable to read it.

514 Cf. Janssen, Prices, pp. 438-440.

515 Whether this refers to strength or length is not clear, but the subsequent reference to the length might imply the former.

510 nfr $n$ fr.

517 Janssen (Prices, p. 439 n. 22) suggests 1400, as is logical from the following price.

518 Whether the line after the "thousand" refers to one - and only one - thousand?

519 Cf. Janssen, Prices, pp. 378-379.

520 Botti/Peet, Giornale, p. 11, probably correctly do not hesitate to restore deben, but kite remains a possibility. 
1,19 cedar, $\operatorname{tr}[$ unk, of cubits $x], 1$, making silver deben $[\ldots$.
$1,21 \quad[\ldots$.$] making kite [....$
$1,22[\ldots$.$] making kite [\ldots .$.
$1,23[\ldots]$ mhf of cubits 2, 1, making silver
1,24 [....] making silver kite
$1,25[\ldots .]$.20 , making silver kite 1
1,26 [.... 1, making silver kite 1
1,27 [...grain?], 1, making silver kite
1,28 [...grain?], 1, making silver kite 1
1,29 [....grain?], 1, making silver kite 2
$1,30[\ldots .$.$] grain, 1, making silver kite 2$

2,1 cedar, ịn-beam, ${ }^{521} 1$, making silver $\left[{ }^{\star} k i\right] t e^{522}, 3$

2,2 cedar, $\underline{d} p h$-piece, 1, making silver $\left[{ }^{*} k i\right] t e^{523}, 1$

2,3 cedar, mast, $[\ldots$ of of cub> $]$ bits $30(?)$, making sil $[<$ ver $>]$ deben 4

2,4 cedar, mast, small ${ }^{524}($ ) $)$, of cubits 38 , making silver deben 3 , kite 8

2,5 cedar, mast, of cubits 35 , making deben 3 , kite 8 .

2,6 cedar, mast, of cubits 30 , making silver deben $3[+x$ ? $]$

2,7 cedar, tpt-piece, of cubits $4030[\ldots .] 30,$.1 , making silver kite 5 .

2,8 cedar, tpt-piece $[. .$.$] of cubits 28[\ldots .] 27,.[<$ makin $>$ ] $[<$ silver $>]$ kite $[. . .]$.

2,9 cedar, tpt-piece $[\ldots .<$ pre> $]$ pared ${ }^{525}$ of cubits 20,1 , making silver kite $11 / 2$

2,10 cedar, ke[<e>]1, ${ }^{526}$ [A]A quality, of cubits 40, 1, making silver deben 8

2,11 cedar, ke[<e>]I, [A]A quality, of cubits 30, 1, making silver deben 6 .

2,12 cedar, $k e[<e>]$, second rate, 527 of cubits 30,1 , making silver deben $4, k i t e[\ldots]$

2,13 cedar, $\underline{d}^{3} t_{1}$, good, of cubits 30,1 , making silver deben 6

2,14 cedar, $\underline{d}^{\prime} r t$, second rate, of cubits 35,1 , making silver deben [...] kite 5 .

2,15 cedar, ribbing, ${ }^{528}$ good, of cubits $[. .], 1$, making silver $[.$.

2,16 [<cedar $>$, ribbing, second rate, ma[<king silver >....]

2,17 [<cedar $>$ styw, ${ }^{529}$ good, making silver $[\ldots]$

$2,18[<$ cedar $]$, ribbing, $[\ldots] 1$, making sil $[<\operatorname{ver}>\ldots .$.

$2,19$ [<cedar $],$ st $[<y$ s s....]

$3,1 \quad[\ldots .$.

3,2

3,3 
3,4 cedar, $s k[<t y$-vessel $>\ldots .$.

3,5 its $t 3[\ldots]$

3,6 cedar, skty-vessel $[\ldots .$.

3,7 cedar, skty-[<vessel $>. .$.

3,8 cedar, $d^{3} y-[<$ barge $>530 \ldots$.

3,9 cedar, $\underline{d}^{3} y$-[<barge $\left.>. ..\right]$

$3,10$ cedar, qrr-[<boat $>. . .$.

3,11 cedar, $m n s ̌-[<$ barge $>\ldots . .$.

3,12 cedar, $b ;[<r$-freighter $>\ldots .$.

3,13 cedar, $b ;[<r-f$ reighter $>\ldots . .$.

3,14 cedar, $b ;[<r$-freighter $>\ldots .$.

3,15 acacia, $[<$ cattle-> $]$ ferry $[. .$.

3,16 acacia, $[. .$. - $]$ boat, of cubits $[. .$.

3,17 acacia, $[<$ cattle-> $]$ ferry $[\ldots .$.

3,18 acacia, $[<$ cattle-> $]$ ferry $[\ldots .$.

3,19 acacia, $[\ldots$.

$[\ldots . \text { Textual Omission... }]^{531}$

\section{ReMARKS}

The purpose and nature of this papyrus are obscure, and it will be noted that there is not one single reference to taxation, but that a number of the items mentioned also figure in P. Harris 1 (cf. infra pp. 194ff.; pp. 306ff.) which is intimately related to taxation.

530 Jones, Glossary, p. 88 . It is logical to assume that these were "barges" in light of their usual contexts.

531 The verso deals with activities of the Gang at Deir el-Medineh. 
INSTRUCTIONS FOR THE VIZIER 532

\section{TRANSLATION OF EXCERPTS}

1 Instructions for the term ${ }^{533}$ of the Vizier and mayor of Thebes (nwt rsyt) and (the vizier) of the Residence in the office of the Vizier. Concerning every act of this official, the vizier, when deliberating (in the office of the vizier $[\ldots]$

$2[\ldots]$

$3[\ldots]$ He should be promptly informed concerning the opening and closing of the secure rooms. The condition of the fortresses of southern and northern Egypt is to be reported to him. The exit of every expense (prrwt) of the royal household ${ }^{534}$ is to be reported to him, as is the arrival of all income (' $q w$ t) into the royal household. As for all income and expenditures for the land ${ }^{535}$ of the residence: whether income or expenditure, it is his agents who are to permit delivery and enable expenditure.

$4-16[\ldots]$

$17[\ldots]$ As for anyone who shall petition the vizier concerning land, he is ordered to him, the vizier, aside from listening to the

532 Urk. IV: 1103-1117; Davies, Rekh-mi-Réc, pls. 26-28. Only excerpts from the text are presented here, as deemed relevant to the task. Cf. Boorn, Duties; Helck, Verwaltung, pp. 29-43; W. Helck, "Dienstanweisung für den Wesir," $L \ddot{A}$ I: 1084; James, Pharaoh's People, pp. 51-72; D. Lorton, "What was the pr-nsw and who managed it? " SAK 18 (1991): 291-316.

The text was dated to Dynasty XIII, prior to van den Boorn's early Dynasty XVIII dating, in his commentary (Duties, pp. 333ff.). J.-M. Kruchten's doubts (Bi Or 48 [1991]: 821-831) apparently threw the date backwards once again, but Kruchten's own comments on the word htr indicated that its fiscal significance was restricled to the New Kingdom ("Le verbe hitr et ses dérivés jusqu'à la fin du nouvel empire," AIPHOS 24 [1980]: 39-52), so that he undermined his own argument before advancing it, as the word appears in this lext. The index of Quirke, Administration, does not cile the word. It is probably a mixture of various strains and the present text must have been established at a very early date in the New Kingdom.

533 Van den Boorn translates hmst as "session" following Faulkner (CDME, p. 170), while Helck (Verwaltung, p. 29) does not translate it. "Session" would suggest that it should be followed by nbt ("every", "each", "any"), as so often in the text, while the singular is perhaps not appropriate, as "session" refers to a specific event, while "term" can be used with reference to an individual session, or to the entire period of the occupation of the office as such, and this is more suitable in this context. Cf. e.g., Uik. IV: 288, 13, which clearly refers to the "reigning" king (i.e., the king in his "lerm" of office), while Urk. IV: 349,10 refers to a specific "session".

534 pr nsw is probably more than the "palace" here. Cf. J. J. Janssen's remark that pr-" or nswt should be occasionally understood as referring to the "state", "bikw: From Work to Product," SAK 20 (1993): 94 n. 78. Cf. D. Lorton, "What was the pr-nsw and who managed it?", SAK 18 [1991]: 308-309.

"qut and prrwtcould conceivably refer to mere "comings and goings" in the palace. However, Urk. IV: $1106,13-17$ prescribes that when the doors are opened at the proper time, the scribes should control the "comings and goings" in writing, and a protocol will probably have been kept of these interviews. The nolebooks of $P$. Boulaq 18 (A. Scharff, "Ein Rechnungsbuch des königlichen Hofes aus der 13. Dynastie," ZÄS 57 [1922]: 51-68, pls. $\left.1^{* \star}-24^{\star \star}\right)$ use the word ' $q w$ for income. The $t$ may have originally been the bread sign. Cf. Quirke, Administration.

535 rs sitw. Lit., "for/to the ground/floor". James (Pharaoh's People, p. 63) renders "from the floors"; Helck (Verwaltung, p. 31) "in das Gebiet". The text would appear to deal with the palace and the adjoining offices. That some land would be associated with this is not remarkable. This suspicion receives support from the careful distinction between pr-nsw and sitw $n$ hnnw. Cf. W. Helck ("Eine Stele Sebekhoteps IV. aus Karnak," MDAIK 24 [1969]: 196, h) This is better than the "area" used by van den Boorn (Duties, pp. 43;50,8). It could be either a matter of commercial activity or merely the sources of provisionment for the palace. 
18 overseers of land, together with the magistrates of the Cadaster Survey. ${ }^{536}$ He will act within two months for his fields in Upper and Lower Egypt. As for his fields which are in the vicinity of Thebes (nwt rsyt) or the Residence, he will act within three days, $^{537}$ as

19 corresponds to the law. He must listen to every petitioner according to this law which is at hand. He also must bring logether the land-courts, and it is he who sends them out that they may report to him the state of their lands. Every imyt-pr testament ${ }^{538}$ is to be brought to him, and it is he who seals them.

20 It is he who makes land-endowments with each $\check{s} d w$-plot. As for any petitioner who says, "our boundary line has been shifted." and it is demonstrated that this is the case, under the seal of the appropriate official, he will read the šdw-plots to the magistrates, who will cause that they be shifted (back). ${ }^{539}$ And as for any mine whose "owner" shall come to it, examining the things within it: a petition shall be made in writing. He will not be permitted to petition a judge, and the same applies to any of the lord's petitioners, after he has made it in writing. ${ }^{540}[\ldots]$

$24[\ldots]$ It is he who shall despatch the courts of the land to make weirs ${ }^{541}$ in the entire land.

The virtually undocumented tm?; known from BM 828; Cairo 20056; Leiden V 3; Urk. IV: 1110,$13 ; 1113,14$ The early New Kingdom terms may bear little relation to the later terms. An unknown verb (Faulkner, CTIII: $33 \mathrm{n}$. 3) could be related.

537 This reference to "his fields" (zhw.t.f) would be most interesting were it to imply either personal or ex officio ownership. This section seems to concern assorted immobile property under his authority, such as fields awarded to people, testamentary property arrangements and perhaps the quarries mentioned at the end. Interpreting these as belonging to Pharaoh - but over which his subjects had considerable freedom to deal - is probable.

538 At the risk of over-simplification, imyt-pr seems to refer specifically to the emoluments associated with an office furned over to another individual. For imyt-pr in the New Kingdom, cf. K. B. Gödecken LÄ III: 141-145; VI: 6-8. For the controversy about the stele of Ahmes-Nefertari: B. Menu, "La 'Stèle' d'Ahmès Nefertary dans son contexte historique et juridique," BIFAO 77 (1977): 89-100; M. Gitton, "La Résiliation d'une fonction religieuse," BIFAO 76 (1976): 65-89; B. Menu, "Quelques Remarques à propos de l'étude comparée de la stèle juridique de Karnak et la 'stèle' d'Ahmès-Nefertari," RdÉ 23 (1971): 155-163; I. Harari, "Nature de la Stèle de donation de fonction du Roi Ahmôsis a la reine Ahmès-Nefertari," ASAE 56 (1959): 139-201; 2 pls. The uninitiated are warned that a lacuna in II. 5-8 of this important text has deprived our science of some very important evidence, but given complete freedom to speculation. Clear is that an imyt-pr was (1) a testamentary arrangement (2) transferring certain rights to another person (3) affecting the heirs of both parties, (4) specifically associated with the performance of an office, (5) of which the Vizier was obliged to certify the validity with his seal. The offices could be either secular or sacerdotal.

539 This rendering attempts to avoid supplying missing words (as Helck, Verwaltung, p. 35 and James, Pharaoh's People, p. 65), while providing an understandable text. The text has obviously suffered considerably in the course of the centuries, so that many readings are feasible, but the Egyptians withdrew $($ s $d i)$ something from $(\mathrm{m})$ someone and not to $(n)$ him.

540 "These sentences are very obscure" (James, Pharaoh's People, p. $72 \mathrm{n}$. 18). Thus the divergence of this translation from James'. Assuming that these instructions deal with the mundane and not the spectacular, miracles are nol expected. Quarries will have differed from agricultural land in that difficulties at the former were not necessarily urgent, requiring a decision before the termination of the inundation, in contrast to the latter. Using $n b$ ("owner", "lord") does not mean that it is not really the "boss" but the data are totally insufficient for speculation. Van den Boorn (Duties, pp. 195ff.) excludes $m \check{s}^{c}$ here, but quarrying and mining may have been part of the private sector, as copper mining in the Sinai does not appear to have been either a royal or even Egyptian preserve (cf. supra, pp. 105ff.)

5415 -mw does not invariably mean "dyke". In the Kahun Papyri (Griffith, Kahun Papyri, pl. 2, 12) it should, but in the Nauri Decree $(K R I) ; 48,5)$, it is perhaps better translated "pool" or "channel", and the English word "weir" can signify either "dyke" or "pool", and may thus match the Egyptian term as used. 
25 It is he who despatches the mayors and district officials to plough in summer. [...]

$26[\ldots]$ It is he who despatches the expeditions and scribes of the cadaster survey ${ }^{542}$ in order to conduct the business of the lord. The nome

27 records will be kept in his office, for hearings concerning any fields. It is he who fixes the borders of the nomes, all fields (?) of divine offerings, and all changes of ownership. ${ }^{543}$ It is he who makes all proclamations (official?). It is he who judges conflicts, when a man speaks out against his fellow. It is he who makes every appointment

28 to the Hall. ${ }^{544}$ Every inquiry from the Palace (pr nsw) should come to him. It is he who notes every decree. It is he who notes all shorffall in the divine offerings. It is he who htri every/all htri from the income of all to whom it is given. $[\ldots . .]^{545} \mathrm{It}$ is he who seals

29 it with his seal. It is he who listens to every conflict. It is he who fixes the inw-duty of the administrative units. ${ }^{546}$ The Great Council will report to him their htri and income $[\ldots$.$] at its side. [...] It is he who supervises everything brought to (?)^{547}$

30 the hall ( $r$ ryy) and every transfer to the hall. It is he who notes this. It is he who opens the House of Gold together with the treasurer (imy-r sdiwty). ${ }^{548}$ It is he who supervises the inw of the $\mid[<a n d s>\ldots . .]^{549}$

31 imy-r pr wr together with the Great Council. It is he who makes the cattle commissions, making the commissions from them.

[...textual omission.. 32]

All the mayors, village headmen, $[\ldots]$, report to him their inw. $[.$. textual loss... $]$ the monthly festival requirements to define the in $w^{550}$ [...textual omission...] Harageh 3, 26 (P. Smither, "A Tax-Assessor's Journal of the Middle Kingdom," JEA $27[1941]$ : 74-76, pl. IXA,
25 [but also pl. IX!]). Cf. also, R. Krauss, "Detailfragen der altägyptischen Getreidewirtschaft," in Fs Fecht,
pp. 268-269, for the dates of the field measurements. Sethe's reconstructed text (Urk. IV: 1115,1 ) suggests $n$ rather than the expected r, but Davies, Rekh-mi-Réc, II: pl. 28 has a fragmentarily presenved sign that can only with extreme imagination be construed as an $r$, but even more would be required to read $n$. Cf. Pз-hq;-mn, Guksch, Paheqamen, pl. 9; H. Guksch, "Das Grab des Benja, gen. Paheqamen: Theben Nr. 343," MDAIK 38 (1982): 195-199.

In principle, the translation and interpretation of these sentences would dictate their being excluded, but the matters of the divine offerings and "land-ownership" compel their inclusion. For him, Urk. IV: 808,2 can be cited, meaning, "to hand over".

"rnyt. The oriental concept of "speaking justice al the gate" may lie behind the use of "rnytas "hall of judgment", but this is not apparent from the Egyptian sources. Faulkner (CDME, p. 45) cites (1) Peasant, B 1,35; (2) P. Kahun, pl. 15,34; (3) Urk. IV: 1073,3; and (4) Urk. IV: 1107,5 as references. With the exception of the last, and the one here, this rendering is not justified, and here it is not compelling. It should be discarded in favour of the less satisfying but more accurate "administrative department" as Spencer (Temple, pp. 151-152) has shown that it had a "rather less specific [meaning] than has been previously recognised".

Only a few signs are preserved in these lines.

Does hbi-inw refer to the income (in taxes paid by others) of the gs-prw, or the levies on them, which would robably be expressed with $m$ and not. $n$ ? This is a special land tax recorded in the Middle Kingdom, cf. $P$. Reconstruction impossible.

Virtually the same as Gordon, inw, pp. 174-175, where van den Boorn is rightly cautious. 
This text poses many difficulties, and far more commentary would be required to deal with the text properly, but it is clear that this text clearly reveals that the Vizier is responsible for deciding the $h t r i$, and the inw, and recording the deliveries. He is also the last resort for land disputes and responsible for the divine offerings. As inw rather than htri is the word that appears in the actual products brought ${ }^{551}$ the suggestion that a distinction between conceptual and concrete distinctions be potentially regarded as valid should be considered. The fact that several of the key words used for this study do not appear in this text is certainly cause for alarm signals to be emitted before the conclusions are given undue authority for providing the definitive interpretation of the Egyptian fiscal system. 


\section{The BIIGAI Stele 552}

TRANSIATION

a $[\ldots .<$ give $>]$ thee $[<$ countless $>]$ jubilee festivals $[\ldots .$.

$b[\ldots .$.$] gods$

1 Horus the Steer $[\ldots<$ their $>(?)]$ enemies

$2[\ldots .<$ Seth $>$ Son of Nut $[]$.

3 to the effect that (?) $[\ldots<$ Seth $>]$

4 Son of Nut $[. .$.$] principal [<$ wife $>$ ? $]$ of

6 Amun of $W_{s r}-\left[\left\langle M_{3}^{3} t\right\rangle\right]-R^{c}$, $[<$ elect of $R e>\ldots$.$] then [\ldots$.

$7[\ldots .$.$] the divine offerings$

$8<\mathrm{on}>$ their places of $[\ldots .$.$] the town. They are as go [\langle\mathrm{d} s>]$

9 great in hea $[<v e n>\ldots$, $<$ the temple of millions $>$ ] of years of the King of Upper and Lower Egypt $[. .]<$. in the Estate of

10 A $>$ mun on the West of Thebes. The Stew $[<\operatorname{ard}>\ldots .$.$] the obedient servant [<$ made> (2)....]

$11\left[\ldots .\right.$. Wsr-Mic $M^{c} t-R^{c}$ elect of $\operatorname{Re}[\ldots<$ gis $>$ ven eternity on $n a[<m e>(?) \ldots$

$12[\ldots .$.$] of the whole land, they satistying him [(?) \ldots .].(?)$

$13[. .$.$] He made [...] from his granary, he made [...]$

$14[\ldots .$.$] cubit [\ldots .$.

vso.

$1[\ldots$.$] Heliopolis which is in the South, Heliopolis Proper 553[\ldots$.

$2[\ldots .$.$] with the park { }^{554}$ of Amun of $W s r-M_{3}{ }^{c} t-R^{c}$, elect of Re for eternity $[. . .$.

$3[\ldots .<$ after the $f]$ orm (?) of the House of Amun of Wsr-M $M_{3}^{c} t-R^{c}$ elect of Re. No claim shall arise from any brother, sister or relative of mine. [...]

$4[\ldots<$ As for any Coastal Defence Officer $>$ yet to come, who shall disregard this chapel made by [the] great $[<f e m a l e ~ k i n g>(?) \ldots .$.$] for the L o[<\mathrm{rd}$ of all the Land $>(?)$,

$5\left[\ldots .<h>\right.$ er Father, or who shall prevent Amun of $W_{s r}-M_{3}{ }^{c} t-R^{c}$, elect of Re, from resting within it at his every appearance at each festival, or who shall

6 [<remove peos] ple from it, employing them elsewhere, beyond the jurisdiction of this chapel, he shall be under the power of Amun of

7 Wsr-M: ${ }^{c} t-R^{c}$ elect of $R e$, he shall be despised by the gods of the heavens, and by the gods of the earth, as well as by the King

553 At the time, Sir Alan (ZÄS 50 [1912]: 50, 54) made little sense of these lines. Here, it is assumed that / wnw rsy refers to Hermonthis while /wnw' 'ray is taken to refer to the real Heliopolis, in the North.

554 CF. AEO II: $216^{*}$. The image created by the parallel in P. Harris I 8,3 has been used here. 
8 of his own day. No one shall accept any of his oblations. He shall not stand upon the firm lips of his brothers. ${ }^{555}$ Neither shall his son take up his position. Nil shall be all his deeds.

9 He shall not master anything he undertakes.

And as for any Coastal Defence Officer who shall bear responsibility for the House of Amun of Wsr-Mict-Rc elect of Re

10 attending to this chapel made by the grea[<t female king $>$ ? ] of all the land for her Father Amun of Wsr- $M_{3}^{3}{ }^{c}-R^{c}$ elect of Re, letting Amun of $W_{s r}-M_{3}{ }^{c} t-R^{c}$ elect of Re rest within it

11 at his every appearance at all his festivals, who shall not remove people from it, employing them elsewhere, beyond

12 the jurisdiction of this my chapel, made for $<$ the $>$ grea $[<t$ princess $>$ ] of all the land for Amun of Wsr-M: $M_{3}^{c} t-R^{c}$ elect of Re, her good father, he shall be praised

13 by Amun of $W s r-M_{3}{ }^{c} t-R^{c}$, elect of $R e$, and by the gods of the heavens, and by the gods of the earth, as well as by the King of his own day. He shall stand upon the firm lips

14 of his brothers. He shall retain his office as Fort Commander (i.e., Coastal Defence officer), his son following him in his position. Sent on a mission, he shall relate his report.

15 His children shall remain as he has educated them to be.

I speak to the royal scribe and Steward of the Mansion of Millions of Years of King [Siptah]

16 in the Estate of Amun on the West of Thebes and the Steward P3-b3-s 3 of the Temple of Sthy mry-n-Pth in the Estate of Amun: "I am an official beneficent to his lord, fulfilling the šmw, fulfilling the šsyt. Extraordinary was my

17 (delivered) excess šmw and šštt. ten-fold my htrri of šmw and šsyt. 4'632 mnt-jars of wine was

$18<\mathrm{m}>\mathrm{y}$ bikw-rmt, but I let them bear away $30^{\prime} 000$ : a surplus of $25^{\prime} 368$. Nd $\mathrm{dm}$ the supervisor did not

19 (come to aid?) me in any (thing?) which I did at all, ever. $70 \mathrm{mnt}$-jars of honey were my honey htri. I of my efforts brought 700

20 [meaning a surplus o] $630.70^{\prime} 000$ mc was my annual šmw. I brought 140'000, a surplus of $70^{\prime} 000 .[\ldots]$

555 The meaning of this expression is not entirely clear. According to Wb. IV: 10,17, it refers to the retention of an official position, but this interpretation is clearly based on this text. It would seem more likely that it signified either (1) that the person would be forgotten (as his brothers would not mention his name, and he would thus cease to exist), as the following line refers to the position, or (2) simply that the person would stand in good or bad repute. 
Sir Alan Gardiner suggested that the inland situation of Bilgai (and presumably the lack of other Pharaonic monuments there) implied that the stele came from somewhere else, and thus the structures mentioned in the text must be sought elsewhere. Equally astutely, he dated the stele to the close of Dynasty XIX, and specifically to the reign of Tawosret. Although the stele bears certain royal features, it appears to be the work of a private person, a Coastal Defence Officer, ${ }^{550}$ who boasted about his economic accomplishments to the Steward of the Mortuary Temple (of Pharaoh Siptah?) in the Estate of Amun. There are references to a temple (pr) and a (barque shrine) chapel (ipt) of Amun of Ramesses II, which the official made under the auspices of someone who would appear to have been Queen Tawosret. The payments referred to will have gone to the mortuary temple of Siptah however, as it is to an official of this institution that the author of the stele addresses himself. It would appear that they were the produce of temple dependents, dependents who were not to be removed from the temple. This means that the whole would appear to have concerned the temple economy, the involvement of the government being incidental, insofar as our unnamed official was a Coastal Defence Officer, and thus a government official. The repudiation of the right of his relatives to claim the land donated along with the barque shrine would tend to indicate that the official in question took land from his own private resources to establish and endow the barque shrine.

This barque shrine would appear to have been made at his own private initiative, as it is mentioned separately from the fulfillment of his obligations. If this interpretation is correct, the obligations would have been his regular dues related to his regular duties. As he has no sacerdotal titles, it would seem that his obligation to provide the Estate of Amun was an exofficio responsibility (perhaps comparable to many officials in, e.g., P. Wilbour).

The actual transfers mentioned are: the expected bikw-rmt, $4^{\prime} 632 \mathrm{mnt}$-jars of wine, (delivered $\left.300^{\prime} 000\right)$; the expected $h+1 r i, 70 \mathrm{mnt}$-jars of honey (700 delivered); the expected šmw, 70 '000 mc (140'000 mc delivered). "Extraordinary was my (vs. 17) (delivered) excess šmw and šsyt: ten-fold my htri of šmw and šsyt". The non-corn deliveries were šzyt and the corn, $\check{s} m w$, while both are htri. The htri is also mentioned as a specific item, namely a quantity of honey. The separate $b^{3} k w-r m \underline{t}$ is specified as being of wine.

The units of the šmw are of interest, as W. Helck ${ }^{557}$ reads khar whereas the text can be understood as referring to oipe (thus "mc"; "measure of corn" in the text). According to the evidence of H.O. 81/82 and P. Bologna 1086 (cf. pp. 144 n. 408, supra), a field worker was expected to deliver 200 khar as his share. If we assume that 140'000 khar were delivered annually, it would imply the employment of 700 workers, 558 on a surface of between $7^{\prime} 000$ and 14'000 arouras (using the assessments of the Wilbour Papyrus) which would be a large holding indeed, and even a quarter of this (reading oipe) would still be a large holding. It is however improbable that a mere Coastal Defence Officer had 700 field

550 imy-r htm n p: ym.

557 Materialien p. 472.

${ }_{558} \mathrm{P}$. Harris I lists the bikw-corn of the Estate of Amun at a modest $309^{\prime} 950 \mathrm{khar}(12 \mathrm{~b}, 3)$. 
workers and 14'000 arouras at his disposal, so that we may assume initially that oipe are meant (still implying 175 field workers on an annual basis), and suspect that he may have totalled up his "annual šmw" for several years, so that several years are subsumed together, potentially reducing the number of field labourers and the size of the holding by a factor of ten.

This however does not reduce the validity of his statement that his efforts were "extraordinary" as the excess šmw was still twice his obligatory quantity, and even reduced in the above fashion, it is remains significant. The $700 \mathrm{mnt}$-jars of honey-htri compare favourably with the 1'370 mnt-jars (P. Harris I 15a,3; 18b,7) which the Pharaoh himself, Ramesses III, awarded to the Estate of Amun in the 30 years of his reign. The $30^{\prime} 000 \mathrm{mnt}$-jars of wine-bikw-rmt likewise approach half of the 62'000 for which Ramesses III took credit for having delivered to the Estate of Amun during his entire reign $(15 a, 14 ; 18 a, 11)$.

We will return to this in the final chapter, infra, pp. $325 \mathrm{f}$. 


\section{The Rewards of the High Priest of Amun, Imn-hipp 559 .}

TRANSLATION

1

1 The King himself said to the officials and courtiers who were at his side: "Yield up much praise and numerous rewards in beautiful gold and silver

2 and millions of every good thing to the High Priest of Amonrasonther, Imn-h.tp, deceased, on account of the many excellent monuments which he has made in the Estate of Amonrasonther, in the great name of the great god.

3 The King of Upper and Lower Egypt, $\mathrm{Nfr}_{\mathrm{k}} \mathrm{k}_{3}-\mathrm{R}^{\mathrm{c}}$, elect of $\mathrm{Re}$

4 The Son of Re, Ramesses (IX), beloved of Amun, $H^{i} w-(m)-w^{3} s t$

5 Given Life and Power like Re,

6 All Security, Life, Power and Health, and all above it, like Re, forever.

1 Regnal Year 10, III sht 19, in the Temple of Amonrasonther: the High Priest of Amonrasonther Imn-htp, deceased, paraded at the Great Forecourt ${ }^{560}$ of

2 Amun. (The Royal) One spoke to him, uttering his praise, in order to commend him with fine chosen words of the officials who had come in order that he be praised: the Superintendent of the Treasury of Pharaoh

3 and Royal Attendant, ${ }^{561} \mathrm{Imn}$-htip, deceased; the Royal Attendant, Nsy-Imn; the Scribe of Pharaoh and Royal Attendant and Herald of Pharaoh, Nfr-k $3-R^{2}-m-p r-I m n$.

4 What was said to him consisted of the praise and vaunting on this day at the Great Forecourt of

5 Amonrasonther: Monthu was praised, the $k$; of Amonrasonther was praised; Paraharakhte;

6 Ptah the Great, South of his Wall, the Lord of Memphis ("nh-tiwy); Thoth, the Lord of Divine Words; (and) the gods of the sky; (along with) the gods of the earth.

7 The $k^{3}$ of $\mathrm{Nfr}-k_{3}-\mathrm{R}^{c}$, elect of Re, the Son of Re, Ramesses (IX), beloved of Amun, $H^{c} w-(m)-W i s t$, the Great Ruler of Egypt was praised, the scion

8 whom all the gods love, on account of the performance which you have made of the šmw, šsyt, bikw-

501 wb; nsw, literally, "royal butler". Sir Alan Gardiner points out (AEO I: $\left.43^{\star}-44^{\star}\right)$ that these officials actually did serve the King, but that this merely emphasized - rather than diminished - their importance. 
9 -rmt of the Estate of Amonrasonther under your authority. You have brought them, filling the magazines ${ }^{562}$ having caused

10 [<the perform $>$ ] ance, having it done in the inner chamber $(s)$ of the treasuries and storehouses and granaries of the Estate

11 of Amonrasonther. And from you are the inw and tpw- $\underline{d} t$ : the material support ${ }^{563}$ of Amonrasonther.

$12[\langle t$ is $\rangle]$ your [ $[$ causing that one bring to $\rangle]$ Pharaoh, your lord what is done by a good and efficient servant

$13[$ <of Phar > ]aoh, his Lord. Being strong in order to act efficiently for Amonrasonther

14 the Great God, (and) in order to act efficiently for Pharaoh, his Lord. [etc....]"

A similar speech is less well preserved (and W. Helck has restored it):

$14[\ldots]$

as servant

15 of the Estate of Amun. And from you are the performance, making the šmw, šsy of the Estate of Amun

16 under your authority. You caused that the inner chamber(s) of his treasuries, storerooms,

17 granaries

$20[\ldots]$ the inw, tp- $\underline{d} t$ material support. It is your causing that one bring to the royal warehouses $[\ldots]$

\section{REMARKS}

Inscribed on the exterior of the connecting wall between the VII and VIII pylons of the temple of Karnak is this text relating how the Pharaoh (Ramesses IX) commanded the royal court to pay homage to the High Priest of Amun, Imn-htp It is specifically stated that he arranged for the payment "of the šmw, šsyt, bikw-rmt, of the Temple of Amonrasonther" (text II. II: 8-9), and that the inw and the tpw- $\underline{d} r$ likewise belonged to the temple (text II. II: 11). This inscription details fiscal responsibilities using most of the words discussed in this study.

It would appear that each item is understood to be a specific term with a specific meaning land it is interesting that the word htri is not used, as this term seems occasionally to subsume the others). The actual material is understood as being delivered directly to the temple, with the exception of the inw and tpw-drt which seem to have belonged to the temple, but may have been rendered to Pharaoh.

It is significant that the High Priest is credited by the Pharaoh with having built many great monuments for Amonrasonther.

562 For ' $h$ ' as magazine, Gasse, Données Nouvelles, p. 37.

503 "Provisioning" or "Victuals"? , cf. P. Greg, supra, pp. 152ff. and Janssen, Commodity Prices, p. 458. 


\section{THE DeCREE OF HOREMHAB 504}

\section{TRANSLATION OF EXCERPTS}

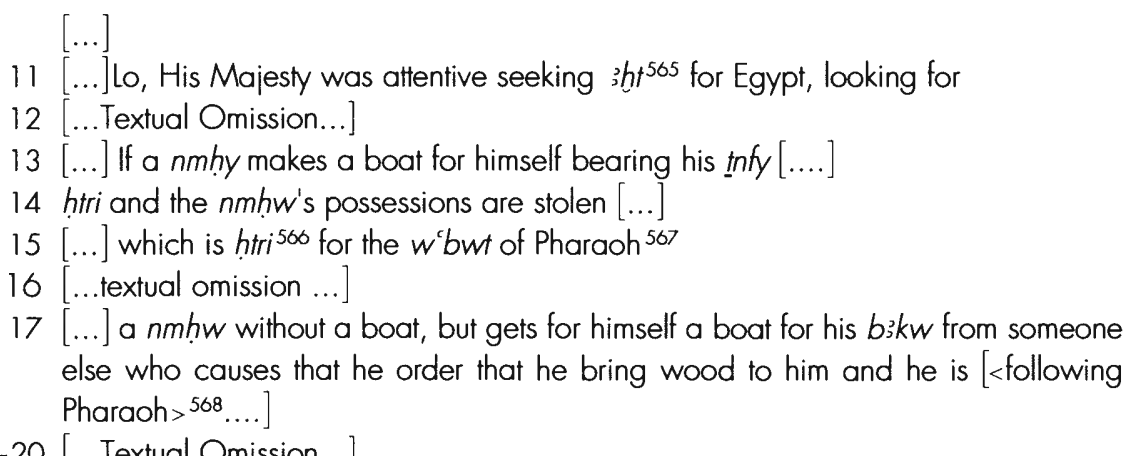

18-20 [...Textual Omission...]

21 And likewise, any $s \underline{d} m$-official of a chamber $\left({ }^{c} t\right)$ hnkt of Pharaoh (L!P!H!) going into the villages for corvée labour $\left(k f^{c}\right)$ for taking safflower ${ }^{569}[\ldots$ <taking the male or female slave of the $n m>] h w^{570}$

$22[\ldots]$

$23[\ldots]<$ the $b_{3}$ k $w$ of these servants will be extracted from him>

24-30 [...Textual Omission...]

$31[\ldots<$ And like $>]$ wise, the for $<$ agers $>$ of the $w^{c}[<b w t$ of Pharaoh $(L ! P ! H !)$ going from the $>$...]

$32[\ldots<$ and the gardens of the $>]$ nmhw taking their forage $(s m w)$ daily, saying, "it is for the $b_{3}$ k $w$ <of Pharaoh (L!P!H!)" (thus) giving themselves over to stealing (from) these $n m>]$ hw for their pšs-work. To the effect [<that this is wrong: Let the foragers of the w'bwt

33. of Pharaoh (L!P!H!) go forage for the $b_{3} 3 \mathrm{kw}$ of Pharaoh (L!P!H!) from the magazines $>$....

$34 \ldots<$ taxing $(m s \tilde{s} t)$ in the southern and northern districts extracting corn and flax and vegetables from the burghers $[\ldots]$

504 Excerpts only are presented here, as the text has been admirably edited, cf. Kruchten, Horemheb.

505 The word sht appears where "beneficial things" are sought. Kruchten's "action bienfaisante" for nfrw and "ce qui est utile" for shr (Horemheb, pp. 20-21), may overlook the fact that shr may in fact be the very goods we are looking for.

sos Kruchten, Horemheb, p. 30, "meltre au travail".

567 Cf. Kruchten, Horemheb, pp. 42-44.

508 Although the text is quite fragmentary, logic suggests that the victim has acquired the boat in order to carry out his bikw, but the owner is demanding rent before the bikw has been accomplished, and that this is what is to be prevented.

569 Cf. Germer, Flora, p. 174: safflower, not safron, p. 199

570 Kruchten (Horemheb, p. 195) translates "qui du serviteur, qui de la servant", but the text can be read straight without restorations. 
Right side

$5[\ldots]$ And as for the šzyt of silver and gold $[\ldots]$

$\sigma$ [<My majesty ordained>] one should cause to be halted the permitting of exacting the šsyt of anything from the courts of Upper and Lower Egypt [...] that extracting diw from a single double granary $[. .$.

\section{COMMENT}

The Decree is (very badly) preserved on a large stone stele at the southern side of Karnak, on the north side of the IX Pylon. From the lamentably mutilated text it can be concluded that the $b^{3} k w$ was a payment from the nmhw to Pharaoh unrelated to the obligations of his officials, which were also apparently termed $b_{3} k w$. There are some tantalizing items in the final part of the text, but to include them would drive us into the realm of speculation. It is however clear that Kruchten is correct in assuming that the question of the legal size of corn measures is touched upon in the text. The text attempts to re establish order in a very detailed level, assuring both the king his rightful revenues, and the people their rights.

This text is the only text to mention the $b_{3} k w-n-p^{-c_{3}, \text { the }} b^{3} k w$ of Pharaoh. The term is not preserved a single time, but Kruchten found the term in the copies of his predecessors and does not indicate that it is one of his (commendably conservative) proposed restorations. This text is the only royal text of its kind. 


\section{TRANSLATION OF EXCERPTS}

1 Regnal Year 4, I prt I. The beginning of eternity, the commencement of happiness, of eons of contentment, of millions of jubilee festivals on the throne of the horizons of eternity, in the reign of Atum, under the Majesty of [...]

$2[$ Seti I $][\ldots]$ Lo, his Majesty was in Memphis $(d m i n$ hwt-kz-Pth $)$ earning the praise of [the major gods of Egypt]

3-5 [... Textual Omission....

6 [who are saying: "...] The heart of the Lord of the Necropolis [Osiris] is joyous seeing thee upon the dais like Re, for thou art upon earth ordering the Two lands, making festive the houses and cities, $[\ldots]$

$7[\ldots]$ construct(ing) his [Osiris'] House [...]

$8[\ldots]$ the palace within it richly adorned with new $\underline{d}^{c} m$-gold from the mountains $[. .$.

9-13 [...Textual Omission...]

$14[\ldots][\langle$ The treasuries $\rangle]$ are full, with $[\langle$ ric $\rangle]$ hes, silver $[\langle i n\rangle]$ heaps from the earth

15 , royal linen and textiles in every (quality), millions of moringa oil, incense, wine, honey, beyond measure [...There are fowl, cattle, slaves, poultry farms, etc....

16-18 [...Textual Omission...]

$19[\ldots .$.$] beyond means of counting$

20 their abundance. $[\langle$ Their $(?)>]$ htri $[<$ re- $(2)\rangle]$ new $($ ed $)$ for their days in the commands of divine possessions. [...Cattle in herds: with herdsmen, with transport vessels, and good pasture land are provided ....

21-23 [...Textual Omission...]

$24[\ldots] \mathrm{He}\left[\right.$ Seti II] has made for him [Osiris] cadastre lists ${ }^{572}$ with hundreds of thousands of plough-lands, ${ }^{573}$

25 islands, high-lands: all cultivable fields ideal for harvest. ${ }^{574} \mathrm{He}[$ Osiris] may count

57i KRI I: 45-58; KRIT I: 38-40; KRIN I: 48-55; F. UI. Griffith, "The Abydos Decree of Seti I at Nauri," JEA 13 (1927): 193-208; W.F. Edgerton, "The Nauri Decree of Seti I: A Translation and Analysis of the legal Portion", JNES 6 (1947): 219-230; A. H. Gardiner, "Some Reflections on the Nauri Decree", JEA 38 (1952): 24-33.

572 Cf. supra p. 167 n. 483.

573 For nhb cf. A. H. Gardiner, Wilbour Il: 28-29, n. 10 and pp. 178-181. The translation "fresh-land" is based on the contrast between tni- or "tired"-land, as well as the verb, "to open". One can however also "open" land by ploughing it. This ambiguous interpretation has been selected in order to emphasize the distinction between $n h b$ "plough"-land and $\mathrm{m}^{3} \mathrm{w}^{\prime}$ "new"-land, while avoiding the misleading impression that the question has been satisfactorily resolved. But of supra p. 41 n. 60.

574 wihyt: cf. Caminos IEM, pp. 412-416. Translated "abundance" by A. H. Gardiner, R. Caminos correctly remarks that it also meant "yield", as pointed out in Wb. I: 258, 8. R. Caminos (loc. cit.) also identified the connection with $n f r$, while avoiding the logical but perhaps incorrect distinction made in the Wb. (1: 258, 8; II: 261,4$)$ between $n f r=b a r l e y$ and wihyt=wheat (Spelzen, whereby emmer would be meant, as Triticum spelta is not found in Egypt: cf. D. M. Dixon, "A note on cereals in ancient Egypt," in Ucko/Dimbleby, Domestication, p. 131). Interesting is the use of the word in Urk. IV: 925,5 (TT 85; P-MI: 170-175), where it is said of the Harvest gaddess: "Renenutet, she gives the whhyt." Harvest is perhaps the most appropriate meaning here (cf. 
them, offered to his $k_{3}$. He [Seti 1] has made for him [Osiris] $k^{3}\left[\left\langle r_{3}^{3}\right\rangle\right] r t$-boats to transport [<the> ]ir every harv[<est>] (wshyt). The granaries are swollen with corn, the heaps of it reaching heaven. $O[<n e>]$ [Pharaoh $]^{575}$ has made a decree command26 -ing that its [ the temple's] serfs throughout the $t s w^{570}$ of Upper and Lower Egypt, and all its [the temple's] people are exempted and protected like the geese on the (river) banks in all their desires and occupations dedicated [<to $>]$ his $k_{3}$, in the great $[<t e r-$ ritory $>]^{577}$ that he loves. They shall not be taken away (?) by others, nor shall they be interfered with,

$27[\langle f\rangle]$ rom son $[<$ to son, estab $>$ ] lished in their occupations to the ends of the limits of eternity. I SSeti I] have purified Your ${ }^{578}$ Mansion millions of times. I have exempted those within it repeatedly. I have placed the serfs who came into existence for me ${ }^{579}$ into Your Mansion. You will not (be) part(ed) from them. I began there. From Your childhood

28 until the ruler (of?) Pth $580[\ldots .$.$] content (?) in performing m^{3}{ }^{c} t,[<$ sweetening $>$ their? $]$ bringing to them the $\check{s}_{3} y t^{581}$ I gave to Him the whole of Upper Egypt as well as Lower Egypt as the sustenance of His ki's.

29-40 [...Legal Sanctions and Guarantees...]

$41[\ldots]$ As for ${ }^{582}$ any Viceroy of

42 Cush, any military official, ${ }^{583}$ any Mayor,

43 any Controller ( $w d w$ ) or any person who removes any people from the Mansion of $M n-M_{3}^{c} t-R^{c}$, Heart's Ease in Abydos forcefully $\left(m k f^{c}\right)$ from district to district, as

also KRI II: 326, 14). The Vizier (Urk. IV: 1390,14; T 93; P-M I: 190-194) is called the lord of the withy" where "harvest" is perhaps superior to bounty or abundance as it refers to neither Pharaoh nor a god, but a mere human. Cairo JdÉ 28569 (G. A. Gaballa, "Three Acephalous Stelae," JEA 63 [1977]: pl. 22, x+2) refers to "increasing the whthyt in this land" where harvest is again the most suitable translation. The text of the "Blessing of Ptah" (KR/II: 267,$1 ; 3)$ refers to npri withyt, "the corn of the harvest", if the lext is suitably emended. P. lansing 12,4 (IEM 111,2) can be translated with "harvest-corn" as harvest alone is not appropriate here, as far as this peculiar text can be understood. The principle may be that wshyt was a general word for harvest, with šmw bearing a more specific meaning ir $<t>W$. In F. Ll. Griffith's facsimile (JEA 13: pl. 40, 1. 25) there appears to be sufficient space for a $t$ to be restored. While K. A. Kitchen $(K R \mid$ I: 50,4$)$ resists temptation, it is not unreasonable to succumb.

576 F. Ll. Griffith renders "districts".

$5 \pi$ Cf. KRI I: 50,6 with K. A. Kitchen's note $(K R \mid 1: 50,16)$ against F. II. Griffith's facsimile, JEA 13: pl. 40, I. 26.

578 There seems to be a consistent effort to distinguish the seated man from the divine determinative, indicating that these are to be translated differently. Thus the divergence from F. LI. Griffith's translation, where both are rendered with the first person singular. This and the following references of a similar nature should be understood as referring to Seti (first person singular) and Osiris (second person singular), etc.

579 Or: "which I have created". CF. K. A. kitchen's note, KRI I: 50,16.

580 F. U. Griffith's rendering does not take account of the difficulty posed by im, which is not followed by a suffix, but a preposition (according to the translation), aside from the clear presence of the divine determinative. Thus, nhn is rendered as a sdm.f form here, followed by a conventional use of nfryt $r$. The philosophical meaning is not however enhanced by a correct reading.

581 As. K. A. Kitchen points out $(K R \mid l: 50,16)$, it is not at all certain that this mutilated passage uses šzyt, and not hazyt, although probable.

582 F. U. Griffith correctly emended the text here to ir.

583 hry $p \underline{d}$ : Whether this refers to an officer, literally "Chief of Archers" or to an official responsible for foreigners is not clear. Helck, Militärführer, p. 73, translates "Oberst" (Colonell); Schulman, Rank, p. 4 and passim, translates "commander of a host". 
pressed to corvée labour, ${ }^{584}$ to plough as

44 corvée labour or to harvest; or who shall likewise remove any woman or any man of the Mansion of Mn-M: ${ }^{c} t-R^{c}$, Heart's Ease in Abydos; or likewise any of their slaves forcefully for any task

45 which is anywhere in the entire land; or likewise any charioteer, any stable master or any other person belonging to the Crown Estate sent on any mission of Pharaoh (L!H!P!) who shall take any people of the Mansion of $M n-M_{3}{ }^{c} t-R^{c}$, Heart's Ease in Abydos

46 from district to district as pressed or corvée labour to plough as corvée labour or to harvest, or likewise do any task: the Law shall be enforced against him, in that he shall be beaten ${ }^{585}$ with 200 blows and five deliberate wounds, 580

47 together with exacting from him the bikw of the Mansion of Mn-M; ${ }^{c} t-R^{c}$, Heart's ease in Abydos for every day he shall spend with him. And he (himself) shall be given over to the Mansion of Mn-M; ${ }^{c} t-R^{c}$, Heart's Ease in Abydos. And as for

48 any Viceroy, any Military Official, any Mayor, and Controller, and any person sent on a mission to Cush who shall detain any vessel of the Mansion of $M n-M_{3}^{3} t-R^{c}$, Heart's Ease in Abydos, and likewise the boat of any controller of the Estate

49 mooring it for even a single day, saying, "I will seize it as the requis[<ition>] from him $f[\langle 0 r\rangle]$ any $[\langle$ mis $\rangle]$ sion of Pharaoh $(L ! H ! P !) "$ : The $L a[\langle w\rangle]$ shall be enforced [<against>] him, [<in that he shall be beaten with>] 200 blows and five deliberate wounds.

50 The b3kw of the boat shall be exacted from him for every day that he shall have moored it. And he (himself) shall be given over to the Mansion of $M n-M_{3}^{c} t-R^{\prime \prime}$, Heart's Ease in $A b[<y d>]$ os. [ $<A n d>]$ as for any official, any Field Supervisor of this Estate,

51 any plough herdsman ${ }^{587}$ and any controller who shall violate the boundaries of the fields of the Mansion of $M n-M_{3}^{c} t-R^{c}$, Heart's Ease in Abydos to shift the boundaries: the Law shall be enforced against him, culting off his nose and his two ears,

52 and he shall be given over to be a cultivator in the Mansion of Mn-M3ct- $R^{c}$, Heart's Ease in Abydos [............

For the expressions brty and bhw, cf. A. H. Gardiner (JEA 38: 28-29) where he correctly points out that "brt in our decree cannot mean corvée, since that is the meaning of bhw which follows". That it cannot refer to an ordinary type of "contract" labour (his own rendering with "?") he himself made quite clear. It can only refer to some kind of "assigned" or "enforced" labour. It is usually associated with the Hebrew brt", "covenant", "pact". Although the use of the normal $r$ in place of the lion $r$ would speak against the reading of an $I$, the Akkadian bilt and Aramaic blt suggest themselves.

585 Sir Alan renders this quite correctly (JEA 38: 30).

586 F. LI. Griffith (JEA 13: 201, n. 15), W.F. Edgerton (JNES 6: 223, n. 28) and K. A. Kitchen (KRI I: 53: 7; 17) concur in the exclusion of the single superfluous stroke. The rendering of wbnw sd is a variation on that provided by F. U. Griffith and W.F. Edgerton ("pierced wounds"), since wbnw themselves are "open wounds" (Deines/ Westendorf, Wörterbuch l: 178), while sd has the meaning "to inflict" (CDME, p. 257). Without any unduly sadistic thoughts one is obliged to assume that five intentional wounds are to be inflicted upon any law-breaking official who has the misfortune to suffer several (unintentionall) open wounds in the course of the flogging.

CF. G. R. Hughes, SDIL, pp. 45-47, for the Demotic references to ' ${ }^{3} m ;$ Wb. V: 384, 14-385,9. 


\section{COMMENT}

The Nauri Decree of Seti I is intended to protect the lands and servants, and therefore the income of the temple of Osiris at Abydos. Seti I awarded the temple massive donations of land and supplies and serfs, "htri anew", ${ }^{588}$ and, perhaps "bringing the šsyt (?)". ${ }^{589}$ In the legal sanctions he stipulates that "the $b ; k w$ of the boat will be exacted" from a miscreant official "for every day he shall have moored it". 590 It seems to be clear that the bikw referred to here are for the temple, in contrast to the bikw of Pharaoh in the Horemhab decree. There is no evidence of any exemptions or special arrangements, as the evidence merely indicates that the temple personal are protected from interference, and threatened with grave sanctions should they violate the property rights of the temple.

589 I. 28. K. A. Kitchen $(K R I I: 50,16)$ points out that it is not even certain that this is šzyt, and not hizyt, but the former is possible. 


\section{P. HARRIS 1591}

Summary OF THE COMPLETE. TEXT

I INTRODUCTION: 1, I-1,8

The Pharaoh Ramesses III announces that he intends to delineate all of the gifts which he has arranged that the gods receive during his prosperous reign

II THEBES: $3,1-23,6$;

preceded by vignette

a Introduction: $3,1-9,9$

The King begs the gods to take care of his soul and reminds them of all the wonderful things which he has done for them, including everything from massive construction projects to overflowing granaries and precious trinkets. Among these general statements are sentences including htri and bikw

b The List: 10,1-11,11

of the of the temple dependents, cattle, gardens, forests, lands, boats, lumber and villages which the Pharaoh has presented to the temples

c The List: 12a, 1-12b,13

of the $\breve{s}_{3} y t, b 3 k w-r m t$ products from mining, agriculture, manufacturing, etc. characterized as the "annual htri" of the dependents of the temples which the King gave the temples during his reign

d The List: 13a, $1-16 b, 12$

of precious metals, precious stones, linen, oils, wine, animals, etc., (referred to as inw) which the King himself presented during his entire reign

e The Grain Offerings: 16b, 13-16b, 15

of the entire reign $(2,981,674$ khar $)$

f The List: $17 a, 1-21 b, 10$

of the Festival Offerings: cakes, loaves, dates, flowers, incense, etc., but also cattle, fowl, fish, etc., provided by the King himself

$g$ The List: $21 b, 11-21 b, 16$

of the divine images made of metal and wood

h The final prayer: $22,1-23,6$

591 Only excerpts are provided in the translation following the summary, with the page, line (e.g. 48b,7) numbers of those of the original text (Birch, Facsimile, used by Erichsen, Harris). Roman numerals (e.g., IVa) refer to the sections of the text in the summary. Grandet (Papyrus Harris, pp. 20-22) has produced a comparable organization of the text, and cites those of his predecessors as well. Those requiring the entire text are referred to Grandet, Papyrus Harris and BAR IV: 87-206.

The purpose of the passages quoted here is to provide the reader with an image of what $P$. Harris $\mid$ contains, not a comprehensive account. This translation was made prior to the publication of Grandet, Papyrus Harris, which is the authoritative translation. 
III Helopolis: $25,1-41 b, 6$

preceded by vignette

a Introduction: $25,1-30,6$

as above for Thebes

b The List: $31,1-32 a, 6$

of temple dependents, cattle, gardens, forests, land, boats, lumber, and villages which Pharaoh presented to the temples

c The List: 32a,7-32b, 14

of the $\breve{s}^{3} y t$ bikw-rm! products from mining, agriculture, manufacturing, etc., characterized as the "annual htri" of the dependents of the temples

$d$ The List: $33 a, 1-34 b, 5$

of precious metals, precious stones, linen, oils, wine, animals, etc. /characterized as inw), which the King himself presented during his entire reign

e The Grain Offerings: $34 b, 6-34 b, 9$

of the entire reign ( 1 '097'624 khar)

$f$ The List: $34 b, 10-37 a, 13$

of the Festival Offerings: cakes, loaves, dates, flowers, incense, etc., but also cattle, fowl, fish, etc., provided by the King himself

$g$ The Nile Offerings: $37 b, 1-41 b, 6$

of precious metals and precious stones, as well as loaves, beer, oils, incense, greens, honey, etc., which the King presented to the Nile at Heliopolis

h The Final Prayer: $42,1-42,10$

IV MEMPHIS: $44,1-56 b, 10$

a Introduction: $44,1-50,1$

preceded by vignette as above for Thebes

b The List: $51 a, 1-51 b, 2$

of temple dependents, cattle, gardens, forests, land, boats, and a village which the Pharaoh presented to the temples

$c$ The List : $51 b, 3-52 a, 3$

of the $\check{s}^{3} y t$ bikw-rm! products of mining, agriculture, manufacturing, etc., characterized as the "annual htri" of the dependents of the temples

$d$ The List: $52 a, 4-53 b, 11$

of precious metals, precious stones, linen, oils, wine, animals, etc., which the King himself presented during his entire reign

e The Grain offerings: 53b, 12-54a, 1

of the entire reign ( $947^{\prime} 688$ khar) 
$f$ The Nile Offerings: $54 a, 2-56 a, 12$

of precious metals, and precious stones, as well as loaves, beer, oils, incense, vegetables, honey, etc. which the King presented to the Nile at Heliopolis

$\mathrm{g}$ The Final Prayer: $56 \mathrm{~b}, 1-56 \mathrm{~b}, 10$

V THE SMALIER Tempies: $57,1-666,10$

a Introduction: $57,1-60,10$

The King describes the various services which he has caused to be rendered to the less significant sanctuaries of the land, in general terms, without once referring to htri, šsyt, b3kw, b3kw-rm!, etc. with the specific meaning of "imposition", "levy" etc., in stark contrast to the regular use of these terms in the parallel paragraphs for the temples of Thebes, Heliopolis and Memphis

b The List: 61a, 1-62a, 10

of temple dependents, cattle, land, gardens and shipyards, which the Pharaoh himself presented to the temples

c The List: 62a, 11-62a, 13

of grain, greens and flax, equivalent to, but not explicitly stated to be the annual htri of the temple dependents

$d$ The List: $62 b, 1-65 c, 16$

of royal gifts: precious metals and precious stones, linen, incense, honey, oils, fowl, cattle, lumber, leather, gardens, land, etc., as inw as above in parallel paragraphs

e The List: 66a, 1-66a,4

of grain provided for the divine offerings

$f$ The Final Prayer: $66 \mathrm{~b}, 1-66 \mathrm{~b}, 10$

as above, with a reference to the inw as part of an optative form

VI THE TOTALS: $67,1-74,12$

a Summary: $67,1-68 b, 3$

of everything which the King has turned over to the various temples

b The list: $68 \mathrm{~b}, 4-70 \mathrm{a}, 2$

of the šsyt bikw-rmt "which the King gave to the various temples "as their annual htri"

c The List: 70a, 3-74, 10

of the royal gifts

d The List: 74, 1 1-74, 12

of the grain provided for the festival offerings (khar $5^{\prime} 279^{\prime} 552$ )

Vil The Historical summary: 75, 1-79, 12

The King explains himself 
The paragraphs must evidently be distinguished from one another, not only based on the items listed under each heading, but primarily according to the headings themselves. The same types of items appear under two different headings, with respect to one and the same temple. The King provided various temples and sanctuaries with dependents, as well as large numbers of articles from his own reserves. He seems to have taken credit for the objects given by the dependents to the temples as "their annual htri". The smaller temples did not receive any deliveries from their dependents classified as $b_{3}{ }^{k} w w-r m t, ~ \breve{s}_{3} y t$, or htri. The King alone is responsible for the items termed inw being delivered to the temples, as they do not seem to have their own inw income.

\section{TRANSLATION OF EXCERPTS}

\section{INTRODUCTION 1, 1-1,8}

1,1 Regnal Year 32, III šmw 6 under the Majesty of the King of Upper and Lower Egypt, Ramesses III [...] beloved of all the gods and goddesses

$1,2[\ldots]$

$1,3[\ldots$ who $]$ relates in praise, adoration and adulation the mighty and numerous presents which he has made as King and Ruler while still on Earth [for] the Estate ${ }^{592}$ of his august father, Amonrasonther

1,4 and Mut and Khons and all the deities of Thebes and for the Temple of his august father Atum, the Lord of the Two Lands at Heliopolis and Ra-Harakhte, Iw.s- 'ss.t, Nb.t-hip and all the deities of Heliopolis, and for the Temple of his august father

1,5 Ptah the Great, South of his Wall, the Lord of Memphis ('nh-t3-my), and great Sakhmet, consort of Ptah, and Nefertem, the Shelter of the Two Lands, and all the deities of Memphis $\left(H_{w} w_{-}-k_{3}-P_{t h}\right)$, and for his august fathers, all the gods and goddesses [sic!] of Upper

1,6 and Lower Egypt, (and) namely the beautiful and [<numerous $>$ gifts [<made by the peos]ple of the Land of Egypt, (and) every land, assembled in their entirety in a single account ${ }^{593}$ in order to inform

592 The translation of the word $p r$ in such contexts has always been difficult. In the text of this book, it is frequently rendered as "Temple" or "Estate" (in the case of Amonrasonther). Cf. P. Spencer, Temple, p. 20.

593 This restoration differs from that of Erichsen and Breasted; and Grandet (Papyrus Harris, p. 221) has followed them, although he likewise translates the sentence as ending with a single complete list. The present writer has some difficulty in thinking of presents made to the people, as none such are listed, while it is frequently stated that Egyptians and foreigners were responsible for certain categories of gifts. The unanimous acclaim is more logical if it is from the foreigners for the gods, rather than if we assert that Ramesses III actually wanted to help the foreigners! It is the duty of the people to make giffis to the gods. The reading "land/ every land" is not satisfactory, but this matches the text, although very probably something is missing here. 
1,7 the fathers: all the gods and goddesses of Upper and Lower Egypt [sic!]; the people: nobles and commoners all; and the sunfolk, of the many numerous and mighty presents

1,8 which he made while still on Earth, as great ruler of Egypt.

II Thebes: 3, 1-23,6

Ila

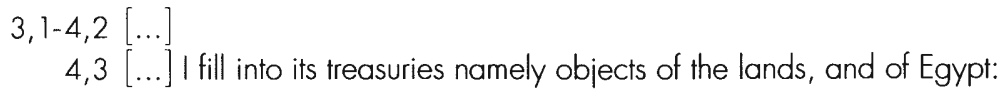

4,4 gold and precious stones, all ${ }^{594}$ (abundant) by the hundred-thousand. 595 Its granaries overflow with the good corn of successful harvests. [lts] cultivable land, its herds: their numbers like unto the sand grains of the river banks. I have htri for it

4,5 Upper and Lower Egypt. Nubia and the Phoenician Coast are burdened with their bikw for it. Filled with the plunder which thou hast given me from the foreign enemies $[\ldots]$

$4,6[\ldots]$

$7,4[\ldots]$ I have endowed for thee festival offerings for the festivals of seasonal commencement, to be presented ${ }^{596}$ before thee at thy every appearance, provided with bread and beer, cattle and fowl, wine, incense varieties, (all) beyond count. They were htri anew ${ }^{597}$ to the officials and controllers 598 in excess of all the gifts which I have made for thy $k_{3}$. [...]

$7,5-9,1 \quad[\ldots$ Textual Omission...]

$9,2[\ldots]$ The foreigners of Syria (Rtnw) came to it

9,3 bearing their inw to it, as appropriate for its divinity. I have drawn the earth (?) as a whole to thee, burdened with their $b 3 k w$ to offer it to Thebes, $9,4-9,9[\ldots]$

594 Since ' $3, t$ is a feminine, such a scrupulous scribe would have written $n b . t$ correspondingly, were we to follow Breasted.

595 One could be tempted to render this as "like tadpoles" as suggested in the following sentence, using a simile with grains of sand, but the corresponding entry for Heliopolis $(28,1$, infra) shows that a figure is to be understood, and not a simile.

590 The text has $r-m^{3}$, which could be interpreted 'renewed", but in analogy to the similar passages, an $s$ is missing, which has been restored here, for the reading, "presented".

597 iw.sn htri $m$ miwt.... One would expect iw.sn hr htri in a text of this quality. It is possible that this is a past passive participle, "they being htri anew to". As the goods are not identified as htri, bikw, etc., it is possible that this use of htri actually means "assigned to" in a general sense and not in a specifically fiscal sense.

598 Cf. J.- M. Kruchten, "l'évolution de la gestion dominiale sous le nouvel empire égyptienne," in: Lipinski State and Temple, II: 517-525; j. Černý, Community, pp. 255-259.

599 Or "mysterious". 
$\mathrm{IIb}$

10,1 Summary of the possessions, herds, gardens, fields, mnš barges, dockyards, villages, which Pharaoh (L!H!P!) gave to the Estate of his august father,

10,2 Amonrasonther and Mut and Khons and all the gods of Thebes, imy-pr ${ }^{600}$ eternally and forever.

$10,3-10,16[\ldots]$

1 1,1 Divine images, divine tabernacles, divine statues of favourites ${ }^{601}$ for which bikw the officials and standard bearers, agents, and people of the land,

11,2 which Pharaoh $(L ! H ! P !)$ caused made as endowment $($ hr sdf $)$ of the Estate of Amonrasonther under the authority of those responsible for them, for eternity and forever.

11,3 gods

making individual pieces, total

11,4 heads total

11,5 cattle and sheep and goats

11,6 gardens, etc

11,7 fields arouras

$11,8 \mathrm{k} 3 \mathrm{r}$ - and mnš-vessels

11,9 carpenters' workshops

11,10 villages in Egypt 56

11,11 villages in Syria and Nubia 9, total $2^{\prime} 756$

5'164

$86 ' 486$

$421^{\prime} 362$

433

$804^{\prime} 168.25$

83

46

65

Ilc

12a, I ltems: the šsyt bikw-rmt of all the serfs of the Mansion ${ }^{602}$ of the King Ramesses III [...] in the Estate of Amun

12a,2 in the Southern and Northern districts [of the Land of Egypt] under the authority of the officials of the House of Ramesses III [...] in the Estate of Amun in the city; the House of Ramesses III [...] in the Estate of Amun;

$12 a, 3$ the Mansion of Ramesses III [...], united with joy ${ }^{603}$; in the House of Imnm-ipt; the House of Ramesses III [...] in the House of Khons, the five herds

12a,4 made for this House given by the King Wsr-Mi: ${ }^{c} t-R^{c}$, beloved of Amun $(L ! H ! P !)$, the great god, to their treasuries, magazines, and granaries

12a,5 as their annual htri.

Cf. supra p. 179 n. 538.

ib-ib, cf. Caminos, LEM 29.

CF. P. Spencer (Temple, pp. 21-27), where hwt ("Mansion") is shown to be a specific term for the mortuary temples, although frequently used with other or broader meanings. The temples listed are the Medinet Habu Complex, the barque shrine at Karnak, the temple at Luxor, the temple of Khons and the southern Karnak temple. C. I. 5,7, as indicated by W. Erichsen's "sic". 
$12 a, 6$ fine gold

$12 a, 7$ gold of the mountain of Coptos

$12 a, 8$ gold of Cush

$12 a, 9$ total: fine and desert gold

$12 a, 10$ silver

$12 a, 11$ total: gold and silver

$12 a, 12$ copper

$12 a, 13$ royal linen, fine thin textiles:

total:

$12 a, 14$ linen

$12 a, 15$ incense, honey, sesame oil

$12 b, 1$ sweet wine (2), wine

12b,2 silver, as objects: the bikw-rmt, consecrated for the

$12 b, 3$ measured corn: 607 the $b 3$ kw of the cultivators

$12 b, 4 \quad$ fresh greens

$12 \mathrm{~b}, 5$ flax

$12 b, 0 \quad$ waterfowl: the $b 3 k w$ of the fowlers and fishers

$12 b, 7$

$12 b, 8$ oxen; ox calves; short-horned cows; registered cattle entered, of the herds of Egypt ${ }^{\text {oil }}$ oxen, ox calves; short-horned cows; cattle: the $b: k w$ of the Land of Syria $(t 3 . w n$ his $)$ total:

$12 b, 9$ live geese as క̌syw

$12 b, 10$ cedar skty-ferries ${ }^{011}$

\begin{tabular}{|c|c|c|c|}
\hline & & $\infty 04[$ & $\mathrm{kg}$ \\
\hline 217.5 & deben & & 19.79 \\
\hline 61.3 & deben & & $5.58]$ \\
\hline 290.8125 & deben & & $26.46]$ \\
\hline 569.6125 & deben & & 51.83 \\
\hline $10^{\prime} 964.9$ & deben & & 997.8 \\
\hline 111546.8 & deben & & l'050.76 \\
\hline *[ $\left.111^{\prime} 534.55\right]$ & deben & * & I'049.64] \\
\hline $26 \cdot 320$ & deben & 605 & 2395.12 \\
\hline
\end{tabular}

3722

3'795

1 '047

$25^{\prime} 405$

fine thin garments

deben

$3^{c c}$ vessels 600

$3^{\text {cec }}$ vessels

3'606.1 deben

328.2

$309^{\prime} 950$

$24 ' 650$

khar

$64^{\prime} 000$

${ }^{\infty} 289 ' 530$

miw-bundles ${ }^{\mathrm{b} 08}$

$n$ b w -bundles

604 The figures between square brackets are there to orient the modern reader in the relative value of the items. Figures in square brackets preceded by an asterisk are the figures produced by adding up the preceding figures, and are thus the tolals corresponding to the text, but need not necessarily be correct, as the mistake may lie in the scribe having written the inappropriate figures rather than having made a mathematical error.

605 The proportions of gold and silver presented here are quite curious, when compared to the relative values of these metals. While the exchange value of gold: silver: copper was $1: 2: 120$ at the time (ct. J. J. Janssen, "Prolegomeno to the Study of Egypt's Economic History," SAK 3 [1975]: 155-156), the ratio of the objects presented is 1:20:40. The aciual quantity of gold reported does not compare favourably with the more than $15^{\prime} 000 \mathrm{~kg}(\mathrm{sic}$ ! cf. Janssen, SAK 3: 154) presented by Thutmosis III.

600 It is not entirely clear what value these vessels signified, cf. Janssen, Prices, pp. 337-338.

$\infty 07$ šs hq";: strictly "corn measure corn". The tolal would be the quantity expected of 1550 workers with an obligation of 200 khar each (cf. O. Gardiner 86, vso. 3/H.O. 82,3; supra pp. 144-145 n. 408), which is not incompatible with the extraordinary numbers of temple dependents.

$\infty 08$ The value of these bundles is unknown, cf. Janssen, Prices, p. 360.

809 Although the quantities appear a bit fantastic, a comparison with the recto of the Turin Canon shows that extraordinary quantities of fish and birds were actually collected. Cf. supra p. 160 and Gardiner, Royal Canon, pl. 6: 3,5 with 200 '000 tish in a single entry.

sio "[... ] ihw $n$ qdwt $n r^{3} n$ mnmnwt kmt". The mearing of $q d t$ in this context $(W b . V: 80,6)$ is as mysterious as that of $n r^{3} n$ mnmnw ( $W b$. II: 392, 12). qdt (in this sense) might appear in Gurob Fragment $F, 1,7(R A D$, p. 19,3). which is not particularly enlightening, while the second term is not present elsewhere. II is possible that $P$. Tuin 1882, vs. 2,8 (LEM, p. 123,1; Caminos, LEM, pp. 453-454; A. H. Gardiner, "Ramesside Texts Relating to the Taxation and Transport of Corn," JEA 27 [1941]:21) provides a hint for the proper translation, and this opportunity has been exploited here in the interest of readability.

011 S. Glanville ("Records of a Royal Dockyard of the Time of Thutmosis III: Papyrus British Museum 10056," ZÄS66 [1931]: 105-121 and Z̈̈S 68 [1932]: 7-41; 68: 14-15, $31 \mathrm{n} .2$ ) suggests that these vessels were either foreign boats themselves or Egyptian copies of such boats. Another novel suggestion is that the names denote the ports of call of these various ships. Jones, Glossary, pp. 145-146 is less committal. 
$12 b, 11$ acacia skty-boals; floating stalls; $h w$ hnt-ih callte transports; ${ }^{612}$ t3riti-skiffs and $k_{3}^{3}$ r corn transport vessels 71

$12 b, 12$ lotal of cedar and acacia vessels

$12 \mathrm{~b}, 13$ items: from the oasis/foreign wood in greal quantities for the divine offerings

Ild

13a, 1 Silver and gold, real lapis lazuli, real turquoise, all real precious stones, ore, garments of royal linen, extra ${ }^{613}$ linen,

13a,2 thin linen, fine thin linen, decorated garments, jars, fowl, and all things which Wsr-M:ct-Rc beloved of Amun (L!P!H!), the great god,

13a,3 gave as inw of the Lord (LIP!H!) for the provisionment of the estate of his august fathers, Amonrasonther, Mut and Khons

13a,4 from Regnal Year 1 to Regnal Year 31, making thirty-one years.

\section{makes}

$13 a, 5$ fine smithed gold total 42

13a,6 fine gold, chased, ${ }^{014}$ rings of Asia (?), 22

$13 a, 7$ fine gold in inlay, rings of Asia (?), 9

$13 a, 8$ fine gold in chased work, with inlay of precious stones, all real, šaqw of a column for Amun, 1

$13 a, 9$ fine gold incised (a) 015 tablet, 1

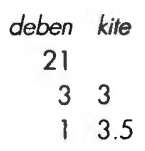

225

$\begin{array}{ll}9 & 5.5\end{array}$

575

*[57 57$]$

45.5

305

$\begin{array}{ll}35 & 0.5\end{array}$

$\begin{array}{lll}16 & 3.5\end{array}$

$48 \quad 4$
19

198

62

907.5

1835

1125

123

277

$\begin{array}{ll}57 & 4.5\end{array}$

1054

$74 \quad 4$

303

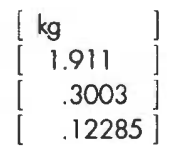

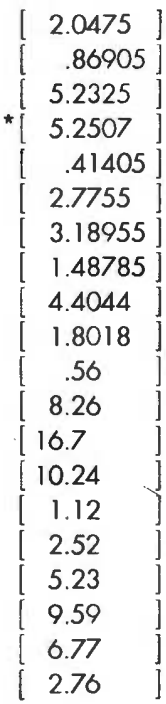

CF. Naville, Tb. II: 89: Sp. 26, 4.

CF. Janssen, Prices, pp. 489 .

CF. BAR IV: 129, "raised work". The weight would confirm the suspicion. $m$ qhah is used of metal and stone: culting into metal - incision - would appear to be the suitable elymological guess here. (BAR IV: 130, "hammered" is elymologically less likely).

nbw $n$ sp sn.

Cf. Janssen, Prices, p. 409. The weight seems far too great for simple cups.

Taking account of determinative after $\underline{h} \underline{d}$. 
13b, 13 silver incised (2), rablet, 1

\begin{tabular}{|c|c|c|c|}
\hline 19 & 3.5 & & 1.76 \\
\hline 287 & 0.5 & & 26.12 \\
\hline 100 & & & 9.1 \\
\hline 827 & 1.25 & & 75.27 \\
\hline *[826 & 4.5] & $\star$ & 75.21 \\
\hline 1'010 & 6.25 & & 91.97 \\
\hline * $\left[11^{\prime} 010\right.$ & $3]^{619}$ & $\star$ & 91.94 \\
\hline
\end{tabular}

14a,2 lapis lazuli, real stones, 2

14a,3 copper, incised (?) Iablets,

$13 \mathrm{~b}, 14$ silver incised (?), tablet, 2

14a,4 myrrh, dried

140,5 myrrh, dried, hq,?

140,6 myrrh, dried, hin

140,7 myrrh trees

140,8 myrrh seed, in oipe $\quad 100$

$14 a, 9$ royal linen, dw-garments 37

$14 a, 10$ royal linen, dw-upper garments 94

14a, 11 royal linen, hmn-garments $\quad 55$

$14 a, 12$ royal linen, disw-garments 11

14a,13 royal linen, Horus-wrappings (a) 2

$14 \mathrm{a}, 14$ royal linen, $\underline{d} w$-garments 1

$14 a, 15$ royal linen kerchiers $\quad 690$

$14 a, 16$ royal linen, mss-garments $\quad 489$

$14 a, 17$ royal linen, garments of the august statue of Amun 4

$14 \mathrm{~b}, 1$ total of royal linen garments $\quad 1$ '383

$14 \mathrm{~b}, 2$ mk-shawl 020

14b,3 mk-cloak ${ }^{621} \quad 1$

$14 \mathrm{~b}, 4 \quad m k$-covering of cloth for the august image of Amun 1

$14 \mathrm{~b}, 5$ total of mk-clothing: 3

$14 \mathrm{~b}, 6$ fine thin $d w$-garments $\quad 2$

$14 b, 7$ fine thin dw-garments 4

$14 \mathrm{~b}, 8$ fine thin $d w$-upper/over garments 5

$14 \mathrm{~b}, 9$ fine thin scarves 31

$14 \mathrm{~b}, 10$ fine thin mss-garments $\quad 29$

$14 b, 11$ fine thin kilts (?) 4

$14 \mathrm{~b}, 12$ total fine thin clothing 75

$14 \mathrm{~b}, 13$ smooth disiw-garments $\quad 876$

$14 \mathrm{~b}, 14$ smooth mss-garments $\quad 61779$

$14 \mathrm{~b}, 15$ lotal smooth clothing $\quad$ 7'125

$4 \mathrm{~b}, 16$ total royal, $m k w$, fine thin, thin smooth articles of clothing

8.586

*[9' 116$]$

15a,1 white incense, mnt-jars ${ }^{\circ 22}$

2'159

s19 The total here are particularly difficult: 1 '010.625 $\rightarrow 827.125=183.5$, so that lines $(14 a, 1),(13 b, 16)$ and $\{13 b, 5)$ are internally inconsistent. $(13 b, 5\}$ is however erroneous, as Breasted pointed out, and should read 57.7. This correct figure was used for the sum, so that the interim reckoning was not used, demonstrating that the whole document may have been copied line for line, and that searching for errors is amusing but futile, as it is rarely clear exactly which btal is inaccuraie.

o20 Cf. Janssen, Prices, p. 290.

621 Cf. Janssen, Prices, p. 278.

¿22 Cf. W. Helck, "Maße und Gewichte," $L \ddot{A}$ III: 1203, who indicates that a mnw-vessel was an amphora of $20 \mathrm{hin}$, while the preceding page of the same article ( $L \ddot{A} \mid I I: 1201)$ says that the mnt-vessel was an indefinite 
$15 a, 3$ honey, mnt-jars

15a,4 Egyptian sesame oil, ${ }^{623}$ mnw-jars $\quad 2743$

$15 a, 5 \quad$ Syrian sesame oil, msh-jars ${ }^{624} 53$

15a,6 Syrian sesame oil, mnt-jars $\quad 11757$

$15 a, 7$ white animal fat, mnw-jars $\quad 911$

$15 a, 8$ goose fat, $m n w$-jars $\quad 385$

$15 a, 9$ curds, ${ }^{625} \mathrm{mnw}$-jars $\quad 20$

$15 a, 10$ tolal of ; ${ }^{\text {cc }} \mathrm{f}$-jars, ${ }^{, 20}$ full $\quad 9^{\prime} 125$

$15 a, 11$ sweet wine, mnw-jars $\quad 1377$

$15 a, 12$ sweet wine, $k b$-jars ${ }^{027} \quad 1111$

$15 a, 13$ wine, mnw-jars $\quad 20^{\prime} 078$

$15 a, 14$ total of sweet wine and wine mnw and $k b \quad 22: 556$

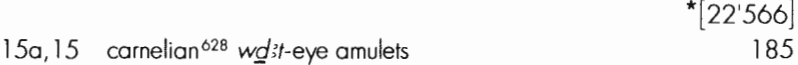

measure, of between 20 and $40 \mathrm{hin}$. The Wb. (II: 66, 4-10) does not distinguish the two. Certainly the traditional identification of the vessels held by the kneeling king at offering scenes as $m n w$-vessels would speak against a volume of $20 \mathrm{hin}$ (10 litres). J. J. Janssen (Prices, p. 330) points out however that P. Turin 1894, 4 suggests that " $5 \mathrm{mnt}$-jars are said together to contain 49 hin. [.. ] mean[ing] that the capacity was $\mathrm{c}, 10$ hin for each". The jars thus probably contained an unspecified quantity of liquid, as the hin measure was occasionally a value measure and not a measure of fluid volume (cf. Janssen, Prices, pp. 108-109).

As a measure of volume, the hin would be roughly half a litre (cf. Gardiner, Wilbour, II: 64). J. J. Janssen (Prices, p. 108) suggests that when measuring sesame-oil, the unit did seem to have been a value as such, with one hin equal to one deben. This raises the question of whether these quantities - in P. Harris I - are values and not quantities, but texts such as $P$. Turin 1894 suggest that it was the quantity and not the value that was measured, so that the quantities given in P. Harris I are probably volume, but the total quantity of sesame-oil in these lines would be dependent upon reading the msh value, and assuming that the mnt-jar had a specific volume value. The total volume of the Syrian and Egyptian sesame-oil in mnt-vessels is the curiously round 4500, which cannot be divided by 31 (even if we add in the 53 msh vessels), but comes out to roughly 145 vessels a year. If we follow Janssen (Prices, pp. 340-341) assuming that the mnt-jar of sesame-oil was 10 hin, the figure would be roughly 22'500 litres.

623 I am sorely tempted to accept Grandet's logically sound suggestion that "sesame oil" should be changed to "olive oil" (pace Grandet, Papyrus Harris II: $47 \mathrm{n}$. 178), but the botanical evidence seems less persuasive (ct. R. Germer, "Olive," LÄN: 567).

624 Through a lapsus calami Erichsen has mnt; BAR correct. J. J. Janssen (Prices, p. $330 \mathrm{n}$. 7) suggests that the volume of the msh was indefinite; cf. Janssen, Ship's Logs, pp. 71-72. W. Helck ("Maße und Gewichte," LÄ III: 1203) suggests that $P$. Turin 68,10 suggests that the msh-jar contained 46 hin, but this is precisely the reference used by Janssen (Prices, p. 330 n. 7; Ship's logs, pp. 71-72) which can only be used to suggest a capacity of C. 55 hin, but only if you disregard the order in which the jars are listed individually. W. Helck intended to cite $P$. Turin $1894(P / R$, pl. 34,3) where two msh jars contain 92 hin, which need by no means be interpreted as suggesting that each held 46 hin.

W. Helck (LÄ HI: 1203) points out that the msh corresponds to the masahta, but the Akkadian mashartu $(m)$, masharu(m), or mashatu (v. Soden, AHW II: 618; CAD 10/1:323) refers to vessels containing oil, without a volume value (q. v. "Maße und Gewichte," RLA VII: 457-530 where it is not listed, even under informal Syrian measures).

025 Cf. Janssen, Prices, pp. $352 \mathrm{ff}$.

s2b For the ;"c-jar as a generic term uniting mnw and msh-vessels, cf. Janssen, Prices, p. 338.

027 Amphora?

o28 Harris (Lexicographical Studies, p. 120) notes for hrst that "there cannot in fact be any doubt that the WÖRTERBUCH'S translation 'carnelian' is correct", while C. Müller-Winkler (Objekt-Amulette, p. 124) notes that carnelian wd steye pieces of Dynasty XVIII date are far more common than those preserved from the Ramesside period. ("Carneol bleibt jedoch die weitaus beliebteste Steinsorte in Dynasty XVIII, Müller-Winkler, Objekt-Amulette, p. 118 ). 
15a, 16 lapis lazulio29 wdit-eye amulets

217
62
224
224
62
165
$62^{632}$
1550
5500
155
31
1
6
1
610
800
17
246
82
52
125

$15 \mathrm{~b}, 1$ red jasper ${ }^{630}$ scarabs

$15 \mathrm{~b}, 2$ turquoise scarabs

224

$15 b, 3$

scarabs of amethyst and quartz (?) 631

224

$15 b, 4$

lapis lazuli scarabs

62

wd't-eye amulets of precious malerials

165

$15 \mathrm{~b}, 6$ seals and $y t$-amulets of precious materials

$62^{632}$

faience seals

$15 b, 8$ faience beads

1550

$15 b, 9$ faience hin-jars

155

wooden stucco cartouches 31

$15 \mathrm{~b}, 11$ block ${ }^{033}$ of alabaster

$15 b, 12$ cedar beams

$15 b, 13$ cedar $t p t^{634}$

15b, 14 nnyb-wood,, 353 , making deben

6

$15 a, 15$

ady-wood, ${ }^{\circ 30} 1$, making

610

$15 \mathrm{~b}, 16$ reed, $^{037}$ bundles

800

16a, 1 tišps-plant, ${ }^{638}$ msti-sacks, $^{039}$

$16 \mathrm{a}, 2$ tišsps-plant, bundles $\quad 82$

$\begin{array}{llr}16 a, 3 & \text { grapes, msti-sacks } & 52 \\ 16 a, 4 & n k p t i-p l a n t & 640 \\ & \text { msti-sacks } & 125\end{array}$

029 C. Müller-Winkler (Objekt-Amulette, pp. 96; 173-177; 498) noles that wdit-eye lapis lazuli amulets are rare al all periods. H. Harris (Lexicographical Studies, p. 129) notes that hsbd also means faience imitations. The figure of 217 would thus initially appear to be surprisingly high (if lapis lazuli is meant) or low (if faience is meant). If however the figure in the preceding line of 185 refers to real carnelian pieces manufactured during Dynasty XX (and not Dynasty XVIII heirlooms), then the two figures are extravagant, but credible. As the following entries indicate that they are in fact to be regarded as "real", it is interesting that these various malerials are not designated as "real", while the word is used in $1.14 a, 2$.

630 J. Harris (Lexicographical Studies, p. 124) indicales that hnmt means either red jasper or the glass imitations. The figure indicales that it need not be understood as an imitation. B. Jaeger (Scarabees Menkhéperre, p. 21) notes that published information about the materials of scarabs is unreliable, while E. Hornung and E. Staehelin (Hornung/Staehelin, Skarabäen, pp. 22-23) suggest that red jasper was generally rare, but particularly apprecialed in the Ramesside period.

031 Harris, Lexicographical Studies, p. 110.

632 It will be noted that the figures 62 and 224 appear repeatedly: 62 is two a year for 31 years, while 217 $(15 a, 16)$ is seven a year, and 224 is seven a year, plus seven. (155 is thus likewise five a year).

$633 \mathrm{Cf}$. Osing, Nominalbildung, $723 \mathrm{n}$. 850. This context indicates that ipip $(t)$ is more probably the brick itself than the material, i.e., not "material for bricks", but "material as bricks".

634 Jones (Glossary, p. 192) is non-committal.

635 R. Germer (Flora, p. 147) is cautious about the identification.

636 R. Germer and L. Keimer (Gartenptlanzen II: 34) doubffully suggest a foreign conifer, which would sound appropriate here, but the price is extremely high, cf. supra pp. $175 \mathrm{H}$.

637 Keimer, Gartenpflanzen, 11: 74.

038 R. Germer (Flora, p. 14) comes out decisively against the identification as cinnamon, on the assumption that there was no trade between Ceylon and Nubia or Egypt. She does not however propose an alternative interpretation, but assumes that it comes from Nubia.

o39 Cf. Janssen, Prices, pp. 403-406. Curious is the existence of a msti-boat, Jones, Glossary, p. 140. Does this suggest that msti designates something that "carries' something, rather than a specific item? Or is the msti-ship a container vessel?

\$40 Keimer (Gartenpfianzen, I: 138-39; 186) hesitatingly suggests mint. It is probably related to Akkadian nik/ qiptulm), defined as "a plant" (CAD $11 / 2: 222)$ or equally clearly as "ein Euphoria-Strauch?" (v. Soden, AHW II: 788). 


\begin{tabular}{|c|c|c|}
\hline $16 a, 5$ & iwfyt-plant, ${ }^{641}$ msti-sacks & 101 \\
\hline $16 a, 6$ & hqq-plant, from $\mathrm{H}_{3}$ iw, $^{642}$, msti-sacks & 26 \\
\hline $16 a, 7$ & cucumbers $(2),{ }^{643} \mathrm{hqt}$ & 46 \\
\hline $16 a, 8$ & grapes, $\rho d r$-sacks & $1 ' 809$ \\
\hline $16 a, 9$ & grapes, bunches & $1 / 869$ \\
\hline $16 a, 10$ & pomegranates, pdr-sacks & 375 \\
\hline $16 a, 11$ & bki-plant, 044 in oipe & $1 ' 668$ \\
\hline $16 a, 12$ & cattle, various & $\underline{297}$ \\
\hline $16 a, 13$ & geese, living & $2^{\prime} 940$ \\
\hline $16 a, 14$ & trp-geese ${ }^{045}$ & 5200 \\
\hline $16 a, 15$ & water-fowl, living & $126 \cdot 300$ \\
\hline $16 b, 1$ & fat geese from the traps $\$ 40$ & 20 \\
\hline $16 b, 2$ & natron blocks & $44^{\prime} 000$ \\
\hline $16 b, 3$ & salt blocks & $44^{\prime} O C$ \\
\hline $16 b, 4$ & palm leaves, ${ }^{047}$ bound (2) & 1 \\
\hline $16 b, 5$ & polm leaves, loads & \\
\hline $16 b, 6$ & paim leaves, shoots & 77 \\
\hline $16 b, 7$ & palm leaves, fibres & \\
\hline $16 b, 8$ & mats & $\mathrm{C}$ \\
\hline $16 b, 9$ & split mats (a) $\$ 48$ & $1 ' 150$ \\
\hline $16 b, 10$ & idniniw & 0 \\
\hline $16 b, 11$ & onions, msti-sacks & \\
\hline & at webbing ${ }^{549}$ deben & \\
\hline
\end{tabular}

lle

16b, 13-16b, 15 [...Textual Omission...]

Iff

17a, 1 Oblations of the festivals, endowed by King Ramesses III [...], the great god for his father,

17a,2 Amonrasonther, and Mut and Khons and all the deities of Thebes in the twenty days of oblation festivals of

17a,3 "Ramesses III [...] Making Thebes festive for Amun" in I šmw 26 until II šmw 14,

64) W. Helck ("Kyphi," IÄ IIt: 902-903) points out that $n k p t i$ and $i w f y t$ (= fd) appear together, and contributed to an ancient incense mixture.

642 Cf. Janssen, Prices, pp. 356-357, esp. p. 356 n. 80. W. Helck ("Ernährung," LA I: 1268; 1270 n. 37) suggests bananas.

643 Cf. Keimer, Gartenptlonzen, I: 131-132.

044 Cl. Keimer, Gartenpflanzen, II: 68.

645 Cf. Helck, Materialien III: 504; Caminos, IEM, p. 130.

o46 That stt would mean "trap" would seem /from the context and suggested root) at least as probable as that it means flock seems evident, but is not certain.

647 Wallert, Palmen, p. 48. Just how the words following wd are to be understood, as products, measures, etc. is unclear; cf. W. Helck, "Maße und Gewichte," LÄ III: 1208 n. 174.

¿48 Wb. 1: 470, 14: "nöhere Bezeichnung für eine Matte".

o49 Caminos, IEM, pp. 435 f. 
17a,4 making twenty days from Regnal Year 22 to Regnal Year 32, making eleven years together with the oblations of

17a,5 the festival of Southern Opet in II sht 19 until III sht 23, making 29 days from

17a,6 Regnal Year 1 until Regnal Year 31, making thity-one of years.

$17 a, 7$ fine oblation bread, large sacks $\quad 1$ '057

$\begin{array}{ll}17 a, 8 & \text { fine bread, large heaps } \\ 17 a, 9 & \text { fine }\end{array}$

$17 a, 9$ fine bread, large $b$ inh-measures $\quad 1277$

$17 a, 10$ fine bread, heaps on the earth $\quad 440$

$17 a, 11$ oblation bread, large sacks $\quad 43^{\prime} 620$

$17 a, 12$ papyrus raw ( $\underline{d} w$ ? $)$ of the House of Incense $\quad 685$

$17 a, 13$ beer from the beer stores, 4401 , making [incomplete]

$17 a, 14$ fine bread, meat, $\breve{s}^{c}$ y.t-cakes, rhs-cakes, htp-baskets ${ }^{050}$ for display 051

17a, 15 fine bread, meat, $\breve{s}$ y.t-cakes, rhs-cakes, gold trays $\quad 485$

$17 b, 1$ fine bread, meat, $\breve{s}^{c} y, t$-cakes, ths-cakes, trays for consumplion

17b,2 fine bread, meat, $\breve{s}^{c} y \cdot t$-cakes, rhs-cakes, trays, t.3y-baskets ${ }^{052}$ for consumption

17b,3 fine bread, meat, $\breve{s}$ y.t-cakes, rhs-cakes, trays, $g^{3} y$-vessels ${ }^{053}$ for official ${ }^{054}$

$17 \mathrm{~b}, 4$ fine bread of the divine offerings, dnit-baskets 055 of gold outfitted

$\begin{array}{llr}17 b, 14 & \text { fine bread, bnbn-loaves } & 46 ' 500 \\ 17 b, 15 & \text { fine bread, kyllestis-bread } & 44 l^{\prime} 800\end{array}$

Cf. Caminos, LEM, p. 205; Janssen, Prices, pp. 160-161. J. J. Janssen indicates that he reads hip as "tray" (pers. comm.)

${ }^{651}$ The significance of these phrases is obscure, but probably it is to be distinguished from $(17 \mathrm{~b}, 1)$ "for consumption".

o52 Janssen, Prices, pp. 204-205.

o53 Janssen, Prices, pp. 426-428 (bronze vessels).

054 Peculiar, but the form is more likely sr than wr (cf. Möller, Paläographie, II: nos. 11; 13; BAR IV: 135), which does not aid in elucidating the meaning, as no official is specified, and the expecled plural strokes were clearly not intended, nor is there an anticle.

055 Janssen, Prices, pp. 140-143.

o56 Janssen, Prices, pp. 344ff.

${ }_{057}$ Janssen, Prices, p. 346.

658 Hieratic uncertain.

o59 Cf. Verhoeven, Grillen, pp. 170-171. 


$127^{\prime} 400$
$116^{\prime} 400$
$262^{\prime} 000$
$2^{\prime} 844^{\prime} 357$
$\left.2^{\prime} 806^{\prime} 407\right] \quad 000$
344
$48^{\prime} 420$
$28^{\prime} 200$
$3^{\prime} 130$
$2 ' 210$
310
$39^{\prime} 510$
$42^{\prime} 030$
$219^{\prime} 215$
93
$1^{\prime} 100$
62
$304^{\prime} 093$ making
778
31
93
$110^{\prime} 000$
310
93
62
155
31
31
44
$33^{\prime} 100$
220
155
310
620
620
$559^{\prime} 500$
$78^{\prime} 550$
310
$1^{\prime} 410$
55

$18 a, 2$ flour (?) for white loaves

(n)

18a,5 šcy, rhts bread, tmım-measures

$18 a, 6 \quad s^{c} y$, oipe

18a,7 rhsw oipe

$18 a, 8$ sk-flour "-jars

$18 a, 9$ sweet wine (?), mnw-jars

$18 a, 10$ sweet wine, jars

$18 a, 11$ wine, $m n w$-jars

$18 \mathrm{a}, 12$ Total, sweet wine, $\mathrm{mnw}$-jars and jars

$18 a, 13$ beer, hnw-vessels

$18 a, 14$ sweet $b q, m n w$-jars

$18 a, 15$ sweet bq, hin-jars

$18 \mathrm{~b}, 1$ white incense, $m n w$-jars

$18 b, 2$ incense, oipe

$18 b, 3$ incense, sqw (for burning?), mnw-jars

$18 \mathrm{~b}, 4$ red bq, mnw-jars

$18 \mathrm{~b}, 5$ sesame oil, mnw-jars

$18 \mathrm{~b}, 6$ sesame oil, hin

$18 \mathrm{~b}, 7$ honey, $m \mathrm{~m} w$-jars

$18 \mathrm{~b}, 8$ white fat, $\mathrm{mnw}$-jars

$18 \mathrm{~b}, 9$ olives, $m n w$-jars

$18 \mathrm{~b}, 10$ thin diw

$18 \mathrm{~b}, 11$ thin rdiw

$18 b, 12$ decorated sheets

$18 \mathrm{~b}, 13$ decorated ms-garments

Total

18b, 14 wax, deben

$18 \mathrm{~b}, 15$ all good fruits, kbs-baskets

$18 \mathrm{~b}, 16$ all good fruits, t? $y$-baskets

$19 a, 1$ fruits, trays

19a,2 fruits, dni-baskets

19a,3 figs, bikw, oipe

19a,4 figs, bikw mh;

19a,5 figs, bikw ${ }^{\infty} 1$ msfi-sacks

$19 a, 6$ figs in oipe

$19 a, 7 \quad$ figs, t33y-baskets

19a,8 mhiwt

19a,9 tišss-plant, trays

19a, 10 tišps-plant, msti-sacks

$559 ' 500$
$78^{\prime} 550$
310
$1 ' 410$
55
$15 ' 500$
310
$3^{\prime} 100$
220
155

sol J. Breasted (BAR IV: 137) renders these three items as "of the impost", but the usual use of the fiscal term bikw in P. Harris identifies it with a particular group, e.g., the cultivators $(12 b, 3)$ or the fowlers $(12 b, 6)$, and here only the measures are listed. It is also perhaps significant that according to the interpretation advanced here, none of the "fiscal terms" appear in this section of the text, but bikw as "worked" does appear, e.g., 2la,2, infra. This is the reading advocated here. 
$19 a, 11 s^{5} m^{602}$ trays 1 '550

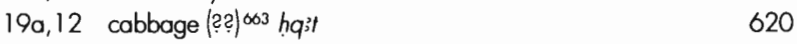

$19 a, 13$ garlic, ${ }^{064}$ hq: $\quad 310$

$19 a, 14$ garlic, $\$ 05$ 'nbw-bundles $\quad 6 ' 200$

$19 a, 15$ gropes, msti-sacks $\quad 117$

$19 a, 16$ grapes, !3y-sacks $\quad 1 ' 150$

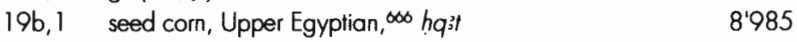

$19 \mathrm{~b}, 2$ alfalfa-grass mats $\quad 620$

196,3 papyrus sandals, pairs $\quad 15^{\prime} 110$

$\begin{array}{ll}19 b, 4 \text { salt, khar } & 11515\end{array}$

$19 b, 5$ salt, blocks $\quad 69^{\prime} 200$

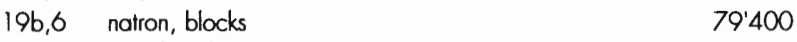

$19 b, 7 \quad$ thick (cloth), diw-garments ${ }^{607} \quad 150$

$19 b, 8$ flax mats (?) $\quad 265$

$19 \mathrm{~b}, 9$ rushes, mm-bundles $\quad 3 ' 270$

196,10 reeds, mw-bundles $\quad 4^{\prime} 200$

$19 b, 11$ leather sandals, pairs $\quad 3 ' 720$

$19 \mathrm{~b}, 12$ hqq-fruit in oipe $\quad 449 ' 500$

$\begin{array}{ll}19 \mathrm{~b}, 13 \text { pomegranates in oipe } & 15^{\prime} 500\end{array}$

196,14 pomegranates in pdr-sacks $\quad 1 ' 240$

$19 b, 15$ olives, $g$ 'y-vessels $\quad 310$

$19 \mathrm{~b}, 16$ jars and pots of the mouth of the canal 9'610

$20 a, 1$ papyrus raw (?) in oipe $\quad 3 ' 782$

$20 \mathrm{a}, 2$ ndb-baskets oipe 930

$20 \mathrm{a}, 3$ iw'-calle $\quad \underline{419}$

$20 \mathrm{a}, 4$ young stock of $i w_{3}^{3} \quad \underline{\underline{290}}$

$200,5 n g$;-cattle $\underline{18}$

$20 \mathrm{a}, 6$ heifers $\underline{281}$

$20 \mathrm{a}, 7$ bullocks

$200,8 \quad w n \underline{d} w$-cattle $\quad \underline{740}$

$20 a, 9 \quad \operatorname{tpy}(?) \quad \frac{19}{19}$

$20 \mathrm{a}, 10$ cattle $\quad \underline{1 ' 122}$

$20 a, 11$ Total of bulls and heifers $\underline{\underline{2} 892}$

$20 \mathrm{a}, 12$ male orynx i

$20 a, 13$ orynx 54

$20 a, 14$ ibex 1

$20 \mathrm{a}, 15$ gazelles $\quad 81$

$20 \mathrm{a}, 16$ Total 137

$20 \mathrm{a}, 17$ Total of herds $\quad 33^{\prime} 029$

$20 \mathrm{~b}, 1$ live geese $\quad 6^{\prime} 820$

$20 b_{t} 2$ ht-'s birds, live $\quad 1 ' 410$

20b,3 mp geese, live I'534

$\$ 2$ Germer, Flora, p. 182

663 Uncertain, cf. Germer, Flora, p. 51.

o64 Far from certain, cf. Germer, Flora, p. 195.

605 Uncentain, cf. Germer, Flora, p. 202.

os Or is this a dictation enror, with the almost homonymous "blossom" (Wb. IV: 472, 1-3) intended?

$067 \mathrm{~J}$. J. Janssen (pers. comm.) suggests this rendering, but asks if this is out of place. But, if "thick cloth" is the meaning, then some of the preceding items may have been wrapped in this material? 
$20 \mathrm{~b}, 4$ cranes, live

$20 \mathrm{~b}, 5$ live hatching fowl 4'060

$20 \mathrm{~b}, 6$ live water fowl $\quad 25^{\prime} 020$

$20 \mathrm{~b}, 7$ mnit-birds, live $\quad 57^{\prime} 810$

20b,8 pit-birds, live 21 '700

$20 \mathrm{~b}, 9$ common fowl, live $\quad 1 ' 240$

$20 \mathrm{~b}, 10$ birds of the sky $\quad 6{ }^{\prime} 510$

$20 \mathrm{~b}, 11$ Tolol of fowl 126'250

20b, 12 qrh-vessels filled with fish, with non airtight lids(?) 440

$20 \mathrm{~b}, 13$ white lish 2'200

$20 b, 14$ eviscerated $\check{s}^{\prime}$-fish $\quad 15 ' 500$

$20 b, 15$ gutted fish $15^{\prime} 500$

$21 a, 1$ whole fish $441^{\prime} 000$

$2 l a, 2$ blossoms worked $(b ; k w)$ as flowers of fans ${ }^{6 / 8} \quad 124$

$21 a, 3$ flowers, tall bouquets 3'100

2la,4 blossoms worked (bikw) as flowers of perfume blossoms ${ }^{609} \quad 15^{\prime} 500$

$21 a, 5$ papyrus blossoms (2) 070 , oipe 124:351

$21 a, 6$ flowers, wreathes $\quad 60^{\prime} 450$

$21 a, 7$ flowers, krht-bunches ${ }^{671} \quad 620$

$21 a, 8$ lapis coloured flowers, ${ }^{672}$ tied ${ }^{673} \quad 12^{\prime} 400$

$21 a, 9$ flowers, handfuls $\quad 46^{\prime} 500$

$(21 a, 10)$ flowers, heaps 110

$(21 a, 11)$ lotus blossoms, handfuls $\quad 144^{\prime} 720$

$(21 \mathrm{a}, 12)$ lotus blossom bouquets $\quad 3^{\prime} 140$

$(21 a, 13)$ lotus blossoms handfuls $\quad 110^{\prime} 000$

$(21 a, 14)$ papyrus bouquets $\quad 68^{\prime 2} 200$

(2la,15) papyrus, pieces $349^{\prime} 000$

$(21 \mathrm{~b}, 1)$ large 'bw-flowers, worked (bikw) as blossoms $\quad 19^{\prime} 150$

$(21 b, 2)$ dates $m^{2}{ }^{2}{ }^{\prime}$-measures ${ }^{674} \quad 65^{\prime} 480$

$(2 \mathrm{lb}, 3)$ dates, hink-measures $\quad 3^{\prime} 100$

$(21 \mathrm{~b}, 4)$ greens, ${ }^{675}$ heaps $\quad 2^{\prime} 170$

$(21 b, 5)$ greens, hrš-bundles $\quad 77^{\prime} 200$

$(21 b, 6) \quad$ flowers, 676 handfulls $\quad 128^{\prime} 650$

$(21 b, 7)$ ears of corn $(2: i t-m-i t)$ as bouquets $\quad 11^{\prime} 000$

$(21 \mathrm{~b}, 8)$ ears of corn, handfulls $31^{\prime} 000$

$(21 b, 9)$ flowers, bouquets $\quad 1^{\prime} 975^{\prime} 800$

$(21 b, 10)$ flowers, trays 1'975'800

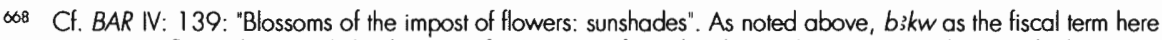
seems superfluous, but it might be the case, if it does not refer to their having been "prepared" or "worked" in some way, which is an interpretation permitted by the text. Cf. also Dittmar, Blumen, pp. 58; 60.

669 Cl. Dittmar, Blumen, p. 59.

670 Cf. Dittmar, Blumen, pp. 54-55. Whether the blossoms were really packed in oipe units would appear to be doubfful on aesthefic grounds, but these can hardly have been mere plants as J. Dittmar clearly demonstrates.

o71 Cl. Dittmar, Blumen, p. 44.

672 J. Harris (Lexicographical Studies, pp. 148-149) makes it clear that the reference is purely to hue.

o73 Cl. Janssen, Prices, p. 186 n. 24.

674 CF. A. H. Gardiner, "The word $m^{\prime} d$ '? and its various uses," JEA 26 (1940): 157-158; O DeM 106, vs. 5; O. DeM 318, 9-10. (I am indebted to J. J. Janssen for these references).

675 Cf. Dittmar, Blumen, p. 61: "Kraut".

676 Cf. Diltmar, Blumen, pp. 54-55, for the logic. 
Ilg

Ith

III Heliopolis
[...Textual Omission...]

$[\ldots$ Textual Omission...]

IIla

$25,1-27,11[\ldots$...Textual Omission...]

27,12 I have made for thee khato-lands anew with pure barley. I increased 677 for thee their cultivable fields, having been barren ${ }^{678}$ in order to multiply divine offerings in great quantities for your august and beloved name.

28,1 I made for thee many fields (of arable land), on islands and new land in the southern and northern districts, like tens of thousands, ${ }^{679}$ attaching to them wooden (and stone?) boundary stelae in thy name established for thee by decree forever.

28,2 I have made poultry houses for thee, filled with the denizens of the sky. I caused water fowl to be conveyed to your city Heliopolis, to be presented to your $k_{3}$, father $\mathrm{Re}^{c}$, brought to thee, and to thy Ennead, which is your following.

28,3 I have made for thee troops of honey gatherers and incense porters who render up their annual bikw to thy august treasury.

28,4 I have made for thee troops of hunters to bring orynx that they may be presented to thy $k^{\prime}$ at thy every festival.

28,5 I have made for thee rowers and towers, ${ }^{680}$ which I formed in order to exact the bikw of the Two lands, the htri, the šsyt, to be transported to thy treasury in the House of $\operatorname{Re}^{c}$, to increase thy divine offerings by millions.

28,6-30,6 [...Textual Omission...]

IIIb

$31,1-32 a, 6[\ldots$ Textual Omission...]

or7 Literally "doubled"

678 Or "fallow"?

679 A curious expression, if correctly rendered, but cf. esp. 4,4, supra p. 198 n 595.

${ }_{800}$ The word mškbumw has attracted a good deal of attenlion. A. Alt ("Eine syrische Bevölkerungsklasse im ramessidischen Ägypten," ZÄS 75 [1939]: 16-20) originally suggested the Semitic mškbm - an Old Aramaic word for a particular caste - as the origin of the word. While this has not met with general acceptance (J. J. Janssen, Ship's Logs, pp. 34-35; Schulman, Rank, p. 48; A. Schulman, "Mhr and Mškb, Two Egyptian Military Tities of Semitic Origin," ZÄS 93 [1966]: 123-132; Gardiner, AEO 1:92*; R. Faulkner, "Egyptian Military Organization," JEA 39 [1953]: 47; Jones, Glossary, p. 76), he was probably correct in rejecting the idea the mškbw were directly responsible for tax-farming (contra BAR IV: 266 and DIE I: 247). The Egyptian meaning is unfortunately as unclear as the identity of its Semitic predecessor. While Schulman favours a military title, its appearance in non-military texts is sufficiently frequent (given the relative rarity of the word, this is perhaps misleading) to indicate that it refers to groups of men, employed by the State, and at least several times in connection with river-shipping. 
IIlc

32a,7 ltems: šsyt bikw-rmt of the Mansion Ramesses III [...] in the House of Re $32 a, 8$ and of those of the Mansion Ramesses III [...] in the House of Re to the North of Heliopolis, the chapels, villages, and cartle herds of this House $32 a, 9$ under the authority of the officials, as their annual htri:

$32 a, 10$ silver

$32 b, 1$ copper

$32 b, 2$ royal linen, textiles, very fine thin,

fine thin, fine smooth, total:

$32 b, 3$ incense, honey, sesame oil, total:

$32 b, 4$ sweet wine, wine, total:

$32 b, 5$ silver: objects of the $b_{3} k w-r m !$ for the divine offerings

$32 b, 6$ corn: $b 3 k w$ of the cultivators

$32 b, 7$ fresh greens

$32 b, 8$ flax

$32 b, 9$ water fowl: bikw of the fowlers and fishers

$32 b, 10$ oxen; ox calves; short-horned cows; and registered cattle of the herds

$32 b, 11$ live geese, of šsyt

$32 b, 12$ a cedar ferry-boat

$32 b, 13$ acacia barges and $k$;r-vessels

$32 b, 14$ items: foreign/oasis in great quantities for the divine offerings

\begin{tabular}{|c|c|c|}
\hline \multicolumn{2}{|c|}{586.37 deben } & 53.36 \\
\hline $1 ' 260$ & deben & 114.66 \\
\hline i'019 & garments & \\
\hline 482 & $3^{4 c}$-vessels & \\
\hline 2'385 & $3^{c c}$-vessels & \\
\hline 456 . & deben & 41.528 \\
\hline
\end{tabular}

$17^{\prime} 100$ khar

4'800 mrw-bundles

$4^{\prime} 000 \quad n^{c} \not w$-bundles

$37^{\prime} 465$

98 head

$540.5[$ sic! $]$

1

Illd

Ille

IIIf

IIIh

$$
\begin{aligned}
& {[\ldots \text { Textual Omission... }]} \\
& {[\ldots \text { Textual Omission... }]} \\
& {[\ldots \text { Textual Omission... }} \\
& {[\ldots \text { Textual Omission... }]}
\end{aligned}
$$

IV Memphis

IVa

$44,1-48,1[$...Textual Omission...]

48,2 I made for thee troops of honey gatherers and incense porters, founding for them companies to assemble them to exact their annual bikw for thy august treasury, to fill the magazines of thy House with great quantities, to multiply thy divine offerings to present them to thy $k$ ?

48,3 I made for thee granaries filled with barley and emmer, great heaps reaching unto the very sky, the daily offerings of thy temple, for thy beloved face, the eye $e^{681}$ of Heaven. 
48,4 I made for thee royal statues (L!P!H!), with chased work in gold, others with chased work in pure silver, as well as covering the earth in thy presence with dnit-vessels, ${ }^{682}$ festival offerings, divine offerings, of bread and beer to be presented in thy presence daily.

48,5 For thy forecourt, 683 I made for you a great jar rack decorated with beautiful gold, its jars in gold and silver engraved with thy name and provided with divine offerings, all good, to be presented in thy presence at dawn.

48,6 I made for thee $k^{3} r$-vessels and mnš-barges (traveling) in the midst of the Sea, manned mnš-barges plied their trade in great numbers transferring the produce of the god's land, the bikw of the Land of Palestine, for thy great treasuries in thy walled city.

48,7 I made for thee great festival offerings, endowed anew to offer them to thy $k_{3}$ : at thy every appearance. They included bread, beer, cattle, fowl, incense, fruits, greens, swaet wines and wine, royal linen, numerous good this textiles

48,8 , sesame oil, incense, honey, dried myrrh, flowers, and everything good, sweet and fragrant, for thy beloved face, lord of the gods!

48,9 I made for thee great festival offerings at the commencement of the lnundation in thy august and beloved name Ptah-Nun Father of the Gods, being provided with bread and creations of the water ${ }^{684}$ in thy great and

682 Cf. J. J. Janssen, Prices, pp. 140-143, for dnit-vessels.

683 P. Spencer (Temple, pp. 4-13) has shown that the wb; was not necessarily a forecourt, tentatively concluding that $w_{b}$; is a term describing no specific part of a temple, but rather the entire sacred precinct, the temenos. Combining textual and archaeological evidence is difficult, but $R$. Caminos (IEM, p. 28) renders cautiously "open court", and this is probably the most suitable.

Spencer's evidence included the Lateran Obelisk (erected by Thutmosis IV where Thutmosis ill had intended to erect it) with its inscription, identifying the wb; hry hwt ntr $r$ hw ipt-swt (Urk. IV: 584, 10) as the sb; hry $n$ ipt-swt hit hr $n$ Wis.t (Urk. IV: 1550, 18). Although this is plausible, she adds that, "It is inconceivable that this area, at the back of the Amun temple, could have been regarded as a 'forecount" (p. 8). While valid, it is indicated to be an "upper $w b_{3}$ ", to the east of the $3 h-m n w$, near a gate, and a pair of obelisks. Obelisks not being rear wall ornamentation, the Tuthmosides cannot have viewed this area as a neglected backyard.

P. Cairo JdE 52002 (vso. 2) refers to men "demolishing in the forecourt", which would suggest sacrilege if the whole temple was meant, but the author was probably referring to activity in a specific place, which suggests that the Egyptians regarded the $w b$; as a specific part of the temple, although they may have had a different way of viewing space than we do. (CF. P. Posener-Kriéger, "Construire une tombe à l'ouest de mn-nfr (P. Caire 52002)," RdÉ 33 [1981]: 52; KRI VII: 265,9]

Spencer however concludes that since Ramesses IIl established his bark station before the wb; of Amun (P. Harris, $5,4)$, and thus in front of the contemporary facade, wb: can only be interpreted in the broadest possible sense. Seti I refers to his hypostyle hall as an wb: KRII: 201,5; L.-A. Christophe, "La face sud des architraves surmontant les colonnes 74-80 de la grande salle hypostyle de Karnak," BIFAO 60 [1960]: 73-74), a structure which was behind Horemhab's Pylon (the contemporary temple front) and thus Ramesses' bark station just before that wb: suggests that this source be eliminated

Spencer's recommended use of the Greek temenos is unfortunate as the etymology is from tź $\mu v \omega$, "to cut", "to sever" (in the sense of being cut off by walls), while wb; means "to open up". Ramesses would however hardly have erected a temple on land which was per definitionem profane, being "before the temenos", i.e., outside of it. The same is true of the "upper wb;" as "upper temenos", as there is no striking baundary with Tuthmoside Karnak which would enable the student to separate two different holy enclosures, and thus the term wb; must refer to an open court of some kind, usually between the pylon or a major wall and the brick enclosure walls, which generally means "forecourt", but not invariably.

${ }_{084}$ qm? $n \mathrm{mw}$. One parallel is BD 125 (E. Naville, Tb. It: 325/Spell 125, 27-28), usually translated (pace, e.g. Allen, Book of the Dead, p. 100) "and threw (them) into the lake"; equally close is the "toyalist Instruction," on the 
august forecourt of the Crocodile Enclosure ${ }^{685}$

48, 10 for all thy statues, and the Ennead of the Eternal Water. Their entire htri is in thy treasuries, magazines, granaries, cattle stalls, bird pens, every year in order to satisfy the great collegium of Nun, the Elder, content and joyful at the festivals of the Views.

48,11 I built thy august barque, Nb-nhh, $[\ldots]$

\section{8, 12-50,4 [...Textual Omission...]}

$\mathrm{IVb}$

\section{$[$...Textual Omission... $]$}

IVC

$5 \mathrm{Ib}, 3$ Items: the šzyt bikw-rmt of the Mansion Ramesses III [...] in the House of Ptah

516,4 , the herds Ramesses III $[\ldots]$, the town

516,5 on the western Canal, the House Ramesses III [...] in the House of Ptah, the chapels and settlements of this House which tow to

516,6 their treasuries as their annual htri:

$51 b, 7$ silver

$51 b, 8$ linen, fine, thin smooth

$51 b, 9$ wine

$51 \mathrm{~b}, 10$ silver as objects of the $b_{3} \mathrm{k} w$-rmt for the divine offerings:

$51 b, 11$ corn as the bikw of the cultivators

$51 b, 12$ fresh greens

$51 \mathrm{~b} \quad 130$ oxen, calves of oxen, short-horned cattle, and registered cattle of the herds

$52 a, 1 \quad$ live geese of $\breve{s}$;yt deben garments mnt-jors

144.31 deben

37 ' $400 \quad$ khar

$600 \quad$ mrw-bundles

Shtp-ib-R stele (Sethe, Lesestücke, p. 69,1) translated again (pace W. K. Simpson in Simpson, Literature, p. 200), "cast to the waters". In each case, the $n$ is translated as if an $r$ of motion (Gardiner, $\S 164,1$ : "whereas $r$ is used of movement 'to' or 'towards' a thing"). The phrase in the Loyalist insiruction can be intelligibly translated: "and his corpse will be as a reed of the swirling waters". The meaning would in any case be diametrically opposed to that intended in P. Harris, as the $q m^{\prime}$; $n \mathrm{mw}$ there are directly associated with the life-giving walers of the gods. (The reference in the Book of the Dead is, as so often, somewhat obscure).

Cf. P. Harris I II. 47, 1 and 49,7 as well. P. Montet (Géographie I: 33) prefers to translate "le Mur de Sobek", citing P. Sallier IV, vso. 1,9 (LEM p. 89,1 1), but R. Caminos (LEM, pp. 333; 340) prefers to read "Mi-wr" (i.e., Mr-wri, Gurob) in this case, removing Sobek from Memphis, where he is otherwise not recorded. When inb appears in the singular, it seems preferable to read "enclosure" rather than "wall" in certain cases.

$w b$; appears several times in the Memphite paragraphs of $P$. Harris $\mid(46,3 ; 48,5 ; 48,9 ; 49,7)$, hinting at several distinct structures, unless this $w b$; is the entrance hall to the Ptah Temple built by Ramesses II and embellished by Merenptah and Ramesses III himself: the "west hall" excavated by W. M. F. Petrie (Memphis I: pp. 5-6; pls. $1-2 ; 22-23)$. This might aid in clarifying the location of the jar rack $(48,5)$. The role of the crocodile remains mysterious. 
$52 a, 2$ items of Egypt and items of the god's double country, ${ }^{680}$ items of Syria, items of Cush, and the Oasis for the divine offerings in great quantities

$52 a, 3$ and the Oasis for the divine offerings in great quantities.

$\begin{array}{ll}\mathrm{IVd} & {[\ldots \text { Textual Omission...] }} \\ \mathrm{Ne} & {[\ldots \text { Textual Omission...] }} \\ \mathrm{IVf} & {[\ldots \text { Textual Omission...] }} \\ \mathrm{IVg} & {[\ldots \text { Textual Omission... }}\end{array}$

$\checkmark$ The SMALL TeMPLES 687

[...Textual Omission...]

VI THE TOtals

Vla

[...Textual Omission...]

$\mathrm{Vlb}$

$68 b, 4$ liems šsyt bikw-rmt of the serfs all 688 of the Mansion and

$68 \mathrm{~b}, 5$ chapels and settlements and Houses which he gave them as their annual htri: 089

680 The immediate reaction is to regard this as a lapsus calami, but this strange reference may be explained with the reference in the Deir-Bahri temple to Punt being hr gs-my wid-wr, "on both sides of the sea", Urk. IV: 325, 13. This would of course resolve the problem of whether Punt was in Africa or South Arabia, for the obvious inference is that it was on both sides of the Red Sea, just as Egypt was on both sides of the Nile.

087 At comparable places in the texts relating to the small temples, all references to htri, šsyt and $b 3$ ikware missing, not only in the introduction $(57,1-60,10)$, but also at the appropriate point in the lists $(62 a, 11)$, where products similar to those listed above appear. There is no reason to believe that an oversight is responsible for this double omission.

o88 Or: "bikw of the serfs and people all".

689 The formulation of these introductory sentences (P. Harris, $12 a, 1-5 ; 32 b, 7-9 ; 52 b, 3-5 ; 68 b, 4-5$ ) varies in each case. One aspect of this final version is the statement $(65 \mathrm{~b}, 5)$. "which he gave to them as/from $(\mathrm{m})$ their annual htri". The translation of $m$ in the sense of the $m$ of predication (as opposed to the preposition, "from") is based on the assumption that "their annual htri" refers to the temples, not the dependents, and thus that the Pharaoh took credit for the delivery of an annual htri, which was in essence already the property of the temples, as the produce of the temple dependents. It can also be plausibly argued that the Pharaoh set aside a part of the dependents' annual htri that was due to him, and returned this to the temples. This is however not supported by the version in the paragraph dealing with the Theban temples. There $(12 a, 3-5)$ it is clear that the dependents of the temples which Ramesses III created provide an "annual hitri" which must refer to the temples themselves. It could nevertheless be asserted that the "annual htrit was due to the Pharaoh, and that he merely left the temples a portion of their dependents' produce, which rightfully belonged to him as their taxes. The structure of the sentences never gives a hint which would support this. 
68b,6 beautiful gold of the desert, used gold 690 as vessels, jewely and scrap

$68 \mathrm{~b}, 7$ silver vessels and scrap

$$
\begin{array}{r}
2289.45 \text { deben } \\
14^{\prime} 050.12 \text { deben }
\end{array}
$$

68b,8 Total: gold and silver as vessels,

$$
\text { jeweiry and scrap }
$$

$16^{\prime} 339^{\prime} 65$ deben

[ 1 '486.908 ]

68b,9 assorted gold, precious stones,

necklaces, jewely and wreathes

$68 \mathrm{~b}, 10$ silver fittings from Thoth's remainder ( $w d ;$; $)$

$68 \mathrm{~b}, 11$ copper

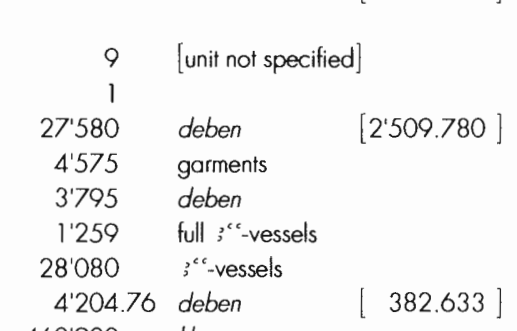

$68 \mathrm{~b}, 12$ royal linen, textiles, fine thin cloth

69,1 linen

$460 ' 900$ khar

69,2 incense, honey, sesame oil

69,3 sweet wine, wine

69,4 silver in objects of the bikw-rm!

69,5 corn as the $b ; k w$ of the cultivators

69,6 fresh greens

32 '750 mw-bundles

$69,7 \quad$ flax

71 '000 n'thw-bundles

69,8 water-fowl as the $b^{3} k w$ of the fowlers and fishers

$426 ' 995$

69,9 oxen, calves of oxen, short horned cows, registered cattle entered of the herds of Egypt

$\underline{961}$

69,10 oxen, calves of oxen, long horned cattle, short-horned cows as the bikw of the lands of Syria 19 Toial:

69,11 live geese of šsym

69,12 cedar skry-ferries barges, t? tri and $k$; $r$-vessels

$70 a, 1$ total: cedar and acacia-boats 90

70a,2 items: of Egypt, items of the god's land, items of Syria,

Cush, (the) Oasis, for the divine offerings in great quantities.

$\mathrm{Vlc}$

[...Textual Omission...]

Vld

[...Textual Omission...]

\section{THE Historical SumMARY}

\section{5, 1-76,7 [...Textual Omission...]}

76,8 [After defeating and slaughtering the Peoples of the Sea and the Libyans, the Pharaoh settled the sunvivors in the Delta and exacted payments from them.]

695 sp sn need not be interpreted as second class gold, pace Wb. III: 436, 19. Cf. P. Anast. 1, 10,6 (Gardiner, Hieratic Texts, pp. 19-20). Cf. supra, p. 201 n 616 for re-used. 
$76,9[\ldots]$ I htri all of them: clothing and corn are paid into the treasuries and granaries annually. $[\ldots]$

76, 10-77,7 [...Textual Omission...]

$77,8[\ldots]$ I hewed great $m n s_{5}$-barges and b3r-vessels before them, equipped with numerous crews and lots of retainers. Their

77,9 Chiefs-of-Archers were for the mnš-barges among them, under controllers and chiefs to command them, loaded with the things of Egypt without number $[\ldots]$

$77,11-77,13$

$77,10[\ldots]$ They arrived at the foreign land of Punt $[\ldots]$

$78,1[\ldots]$ I sent out my messengers

78,2 to the country of ${ }^{c},-f i-k_{3}{ }^{691}$ to the great copper mines which are there. Their $m n s ̌$-barges were filled, burdened beneath it [...]

78,3-78,5 [...Textual Omission...]

78,6 I sent forth attendants and officials to the turquoise mountain of my mother Hathor, Lady of Turquoise. Presented to her (was) silver, gold, royal linen, $m k$-linen, and many

78,7 things in her presence like unto sand. Miracles of real turquoise were brought to me [....]

$78,8-79,12[$ [...Textual Omission...]

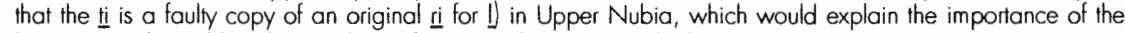
barges, which would not be as relevant for Sinai. The text certainly does not suggest an Egyptian mining mission. 
PART III

The Words 

By definition, the word inyt signifies something "that is brought". T. E. Peet pointed out long ago that the verb ini also signified "to buy". 692 The noun inw has been translated as "tribute" for even longer. ${ }^{693}$ In the administrative texts of the Ramesside Period, inyt appears very often in the sense of supplies being brought to the royal tomb, very frequently for items used in the work at the tomb itself, such as lamps. 694 The fiscal use of the term is probably related to the administrative use of the term, if the Egyptians made any distinction.

\section{INTERNAL ReVenue}

\section{Administrative texts}

P. Northumberland 11695 uses inyt to describe flour being produced from grain.

The term inyt is frequently used to describe certain ordinary deliveries to the Gang at Deir elMedineh during Dynasties XIX and XX (e.g., Ramesses I1096 P. Greg, infra, pp. 152ff). 697 These include fish. ${ }^{098}$ The latter is striking as plaster is classified as bikw in the text referring to fish as inyt. ${ }^{699}$

The extremely fragmentary P. Gurob $M^{700}$ mentions the usual šmw, but also specifies twice (II. 9; 10) the "[toponym] arrears corn of inyt" of a citizeness and a cultivator, seemingly implying that this was šmw corn. Whether this implies that the inyt was šmw is unclear; inyt was possibly used here merely meaning "brought", but the construction is unusual.

P. Greg ${ }^{701}$ is a rather well preserved example of a list recording items brought to the Gang at Deir el-Medineh. A good part of the text has been lost, so that for certain entries we have only the items delivered but not the designation, while other lines have only the designation, the remainder being lost. The text quite clearly details a number of different types of item, which the scribe evidently felt were related. The first lines list deliveries of plaster, after which

T. E. Peet, "The Egyptian Words for 'money', 'buy', and 'sell', in Studies Griffith, pp. 122-127. This will be taken up again in the following chapter.

Ct. Gordon, inw, passim.

Cf. O. Cairo 25536, verso,

KRI I: 241-242; J. Barnes, "Three Hieratic Papyri in the Duke of Northumberland's Collection, "JEA 34 (1948): $35-46$.

KRI III: 509,$1 ; 9$

KRI IV: 168, dated to Merneptah. (O. Cairo. 25753)

KRI V: $582,1,9 ; 583,1$.

KRI V: 583,11 (b:kw); KRI VI: 582, 1; 9; 583,1 (inyt).

Gardiner, RAD, p. 33.

KRI V: 437-448; cf. supra, pp. 152ff. 
the grain payments to the workers are recorded (as diw, II. A 13; C $x+10$ ), 702 and lamps appear further down (I. B 8). Cakes, beer, plaster, lamps, fish, wood, grain and wicks appear in the lines that follow.

Cakes or breads from the royal provisioning and beer from the temples $(r-p r w \mid)^{703}$ are clearly distinguished from one another and identified consistently as inyt. ${ }^{704}$ As this particular text clearly uses words with specific meanings, this is significant. In both cases, deliveries in limited scope - are issued from higher authorities to the Gang under this title.

The very badly preserved third page of the verso of $P$. Turin $2009+1999705$ uses inyt in the context of supplies for the Gang, potentially implying the responsibility of the vizier, and possibly indicating that the temple of Month was a source (II. vso. 3, 10-12).

Exceptionally inyt appears in the same text mentioning the inw in P. Turin 1900.706 It would appear that red jasper is associated with the inyt for a temple within the Estate of Amun (II. 3,3-3,4), delivered to the northern treasury of Amun- $\operatorname{Re}^{c}$, from the Royal mortuary temple.

\section{CONCLUSIONS}

inyt refers to things brought to the tomb as provisions, but also materials necessary for the work of the Gang. inyt appears in administrative texts more frequently than inw, and inyt never appears in propaganda texts as a technical term, but it does not figure in the Tax Lists of the Turin Canon either. The chief difference between inw and inyt is not grammatical, but textual. inw is an ideological word, and a fiscal term. inyt is a simple delivery. The fact that it does not appear in propaganda texts probably indicates that it was not an official designation for a specific type of delivery, although local scribes will have probably understood it to have some particular significance. ${ }^{707}$

One distinction that emerges from the texts is the contrast to $b i k w$, and clearly where fish are delivered (inyt) and plaster is produced $(b ; k w)$, the distinction does not require further elaboration, but what is one to make of the use of red jasper as inyt? Clearly, it was brought and worked, much as the grain in transformed into bread, and likewise labelled inyt, but the plaster underwent the same process, and yet was somehow identified as a product. Evidently an attempt to impose our categories on these concepts would be erroneous.

Cf. supra, pp. 152ff., II. B 10; B 19; Cx+7; vso A x+19; A x+22; vso B 18; B 21; B 24; B 32; B 38; vso C 17 .

704 The same word inyt is used with regard to the same types of products from the same source in the ostraca, e.g. $O$. Cairo 25632, 25810 and O. DeM 249

705 KRI VI: 560-566; Botti/Peel, Giomale, pp. 10-13/pls. 1-7

700 KRI VI: 619-624. Dated to Ramesses IX, year 9.

707 It is possible that the use of inyt implied a completed action. This calls to mind the very curious formulation of Turin Taxation Papyrus 5,6 (Gardiner, RAD, p. 42,4), where a quantity of grain is presumably turned over (iw, "arrived"), with a note that there is a remainder, perhaps implying that the grain did not actually arrive? 
Like the preceding word, inw is related to the word, "to bring", but also "to buy". ${ }^{708}$ inw is assumed to mean literally "what is brought", or "what should be brought". From its frequent use in the annals and private inscriptions in Theban Tombs, the word inw has frequently been translated as "goods" or "tribute", and this has been equally often disputed. ${ }^{709}$ As the word has been studied at length and countless examples adduced, this chapter is merely intended to survey the situation.

\section{INTERNAL Revenue}

\section{Administrative texts}

inw appears in association with a type of land producing htri under the reign of Seti l, 110 but it is difficult to conclude anything from the context.

P. Gurob 711 of Regnal Year 2 of Seti ll states explicitly that (vso. 1b,5) the "inw of the Royal Superintendent of the Throne, given towards the material support of this House", consisted of the ' $q w$ loaves and Syrian beer which precede the break in the text. P. Gurob Fragment $U^{712}$ refers to the "house of the inw" (I. vso., $x+5)$, which may or may not shed some light on the reference in P. Gurob.

Several paragraphs of $P$. Mallet (dating to the reign of Ramesses IV) link a scribe of the House of $i n w^{713}$ with a cattle overseer obliged to a htri of wood, ${ }^{714}$ with references to corvée labour ${ }^{715}$ and "the inw of $(I V, 1)$ Amonrasonther", 16 but also an overseer of the

T. E. Peet, "The Egyptian Words for 'money', 'buy', and 'sell'," in Studies Griffith, pp. 122-127.

Cf. Gordon, inw, but also: M. Liverani, "Memorandum on the Approach to Historiographic Texts," Or. 42 (1973), 191-193; E. L. Bleiberg, "Commodity Exchange in the Annals of Thutmose III," JSSEA $11 / 2$ (1981): 107-1 10; R. Müller-Wollermann, "Bemerkungen zu den sogenannten Tributen," GM 66 (1983): 81-93; W Boochs, "Weilere Bemerkungen zu den sogenannten Tributen," GM71 (1984): 61-66; and R. Müller-Wollermann, "Ein Tribut an die Methode," GM 77 (1984): 51-55; E. Bleiberg, "The King's Privy Purse During the New Kingdom: An Examination of INW," JARCE 21 (1984): 155-167. Wollermann points out that "tribule" refers to payments made under duress, and regular payments of conquered peoples or a tax imposed on a subject population, and suggests that they might be gifts, but her evidence is slender and rests to some extent on her theoretical perspective.

10 KRI I: 259-261, esp. 260,8; Spiegelberg, Rechnungen, pls. 4 etc.; Helck, Maierialien, 638-639

1 Cf. supra, pp. 146ff,; Gardiner, RAD, pp. 14-18; Griffith, Kahun Papyri, pp 94-98; pls. 39-40; A. H. Gardiner, "The Harem at Miwēr," JNES 12 (1953): 145-149.

Gardiner, RAD, pp. 22-24: Materialien, p. 933. The text could date to the reign of Ramesses II, as there is a reference to the Royal Wife M;3-Hr-nfrw-Rc (Fragment a, I. 2).

KRI VI: 67,3-4; Bakir, Epistolography, pl. 22, 3. For this text, cf. Wente, letters, pp. 127-128.

KRI VI: 67,2ff.; Bakir, Epistolography, pl. 22, $1 \mathrm{ff}$.

KRI VI: 66,7; Bakir, Epistolography, pl. 21, 7.

KRI VI: 66,9; Bakir, Epistolography, pl. 21, 9. 
treasury of Pharaoh. ${ }^{17}$ The htri seems to have been destined for the magazine of inw of the temple of Amonrasonther $(V, 2 ; 9)$.

P. Turin $1900+{ }^{718}$ records the $\mathrm{inn}$ (sic) of the High Priest of Amun and the Divine Adoratress of Amun (II. 2,2-3) on two successive days where incense is specifically mentioned. The "inw of the Land of Cush" is associated with the "northern treasury of the Estate of Amun" (II. 3,19; 3,21). In the same context, reference to the "inw of the house of Pharaoh" (I. 3,22) will be found. Although red jasper is associated with the inyt' $(l l .3,3-3,4)$, it is also mentioned as "the inn of the God's father of Amun" (I. 3,8). This paragraph potentially indicates that "true red jasper" was the inw of the Third Prophet of Amun, an Overseer of Cattle, and a herdsman as well as the God's Father. ${ }^{719}$ The crucial phrases of P. Turin 1900+ are however so seriously mutilated that any interpretation would ultimately depend upon guesswork.

P. Turin $1903^{720}$ specifically refers to transfers classified as htri (1. vso. 2,1$)$ from various sources to the Gang of the Tomb. Metal ore from the Mortuary Temple of Ramesses III (I. vso. $2,13)$, another source (I. vso. 2,14), and the vizier (1. vso. 2,15) is termed inw.

Both P. Leiden 1350 verso and P. Turin $2008+2016$ use in w in the context of items brought to ships. It is difficult to judge whether the objects brought (inw) and issued (rdyt) are being exchanged, although Janssen doubts this, and suggests that these are official transactions of some kind. ${ }^{721}$ In the event that the in w are to be understood as payments and not interdepartmental transfers, the basic elements are extremely significant. The inw are received on boats, and the ultimate beneficiaries unidentified, although P. Turin 2008+2016 links that vessel with the High Priest of Amun (vso. 1, 1), and P. Leiden I 350 that vessel with the High Priest of Ptah at Memphis (e.g., 5,23). It would appear that most of the materials received were re-issued during the voyage.

A summary of the transactions in P. Leiden I 350 vso.:

KRI VI: 67,11; Bakir, Epistolography, pl. 22, 10.

KRI V: 619-624; cf. Harris, Lexicographical Studies, p. [266].

It will be noted that the text repeatedly uses inn or in rather than inw, but inyt is clearly written out (e.g., $K R I V I: 620,7)$, and the peculiar inn-form uses an indirect genitive, and in contexts excluding the possibility of reading it as verbol form. For this reason, the reading as in $w$ has been proposed.

KRI VIl: 395-397; Černý, Notebook, 15, pp. 16-20.

Janssen, Ship's Logs, pp. $104-105$ 
milk, waterfowl, calf-joint,

wine, fire wood

Deputy of Chariotry $\quad 2,3-2,6$

looves, beer

Noble Lady

$2,7-2,8$

loaves, waterfowl, wine, grain,

fire wood, charcoal, beer

Charioteer

$2,9-2,13$

loaves, meat, beer, wine,

greens, fire wood

loof

loof

?

milk

walerfowl, milk

loaves

loaves, meat, greens, beer grain

greens

(undefined)

fish

looves

looves

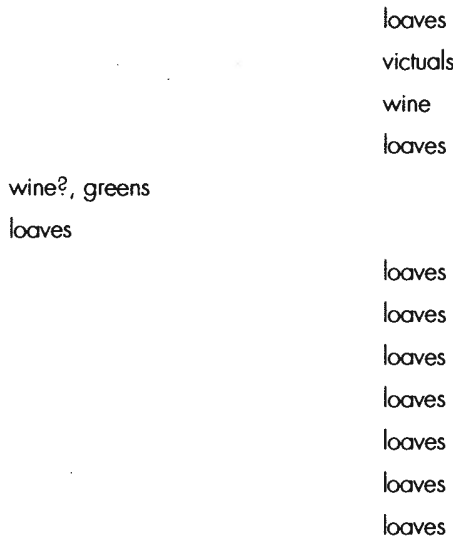

loaves

cattle, milk, greens, poles

loaves

loaves

looves
Scribe

$2,14-2,17$

(Animal) Teams

2,18

(Animal) Teams

2,20

Physicion

man of Cush

2,22

smdt-serfs

2,23

Retainers

2,24

Charioleer

2,25-2, 28

(Animal) Teams

Charioteer

2,30

Scribe

Scribe (?)

(undefined)

3,3

the people

3,5

Servant

3,7

General

3,8

Scribe

3,10

Scribe

$3,11-3,12$

mškbyw

3,15

the people

$3,16-3,21$

Charioteer

3,22

PN

3,25

Crew

3,27

Retainers

3,28

PN

3,29

Retainers

3,30

Crew

3,33

PN

4,3

the people

$4,12-4,16$

htri

4,17

$m$ Princess

$4,20-4,21$

Retainer

4,22

Crew 
The text lists additional entries concerning expenses, before ending with a summary of the inw. Although the word rdyt is not used, the items "expended" are the same. As the first part of the text is missing, it is impossible to establish the veracity of the conclusion, but the tendency is to confirm that the voyage ended without a clear increase:

Summany of the inw.

$\begin{array}{llccc} & \text { inw } & \text { used } & \text { remaining } & \text { line } \\ \text { Consumption loaves } & 55 & 74 & & 6,3 \\ \text { fine bread } & 80 & 200+ & & 6,4 \\ \text { ibśt-looves } & 10 & 10 & & 6,5 \\ \text { milk } & 10 & 10 & & 6,6 \\ \text { wine } & 9 & 7 & 2 & 6,7 \\ \text { waterfowl } & 40 & {[\text { lost] }} & & 6,8 \\ \text { firewood } & 80 & 10 & 70 & 6,9 \\ \text { charcoal } & 10 & & & 6,10\end{array}$

It is curious that beer, greens, meat, cattle, calves, fish and grain do not figure in this list, although they are among the items that were collecled and issued. The income seems to come generally from higher level individuals: a general, a noble lady, a deputy of Chariotry, but some private individuals, including a scribe, a charioteer and a servant also appear as sources. In no case are these associated with any organization. The recipients are all clearly at the lower end of the social scale. In neither case is an indication made that an exchange was the reason for the transfer of ownership. In line 4,17 it is not clear that the word is the term discussed infra (pp. 263ff.) )or a personal name.

Since the ownership of the vessel and the motivation of the transactions is unknown, this papyrus remains tantalizing, except as a basis for speculation. P. Turin $2008+2016$ is quite similar in character, and line 2, 3 notes the receipt of inw at a boat which is unquestionably associated with the High Priest of Amonrasonther, and clearly states that the inw were traded $(2,14)$. Sesame oil delivered by a guard is specifically stated to have been exchanged for garments. ${ }^{722}$

Janssen concluded after reviewing the texts:

In studying these entries one might for a moment presume that ini and rdi are used here not with their general meaning of "to bring" and "to give", but in the idiomatic sense of "to buy" and "to sell". This is not, however, correct since in that case the verb ini must be followed by the preposition $m$ di and not by $n$, while there are no 
examples known of rdi used absolutely for "to sell". We must therefore conclude that the food was really collected and distributed by the ships. ${ }^{723}$

While the first part of Janssen's conclusion would appear to be correct, it is not clear why the possibility that the items delivered as inw were not purchased (ini, meaning "to buy"), excludes the possibility of their having been sold ( $r$ di $n$ being the idiomatic sense of "to sell to someone"). As Janssen's own translation of P. Turin 2008+2016 2,14 reads: "Account of the trading of them..." (p. 71), this would strengthen the argument that the items were collected - without necessarily having been purchased - but that they were in fact sold.

\section{Private Propaganda}

In the Instructions of the Vizier, ${ }^{724}$ the inw of the lower level officials is reported to the Vizier, and one reference indicates that a specific inw was associated with festival offerings.

In a potentially relevant scene, in $\Pi 343, P_{3}$-hqq;-mn "views" the inw of a prwy-h $\underline{\text { d }}$-treasury, but "receives" silver, gold, ivory and ebony from a pr-hd्d-treasury. ${ }^{725}$ Although it is probable that the two treasuries are the same (and presumably royal, as he does not bear religious titles), the actual goods which he receives are named, but not categorized as inw. It is possible that the receipt of the articles is actually related to their being issued to him by virtue of his position as Overseer of Works, and that he did not receive inw payments himself, but took the liberty of labeling them as such in a context where this was permissible, identifying their origin.

In $\Pi$ 125, Dw:-r-nhh details a number of items as inw without specifying their origin (although these appear to be distinct from the foreign items, mentioned infra). ${ }^{726}$ As royal linen is mentioned, the cattle and other items in the same context should be attributed an Egyptian origin. If the context can be properly understood, the tomb-owner distinguished not only the foreign revenue and products, but also the Egyptian products, referring to the "annual htri" separately from the inw. The titles indicate that he was responsible for a gs-pr and a double granary, presumably, but not explicitly those of Amun.

The inscription recording the rewards of the efficient High priest of Amun, Imn-htp, ${ }^{727}$ details fiscal responsibilities using most of the words discussed in this study, but links inw and tp- $\underline{d} t$ apparently as belonging to the temple and the king. As reconstructed his reference would seem to imply that the inw delivered to the temple of Amun may have belonged to Pharaoh,

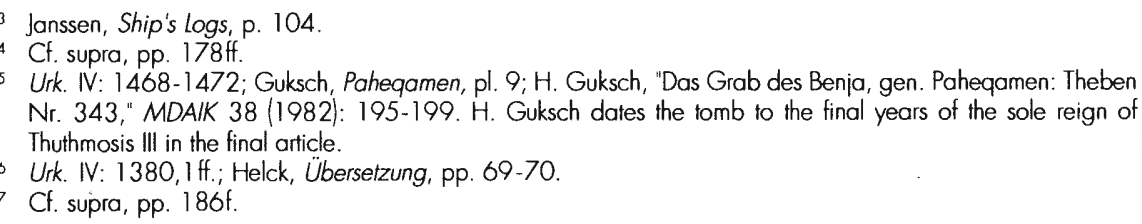


and there is some indication in the text that it actually left the temple. As the inw is elsewhere what the Pharaoh delivers to the gods, one could semantically argue that the Pharaoh is claiming it as his own by virtue of the servant who delivers it to Amun being his servant, but this logic seems torturous.

\section{Royal Propaganda}

P. Turin 1882 includes the passage:

(1) fashioned thy portrait in the sacred shape to make festal thy chapels, which I have caused to come into existence, which I made previously, all the inw of my house $(4,2)$ is loaded rapidly in their sacks, the rest in heaps, I present them immediately (to) thy halls, to propitiate thy names. ${ }^{728}$

It is a commonplace that Pharaohs delivered their inw to the gods, but in many cases it is not clear whether the inw referred to was domestic or foreign in origin. ${ }^{729}$

\section{FOREIGN REVENUE}

\section{Administrative Texts}

In P. Turin 1903, the inw of Cush is termed the annual htri, and identified as being fruit and greens, turned over to the Gang by a Deputy of the Treasury (prwy-h. $\underline{d}$. ${ }^{730}$

\section{Private Propaganda}

In the time of Thutmosis I inw is used to refer to income from foreign countries, turned over to the Estate of Amun. It would appear to represent - at least in part - an annual htri specifically designated from Syria. ${ }^{731}$

Texts in Dynasty XVIII $\Pi 125$ detail that in a construction project directed by the tomb's owner, the "inw of the southern land" supplied the ivory, ebony and special wood which was used in the temple of Amun. ${ }^{732}$ The titles indicate that he was responsible for a gs-pr and a double granary, presumably but not explicitly those of Amun. Černý, Notebook, 15, p. 20; to. 1, 1; KRI VII: 396, 15-16.

731 Urk. IV: 70,4-6. This instance certainly does not support Bleiberg's (JSSEA 11/2:107) assumption that the inw was associated with individual princes, which indicates that using the material from a single reign may be useful as a means of establishing a unique set, but it does not tell us what it means.

732 Urk. IV: 1379, 10; W. Helck, Übersetzung, pp. 69-70. This probably reflects the situation depicted in $\Pi 1343$, supra, p. 225 n. 725. 
In the dynasty XIX tomb of $\mathrm{P}_{3}$-sr $(\pi \mathrm{T} 106)$ he assigned together the inw from "foreign countries and Upper and Lower Egypt into the treasury of Pharaoh," distinguishing this from the "b3kw of the Two Lands", ${ }^{73}$ but he does not identify the destination of the latter. Another text records that the in $w$ of the northern and southern foreign countries went to the royal treasury. ${ }^{734}$

\section{Royal Propaganda}

inw appears constantly in the annals of Thutmosis III, as being what is brought from foreign countries $^{735}$

The Abydos temple received the inw of all the lands (gold, silver, and precious stones) under the reign of Seti I..$^{736}$

The Tyre Rhetorical Stele records the coastal people turning inw over to Pharaoh, the ultimate destination being unclear. ${ }^{737}$

In the hypostyle hall at Karnak, Seti I received the "inw of all the lands," and "commanded the b. $3 w$ of the entire land", presenting it to Amun. ${ }^{738}$

In Seti l's Karnak War Scenes ${ }^{739}$ the $i n w$ of the foreign lands is presented to Amun. Rtnw contributes silver, gold, lapis lazuli, turquoise and precious stones. The same items are also attributed to another region, and all of it is turned over to Amun-Rec. The actual articles are not necessarily products of the lands from which they are received. Slaves and prisoners are also in mentioned (the latter in one instance as plunder, $h, q^{3}$ ). After having benevolently been depicted as the ultimate recipient of the inw, Amun-Re himself says to Pharaoh:

I cause $(5)$ that the great ones of the southern foreign lands come to you, and that they let you receive inw consisting of [...] I cause that $(9)[$ <foreign countries ignorant of Egypt>] come to you [<bearing>] their inw, loaded with silver, gold, lapis lazuli, and all noble precious stones of the god's land [....(1 1 1).... < the Land of Punt, their $i n w>]$ consisting of resin, noble myrrh $[\ldots]^{740}$

It is not probable that the Egyptians saw a contradiction in Amun-Rec receiving the inw, which he says belonged rightfully to Pharaoh, for the tenor of the speech is merely to emphasize that Amun-Re' has given Pharaoh domination over the lands in every direction (North, South, East and West), and created wonders in the Heavens and the very Earth itself for him. That Amun-Re had a right to be rewarded with what he had made it possible for Pharaoh to receive was only normal. The victories are Pharaoh's, the proceeds are Amun-Re's.

\footnotetext{
$K R / 1: 299,11-12$

KRI III: 9,7 .

735 Cf. e.g., Bleiberg, JSSEA 1 1/2: 107ff. In light of this article and of Gordon, inw, the following references to the texts are merely representative, and have been restricted to $K R /$ references unavailable at the time.

$736 \mathrm{KRI}$ : 197,8 . Curiously a similar phrase is not present in the Nauri inscription.

$737 \quad K R I$ I: $117,10$.

$738 \quad K R /$ I: $201,5-6 ; 205,3$.

739 KRI I: 6-32, esp. 10,11-13; 15,8-9; 19,6-11; 23,3-6. Gold, silver, lapis lazuli, turquoise, precious stones are the inw (hiat) given to Amun. Most of it came from the Syrian coast.

740 Speech of Amun-Re': KR/ I: 26-27; 30-31.
} 
In the inscriptions of Seti I at the temple at Kanais ${ }^{741}$ Pharaoh records that he smites the foreign lands, his heart lusting after their inw of loads of electron (text B, 2). As Pharaoh went on to consider the plight of his expedition, bereft of water on the road, it is obvious that the in where was not necessarily a tribute brought without infrastructural support. And the following text (C) records arrangements for water transport with q3r-vessels for his gold washers.

Seti II received the inw of the foreigners bent beneath its weight. ${ }^{742}$

The introduction of the Blessing of Pth- $t_{3}$ - $-\mathrm{hnn}^{743}$ states that the princes of foreign countries are there that they bear the inw to Pharaoh (II. 4-5), while text emphasizes of Hatti alone that it renders inw, b3kw, and hiar (I. 25), applying the other terms in a different fashion. The inscription Seti I left at the Karnak Ptah temple, states the same concisely, but notes that the inw (which is hiaf) would be turned over to Amun- $\operatorname{Re}^{c}{ }^{c}{ }^{744} A$ reference to filling the granary might explain why gratefulness to Ptah would be expressed by rendering the goods to Amun, if the Estate of Amun basically dominated the granaries at Thebes.

The Bentresh stele records that foreigners delivered the inw of gold, silver, lapis lazuli and turquoise to Pharaoh. ${ }^{745}$

The Hittite marriage texts record that "the great ones of every foreign country" were forced to bear their inw of gold, silver, amulets, herds of horses and livestock to Pharaoh. ${ }^{76}$ Part of this was designated for Ptah. ${ }^{77}$ Part of this inw may have been dowry, as is specified elsewhere of the inw with the daughter, gold, silver, slaves, and cattle uncountable. ${ }^{748}$

Egypt itself is the designated destination of inw brought by foreigners in a text from Tanis. $^{749}$

In the inscriptions at the temple of Luxor, Ramesses II puts the inw and bikw of Asia together, and it would appear that both Pharaoh and temple were recipients. ${ }^{750} \mathrm{On}$ the Luxor obelisk the inw is expressly given to Pharaoh. ${ }^{751}$ Part of this inw may have been dowry.

In the Memphis lists of Ramesses II, inw is designated of foreign origin and received by Pharaoh, ${ }^{752}$ and the same is stated in a text from Tanis. ${ }^{753}$

Ramesses II's rhetorical stele at Abu Simbel records that defeated foreigners rendered the in w to the Palace. ${ }^{754}$

742 KRI IV: 259,15. This text is from Karnak, and the recipient is the King himself.

743 KRI II: 258-281, esp. 260,4-8; BAR III: 175-182; Schlögl, Tatenen, pp. 64-66. The text dates back to Ramesses II, but numerous copies were made.

744 KRI I: 41,3-4

$745 \mathrm{KRI}$ II: $285,2-3 ; 6-7 ; 286,16 ; 287,1$.

$746 K R I$ II: 283,$2 ; 7-8$.

747 KRI II: $283,13$.

748 KRI II: $247,4-6 ; 257,11 ; 253,10-11$. This is an illustration that inw need not represent reciprocity, as Liverani (Or. 42: 192) suggests, but is simply used for those foreign goods arriving at the Egyptian court of foreign origin, if this is the dowry.

749 KRI II: 294,11 .

750 KRI II: 608,12 .

751 KRI II: 603,$2 ; 10$.

752 KRI II: $490,12$.

753 KRI II: 290,2 .

754 KRI II: $317,15-16 ; 318,7-8$. 
In the texts at Abydos, Ramesses II implies that the inw is for the temple. ${ }^{755}$

In the war scenes, Ramesses II presents the inw received from the foreigners of silver, gold, lapis lazuli, turquoise and precious stones to Amun-Re ${ }^{c}{ }^{750}$ The inw and the h'qutare delivered to Amun after a successful campaign. ${ }^{757}$ The Princes of Rtnw likewise declared that they desired to present the inw to Amonrasonther himself. 758

The Kadesh texts explicitly relate that the inw of silver, gold, lapis lazuli, turquoise and precious stones rendered up by the rebellious foreigners was delivered to $\operatorname{Re}^{\mathrm{7} 759}$ Deliveries of inw were also designated for Amun. ${ }^{760}$

Ramesses III received the inw of foreign princes. ${ }^{761}$

Ramesses III records receiving inw from foreigners, which may have been passed on to the gods. ${ }^{762}$ Amun was definitely the recipient of the "inw of every land inundating" his treasury and compounding the holdings of his granary. ${ }^{763}$ The entire world supplied inw for the gods, which was also htri and bikw, presumably collected after establishing fortresses for provincial governors' palaces?, bhnwt) in Egypt, Nubia and Asia. ${ }^{764}$

Ramesses III presented a monument to Amonrasonther, providing the inw (perhaps of Rtnw) as the endowment. ${ }^{765}$

Ramesses III records taking natron and salt from the "magazines of inw" of Medinet Habu, presumably for use in divine services by the temple staff. 760

KRI II: 514,14-16.

KRI II: 207,13

KRI II: 171,6; similar in 156,8; 162,12; 167,7.

KRI II: 154, 10; 12-14.

KRI II: 147,9ff. It was precisely the division of $\operatorname{Re}^{c}$ thiat was eliminated in the battle of Kadesh, and thus this

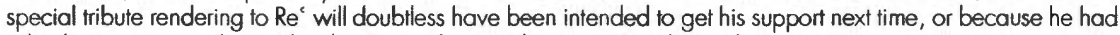
a bad conscience in losing the division and wanted to propitiate the god.

KRI V: 1 10,7. Amun received part of the tribute after the Nubian war (KRIV: 9,3), but whether Pharaoh or Amun received the foreign inw in other instances (KRIV: 27,6;65,14;68,10;93,4;97,9;302,14;317,5) is unclear. Whether Pharaoh or Amun-Rec-Harakhte received the $(K R)$ V: 97,3$)$ foreign inw of gold silver, lapis lazuli and precious stones is likewise unclear. In the case of Ramesses lli, enough inscriptional material is available to attempt to distinguish between texts at Karnak and Medinet Habu, but there is no evidence of items specifically designated for Pharaoh or god differing significantly between the two temples. In speeches of Amun preserved at the temple of Karnak $(K R \mid \mathrm{V}: 219,16 ; 280,2)$ the foreign inw is specifically stated to be delivered to the King. The same is clear from another text at Karnak (KRIV: 225). Another text from Karnak (KRI V: 240,7; 242,2; W. Helck, "Ramessidische Inschriften II," ZÄS 83 [1958]: 32-33) records that the foreign inw is for Amun.

$K R I V: 216,12$.

$K R I V: 218,3$

$K R / V: 177,13 f$.

$K R I V: 321,2$. In this case precious metals are mentioned, and the inw is the result of compulsion, not a voluntary act, according to the text.

KRI V: 144,$1 ; 4$. 
Gordon basically concluded that inw could mean "tribute", "goods", "offerings" or "revenues". This may be perfectly true, but he also asserts:

When used in the context of the king's relations to foreigners, with the Egyptians, or with the gods, inw almost always is tribute. ${ }^{767}$

R. Müller-Wollermann approached the problem slightly differently, turning to anthropological sources to redirect the discussion, providing the criteria identifying tribute as colloquially understood, and then went on to state that political anthropology established that tributary relations do not have a specific mode of production, and that they can be assigned to any social system, but that those who pay and those who receive do not belong to the same ethnic and social group, and that those who pay have their own means of production, and are exploited by non economic coercion attached more to the collective group than to the individual. 768

While this does match her source more or less, the source specifies that what she assigns colloquial meaning is that used by historians, who use tribute to refer to "requisitions from the conquered" and ethnographers who apply it for "occasional or regular requisitions from conquered tribes." And "that tribute is a word with many meanings. " 769 Since Egyptologists have a right to claim to be historians, it is only fair to point out that the way Egyptologists use the word is therefore correct, according to the context, and it need only be noted that if our method is less thorough than political anthropology, it is not necessarily Egyptology that errs. She concludes from the evidence of the New Kingdom that inw was given by Egyptians and foreigners, from individuals and groups, but that it was never collected and that a reciprocal giving was not accomplished. She contends that it was not made regularly, and after examining the texts of the Old Kingdom and the Middle Kingdom believes herself justified in asserting that "gift" is the most suitable rendering for inw. ${ }^{770}$

$W$. Boochs responded to this by citing the $W b$. and reestablished the argument that inw could mean "tribute" by indicating that there was considerable evidence of the use of duress, and that voluntary submission of inw might represent a logical decision on the part of the giver, but that this did not compel the interpretation that it necessarily represented a giff. ${ }^{771}$

767 Gordon, inw, p. 389.

708 R. Müller-Wollermann, GM 66: 81.

769 A. I. Pershits, "Tribute Relations," in Seaton/Claessen, Political Anthropology, p. 149.

770 Müller-Wollermann, GM 66:88-90. It should be borne in mind that her conclusions are marred by her method of employing the data. E.g., she cites RAD 18, 2 (cf. supra, p. 148) saying that the payment of the inw is made by a private person. The title of the unnamed person does not imply that the payment is made in a private capacity, and it is difficult to use "private person" for anything except nmbw and "nh-n-nwt without facing insurmountable philological and semantic difficulties. This is an unusual error for one otherwise so inclined to specifications.

77 W. Boochs, GM 71: 61-66. R. Müller-Wollermann's response to this (GM 77: 51-55) indicated that one had to examine the question in a different light. As Müller-Wollermann originally approached the problem with the conviction that by employing Polanyi's interpretation of "exchange" and "reciprocity" while Boochs was using iconographic evidence, and Müller-Wollermann's response took refuge in Wontfeldtheorie, it became a dialogue des sourdes. 
E. Bleiberg supported an interpretation which involved intricate distinctions between the King's Privy Purse and the rest of the administrative system. His evidence is that inw is always received by the king "or through a representative who has the authority to act on the king's behalf." 772 As the vizier is entrusted with duties on behalf of the king, it is clear that by this definition attention to the inw can also be so classified. Not only however do the references to inw in the "Instructions for the Vizier" not figure in the sections of the text dealing with the palace or the king, but rather expressly in those paragraphs dealing with the management of the land as a whole ${ }^{773}$ - and figures with htri - so that a compelling argument can be elaborated that the inw was one of the most significant official designations for government income during at least part of the New Kingdom. ${ }^{774}$

He completely neglects P. Turin 1900+, P. Mallet and the Ship's Logs which record inw being quite distinct from the royal inw, and having no demonstrable relationship with the king at any level. Therefore the torturous logic which Bleiberg pursued was superfluous, as the vocabulary cannot be defined in the fashion advocated by his approach. A part of the inw may have been designated for the king's privy purse, but that is not the fundamental meaning of the term, and there is certainly no evidence.

His evidence for the contention is selective. While contending that inw is an aspect of kingship, the evidence does not reveal that the inw was turned over to the king as king. His own examples include a reference to the king receiving inw as "Lord of the Two lands", which is certainly an official designation. ${ }^{775}$ Accounting for the inw as intended for the privy purse is however not based on an objective view of the texts, but rather on the assumption that the inw was distinct from temple income, which was termed b:kw. ${ }^{70}$

The $[. .$.$] examination of b^{3} k w(t)$ will depend on the same theoretical considerations [...] The most fundamental of these ideas is that ancient Egyptian economic transactions were named according to the ultimate destination of the products. ${ }^{777}$

Not only is this distinction impermissible, as there are numerous texts uniting inw with bikw which show it heading in the same direction, ${ }^{778}$ but the bikw of Pharaoh is a legal term, ${ }^{779}$ so that the logic is at fault. The distinction between the two terms is clearly the origin and designation, but not the destination.

$\pi 72$ Bleiberg, JARCE 21: 157. Since - through the length and breadth of Egyptian history - we have very few cases of people who acted independently of the king and lived to build a tomb in which they could commemorate this fact, this evidence amounts to a tautology.

$\pi 3$ Cf. Urk. IV: 1114,$13 ; 1115,4 ; 12 ; 1116,2$

74 It is of course possible that my selection of words was erroneous, and that other words with fiscal significance should be sought. The words 1 chose are those which are statistically significant in the literature as it is preserved (which means very little), which other authorities have identified as having this meaning.

75 Bleiberg, JARCE 21: 157-158. Or perhaps the relevant question is: how large was the royal privy purse? $\pi 343$ (cf. p. 225 n. 725 supra) shows clearly that the inw wandered through the administrative apparatus to someone who was Overseer of the Craftsmen of the Lord of the Two lands.

776 E. Bleiberg, "The Redistributive Economy in New Kingdom Egypt," JARCE 25 (1988): 157.

77 Bleiberg, JARCE 25: 157.

778 KRI I: 201,5-6 distinguishes inw as foreign, bikw as Egyptian. KRI II: 608, 12 puts the two in the same category as far as recipients are concerned, while distinguishing their origin and nature. Similarly, KRI II: 260,4-8; V: 117,14

779 Cf. "The Decree of Horemhab", I. 33, supra, pp. $188 f$. 
His final conclusion is however,

The institution of inw was neither trade nor tribute but rather represents a system of gift-giving to the king by a variety of people both Egyptian and foreign. ${ }^{780}$

An examination of his conclusions reveals that his title and thesis is far narrower, for he fails to state clearly whether he regarded the inw as the main source of government income or not, merely indicating that it was officially separate from temple income. What he seemingly means is simply that subject peoples rendered up the inw - Egyptian or otherwise - to the king, but he does not distinguish in his detailed analysis just why he suggests that it be for the royal privy purse.

His illustrations of the distribution of the inw fail to demonstrate that the inw was the exclusive personal property of the king, although there can be little doubt that the inw was accounted for, and that it reached various parts of the administration, so that this is another weak link in his argument. If one shifts the weight of his argument from the contention that it was the privy purse to the contention that it was royal, then his conclusions match $h$ is evidence (although failing to match th e evidence). An indication that this was in fact what he meant is to be found in a simple statement:

The Egyptian system is based on what Polanyi would call a redistributive model. Goods were collected by the temple for eventual redistribution to the people. Rations were distributed from the temple to people on the basis of rank rather than need or ability to buy goods. ${ }^{781}$

We thus see that from an interpretation influenced by Polanyi, R. Müller-Wollermann comes to the conclusion that inw means "present" while Bleiberg concludes under the same influence that it is the income of the king's privy purse. This despite the fact that both of them aver that one should not be influenced by modern categories. ${ }^{782}$ Neither has actually reviewed all the evidence before reaching their conclusions, and the conclusions of both fly in the face of the other evidence.

Each has in fact been biased by an attempt to fit the concept of inw into modern categories. Modern categories are completely essential to gain understanding, but they certainly make the task difficult. Müller-Wollermann, e.g., wanted to remove the modern category of "tribute", and yet found herself applying another modern category, that of "gift". As both were equally inappropriate, the endeavour did not advance our science, as even Boochs' references to the $\mathrm{Wb}$. were able to re-direct the argument. 


\section{CONCLUSiONS}

It will be noted that previous discussions did not try to track all of the variables involved in the delicate task to which we have addressed ourselves in this work, to wit:

Who paid what to whom and why?

It is true that from the Egyptian standpoint, inw could well imply tribute or presents, but the story of $\mathrm{Wn}$-Imn contains an interesting detail concerning trade when discussing the purchase of materials with the Prince of Byblos.

He caused that the records of the days of his fathers be brought, and he had them read in my presence, and they found a thousand deben of silver, all of which was in the records. ${ }^{783}$

This text indicates that the Egyptians customarily paid for their acquisitions from Syria, and it is unlikely that the author would have invented the incident - which is not very flattering to him or his masters, let alone the earlier Pharaohs - unless there were at least a grain of truth in the matter. Liverani pointed out that inw could well be part of a reciprocal trade, ${ }^{784}$ and it is known that the word can be related to the word for "to buy", and therefore it could mean that inw was what was "bought" or trade goods as has been frequently advocated.

Egypt doubtless took tribute and plunder when their armies were marching through foreign countries, but the things that arrived in Egypt from outside are invariably termed either higt, inw or b3kw, so that we cannot distinguish between trade goods and tribute, but must assume that trade goods and presents /offered in the spirit of reciprocity) were the rule rather than the exception. It is possible that bikw payments from Asia are more common than $b_{3}{ }^{3} k w$ payments from Nubia, while inw from Asia and Nubia appear to be equally common. References to Punt delivering $b_{3} k w$ are far less common. ${ }^{785}$ The dowry offers a classic case in point, for dowry cannot be tribute, any more than plunder offered voluntarily is booly. inw would appear to figure not only in the same texts and contexts as bikw, as has been

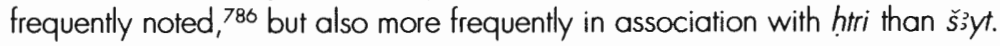

Ideologically there is evidence that the Pharaoh was awarded a conquest by virtue of the support of the gods - Amun-Re in particular - and that the resulting income was turned over to the temples, where it was kept, but that Pharaoh had access to this. It is also possible that some of the foreign inw went to the Pharaoh, but the extent to which the receipt of regular

783 LES 68, 1-3.

784 Liverani, Or. 42: 192-3.

785 I know of none. This might be evidence of inw meaning trade goods, as Punt surely did not render tribute to Egypt, in the sense of obligatory payments impressed by the use of military force. Following the same logic, one would suspect that Egypt took items titled b3kw from countries where there was an administrative structure under Egyptian influence, while inw came from countries where such a presence did not exist las a consequence of either trade or military conquest). Given the evidence and the free use of $b ; k w$, this cannot be justified on philological grounds.

786 Cf. e.g., Bleiberg, JSSEA 11/2: 107ff. 
payments went to either the Pharaoh or the temples on a regular basis cannot be elucidated from the lexts. The inscription of the High Priest Imn-htp can be interpreted as implying that in w went via the Estate of Amonrasonther to the Pharaoh (although this is not compelling). ${ }^{787}$

$\Pi 343$ illustrates that the goods derived from the inw then became part of the properties of the treasury - and were used - as goods. Other texts indicate however that the inw as such - not merely the goods, but also the designation - was passed on to another authority (as e.g., in the inscription of the High Priest of Amun, Imn-hip, pp. 186f., supra), where it was transferred from the temple to Pharaoh.

While a great deal of attention has been devoted to the foreign inw, the Egyptian evidence has been neglected. The inw of P. Gurob may have been termed such because it was of Syrian origin, and the same is could hold for the red jasper of P. Turin 1900+. The other references to internal inw are insufficiently precise to permit an identification, but certainly, the evidence of $\Pi 100$ should support the contention that one form of obligatory payment in Egypt itself was termed inw. The details of the "Instructions of the Vizier" tend to imply that during Dynasty XVIII, inw was the single most important type of revenue for which the vizier was responsible, as htri is used in fewer contexts, while inw is applied for rural income, festival offerings, and for administrative units.

P. Harris I definitely distinguishes between the inw, as this is the label applied to the royal giftts given to the temple of Amun, and the annual htri of the temple which is classified as šzyt and $b^{3} k w-r m t .{ }^{788}$ Of the two lists, one striking difference is the detailed listing, lumping all of the categories together in the latter lists, while detailing the silver, textiles, incense, and wine, etc. as inw offerings to the temple. Perhaps significantly, precious stones figure only in the inw list, whereas otherwise, the same types of items are listed exhaustively in the in $w$ list and briefly in the htri list.

This suggests that the temple itself did not receive any inw income, apart from what the Pharaoh gave it. ${ }^{789}$ This would correspond to all of the other references to the foreign trade items as well, so that the inw income assessed in the Instructions of the Vizier, and the inw income from the foreign countries belonged, at least initially and superficially to the King, and that he then turned over part of this to the temples.

The fact that precious stones and faience were exclusively in the hands of Pharaoh and were not part of the normal temple income is striking, and suggests that the evidence from P. Turin $1900+$ need be recognized as indicating a royal monopoly on supply. ${ }^{790}$ Thus, the relevance of these texts for the understanding of the word inw may be misleading.

If inw was the principal designation for the non-temple income of the state, then it is logical that Pharaoh and the Egyptians in general will have been more interested in representing the

787 Cf. supra, pp. $186 f$.

788 The Bilgai stele likewise does not employ inw, but does use šmw, htri, š3 $y t, b 3 k w-r m t$.

789 R. Müller-Wollermann (GM 66: 86) errs in translating that Rh-mi- $R^{c}$ counted the inw in a temple. Only gs-pr is written, without a further specification.

790 Clearly, this involuntarily feeds speculation about royal monopolies on foreign trade, but the evidence is slim. 
foreign inw (i.e., whatever they received from foreign countries under any circumstances) as this indicated supremacy - the ability to oblige another to make a payment - and would explain why so few references to Egyptian inw are preserved, for it was not interesting in terms of their Weltanschauung.

It is extremely difficult to incorporate the evidence of the Ship's Logs into this argument, for the evidence tentatively indicates that the vessels were not royal. The transactions recorded in P. Turin $2008+2016$ state that that vessel was associated with the High Priest of Amun (vso. 1,1 ), and the suggestion that the inw were not purchased but simply received, and re-issued, would tentatively speak against a private trading venture by the High Priest. The transactions of $P$. Leiden I 350 seem to be associated with the High Priest of Memphis. Both papyri record the receipt of inw, and the context would indicate that the acquisitions need not be understood as purchases, yet the recipients to whom they were subsequently "given" may been purchasing them. In general it can be stated that those delivering goods to the vessels are of a higher social standing than those receiving them. The articles are those characteristic of P. Harris: grain, garments, fish, papyrus, sesame-oil, etc.

This evidence would indicate that inw-articles belonging to the temples are being collected by the ships. It is however difficult to state whether those delivering the inw were doing so ex officio, or meeting a personal obligation, or being compensated for their goods. It is permissible to suggest that the goods were being sold, and that the profits of the transactions went to the owners of the vessels. If the inw brought to the vessels was not purchased, it must be assumed that this was some kind of obligatory payment, i.e. a "tax" or "tribute". It definitely cannot be documented that the Crown benefited from these transactions.

As there is very little administrative evidence for inw from Egypt, aside from the Ship's logs, it is legitimate to state that comparing the inscriptions with the records may be dangerous. If is however interesting to note that Pharaoh takes credit for the delivery of the in $w$ in the propaganda text P. Harris I (IId, IIId), and that Pharaoh seems to make some claim to the inw in the propaganda inscription of Imn-htp. Since the administrative records do not demonstrate this at all, indicating that the temples received the inw directly, there would appear to be a superficial contradiction.

The regularity of the foreign payments is uncertain. Certainly those kings who were willing to collect inw personally on regular visits to Syria and Cush could assure that payment was regular, but in general the data cannot guarantee that payments - even from areas under nominal Egyptian suzerainty - were made regularly. Deliberate maintenance of trade connections was probably logistically difficult in antiquity, so that foreign trade missions were probably not functioning on a basis which guaranteed delivery of products on a regular basis. It will be recalled that the red jasper and turquoise scarabs were delivered to the temple at the rate of 2 a year under Ramesses $111{ }^{791}$

791 Cf. P. Harris, supra, pp. 203-204 n. 632. This is a very curious item: the higher number of carnelian items as opposed to lapis lazuli, and red jasper would suggest larger supplies and thus easier access to carnelian, yet carnelian supposedly came from India, while lapis lazuli was from Afghanistan. Did the carnelian come in fact from Punt? 
If the Instructions of the Vizier are correctly understood, the collection of inw within Egypt may have been standardized, possibly based on annual assessments. ${ }^{792}$ The local administrative officials will have been responsible to the next level up. ${ }^{793}$

The evidence indicates however that there were several different types of payment designated as inw. Some in w was income destined for Pharaoh or the non-temple state administration assessed in Egypt. ${ }^{794}$ The evidence from the Ship's logs and the inscription of Imn-hitp would indicate that the temples had their own inw-income. It is difficult to judge the degree to which the evidence of the Ship's logs can be taxed. The income was apparently delivered directly to the temple vessels, and was apparently distributed or sold by those vessels, presumably for the benefit of the temples. There is however no evidence for the inw within Egypt which was ultimately delivered to Pharaoh having been purchased or acquired by exchange. It is however extremely probable that some of Pharaoh's foreign inw-income was acquired through purchases.

Sh. Allam did not elaborate on his interpretation, but it is possible that he is on the right track in indicating that the term does not have a precise meaning. ${ }^{795}$ This discussion has likewise accomplished little more than underline that Bleiberg and Müller-Wollermann were overly ambitious, and to confirm that Gordon's conclusion - that the word cannot be assigned a precise definition - is correct. It must be noted however that the foreign inw included both payments made under duress ${ }^{796}$ and trade goods, as well as voluntary gifts.

792 This is an assumption based on the contexis. As pointed out above, the inw is associated with the htri, in many contexts, and htri is frequently annual, so that it can be deduced that the inw is also annual. We will see below that the difficulty is that the htri seems to subsume the other categories, so that an annual hitri can be understood as an abstract annual obligation to carry out a certain task which involves the delivery of concrete goods. Those goods (inw, etc.) may be delivered annually, but the obligation to deliver them need not be expressed as an "annual inw" since the concrete goods are what is delivered in compliance of the "annual htri" obligation.

The Tax Lists of the Royal Canon, 2,4-5 (supra, p. 159) do however hint that the inw may have been annual. R. Müller-Wollermann (GM 66: 88) categorically rejects regularity, but this is exaggerated. If the annual htri assessments arrived as inwgoods, the Egyptians did not need to specity the regularity of the inw, because it was a different category from the assessment, which is correct. This does not alter the interpretation available to us: that inw-goods were seemingly rendered up on a regular, obligatory basis within Egypt, and on an irregular basis outside Egypt, dependent upon military campaigns and trade missions, and diplomatic connections

793 R. Müller-Wollermann (GM 66: 88) states that "Von einer Eintreibung ist nie die Rede". Urk. NV: 1115,12 certainly suggests that the Vizier had to keep very close track of the inw.

794 Without implying that Bleiberg is necessarily correct in assuming a distinction between royal private and public income.

795 Allam, S., "msw = Kinder/Volksgruppe/Produkte/Abgaben," SAK 19 (1992): 13

790 R. Müller-Wollermann (GM 66: 85) remarks that inw is never associated with force. While the inw was peacefully and voluntarily given to Amun in Karnak, the means of acquisition favored by Seti I would suggest that during the Ramesside period inw was acquired by force (cf. e.g., KR/I: 23, where Seti produces inw which he explicitly attributes to his might), and taken to Karnak, where it was freely given to Amun. (The implications of a text like Urk. IV: 691,10-13 do not imply that the delivery was voluntary, and the same applies to Urk. IV: $712,7)$. In general R. Müller-Wollermann's statement must be based on a different definition of force than that usually understood by those familiar with Clausewitz. 


\section{$b^{3} k w$}

THE WORD bikw ${ }^{797}$

In Dynasties XIX and XX, the word bikw $(t)$ appears to refer to work in the sense of the products of activity (working) or tasks, ${ }^{798}$ perhaps as distinct from the significance of $k^{3} w$, meaning "public works" or "projects", so frequent in titles of Dynasty XVIII. In the administrative texts from Deir el-Medineh of Dynasties XIX and XX, it is used to refer to the tomb of the reigning pharaoh in the expression, the "work in progress" ${ }^{799} \ln O$. Cairo $25536, b^{3} k w$ is used several times in precisely this sense, referring to the commencement (line rto. 1) of the tomb of the Pharaoh Siptah, and to the further progress (line rto. 2), using both the idiomatic expression and the word alone. Etymologically and fiscally, it also refers to something that is "worked" or "produced" or a "product" that is traded, or rendered up to meet an obligation.

\section{INTERNAL REVENUE}

\section{Administrative texts}

The miscellany text states concisely that the scribe's bikw was in writing (P. Anast. V, 17,2). ${ }^{800}$ What he did was write, and what he produced was writings, and this was not subject to hitri. Leistungen," VA 3 (1987): 207-214; E. Bleiberg, "The Redistributive Economy in New Kingdom Egypt: An Examination of Bikw(t)," JARCE 25 (1988): 157-168; Loton, Terminology, pp. 90-105. J. Cerný, "An Hieroglyphic Ostracon in the Museum of Fine Arts at Boston," JEA 44 [1958]: 23-25.) uses b3kw in the sense of "performing a service for the lord of the gods"; which J. Cerny (JEA 44: 23) renders "to be a servant". CF. also KRI VII: 266,8 (P. Cairo JdÉ 52 003) for work carried out on a lemple in the Delta, which could be the mortuary temple of Ramesses III associated with his cenotaph there. An ostracon from Thebes (O. Cairo 25241, erroneously attributed to Abydos, KRI VII: 7, 5) also refers to bikw as the work of stone masons and brick makers at a temple, but it is possible that they were paid (for which no evidence either way!). Workers' pay bikw may be recorded in another text, relating to the tomb of an officer (KRI VII: 263-265; P. Cairo 52002). A jeweler is required " $r$ bikw in the mansion of the enlightened soul of Ramesses, beloved of Amun (LIP!H!) in the temple of Ptah" (KRI VII: 102-103). Stones are given to him, and the work is potentially an obligation. Another obscure text uses bikw with large numbers of unclear significance (KRI VII: 284-285; O. Berlin P. 1268; S. Allam, "Einige Hieralische Ostraka der Papyrussammlung der staatlichen Museen zu Berlin, "FuB 22 [1982]: 52-53).

Aside from these and texts which are cited below, and others which re-produce the same phraseology, there are dozens of examples where it is not entirely clear that a fiscal transaction could conceivably be involved, and these have been silently omitted on the assumption that being comprehensive does not necessarily require being exhaustive. meaning. 
P. Munich 809 (formerly P. Mook) ${ }^{801}$ specifically refers to a bikw payment traditionally due to the goddess Hathor ("since the days of Nb-phtry- $\mathrm{R}^{c \text { ") }}$, which was confirmed in the reign of Thutmosis IV. The fragmentary nature of the text makes interpretation difficult, but it would appear to be certain that the obligation was that of a private individual, and that his obligation to pay was confirmed by a court composed of the highest civil officials (the two Viziers, deputies and fan-bearers) and not temple officials.

The word appears repeatedly in connection with deficit obligations in P. Brooklyn 35.1453 B. ${ }^{802}$ The $b 3 k w$ would appear to be measured in deben, although also counted in jars of honey. The purpose of the text is unclear but it clearly relates quotas with monetary values.

The Tax Lists on the Turin Canon state that a specific fisherman's personal $b$; $k w$ was collected in fish, while a guardian apparently paid a $b 3 k w$ in gold, that of the mat weavers was in textiles, but the nature of another official $b_{3} k w$ defined as a regular $\check{s}_{3} y t$ is not preserved. Another delivery of fish is categorized as šdyt. The entries are phrased "his annual $b_{3 k} k$ " $(3,1-3) .803$

The term $b_{3} k w$ is used in the texts of the Gang at Deir el-Medineh during Dynasties XIX and XX. ${ }^{804}$ In concrete terms, plaster can be termed $b 3$, $w$, but fish or firewood are generally not in the texts where two of these appear. ${ }^{805}$ In one transaction text, ore is referred to as $b_{3} k^{3} w^{806}$ while in a dispute, ore is referred to as inyt. ${ }^{807}$ Plaster is classified as $b_{3} k w$ in a text referring to fish as inyt. ${ }^{808}$ Honey for the temple of Amun also appears on dockets, where the deliveries are termed $b{ }^{3} k w$, but are actually the $\breve{s}^{3} y t$ of an official. ${ }^{809}$ The honey is from the "bearers of honey" of the mortuary temple of Seti I.

bikw is however the generic term for the obligatory quantities of fish to be provided on a monthly basis by the fishermen supplying the Gang. ${ }^{810}$ In year 25 of Ramesses III, Nfr-hitp

801 W. Spiegelberg, "Ein Gerichtsprotokoll aus der Zeit Thutmosis' IV.," ZÄS 63 (1927): 105-115; Allam, HOP Tafelteil, pls. 102-103.

802 Cf. V. Condon, "Two Account Papyri of the late Eighteenth Dynasty," RdÉ 35 (1984): 57-82, esp. p. 77. It would appear that Condon's "wages" reverses the situation, as it is the failure to deliver the bskw that is meant. It should refer to honey.

803 Cf. supra, p. 160

804 E.g., KRI IV: 164f. (P. Gard. 8/Ashmolean 1960.1283; C. J. Eyre, "An Account Papyrus from Thebes," JEA 66 [1980]: 108-1 19); KRI V: 536, 14 (O. DeM 165); KRI V: 527,6 (O. Gard 150; H.O. 71,3); KRI V: 460 (O DeM 92 - excavating the tomb); KRI VI: 120,2 (O. DeM 45 - temporally specified obligation of potter); KRI V: 609,12 (O. Cairo 25591 - bikw of polter; inyt of Chief of Provisions of Pharaoh); KRI V: 610, (O. Cairo 25 633 - bikw of potter; wood nol specified); KRI VI: 367,7; 368,2-3 (P. Turin 1923); KRI V: 399,6 (P. IFAO sans; Y. Koenig, "Livraisons d'or et de galène au trésor du temple d'Amon sous la XXe dynastie," Hommages Sauneron I: 185-220); KRI VI: 409, 1 (P. Turin 1907/8; J. J. Janssen, "A Twentieth-Dynasty Account Papyrus," JEA 52 [1966]: 81-94); KRI VI: 566,4 (Giornale).

805 KRI IV: 421,12 (O. Cairo 25593 ).

800 O. Cairo 25722

${ }_{807}$ KRI III: 545 (P. Berlin 11239, 2.)

sо8 KRI VI: 583, 1 I (b;kw); cf. KRI VI: 582, 1; 9; 583, I (inyt); KRI VI: 682,1, etc.

809 KRI VII: $84 f f .$, esp. 84,$8 ; 16$.

810 KRI VI: 681 If.; P. Turin 2075 (Černy, Notebook, 15, pp. 23-30), dating to Ramesses IX and Ramesses X. Cf. also KRI VI: 653,4 . N.B. these are texts where no contrast is made to wood, pots or plaster. It is difficult to distinguish with certainty, but it would appear that the obligation is $b 3 k w$, while the actual delivery is unlabelled. (Prof. Janssen drew this distinction to my attention in this text.) What is actually delivered is elsewhere inyt/cf. e.g., KRI VI: $582,9-10$ ). 
received Imn-hु' $w$ 's bikw of fish, amounting to 380 deben. ${ }^{811}$ In Year 19 Ramesses IX, three fishermen each provide 50 deben of fish daily each month, making a total of 4500 deben monthly. ${ }^{812}$ The term used is šdi, "to exact". ${ }^{813}$ In one case Hnsw-ms delivers eight khar of emmer which are reckoned into fish, but obviously regarded as the fulfillment of his fish $b^{3} k_{w}{ }^{814}$ This use of a substitute $b^{3} k w$ should not be confused with the term used for deliveries of other goods to the tomb where the word fails to appear. ${ }^{815}$ Responsibilities appear confused when the water carrier $\mathrm{H}^{\text {' }} \mathrm{pi}^{-}{ }^{\text {'? }}$, delivers emmer, sheep and a bowl, all classified as his $b_{3} k w^{816}$

In the particular context of Deir el-Medineh, it would seem that the word bikw is used (1) to identify specifically the obligatory deliveries of the servants of the tomb, but also (2) to identify other payments made, and specifically (3) the supplies issued to the Gang in order to carry out their work in the tomb.

O. Cairo 25536 uses bikw to refer to the work in the tomb.

(1) Regnal Year 1, II sht 12. Day of receiving the bikw by the mayor and Vizier Hri.

(2) The further progress: 13 cubits which were made from it. Progress (3) since affer the receipt by the Vizier. The bikw cubits [...]

This text clearly uses bikw referring to the "site" of the royal tomb or the "work in progress" as Cerny translates. ${ }^{817}$ Technically it is here a measure of work, and the receipt of the $b^{3} k w$ must be understood as meaning that it was "recorded" or "observed" /unless šsp means "beginning" or "commencement" here, which would mean that the text refers to the start on work on the new royal tomb after the burial of the deceased).

0 . Cairo 25722 uses $b_{3} k w$ without the definite article in a context which appears to be a private commercial transaction, a payment being made for the rearing of a bull, but the text is not completely preserved.

P. Anast. VIII ${ }^{818}(1,13)$ refers to the (2) "bskw of $h<i s>$ fisherman". $(3,3)$ and $(3,12)$ seem to refer to a papyrus b3kw. The entire text is obviously related to the transport of commodities, but it is not clear under what title, for whom and from whom.

P. Bib. Nat. 199, $2^{819}$ seems to indicate that a piece of land was assigned by or to the Mayor of Thebes to a cultivator "in order to perform his b3kw". Specifically, the text indicates that a number of foreigners were assigned to work a piece of land, to provide the $b_{3} k w$. At the heart of the administrative letter P. Cairo 58056 the unidentified author ${ }^{820}$ states to the Standard-bearer, 'h-pt:

811 KRI VII: 292-293; O. Campbell 2,3. McDowell, Ostraca, pp. 4-5.

812 KRI VI: 653,12-13; P. Turin 2075, 2,5; vs. 1,1.

813 KRI V: 682,10; P. Turin 2075, 3,2.

814 KRI V: 682,11 ; P. Turin 2075, 3,3.

815 E.g., KRII: $365 \mathrm{ff}$. (fire wood); KRI IV: 421. KRI VI: 603, 15 refers to "corrying bikw which is his obligation", but the text is fragmentary. KRI VI: 639,15 may refer to "carrying bikw [...] Pharaoh".

816 KRI VI: 603-604, esp. 603, 15-604, 1; P. Turin 2084 + 2091, 2, 1-2,5.

817 Černý, Communily, pp. $81 \mathrm{ff}$.

818 KRI III: 499-504; Bakir, Epistolography, pls. 28-32/XXXVI-XXXVII; Wente, letters, p. 120.

819 LRL, p. 53; Wente, LRL, p. 69.

820 The rank of the author will not have been notably below that of the recipient, as his name and title are lost at the beginning of the text, and these would have followed those of the recipient, were the latter significantly higher. 
Look! Two kir-vessels of yours (5) are here in Memphis (Mn-nfr). And I have been told that you sent them when you came here (6) in the military manoeuvres (?). You said to me, "Be still and make not conversation. I will cause the kir-vessel to be brought to you." (7) At my arrival, please send to the soldier $P_{3}$-s3-nsw that he give to me the $k_{3} r$-vessel and I will give $b_{3} k w(8)$ the day of its $b_{3} k w$. And may Ptah give you health, and that you not begrudge giving the k3r-vessel.[... $]^{821}$

As the letter ends with what appears to be a matter of private debts, it is possible that the $b 3 k w$ here is a private matter as well, but not absolutely certain. The reference to the use of a boat to carry out $b_{3} k w$ is similar to the reference in the Horemhab decree, ${ }^{822}$ possibly suggesting a public obligation carried out with private means, and that the lender is acting in a private capacity, while the borrower is doing so as private person with a public obligation. If the donkey texts suggest that $r b_{3}$ kw. $f$ means so much as "rent", the "the day of its bikw" might correspondingly refer to the rate. But, "the day of its bikw" may refer to the day when one comes to collect its $b_{3} k w$, as in the following case, indicating that there is a $b 3 k w$ which must be paid regardless of possession or use, which cannot be rent.

The letter P. Cairo 58057 from the herdsman Dhwity-ms of the Mortuary Temple of Ramesses I to $P_{3}$-iry, an Overseer of Cattle, records the former saying,

[...and to] say, please let the hoof-in-ore-donkey ${ }^{823}$ be brought which is with you, through the servant Pizy (3) since it was given to him.for its hoof-in-ore for the field of the Mortuary Temple of Ramesses I in the island of Phz under the authority of (4) the soldier Mšs of the Mortuary Temple of Ramesses I. That you may know it, there has been given to you a donkey by the soldier Tnn of the Phyle Dazzling (5) like Aten in Year 1 of the troop of Dipr. He said to you, "Give it to Dhhwty-ms." You did not give it. (6) I (filled you in?) here in Memphis together with the stable master Imn-ms, saying, "Give it!" And you said to me, "Do not take me (7) to court. Behold the donkey is with me. Had you sent someone to take it, would I not have given it? " So you said. (8) You made an oath of the Lord (LIP!H!) saying, "I will let it be brought," Look, you have not had it sent, and one comes (9) to exact the bikw from me year for year, and beast is with you. ${ }^{824}$

This rather obscure text hints that a b3kw was collected for donkeys, and that the administrative measures employed did not associate the presence of the donkey with the obligation, but

KRI III: 254-255; Bakir, Epistolography, pls. 4-5/VII. S. Allam ("Trois Lettres d'Affaires," Mélanges Mokhtar, I: 19-23) translates, "[... il me cède le bateau (de sorte que) je (puisse) donner (du) travail (à exécuter). (1. 8.) C'est (justement) le jour de son travail [... . " One might equally read, "[...] that I may cause to be used $(8)$ the day of its $b_{3} k w[\ldots]^{4}$. The implication of a particular significance about the b3kw induces the translation presented above. "[ $<$ As for $>](1.17)$ any private person without a boat who gets for himself a boat for his bikw from another and he causes that he be ordered to get wood for him"; cf. supra, p. 188.

823 "giwt.f $m$ bis. "Hired" or "borrowed" is the usual interpretation, but the context of the word generally falls into the field of the fiscal so that the expression is left. Cf. supra, p. 134-135.

824 KRI I: 238; Möller, Lesestücke III: 8; Allam, HOP pp. 287-289; Tafelteil 86 
rather that the obligation existed independently of access to the donkey. ${ }^{825}$ The reference to the "hoof-in-ore" is difficult, as the term seems to suggest to certain scholars that this is a reference to a rental agreement, and other texts relate it specifically to donkeys as well, but the term never appears in Deir el-Medineh, where donkey rentals are common place. ${ }^{826}$ The usual phrase in 27 texts from Deir el-Medineh is that so-and-so has taken a donkey "for its $b_{3}{ }^{3} w^{\prime \prime} .{ }^{827}$ Were it not for the present text (and a couple of unpublished references), ${ }^{828}$ this would generally be assumed to mean that so-and-so was taking the donkey "for his work". As however, the last line of this text states that a $b_{3} k w$ is exacted for the donkey, whereas the first line dealing with the donkey refers to its "hoof-in-ore", it is not inconceivable that the two are related. The animal has been waylaid on its way to Dhwty-ms by the Overseer of Cattle, while it was ultimately supposed to have been with Pizy. That $\mathrm{P}_{3}$-iry is somehow profiting from this "hoof in ore" seems to emerge from the first part of the text. The creature is apparently either the property of a major temple administrative complex or the Mortuary Temple of Ramesses I (less probably that of its servant, Dhwly-ms), so that the "hoof-in-ore" would appear to be the actual value of the work to the one using it, seemingly equivalent to the $b_{3}$ k w. If this torturous logic is correct, the "hoof-in-ore" which perished in the miscellany was the value of the work, while here the "hoof-in-ore" benefits the Overseer of Cattle, which was actually to benefit the temple ("for its hoof-in-ore for the field") for which the herdsman pays the $b_{3} k w$, and therefore it is an expression relating to fiscal transactions and not rental.

Neither of these texts has however indicated to whom the bikw is paid, or rather who collects it. Apparently the obligation to account for the donkey owned by the Mortuary Temple of Ramesses I was not collected by that organization: the "hoof-in-ore" was intended for the benefit of that institution, but not the $b_{3}^{3} k w$. The $k_{3}^{3} r$-vessel is the responsibility of the Standard Bearer, but the unknown author of the letter requires the boat, potentially for its $b_{3} k w$, but assuredly for a $b_{3} k w$ that the author of the letter was obliged to provide.

P. Turin $2084+2091$ does not do more than throw some more dim light on the subject, but although the text is terribly mangled, it nevertheless emerges that a complaint is made (once again) concerning "five donkeys of the tomb" which had to be accounted for "when they were not with Pharaoh (L!P!H!) their owner and not bearing [...]".829 This could concern the donkeys used by the smdt, but regardless implies that the donkeys had to be accounted for at all times.

P. Cairo JdÉ $52002^{830}$ appears to describe work on a royal cenotaph near Memphis, stating that there is a site $\left(r^{-}-b 3 k w\right)$ which a Chantress of Thoth was to visit. In this context,

825 "Hoof-in-ore" cannot be a mere idiomatic expression for "borrowed" as the miscellany rext - supra, pp. 134-135 - emphasizes that the "hoof-in-ore" has perished, as well as the team, so that the term seems to refer to the value there, while the lext here emphasizes the character of the arrangement. Cl. supra, p. $134 \mathrm{nn}$. 346-350.

827 Janssen, SAK 20: 81-94.

828 Janssen, SAK 20:82 ก. 9.

829 KRI VI: $603-608$; P. Turin $2084+2091,2,9$. The divine determinative after $n b$ indicates that the text should not be understood as "with Pharaoh (LIP!H!) or their owner", and that pharaoh was their owner.

830 KRI Vil: 263-265; cf. P. Posener-Kriéger "Construire une tombe à l'ouest de Mn-nfr," RdÉ 33 (1981): 47-58, pls. 3-4. 
grain is collected for the diw of the workers (II. 9; 17), which is termed bikw, when collected. ${ }^{831}$

$P$. Turin $2008+2016$ uses bikw in the context of items brought to a ship. ${ }^{832}$ The ownership of the boat is not clear, and thus the ultimate recipients unidentified. P. Turin $2008+2016$ vso. 2, 2 lists the bikw of papyrus possibly brought to the boat.

The accounts papyrus P. Cairo $58096^{833}$ seems to relate to the distribution, handling and collection of items, detailed as bikw:

$1,1[\ldots . .(?)] 834[\ldots .$.

$1,2[\ldots]$ together with the lapidary Nfr-hr $[\ldots$.

$1,3[\ldots . .$.$] to field [left Blank]$

$1,4[\ldots<$ Total of $(2)>]$ the deben of red jasper $[\ldots .$.

$1,5\left[<\right.$ given for $\left.b_{3} k w(?)>\right]$ at the gate of $[\ldots .$.

1,6 given for $b 3 k w$ together with lapidary $[\langle P N>\ldots]$.

1,7 Total day 1 D 17 [Left Blank]

1,8 Again: given through lapidary Sw-n-r red jasper, t $^{c} r$-vessel ${ }^{835}$ (items) 70

1,9 red jasper, beads [Left Blank] 80

1,10 red jasper (?) [Left Blank < withdrawn(?) from the Gold House > $]^{836} 60$

1,11 red jasper bs-block (?) ${ }^{837}$ [Left Blank] in Regnal Year $43 \|$ s $h t 18^{838} 6$

1,12 I sht 18. Day of commanding lapidary Nfr-'bt to $b 3 \mathrm{kw}$ in the Mansion of the

1,13 enlightened soul of $R^{c}$-mss-sw mry-Imn (LIP!H!) in the Estate of Ptah.

1,14 Given through scribe lyt red jasper beads, ${ }^{839} 20$; pieces, 45

1,15 Given [<through the lapidary (?) >1 Sm pieces 100 .

2,1 Given through the lapidary $S_{[}[<\mathrm{m}>]$, pieces, 200(?). Again for silver plating(?), beads 12

831 On the meaning of diw, cf. infra, pp. $264 \mathrm{ff}$.

832 Janssen, Ship's Logs, pp. 64 and 66.

833 KRI VII: 102-103; Cerný, Notebook, 145, p. 41.

834 Cerný may have read $s \underline{d} m$ here.

$835 \mathrm{~J}$. J. Janssen (Prices, p. 338) refers to a tr-vessel which is a rare word, for a container of perhaps $11.5 \mathrm{hin}$. (CF. O. DeM 46, vso. 10; 0 . Cairo 25678,39 ). If the word is the same, the lapidary has returned a vessel filled with pieces, numbering 70 in this case.

836 Partially represents restoration suspected by Černý.

837 J. J. Janssen (Prices, p. 206) has identified a bs-container, perhaps a pail. It is tempting to have this filled with the stones, but the determinative does imply that these are the products rather than the container land Cernýs franscription - which I have before me - does not indicate any doubt in his mind that this part of this line ended here), but the scribe did clearly make later additions, and therefore the determinative may have been meant to apply to what should have followed, rather than to the preceding word.

The second determinative used indicates however that the scribe could not decide whether a bs was a "bead" or a "block" $(2,3)$, so that tending to the latter conclusion is more in keeping with the text.

$838 \breve{C}$ erny evidently had reason to suspect that the date was added later.

839 inhm. The elymological origin of "pomegranate", inhmn, being unknown (H. Brunner, "Granatapfel," $L \ddot{A}$ H: 891 892 ), it is here assumed that inhm means "bead", and that this is the origin of the word for pomegranate, the Egyptians having conceived of the fruit as full of "beads". Drenkhahn, Handwerker, p. 49 categorizes the nšdy as a "bead maker", but this is surely too narrow, although in this case, the lapidary was certainly making beads. 
2,2 Given through lapidary Sw-n-r t'r-vessel (items) $70^{840}$

2,3 Given through lapidary Sw-n-r bs-blocks, 6

2,4 Given through Scribe lyt red jasper beads 20 pieces $45^{841}$

2,5 Given through lapidary $S_{w}-n-r$ red jasper pieces, 60

2,6 Given through lapidary Sw-n-r red jasper beads 80 vso.

1, 1 I spent 8 days in the Mansion of the Enlightened Soul Rc-ms-sw mry Imn, and I left, 1,2 and I was ordered to $b 3 k w \|$ smw 16 in the |pet-Festival. ${ }^{842}$

The initial impression is that the most interesting element in this rather confusing text is a reference to what would have been the Mortuary Temple of the Cenotaph of Ramesses $I 1$ in Memphis (1. 12). As it would appear that his successor Merneptah had a Cenotaph in Memphis, ${ }^{843}$ this hint is of interest. The remainder of the text is so damaged that drawing any firm conclusions would appear to be ill-advised.

The text demonstrates conclusively however that a lapidary who was definitely not on the staff of the Mortuary temple was commanded to perform a bikw for the temple. As usual, in contexts referring to the fiscal term, the P. Cairo 58096 does not use the article, or say "perform bikw" (irt b3kw), ${ }^{844}$ but uses the simple $r$ b3kw familiar from other texts, as e.g., the donkey texts, "r $b 3 k w$. $f$ ". It is not clear that the lapidary was obliged to work stones provided by the temple or whether he and the others contributed stones as well as work.

The actual scribe of the papyrus concerning stones notes that he was ordered to bikw at the Ipet-festival (vso. 1,2). One recalls the miscellany text,

[Everyone is taxed] except for the scribe who controls everyone, and is not assessed (htri) (for) his bikw is in writing. ${ }^{845}$

In this case, however, while it is possible that this scribe was to be recording other peoples' $b_{3} k w$ 's (his alleged $\left.b_{3}{ }^{k} w w\right)$ the scribe lyt did turn over stones $(1,14)$. It could be suggested that he collected the stones from elsewhere, but this is not noted, as is usually done. The whole text should probably be interpreted as such a note.

A wood bikw specifically associated with a door in Memphis is recorded, but the context does not allow interpretation. ${ }^{846}$

Another ostracon ${ }^{847}$ records the bikw-work done at a gate, enumerating in each case the nature of the $b 3 k w$ in question. In this case, various parts of things are mentioned, but the

The repetition of the figure indicates the size of the unit. These are clearly not beads - they are not identified as such - if 70 pieces fill about 5.3 litres! But, if the same as the trb-vessel, it will be smaller, and the pieces correspondingly smaller (cf. Janssen, Prices, p. 435).

841 Unless these are the same pieces as in $(1,14)$ it is clear that the quantities were carefully noted

${ }_{842}$ Beginning in III $s$ mw, and therefore as part of the preparations.

843 W. Helck, "Zum Kult an Königsstatuen," JNES 25 (1966): 32-33.

844 The scribe was however notably reticent in the use of articles in the short hand of this text.

845 P. Anast. V 17,2; LEM, p. 65; Caminos, LEM, pp. 247-250.

846 KRI I: 263, 8; 266, 9; P. B.N. 209; Helck, Materialien, pp. 895; 897.

$847 K R I$ II: $671-672$ 
relationship between the objects is not clear. In each case, the dimensions or position of the item is listed, but not its value, so that probably only the activity and the parts are implied, but the use of the term "gate" raises the suspicion that bikw here contains both meanings of the word.

P. E[gyptian] P[apyrological] S[ociety] is a single roll with several documents glued together, according to the editor ${ }^{848}$ Concerning primarily eye paint occasionally called bikw and dating to the reign of Ramesses IX, the first document identified by W. Helck appears to be a typical semi-official letter instructing the recipient to seek out and ship him eye-paint. The second takes up the matter with a more official tone, and can be rendered:

22 The Royal Ordinance of the High Priest of Amonrasonther, $R^{c}$-mssw-nht

23 to the effect that: this Royal Decree is brought to you to say, "I sent to you through the Steward of the Royal Treasury ${ }^{849}(L ! P ! H !)$,

24 the Royal Butler, Imn-htp, saying, "Let $A A^{850}$ quality msdmt-eye paint be brought -

25 worthy of $s \underline{d} m$-eye paint of Pharaoh (L!P!H!) - to the place where (The Royal) One is." And you let

2615 deben of msdmteye paint be brought through him. And after it was given to the physicians

27 of Pharaoh's (L!P!H!) residence medical staff for his b3 3 w,

28 it was found to be weak msdt-eye paint, not worth

29 the $s \underline{d} m$-eye paint of the $b_{3} k w$ of Pharaoh (L!P!H!), in it one deben only of msdt-eye paint was what was found. ${ }^{851}$ Look, it will be brought (back) to you, and when this dispatch of Pharaoh (L!P!H!), your Lord, reaches you [...]

The dispatch goes on to detail instructions to dispatch higher quality paint. If this understanding of the text is correct, it would refer to this bikw as income of Pharaoh himself, collected - not inappropriately - by the Pharaoh's personal treasurer.

Document $C$ of the P EPS text refers to "bikw-gold" (1. 60), but in a context so obscure that there is little point in using it as evidence, although it would appear that the text deals with workers employed by and supplying the Estate of Amonrasonther with gold directly. Probably not in exchange for this, but as a kind of rations, they are supplied with the goods listed in Document D, items of clothing, metal, bread, and even some service donkeys (II. 74-84).

KRI VI: 517-522; W. Helck, "Eine Briefsammlung aus der Verwaltung des Amuntempels," JARCE 6 (1967): $135-151$

imy-r $p r-\underline{h} \underline{d}-n-p r-^{-3}$, i.e., not the national treasury "of the Two Lands". Or is the office holder the same?

Helck translates the bikw understanding that it was "worked" in the first instance and uses Gebrauch in the second case, presumably from verarbeitet. It must be noted however that in both instances the determinative is the scroll, and that the active man is not present in the second instance. $r b^{3} k w$. $f$ is practically a terminus technicus, referring to some kind of obligation to pay. The New Kingdom genitives are usually expressed with the pronominal form, rather than the suffix, and verbal forms with the Hw. f suffix, neither of which is in evidence here. If we follow Helck there was likewise no reason to return the deficient material, and it would merely have sufficed to repeat the order. 
P. Turin $2084+2091$ from Deir el-Medineh ${ }^{852}$ refers to an obligatory b:kw with some items (grain, sheep and a bowl) associated with a water carrier (II. 2,2-2,5). As water-carriers presumably delivered water as their $b_{3} 3 \mathrm{kw}$, the items could represent a kind of remuneration. ${ }^{853}$ A cultivator is recorded as having delivered some grain (1. 2,7). A note concerning the "five donkeys of the tomb" seems to indicate that a payment was exacted for time during which they were not serving Pharaoh (II. 2,8-2,9). It seems that gold was received "which they consumed each" year (?). A reference to "exchange", perhaps in connection with a wood cutter, and the quantity of 90 deben, is enigmatic. diw is used but it is not clear for whom. The papyrus is badly preserved and thus difficult to interpret on its own. It would appear that the text deals with income and expenditure, but whether bikw refers to both sides of the transactions is unclear.

P. Greg ${ }^{854}$ uses the term bikw with reference to potters and wood cutters. B 21 records a wood delivery of 500 unspecified units as $b_{3}, k w$. B 24 has 2 unspecified units termed $b_{3} k w$ of the potter. ${ }^{855} \mathrm{Vso}_{\mathrm{so}} \mathrm{B} 12$ is incomplete, but refers to the $b_{3} \mathrm{kw}$ of the potter, while B 13 reads "left, wood, 2000; bikw of the potter [....]" It is possible to imagine that wood was delivered by the wood cutters to the potters for firing their kilns, but they were responsible for supplying the village directly, so that these must be two sets of deliveries to the village.

The word bikw figures in P. Turin $1900^{850}$ in a text elsewhere mentioning htri and inw, but the actual context of $b 3 \mathrm{kw}$ forbids any deductions.

P. Turin 2075 from Deir el-Medineh ${ }^{857}$ identifies the $b^{3} k w$ of three fishermen for the right side. In regnal Year 19, IV sht 9, each is stated to be obliged to deliver 50 deben of fish daily for a month, making a total of 4'500 deben of fish. On IV sht 24 and 27, the actual deliveries are enumerated in a list, the end of which is unfortunately missing, so that the numbers do not add up. In the following lines, the lists of actual exactions (šdi) continue, with the verso repeating the $b^{3} k w$-obligation to provide $4{ }^{\prime} 500$ deben of fish/month. ${ }^{858}$ The deliveries did not take place daily, but in quantities of several hundred at a time.

The papyrus is badly damaged, but it is conceivable that the system of recording was similar to that of $P$. Louvre E 3226, with deliveries offset against one another. ${ }^{859}$ Otherwise there would be no logical reason for listing the fish bikw of 4'500 deben for $19 \mathrm{NV}$ sht twice. In

S3 This is however not demonstrated, as water is specified but not designated. Cf. the references cited by S. Eichler, "Untersuchungen zu den Wasserträgern von Deir-el-Medineh I," SAK 17 (1990): 144-145. Eichler assumes that water carriers are a protessional group. Valbelle (Ouvriers, pp. 103-105) demonstrates that the Gang consisted of some 40-80 workers as a rule, and that under Ramesses III, the figure was about 40, while for the same period Eichler (SAK 17: 141) identifies some 24 water-carriers. As it is impossible to establish the quantities of water which they were expected to provide, the mere proportions should suggest that it was possible that the title was "awarded" to some unlucky souls in the neighbourhood, and that they had to deliver water periodically on a regular basis, as priests had occasional employment in the temples, but that they were not a group of professionals.

Or does this mean 2 polters?

KRI VI: 624,7 vso. 2,7

KRI VI: 653-655; 681-684; Černý, Notebook, 15, pp. 23-30.

Vso. 1, 1; KRI VI: 654, 7-8

Cf. Megally, Recherches, passim. 
this context the reference $(1.3,3)$ to a delivery of " 8 khar of emmer making 3'200 deben of fish" is potentially relevant. The reference indicates that the fisherman was permitted to substitute grain for fish, but the value to the workmen of such a delivery is unclear.

P. Turin $2014 / 223^{860}$ may have a reference to b:kw turned over to the Gang in the context of a smaller sum of 500 khar distinguished from the 10'000 khar of grain otherwise discussed $(1,10 ; 1,14)$. It is possible that this was related to the Mansion at Medinet Habu, but the context is unclear.

\section{Private Transactions}

The word bikw serves many purposes, and Giornale Verso B 8-9801 supplies an example of its use in a private transaction where the Chantress of Amonrasonther T3-ndmt contracts work for her tomb equipment out to the Gang. The objects (coffins) and the delicate craftsmanship are valued in deben, following which is the "total of money $(h \underline{d})$ as $b 3 k w$ of/for the artisans and draughtsmen" (I. B8, 12). As far as the damaged text permits one to conclude, the work itself is termed "tasks", while the total value is termed b3kw. Although abstractly it could be contended that the bikw is T3-ndmt's obligation, it is far more probable that the formula simply expresses the monetary value of the work $(b 3 k w)$.

\section{Private Propaganda}

$b 3$ ikw is collected from the overseers, mayors and villages chiefs of Upper and Lower Egypt in an XVIII Dynasty text of the "clever scribe Inff". ${ }^{862}$

A Dynasty XVIII inscription records that Dhwwly, an Overseer of the Treasury, received the $b 3$ ikw of the mayors, and that he was praised by the king. ${ }^{863}$

$\mathrm{Sn}$-nfr received $b$; kw associated with ššyt and htri, after having been appointed Overseer of the Double Granary. ${ }^{864}$

$\ln \Pi 125$, the owner recounts that he "counted as b:kw the reckoning in grain (barley) as the annual htri. ${ }^{8805}$ This was probably carried out at and for the temple of Amun.

In the Dynasty XVIII tomb (EK 3) of P3-hry in El Kab, a field worker states that "I am going to make an excess on the bikw for the official. ${ }^{8060}$

$\ln \Pi 188, P_{3}-\mathrm{rn}-\mathrm{nfr}$ records dogmatically that the $b_{3} \mathrm{k}_{\mathrm{k}}$ of each god is measured, while that for Aten overflows. ${ }^{867} \mathrm{~W}$. Helck suspects that he did this by virtue of his position as Overseer of all the Prophets of Upper and Lower Egypt. ${ }^{868}$

800 Černyं, Notebook 23, pp. 20-23.

801 KRI VI: 590-594; Bolti/Peet, Giornale, pl. 40; Allam, HOP, pp. 331-335. Cf. also Janssen, Prices, pp. $216 f f$. (no. 26).

802 Urk. IV: $973,3-4$

803 Urk. IV: 436,13

804 Urk. IV: $530,13-16 . \pi 99$.

805 Urk. N: 1379-1380; W. Helck, Übersetzung, pp. 69-70.

${ }_{8 \infty}$ In the scenes of daily life, pl. 3, middle register, in: Tylor Paheri. Cf. James, Pharaoh's People, p. 109.

${ }_{867}$ Urk. IV: 1996, 11; N. de G. Davies, "Akhenaten at Thebes, JEA 9 (1923): 132-152.

808 Helck, Verwallung, p. 269 n 4. 
The "receipt of the b3 ${ }^{3} \mathrm{kw}$ of the craftsman of the Temple of Amonrasonther" is recorded in a Dynasty XIX inscription. ${ }^{869}$

In the tomb of $\mathrm{P}_{3-\mathrm{sr}}(\pi \mathrm{T} 106),{ }^{870}$ the text clearly distinguishes between the inw of foreign countries, and the bikw of the wo lands, both of which he was authorized to receive, in his role as Vizier. His role was mainly that of a government official.

One dynasty XIX official claims to have been the "accountant of the bikw of the lands and deserts". ${ }^{871}$ His efforts went to the benefit of the Treasury of the Lord of the Two Lands, presumably. Another claims to have counted all the $b_{3} \mathrm{k} w$ of the entire land, for the benefit of the state. ${ }^{872}$

$B: k w-r m t$ is mentioned in the Bilgai stele and the Inscription of the High Priest of Amun Imnhtp, but not bikw.

\section{Royal propaganda}

In Dynasty XVIII Thutmosis III records that some defeated foreigners confirmed a bikw destined for "your treasury" - meaning his majesty - but in a context at the temple of Karnak where it was ultimately destined for Amun. ${ }^{873}$ While it could be debated to what extent Syrian princes were familiar with Egyptian fiscal terminology, it is probable that the scribes responsible for the inscription used the word correctly, and that the bikw was that of the king voluntarily rendered by him to the temple.

The Horemhab Decree ${ }^{874}$ uses bikw in a context (I. 17) indicating that a private person (nmhw) could be obliged to borrow a boat from another person in order to carry out an obligation which appears to have been to the Pharaoh. ${ }^{875}$ Elsewhere (1. 23) a sdm-official will be held responsible if he takes a slave from a private person, so that the $s \underline{d m}$-official will be obliged to render the slave's $b_{3} k_{w} w$, due to Pharaoh. Forage-bikw for the Pharaoh is clearly identified as being something that should be collected by the officials of the w'bwt from specially designated magazines, and is not to be taken from private peopie (ll. 31-33). In its present state, the text is quite mutilated, but it can be concluded that the $b 3 \mathrm{kw}$ was a payment from the nmhw to Pharaoh unrelated to the obligations of his officials, which were also apparently termed $b_{i k w}$.

KRI III: 330,$2 ; \pi 178$.

$K R I$ I: $299,11-12$.

$K R /$ III: 136,7

KRI III: 54, 15-55,1. The significance of KRI III: 16,6; 21,9; 841,14 may have been similar. A Dynasty XIX inscription from the Deir el-Medineh Hathor temple uses $b_{3} k w$ as an obligatory payment, which may have been rendered unto a god, but the text is very unclear $(K R I \|: 705,14)$.

Urk. N: 759 .

Cf. supra pp. 188f.; J.-M. Kruchten, Horemheb, il. 17, 23, 32, 33.

Pharaoh's concern becomes apparent in 1.33 where the " $b 3 k w$ of Pharaoh is specified." The context is clear, but Kruchten interprets the text.as meaning that the nmhw has gotten wood for himself ("pour son compte personnel, du bois," Horemheb, p. 194), whereas it can also be interpreted as meaning that the second party (the lender of the boat) is requesting that wood be rendered up to him, before the completion of the bikw. It is obviously in the king's interest to prevent people from hindering the preparation of payments due to the state $(b ; k w)$, and thus a logical addition to the code. 
Seti I "commanded the bikw of the entire land, presenting" it to Amun-Rec. ${ }^{876}$ His mortuary temple was the beneficiary of the $b^{3} k w$ of precious metals delivered by the rhyt. ${ }^{877}$ The Nauri Decree ${ }^{878}$ specifically enunciates that any misappropriated $b 3 k w$ will be punished, by the (equivalent of the) bikw itself being turned over to the temple ("exacting the bikw from [the miscreant official]") and the misbehaving official being obliged to work for the temple an equivalent period of time ("for every day he shall spend with him", I. 47). It is clear that in this case, the bikw is at once the time spent, and the work done for the temple, and the objects produced, as the legal terminology stipulates that temple dependents are not to be diverted to any other tasks, and that the $b_{i} k w$ will be collected. As in the Horemhab Decree, the bikw is directly linked (II. 48-49) to a boat:

[virtually any official] who shall detain any boat of the [temple], and likewise the boat of any controller $(r w \underline{d} w)$ of this estate mooring it alone for a single day, saying, "I will seize it as the requis [<ition $\rangle]$ from him $f[\langle\dot{0} r\rangle]$ any $[\langle\mathrm{mis}\rangle]$ sion of Pharaoh $(\lfloor! P ! H !) ":$ The la $[\langle w\rangle]$ shall be executed [<against $\rangle]$ him, [ $[$ in that he shall be beaten with>] 200 blows and five deliberate wounds. The bikw of the boat will be exacted from him for every day he shall have moored it. And he (himself) shall be given over to the [temple].

W. F. Edgerton made a lengthy detailed analysis of the exact wording of the legal aspects of the decree, but Sir Alan quite correctly pointed out that this probably infers too much from the specific wording, and fails to take account of the general meaning of the text, Sir Alan pointing out that the purpose of the decree was quite simply to protect the income of the temple by assuring that its servants could operate unmolested. The b3kw of the boat is thus the value of the time, and here "fine" would be more appropriate than "rent" or "fee" but the word is the same.

In the Inscription dédicatoire at Abydos Ramesses II indicates that the traders traded to produce a bikw of gold, silver and bronze. ${ }^{879}$ This was a hitri, and the context supports a meaning very similar to that which is delineated at length in P. Harris. There is no question that the King is taking responsibility for having given these resources to the temple, or made them available. The other items listed as $b 3 k w$ are less clear, but the quantities were such that transport vessels were required to move them.

$b^{3} k w$ appears as the product of Egypt and foreign countries, destined for Amun in several texts by Ramesses III at Karnak. ${ }^{880}$ This suggests that at least part of Pharaoh's bikw were really intended to be delivered to the god.

KRI I: 201,$6 ; 205,3$. The text from the hypostyle hall uses the usual distinction between inw for foreign countries and bikw for Egypt.

KRI I: 79,11-13. Inscription at al-Dibabiyah, opposite Jebelein.

CF. supra, pp. 190ff.; KRI I: 45-58; F. LI. Griffith, "The Abydos Decree of Seti I at Nauri," JEA 13 (1927): 193208; W. F. Edgerton, "The Nauri Decree of Seti : a Translation and Analysis of the Legal Portion," JNES 6 (1947): 219-230; A. H. Gardiner, 'Some Reflections on the Nauri Decree,"JEA 38 (1952): 24-33.

$K R / 11: 333,1-2$

KRI V: $225,1-3$. Specified are things, booly and inw as htri (2), but also $b$; kw, so that $b$; kw implies more than mere iht (things). Cf. also, KRI V: 239,12; 241,13;244,9; 245,11, etc. 
P. Harris I uses bikw to specify particular entries under the heading of the "annual htri", which itself is defined as being šzyt bikw for the major temples (Thebes, Heliopolis and Memphis). The corn delivered to the major temples is the " $b^{3} k w$ of the cultivators" (12b,3; $32 b, 6 ; 51 b, 11)$, and the waterfowl of the fishers and fowlers delivered to the temples of Thebes and Heliopolis bear a similar designation $\langle 12 b, 6 ; 32 b, 9)$.

The bee-keepers and incense porters take "their annual $b ; k w$ to your august treasury" in Heliopolis (P. Harris I, 28,3), and to the treasury of Ptah at Memphis $(48,2)$.

The "b3kw of the two lands" (along with the šzyt and htri) is likewise "to be transported to your treasury in the Temple of $\operatorname{Re}^{c}\langle P$. Harris $\left.|, 28,5\right)$.

The Karnak Festal Stele ${ }^{881}$ uses bikw twice with reference to the preparation of grain (as loaves and cakes) for Amonrasonther (II. col. ii: 39; 42), but it would appear that although the offerings take place at Medinet Habu, it is the "pure granaries of the Estate of Amun" that will provide the grain.

\section{FOREIGN REVENUE}

\section{Private Propaganda}

Sn-Mwt asserts responsibility for the bikw of every land. ${ }^{882}$

Min-msw, a retainer of Thutmosis III, states that he "informed the princes of Rtnw of their annual obligatory bikw (bikw.sn $n \underline{h} r t$ rnpt)," 883 but does not specify any further.

In EA 8, the Chamberlain Twtw states that King Akhenaten "commanded for him [Aten] bikw of his Asiatics". ${ }^{884}$

These texts emphasize the royal command for the foreign bikw.

\section{Royal Propaganda}

Thutmosis III donated villages in Upper Rtnw to Amun, designating the htri as bikw for the god as well ${ }^{885}$ The bikw of $W_{3}^{3} W_{3}^{3}{ }^{880}$ Cush $^{887}$ and $R_{3} 3-m_{n n}{ }^{888}$ was likewise assigned to Amun.

In the dedicatory inscription at the Temple of Month at Karnak, Amenophis III states that the Asian and Nubian bikw provided the adornment of gold, electron, precious stones and bronze for the temple. ${ }^{889}$

889 Urk. IV: 1668,3; 5. The list as such includes electrum, gold, copper, lapis, turquoise and bronze. As some of the copper is specified to be Egyptian, and the turquoise may have been mined by the Egyptians, this list combines
} 
In the smaller Beth Shan Stele of Seti 1,890 a hint at military force in Palestine encouraged the locals of Yarmouth to come bearing bikw (II. 16-18). It is not stated whether the payment was intended for the estate of Amonrasonther, or indeed what it was. Seti l's Beth Shan stele can be interpreted as referring to obligatory bikw the delivery of which was interrupted during the rebellion, or to a new obligation. The people of Yarmouth delivered their bikw voluntarily, after the necessary encouragement. ${ }^{891}$

The bikw of the gold washers is the object of various projects mentioned in the inscriptions of Seti I at the temple at Kanais. ${ }^{892}$ After initially establishing his interest in the gold, Pharaoh arranged for wells to be sunk along the route, and subsequently had $q^{3}$ r-vessel crews take over the gold washing (Text $C, 6-8)$. Drawing on the b $3 k w$ of the temple of $M n-m_{3}^{a} t-R^{c}$, divine figures were manufactured. In passages similar - but far briefer - than those of the Nauri decree, he guarantees the security of the gold-washers, forbidding anyone from diverting "their bikw in gold" from the temple. ${ }^{893}$

The Karnak War Scenes of Seti ${ }^{894}$ use bikw to define articles received which are to be turned over to Amun. inw is the term used in the longer texts.

"Their inw consisting of bikw of Asia" is turned over to the Pharaoh or the temple in a text in the Luxor temple of Ramesses $11 .{ }^{895}$ In inscriptions from Tanis, Ramesses II claims that the $b_{3} k w$ is borne to the palace. ${ }^{890}$

The Blessing of Pth- $\mathrm{t}^{3}-\mathrm{tnn}^{897}$ uses $b_{3}{ }^{3} \mathrm{kw}$ several times with reference to income from foreign countries:

(Speech 1) Recitation by Pth-t3-tnn [...(4) ... I have decreed for thee [i.e., Pharaoh] lands, I have created their princes $(5)$ bearing their bikw to thee coming to thee burdened with $(6)$ their great inw ${ }^{898}[$.... Main Text 14) ...] I have caused foreign mountains of all precious noble stones to be created for thee $[. .$.$] I have put it into the$ heart of all the world to offer their bikw to thee themselves, princes, courtiers, and

local and foreign objects, and only the general statements in the text can be relied on. As it stands, the text may indicate that the cedar doors were bi $\mathrm{k}_{\mathrm{k}}$, but the bikw may refer in fact only to the bronze adornment; but it is certain that this is the revenue $b: k w$ and not merely the word for "worked". The lext also refers to foreign inw in the same general way.

KRI I: 15-16; W. Helck, "Besan," LÄ I: 727

891 KRI I: 16,14-15.

892 KRII: $65-70$

$893 \quad K R / 1: 70,2 ; C, 16-19$

$894 K R I 1: 6-32$.

895 KRI II: 608,12

896 KRI II: 416, ]. Foreigners are possibly meant. Foreigners are definitely mentioned, specifically defeated Asian princes who bore their bikw to Egypt (KRI II: 289,15$)$. The $\check{s}_{3}$ sw also bring bikw to Egypt (KRI II: 294, 14). Cf. also KRI II: 182, 1 1; 186, 10; 297,16. Cf. at Abydos (Inscription dédicatoire, KRI II: 333,2, 8; 10) where bikw also appears. bikw appears as work here as well (KRI II: 330,7; 327,6).

897 KRI II: 258-281; BAR III: 175-182; Schlögl, Tatenen, pp. 64-66. The lines cited are those of Abu Simbel Text (Kitchen "II), with free restorations from the parallels. This text plays on the words $k 3 w t$-works and bikw-works, making the distinction between them that of general public works $\left(k_{3}^{3} w\right)$ and specific items $\left(b_{3}^{3} k w\right)$. In I. 15 Ptah says to the Pharaoh, "I have caused that all works ( $k$ : wt $)$ are beneficial to you, and all $b_{3}^{3} k w$ (are) for thee[...]". In 1. 32 Pharaoh replies to Ptah saying, "I have enlarged thy mansion in Hwt-ki-Pth, protected with eternal works (kiw) consisting of excellent workmanship (bikw). 
others, with (16) one desire of benefiting thy $k_{3}$, King of Upper and Lower Egypt, Ramesses [...] I have made (25) for thee the land of Hatti [...] serfs of thy palace, I have put it into their heart to offer themselves [...] to thy $k_{3}$, burdened with their $b_{3} k^{k} w$, and the booty $\left(h^{3}\right.$ igt $)$ of their chiefs, all their belongings as inw for (26) the power of thy majesty $(\mathrm{L} ! \mathrm{P!H})[\ldots]^{899}$

The basic purpose of the text is to assert Pharaoh's dominion over all the countries of the world, delivering their products $\left(b_{3} 3 \mathrm{k} w\right)$ voluntarily and with pleasure. The reference to booty $\left(h{ }^{3}{ }^{\prime} t\right)$ being delivered quasi-voluntarily is somewhat original. ${ }^{900}$ The goods are clearly awarded to Pharaoh.

Merneptah received a yearly $b_{3}, k w$, from Cush or the libyans, but it is not clear whether this went to the temple or Pharaoh. 901

The Medinet Habu inscriptions associate bikw and htri destined for the god. ${ }^{002}$ Wretched Cush is specified as the source of $b_{3} k w$ for the Two Ladies as well. ${ }^{903}$ The $b^{3} k w$ of Rinw was collected for the benefit of Amun-Re. 904

P. Harris I rhetorically states that "Nubia and the Phoenician coast are burdened with their $b^{3} k w$ for" the Estate of Amonrasonther $(4,5)$. The cartle delivered to the same temple are termed the " $b 3 k w$ of the Land of Syria" $(12 b, 8)$. None of the other temples are specifically recorded as having received items as foreign revenues, but the introductory paragraph for Memphis includes a reference to the " $b 3 k w$ of the Land of Palestine, for your great treasuries of your walled city" $(48,6)$, and the final line $(52 a, 2)$ of the lists of the š3yt bikw-rm! mentions items from Syria and Cush, and the oases in a general fashion: "in great quantities". The corresponding line $(32 b, 14)$ for Heliopolis merely indicates foreign sources in an even more general way.

\section{Previous Discussions of the Word $b 33 k w$}

D. Lorton concluded that the context indicates that $b_{3}$ k w "is clearly employed in Dyn. XVIII in reference to an exchange of goods, a meaning which is in accord with the use of the root in domestic Egyptian contexts." 905 He noted that in one context, "the fact that these goods are called b: kw implies that upon receiving them, Thutmosis compensated the native chiefs

00 . $208-274$

90 Does this imply that by the time of Ramesses II, Egyptians no longer knew the meaning of higt as booly of war? More probably this is a failure to recognize the consequences of the battle of Kadesh.

90! KRI IV: 10,2

$902 \mathrm{KRIV}: 50,12 ; 117,13 \mathrm{f}$. Cf., however KRI V: 318,5 for gold and precious stones as bikw for the King, from foreigners.

903 KRI V: 9,8-9. An inscription of Siptah at Buhen seems to indicate that the bikw of Cush went to the Estate of Amun $(K R I$ IV: 368,7$)$.

904 KRI V: 321,2 . Precious metal is implied here, but it may not be from Rtnw, although this would appear to be the case. Cf. also KRI V: 225,3;239,12;241,13;244,9;245,11 for b; kw from every land for Amun.

905

Lorton, Terminology, p. 103. 
for their activities on his behalf." 900 This interpretation confuses several of the different meanings of $b: k w$, and therefore the conclusion is not necessarily inevitable, aside from confusing premises with proof.

E. Bleiberg's discussion of $b ; k w$ logically followed his treatment of inw. He defined inw as the king's income and bikw as the temple income because of his interpretation that redistribution was accomplished exclusively through the temples. He distinguished according to presumed destination rather than designation or origin. ${ }^{907}$ Many of his examples indicate that, like the $i n w$, the $b 3 k w$ was given by the king to the temples, so that he distorts the evidence for both categories equally. ${ }^{908} \mathrm{He}$ concludes " $B 3 \mathrm{kw}(t)$ is an economic transaction between foreign lands or groups of foreigners or Egyptians and the temple. "909

$W$. Boochs commented that $b$ skw appeared far more frequently in association with foreigners than with Egyptians, and associates this with tribute type payments, disputing the suggestion that they were mere trade arrangements. For the internal sources, he assumes that the King had the right to everything in the land and therefore the work of the people as well, and that this is the character of the bikw payments, which were regularly assessed. He concluded that some of the foreign bikw were the result of contractual purchasing done for the King, and that the internal $b 3 k w$ were obligatory payments made to the king. ${ }^{910}$

Although this could be ascribed to the nature of the Egyptian altitude or to the accidental preservation of the texts, the term does not appear in the Instructions of the Vizier, so that it was not a principal source of government revenue at the time that that text was established. The number of cases where temples receive the $b_{3} k w$ does not support this interpretation, either.

J. J. Janssen concluded that the word meant both work and product, and noted that

we have not as yet discovered the leading principle according to which the Egyptians termed some deliveries to the state and the temples $b$ ikw, others inw. [...] Did inw mean no more than the goods which were actually 'brought', bikw that they were the 'products' of some work? 911

906 Lorton, Terminology, p. 104

907 E.g., P. Greg (supra, pp. 152ff.) shows quite clearly that the Egyptians distinguished by type of object and origin, but not by destination. It is particularly important here that in Deir el-Medineh fish and wood are not invariably $b 3 \mathrm{kw}$, but plaster and pots are

908 Bleiberg, JARCE 25: 157-159.

909 Bleiberg, JARCE 25: 168.

910 W. Boochs, VA 3: 212-213

911 Janssen, SAK 20: 94. 


\section{CONCLUSIONS}

Virtually all of the commentators are agreed that the evidence suggests that $b ; k w$ implies some kind of obligatory payment or delivery, and it would appear that the administrative and monumental evidence from the Egyptian sources is more or less uniform in supporting this contention. One issue of dispute is the discussion of the basis on which the sovereign authorities of the land claimed a right to these payments. Before proceeding any further, it is therefore perhaps advisable to make an effort to define some implications of the hypothetical relations implied on any politically based contractual assumptions of reciprocity. It is routine in agricultural societies for people to carry out obligations to the state through labour for which they receive no remuneration, as in feudal societies, where peasants simply owe an obligation to their lord, by virtue of their lord being a lord and the fact that they accept his right to rule (by not, e.g., becoming bandits), or an obligation is owed to the community, for which there is no remuneration. By accepting the right of the ruler, the peasant has accepted an obligation to pay. Theoretically the feudal lord or king or church may owe an obligation to the peasant to provide protection or to guarantee the application of the law, and this forms the bridge of the reciprocal contractual arrangement. In practice, the recognition of the title to limited amounts of private property, the possession and security of which are guaranteed by the sovereign authority probably lighten the load of the peasant, and the hope of an improvement makes his life bearable. The feudal lord may thus receive many types of object, and may be obliged to trade to acquire the mix he requires from the mix he has acquired.

The peasant can renounce this relationship voluntarily or involuntarily by altempting to flee the jurisdiction of his lord, or by placing himself completely at the service of the sovereign (be it a lord or the church or some other authority), so that the relationship is no longer that of an independent being to another independent being, but that of master and slave or serf. The implications of slavery and serfdom are manifold, but the evidence from Egypt does not suggest that there is any reason to believe that the entire population or even a large part of it was the private property of Pharaoh, the temples or feudal landlords. Failing this interpretation, the people will have enjoyed their limited freedom at the cost of some regular material transfers from themselves to Pharaoh or the temples or their lords. The following notes are made on the assumption that the implications of the Nauri decree are that violations of the principles of the obligatory payments could lead to a loss of freedom, and therefore that officials did enjoy a certain degree of freedom, while the Horemhab decree likewise assumes that at least that group termed nmhw likewise enjoyed some freedom, but that both decrees demonstrate that both $n m h \mathrm{w} w$ and officials can be assumed to have been bound by obligations. The fact that officials were threatened with a loss of freedom in the Nauri decree supports the contention that at least a proportion of the people of ancient Egypt did not enjoy even the relative freedom of the nmhw and the officials. The term bikw seems to be connected with payments to the state by all of these respective groups, and therefore the term cannot be understood as meaning only one thing in our translations and interpretations, but this does not imply that the Egyptians did not understand the concept. 
Therefore, once one has stepped beyond the basic facts, even with general agreement on the principles, the evidence can be interpreted in very different ways. The interpretations thus range widely, from a general concept of $b ; k w$ meaning product to the specific provisioning of either the king (Boochs) or the temples (Bleiberg), and in character from tribute to trade.

Certainly relevant here is the fact that $b 3 k w$ is written in red ink in the Tax Lists of the Turin Canon (cf. supra, pp. 159ff.; Gardiner, Royal Canon, pl. 6: 3,1) where other relevant

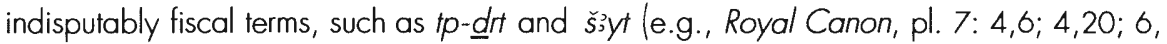
$x+19)$ are likewise entered in red, suggesting that it had a very specific meaning in Egyptian. One set of payments was of fish, in kind, and thus this clearly official bikw may be defined as the product of labour, even if it is not produced. Another payment recorded there was in gold, but this will have been improbably produced by the guardian of natron - in his official capacity - and therefore is more likely to signify either a substitute for in kind deliveries, or a "tax" on his turn-over. In either case, it is not the product of his work, and therefore it cannot be logically contended that even if the bikw was more than a product that it was merely a kind of corvée in kind, based on some abstract principles.

That the term is used in particular contexts in P. Harris I, where hundreds of "products" are lined up, but only a fraction of them labelled $b 3 k w$, demonstrates that neither a vague "obligatory payment" nor a mere "product" is meant. Logically this raises the suspicion that expressions like "their annual $b$; kw" (P. Harris 28,3; cf. Tax Lists) identify a specific payment. This however still does not demonstrate that this corresponded to the exaction of a "fraction" of production, and therefore a "tax" or "rent". It does however confirm that it is something quite specific of a fiscal nature. In P. Harris the $b^{3} k w$ of the temple is distinguished from the inw of the king, which the king awards the temple. More specifically, the cultivators and the fishers and fowlers are attributed a specific $b 3 k w$, delivering grain and fish and fowl. Although the precious metals as such are not listed as bikw, the Inscription dédicatoire indicates that they were a bikw as well: that of the traders.

In P. Brooklyn 35.1453 B, bikw are measured in deben as well as hin of honey. ${ }^{912} \mathrm{ln}$ another context, slaves are also listed as b3kw, ${ }^{913}$ and it is inconceivable that the basic meaning of the term as understood by the Egyptians can have been merely "product" - as opposed to an exacted payment of some kind - if they include what we would term human beings among the means by which the $b$; kw obligation could be fulfilled. This demonstrates that $b^{3} k w$ was a specified quantity which could be paid in kind and is therefore associated with part of the income of the state, but that the term was understood by the Egyptians as signifying primarily a payment, not a product.

There are numerous propaganda texts recording the receipt of the $b^{3} k w$ by both the government and the temples, from government officials and from craftsmen, and foreign countries. In the administrative texts, concrete obligations termed bikw were the responsibility of individuals in certain contexts, and could be paid to government ${ }^{914}$ or temple authorities. 915

\footnotetext{
912 Condon, "Account Papyri," RdÉ 35: 77.

913 Urk. IV: 708,$11 ; 734,4$.

914 This was very frequent at e.g., Deir el-Medineh.

915 P. Munich 809, cf. supra, p. 238.
} 
Deliveries of plaster or honey given by those engaged for the purpose le.g., "bearers of honey") clearly represent the fulfillment of contractual relationships and perhaps a form of taxation or corvée labour delivered as products. 916

The workmen of Deir el-Medineh delivered a $b 3 k w$ - the excavation of the royal tomb - for which they were remunerated with regular income, some of which was itself termed $b ; k w$. While it is not clear that the smdt who served the tomb were paid for their efforts, ${ }^{917}$ the workmen were, and therefore the two types of $b^{3} k w$ are quite different. The scribe's bikw of writing is a similar example, if less concrete. ${ }^{918} b^{3} \mathrm{kw}$ could be used in private transactions to refer to the same type of contractual agreement, where the delivery of objects in return for services was reciprocal. The receipt by the temple of Amonrasonther of $b 3 k w$-gold from workers, in exchange for rations could potentially be the same type of contractual arrangement. At least one text indicates that a craftsman could work at a temple, carrying out a bikw obligation, 919 while others supplied items. In another case, a similar system applies to provisions for Pharaoh. ${ }^{920}$ The Deir el-Medineh texts use $b 3 k w$ in contexts associated with donkeys relating that so-and-so took a donkey $r-b 3 k w$. f, which was previously understood to mean "for his work", but seems to imply "for the value of its work", and it is not clear to whom this work is valuable or just why it is recorded in this fashion - after all it is evident that one takes a donkey to use it. ${ }^{921}$ The meaning must be "rent", in which case, it is not "for its value", but "against its price", as Janssen has shown to be the semantic significance.

The other text relating to a missing donkey refers to its $b^{3} \mathrm{k} k w$ which is collected year for year, and here the payment should correspond to the value of the work of the donkey. ${ }^{922}$ This bikw cannot however be construed as a type of corvée labour or tax, as the bikw is undoubtedly that of the beast and not the borrower or the owner, and the beast owes no $b^{3} k w$. This is even less true when applied to a boat (as in the Nauri decree, and substantiated in P. Cairo 58056) so that the bikw was an obligatory payment representing a value, which could be met by producing equivalent products, and this value could be termed a "use tax", but the meaning is that the donkey or the boat are intended to be used at the institution to which they are assigned, and that the bikw is exacted from the responsible officials when it

910 Contractual in this sense means merely "obligatory and specified". Whether the providers were remunerated for this work is very doublful, but they were obliged to do so, and did not do so voluntarily. Whether mere threats sufficed to encourage them is unknown. The one hint at preserved evidence of a reciprocal arrangement would appear to be in the text P. Turin 2075 (Černý, Notebook, 15, pp. 23-30) where deliveries may be offset one against the other, as in P. Louvre E 3226.

917 My own interpretation is that advanced earlier, that some peasants were simply assigned to bear things up to the tomb, and that this was their obligation by virtue of existing within society. But there are a few references which support the assumption that the smdt were paid, and Eichler (SAK 17:157) identified O. Cairo 25597 and $O$. DeM 149. While the former is doubfful, the latter is possible. Her use of P. Turin 2003 (SAK 17: 158ff.) is interesting, as the text does not bear any resemblance to other texts which could be interpreted in this fashion. It bears however an uncanny resemblance to, e.g., Giornale, Verso 8 (Botti/Peet, Giornale, pl. 40; KRI VI: 590ff.; Allam, HOP, pp. 331-335) which is quite a different kind of text altogether.

918 P. Anast. V 17, 2; cf. supra, pp. 133-134.

919 KRI VII: 102-103; P. Cairo 58096.

920 KRI VI: $517-522$

921 Cf. Janssen, SAK 20: 81-94.

922 KRII: 238. 
is not used as intended, apparently whether deliberately or not. In a private context, this could be understood as "rent", while in a public context, this particular type of bikw could be rendered as "fee" or "fine". 923 One paragraph of the Horemhab Decree (line 23) uses $b_{3} k w$ in both of the latter senses, while another paragraph (line 17) uses it in the former sense. One cannot avoid the impression that $b 3 \mathrm{k} w$ was measured on a daily basis in many cases, but it is difficult to judge if the quantities delivered by the smdt at Deir el-Medineh were likewise measured this way. Thus some bikw would be payments measured in time, and some in quantities.

Officials of both temples and government were obliged to provide $b_{3} k w$, but this will have been part of their duties as officials, and it is probable that the concrete goods received were the bikw, and that these were then regarded as the šsyt or htri of the official, but in making quick notes, these subtle distinctions may have been lost.

The word bikw also seems to apply to activities which can not even remotely be construed as "taxes". bikw would thus seem to be simply work carried out, for which remuneration would be provided. In the dogmatic propaganda texts, the exchange character of $b 3 \mathrm{kw}$ might be forgotten. The Gang at Deir el-Medineh was paid to carry out their bikw, which was the excavation of the tomb. Scribes were paid to carry out their bikw, which was writing, and counting. The $b_{3} k w$ with which they were remunerated could also be the htri of another official. But the bikw of the individual members of the Gang who worked for the wealthy officials of Thebes was their "wages", the money they received for working.

"Rent", "fee", "corvée labour (in kind)", "fines", "contractual labour", or even "wages" are probably all equivalent to certain examples of b3 $3 w$. Obviously, the products delivered from foreign countries would occasionally be acquired under duress, and these products could also be classified as inw or higt. The primary significance of the technical term bikw was however that of obligatory "payment" or "delivery", and secondarily the fact that it was produced or acquired by labour.

The bikw supplied by certain private people, groups of people, people using donkeys and boats, or craftsmen delivering objects may potentially be construed as a kind of obligatory exacted payment, a corvée in kind or a "tax" equivalent to the value work but not necessarily either a product of the work or the work itself, which is payable to either Pharaoh or a temple, depending up the type of arrangement. The documentation does not suffice to make any statement concerning the proportion of the population obliged to submit b'kw "taxes" to the temples or the government, nor can any specific proportion of income, wealth or time be RdÉ 33 [1981]: 50) translates, "[...] le scribe Bwkntuf partit avec les gens qui étaitent sous son authorité avec un bateau destiné à ses fournitures $[r$ bikw. $f$ pour la ville $[. .$.$] . While clearly a reference to this type of payment,$ it is not certain whether it was a boat rented from the authorities or from a private person. If the former, it is clearly a "fee" and not a "fine" as he took it without violating the any principles. For the Egyptians a payment made to the government would be a payment, regardless of whether a "fine" or a "fee" for us. In the Horemhab Decree, some of the paragraphs were intended to protect a private $b^{3} \mathrm{kw}$, if the boat was rented by a boatless person to carry out some task for Pharaoh, the king wanted to protect that person from abuse (cf. Horemhab, line 17, and supra, pp. 188f.), and thus protecled the "rent" agreement. 
identified in these cases, but it would appear that virtually the entire population could conceivably have been rendering some kind of bikw to the state in one way or another, and that this was the most significant part of the "revenue" of the state. Whether the plastermakers delivered part of their production to the state and sold the rest on the private market, or whether the water-carriers were peasants detailed to corvée duty at the tomb, or whether the potters sold most of their production and turned over a mere fraction of it to the government - these are all questions which cannot really be answered, but evidently, the interpretation of b;kw as a "tax" depends upon this knowledge. Therefore the use of "tax" for translating $b 3 k w$ is only justified in very specific contexts. In official texts it generally refers to an "obligation", but it is clear that as early as Dynasty XVIII bikw meant a payment which could be made in products, and not merely a "product".

It would appear that the official $b 3 \mathrm{kw}$ was the most important element of Egyptian society as the scribe says, everyone had a bikw: scribes, the Gang, craftsmen, traders, smdt-serfs, etc. Some were rewarded with provisions or by bits of land, but for most it was an obligatory burden, a kind of corvée in kind which had to be fulfilled by lapidaries going to temples or peasants serving as wood cutters, fishermen, water-carriers, etc. It is probable that most of the population pursued such activities in their free time, but others will have had other - more arduous and demanding - obligations to Pharaoh or the temples by virtue of their having been assigned to specific onerous duties, for reasons which remain unelucidated, and this was also termed $b ; k w$, but potentially the type of $b: k w$ described in the next chapter. It was the $b: k w$ that made Egypt go round. 


\section{bikw-rm!}

\section{THE TERM bikw-rm!}

$b_{3}$ kw -rmt means literally the "work of a man (or men)", and is merely a variant writing of the b. $3 w$ type of obligation, appearing in a few cases as a specific item. The existence of the term has been widely overlooked, as it is not at once evident that the term is being used, but it does appear in several contexts. One example which could potentially illustrate the use of the term is an otherwise useless reference in Tax Lists of Turin Canon $(3,19)$ where the "šs of the smdt" (šszyw $n$ smdt) is used analogous to the "šs syt bikw-rm! smdt" of P. Harris I (e.g., 12a, 1), where the $b_{3} k w$-rmt is simply inserted in between, indicating that it is another type of obligation, of the same type, perhaps significantly applied to the smdt.

\section{INTERNAL ReVENUE}

\section{Administrative texts}

The term $b_{3} k w$ is used in administrative texts, but the term $b_{3}^{3} k w$-rmt appears primarily in propaganda texts. This corroborates the suspicion expressed in the last chapter that the various terms labeled $b_{3} k w$ are not all the same thing.

\section{Private Propaganda}

b 3kw-rmt is used in conjunction with many of the other words appearing in this work in two private texts, the Bilgai Inscription (htri, šmw, $\left.\check{s}^{3} y t\right)$ and the inscription of the High Priest of Amun, Imn-ḥtp (šmw, ššlt, tp-drtt, inw).

In its present condition, the Bilgai Inscription does not specifically state that temples received the goods, but it is certainly not rash to conclude that the deliveries arrived at chapels associated with the Estate of Amun and the Mortuary Temple of Siptah. It does however state that the $b_{3} \mathrm{kw}$-rmt was 4,632 mnt-jars of wine, and that our noble servant of the state delivered "30,000, a surplus of 25,368 " (11. vs. 17-18). 924

The inscription recording the rewards of the efficient High Priest of Amun, Imn-htp, ${ }^{925}$ details fiscal responsibilities using most of the words discussed in this study.

[...(8)...] on account of the performance which you have made of the šmw, šsyt, $b_{3} k w$-(9)-rmt of the temple of Amonrasonther under your authority. You have brought

924 KRI N: 341-343; A.H. Gardiner, "The Stele of Bilgai," ZÄS 50 (1912): 49-57; cf. supra, pp. $182 \mathrm{ff}$.

925 KRI VI: 455-458; W. Helck, "Die Inschrift über die Belohnung des Hohenpriesters 'Imn-ḥtp," M/O 4 (1956): 163-178; cf. supra, pp. $186 f$. 
them, filling into the magazines. $[. .(11) \ldots]$ And from (you) are the inw and tpw- $\underline{d} r t$ : the material support $\left(p^{\prime}{ }^{i} n h w\right)$ of Amonrasonther (12) <which> you <have given to> Pharaoh, your lord. [...]

Imn-hip's inscription does not detail what the payments were, but indicates that they were definitely intended for the temple of Amonrasonther, with the exception of the inw and the tp- $\underline{d r}$.

\section{Royal Propaganda}

$b 3$; w-rmt is clearly used as a technical term in P. Harris I, consistently referring to the work of silver smiths in the temples $(1 \| .12 b, 2 ; 32 b, 5 ; 51 b, 10 ; 69,4)$. It would be tempting to refer to the work of the lapidary referred to as $b ; k w$ in $P$. Cairo $58096,{ }^{926}$ and assume that this $b^{3} k w$ was actually a $b^{3} k w-r m \underline{t}$. The headings of the totals for the whole text and the larger temples include $b_{3} k w-r m t(\| 1.12 a, 1 ; 32 a, 7 ; 51 b, 3 ; 68 b, 4)$, but not that for the smaller temples, where the entire heading is omitted.

\section{CONCLUSIONS}

Given the fact that the Bilgai Stele and the Inscription of Imn-htp are the two texts in which several of the terms concerning fiscal activities are scrupulously listed or delineated, it can be concluded that $b: k w-r m t$ was a fiscal term with a specific meaning. It is thus very probable that what frequently appears as $b 3 k w$ in the administrative and other texts, was occasionally officially designated as $b 3 k w-r m t$, which simplifies part of the interpretation of the fiscal term $b: k w$, as the private $b 3 k w$ will obviously be a separate category.

The $b_{3} k w-r m !$ will have been complimented as the $b: k w$ of the cultivators (e.g., P. Harris I $12 b, 3)$ and the $b_{3} k w$ of the fishers and fowlers (e.g., P. Harris $\left.12 b, 6\right)$, as these are items delineated under that title. ${ }^{927}$ If we follow the logic of the preceding chapter, these could either have been the products of the serfs of the temples or free people delegated to provide these things. If the text is to be taken at face value, the payments listed in this general category were all those of the smdt of the temples (e.g., P. Harris. 1 12a, 1), but as we have no evidence that the smdt at Deir el-Medineh were paid for their efforts, rather that they may have been mere peasants delegated with the relevant duties, potentially as corvée labour, on a part time basis, we are unable to reconstruct whether this is a tax, or a kind of obligation, or the result of full time employment.

Potentially relevant is that the $b: k w$ of the cultivators was listed under the $b: k w-r m t$ in $P$. Harris (e.g., 12a, $1 ; 12 b, 3$ ). The word $b 3$ k w does not figure in the two cases where the production

Cf. supra, pp. 242f.; KRI VII: 102-103; Čený, Nolebook, 145, p. 41.

The $b 3$ kw of Pharaoh from the Horemhab decree would then be the real exception following another rule, it must have been bikw for Pharaoh, cf. Horemhab Decree, supra, pp. $188 \mathrm{f}$. 
quota of $200 \mathrm{khar} /$ worker is stipulated. ${ }^{928}$ Regardless of how the figures are interpreted, they would seem to imply a large portion of responsibility and time, so that if this type of responsibility is the source of the bikw of the cultivators in $P$. Harris I, that $b ; k w$ implies a different scale of commitment from that of the smdtat Deir el-Medineh, but the proportions in P. Harris suggest that the $b_{3} k w$ listed was not intended to be heary. ${ }^{929}$

The incredible surplus produced by the author of the Bilgai Stele indicates that bikw-rm! was, in principle, a proportion of the production that was furned over to the temples, i.e., a "tax", as otherwise it would not have been possible to produce such an extraordinary surplus. Like other $b_{3} k w$ the $b_{3} k w$-rmt will have been assessed at a set rate, the hiri. All the known examples of $b_{3} k w$-rm! are related to temple income, which raises the question of what the bikw of Pharaoh was. Harris $\mid 11,4 ; 12 \mathrm{~b}, 3)$ makes a mere $15.5 \mathrm{khar} /$ head, which is not onerous, being the recorded yield of merely 3 arouras of ordinary land in P. Wilbour. Dividing the total surface area donated to all of the temples by the number of khar delivered annually indicates an income of $2 \mathrm{khar} /$ aroura. If we assume that the number of khar delivered annually by the smdt was correct, but that the temples "owned' five times as much land prior to the new gifts under Ramesses, 460'900 khar divided by 6 million arouras gives a yield of $3 / 4$ khar/aroura. All of which suggests that the revenue was only a small proportion of the yield, and that the smdt were not more than tenants obliged to pay a proportion of their income to the temples. 
THE WORD hïgt

The term h.? Presumably, the distribution of plunder was a royal prerogative It was generally applied to foreign countries. The only reason for its inclusion here is the potential transformation of the meaning of the word by the end of the New Kingdom. The citations make no pretense of being complete, as the word is familiar.

FOREIGN REVENUE.

Private Propaganda

One of the earliest inscriptions of New Kingdom date records that I'h-ms was awarded hiqt when his majesty plundered. ${ }^{930}$

Royal Propaganda

Ramesses II turned over hiqqt to Amun after a successful campaign. ${ }^{931}$ An inscription at Abydos probably records that the King relinquished the hiqt of foreigners to the temple. ${ }^{932}$

In the context of the Hittite marriage texts, Ramesses II records that the hiqut of Hatti, Ksks, Irty and Qdy were brought by the great prince of Hatti. ${ }^{933} \mathrm{He}$ even ascribes piety towards Seth to the great prince of Hatti, and seems to imply that the great prince of Hatti gave higt to Seth directly. ${ }^{934}$

Ramesses III's Karnak prayer relates that the Pharaoh plundered (h: $; q$ ) Punt for Amun. ${ }^{935}$ The Blessing of Pth-t3-tnn ${ }^{936}$ records that "the booly $\left(\mathrm{h}^{3} \mathrm{q} \mathrm{GW}\right)$ of the great princes" is presented (I. 20), and particularly that chiefs of the land of Hatti delivered their hizt (I. 25).937 


\section{REMARKS}

It is conventionally assumed that "plunder" is acquired by conquest, and that "tribute" is either the result of military conquest, or the threat thereof. Rendering hiqf as "plunder" is probably justified in many cases, and in the case of Punt, one can assume that Pharaoh somehow thought that he had conquered a country which his army had never visited, but such hyperbolic claims cannot be used to justify the Prince of Hatti voluntarily turning plunder over to Pharaoh and Seth. These two cases simply illustrate the point that the Egyptians used the words loosely, and that hiqt could as easily mean "tribute" or probably "presents", although from the Egyptian standpoint the objects offered would have been "tribute". 
THE WORD hitri

Meaning "doorpost", "team of horses", or "pair of pillars", 938 as a noun, htri has an etymological connotation signifying both "symmetry" and "support" and "pair". The verb is less clear. ${ }^{939}$

INTERNAL ReVENue

\section{Miscellanies}

P. Sallier 1940 is a letter purportedly from a chief archivist of the treasury of Pharaoh to a scribe relating that a stable master of the great stables of Pharaoh was given 30 arouras of land for "fodder for the htri of Pharaoh" $(1.9,3)$. Even though the following relative phrase is in the singular, the reference is doubtless to the "teams of Pharaoh" and not to the fiscal term.

The miscellany P. Bologna $1094^{941}$ purports to be a letter from a prophet of the Temple of Seth to a Steward, in which the latter is instructed:

When my letter reaches thee, thou shalt go together with the Standard-bearer $(6,4)$ Pth-m-mnw and thou shalt report to the Vizier concerning the great sums of money concerning which the Retainer lsy has said, "give it." $(0,5)$ This is surely not my htri! Thou shalt take document (?) of the money inw with the documents to the south. And

87-88: Caminos, IEM, pp.

LEM, pp. 5-6; Caminos, LEM, pp. 17-20; Gardiner, Wilbour Il: 163. This translation differs from that of Caminos and Gardiner slightly. The divergence is greatest at the close of the cited passage, where Caminos and Gardiner assumed that the prophet was comparing the comparative plenty available to the other temples with his own lack of means, while we suspect that he is comparing the assessments. This interpretation hinges on three unclear words: ' $h$ ', ț and šs $w$.

ts appears occasionally in $\underline{t} s$-prt, translated as "sowing order" but the word is sufficiently rare as to make an extended analysis fruitless, although the usual rendering may not be completely suitable. In P. Bologna 1086, 21 (cf. supra, pp. 144-145 n. 408; b:kw-rmt, pp. 167-168; W. Wolf, "Papyrus Bologna 1086," ZÄS 65 [1930]: 95-96) it is clear that the Is-prt is the assessment order - not the sowing or havesting order. In P. Berlin $3040 \mathrm{a}$, vso. 9, "the Isw-prthe made for you" $(K R I) 1 \mathrm{ll}: 160,15)$ is likewise clearly an assessment in khar of grain.

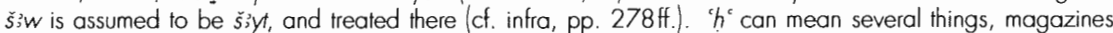
among them, and it is very difficult to distinguish when the one and when the other is meant. It is possible that ' $h$ c occasionally refers to a kind of assessment or perhaps land or labourers associated with a specific type of assignment (cf., e.g., supra, pp. 172ff., where the "hiw of Pharaoh are put onto the account of the Scribe of reckoning of the temple of Amun (II. 5,5-5,6). The term does not appear with sufficient regularity to justify any more precise statements. 
thou shalt place them $(0,6)$ in the presence of the Vizier. And thou will say to him that he should not htri (my?) people, for their are no people with me. But the $m n s$-vessel $\langle 6,7\rangle$ is in my charge. And the House of Nepthys is likewise in my charge. And look to the ' $h$ ' of the gs-pr which are in the district. $(6,8)$ They are not like mine. I am exceedingly deficient. The deficiency limits that which can be done against me. And look $(6,9)$ the people are the same today. And speak with others there about the great ts which has been set $(6,10)$ against me as the šsw of the House of Seth together with the $h$; - t;--land of Pharaoh (LIP!H!) under my authority. Look (how) small (they are)! Likewise $(7,1)$ do not throw thy hand together with the standard bearer Pth-m-mnw. Stay well!

Matters dealing the htri are dealt with by the Vizier, as in the case of the supplies for the Gang at Deir el-Medineh. ${ }^{942}$ A Retainer of Pharaoh has made financial demands of a Temple Prophet, who asserts that he does not have people. He does not say that he has people who are not obliged to submit to the htri. He merely pleads a lack of people and land, suggesting that he would be subject to pay the htri if he were better off. It would appear that the assessments concerning the obscure $t s$ and the khato-lands are not related to the htri, although it is highly probable that they are likewise fiscal in nature. ${ }^{943}$

\section{Excursus on htri and diw in the Deir el-Medineh texts}

The term htri is used to describe the ordinary deliveries to the Gang at Deir el-Medineh during Dynasties XIX and XX. These include almost all the products except grain. ${ }^{944}$ At least occasionally it is specified as having come from the treasury of Pharaoh, ${ }^{945}$ or the office of the Vizier, ${ }^{946}$ or the Mayor and Vizier. ${ }^{947}$

A letter from the Vizier $\mathrm{H}^{c} \mathrm{y}$ to $\mathrm{Nb}$-nfr asks whether he has "inquired about the htri of the Gang which is upon the house of the Treasury of Pharaoh" 948 and records that he had sent a controller "on account of our htri". ${ }^{949}$ A pseudo-missive concerning the office of the Vizier

942 Sir Alan Gardiner ("A Later Allusion to Akhenaten," JEA 24 [1938]: 124) noted that the author of P. Berlin 3040a "possessed authority to remit or alter the tax assessment of [...] Ra'mose, prince of the West of Thebes", while we note here that this must go to the Vizier. In the Instructions for the Vizier, we note, "It is he who htri every htri from the income of all which it has been given to him" (Urk. IV: 1114,9 cf. supra, pp. 178ff.). The important element here is not that we have an administrative confirmalion of the statement in the Instructions, but that it is clear that not all of the hiri of Egypt fell under his domain according to the Instructions (Urk. IV: 1114, 14). The question is where to draw the line.

943 Cf. supra, p. 210; II. 27, 12; 28,5. In P. Harris the khato-lands are associated with the htri, but it is difficult to establish the direct relation.

944 E.g., bread, beans, fruit and meat are mentioned in one case (KRI III: 145 146; HPB Iil: pl. 31; O. Berlin P. 12337); greens, beer, milk, fish and firewood in another (KRI II: 161, 1 1; HPB III: pl. 32; O. Berlin P. 1 1238). Cf. D. A. Warburton, "Keynes'sche Überlegungen zur altägyptischen Wirtschaft," ZÄS $118(1991): 76, \mathrm{n} .1$.

845 E.g., KRI III: 45, 14; O. DeM 114

940 E.g., KRI III: 29,10 and 12:H. O.: pl. 30; O. Gard 13. This is a model letter but most probably uses the terminology properly.

947 E.g., KRI VII: 455,5 (replacing $K R /$ VI: $151,1-4$ ).

948 KRI III: $45,13-14 ;$ O. DeM 114.

949 KRI III: $45,14-46,1 ; O$. DeM 114. 
orders that "the controllers from outside receive it that they may take it [i.e., htri] to the Royal Necropolis." ${ }^{950} \mathrm{O}$. Cairo 25832 mentions the Vizier and his concern that the Gang receive its htri.

One text states that the htri of the Royal Necropolis consisted of "greens, fish, fire wood, beer, pots, livestock, and milk" .951 A model letter ${ }^{952}$ refers to "their htri of annual requirements" listing bread, beans, fruits, fish, greens, and seemingly even various kinds of meat. The quantities suggest that an entire year's supplies may be listed, with such items as "fish various, 32'700". 953

In O. Toronto A 11, the Police Chief Min-inimy informs the Mayor and Vizier $\mathrm{H}^{c} \mathrm{y}$ that "(15) The annual htri is borne, <i>t being in very good shape consisting of wood, greens, fish, b<eer>".954 He goes on to refer to "(19) ...the annual htri of Pharaoh (L!P!H!)," which is associated with an sht field. There is a reference to a dispute about sht and sht fields suggesting that they had some relationship to the htri of Pharaoh. It is possible that the htri of Pharaoh referred to in I. 19 is not the same as the htri of I. 15, but a reference to "greens" (I. 27) supports the assumption that they are.

O. DeM 306 records actual deliveries under the title htri: wood, vegetables and fish. P. Turin $2007^{955}$ notes that the Gang actually received its htri, rather than the usual note that an official had ordered that it be attended to. $O$. DeM 100 records a delivery of the htri consisting of bread, vegetables and beer. P. Turin $2104 / 223^{956}$ appears to use htri as a generic term subsuming both deliveries of garments and the 8'000 khar of diw for the Gang. Both the garments and the grain would appear to be provided by the treasury of Pharaoh $(1.1,9)$. The diw would appear to have been partially the responsibility of the Mansion (i.e., Medinet Habu). The final lines of the first page refer to šsyt of Cush and all htri given to the Temple (i.e., the Estate of Amun?).

P. Turin 1903 records "all htri given to the Great and Noble Tomb of Millions (vs. 2,2) of years of Pharaoh (LIP!H!) on the West of Thebes [...] by the Overseer of the Treasury Wnn-nfr of the Treasury of Pharaoh (L!P!H!)." "957 Specific references to the hitri are:

vso. $(2,8)$ Received from the Deputy of the Treasury $[. .$.$] as their (vs. 2,9)$ annual htri of Year 4.

(vso. 2,25) Delivered as the sgnn-oil of the šrdn which is the htri of the vizier.

$(1,1)$ Delivered through the Deputy of the Treasury, Hri, as the annual htri from the inw of Cush.

951 KRI III: 161; O. Berlin P. 11238; HPB II: 32; Wente, letters, pp. 134-135. O. Cairo 25832 seems to indicale that plaster - presumably for work in the royal tomb - was included in the htri. CF. Wente, letters, p. 47.

Q52 KRI III: 145-146; O. Berlin P. 12337; HPB III: 31

953 1. 5. This is, of course, a model letter, but the actual deliveries recorded (e.g., 200'000 fish, supra, p. 160) cite figures which suggest that this is hardly unreasonable.

954 KRI Iil: $41-43$. hitri also appears in an unclear context of the same ostracon, KRI III: 31,12 .

$955 \mathrm{P} / \mathrm{R}, \mathrm{pl} .83 \mathrm{~A}$.

950 Cerny, Notebook, 23, pp. 20-23. IÄ IV: 735 reports that the recto contains unpublished accounts, but Cerny's note says that the recto is the Calendar of Lucky and Unlucky Days, while the verso is the accounts text, cited here

957 Černy, Notebook, 15, pp. 16-20. 
The items following this last entry would appear to be fruits and greens. The final lines (rto. 1,7 and 1,8) may refer to something that followed rather than what preceded. It would appear that the various sources of the material came from various sources, some of which were classified as inw.

An official letter states that "the htri of my Lord is in order, I am giving grain daily. Another matter: $[\ldots]$ give the diw of the army men together with the " $p r w$ ".958 From the plenitude of references to htri related to Deir el-Medineh, there are a number of texts which could throw more light on the subject. ${ }^{959}$

These records make it clear that the htri $n p^{3}$ ist, the htri of the Gang at Deir el-Medineh (also termed the htri $n$ p: hr, the htri of the tomb) consisted of items consumed daily by the Gang at Deir el-Medineh. It is however less clear that one can call such items "wages".

J.J. Janssen notes that "from all this it is clear beyond a doubt that the workmen's wages were called htri," suggesting that the "original meaning of the word is probably 'what one is obliged to pay '".960 O. Berlin P. 12337 is probably a model letter, ${ }^{961}$ and therefore the use of htri is relevant, as the purpose of studying was doubtless to learn the proper use of terms (and forms of address, etc.) although the numbers might be absurd. ${ }^{962}$

It is however generally agreed that the real wage "income" of the Gang consisted of the grain, the emmer and barley, ${ }^{963}$ and the word used for issuing these was diw, ${ }^{964}$ while htri was used as noted above for the assorted deliveries, which did not include the grain. They used the grain to some extent for exchange transactions, but the real significance of the grain was that it became a unit of account in the community, and therefore - of all the things that they received - is the only one that has been called "money". 905 The word diw would

958 KRI III: 250-251, I; P. Leiden I 349, I. 14; Bakir, Epistolography, pls. 17-18, XXIII-XXIV

959 KRI IV: 178 (O. Mich 66); KRI IV: 164-165 (P. Gard 8/Ashmolean 1960. 1283/C. J. Eyre, "An Accounts Papyrus from Thebes," JEA 66 [1980]: 108-1 19); KRI VI: 151,2 (O.Cairo 25 271); KRI VI: 364,9 (H. O. pl. 68,1/O. BM 50722 + O Cairo 25726); KRI VI: 571,8 (Giomale); KRI VI: 572, 10 (Giornale); KRI VI: 580,7 (Giornale).

960 Janssen, Prices, p. 457.

901 CF. A. H. Gardiner (HPB III: XXXla, identified as "Musterbrief") and J. J. Janssen (Prices, pp. 456 n. 3; 491), although W, Helck (Verwaltung, pp. 472-473 and Materialien, pp. 819-820) dates Seti, the Overseer of the Treasury, to the reign of Ramesses II. A. Fakhry ("Une statuette du nouvel empire," ASAE 39 [1939]: 94) favours identifying this Seti as the one in question.

902 CF. J. J. Janssen, "Prolegomena to the Study of Egypt's Economic History during the New Kingdom", SAK 3 (1975): $175-176$.

903 Cf. Janssen, Prices, 460; Valbelle, Ouvriers, pp. 148-152

904 For the sake of clarity, it must be mentioned that this word appears under spd in the Wb. N: 112, 2-5, "Proviant an Getreide der regelmässig verteilt wird". Urk. IV: 64, 1; P. Anast. VI, 42 (IEM, p. 75, 14; Caminos, LEM, p. 292); and the Decree of Horemhab, r. side, I. 9 (Urk. IV: 2158, 17; supra, p. 188) are examples showing that the rendering with rdi (Gardiner, Grammar, Sign-list X 8 ) is to be preferred to spd (Gardiner, Grammar Sign-list [(M 44)] before Z 9), as Sir Alan remarks (Grammar, p. 533). For diw specifically associated with the delivery of grain, ct. O. Cairo 25517 , to. col. 1; 25592, 1; 25608,2;25620, 1; 25698, 1; 25763, no. 1; 25765, กo. $1: 1$; $O$. Turin 57072,1 . Interesting is the case of $O$. Cairo 25588 , to. enumerating the grain given outside, avoiding the word diw, using merely bity ('emmer"). O. Cairo 25620, 4 and 25698, 7 refer to diw given to the servants (hmwt). H.O. 58, 1,4 distinguishes, the deliveries (enumerated individually, as greens, wood, fish, beer, garments, oill individually, without terming them htri, with the diw (which is not enumerated as barley and emmer).

965 Janssen, Prices, pp. 109-111 
thus at least conform to what are customarily termed "wages" and the word htri would correspond to what are generally termed "rations", "deliveries" "supplies" or "board". Both are of course in kind payments, as the ancient Egyptians did not have any other kind of payments except "in kind" ones, but the Egyptians obviously distinguished between the two, and modern scholars have also tended to separate the grain payments from the general commodities turned over to the Gang, although conventionally terming the grain payments as both wages and rations, they are here distinguished from one another on the basis of the divide that one served as "money" while the other did not, with htri as "rations" and diw as "wages".

P. Turin $2009+1999960$ records that there was "no diwfor III šmw IV šmw" (vso., 1,9; 1, 10), while the quantities of grain are added up in the preceding lines (vso. 1,5). The text is badly preserved, but the fact that the usual lists of names and numbers are missing, suggests that the 726 khar mentioned are a demand for 65 days of work, rather than an issue. The statement that there is "no grain for III šmw IV šmw" (vso. 1, 17) seems to correspond completely, thus clenching the argument that the diw were the grain-wages, as vegetables were in fact brought (vso. 1,1).

diw appears as "wages" for workers in a potentially private context. ${ }^{967}$ diw appears in a private context in Deir el-Medineh, where it would appear to refer to the grain payments as physical entities changing hands, but the damaged text does not permit further interpretation. 968

diw is used repeated to identify the grain wages of the Gang in P. Greg $(C x+10 ; C x+14$; vs. $A x+27$; vs. C 5 ; and probably A 13). In this text, the deliveries are each identified, and htri is not used anywhere, and htritype deliveries are not listed. diw is used in the sense of "wages" for a fisherman in the Turin Taxation Papyrus. 969

J. Černý termed diw "income in grain" in his commentary on the private papers from Deir elMedineh, ${ }^{970}$ correcting $O$. DeM 108, 7-8, referring to income arrange for by ist, which cannot be subsumed under the heading "wages". "Ration" would be possible here, but "payment" fits as well or better. The verb, rdi, "to give", in economic transactions means "to sell", as T. E. Peet pointed out. ${ }^{971}$ In Egyptian one can either sell "goods" for "money" or "money" for "goods", as it was all the same, depending upon the understanding of those involved in the transaction. rdi could thus also mean "to pay", suggesting that the diw of the Gang will have been their "pay" or "wages", and not their rations. This semantic interpretation is economically supported by the substantial size of the grain payments, which exceeded that necessary for consumption, and with the "grain standard" economy of ancient Egypt provided the members of the Gang with liquid assets. That grain was as good as copper lif

$9 \infty 6$ KRI VI: 560-566, Botti/Peet, Giomale, pp. 10-13/pls. 1-7.

987 KRI VII: 263-265, esp. 264, 11; 265,5 (P. Cairo JdE 52002, II. 9; 17). P. Posener-Kriéger, "Construire une tombe à l'ouest de Mn-nfr, "RdÉ $33(1981): 49-58$

9s8 Giornale vso B 9, 1; KRI VI: 590-594; Bolti/Peet, Giornale, pl. 40; Allam, HOP, pp. 331-335.

969 Gardiner, RAD, pp. 40,7, I. 4,3

970 "The Will of Naunakhte and the Related Documents," IEA 31 (1945): $41 ; 53$

271 "The Egyptian Words for 'money', 'buy' and 'sell'," in Studies Griffith, pp. 123-124 
not gold) is clear from the use of the sack of grain, the khar as a monetary unit in transactions, along with the copper deben. ${ }^{972}$

It would appear that the htri of the tomb was rendered up to the Gang, at least in part from the Royal Treasury, on the instructions from the office of the Vizier, and that it consisted of fish, beer, vegetables, milk and firewood, but excluded the diw grain wages for the most part. ${ }^{973}$ These grain wages were likewise the responsibility of the Vizier, but the grain could come from different offices. ${ }^{974}$

(End of Excursus)

\section{Administrative Texts}

The "htri of the Nubians of the new lands of the inw under the authority of the $(1,20)$ Royal Scribe Nb-nfr" is the designated origin of grain issued to the bakers for making "qw-loaves in a text dating to the reign of Seti $1 .{ }^{975} \mathrm{q} w$-loaves appear as a form of income in the stele of St?w, ${ }^{976}$ where they seem to be the bounty of Pharaoh, and it is likewise termed htri. In this case the recipients are "under authority of the Mayor of Memphis". 977 Nubians near Memphis being issued loaves, were probably not working on the land, but employed on a project.

P. Gurob ${ }^{978}$ of Regnal Year 2 of Seti II (II. 2, 12; vs. 1b, 2) states explicitly that a htri of fish was a Mayor's obligatory payment collected by Pharaoh. The quantity involved (2' $600 h q^{3}+$ ) is not given in a specific time frame. P. Gurob Fragment J explicitly states that the fish of another Mayor (Hri, of Mr-wrt) "are given to the people of the hnty in Mr-wrt." ${ }^{279}$

In $\bigcirc$. Gardiner $86^{980}$ htri appears as a verb, following a list of professions, preceding a second listing of the same professions with their responsibilities or obligations. It would be possible to interpret the term as meaning, "I have assigned", but this would not be strictly correct, as the 200 khar per field worker is assigned by definition ("each one of them under the obligation"). "I have assessed" would be equally inappropriate for the same reason, if applied to a single group of items. If however, htri is an all-embracing term for "recording assessments", this would be possible. ${ }^{981}$ It would not appear from the context that the actual collection is meant.

It is interesting to note that $O$. Berlin $P$.

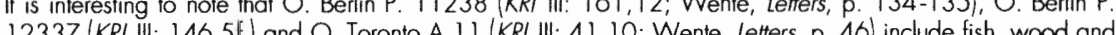
pots although these are the $b i k w$ of the $s m d t$ in principle. This confirms that the items are distinguished according to source more than character or destination.

974 This may be related to the fact that at least towards the end of Dynasty $X X$, the granaries of Amun were the major public granaries in Thebes, and that they also held grain belonging to other authorities. The evidence in favour of this conclusion is slight, but cf. e.g., supra, pp. 170ff.

975 KRI I: 260,8; Spiegeiberg, Rechnungen, pls. IV etc.; Helck, Materiolien, 638-639.

970 KRI III: 92,9

977 KRI III: 260,10

978 Cf. supra, pp. 146ff.; Gardiner, RAD, pp. 15,7; 17,14

979 Gardiner, RAD, pp. 26, 18-27,2.

980 H.O. 81, 14; cf. supra, pp. 143ff.

981 Cf. P. Harris $1,4,4 ; 7,4$ indicates the same, with "htri anew". 
"My annual htri" is how an overseer of cattle defines his obligation to provide wood and charcoal to a scribe of the inw magazine in P. Mallet (II. V , I- VI, 3). ${ }^{982}$ He goes on to insist that he paid an excess htri $(V I, 4)$. As he refers to the overseer of the treasury of Pharaoh in this context, it is tempting to assume that the hitri was somehow owed to Pharaoh.

P. Leiden I 350 verso 4,17 may refer to the inw of the htri. ${ }^{983}$ The context is obscure.

\section{Private Propaganda}

The Instructions to the Vizier 984 state that "(28) [...] It is he who notes all shortcomings in the divine offerings. It is he who hitri every/all htri from the income of all to whom it is given." Following a reference to inw, is: "(29)[...] The great council will report to him their htri and income $<\ldots . .>$ ". The preceding reference to the divine offerings may be relevant or not, as this part of the text moves rapidly from one matter to another, e.g., the in w being separated from the hitri by some damaged text, following which is a reference to the use of seals, and conflict resolution. The dominant theme of these paragraphs is land management and the income generated by it, so that the htri and inw appear as technical terms referring to specific types of income. hitri is used as a verb applied to the noun htri, with regard to income already delivered. From the context it cannot be exaction or collection, but can be "it is he who assesses every allocation from the income". This would indicate that the hitri is an assessment of the total income "given him", and that it could potentially refer to the "divine offerings" in the preceding sentence. This could simplify the interpretation of the following reference where htri and income of the great council are likewise distinguished. As the Vizier would be responsible for "assessing the htri-allocation of the total income (of his office)", the great council would be responsible for their htri-allocation, and thus two types of state income can be identified, each of which is sub-divided. The Vizier is responsible for both, but receives only the first kind.

One Dynasty XVIII treasury official recorded measuring "the receipt of myrrh as the annual htri" "985 Another Dynasty XVIII Overseer of the Double Granary reports having received millions of "their b3kw" as the "šsyt of their cities" classified as the "annual htri" ${ }^{986} \mathrm{Mn}$-hpr-R'-snb, the High Priest of Amun under Thutmosis III recorded "receipt of the gold of the Land of Coptos and of wretched Cush as the annual hitri" ${ }^{987}$

Dw3-r-nhth records that he inspected and counted bikw grain as the annual hitri for the temple of <Amun $>$ at the behest of Hatshepsut. ${ }^{988}$ He details a number of items as inw of

KRI VI: 67, 10; Bakir Epistolography, pls. 21-22; XXVII-XXX; Wente, Letters, p. 128.

Janssen, Ship's Logs, pp. 43

Cf. supra, pp. 178ff.; Urk. IV: 1114 ; van den Boorn, Duties, p. 283; Helck, Venwaltung, pp. 38-39; W. Helck, "Dienstanweisung für den Wesir," LÄ I: 1084; James, Pharaoh's People, pp. 66-67. Boorn (Duties, pp. 333376) has pushed the date of this valuable lext from Dynasty XIII to XVIII, so that the use of the terms may correspond to those of the Ramesside period, an argument which would be less defensible if the text were dated to Dynasty Xill (but cf. supra p. 178 n. 532)

Urk. IV: 503,$8 ; \pi 127$

Urk. IV: $530,11-16 ; \pi 99$

Urk. N: $931,8-10 ; \pi 86$

Urk. IV: $1379,18-21 ; \pi 125$. 
foreign origin separately. ${ }^{989}$ Clearly distinct from the foreign items, and seemingly not the hitri are Egyptian products labeled as inw. 990 If the context can be properly understood, he distinguished not only the foreign revenue and products, but also the Egyptian products, referring to the "annual htri" separately from the inw. The titles indicate that he was responsible for a gs-pr and a double granary, presumably those of Amun.

htri is used in an unclear context where the Chamberlain Twtw speaks before the collected officials of the land. The context would indicate that htri could refer to his own income (text 1, 1. 6).991

htri is mentioned in the Bilgai stele, 992 where the unidentified author states to the Royal Scribe and Steward of the Mortuary Temple of Siptah in the Estate of Amun, $P_{3}$ - $b_{3}$ - $-s_{3}$, that he fulfilled the šmw and the šsyt, identifying both as his own personal hirr (II. vso. 15-17).

Extraordinary was my (vso. 17) (delivered) excess šmw and šsyt. ten-fold my htri of šmw and šsyt. [...] $70 \mathrm{mnt}$-jars of honey were my honey htri ${ }^{993}$

His htri is also identified as $70 \mathrm{mnt}$-jars of honey, while he actually rendered up "700, a surplus of 630" (II. vs. 19-20). htri is thus here a term used to identify an obligation to pay a specifically quantified amount of something to a temple, possibly subsuming the šmw, $\breve{s}$ syt and $b ; k w-r m t$, i.e., a generic term for his assigned or allocated assessment. If the manifold excess is to be taken at face value, it would mean that the assessment was meant to be only a fraction of the available production, and not even a significant portion of total possible production, for an assessment erring to the low side to this extent would be unexpected. The St3w Stele ${ }^{994}$ uses htrri in three different senses, the first being his own income (I. 4) as a scribe of festival offerings, the second to the fiscal term when he was chief scribe of the vizier, and the third with reference to income from Cush when viceroy of Cush. In the Vizier's office, he "htri the entire land with a mighty pen" (I. 5). Although he states that what he does is beneficial to his Lord (i.e. Pharaoh), and confirms that offerings are consecrated to the gods, and even in excess (1. 8), he does not tell us what it was.

A Dynasty XIX tomb inscription records that the owner was a prophet of $M_{3}{ }^{c} t$ and that he filled both treasury and granary, receiving payments collected for the offering table. He uses the word htri in a difficult metaphor in this context, but clearly referring to things collected from the temple dependents for the benefit of the temple of Onuris. ${ }^{995}$

Urk. IV: 1379,10 .

990 Urk. IV: 1380,1-4; cf. supra, pp. $221 \mathrm{ff}$.

991 Urk. N 201 1; EA 8; Davies, Amarna VI: 11-12

992 Cf. supra, pp. 182ff.; KRI IV: 341-343; A. H. Gardiner, "The Stele of Bilgai," ZÄS 50 (1912): 49-57.

993 KRI N: $343,7-12$.

994 KRI III: 91-94; esp. 92,9; 11; W. Helck, "Die große Stele des Vizekönigs Stïw aus Wadi es-Sabua," SAK 3 (1975): 85-1 12.; K. A. Kitchen, "The Great Biographical Stela of Setau, Viceroy of Nubia," OLP 6/7 (1975) 1976): 295-302.

995 KRI VII: 226ff. (esp. 231, 12), replacing KRI IV: 143-144. Dated to Merneptah. 
In contrast to the usual "annual htri", Thutmosis III promises an "solid eternal htri" of live geese offerings for Amun. ${ }^{996}$ Among the objects listed as having been given by Thutmosis 111 to the temple of Amun, some vessels are listed as being "numerous large [vessels] as the annual htri", where a number is otherwise specified. ${ }^{997}$ Elsewhere the unidentified "annual htri" is assigned to Amun (which is the inw). ${ }^{998}$ Divine offerings and grain are specifically stated to be the excess $(h, w)$ of the hitri awarded to Amun. ${ }^{999}$ More detail is provided in one instance:

My Majesty founded for [Amun...] fields from the choicest of Upper and Lower Egypt, in order to cultivate. To command the grain thereof for the divine offering of each day, My Majesty founded anew in excess of that which was before.

My Majesty founded anew divine offering for him in order to make their praise in his mansion at Karnak. The annual obligations of bread, cattle, fowl, incense, wine, and every good thing as the annual htri. 1000

The annual htri was commanded by Thutmosis III for the benefit of both Khnum and Sesostris III. ${ }^{1001}$ Grain and trees are enumerated, and it is said that at least part of this was provided by the mayors of the southern district (tp) of Abydos.

In the Horemhab Decree 1002 htri appears as a noun, referring to "htri for the w'bt of Pharaoh" (I. 15). In the previous line (14), htri is associated with a nmhw in an unclear passage. While the context does not encourage over-interpretation, one can associate private people with an obligation to provide goods to the $w^{c} b t$ of Pharaoh /and note that officials are supposed to extract bikw from the $w^{c} b t$ of Pharaoh, and not directly from the private people, II. 31-33; q.v. bikw, supra).

At Gebel Silsile East, Seti I recorded ${ }^{1003}$ the provisionment of the expedition which was bringing a major monument north. Among the various items listed is "the daily htri of corn 6 khar" from the granary.

In Seti l's West Silsile Nile Invocations ${ }^{1004}$ Pharaoh emphasizes the significance of the Nile's role in the life of Egypt, mentioning "the things of the offering table from (11) I sht 15 to ll šmw 15 from the annual htri." The list of divine offerings from the granary of divine offerings of Amonrasonther includes: calves, goats, geese, bread, lizards, hippopotami, wine, curds, honey, milk, silver, gold, bronze, etc. Pharaoh evidently did not mind plundering one temple's treasury in order to provide offerings for another, and it must be assumed that the gods likewise acquiesced to the practice.

996 Urk. IV: 745,5. In P. Harris, the live geese are specifically termed šsyt $\mid 12 b, 9\}$, as part of the annual hiri.

997 Urk. IV: 641,11.

998 Urk. IV: 70, Iff. Another (Urk. IV: 753,9) text alleges that the King himself "htri the start of the season", but the text is unclear. It is tempting to speculate that the annual htri was assessed at a particular moment, and that this text refers to the season of the htri, but it is unjustified. He may have "fixed" the season.

sag Urk. IV: 163,13-14.

1000 Urk. IV: 746.

1001 Urk. IV: 195-196.

1002 Urk. IV: 2144, 10; 19. Cf. supra, pp. $188 \mathrm{f}$.

1003 KRI 1: 60-61, esp. 61,4.

$1004 \mathrm{KRI}$ ।: 81-96, esp. 90,14 
In the Nauri Decree ${ }^{1005}$ Seti I affirms that fowl, cattle, slaves, poultry farms, honey, moringa oil, incense, wine, textiles, etc., are guaranteed to the temple of Osiris at Abydos. ${ }^{1006}$ htri appears in the midst of these offerings (I. 20), without being associated with specific objects. Ramesses II referred to the htri in the context of the Inscription dédicatoire at Abydos. ${ }^{1007}$ "Thy treasury is filled with the desired things which I have given thee together with the htri" ${ }^{1008}$ The King himself has htri for Osiris. ${ }^{1009}$ The officials around Ramesses II assured him that he, Pharaoh, "htri in order to strengthen Egypt". 1010 The htri seems to be bikw, and it is specified that the bikw of the traders was in metals, while other htri and bikw require transport vessels to move them. To a considerable extent, the items and responsibilities correspond to those of the relevant paragraphs of $P$. Harris I.

Ramesses III associated construction in Egypt, Nubia and Asia with htri, b3kw, and inw. ${ }^{1011}$ He also associated $h t r i$ and $b 3$ ikw, of foreign origin, destined for Amun. ${ }^{1012}$ In another context Ramesses states bluntly that on orders from Amun, he received the htri of the $m r w$-serfs for his own treasury. ${ }^{1013}$

In P. Harris I $^{1014}$ Ramesses III says that he "htri Upper and Lower Egypt" providing gold, precious stones, cattle and corn for the Estate of Amun (II. 4,4-4,5). Although in this general context, he distinguishes this local Egyptian income from the $b_{3} k w$ of Nubia and Phoenicia, it is stated that "their annual htri" (i.e., what was awarded to the temple) was the šsy.t and bikw (Section Ilc of the text, supra). One specific paragraph definitely distinguishes the Pharaoh's gifts from those which rightfully belonged to the temples, using the verb htri:

$(7,4)$ I have endowed for thee festival offerings $[. .$.$] to be presented before thee at$ thy every appearance, provided with bread and beer, caltle and fowl, wine, incense varieties, (all) beyond count. They were htri anew of the officials and agents in excess of all of the gifts which I have made for thy $k$ ?.

The statement precedes the lists, which included, gold, silver, copper, linen, incense, etc. With the exception of the 309'950 khar of corn and the 82 vessels for transporting these and other things, the objects are precisely what would be required for the execution of temple tasks. That Pharaoh emphasizes renewing the htri can be interpreted as rhetoric, or placed in an historical perspective, as it may have been that as late as Dynasty XX the possessions of the Estate of Amun - expropriated under Amenophis N - were still being returned to it.

1005 Ct. supra, pp. 190ff.; KRI I: 45-58, esp. 49,5.

1000 Although there are some difficulties with the name and the aftributes, the text is evidently intended to guarantee income for Seti's magnificent temple at Abydos.

1007 KRI II: $333,6$.

1008 KRI II: 332,15

1009 KRI II: 332,8

1010 KRI II: 197,10.

1011 KRI V: $117,13 \mathrm{f}$.

$1012 K R I V: 50,13$

1013 KRI V: 284,3

1014 Cf. supra, p. 198 
Thutmosis Ill claims to have turned some $15^{\prime} 000 \mathrm{~kg}$ of gold over to Amun, ${ }^{1015}$ while P. Harris records less than $60 \mathrm{~kg}$ ! 016

Not included under these headings are the temple dependents, cattle, corn, dockyards, gardens, divine images, etc., which Pharaoh gave of his own volition (Sections Ilb, Ild - inw-, $\|\mathrm{le},\| \mathrm{fl}$; thus distinguishing these items from those that the temples produced for themselves, presumably thanks to the labour of the dependents which Pharaoh awarded them.

The lists of Pharaoh's own offerings are far more detailed, e.g., the htri offerings have 4 lines of text for $51 \mathrm{~kg}$ of gold $(12 a, 6-12 a, 9)$, while the king's offerings use 6 lines of text for about $5 \mathrm{~kg}(13 a, 5-13 a, 10)$. The same detail appears when comparing the htri-lists (Ilc) with those of the royal lists (Ild) for incense, clothing, honey, wine, precious stones, etc., etc. This might suggest that the king actually authorized the distribution of his own resources on a detailed basis, but that he was merely kept informed about deliveries going directly to the temple. Despite the detail, the total transfer of wealth from Pharaoh to temple remains modest in comparison with the htri.

For Heliopolis, Ramesses likewise asserts that the htri was "transported to your treasury in the Temple of $\operatorname{Re}^{c \mid}(\mathrm{P}$. Harris 28,5), and the total supplies are again counted as "their annual htri" $(32 a, 9)$. The list is an abbreviated version of that for Amonrasonther, and the list for the Memphite temples follows the same pattern, where "their entire htri is in thy treasuries, magazines, granaries, cattle stalls, bird pens" (P. Harris 48,10).

The paragraphs preceding the lists for the smaller temples deliberately exclude the use of the terms bikw, šzyt and htri.

Ramesses III's Karnak prayer ${ }^{1017}$ uses the "annual htri" in a fashion indicating that the Pharaoh commanded it for the benefit of Amun (1. 22), suggesting that it may be specifically grain, but other items are mentioned. htriappears in a damaged context (I. 20) perhaps with reference to bikw which was transported to the granaries.

\section{FOREIGN REVENUE}

\section{Private Propaganda}

Dhwty, an Overseer of the Treasury in the middle of Dynasty XVIII, recorded that he received ivory and ebony of "this foreign country as the annual htri" ${ }^{1018}$ As the last line of the relevant passage states that His Majesty praised him, the text should doubtless be understood as fiscal in nature. ${ }^{1019}$

10:5 Urk. IV: 629-634. Cf. J. J. Janssen, "Prolegomena to the Study of Egypt's Economic History during the New Kingdom," SAK 3 (1975): 154.

1016 To the temple of Amun. Altogether he donated more than ten times that much to all the temples: (P. Harris I $68 \mathrm{a}, 4)$, some $650 \mathrm{~kg}$.

1017 KRI V: 221-225; esp. 225,2;8.

1018 Urk. IV: 436,6; ПT 11.

1019 And not a mere interdepartmental transfer (cf. $\Pi$ 343, supra, p. 225). Whether the ivory and ebony were products of Egypt is less clear, and whether they were destined for the royal treasury is another matter. 
According to his autobiographical stele, Min-msw was a retainer of Thutmosis III who followed his ruler to Nubia and to Syria. ${ }^{1020} \mathrm{He}$ details fiscal activities in Nubia and Syria, stating, "(8) [...] I htri Upper Rțw namely silver, gold, lapis, all precious stones, chariots, steeds, un-(9)-countable; cattle and sheep like unto millions (mi $\left.3_{s} \breve{s}^{c} . s n\right)$. [Reference to $b{ }^{3} k w . .$. ]. (10) I htri the princes of T3-nhsy in electron $\left(\underline{d}^{c} m\right.$ hr $\left.\underline{d} t^{c} w . f\right)$, in gold, in ivory, African blackwood, ${ }^{1021}(11)$ numerous boats, palms, as the annual htri like serfs (mrt) (12) of his palace.

The objects which are the object of the verb htri do not include corn, but precious materials and animals. The following paragraph indicates that it was deposited in a treasury after being "counted" (although uncountable), but does not specify which treasury, although the simile refers to the "serfs of his palace". ${ }^{1022}$ As the paragraphs following the foreign activities of the hero refer to temple activity, it can be suggested that he was acting as an agent of Pharaoh as king, and not (yet) in the name of the temples. Assessment and collection seem to fall together here as htri.

When Viceroy of Cush, St? ${ }^{1023}$ asserts that "I brought all htri of this land of Cush two fold" (l. 12).

\section{Royal Propaganda}

Under Thutmosis III, an annual obligatory htri as bikw is assured Amun, in the form of divine offerings from various villages in Upper Rtnww. ${ }^{1024}$ Various seasonal offerings are also called an annual htri for Amun. ${ }^{1025}$ The harbors of coastal Syria "make ready all things as their htri, as their annual custom $\left(n t^{c}\right)$, probably for Amun. ${ }^{1020}$ Both wretched Cush and various Syrian villages are obliged to deliver $h$ tri as $b_{3}{ }^{k} k w$ to Amun. ${ }^{1027}$

Seti I instituted htri associated with a festival for the chapel of his father Ramesses I in Abydos. ${ }^{1028} \mathrm{He}$ also provided the annual htri for $\mathrm{H}^{\mathrm{c}}$ py and the gods in the Nile invocations at West Silsile. ${ }^{1029}$

In the context of the Hittite marriage, Ramesses II has the Hittites praise him for being the son of Seth, born of $M_{3}{ }^{c} t_{t}{ }^{1030}$ who caused the land of Hatti to prosper for the Pharaoh: "We htri in love of thee, we bear it to thy noble palace". ${ }^{1031}$ Ramesses III recorded that every land bore its inw, htri and b3 kw to Pharaoh, most probably to be delivered to Amun at Karnak. ${ }^{1032}$

1020 Urk. IV: 1441-1445; esp. 1442,8; 11.

1021 Lucas's suggestion (Lucas-Harris, Materials, p. 435), supported by Germer (Flora, pp. 97-98), has been reputedly confirmed from material salvaged from the wreck off the Turkish coast at Ulu Burun.

1022 It is possible that this could signity that the serfs paid a htri to Pharaoh, but the evidence is slim.

1023 KRI III: 91-94; W. Helck, "Die große Stele des Vizekönigs Sł’w aus Wadi es-Sabua," SAK 3 (1975): 85-1 12. ;

K. A. Kitchen, "The Great Biographical Stela of Setau, Viceroy of Nubia," OLP 6/7(1975/1976): 295-302.

1024 Urk. IV: 744,7

1025 Urk. IV: 750-751, esp. 751,4

1026 Urk. IV: 700,6.

1027 Urk. IV: 185-186, esp. 186,3

1028 KRI I: $114,4$.

1029 KRI I: 90, 14-16.

1030 Probably the King, rather than Seth, who was usually the Son of Nwt.

1031 KRI II: 245,7-9.

1032 KRI V: 221-225, esp. 225, 1-2. 
P. Harris I ends with a statement to the effect that after defeating the Peoples of the Sea, they were settled in the Delta, and that they were htri as well, "clothing and corn are paid into the treasuries and granaries annually" $(76,9)$. This is a rare reference to a htri of corn, and not necessarily a reference to foreign revenue, as the "foreigners" were settled in Egypt.

\section{PreVIOUS DISCUSSIONS OF THE WORD htri}

W. Helck termed the htri an "obligation" or "quota". ${ }^{1033} \mathrm{~J}$. J. Janssen suggested that the htri deliveries in Deir el-Medineh were termed such since they were the "deliveries" from elsewhere being re-circulated through the system, rather than interpreting the abstract obligation from Pharaoh to his workmen. ${ }^{1034}$

In his discussion of the word and its contexts, J.-M. Kruchten defined the fiscal significance of the verb htri as "putting to work" and the substantive as indicating "what is produced by putting to work". ${ }^{1035}$ More specifically, while concurring with the dictionary definitions, suggesting that it meant "to subject someone to tax or tribute," he distinctly emphasized that what it really meant was more "to put someone to work" than "to subject them to a contribution". 1036

Given the discrepancy between the prescribed htri and the produced htri in the Bilgai stele, we cannot however escape the conclusion that the prescribed htri represented a mere proportion of the produce, and therefore it cannot mean "to put someone to work", but must mean to "assign" or "impose an obligation" to pay a portion of the produce, i.e., to make a contribution. As the prescribed htri must be our point of departure (for those issuing the instructions will have understood the word correctly), the conclusion is self-evident.

Kruchten's assessment likewise ignores the fact that none of the determinitives signifying action is associated with the word during the New Kingdom. While those used vary, the papyrus roll determinative suggesting an abstract meaning is common, particularly so in the carefully written script of $P$. Harris I. This alone would suggest that it is not a verb of action, and that the substantive cannot be a "product of labor".

In his study of P. Harris I, Grandet indicated that Kruchten's philological reasoning was methodologically flawed, but himself confused philology and economics:

Taking account of the semantic virtualities of the root hir, "to join", and the theoretical administrative virtualities of economic systems based on redistribution, as discussed above, and avoiding a discussion in terms of "fiscality", a notion with modern economic connotations, which cannot be anything except a source of anachronisms,

1033 LÄ|: 7.

1034 Janssen, SAK 3: 176.

1035 J.-M. Kruchten, "le verbe hitr et ses dérivés jusqu'ò la fin du nouvel empire. Sens et Traduction," AIPHOS 24 (1980): 39-52, esp. p. 52

1030 Kruchten, AIPHOS 24: 40-41 
as stated at the start, we believe that it is possible to establish the economic and administrative meanings of the verb and the noun htr in the following fashion. ${ }^{1037}$

He thus establishes that his objectivity consists of rejecting fiscal thinking and assuming redistribution. His definition of the verb htr consists of "linking" two groups, avoiding the necessity of delivering things to the central administration whence it must have been redistributed. His definition of the noun "conforms to the definition" of the verb, and thus ties the concepts of "wages" and "tax", as an obligatory payment which is "allocated" in terms of administrative measures, and economically corresponds to a fraction of production. ${ }^{1038}$ As we will see below, this philological interpretation is marred only by the economic interpretation, and had the two been separated, his interpretation of the word would have been philologically impeccable.

\section{CONCIUSIONS}

htri definitely expresses an abstract obligation to render certain concrete articles to a higher authority, be it the government or the temples, but clearly only a portion of what is produced, for both the Bilgai stele and the inscription of St? ${ }^{3}$ w emphasize that they produced considerably more than the htri, and delivered it. While bikw can also be used in private contexts to refer to work carried out for another person on a private basis, htri is apparently never used in this sense. It thus had a specifically fiscal significance, which was not equivalent to $\check{s}^{3} y t-$ although many of the texts give the impression of a complimentary character - but more probably it defined the šzyt, or rather htri seems to subsume šzyt, ${ }^{1039}$ while being used abstractly, but the htrican also be more specific. Given the number of complaints concerning htri, it must have been the most demanding of the official obligations. ${ }^{1040}$ The text referring to the bikw of a fisherman which is classified as the htri of the Mayor and Vizier ${ }^{1041}$ is probably the most useful reference for a comparison of these two terms. The Mayor and Vizier is responsible for the income, it is imposed upon him, and those who actually carry it out deliver it as their work. From the official standpoint, htri applied to people ${ }^{1042}$ would thus imply a bikw type obligation on the people, which was the htri of the official.

htri thus appears to have had several fiscal meanings. The nouns and the verbs were closely related, but the verb seems to be exclusively fiscal, in the sense that the provision of supplies

1037 Grandel, Papyrus Harris II: 63. [My translation].

1038 Grandet, Papyrus Harris H: 63-66

1039 In P. Harris I (pp. $194 \mathrm{ff}$., supra), the b3kw šsy of the dependents are termed the annual htri (sections Ilc, IIlc, IVC). The $\breve{s}^{3} y t$ of live geese is specified, under the htri. In the Bilgai Stele (pp. $182 \mathrm{ff}$. supra), the šsyt is not identified, while the htri is specifically identified as the honey deliveries, but both the $\breve{s} 3 t$ and the šmw are termed htri.

1040 P. Cairo 58057 (KRI I: 238; cf. "bikw", supra, p. 240) illustrates this, in that the author of the letter merely tells the recipient, that the $b i k w$ is being exacted from the author while the creature is with the recipient. Complaints concerning the htri are more emphatic.

1041 KRI VI: 650-652, esp. 650,14; 651,6.

1042 As, e.g., P. Bol. 1094, II. 6,5-6,6 (LEM, pp. 5-6; Caminos, LEM, pp. 17-20) 
for the Gang at Deir el-Medineh was never referred to using the verb htri, while both Pharaoh and the vizier htri the htrri, with an apparently direct relationship to income. The verb thus refers exclusively to activities relating to arranging income on a fiscal (as opposed to administrative) basis.

The noun seems to refer to (a) "supplies in kind" at Deir el-Medineh, and (b) "their annual htri" appears to be the "assessment" or "levy", rather than the "dues" themselves, as implied in statements like "I have htri anew", which could mean "assessed again" or "levied again", or "It is he who assesses every assessment", 1043 in the sense of "fixes" rather than examines.

The fact that htri does not appear in the inscription of Imn-htp would imply that he is listing what has been delivered, and not the assessments, and this explains its absence.

The English word "levy" means both "to impose" or "collect" and "assessment", "dury", "impost", "tax" 1044 and thus matches the difference in meaning between the verb htri, "to assess" and "to collect" while the noun could signify "dues", which could be interpreted as the obligation (1) imposed by Pharaoh in terms of deliveries to Pharaoh or the temples, and (2) of Pharaoh to provide for his dependents. From the Bilgai stele, where the author produced a ten fold htri, it may be deduced that the "levy" was only intended to be a portion of the produce /and thus the equivalent of a "tax"l), and that in this case, an exacting official became over ambitious. It is also clear that "assessing anew" would not be necessary if all of the produce was taken from the producers in similar contexts. htri thus signifies "tax-assessment" in many cases, and occasionally a type of "income tax-assessment", payable to the temples or the government. It was however an assessment for which officials were expected to take the final responsibility, like the $b$; $k$ w exacted from the mayors. From P. Harris I there is however considerable evidence that the htri of the temples was actually produced by temple labour. In either case, however, it was a specific obligation to supply goods to the temples and the government.

The verb htri meaning "assess" would appear to be the fiscal term par excellence for assessing what is due, whether šštt, inw, šmw, htri, or bikw. Understanding htri as meaning "assess", "assessment", "levy" is probably the best consistent rendering, and since it signifies "assessing" only a proportion of the production, the implications are that of necessity the other words modified by htri cannot be other than the equivalent of "taxes" imposed on a total production, of which only an "assessed" fraction was to be paid to the authorities. 


\section{$\check{s} 3 y t$}

THE WORD $\check{s} 3 y(t)$

šzy $(t)$ normally means "destiny", related to the god of destiny, šs ${ }^{1045}$ The fiscal term is also

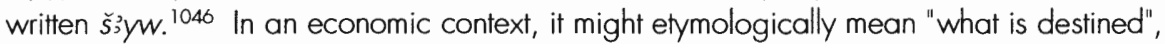
"what has been decided".

INTERNAL ReVEnUE

\section{Administrative texts}

The miscellany text states concisely that the scribe does not pay the $\breve{s} 3 y$ (P. Anast., V, 17,2-3) 1047 . Another miscellany, P. Bologna 1094, records the request of a temple prophet that a Steward intercede for him in the Vizier's office, "And speak with others there about the great $t s$ which has been set $(6,10)$ against me as the šsw of the Temple of Seth together with the khato-land of Pharaoh (L!P!H!) under my authority. " 1048 In P. Harris I, šżyt is written šży $(69,11)$ possibly corresponding to the contemporary pronunciation. The khato-lands and the šzyt are mentioned in the same general context in $P$. Harris $(27,12 ; 28,5)$, where the income of the temples of Heliopolis are described. In the case of P. Harris I, the payments are clearly to the benefit of temples, whereas in P. Bologna 1094, the Vizier is to be consulted about a matter of temple income managed by a prophet. P. Berlin 3040 a likewise indicates that obligations were in fact one of the major concerns of the top officials, ${ }^{1049}$ as would be expected from the text of the Instructions of the Vizier (cf. supra, pp. 178ff.).

Honey dockets seem to imply that honey could be the bikw of the honey bearers (cf. P. Harris I: 28,3 ), but that at the same time it is the $\check{s}^{3} y t$ of an official, ${ }^{1050}$ the one being concrete, the other potentially abstract. (Only a htri of honey is recorded in the Bilgai Stele).

In a semi-official letter, ${ }^{1051}$ the Scribe Twr greets "his mother, the Chantress of Amun", and a fragmentary passage indicates that in some way a Vizier associated with the author of the letter has sent or instructed someone "to exact šzyt of his controllers ( $r w \underline{d} w)$ who are in the fields" dealing in some way with a deficit from the preceding year (II. 6-7). The fragmentary text refers to registering this backlog in the "granary of Pharaoh" (1. 8).

1045 Cf. Quaegebeur, Shaï.

1040 Quaegebeur (Shaï, p. 58) points out that the written form does not signify the existence of a masculine, and that there is thus one single feminine term for this meaning of the word. Cf., e.g., P. Harris I, II. 12b,9; 32b, 11; $52 a, 1 ; 69,11$. Half of the examples are without the $t$, although all are the same word. For this reason, it is difficult to imagine that a difference between the forms with and without the $t$ indicates a difference between prospective and accomplished.

1047 LEM 65,6.

1048 LEM, pp. 5-6; Caminos, LEM, pp. 17-20

1049 KRI III: 160, 11 ff.; A. H. Gordiner, "A Later Allusion to Akhenaten," JEA 24 (1938): 124.

$1050 \mathrm{KR}$ I VII: $84,8-16$. Another text of the same type suggests a similar interpretation for the use of the word $\breve{s}^{3} y^{\prime}$ (KRI VII: 85,12 )

1051 KRI VII: 190-191: The recto of O. Cerny 3 + O. Fitzwilliam 1; Wente, Letters, pp. 146-147. 
The Tax Lists of the Turin Canon ${ }^{1052}$ refer to a regular ššy (written in red) associated with an institution $(3,4)$. Whether this might modify the following lines, or itself be modified by the lines relating to $\underline{b_{3} k \mathrm{kw}}$ above is speculative, but improbable, for the relationship between šzyt and $b_{3} k w$ and $t p$ - $\underline{d} r$ seems to be parallel rather than complementary, so that it would be more likely - in comparison with P. Harris I - for šzyt to be the same type of obligation as the $b_{3} k w$, or to subsume the $b_{3} k w$, rather than to be subsumed by it. The šzyt of the smdt mentioned in a very fragmentary context $(3,19)$. We cannot therefore draw any conclusions which are not wholly speculative from col. 3. Col. 4 likewise associates an institution with the šsyw, but in a fragmentary context.

Col. 7 of the Tax Lists specifies the obligatory annual payment of head of cattle, with totals that lead to large figures. The arrangement suggests that similar records of cattle in col. 4 be reconstructed and likewise assigned to the šsyw. If this line of speculation is correct, the šszyw will have been a obligation held by an individual (the suffix .f being attached to it)

\section{Private Transactions}

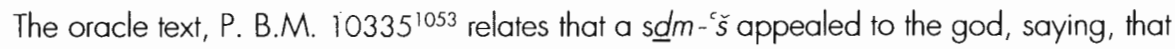
when he was in pi-hnty, those guarding the granary were exacting its šzyt, and that some of his garments were stolen, and it not clear that any logical or persuasive conclusions can be drawn from this text, aside from the association of the šsyt and the granary. The use of the term $s \underline{d} m-{ }^{-} \breve{s}$, rather than $r m \underline{t}-i s t$, indicates a deviation from the standard terminology of daily life, but would not appear to be important, and it can probably be accepted that the use of the term šsyt does not diverge from normal use.

\section{Private Propaganda}

A Dynasty XVIII inscription records the collection of the "šzyt of their cities". ${ }^{054}$ b3kw and htri appear in the same context, suggesting the tentative conclusion that their bikw-payments corresponded to the šsyt which was the htri assessment.

$\breve{s} 3 y t^{3}$ is mentioned in the Bilgai stele, ${ }^{1055}$ where the unidentified author states to the Royal Scribe and Steward of the Mortuary Temple of Siptah in the Estate of Amun, P3-b3-s;, that he fulfilled the šmw and the $\breve{s} 3 y$, identifying both as his own personal htri (II. vs. 15-17). He does not associate the šsyt with any specific items, as he does in the case of the other terms, but it is possible that a direct liaison with grain is possible. ${ }^{1056}$

1052 Cf. supra, pp. $159 f$.

1053 W. R. Dawson, 'An Oracle Papyrus. B.M. 10335,"JEA 11 (1925): 247-248, pls. XXXV-XXXVIII. A.M. Blackman, "Oracles in Ancient Egypt," JEA 11 (1925): 249-255.

1054 Urk. IV: 530,13-16; ПТ 99.

1055 Cf. supra, pp. 182ff.; KRI IV: 341-343, esp. 343 ,7ff.; A. H. Gardiner, "The Stele of Bilgai," ZÄS 50 (1912): 49-57.

1050 Another-administrative - text of unclear content dating to Ramesses II, refers to the šsyt from the fortress of the sea $|K R|$ VII: 93,9|. 
The inscription recording the rewards of the efficient High priest of Amun, Imn-htp, ${ }^{1057}$ details fiscal responsibilities using most of the words discussed in this study, but does not identify the šsyt further than to confirm that it was allotted to the temple directly, and this along with the other products filled the magazines. The word hiri does not appear in this text.

\section{Royal Propaganda}

In the Nauri Decree, Seti I states that "they bring the šsyt which I have given to him [i.e. Osiris]". 1058

In P. Harris $\left.\right|^{1059}$ a number of categories termed the "annual htri" $(12 a, 5)$ are specified to be the "šzt bikw-rmt of the smdt of the Mansion" (12a, 1; cf. wording from Tax Lists, supra), his funerary temple in the Estate of Amun: gold, silver, copper, linen, wine, corn. Although b3kw appears repeatedly, $\breve{s} 3 y t$ is not the subject of a specific entry, except for the "live geese as šzyt $(12 b, 9) .1050$

The same formulae are used for the temples of Heliopolis $(32 a, 7-32 a, 9)$, but in the preceding rhetorical paragraphs $(28,3-28,5)$ šzyt appears as being equal in importance to / rather than a part of the $b_{3} k w w$ and htri. The "live geese as šsyt" form a specific item $\langle 32 b, 11\rangle$. The comparable paragraphs concerning Memphis repeat the pattern for Thebes, with the "live geese as $\breve{s}^{3} y t^{\prime \prime}(52 a, 1)$.

The final summary of the lists $(68 b, 4-68 b, 5)$ defines the šsyt $b 3 k w$-rmt smdt as being the annual htri. The total of the silver and gold (of all kinds, $68 \mathrm{~b}, 8$ ) seem to exclude both the (non-šsyt bikw) objects given the small temples and the Pharaoh's own gifts to the Estate of Amonrasonther. ${ }^{1061}$ Despite some mathematical discrepancies, the same seems to have been intended to be true of the totals for the "garments" 1062 and "incense, honey and sesame oil". ${ }^{1063}$

1057 Cf. supra, pp. 186f.; KRI VI: 455-458; W. Helck, "Die Inschrift über die Belohnung des Hohenpriesters I/mnhip," M1O 4 (1956): 162-178.

1058 KRI : 50,10. In the Hermopolis Decree $(K R / 1:$ 125-126) Seti I also arranges for the protection of temple income, but does not use any of the usual vocabulary (except $\tilde{s}_{3} w, K R / 1: 126,5$ ). Is this another case of the major temples having a different vocabulary to the smaller temples?

1059 Cf. supra, pp. 194ff.

1000 The final $t$-suffix is in fact missing here. Entries $(32 b, 1)$ and $(52 a, 1)$ have $n$ rather than $m$, so that "live geese as šsyt" is probably correct.

1001 When added together, the equivalent lines from Memphis, Heliopolis and Thebes total less than the final total given, $16^{\prime} 339.65$ deben $(68 \mathrm{~b}, 8)$, but if the $4^{\prime} 204.76$ deben of the silver $b 3 \mathrm{kw}(69,4)$ are added, the balance indicates a difference of some 80 deben, or an error of less than 0.5 per cent. of the total. That the bikw-rmt silver may have been included twice can be either an oversight or an error, or may be substantially more significant. A simple error of some 25 per cent. need not however be excluded a priori (cf. note on incense, infra p. $280 \mathrm{n} .1063$ ). It could be suggested that the scribes were far more careful in accounting for the silver than for garments and incense, but this is pure speculation.

1002 The error is that the final total is 301 items short of the mathematical total of the totals of the individual entries fan error of ca. 7 per cent.). As Pharaoh claims to have given twice as much clothing to the Estate of Amun from his private sources $\left(8^{\prime} 586\right.$ items, $14 \mathrm{~b}, 16$; as against $4^{\prime} 575$ items, $\left.68 \mathrm{~b}, 12\right)$, neither this nor the gifts to the small temples - which would have inflated the figure even more - can have been included here.

1063 The error is again that the final total is 270 items short of the corresponding entries in the lists (the error being nearly 25 per cent. here). Again, from Pharaoh's personal reserves, far more than this has been furned over to the temples. 
FOREIGN REVENUE

Administrative texts

The first page of $P$. Turin $2104 / 223^{1064}$ uses the terms bikw, htri, diw and šs syt, primarily with reference to garments and grain for the Gang at Deir el-Medineh. It would appear that the šzyt of Cush (and) all the htri were turned over to a temple, probably the Estate of Amun, from the treasury of Pharaoh. The goods are not defined.

\section{Private Propaganda}

A Dynasty XVIII inscription records "receiving the šzyt of silver, gold, precious stones" by an overseer of the gold of foreign lands (or deserts). ${ }^{1065}$

\section{CONCLUSIONS}

It is clear that the term had a specific meaning for the Egyptian administration, and the evidence from the Tax Lists of the Turin Canon and Harris would initially seem to suggest a payment in livestock, as it is associated with cattle, geese and honey, as opposed to products, as if to distinguish the two, yet, the Syrian livestock in P. Harris are termed $b$; kw, so that this line of logic cannot lead anywhere.

While it is striking that the šsyt is associated with geese on two occasions, in another case, is that of "their cities". In the Decree of Horemhab, it would certainly seem to imply a direct legal term associated with the courts. That it is not purely abstract comes close to being proven in the Rewards of the High Priest Imn-htp, because there the abstract htri, assessment, fails to appear, yet the šsyt does. ${ }^{1006}$

Therefore, although šsyt would generally appear to imply an abstract obligation from an official to the administrative apparatus, of the temple or government, and does not seem to represent a specific class of goods (since cattle, geese, precious metals and stones, garments, and other items are included), nor to be associated either exclusively with either individuals or administrative centres, it is difficult to isolate. The šsyt can be awarded to the temples by Pharaoh, but temple income can also be termed šsyt. It seems to be employed with regard to both domestic and foreign articles. The šsytobligations are determined by the htri assessment.

1004 Černý, Notebook, 23, pp. 20-23.

1005 Urk. IV: 530; П 99

1000 Cf. supra, pp. $186 f$. 


\section{THE WORd šmw}

The term šmw is frequently encountered in administrative texts dealing with the collection of grain. The word itself means either "summer" or "harvest", and thus the traditional rendering "harvest-tax" may appear to be suitable, as "harvest" does have a specific meaning, and this payment represents something collected by the authorities after the harvest. "Tax" has however likewise a specific meaning, usually that it is a fraction of something (wealth or income) paid by members of a community (individuals, corporations, etc.) to the government of the community. The word appears very frequently in certain texts, and its meaning is more or less clear.

\section{INTERNAL REVENUE}

\section{Administrative texts}

The miscellany text ${ }^{1067}$ indicates that the šmw was a grain impost, paid by the cultivators and collected by scribes. The text emphasizes that there is "no grain", and it might be thought that the šmw consisted of all of the grain harvested, as one might speculate that the cultivator would be even more put aback, if whatever was left by the animals were to be taken by the predatory tax collectors. This surmise is not however matched with those documents where specific proportions can be guessed at.

P. Northumberland $\| 1008$ states that the daily rations (mnt) of the army (i.e., expedition, or squadron) were taken from "the šmw of Year 2 of "Seti I (I. 3). They are defined as having been inyt (II. 5-7, 9; 11), which could mean "brought", or the fiscal term.

In a letter dating to the reign of Ramesses $\|^{1069}$ the Overseer of Cattle Swnr reports to the

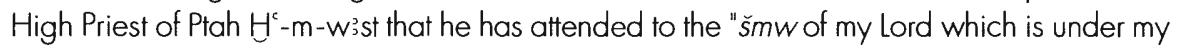
authority" (I. 4), with a reference to the temple of Ptah in the same partially preserved sentence. This seems to imply that the šmw could belong to the temple of Ptah, it being less probable that it is the personal or hereditary obligation of the Prince. It could also conceivably be an obligation that the temple owes to a third party.

1007 Cf. supra, pp. 133-134; LEM 64-65; Caminos, LEM pp. 247-250.

1008 KRI I: 241-242; J. Barns, "Three Hieratic Papyri in the Duke of Northumberland's Collection," JEA 34 (1948): 35-46.

1009 KRI II: 894-895, esp. 895, 1; P. Leiden | 368; J. J. Janssen, "Nine Letters from the Time of Ramses II, "OMRO 41 (1960): 45-46; Bakir, Epistolography, pls. 16-17, XXII. 
A text from Deir el-Medineh dating to Ramesses II likewise records the receipt of the šmw as emmer, delivering several thousand khar of grain to a granary, perhaps that of Pharaoh. ${ }^{1070}$ $P$. Gurob Fragment $L$ is clearly dated to the very close of the reign of Ramesses $\|$ and the first year of that of Merneptah ${ }^{1071}$ and consists of lists of quantities of grain delivered. Most of the quantities in Fragment $\underline{a}$ are multiples of $12 / 4$ khar, those of Fragment $\underline{b}$ also include figures of 100 and 114 . It is stated in both texts that the corn is $\check{s} m w$, in several cases referred to as "interest corn" (Fragment a, 1,7; 2,3; Fragment b, 3,6; 3,9). 1072 The assessments will have been annual, as it is stated that the grain of Year 67 was reported and delivered in Year 1. Some of the grain seems to be derived from small holders (as in P. Gurob M and the Papyrus Wilbour apportioning paragraphs), the corn would appear to have been recorded as having been turned over to the "granary of the Mayor of the Southern Lake, Imn-m-ipt" (I. 2,2). It was unsurprisingly loaded onto cargo vessels for transport. The text is quite fragmentary, but it would appear that annual assessments were carried out in Year 67, and that the assessment corn plus a penalty was collected in Year 1 (which was the same year). Either this corn or other corn was delivered to the granary of the Mayor. This was then transported elsewhere, ${ }^{1073}$ the Mayor's granary having merely served as a an intermediary point.

O. Petrie $47^{1074}$ appears to mention the "šmw of Pharaoh". It would be rash to speculate on the purpose of the text.

The undated and extremely fragmentary $P$. Gurob $M^{1075}$ mentions the usual titles associated with the šmw ("agents", "cultivators", "citizenesses"), 1076 but also specifies twice (II. 9; 10) the "corn of inyt of arrears (hr-s; $)^{\prime}$ of a citizeness and a cultivator, seemingly implying that this was šmw corn. Whether this implies that the inyt was šmw is probably doubfful; inyt was probably used here merely meaning "brought", but the construction is unusual.

šmw does not appear in $\mathrm{O}$. Gardiner $86\left(\right.$ H.O. 82,3) ${ }^{1077}$ where the obligations of 8760 men are specified as being 200 khar each. It may however be specifically mentioned in P. Bologna $1086^{1078}$ where the same obligation per man is stated and the missing man's

1070 KRI VII: 175-176; O. Gard 227

1071 Gardiner, RAD, pp. 30-32; Gardiner, Wilbour II: 206-207. If $(2,5)$ should be read 1 sht 19,1 sht $18(2,1)$ is the last official day of the reign of Ramesses II (ct. Hornung, Untersuchungen, p. 95 n. 3)

1072 There is little evidence of "interest" from ancient Egypt, and Sir Alan (Gardiner, Wilbour ll: $206 \mathrm{n}$. 10) summarizes the situation well in confirming that the Coptic indicates ms as the elymological source, but that the GraecoRoman sources do not support the intermediate step with solid evidence. If "interest" is interpreted, this merely gives the "rate" at which the "penalty" would be given, but the word - for the Egyptians - would be the same. S. Allam ("msw = Kinder/Volksgruppe/Produkte/Abgaben," SAK 19 [1992]: 1-13) suggests that interest is not demonstrated for the Pharaonic period, while Quack (Ani, p. 100-101) understands that the word was used with this meaning in the Pharaonic period. The context certainly indicates that property in general - and not grain should increase in quantity and value.

1073 As the Papyrus reportedly comes from Gurob (Kom Medinet Ghurab), it may be assumed that the scribe in Gurob was responsible for noting ifs origin and departure, and that the scribe aboard the vessel will have recorded its destination, meaning that the latter information is on another papyrus which we do not have for at least to my knowledge).

1074 KRI III: 261-262; H.O. pls. 17, 3; 114,4

1075 Gardiner, RAD, p. 33.

1070 Cf. J.-M. Kruchten, "L'évolution de la gestion dominiale sous le nouvel empire égyptien," in Lipinski, State and Temple, pp. 517-525

1077 KRI III: 138-140; H.O. 81-82; cf. supra, pp. 143ff. n. 408

$1078 K R I N: 78-81$ 
"šmw will be counted as a loss against you, if he is alive. "1079 This quote must however be qualified by the preceding sentence, where it is stated that a Syrian cultivator has been given to the letter's recipient for "the months of šmw." Thus, the potential loss of this man's šmw could either be his "summer" or his "harvest". ${ }^{1080}$

The expression šmw pš gave its name to the paragraphs rendered as "Apportioned harvesttaxes" in the translation and commentaries to P. Wilbour. ${ }^{1081}$ They are almost exclusively the fields of smaller temples, and characterized by being mainly lands tenanted by less exalted members of the bureaucracy, stable-masters, charioteers, priests, the occasional scribe, and quite a few women (who may be widows having inherited the land from their husbands, fathers, brothers, etc.). Under these paragraphs are also khato-lands which appear to take the form of normal domains, but it would appear that there is a high (but not complete) degree of correlation between the presence of fields with the usual type of domain assessments which are frequently khato-lands, associated with posh-entries in these paragraphs. As the Turin Taxation Papyrus ${ }^{1082}$ indicates a correlation between šmw and khato-land, and $P$. Valençay 1083 supports the contention that the income from khato-land could be assigned to the temples, the general tendency is to identify the šmw of P. Wilbour with temple income, potentially as a kind of Pharaonic support, or by means of Pharaoh's resources.

šmw appears twice in the "Turin Taxation Papyrus". 108480 khar of emmer are collected in association with grain from khato-lands of Pharaoh $(1,7 \& 2,4)$. Direct responsibility for the grain is borne by the policeman who turns it over, but it would appear that overall responsibility for the delivery belonged to various officials of the temple of Sobek. The grain was turned over to the Mayor of West Thebes, perhaps for the use of the necropolis Gang $(1,7 ; 2,5)$. Grain turned over to the Necropolis Scribe by the Cultivator Sih-t3-nfr is classified as "his šmw" $(1.3,12)$, and is specified as being a "detail" of the grain collected from the temple of Khnum and Nebu at Esna $(1.3,11)$. It is likewise furned over to the mayor of West Thebes.

P. Turin 2106 [Frag. 387] ${ }^{1085}$ records that 10 khar of emmer were received from a w'b-priest "in the temple of Amun" as šmw (I. 4). This is added to some other grain, some from khatolands of Pharaoh managed by a Ramesside mortuary temple.

\footnotetext{
1079 Gardiner, Wilbour II: 115.

1080 It is suggested elsewhere here that this is the bikw obligation, cf. "bikw" and "bikw-rmt", supra, pp. 237ff.; $258 \mathrm{f}$.

1081 Gardiner, Wilbour ll: 24-25.

1082 Cf. supra, pp. $170 \mathrm{ff}$

1083 Cf. supra, pp. $136 f$.

1084 Gardiner, RAD, pp. 35-44; Sir Alan Gardiner "Ramesside texts Relating to the Taxation and Transport of Corn," JEA 27 (1941): 22-37; supra, p. 172.

1085 Cerný, Notebook, 16, p. 81.
} 


\section{Private Propaganda}

In the Dynasty XVIII tomb of P3-hry, the religious text at the back of the tomb assures the deceased that "šmw shall be delivered to you from the harvest." 1086 Another pious Dynasty XVIII inscription records that the "šmw will be brought from the harvest (whizyt)". 1087

$H^{c}$-m-h the šmw of the Great Nile of the first Jubilee festival" of Amenophis III. He records a total of 3'333'300 mc. of corn, for year 30 (which would explain the numerous "3"s), which he asserts is a surplus. If the text is given credence, this includes the payments from the entire empire from Cush to Nahrain. ${ }^{1088}$

šmw is mentioned in the Bilgai stele, ${ }^{1089}$ where the unidentified author states to the Royal Scribe and Steward of the Mortuary Temple of Siptah in the Estate of Amun, P3-b3-s;, that he fulfilled the šmw and the šsyt identifying both as his own personal htri (ll. vs. 15-17). His šmw is also identified as $70^{\prime} 000$ units ${ }^{1090}$ of grain, while he actually rendered up "140'000, a surplus of $70^{\prime} 000^{\prime \prime}($ I. vs. 20). It would appear logical to assume that the payments were all turned over to the Estate of Amun, perhaps more specifically, the Mortuary Temple of Siptah. The inscription recording the rewards of the efficient High Priest of Amun, Imn-hip, dating to the reign of Ramesses IX, ${ }^{1091}$ details fiscal responsibilities using most of the words discussed in this study. It would appear that each item is understood to be a specific term with a specific meaning land it is interesting that the word htri is not used, as this term seems occasionally to subsume the others), The actual material is understood as being delivered directly to the temple (with the exception of the inw and tpw- $\underline{d} r$ which seem to have been delivered to Pharaoh). The presence of šmw here merely underlines that it was paid directly to the temples. It is not further defined. That he could double it implies that it is only a proportion of the yield. That he could only double it implies that it was a high proportion.

\section{ForeIGN REVENUE}

\section{Administrative texts}

The lachish bowl with two hieratic inscriptions (one inside, one outside) deals with šmw from a regnal year 4. ${ }^{1092}$ The object has been dated to the reign of Merneptah, and it has been asserted that the name Lachish was written on the bowl. ${ }^{1093}$ The toponym is definitely

\footnotetext{
1080 Tylor, Paheri, pl. 9; pp. 29-30; Urk. IV: 115,11-116,15.

1087 Urk. IV: 499,$4 ; \pi 127$.

1088 Urk. IV: 1841, 16; $\Pi$ 57; Helck, Verwaltung, pp. 389-390.

1089 Cf. supro, pp. 182ff.; KRI IV: 343,7-13; A. H. Gardiner, "The Stele of Bilgai," ZÄS 50 (1912): 49-57.

1090 Whether oipe or khar is not clear.

1091 Cf. supra, pp. 186f.; KRI VI: 455-458; W. Helck, "Die Inschrift über die Belohnung des Hohenpriesters I/mnhtp," MIO4 (1956): 162-178

1092 KRI IV: 39, 10-12.; . Cerný, "Report on Inscriptions," in: Tufnell, lachish IV: 133; pls. 44, 47. Cf. O. Goldwasser, "The Lachish Hieratic Bowl Once Again," Tel Aviv 9 (1982): 137-138; O. Goldwasser, "Hierctic Inscriptions from Tel Sera' in Southern Canaan," Tel Aviv 11 (1984): 77-93.
}

1093 Ahiluv, Toponyms, p. 130: "a reading of the name as Lachish is not improbable". Cf. M. Weippert, "Lachis," RLA VI: 412 for doubt. 
not Lachish $\left(r-t y-s_{3}\right.$, not $\left.r-k y-s^{3}\right)$, while the reign is probably correct. The payment was definitely expected in wheat, but the units and quantities and the time frame are not specified. This is the only administrative record recording the collection of the šmw from outside Egypt.

\section{Royal Propaganda}

Thutmosis III claims to have collected šmw from wretched Cush ${ }^{1094}$ and Wíw3t. ${ }^{1095}$

The Syrian šmw collected after the siege of Megiddo amounted to 207 '300 khar. ${ }^{1096}$ As Syria was not at this time under the rule of Egypt, this could be interpreted as referring merely to the captured harvest. The preceding sentence states however that the sht- and ihwt-fields were assigned to the controllers of the palace to harvest. This implies that specific types of fields were responsible for supplying the $\breve{s} m w$ in this case, and that the fiscal term is meant.

\section{CONCIUSION}

The šmw was a specific term for the harvest. In certain cases, it obviously meant a proportion of the harvest, as in the paragraphs of the Wilbour Papyrus. It does not seem to have meant the produce of the domains, where workers may have been expected to produce 200 khar/ head. Virtually all of the sources concur in suggesting that it was destined for the temples, and that it may have been submitted to them from secular authorities working temple fields, sacerdotal or secular officials managing khato-lands, and from tenants, who are specifically identified as beneficiaries of the system, i.e. low level employees of the state. 


$$
t p-\underline{d} r t
$$

THE WORD tp- $\underline{d} r t$

The term $t p-\underline{d} r t$ is one of the most obscure terms, meaning literally "head and hand"?

INTERNAL ReVENUE

Administrative texts

P. Berlin $3040 a^{1097}$ is a badly preserved letter, where the word $t p$ - $\underline{d} r$ appears in an obscure context.

(vs. 4) to [...textual loss...] he is [...textual loss...] (vs. 5) scribe I'h-ms commanded [...textual loss...] Twi3, the Mayor of the Western City, R'-ms. I dismissed his tp- $\underline{d} r t$ because of the record (vs. 6) of account [...textual loss...] And I sent to let her know likewise. Do not let it be done for him [<another time>?....] (vs. 7) [(?)] to the effect that I have caused 700 khar of grain from your $t s w$-prt be remitted for [...textual loss...]

Sir Alan Gardiner drew attention to the quintessence of this text half a century ago, saying that "a miserably broken passage makes it obvious that [one of the parties to the letter] possessed authority to remit or alter the tax assessment of [...] Ra'mose, prince of the West of Thebes". ${ }^{1098}$ Sir Alan indicated that he thought that the letter was written to $\mathrm{P}_{3}-\mathrm{sr}$, but failed to identify the precise $\mathrm{P}_{3}$-sr, suggesting a contemporary of the more exalted $\mathrm{P}_{3}$-sr, and the published text now assigns this letter to an otherwise virtually unknown $\mathrm{P}_{3}$-sr, Mayor of East Thebes. ${ }^{1099}$ It was obviously the author of the letter - and not its recipient - who remitted the tp-drt, and the tsw-prt obligation of 700 khar. ${ }^{1100}$ There is no reason to relate the $t p-\underline{d} r t$ and the $t s w$-prt obligation as signifying the same item. There is however equally no reason to believe that the $t p-\underline{d} r$ was annulled, as the reason for remission was a check with the records, and therefore, it may be assumed that $R^{c}$-ms, Mayor of West Thebes did in fact actually pay a $t p \underline{d} r$.

1097 KRI III: 158-161; A. H. Gardiner, "A Later Allusion to Akhenaten," JEA 24 (1938): 124.

1098 JEA 24: 124.

1099 KRI III: 157.

1100 It is rather peculiar that the other reference to a tsw-prtobligation is likewise for exactly 700 khar (KRI IV: 81,2) Although it is generally assumed here (cf. supra, pp. 144f. n. 408) that we understand this correctly as signifying an obligation of 200 khar per man and 100 for the stripling (as cf. H.O. 82, 3), the coincidence is worth bearing in mind. 
P. Gurob Fragment $G$ lists a number of different types of cloth as having made up the $t p-d r t$ of the Opening of the Year Festival. ${ }^{1101}$ Sir Alan Gardiner assumed that these were withdrawn from the storeroom of the Harim at Mr-wr, 1102 but the reference to "this house" suggests that a temple be considered as equally probably having been the possible source. ${ }^{1103} \mathrm{Sir}$ Alan also assumed that the clothing was produced at the Harim, but there is no evidence to substantiate this. It is clear only that the amounts of clothing are quite insignificant in terms of mere numbers, but the presence of 15 items of $m k$-quality clothing should be noted, as the list of royal gifts in P. Harris I (14b, 2-5) a total of 3 items for Thebes. ${ }^{1104}$ In some unclear fashion, the $t p-\underline{d} t+$ is associated with an inw-obligation.

P. BM 1040' states that a $t p-\underline{d} r$ t obligation was rendered by the Prophet Nb-ntrw of the Temple of Horus Behdety to the "Chief Taxing Master", and that it consisted of a festival cow, 4 kite of gold, 1 smooth cloth $\underline{d}^{3} y$-garment, a cloth, and an ox. ${ }^{1105}$ This $t p$ - $\underline{d} r$ seems to be subordinate to the heading at the beginning of the text, which characterizes the objects assembled as having been $p^{3}$ inw. ${ }^{1100}$ Above all, this text confirms that the various types of payments were distinguished according to origin and not destination or type, for the same items recur in the text without this (or - admittedly - any other precise designation).

P. IFAO sans numero A. 1,11 records 15 deben of msdt-eye-paint as the "tp-drt of the Mountain Chief Knr". 1107 The text makes it clear that Knr was responsible for deliveries of gold and msdt eye-paint, and that large quantities of the former were turned over to the treasury of the Estate of Amun (e.g., A ro. II, 11 ) and the High Priest of Amun (e.g., A rio. II, 15), but it hardly explains why the term $t p$ - $\underline{d} r$ appears here. ${ }^{108}$ As noted infra, the $t p-\underline{d} r t$ was given by the High Priest of Amun, Imn-hip, to the Pharaoh.

In the fragmentary Tax-Lists of the Royal Canon of Turin, ${ }^{1109} t p-\underline{d} r t$ is the most commonly written fiscal term employed, being written out thrice as frequently as the other most common fiscal term $\left(15\right.$ instances to 5 for $\left.\tilde{s}^{2}, y(t)\right)$. They list a tp-drt of 2 silver kite $(2,5)$, as well as the

$1101 R A D, p .20,6 f f . C f$. supra, p. 149. It is impossible to estimate the amount of mk-quality clothing delivered by the temple dependenis, as it is not itemized (cf. e.g., 12a, 13).

1102 RAD, p. $x$

1103 The Scribe Seti is somehow related to the collection of these objects $\{R A D, p .20,9)$, and he is further specified on the verso as having been the "Royal Harim Scribe of this House", which means that he could have been primarily assigned to the Harim, but it would be more logical to suggest that his association with the "house" was more important. In either case, we cannot judge the exact nature of his role: only that the institution in question was rendering up a tp- $\underline{d r t}$.

1104 For a note that $m k$-cloth was appreciated across the Near East, cf. E. Edel, "Zwei Originalbriefe der Königsmutter Tüja in Keilschrift," SAK I (1974): 122.

1105 J. J. Janssen, "Requisitions from Upper Egyptian Temples (P. BM 10401)," JEA 77 (1991): 79-94, esp. pp. 80; 82.

1100 It is worth recalling that the scene involving the counting of livestock in the tomb of $P_{3}$-hry /cf. Tylor, Paheri, pl. 3 , and supra, pp. 137f.) was the only temple activity in which $P_{3}$-hry was involved.

1107 Y. Koenig, "Livraisons d'or et de galène au trésor du temple d'Amon sous la XXe Dynastie," in Hommages Sauneron, pp. 194;216, pl. 34. Koenig attributes the tp-dit as a payment to the treasury of Amun, as he ciles Imn-htp (cf., supra, pp. 186f.) who was praised for having delivered it to Pharaoh.

1108 I believe that Koenig is correct to translate inw (e.g., Hommages Sauneron, p. 193) as "brought" rather than "tribute" or "gift", as the word always seems to be merely the verb and not to be the term discussed supra, pp. $211 \mathrm{ff}$. This means that $t p-\underline{d} t$ is the only fiscal term used in the text, and that it is applied to msdmt-eye-paint, which has been identified with bikw-payments, elsewhere, cf. supra, p. 244.

109 Cf. supra, pp. 159ff. 
tp- $\underline{d} r t$ of a deputy $(1,2)$, some undetermined $t p$ - $\underline{d} t t^{\prime} s(2,19 ; 3,15)$, the $t p$ - $\underline{d} r t$ of a mayor (seemingly connected with money and cattle, 3,6), more deputies $(3,7 ; 6, x+14)$, another mayor $(3,13)$, an overseer $(4,6)$, and a controller $(6, x+19)$. There are two references to the "tp-d $d r t$ of each of them" $(4,13 ; 21)$, and another unrelated mention of a tp-ditt of 2 kite of silver $(5,4)$.

Roughly half of the instances are written in red ink (7 preserved) and half in black ink (8 preserved). In every case preserved in the Turin Canon texts, the term is associated with a secular official where any reference is preserved. In no case is the term preserved in a context suggesting a quantity of grain, although animals are mentioned. Insofar as one can refer to statistics in a text as fragmentary as the Turin Canon, it is significant that the term is thrice associated with quantities of precious metals, 2 kite of silver appearing twice.

$t p$ - $\underline{d} r t$ is never written as a systematic entry followed by ditto marks (as, e.g., bikw and šsyw). The term appears spread all over the page: at the beginning of lines, and in the middle of lines, and at the (seeming) end of lines, yet it never appears as a heading: it appears to be strictly a line entry type category, rather than an overarching one. tp- $\underline{d} r t$ is invariably written with an indirect genitive, never a direct genitive, and never with a suffix. Where other words are modified with $m t r, t p-\underline{d} r t$ is never modified.

tp- $\underline{d} r t$ is written in a context $(3,13-3,14)$ where it is warranted to conclude that the reference to an obligation to Pharaoh may be associated with it. (This naturally fits well with the other uses of tp- $\underline{d}$ t which indicate that it was a payment to Pharaoh, which went through the temples).

All this can be used to suggest that in the context of the Turin Canon, the tp-drt was (1) a payment exacted from officials, (2) which was not a significant fiscal instrument, but rather (3) a designation for a specific type of payment, and (4) that it could be made in the form of metal, which is otherwise rare both in the Turin Canon and elsewhere.

\section{Private Propaganda}

The High Priest of Amun, Imn-hitp under Ramesses IX, separately from the other fiscal terms (text II:10-11), tpw- $\underline{d}$ t and inw are mentioned together (text II:13-14), as "the material support ( $p$; ' $n h w$ ) of Amonrasonther which you cause to be brought to Pharaoh, thy Lord". The inscription recording the rewards of the efficient High priest of Amun, Imn-htp, 1110 details fiscal responsibilities using most of the words discussed in this study.

And from you are the inw and tpw- $\underline{d} r$. the material support ${ }^{111}$ of Amonrasonther. (12) [<lt is > your [<causing that one bring to > $]$ Pharaoh, your lord what is done by a good and efficient servant (13) [<of Phar > ]aoh, his Lord. Being strong in order to act efficiently for Amonrasonther (14) the Great God, (and) in order to act efficiently for Pharaoh, his Lord. [etc.... ]"1112

1110 Cf. supra, pp. 186f.; KRI VI: 455-458; W. Helck, "Die Inschriff über die Belohnung des Hohenpriesters "Imnhtp," MIO 4 (1956): 162-178.

1111 "Provisioning" or "Victuals"? cf. P. Greg, supra, pp. 152ff. and Janssen, Commodity Prices, p. 458.

1112 KRI VI: 456,7-8. 
A similar speech is less well preserved:

$(20) . .$.$] the inw, tp-drt material support. It is your causing that one bring to the royal$ warehouses $[\ldots] 1113$

In each case, the recipient is clearly either the Palace or the Pharaoh, and the origin is clearly the material wealth of the temple.

\section{PREVIOUS DISCUSSIONS OF THE WORD}

W. Helck noted that cattle ${ }^{1114}$ and geese ${ }^{1115}$ were favourite $t p$ - $\underline{d} t$ t deliveries, and associated it with an office tax, referring to the illustrations in the tomb of $R h-m i-R^{c}(T 100) .1110$ These suggestions cannot however aid us in understanding the term.

J. J. Janssen has rendered the expression as "Head-tax (?)," suggesting that the assumption that it represented some kind of office-related exaction was not contradicted by the greater part of the evidence. ${ }^{1117}$

\section{CONCIUSIONS}

The Imn-htp text associates inw and tp-drt, without specifying their significance while the Gurob text identifies the actual items. As these items in P. Gurob $G$, appear to be the counterparts of the unusual use of inw in P. Gurob (vs. 1b,5; supra, pp. 146ff.), where inw

1113 KRI VI: 458,9 10

1114 W. Helck, "Abgaben und Stevern," $L \ddot{A}$ I: 9. His references are to the Turin Canon (where there is only one, and the fragmentary line $[4,25]$ cannot be restored to read $t p-\underline{d} t$ t as the item is modified by a suffix, which is never used for to- $d r t$ in the Turin Canon, so that $\check{s}^{3} y t$ is the most probable restoration, with col. 7 continuing this); "RAD 65,1. 3" (regardless of how this is interpreted there is no way to find a tp-d $d t$ from this source); and "Hayes in: JEA 40, 1960, Tf. 10 Nr. $8^{\prime \prime}$ where there is no tp-drt either (cf. W. C. Hayes, "A Selection of Tuthmoside Ostraca from Ddr el-Bahri," JEA 46 [1960]: 29-52). References to cattle however are confirmed from both the Turin Tax Lists and P. BM 10401, but it was certainly not the main item.

1115 Citing the Royal Canon 2,3 and Urk. IV: 1554, 11, where the tp-d $r$ t is not mentioned.

1116 L $\ddot{A}$ I: 5. He dates IT 100 to Dynasty XIII, probably on the basis that the Instructions for the Vizier date to that period, and that the representations must likewise be assigned this origin. Iconographically the argument is unusual (given the dearth of iconographic material from private tombs at that date) and Boorn (Duties, pp. 375 376) dates the Instructions to the New Kingdom (cf. supra, p. $178 \mathrm{n} .532$ ), so that this argument may ultimately be circular.

To my knowledge the fiscal term $t p-\underline{d} \hat{t} t$ does not appear before the Ramesside Period. In $\pi 100$, the tomb of Rhmi-R' (Davies, Rekh-mi-Réc, pl. 60) the word is used twice in connection with work on statues, and the first time potentially in connection with divine offerings, but the second instance dispels this illusion, as it is the caption to a reference in the middle scene. I would go further than Janssen (JEA 77: 87 n. y) and contend that Sethe's restoration cannot be maintained without additional evidence, and that the term is not relevant to the fiscal system If $t p$ - $d r t$ had a fiscal meaning in the tomb of $R h-m i-R^{c}$, then it would doubtless be employed in the captions to the scenes of deliveries. This does not negate the relevance of the possibility that cattle $t p$ - $\underline{d} n t$ 's could have been paid, but it centainly demonstrates that this was not the term in Dynasty XVIII.

1117 J. J. Janssen, "Requisitions from Upper Egyptian Temples (P. BM 10401),"JEA77(1991): 82; 87-88. There is no reason to associate the "Chief-Taxing-Master" $(3-n-s t)$ with the secular administration, and thus the assumption of "government" involvement is unnecessary. 
appear as items of daily use (as opposed to the type encountered in the usual "tribute" texts), the two texts may refer to the same type of ordinary deliveries, and by no means to an assessment related to an office holder. P. Gurob $G$ specifically associates them with the "Opening of the Year Festival", while Imn-htp is specifically stated to turn over the material support of Amonrasonther to Pharaoh.

P. B.M. 10401 suggests likewise the acquisition of things for a specific purpose, and not a type of regular income, but this is speculative. One should not exaggerate the significance of a "festival" cow, but Janssen quite correctly withdraws support from the concept that these were necessarily "taxes" for which there is no evidence. ${ }^{1118}$ There does not seem to be any reason to believe that this is anything except part of an interdepartmental transfer where some articles are collected, most probably for transport to Thebes, and most probably for a festival. The failure of the scribe to note a date suggests that these payments were not being recorded in a serious fashion. P. Berlin 3040a indicates that careful records were kept of the $t p$ - $\underline{d r t}$, and that it could be adjusted accordingly. Obviously, were the burden onerous and annual (for which there is, e.g, no evidence) the dates would have been recorded as well.

Thus, the key elements, for the texts where tp- $\underline{d} t$ is in any way identifiable are the confirmation that (1) the tp- $\underline{d}$ rt was withdrawn from a temple, or the employees thereof; (2) that it consisted of valuable cloth items, but also metals and minerals (but not grain); (3) that there is no evidence of it prior to the Ramesside period; and (4) that it is not mentioned as being assessed on a regular basis. On the other hand, we find it associated with both temple officials and secular officers, and find that precise records are kept, but without regard to the calendar, but that it can be remitted on the basis of these records., all of which indicates that the $t p$ - $d r t$ was a veritable kind of tax, applied to specific officials, payable with valuable materials and deliverable to Pharaoh, and that Helck's association with the term as a kind of "office tax" may be as close as any is possible until additional materials come to light. 
. 
PART IV

Conclusions 



\section{PHILOLOGICAL SumMary}

A fiscal system is an administrative system which represents the practical expression of the ideological conception of a state. Therefore the notes jolted down on pieces of papyrus in offices do not necessarily reflect the concepts as well as the propaganda inscriptions, which may conceivably have been carefully drafted for public consumption, and thus the use of the various terms in the publicly accessible inscriptions are the best point of departure for a philological summary of the results of this work. The office notes are incomplete in that they leave out many of the details that would aid us, and the monumental inscriptions are not intended to be used as administrative documents, so that a balance is impossible. Each category must be used for its own sake, but the dilemma of interpretation remains.

The principal elements of the fiscal vocabulary as preserved are inw, b3kw, htri and šsyt. 1119 It is however relatively clear that the source material indicates a preponderance of temple activity, while one tends to suppose that the King must have had still larger resources as he supplied not only the temples, but the rest of the system.

The official inscriptions of the New Kingdom convey the image of the inw as the voluntary tribute paid by foreign countries as an expression of respect for Pharaoh as the head of State, whose victories over foreign countries were guaranteed by the gods. ${ }^{1120}$ inw probably meant "trade goods", "presents" and "tribute" in international relations.

inw also appears as a specific kind of domestic income which the lower level officials reported to the Vizier as the representative of Pharaoh, but in the same context it is also associated with the divine offerings. ${ }^{1121}$ inw also appears as a specific label for materials transferred from Pharaoh personally to the temples. in w also appears in administrative texts as routine income delivered directly to institutions acting for temples or in the name of temple officials.

Those delivering the inw appear to include the elite and low level officials.

The inw would appear to have been the concrete expression (i.e., goods) which were rendered up in fulfillment of the htri-levy obligations, whether to the temple or Pharaoh.

All of this confirms the historical interpretation of the development of the Egyptian state, if we assume that the earliest Kings basically ruled Egypt as their own family property, collecting "tribute" from their dependents, and expressing their appreciation to the gods as during the New Kingdom the Pharaohs tended to turn over the spoils of war to the gods.

Thus, the original fiscal system of Egypt will have been one in which the people delivered their goods in exchange for the security guaranteed by the protection of the king and the

1119 For inyt, tp-drt, smmw and $h q$ it, the reader is referred to the relevant chapters, as the present chapter could do no more than briefly summarize the brief summaries there.

1120 Tribute and plunder are difficutt matters for those not directly involved. It is conventionally assumed that "plunder" is acquired by conquest, and that "tribute" is either the result of military conquest, or the threat thereof. Rendering h'qt as "plunder" is probably justified, but, like inw, higt could as easily mean "tribute" or probably "presents". Cf. inw, supra, pp. 121-236.

1121 Supra, pp. 178ff. 
gods, which also enabled the king to enforce payment. ${ }^{1122}$ This ideological attitude apparently remained long after the development of a sophisticated economy. Use of the word inw may have declined in the domestic economy, as the fiscal terminology became more sophisticated. Due to its ideological content, inw continued to be used prominently in contexts including foreigners, even if the Egyptians customarily paid for their acquisitions from Syria and Punt. Probably for historical reasons, some of the income which was eventually turned over to the temples, or transferred from the temples to the government, was also termed inw.

Internally, it probably denoted the oldest and most important types of income received by the King. It appears superficially to be relatively insignificant, but it is not well documented in the material preserved. It is quite evident, that if inw in Egyptian meant something like "tax" or "tribute", the Egyptians will have awarded a considerably higher propaganda role to inw coming from foreign sources than local ones, as it signified sovereignty. The rarity of the word in the administrative documents may be related to the fact that a great proportion of our documentation seems to reflect the temples more than any other part of the administration. It is also possible that this merely reflects the increased use of other words, such as bikw.

The official inscriptions of the New Kingdom record that bikw payments from Asia and Nubia supplemented the in w from abroad. In concrete terms, bikw means "products" in the same fashion that inw means "goods", and the term is derived from the official domestic fiscal vocabulary, the official term probably properly being one of the family related to bikw-rmt, meaning "production of a man (or men)". The domestic terminology was once again applied to the foreign countries, and its use as "tax" is just as much a misnomer as terming inw "tribute". In contemporary international relations, the dowry of Ramesses II's Hittite wife is called bikw, which was merely the modern word for inw in this context, and fiscally meaningless, as it was part of a reciprocal arrangement.

Therefore, both from abroad and within Egypt, bikw specified concrete obligations which were payments. These were the responsibility of individuals in certain contexts, and could be paid to government ${ }^{123}$ or temple authorities. " 224 Craftsmen could carry out tasks or provide objects to temples or Pharaoh ${ }^{1125}$ under the title of $b^{3} k w$. The donkey $b^{3} k w$ could be construed as a type of "fine", "fee", or "tax" if official, "rental" if private commercial. The boat bikw mentioned in the royal propaganda inscriptions seems to be similar. The documentation does not suffice to make any statement concerning the proportion of the population obliged to submit $b_{3}^{3} \mathrm{kw}$-"taxes" to the temples or the government, nor can any specific proportion of income, wealth or time be identified in these cases. Only the statement of the miscellany that

1122 These wild generalizations can be confirmed to some extent by the references to income of the first Kings of Egypl cited by Helck, Winschaftsgeschichte, pp. 24-25. After Scorpion and Narmer the tax vocabulary of the First Dynasty was unified, so that Aha, Djer, Wadj and Dewen of the First Dynasty received inw.

1123 This was very frequent at e.g., Deir el-Medineh.

1124 Cf. supra, p. 238; P. Munich 809 (Allam, HOP Tafelteil, pls. 102-103); W. Spiegelberg, "Ein Gerichtsprotokoll aus der Zeit Thutmosis' IV.," ZÄS63 (1928): 105-I15.

$1125 \mathrm{Cf}$ supra, pp. 242f.; KRI IV: 517-522. 
the scribe's "bikw was in writings" suggests that bikw was a nearly universal type of payment. ${ }^{1126}$

$b_{3} k w$ would seem to be simply work carried out as part of a reciprocal arrangement with remuneration provided. The Gang at Deir el-Medineh was paid to carry out their bikw, which was the excavation and decoration of the tomb. But they were employees with an unusual status.

The smdt of the tomb delivered their bikw, but there is no evidence of their being paid, even though the "slaves" were occasionally paid. If this was merely a part time obligation set on some peasants in the neighbourhood, it would correspond to another part of the social and economic system, for they would be neither employees nor temple dependents. Whether they also had to pay some kind of "taxes" on their lands - if they had any - or the lands where they worked is unknown. These bikw-payments could also be the htri of another official altogether. The use of "tax" for translating b:kw is only justified in very specific contexts. In official texts it generally refers to an "obligatory payment", in kind - the products of labour - but not necessarily the kind of things that this particular peasant did.

The term bikw appears in administrative and public inscriptions, but there was a fiscal term bikw-rm! with a specific meaning and thus what frequently appears as bikw was most probably officially designated the $b_{3} k w-r m !$. The $b^{3} k w$-rmt of the cultivators may have been the $200 \mathrm{khar} /$ worker assignments for grain production on temple lands, but the proportions do not actually support this contention. ${ }^{127}$ The incredible surplus produced by the author of the Bilgai Stele indicates that another kind of bikw-rmt was, in principle, a proportion of the production that was turned over to the temples, i.e., a "tax". Such a payment may have been required of craftsmen - lapidaries and silver smiths, and this might be termed a tax, although it went to the temples.

Officials of both temples and government were obliged to provide b;kw, but this will have been part of their duties as officials, and it is probable that the concrete goods received were the bikw, and that these were then regarded as the šsyt or htri of an official, which will have consisted of products $\left(b_{3} \mathrm{k} w \mathrm{w}\right)$ which were assessed at a set rate, the htri.

Used as a verb, htri can mean "levy" in the sense of "to assign" or "assess". As a noun, it can mean "lev", in the sense of "assignment" or "assessment", and definitely expresses an abstract obligation to render certain concrete articles to a higher authority, i.e., a specifically fiscal significance, which was occasionally equivalent to šzyt. In general htri seems to subsume

1120 P. Anast. V, 17,2; LEM 65,5-6; cf. supra, pp. 133-134.

1127 Cf. W. Helck, Wintschaftsgeschichte, p. 246. There will have been several rates at which fields were assessed, and unfortunately we cannot be sure about the process. But it could probably be postulated - but can hardly be demonstrated - that the workers and officials divided the remainder of the production among themselves. The officials for certain types of fields may have been responsible for production of $200 \mathrm{khar} /$ worker, and the workers on such fields were presumably responsible for the delivery of 5 or $71 / 2$ or 10 khar/aroura (cf. Gardiner, Wilbour, II: 28-29). The surplus was thus probably at their disposal, and thus their benefits from the reciprocal or contractual arrangement. There must however have been a great deal of land which was covered by another type of administration. Aside from the small tenants listed in the Wilbour papyrus, we have the nmhw, but we do not know anything about their arrangements, except that they apparently paid to Pharaoh rather than to the temples (cf. Decree of Horemhab and P. Valençay, supra, pp. 137; 188f). 
$\check{s}^{3} y{ }^{11}{ }^{128}$ while being used abstractly, but the htri can also be more specific. From the official standpoint htri applied to people ${ }^{1129}$ would thus imply a b3kw type obligation on the people, which was the htri of the official.

htri appears to have had several fiscal meanings, with the verb exclusively fiscal, referring exclusively to activities relating to arranging income on a fiscal (as opposed to administrative) basis. The noun seems to refer to (a) "supplies in kind", (b) "dues" and (c) "assessment" or "levy".

The English word "levy" means "to impose or collect" and thus matches the difference in meaning between the verb htri, "to assess" and "to collect" while the noun could signify "dues", which could be interpreted as the obligation (1) imposed by Pharaoh in terms of deliveries to Pharaoh or the temples, and (2) of Pharaoh to provide for his dependents. htri was probably intended to delimit (assess) a portion of the produce (and thus the equivalent of a "tax"). htri thus signifies "tax" in many cases, and apparently a type of "income tax", payable to the temples or the government. The htri of the temples was however actually produced by contracted labour. The verb htri meaning "assess" would appear to be the fiscal term par excellence for assessing what is due, whether šsyt, htrri, or b3 3 kw. šs.yt identifies an abstract obligation from an official to the administrative apparatus, of the temple or government. The šzyt can be awarded to the temples by Pharaoh, but temple income can also be termed šsyt. It does not seem to represent a specific class of goods, as precious metals and stones, cattle, garments, and other items are included. It seems to be employed with regard to both domestic and foreign articles. The šsyt obligations are determined by the htri assessment.

The htri assessment was also applied to the šmw which was a specific term for the harvesttax. In certain cases, it obviously meant a proportion of the harvest, as in the apportioned harvest taxes of the Wilbour Papyrus. ${ }^{1130}$ It could be collected from small holders and from the khato-lands of Pharaoh.

One difficully with the administrative system is that the terms inyt, inw, and bikw were used loosely. inyt simply refers to things brought as provisions or materials necessary. inw can refer to income which is generally the equivalent of "taxes", but when writing the Egyptians did not perceive it in that fashion. That inyt does not appear in propaganda texts probably indicates that if was not an official designation for a specific type of delivery, although local scribes will have probably understood it to have some particular significance. ${ }^{1131}$ The inw

$1128 \mathrm{Cf}$. supra, pp. 194ff. In P. Harris I, the bikw š3yt of the dependents are termed the annual htri (sections Ilc, Illc, $\mid V c$. The šsyt of live geese is specified, under the htri. In the Bilgai Stele (supra, pp. 182.ff.), the šsyt is not identified, while the htri is specifically identified as the honey deliveries, but both the šs $\breve{s}^{\prime}$ and the šmw are termed htri.

1129 As, e.g., P. Bol. 1094, II. 6,5-6,6 (LEM, pp. 5-6; Caminos, IEM, pp. 17-20).

1130 We assume that domain production was bikw-rmt, where the cultivators were expected to produce $200 \mathrm{khar}$ head, and that this was and not a tax in the same way that the other kinds of bikw were. It is not clear who was responsible for the payments, but the domain lands were specifically intended to provide income for the temples, and not to skim off or create a surplus. Cf. supra, pp. 144-145 n. 408.

1131 It is possible that the use of inyt implied a completed action. This calls to mind the very curious formulation of Turin Taxation Papyrus 5,6 (Gardiner, RAD, 42,4), where a quantity of grain is presumably turned over (iw, "arrived"), with a note that there is a remainder, perhaps implying that the grain did not actually arrive? 
probably had a meaning in earlier times, which changed as obligations became responsibilities, etc. The $b ; k w$ was a means of fulfilling an obligation. Sometimes $b: k w$ may have been written where $b_{3} k w$ - rm $t$ was meant, and sometimes the $b 3 k w$ may have been an official payment which was not a tax.

The real fiscal system associated with the inw and the bikw was based on the assessments, the šsyt and the htri, which determined which official had to produce how much. Since certain things did not require emphasis this is insufficiently clear in the documentation as preserved.

Pharaoh and the Vizier thus assessed (htri) all of Egypt, determining the obligations due (htri

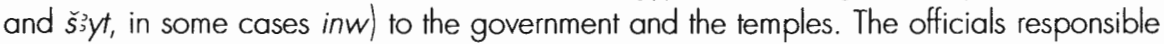
thus assigned the quotas of products or activity $\left(b_{3} k w-r m t, b 3 k w\right)$ which they would exact from the population in order to carry out their missions. Both the harvest taxes and the grain production quotas $(\breve{s} m w, b 3 k w-r m t)$ were the core of the system, as these were then redistributed to the workers providing the $b 3 k w$, where they were not able to retain some grain income. 


\section{ECONOMIC AND INSTITUTIONAL RELATIONSHIPS}

\section{SUMMARY}

Given its nature, the documentation preserved from ancient Egypt necessarily reflects both (1) Pharaoh's concerns with legitimacy and (2) administrative measures concerned with fiscal policy. All discussion must be based on the evidence, which indicates that the resources of Pharaoh and the temples were substantial, and that Pharaoh was primarily responsible for assuring growth through construction projects, while the temples were responsible for the maintenance of their domains. Distinctions between the government, the larger temples, and the smaller temples can also be established using the fiscal data. Distinctions between rent and taxes also suggest themselves, along with evidence for some marginal market activity.

While reflecting a certain reality, this superficial reading need not mean that it be taken at face value, as reflecting the overall character of economic activity in ancient Egypt. Such reflections have led to the conclusion that ancient Egypi was a Redistributive Economy or a Revenue Economy. Inferences made in light of the philological and theoretical discussion suggest that ancient Egypt can be understood as a pre-capitalist market economy.

\section{Legitimacy: State and Temple in the New Kingdom}

In theory, a fiscal system is a practical expression of an ideological conception of the nature and role of the state. In practice, a fiscal system is basically a reflection of state involvement in the economy. If the fiscal system of any country is to be understood, a sound understanding of the state is thus essential. It should be evident to every student of ancient Egypt that the dichotomy of State and Temple must be banished from one's mind. Just as it was once said that "the Church of England is the Tory party at prayer", the temples of ancient Egypt were served by state officials, who frequently bore several titles. Some of these officials were primarily religious administrators, others primarily government functionaries. ${ }^{1132}$ The evidence for the close relationship between the government and the temples has been manifest on virtually every page of the preceding text, and thus it is necessary to consider why.

Legitimacy is a sine qua non of government, as a government without recognized authority cannot assert itself in the face of opposition. The issue of succession is not resolved without legitimacy. Power may be acquired by sheer brute force, and the use of force obliges recognition, but it does not necessarily guarantee legitimacy, in that there is no regulated

1132 The reverse relations were also equally valid: the Vizier was evidently responsible for the Tomb, but his duty consisted in assuring that the temples actually delivered the necessary goods to the Gang, which was employed for the sacerdotal purpose of altending to the King for the Beyond, and thus only the tomb itself, but none of the practical aspects of it interested the Vizier: the King wanted it completed, and as the highest official he had to make sure that it was. Responsibility was delivered to the temples, but authority to the Vizier. 
system of changing government if the possession of force is the only source of power. Government authority may however be acquired by force, but justified post facto in divine terms, and if the governed accept the legitimacy of a government more by virtue of its divine right than by simply submitting to brute force, the divine support provides legitimacy, which provides for a system of succession.

The ruler himself may be divine, ${ }^{1133}$ but the entire legal state organization is not divine, despite the employment of divine right as a source of legitimacy. The ruler himself may purport to rule, but it is the administrative and judicial apparatus which actually govern the country. Pharaoh's responsibility in Egypt was to implement m;'t, "justice", and he was also beloved of $M_{3}{ }^{c} t$, the goddess of justice. Pharaoh ruled through the bureaucracy of scribes. The scribes may have worked in the temples of the gods, but it was the government which ruled, and the gods which sanctified the rule of the government. Assuming that, on the simple theoretical plane outlined here, the government acquired its legitimacy through the approval of the gods, then the gods could not be counted part of the government any more than the population of the country could be regarded as part of the government, even though their recognition of Pharaoh's legitimacy was the very pillar upon which his rule was based. ${ }^{1134}$

The monopoly on the use of the means of force is the means by which a government is able to extend its sway throughout its realm, and those means of force must be at the disposal of the government, and while they assure the capacity to threaten repression, in themselves they do not provide legitimacy. Legitimacy and the exercise of force are two separate aspects of government. The consent of the governed guaranteed by some form of philosophical or ideological justification, supported by force, suggest that three different variables are being discussed.

Divine services and temple construction projects in Egypt were carried out using public means, sanctified and enforced by Pharaoh. This was done as part of the effort to maintain legitimacy. It is thus clear that neither the gods nor the temples could be regarded as part of the government, for they were the very source of legitimacy of the government. These logical conclusions may not seem to apply directly in the case of ancient Egypt, where the people and bureaucracy may not have been conscious of such theoretical distinctions, but following the argument based on this interpretation, we find that Pharaoh was generally proud of his contributions to the temples, and emphasized that he was expressing his thanks to the gods by rendering them concrete homage in the form of temples, obelisks and incense, etc. for divine services.

On the other hand, there are very few inscriptions extolling Pharaoh's virtue for having, e.g., increased the annual budget of the chariot corps of the army. "135 This may result from the fact that there are very few barrack buildings preserved, while temples are plentiful, but it is

\footnotetext{
1133 I.e., he may actually be a god, or regarded as such, or regarded as the member of the state with the closest ties to the gods.

1134 Distinguishing between the right to rule, which was divine right, and the rule itself, which was exercised by vitue of the fact that the people accepted his rule, based upon his own claims to legitimacy, and their own comfort.

1135 I have not seen any.
} 
also possible that this is the result of a distinction between ordinary transfers within the government organs (e.g., from the treasury to the military), and extraordinary expenditures from the government to the temples. If this distinction existed, even if it was not consciously clear to the Egyptians, it does correspond to the theoretical model proposed here, implying that the temples were part of the state, but not the government, and that in return for providing legitimacy, Pharaoh provided the temples with their essentials. The temple economy itself was maintained at a low level and particularly concerned with day to day maintenance, while completely dependent on the Pharaoh for significant growth.

Ancient Egypt had several enormous bureaucracies with interlocking directorships, one of which was the government and the others were the major temples. The temples had land holdings and large numbers of dependents, and thus their own agricultural and industrial production remained within their control and was not distributed back to Pharaoh, while Pharaoh and his government likewise controlled large holdings and large numbers of dependents, the proceeds of which provided for the maintenance of the government, but part of which was voluntarily relinquished to the temples.

These parallel bureaucracies employed many of the same people, and thus it is not surprising that the same terminology is used with reference to temple income and government revenue. These two bureaucracies also dominated the economy of the country to a considerable extent, in that they were the main source of demand, for construction projects and statuary, etc.

The situation in the New Kingdom seems to have been dominated by the growth of the temples as economic entities, completely dependent upon Pharaoh for provision of land, construction and particular products, but themselves major economic actors. It would seem that part of the population was attached to these temples, by virtue of obligatory deliveries of products assigned to the temples, and exacted from the subjects of Pharaoh. Pharaoh's subjects were likewise obliged to render up payments to his treasury and his granary, and the slim corroboratory evidence from the inscriptions of Mes and P. Valençay I indicates that this was centrally organized. It would seem that both the decrees of Horemhab and Seti at Nauri were anxious to establish the freedom of their subjects to fulfill their obligations unhindered by illegitimate bureaucratic interventions. They thus defined the rights of temples and individuals and officials.

The propaganda texts seem to imply that Pharaoh claimed responsibility for the in w income which ultimately came to the temples, especially that which was acquired through military or political victories won with the help of the gods. The administrative texts do not seem to mirror this image, indicating that the temples received inw directly. The distinction may well lie in the fact that ultimately Pharaoh may have perceived himself as voluntarily permitting the temples to benefit from income which was ultimately collected by virtue of the state's monopoly of force. At the same time, the gods will have felt that it was their own right, since they provided legitimacy and victory. Administratively, this may have been a tacitly accepted reality. Politically it will have been unacceptable during the New Kingdom, as recognition of this would ultimately result in the temples assuming responsibility for the state, as happened at the end of the New Kingdom.... 
As it provides excellent comparative material, P. Harris $I$ is the most useful document for commencing an analysis of the institutional relations. ${ }^{136}$ There are several different categories presented to the temples:

- the outright gifts of significant quantities of land, dependents, etc. (IIb, IIlb, IVb, Vb, Vla);

- the produce of the temple dependents $\left(\left\|_{c},\right\|_{c}, I_{c}, V_{c}, V \mid b\right)$;

- the lists of precious metals, stones, etc. which the King gave the temples during his reign (IId, IIId, IVd, Vd, VIc);

- and the following lists of grain offerings, festival offerings and divine images, which the King made to the temples.

Taking the statements in P. Harris at face value, it may be concluded that the three major temple complexes, of Thebes, Memphis and Heliopolis each had their own income from their own dependents. It is specifically stated in sections $\|_{c}$, IIIc and IVc that these products are those of the temple dependents. The only basis for which Ramesses III could justifiably assert - according to the text as preserved - that he was responsible for awarding these to the temples would be the claim in the preceding sections $(\| \mathrm{lb}, \mathrm{Ill} \mathrm{b}, \mathrm{IVb})$ that he had given the dependents, land, gardens, etc. to the temples, and that it was these dependents who provided the material listed in $I_{C}, I_{C}$ and IVC. P. Harris thus allows the conclusion that the King had enormous reserves at his disposal (grain, incense, cattle, land, villages), and that Ramesses III voluntarily parted with a large amount of his own personal, family or ex officio holdings, in favour of the temples. The other sections of each chapter concerning the larger temples confirm that the King retained control of certain categories of his possessions, and that he voluntarily relinquished the produce of these holdings, but not the title to them.

Schaedel interpreted the deliveries of the temple dependents as a special tax levied on the temple dependents, turned over to the temples during the reign of Ramesses III, after which Ramesses IV did not intend to pursue a similar course. ${ }^{1137}$ This would necessarily mean that either the temples themselves or their dependents (which is not the same thing) were regularly taxed, and that these taxes were exceptionally returned to the temples, either wholly or in part (i.e., a tax break, if it was a tax on the temples). Should this logic be followed, it would be necessary to conclude that the temples provided an economically significant part of government income. This would not correspond to the frequent claims that Pharaohs were constantly furning their wealth over to the gods, but does not render it invalid for that reason alone.

The Instructions for the Vizier state that this official was responsible for lands, being obliged to make decisions concerning land disputes, and assigning plots, as well as arranging the fields for the divine offerings. ${ }^{1138} \mathrm{He}$ was also responsible for assuring that the responsible

\footnotetext{
1136 References to the text will be made to the sections identified in the summary supra, pp. $194 \mathrm{ff}$.

1137 Schaedel, Listen, pp. 59-60.

1138 Cf. supra, pp. $178 \mathrm{ff}$.
} 
officials had the fields ploughed. P. Harris itself records the produce of the Crown lands (e.g., IIIf), which is itself evidence of the existence of such holdings. In P. Valençay I reference is made to nmhw who paid up gold to the treasury, and it is specified that this was separate from the khato-lands, which are otherwise known to be some kind of Crown property. ${ }^{1139}$ The Crown thus had various kinds of property and income from it. This will have been the source of the Crown lands which Ramesses III turned over to the temples. "140

In P. Harris, the produce of the dependents is listed at length and the nature of the objects is decisive. It is conceivable that gold, garments, and grain were produced by the temple dependents, and that they were obliged to relinquish a portion of their produce to Pharaoh, and a part of their produce to the temples. It would then be necessary to conclude that they either received some form of income to guarantee their continued existence or that they were permitted to retain a portion of their production. If the portion retained was the greater part, and that delivered the lesser, then the deliveries might be termed a "tax" or "rent". If however, the proportions were the reverse, then this was their way of making a living, and the temples were their employers.

Although it has been widely assumed that Pharaoh dominated the mining industry both inside and outside Egypt, the gold of Coptos and Cush could conceivably have been acquired by the temples or Pharaoh imposing a tax on production. There is evidence that the temple of Amonrasonther at Thebes had access to direct gold production, and little reason to believe that those at Heliopolis or Memphis did, and thus it is not surprising that only the temple of Amonrasonther received gold from its dependents. ${ }^{1141}$ If the gold was thus acquired under this title, as htrri, bikw or šszyt, this would imply that these are not fiscal terms, but actually pertain to basic production, of what was delivered to Pharaoh or the temples, and not that the dependents turned over a mere portion of their income to Pharaoh.

Not only do we know that these were derived from trade as well, but these are the very terms which the Bilgai stele indicates must have defined a mere fraction of production, for the extraordinary surplus delivered would otherwise have been impossible. Therefore, one possibility is to postulate that the gold came originally from elsewhere and was then reworked, i.e., that Pharaoh gave the gold to the temples whose dependents then smithed it. A certain number of silver objects are however designated bikw-rm!, which would imply the work involved, and this conclusion is thus excluded. It would seem compelling to suggest that this gold flowed to the temples from their employees panning gold, ${ }^{1142}$ and from the

1139 Cf. supra, pp. 137, 168ff. Römer (Priesterherrschaft, p. 421) is more cautious.

1140 It is extremely speculative, but worth noting that it was entirely possible that Akhenaten actually expropriated the lands of the Temple of Amun and possibly other gods, and that these were not all given to Aten, but maintained as Crown Property, until Ramesses III tried to refurn (some of?) them.

1141 Cf. supra, P. Harris I; pp. 194ff.

1142 Cf. e.g., KRI VI: 517-522; W. Helck, "Eine Briefsammlung aus der Verwaltung des Amuntempels," JARCE 6 (1967): 140; Y. Koenig, "Livraisons d'or et de galène au trésor du temple d'Amon," in Hommages Sauneron, p. 191ff. B. Kemp ("Temple and town in ancient Egypt," in Ucko, Urbanism, pp. 658-656) fails to rigorously distinguish the gifts from their possessions, lumping them together, but the temple gold washing activities were probably insignificant in comparison to the resources available to the king, so that it could be contended that these actual sources were nearly insignificant, although it cannot be proven. 
merchants in their employ. ${ }^{1143}$ However, the far greater quantity of silver cannot be explained as coming from mines, for this would demand that the temples have access to silver mines, for which there is utterly no evidence, as silver was imported. The Inscription dédicatoire indicates that the bikw of the traders was silver, gold and bronze, ${ }^{1144}$ which reveals the origins of the metals not derived from mining, but it does not elucidate the economic implications of the mode and motive of acquisition, which must account for (1) the implications of the meaning of these various terms as being a fraction of output and (2) identify the purpose for which it was acquired, if it was not intended to be used for statuary and other ornamentation (which would presumably have been the bikw-rmt of the silversmiths, and some of the King's own donations).

Following metals in P. Harris llc are a couple of lines concerning garments. Another set of items suggests that the King likewise donated large quantities (though not comparable) of garments to the temples. Other documents record garments and honey being sold by boats moving from riverbank market to market. ${ }^{1145}$ P. Turin $2008+2016,2$, 9ff. as well as P. Brooklyn 35. $1453 \mathrm{~B}$ list exchanges involving articles appearing in P. Harris. I. ${ }^{1146}$ There is thus both direct and inferential evidence supporting the contentions that the temples were recycling their income by exchange. P. Leiden I 350 verso may represent a similar trading mission organized with a boat belonging to a temple. ${ }^{1147}$

With the exception of limited quantities, the P. Harris Ilc and IIlc sections treating the produce of the dependents do not list incense, ${ }^{1148}$ precious stones, or import products, such as Syrian oil, 1149 which would be of immediate value to the temples for their religious services. These objects were acquired by the king, and delivered by him to the temples, identified as inw.

This fact has a multi-fold significance: for $(1)$ the temples were evidently dependent upon the King for certain essential aspects of the cult; (2) just as they were dependent upon the king for the initiation of large scale construction projects and $(3)$ this underlines that the basic features of the temple revenue indicate that the economic activity of the temples reflected in P. Harris I was not primarily designed to guarantee supplies of certain essential cult items, such as incense or to provide funding for major construction work, but for the mere maintenance

$1143 K R / \|: 333,1-2$.

$1144 K R I \|: 333,1-2$.

1145 Janssen, Markt op de Oever. The papyri referred to were partially published by V. Condon, "Two Account Papyri of the Late Eighteenth Dynasty," RdE 35 (1984): 57-82. The nature of the transactions must remain speculative, but it does seem logical to assume that this was a trading mission.

1146 Cf. Janssen, Ship's Logs, p. 71; V. Condon, "Two Account Papyri of the Late Eighteenth dynasty," RdÉ 35 (1984): 57-82; supra, pp 238 n. 802.

1147 Cf. supra, inw, pp. 222 ff.; Janssen, Ship's logs.

1148 An exception are lines 12a, 15, and 32b, 3 listing 1047 and 482, ;c vessels respectively of incense, honey and sesame oil. The figures are only faintly comparable to the long lists of the king's own donations.

1149 These items are listed as the inw of the king (Section IId), and these are the items which we encounter in the socalled tribute, so that the in w is evidently what was received from foreign countries, and turned over to the temples by the king. This corresponds to the use of inw in the texts: the god awards the conquest of a foreign country to the King, who dutifully passes on the proceeds to the god, while claiming credit for the gift. 
of temple operations on the economic level. It is also clear that the temples engaged in trade to acquire other items, but that, peculiarly, the essential items necessary for temples to function as religious institutions remained in the hands of the King. The perfectly rational conclusion following from this line of reasoning is that the temples were involved in widescale redistribution, for the sheer volume of material listed in P. Harris I makes this appear probable.

It has been emphasized that the most important single element of state income will have been the grain which played a key role in the economy in several respects. The grain in $P$. Harris is termed $b_{3} k_{k}$ of the cultivators. The tomb of $P_{3}$-hry uses $b_{3} k w$ in the sense of work carried out in the fields, as the expected grain obligation of the official, rather than the field labourers. ${ }^{1150}$ There is evidently a specific type of grain levy which is the produce of the labourers working for temple lands, separate from the šmw.

It is possible that this is the production mentioned in O. Gard. 86 and P. Bol. 1086, ${ }^{1151}$ where the word $\check{s m w}$ is not used, but the raw figures of $200 \mathrm{khar} / \mathrm{man}$ are given. ${ }^{152}$ The total quantity is however quite restricted, as P. Harris $\|_{c}(I .12 b, 3)$ lists only 309'950 khar, while the figure from $\bigcirc$. Gard. 86 would suggest that this one official was responsible for the annual production of 1'752'000 khar, or the produce of roughly 100'000 arouras. This might indicate that $O$ Gard. 86 is a school text, but confirms that the figures in the relevant sections of P. Harris I are the annual htri as stated in the text, and not the accumulated donations of the reign, as these are generally specifically indicated as such. ${ }^{1153}$ Were one to assume that the literal meaning of annual htri was that the lists in P. Harris $\|_{c}$ were annual levies, and not the cumulative collections for the entire reign - and as these are specified for the royal donations this is logical - this would still indicate a mere skimming off of excess production, and thus that the primary activity of the temple dependents was not the very essence of the production for the temples.

Waterfowl deliveries are also termed $b_{3} k w$, and these can be assumed to be the catch of fowlers and fishermen, as stated in the text. The live geese are termed šzyt.

It is difficult to interpret the meaning of the cattle provided from the herds of Egypt, but the cattle bikw of Syria must have come from the Syrian villages donated to the temple (19 head from Syria for the Estate of Amun, which does not testify to the significance of this source).

The final lines (of $\mathrm{I}_{\mathrm{c}}$ and $\mathrm{IIC}$ ) concern entire boats and it must be assumed that the materials were placed at the disposal of the boat builders, and that they were remunerated for the work, as they could not retain part of the boat. This particular case emphasizes that this cannot be a simple tax. Either they were dependent on the temples for their income, in which case they were either slaves or employees, or they were entrepreneurs rewarded on an ad hoc basis for their work. In neither case can boats be regarded as a normal item that would be paid as tax, if that word has any specific meaning.

$1150 \mathrm{Cf}$ supra, pp. 138; 246

1151 Cf. supra, pp. 144-145 n. 408.

1152 In O. Gard. 86, this is clearly htri, the term used in P. Harris Ilc, etc.

1153 This would be the logical way of negating Schaedel's assertion (listen, pp. 59-60) that these were taxes made during the reign which were revoked by Ramesses IV, if the logic were compelling, which would superficially appear to be the case. 
In this context, it is useful to refer to a passage in the Giornale text P. Turin $2009+19991154$ which contains a list of items, with a single line devoted to each entry in which each item is given a value in terms of silver deben or kite. In several cases, a note is added to the effect that (a) $r$ hd $m$ h.d or (b) $r h \underline{d} m$ (i)ht. ${ }^{1155}$ Rendering the phrase, (a) "against silver in real silver" (i.e., "purchased with money") and (b) "against silver in objects" (i.e., "purchased by barter") does not appear risky on the philological level, but this interpretation of the text would appear to have striking consequences for the understanding of the Egyptian economy in light of the specific objects in question, and the general interpretation of the text.

The first three lines concern fish, of which the names it and $\check{s}^{\prime}{ }^{c}$ have been preserved. The $\check{s ̆ n}^{c}$-fish is well known from the Deir el-Medineh documentation, ${ }^{1156}$ but the fish delivered to the Gang were usually recorded in terms of deben rather than kite. ${ }^{1157}$

"Palm ropes for the royal barques", cedar trunks, beams, masts, keels, ribbing are listed in the lines that follow, and usually enough of the text is preserved to substantiate the assumption that each was valued in a manner implying that some kind of exchange was involved.

The final lines of the third column list types of wood, followed by types of vessels. The text is however so severely damaged that the significance of the entries cannot be analyzed. Five of the actual boats mentioned are also listed in P. Harris l: $d^{3} 3^{3}$-boats, ${ }^{1158}$ and skty-vessels, ${ }^{1159}$ qrr-boats, ${ }^{1160}$ mnš-barges, ${ }^{1161}$ and bir-freighters. ${ }^{1162}$ Accacia barges ${ }^{163}$ also appear, and the form of the entry is identical, with the wood type preceding the name of the vessel. In P. Harris they are not given values, but merely enumerated. The items in the shipyard texts ${ }^{1164}$ are not given values, and it is not clear that the Giornale entries actually gave a value, but the context suggests that this could have been the case. Whether the boats themselves were purchased, or parts of the boats, or whether they were listed for other reasons is however

1154 KRI VI: 560-566; Botti/Peet, Giomale, pp. 10-13/pls. 1-3; . cf. supra, pp. $175 \mathrm{ff}$.

1155 (a): 11. 1, 13; 1, 15; 1, 17; (b): 1, 12, 1, 14, 1, 16. The editors justifiably translated (a) "contro argento (pagato) in argento" or (b) "ogetti diversi", but noted that "Non siamo riusciti a compredere il senso preciso delle $r$ hd in questa frase." Botti/Peet, Giomale, p. 10, n. 4.

1156 Cf. Gamer-Wallert, Fische, p. 44; Helck, Materialien, pp. 817 f.

1157 It should be noted that deben are generally assumed to be copper unless otherwise indicated, and fish were generally weighed in deben (e.g., KRI VI: 581-590; O. DeM 139,4; 140, verso; 142, passim; 143, passim), whereas this account refers to silver kite, implying that they were purchased in exchange for silver (involving the question of calculating $x$ deben [weight] $=y$ silver kite [value]. It is entirely possible that the same political or economic situation that led the Necropolis Scribe Dhwly-ms to take up lax collecting (cf. supra, pp. 170ff.) may have obliged the state to purchase provisions for the Necropolis towards the end of Dynasty XX. It is however striking that the absence of references to kite in Deir el-Medineh is counterbalanced by their presence in the "tax lists" of the recto of the Turin Canon (Col. 3,8b, p. 160 supra).

P. Turin 2075 (Černy, Notebook 15:23-30), stotes concisely that 3'200 deben of fish equal 8 khar of emmer (I. 3,3), meaning 1 khar 400 deben fish, or 1 copper deben 200 deben of fish, indicating that the deben of fish are generally references to weight, not value. These values indicate that the number of fish mentioned in $P$. Turin $2009+1999$ might actually be in deben, rather than individual fish, in which case the quantities are again comparable to those known from other texts.

1158 P. Harris $12 b, 10 ; 32 b, 12 ; 69,12$.

1159 P. Harris $12 b, 10 ; 59,2 ; 69,12$

$1100 \mathrm{P}$. Harris 11,$8 ; 32 a, 5 ; 51 a, 13$. None of these entries is under the title of a term dealt with in this work.

1101 P. Harris 11,$8 ; 32 a, 5 ; 51 a, 13$. None of these entries is under the title of a term deall with in this work.

1162 P. Harris 8,$1 ; 77,10$ (Jones, Glossary, has reversed the page; line numbers in first reference, p. 137).

1103 P. Harris $12 \mathrm{~b}, 11(11,9$, etc.)

1104 S. Glanville, "Records of a Royal Dockyard of the Time of Thutmosis III: Papyrus British Museum 10056,"ZÄS 66 (1930;: 105-121; Z̈̈S 68 (1932): 7-41. 
immaterial, as the parts listed in the previous lines provide prima facie evidence for purchasing, and in association with types of vessels known to have been given by the King to the temples (in that he provided the dependents, who provided the objects, following the internal logic of P. Harris 1). These are the same vessels known to have been employed for administrative transport of goods.

Among the significant points about the logical role of the temples defined above, it was pointed out that there is no evidence concerning the extent to which the temples had direct access to silver, as opposed to acquiring silver through trade. The fact that Pharaoh built their temples likewise suggests that they did not have access either to the quarries or to the manpower to arrange the transport of stones. It was likewise pointed out that Pharaoh alone provided them with incense, which he acquired from foreign sources. In the case of Punt and Sinai (2) Ramesses III takes responsibility for the acquisition, but not the production of the products. It would thus appear possible that not only incense, but certain common metals were acquired through trade, and it could be postulated that trade was a royal monopoly, although this overtaxes the evidence.

Among the sources listing rations or pay are those related to expeditions, primarily with the object of mining and trade. The temples were guaranteed income, and plentiful supplies of perishables, and their own fields for agricultural products, but the possession of exhaustible resources seems to have been a prerogative of the King. In P. Harris I, Ramesses III delineates his gifts to the temples exhaustively, but fails to mention a single mine, although he does provide gold, silver and copper. He likewise lists temples, and temple furnishings, and gates, etc., but he does not mention having given one single quarry anywhere to any divinity, although there are repeated references to granite shrines, turquoise, lapis lazuli, jasper, etc. and other monuments. ${ }^{165}$ Nor does he give any forests to anyone, although he does detail wood and wood products.

It was noted above that the temples could not have had direct access to silver mines. The copper resources available in Sinai may have been exploited, but the evidence is unclear. It was argued before that the archaeological evidence for the "Egyptian Mining Temple at Timna" was not compelling. This led to the interpretation that the "Theory of Comparative Advantage" would have suggested that copper mining would not have been economically interesting for the Egyptian state. The question which remained was whether Pharaoh was the sole purchaser of the copper smelted in Sinai. According to P. Harris, the dependents of the temples delivered altogether some two and a half tonnes of copper to the temples (annually), the lion's share going to Thebes, which indicates that the temples at Memphis

1165 That temple officials became prominent in quarying missions after the reign of Ramesses III may be significant, but the actual meaning is not clear. Cf. C. Eyre's remarks ("Work and the Organization of Work in the New Kingdom, in Powell, Labor, pp. 180-183) about the makeup of the evidence from quarning expeditions. Reviving the discussion about the relationship between the temples and the king at the end of Dynasty XX would far exceed the scope of this work which is devoted to the longue durée of the New Kingdom, rather than the political struggle, but the impression of increasing royal incapacity and the inability of the temples to assume the royal role cannot be denied, especially as temple participation takes the form of encroaching into royal or government responsibility, but the logic involved cannot be elucidated: was it a deliberate intervention or did the king actually seek this solution? 
and Heliopolis were not able to take advantage of their geographical proximity to Sinai to acquire copper directly from there.

Pharaoh likewise provided the temples with incense, potentially indicating either a royal responsibility or a royal monopoly on foreign trade. The latter has been widely postulated, but it is difficult to grasp. That temple dependents delivered both silver and copper to the temples suggests that if Pharaoh had a monopoly on foreign trade, Pharaoh re-circulated these metals through the private sector economy. This alone would suggest that claims in favour of a royal monopoly on foreign trade are bold, for in a royal command economy it would superficially appear to be far more logical for the king to direct supplies exclusively from his mines or resources to the temples, rather than the round-about fashion of passing them into circulation, obliging the temples to recover the metals on their own.

It is therefore entirely reasonable to suggest that the Pharaohs did not deliberately engage in copper mining in Sinai on a large scale - if at all - and that they did not endeavour to establish a monopoly on copper imports, and therefore, that Egyptian copper was acquired from entrepreneurs operating in Sinai. At what stage Egyptians were involved in this trade is probably impossible to establish, but temple dependents may have been purchasing directly from the producers, using e.g., the textiles at their disposal.

\section{Construction, Administration and Prosperity}

One of the major features of the New Kingdom seems to have been that although the temples owned a great deal of land, and had transport vessels, etc. they do not seem to have carried out their own construction projects, as these were done exclusively by the king. This would imply that the portion of Egypt that was potentially under the control of the temples sufficed to guarantee the income and regular services of the temples at a high level, but did not allow for investment in new constructions. This investment for construction would come from additional lands and resources assigned to the temples by the kings, which would correspondingly increase their holdings, but only guaranteed that a particular project would be executed, and that at the end of construction, the land would be lost. For their own funerary temples, the kings adopted the expedient of transferring lands from the funerary temple of their predecessor to their own, which merely involved a transfer within the estate of Amun, but did not remove it from the hands of the gods entirely. This measure permitted them certainty in being able to construct larger funerary temples, but it did not free the lands from the temples. ${ }^{1160}$

$1100 \mathrm{Cf}$. Gardiner, Wilbour H: 11-12 for the dearth of holdings of earlier temples. The usurpation of fields was an old habit, cf. P. Posener-Kriéger ("Les papyrus d'Abousir et l'économie des anciens temples funèraires de l'ancien empire, in Lipinski, State and Temple 1: 139) who was surprised to find that the supplies for the mortuary temple of Neferirkare came from the king's solar temple, and not from the temple's domains, which purportedly existed when the records were compiled, as much as 200 years later. She assumes that because the domains of the temple figure in the tombs of officials contemparary with the records, that these domains were actually providing sustenance to the $k$;'s of the deceased. It is far more logical that the king assumed that his domains would become a dead letter after his death, and was able to assure his eternal satisfaction by routing the supplies through the temple of a deity. Cf. supra, p. 33 ก 30 . 
It would seem that the temple dependents did not provide the temples with the absolutely essential articles necessary for religious services: the buildings themselves and the incense were provided by Pharaoh, at his discretion: ritual in exchange for legitimacy. Virtually until the end of the New Kingdom, it was still an exclusively royal privilege to construct temples and contribute to their growth. ${ }^{1167}$ On the one hand, Pharaoh could maintain good relations with the gods and the priesthoods, and indicate his preferences, but on the other, the temples could virtually oblige weaker Pharaohs to construct temples for them. If the land transfers continued at a high level, and the temples failed to invest in construction on their own, it is obvious that the Pharaohs would ultimately become prisoners of the temples. With their own administration faltering, the temples were unable to assume their newly acquired responsibility. This meant that the economic growth and activity that had resulted from two millennia of expansion was brought to a halt: what had been a positive feature became a millstone for the economy. Productive resources flowed into temples which were not administratively prepared for the responsibility. The resources available to the King were diminished yet failed to add to those of the realm. ${ }^{1168}$

Many different explanations have been sought to account for the seeming discrepancy between the strikes in Regnal Year 29 of Ramesses III and the seemingly substantial income documented in P. Wilbour, and the temple donations recorded in P. Harris I. ${ }^{1169}$ The preceding conclusions suggest that the workers at Deir el-Medineh were responsible for construction and that they were supposed to be paid from Pharaoh's resources. ${ }^{170}$ It is thus logical to suggest that the gifts Ramesses III presented to the gods (as recorded in P. Harris I) had a direct negative impact on the degree to which Pharaoh was able to meet his own commitments, which led to irregular payments in the Necropolis. This would confirm that the problem was not the donations in themselves, but the administrative responsibilities, which implied that the transfers led to royal depletion. This royal depletion necessarily led to a halt in construction. This suggests that the Royal Domains were of limited extent, and this conclusion necessarily lends weight to the suspicion that the greater part of the land in ancient Egypt was in private hands, and that the ultimate result of Ramesses' generosity was to eliminate the wealth of the royal household.

1167 CF., e. g., the subheading "Building and the State Monopoly of Stone," in W. C. Hayes, "Chapter IX" of CAH"2 II: 391 .

1108 The acute observer will note an apparent contradiction in my assertion (supra, p. 124) that Wolf erred in interpreting the demise of the economy to these transfers, but in that context the desire was to emphasize the irrelevance of the possibility of bankrupting the economy through the lack of a credit system (a macro-economic detail) and the fact that the buildings were a positive feature, macroeconomically, and transfers io the temples would have been economically viable, if the temples had had their own authority to construct, which they apparently did not. If the temples were simply economic entities engaged in trade and acquisition, delivering resources to them was necessarily erroneous.

1169 Cf. e. g., J. J. Janssen, "The Year of the Strikes, BSEG 16 (1992): 41-49; W. F. Edgerton, "The Strikes in Ramesses III's Twenty-ninth Year, ' INES 10 (1951): 137-145; C. Eyre, "Work and the Organization of Work in the New Kingdom, "in Powell, Labor, pp. 179-180

1170 Janssen (Commodily Prices, pp. 455-459) indicates several sources, but the evidence implies that ultimately the Treasury of Pharaoh and the Granary of Pharaoh will have been among the authorities responsible. 
One piece of evidence which could serve to negate this logic is the suggestion that the Turin Taxation Papyrus seemingly implies that the Necropolis was able to acquire provisions directly from temple lands without having to consult temple authorities. The papyrus is however dated to the reign of Ramesses XI, when the Necropolis workmen were no longer building tombs, but probably emplying them, and probably doing so at the behest of the High Priest of Amun. ${ }^{171}$ Under the circumstances, it is very probable that the descendent of those kings whose tombs were being plundered would hardly have felt compelled to arrange for the payment of those engaged in such activities, even if he could conceivably have been held administratively responsible for them.

This evidence clinches the argument that both P. Wilbour and P. Reinhardt probably record temple income and not taxation or royal income, for the wealth of the temples would then be comprehensible vis-d - vis the contemporary relative poverty of the Pharaohs. ${ }^{172}$ At the same time, the relative growth of the market would be easily grasped, as Pharaoh's capabilities diminished. This argument likewise strengthens the case for suggesting that the Crown lands did not cover a large part of the country either before or after the gifts recorded in P. Harris, for neither Crown nor temple possessions could possibly have been extensive if the gifts recorded in $\mathrm{P}$. Harris actually infringed on the ability of the King to pay his employees, while $P$. Wilbour does not suggest that temple holdings were significant.

The interpretation of the redistribution economy and the assumption that all the land in the entire country belonged theoretically to the King will have clouded the understanding of these matters which can be clearly grasped in terms of legitimacy. The failure to distinguish the various aspects of legitimacy, administration, power, etc. has led some commentators to conclude that the temples were merely another department of the state and that their specific role was not decisive:

Everything leads us to believe that the Temple of Amun represented the state in the exercise of that specific branch of the administration concerned with the organization of the land of the country. Thus, the grandiose donations of Ramesses III to the temple were not so much a way of impoverishing the state - it was rather merely a kind of transfer from one part of the administration to another - as the establishment of a more solid basis supporting the growth of the power of the High Priests of Amun. ${ }^{173}$

The temples were ideal recipients of income. They were however administratively unable to expend it in an economically significant fashion, given their responsibilities in ancient Egypt. ${ }^{174}$

1171 Cf. K. Jansen-Winkeln, "Die Plünderung der Königsgräber des Neuen Reiches," ZÄS 122 (1995): 62-78.

1172 Cf. Gasse, Données Nouvelles, pp. 223-236.

1173 Gasse, Données Nouvelles, p. 233. [My translation].

1174 It is interesting that the Imn-htp (as one of the last High Priests of Amun during the New Kingdom) credits Pharaoh with having praised him for the constructions which he - the High Priest of Amun - supposedly made for Amonrasonther (cf. supra, pp. 186f), although architecturally it is difficult to understand what is meant. The significance is that he probably did not build anything, but that such construction projects as followed later may have been adumbrated by the additions to the small temple of Khonsu at Karnak, although it is not possible to prove. 
Thus, when the gifts actually diminished the capabilities of the state, by transferring wealth from that part capable of investing it with profit to another part unable to expend it, the donations were financially serious. According to Ricardo, when government expenses exceed revenue, taxation reduces capital, and that if not increased, the economy would face ruin. ${ }^{175}$ On the Keynesian principle of demand stimulus, the economy would begin to decline when government expansion stopped. Thus, on a theoretical level, the economy was condemned to ruin twice over (once by Ricardo, once by Keynes) when Pharaoh turned over productive resources to the temples which failed to exploit them.

\section{TEMPIES AND GOVERNMENT}

Evidently there is a clear cut relationship between the temples and the government bureaucracy, with each having clearly defined areas of responsibility. The relationship between these two parts of the state bureaucracy was extremely complicated, and it will probably be impossible for the modern student ever to establish the exact significance of certain transfers. Certain goods were received in the treasury because they were material collected to be placed there, others were being exchanged and/or redistributed, but both were "received" or "delivered" there according to the tale told by the principal actor in each case. Furthermore, that these events took place in a treasury, and that a "scribe of the treasury" recorded them can usually be established, but was this the "scribe of the treasury of the Lord of the Two Lands" or the "scribe of the treasury of Pakhet, Lady of the Desert"? Even where the whole formulae can be established questions remain unanswered.

The Turin Taxation Papyrus ${ }^{176}$ indicates that grain collected from various sources was turned over to the Mayor of Thebes and a Chantress of Amun and a Scribe of Reckoning of Amonrasonther. The sources were khato-lands, foreigners, temple lands, the " $h$ ' $w$ of Pharaoh, etc. One part, termed the šmw of the mud flats, was received by the Mayor. It is possible that the goods turned over were specifically attributed to specific authorities, even though the grain was physically held in the same granary as can be detected in the note to the effect that a specific item is "on the account of the Scribe of Reckoning of the temple of Amun", 177 even though the grain came from the " $h$ ' $w$ of Pharaoh. All of the collecting was done by the Scribe of the Theban Necropolis. Several bureaucracies were thus involved in the measures: the secular mayor, the temple of Amun, and the Necropolis.

The distribution of responsibilities within the bureaucracy is equally evident from P. Greg, ${ }^{178}$ which is apparently a journal of events, recorded day by day, concerning the Gang of workman at Deir el-Medineh. Certain lines relate that the Gang worked in the royal tomb, that they were absent, and that the scribe acknowledged receipt of lamps, plaster, wood,

\footnotetext{
1175 Ricardo, Principles, pp. 186-188 (cf. quote at beginning of this book, supra p. 7)

1170 Cf. supra, pp. $170 \mathrm{ff}$.

1177 Gardiner, RAD p. 42, 2-3

1178 Cf. supra, pp. $152 \mathrm{ff}$.
} 
fish, grain, beer and dates. The diw-grain wages are their usual monthly remuneration for their work, and their source is not indicated, but other texts confirm that the Vizier was responsible for the grain issued to them. The grain came from royal and temple reserves, such as those collected by Dhhwty-ms and turned over to the Mayor. In this text they regularly receive inyt deliveries, of various cakes "from the King", and beer from the temples of West Thebes. The cakes and beer are likewise grain products from royal and temple reserves. The deliveries of fish and firewood are elsewhere termed $b: k w$ or htri, depending upon the text, and it is significant that the terms were used in a precise sense, but not consistently. While the other items supposedly arrive at the Necropolis as part of the redistribution system, the smdt who deliver the fish and firewood provide it directly to the end-users at the Necropolis. They are not recorded as having been paid for this work, but there are references to paying the hm-slaves who worked for the Gang, frequently following their htri.

The Turin Taxation Papyrus and P. Greg show the cycle of the collection and expenditure in ancient Egypt, with the grain being collected from the fields, turned over to temple granaries, and paid out to the workman who work on the royal tombs, who used the grain that they did not consume to purchase articles in the barter economy of the village. They were supported by a team of smdtworkers who provided essential commodities such as pottery and firewood, who were likewise state employees, but employed on a piece-work basis rather than given a monthly wage. Both the Temples and Pharaoh also chose to supply them with certain other articles, so that they were completely enmeshed in the bureaucracy between the temples and the government, even though they were effectively government employees, with the vizier responsible for their income. This is clearly a market economy with state employees receiving and spending their salary, and need not be characterized as a "redistribution" economy.

That the Gang and the community of the tomb assumed a relationship to Pharaoh and that the Vizier was responsible for their being paid does not establish a clear division of responsibility between the responsible authorities about who actually distributed the goods. "They were paid and administered as a department of state," in C. Eyre's words. ${ }^{1779}$ The "Crown lands" were the royal domains which were the possession of the secular government. The temple lands were the possessions of the temples, and state servants received small parcels apparently on these plots as rewards, while others enjoyed larger parcels which owed dues to the King. Identifying each of these with modern terms is difficult. Assuming that the major temples were part of the state apparatus does not however guarantee that all the temples of the land were part of the state apparatus, and in fact there are private establishments which were not part of the state apparatus, which were treated differently. ${ }^{1180}$

1179 C. Eyre, "Work and the Organization of Work in the New Kingdom," in Powell, Labor, p. 171.

$1180 \mathrm{It}$ is curious that - in analogy to the specific lack of terms in the P. Harris relating to the smaller temples, etc. - the Hermopolis Decree of Seti I likewise does not employ the conventional terminology (KRI I: 125-126). Seemingly only the temple at Abydos benefited from being raised to a higher level by virtue of Seti's bad conscience because of his name. 


\section{The Egyptian State}

When Sir Alan Gardiner finished his lengthy Commentary to the Wilbour Papyrus, he concluded that the revenues being assessed must have been government income that was somehow diverted to the Estate of Amonrasonther. Religious institutions and government bodies converged at the pinnacle where the highest officials served both, and both together formed the State. This does not necessarily imply that income was diverted from the one at the expense of the other, but that the two formed a unity, and so Sir Alan's interpretation may not have been completely accurate. At the present juncture one can do no more than speculate, but it is certainly plausible to suggest that the domain paragraphs of $P$. Wilbour are not taxation, but the production for the temples by the temples on their own land, and that the apportioning paragraphs represent a kind of taxation with the individual holders of small plots assessed at a low rate: the difference between production and taxation being that in the former case, the greater part of the yield is to be assigned the temple, and in the latter cases, the lesser part.

Grandet assumes that the temples and the king were different organs of the state, and suggests that transfers between the two could make no serious difference, but we have seen that this may have been far from the case. O'Connor divides the Egyptian Government into four parts, the crown possessions, the military, and the religious and civil governments. ${ }^{1181}$ We have argued above that organs of the state and government should be separated on the basis of legitimacy. Although it is difficult to make firm and lasting divisions in a land of interlocking directorships such as ancient Egypt, O'Connor's system thus appears too global, and the flexible approach for identifying political relations adopted by E. Cruz-Uribe would appear to be the key. ${ }^{1182}$

If we endeavour to fit Cruz-Uribe's model to cover the role assigned the government in the model of the state as defined by the General Theory of Custom, War and Technology, identifying the state as a political and cultural organism, the legal state represents the sovereign powers of a political entity, while the government is the agency or apparatus through which authority is exercised. While it can be argued that the temples were part of the sovereign powers of ancient Egypt, they were necessarily not an agency of government.

Analyzing the entity of the state, rather than the process by which states emerged, conventional understanding suggests that the right to collect taxes and conscript people for military for other) service are the usual prerogatives of the administration of the legal state. The government treasuries (both central and provincial) collect taxes, turning the funds over to the various spending authorities. These authorities either have their own employees, or contract the work out to private enterprise, or employ conscript labour. The fashion in which they acquire things depends upon the technology and economic structures available, as well as their desires. It is generally assumed that these works are undertaken for the public good, supplying needs which the private sector may not meet, as e.g., infrastructure and security.

1181 D. O'Connor, "New Kingdom and Third Intermediate Period," in Trigger, Social History, pp. $204-218$.

1182 E. Cruz-Uribe, "A Model for the Political Structure of Ancient Egypt," in Silverman, For His Ka, p. 48 
Modern western states emerged at a period when the palace and the military were the most important divisions of the government. Most commercial activities were in the hands of the trade guilds and agricultural activities were dominated by a landed aristocracy. ${ }^{1183}$ Virtually all religious activity had developed independently of the state, so that some of the Protestant states inherited the wealth of the Church which had its own separate history. After the Reformation, the conflict between the landed aristocracy, the guilds and the church was transformed with the church generally regarded as being a part of the state, but not the government. ${ }^{1184}$ As individuals, members of the aristocracy played a role in both church and government, and, as a collective, they acted as a kind of local government. This means that it is extremely difficult to compare the role of institutions within the states of the ancient Near East.

The government acquires its role by virtue of the state. ${ }^{1185}$ The state basically consists of an independent social organization within a territorial entity, with a population, ${ }^{186}$ and a legitimate government which administers, and makes laws. Laws need not be written down, but the administration must be assumed to be run using certain guidelines, either traditional or ad hoc. The legal system of a country can be independent of the government structure, or it can be part of the government, but the government itself must regulate its own behavior by some system of laws or rules recognized and accepted by the governed. The government may establish its legitimacy through the consent of the governed, and reinforce this by asserting that it enjoys the support of the gods.

The image which emerges from this is that of Pharaoh dominating the means of growth and possibly access to the exhaustible resources of the land, and of asserting his legitimate authority for controlling certain aspects of trade, but the extent of this is not clear. Our documentation suffers from being primarily influenced by information from the temples, and fails to reflect either government or private activity to an extensive degree. Viewed at a

1183 We are woefully under informed concerning the aristocracy and craftsmen of ancient Egypt. It would appear that a bureaucratic meritocracy (potentially based on birth) replaced the aristocracy during the New Kingdom, at the latest. It is far more difficult to state with certainty that all the craftsmen were primarily state employed. There must have been private craftsmen preparing e.g., stele, tomb equipment, and other daily items, aside from house builders, etc. We know that the craftsmen who made the shabtis for Nsy-Khonsu claimed to have been associated with the temple of Amun, but we do not know if the feeling was mutual.

Cf. D. Warburton, "Some Remarks on the Manufacture and Sale of Shabtis," BSEG 9-10 (1984-85): 345-355, for notes on payments to craftsmen for the manufacture of amulets. There can be no doubt that the craftsmen were likewise paid in other cases, cf. J. Černý, "Le Caractère des oushebtis d'après les idées du nouvel empire," BIFAO 41 (1942): 105-133.

1184 There were naturally difficulties when the Catholic Church was governed from Rome, and thus in competition with the local governments of the Christian world before the reformation. Separation of Church and State was likewise a problem where secular rule was in the hands of episcopal officers (Bischoffürsten, Princes-evèques), but it was not the Church that was ruling, but an officer of the Church, which was part of an organization beyond the state. After incorporating the Church into the state (as in England under Henry VIII), it was still not regarded as a branch of the government. Even if the head of state - in the sense of government here - was also the head of the church, the head of state merely incorporated the summit of two organizations within the state.

1185 It is easy enough to define the government as a rule, but there is not "any definition of the state that is accepted by the entire community of scholars", according to $H$. Claessen and P. Skalnik, "The Early State: Theories and Hypotheses," in Claessen/Skalnik, Early State, p. 3. The following generalizations are drawn from this book.

1180 The population of a state can be homogeneous, but it usually suffices if the ruling class is homogeneous, with a common sense of identity. 
slightly greater distance, the state still dominates our attention: the tombs of the officials are full of inscriptions worshipping the national gods, and giving lengthy lists of titles which bond them to the bureaucracy. The temples are likewise covered with scenes and inscriptions paying homage to the gods and providing historical accounts of events.

Liverani has suggested that these scenes in the temples were intended for consumption by "Egyptian public opinion". 187 This observation is particularly interesting, for one conventional view contends that the entire population of Egypt was registered for corvée labour and that they were exploited viciously - that there was no attempt to reason with them. ${ }^{1188}$ Only a small proportion of the population could read, but it is not clear that these texts were directed at the bureaucrats and craftsmen. Presumably the texts were intended for the gods, to whom the spoils of victory were rendered, but a nagging doubt remains that these texts may well have been intended for public consumption, that the people of the land of Egypt were also included in the system, and not merely as the ever subservient labour force, but as participants.

Soldiers, scribes, stable-masters, retainers, priests and other state employees were awarded small plots from which they were obliged to pay a portion to the temples or the government, which could be termed either "taxes" or "rent" depending upon the definition of ownership, and depending upon the precise role assigned to the temples - as a parallel government, a division of the government, or an independent branch of the state superstructure with an as yet undefined role, but the symbiotic nature of the relationship is just as clear as that emphasized in the Horemhab Decree, that people should be left alone to fulfill their obligations to Pharaoh. The Nauri decree emphasizes the opposite, that people should be left alone to fulfill their obligations to the temple. The scribe laughs at the others because his bikw is in writing, but the field workers carried out their obligations, and the state grew wealthy.

As far as the documentation permits clear statements, the only group who can be clearly documented as economically significant beneficiaries of the alleged "redistribution" system was the Gang at Deir el-Medineh, and yet neither did they produce anything collectively, nor did they receive their pay on a regular basis, so that the evidence indicates that although income was accruing, it was not being redistributed, if that term has any specific meaning. Even so, the Gang did not revolt, they went on strike: they expected Pharaoh to deliver the $m 3^{2} t{ }^{1189}$ The necropolis was plundered, but the legitimacy of Pharaoh and the temples was never in doubt.

1187 M. Liverani, "Memorandum on the Approach to Historiographic Texts," Or. 42 (1973): 193. R. Müller-Wollermann, "Ein Tribut an die Methode," GM 77 (1984): 52-53 attempts to distinguish the character of the sources, identitying the categories of religion, politics and art. Given the general agreement that $m$ ' $^{c} t$ was a state ideology, and that construction of monuments was to a large extent dictated by political considerations, and that art was a political tool in ancient Egypl (as elsewhere), it is clear that - with the exception of administrative texts (which she fails to identify) - all of her categories fall ultimately under the rubric of politics. As however, we cannol grasp the true nature of ancient Egyptian politics, the process must be resumed anew, with the desire to understand the specific message, meaning that the source is not as important as the intention, and discerning the intention must be guesswork, intelligent or otherwise, but her categories do not aid the effort.

1188 E. Eichler, "Polanyi - Keynes - Warburton,' GM 131 (1992): 26-27.

1189 Cf. J. J. Janssen, "The Year of the Strikes," BSÉG 16 (1992): 4 1-49. 
The Egyplian State
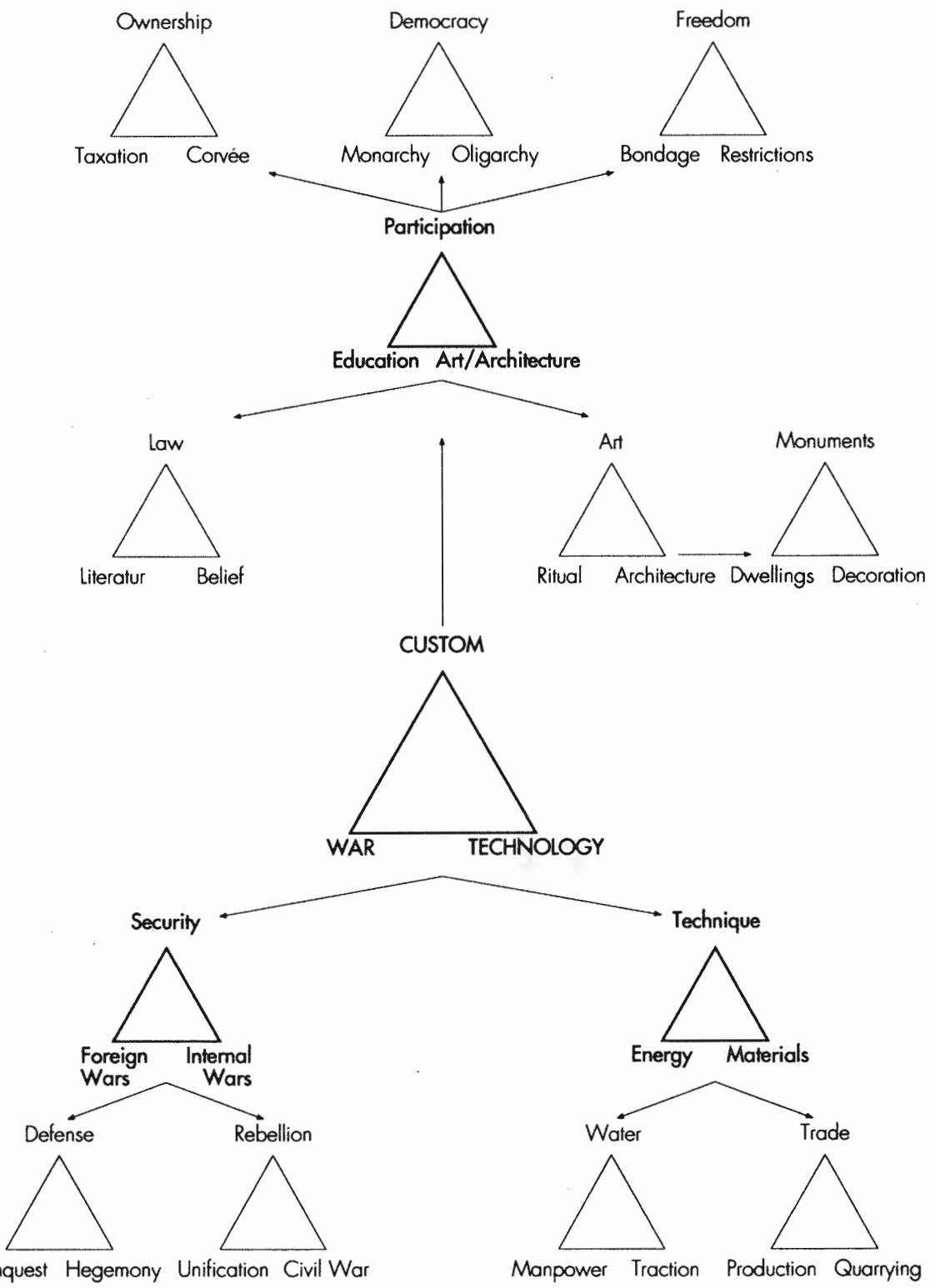

Figure 5. The General Theory of War, Custom and Technology 
The temples and their dependents owned land and collected income, and made exchanges with parts of the bureaucracy which are properly assigned to the government, namely departments for which Pharaoh or the Vizier were responsible. The Egyptian state was at least 1500 years old when the New Kingdom began, and was the product of an evolution from a period when there were no gigantic temples independent of the kings, and craftsmen were mainly associated with either the royal or private sectors, but not with temples. By virtue of its dominance, the Egyptian state was able to direct employment and to transfer the title of land ownership to the temples, and the Pharaohs of the New Kingdom increasingly sought their legitimacy through the gods, which increased the power of the temples.

This meant that the state necessarily failed to evolve a self-generating system of temple support, so that the temples continued to remain dependent upon Pharaoh for the enlargement of their physical plant, which guaranteed a continuous reciprocal relationship: Pharaoh would build, and the temples would guarantee legitimacy. The repressive fiscal measures necessary to assure the continued legitimacy benefited both Pharaoh and the temples, and the ideology of the state assured general stability, as each new King endeavoured to reestablish $m^{3} t$ t on her throne. The technological level of society meant that manpower and agricultural products were the main items of input, but the cultural level of society used these primitive products to create splendours.

The Egyptian state was ultimately responsible for justice and security. Pharaoh may have been responsible for the army, temple construction, some aspects of trade, and possibly education, training and various industries. The legal system need not however have been Pharaoh's responsibility, and private construction (of houses and tombs) was probably not his concern. Specific responsibility was therefore divided between the government, individuals and the temples. ${ }^{190}$

It was the delegation of responsibility and authority that defined the emerging Egyptian state, for these are the issues that lead to the identification of distinctions between the government and the rest. In a land such as ancient Egypt, people were probably not conscious of the distinctions between government and private activity, and merely conscious that the prestige acquired from public activity outweighed that to be gotten through private actions, but some will have observed that financial gains were acquired in inverse proportions. ${ }^{1191}$

The repressive threat implicit in the collection of revenues was exclusively the responsibility of the state, yet those bearing the actual sticks could have been members of the temple bureaucracy, and their ultimate authority will have come from Pharaoh, whose search for

1190 For the importance of education, cf. J. Baines, "Restricted Knowledge, Hierarchy, and Decorum," JARCE 27 (1990): 1-23. Justice was handled much more loosely, those having acquired education being permitted to participate in the process of justice, cf. McDowell, Jurisdiction. It will be noted that through education, the state organs were virtually guaranteed control of society.

1191 I. e. tomb-robbery did not bring prestige, but having a state job did. Having lands did not bring prestige, but did bring wealth, and probably the jobs which brought prestige. High positions probably permitted the office holder to substantially improve his financial position, without recourse to illicit activities, although tomb robbery will have been one of the few opportunities left in a day of declining resources devoted to economic growth, which explains the origins of official involvement. 
legitimacy required the support of the temples. The authority implicit in divine oracles likewise suggests that the temples and their officials could speak justice, but citing the "Law of Pharaoh". The Vizier inspected the tomb to assure that the Gang was working, and that the temples were supplying them. These relationships are decisive for the interpretation of the payments made to the temples, or by the temples to the government as "taxes". "Taxes" are generally understood to be payments made to the government; rents and corvée labor can be rendered up to landlords or proprietors, but they are not taxes.

Thus, as Pharaoh was the guardian of justice, it was his responsibility to altend to the gods, just as it was his theoretical obligation to assure the well-being of the Egyptian people, and his attentions to both people and gods were the ex officio result of his position. In return for the attention, the people consented to Pharaoh's rule, and the gods assured its legitimacy. It was the responsibility of the government to assure that Pharaoh's wishes in this respect were carried out. Thus the temples were one actor in the field of economic and political activity, and their income and possessions were commensurate with their essential role in society, and their wealth guaranteed by the king.

\section{State Income}

We have observed that both the inscription of Mes and P. Valençay I imply that the private land owners were obliged to pay a financial tax to Pharaoh, and that the records pertaining to this were not maintained by the provincial officials. It was observed earlier that the extensive land holdings of the nmhw cannot have been those of the apportioning paragraphs of $P$. Wilbour, as the latter group is dominated by the members of the state system, while the former group is untitled, and lacking in identity. This was not necessarily true of Mes and the higher officials of the land, but their plots and possessions will have been scattered about the land, and these will have most probably made up the 96 per cent. of the cultivable land in the relevant districts that fails to appear in P. Wilbour.

Not all of Pharaoh's income will have come from the governmental taxation of these fields, as he had other fields (aside from the khato-lands), but probably neither Pharaoh nor the temples maintained the greater part of the land in the country. Pharaoh will have enjoyed some income from his land until the middle of Dynasty XX, after which time it is difficult to estimate whether the administrative system was failing or whether the temples had in fact acquired substantial control of the "state" fields of Egypt. The suggestion that the donations in P. Harris prevented Pharaoh from paying his Gang suggests however that by the end of the reign of Ramesses III those gifts impoverished the royal household. This in turn suggests that even after those gifts, during the reign of Ramesses $\mathrm{V}$ - given the interpretation of $\mathrm{P}$. Wilbour as a cadaster of temple lands - most of the land in Egypt did not belong to either Pharaoh or the temples, but to private people, both high ranking and from the lowest classes. Both Pharaoh and the temples received a proportion of the yields of the their fields as income, but this was statistically insignificant in terms of the overall Egyptian economy, while decisive for its character. Different proportions will have been collected from wholly held fields, tenants, small holders, state officials, and ordinary tax-payers. 
Based on the data in P. Harris I, Grandet concluded that the temple dependents will have retained a portion of their production and delivered their obligatory portions to the temples. According to the model proposed here, the field workers did not deliver their entire production, but retained part of it, and submitted part of to the state authorities, and this can be grasped as "taxation" or "rent".

The general implications of the preceding notes suggest that while the ancient Egyptian temples were recipients of payments which would be termed both taxes and rent and "trading income" in the modern world, the temples also had large land holdings from which they produced. The production of these fields and other articles delivered to the temples were obligatory payments which can be termed taxes or "corvée in kind". The temples also received some bounty from the king himself, but they were generally kept on a short leash, and never developed the capacity to express their economic power in terms of trading expeditions, mining, quarrying or construction. In order to maintain their establishments, they traded the products which they received, and contributed to the circulation of goods by exchange rather than redistribution. In the end, the fiscal system should be characterized as a taxation system rather than a redistribution system, as it was the taxation, the forced payments, that permitted the growth of the temples and the construction projects.

This does not however mean that the economy need be characterized as a Revenue Economy, but merely that the fiscal system be understood in this fashion. The evidence for the market, and the fact that the stale used this market indicate that the market was the decisive feature. A fiscal system can work most efficiently if it is based on a market economy.

Returning to the theoretical model of the state, and, having postulated that the government has the legitimacy and the power to force the subjects or citizens to render a proportion of their income, wealth or labour to the government as revenue, it follows that those obligatory payments are taxes, in the sense of fiscal arrangements for the benefit of the treasury of the state. Using its force, the government can also compel its subjects to make payments to organizations other than the state's officially designated government. Thus, rather than collecting the revenues directly and transferring them, the government can oblige them to be rendered directly to a third party. In this sense, such payments should be regarded as taxes, because the obligation to pay is (1) forced by government authority and (2) serves the purposes of the government directly. ${ }^{1192}$

This accounts for those payments which are a fraction or proportion of wealth, income or labour - as from field labourers or cattle herdsmen. It also accounts for the obligation of the smdt to deliver goods to the Gang and of the tenants on temple land to pay their rent. It does not however account for transactions carried out in the name of the temples for which the participants were re-imbursed. Where a transaction involves equal compensation, it is not a tax. Therefore, the $b 3 k w$ of the excavation of the tomb was not a tax, because the

1192 Theorefically, the government could also oblige individuals to fulfill their obligations to third parties in civil or commercial affairs, but these result from their own mutual relationships, and they are neither ordered by the state, nor directly a concern of the state. Taxation must represent an obligation without a tangible reciprocal delivery, i.e., taxation is not a fee for services rendered (although bikw apparently meant both). 
workers were paid for it. If boat-builders were reimbursed, this would likewise not be a tax. If they were given the materials, and their labour was demanded, the boat was not a tax, but their labour was.

The temple tenants (e.g., scribes) paying a proportion of their income were paying a rent or a tax. If the title to the plot was intended to be the remuneration for their official activity, then that part which they retained would be their income, and that part which they turned over to the temple would be a tax. Their activity would be rewarded at a higher rate than that of the peasants who were required to render a higher proportion of the harvest to the temples. Since the scribes may have had to employ workers to till their fields, their gain may have been partially reduced.

It remains to observe that in the case of the monumental inscriptions, the reason for which the information was recorded must have been somehow related to the intention of deliberately disseminating the information and therefore it is logical that the temples benefited disproportionately in this genre of material. That the administrative papyri suggest the same conclusion can be altributed to the physical position of the temple of Medinet Habu on the edge of the desert. This however does not either favour or refute the suggestion that the resources of the crown were far greater. And consequently it is impossible to estimate the proportion of the taxation and rents that went to the temples as opposed the government. On the one hand, the extent of temple and funerary constructions are well known, while on the other, P. Harris indicates that the King had vast reserves at this disposal from which he could supply the temples. That the temples occasionally supplied the King need hardly be surprising, but the greater part of the transfers went directly from the temple dependents to the temples, and from the King to the benefit of the temples, and the means of acquisition correspond to the concept of taxation. In this study, we have not covered the issues of corvée labour and slavery, but it is certainly evident that there is virtually no evidence of economically significant redistribution.

\section{Temples and Taxes}

On a political level, one point which has attracted a great deal of debate is the question as to whether the temples paid taxes. According to the model proposed here, it is suggested that the temples received taxes, and therefore it would be relatively logical to suggest that they can hardly have been expected to pay them. It is however not excluded that some of the dependents and servants of the temples may have paid taxes to the government, but there is no evidence that the temples as such paid taxes, and no reason to believe that they should have. The inscription of the High Priest Imn-htp can be interpreted as indicating that payments characterized as ššlt, šmw, etc. belonging to the Temple of Amonrasonther were rendered to Pharaoh, but the context seems to indicate that the actual articles remained securely in the magazines of the temple, and thus it is difficult to contend that the payments were made to Pharaoh. ${ }^{1193}$ It would be far more logical to suggest that Pharaoh is praising 
him for having arranged for the supplies for Amonrasonther, as this supports Pharaoh's legitimacy. ${ }^{1194}$

P. BM 10401 seems to record payments made by temples or temple personnel to the "Chief Taxing-Master". ${ }^{195}$ The title is however that of the official responsible for the compilation of $P$. Wilbour, and the tentative conclusion discussed here is that P. Wilbour is a temple document, and thus, there is good reason to believe that the "requisitions" listed in P. BM 10401 could record transactions within the temple administrative system, as Janssen concluded.

The mysterious term tp- $\underline{d} t$ does however appear in both the inscription of Imn-htp and P. BM 10401, and this may have been an impost directly related to office-holders (cf. supra, pp. 287ff.). This suggests that if the tp-drt was a tax destined for the government in the modern sense of the word, and the tax was applied to individuals rather than institutions, it would confirm the suspicion that temple officials could be taxed, although their institutions were recipients of taxes. With the exception of the tp- $\underline{d} t$, and the possible exception of the inw, the inscription of Imn-hip clearly states that all of the other items identified as taxes were destined for the temple of Amonrasonther, and this corresponds to the conclusions listed at length in this work. This alone would confirm that the ancient Egyptian State during the New Kingdom had a very sophisticated fiscal policy indeed.

Pharaoh's income seems to have been designated as b3kw and inw, both within Egypt and beyond the borders. The same can be said of the temples, so that both terms designated payments made to both sections of the state. It is thus logical to suggest that both terms corresponded to what was actually delivered in order to comply with the assessments, as was concluded from the philological discussion. Thus, at least part of the evidence suggests that their primary meaning will have been that they represented a proportion of production or the fulfillment of a designated obligation, and that private people had to pay this. ${ }^{1196}$

1194 It could however also be contended that this must be understood in the context of the close of the New Kingdom, and that the inw and the $t p-\underline{d} r$ (although not the other items) were actually considered to have been passed on to Pharaoh, which can be grammatically an acceptable translation of the lext. As the same text relates that the High Priest was responsible for construction projects - which were observed above to have been an exclusively Pharconic responsibility - the context is unusual. Although it is not clear which monuments Imn-hip was referring to, the example of the small temple of Khons at Karnak may be taken as adumbrating the peculiar "construction" of the temple at Tanis - which consisted of transporting and rearranging blocks and monuments from Tell edDaba'a, and can hardly qualify as being monumental construction in the style of the earlier New Kingdom Pharaohs. Although they were hardly above this type of plundering, on occasion they did actually erect totally new monuments.

1195 J. J. Janssen, "Requisitłons from Upper Egyptian Temples (P. BM 10401)," JEA 77 (1991): 79-94.

1196 These conclusions emerge from the evidence, reinforcing the conviction that the major part of our documentation was derived from temple sources, and that the system of Pharaoh's own system of finance is not well represented in the literature as preserved. It's overall significance can best be judged by remarking that the temples did not seem to have had the resources for major construction projects, and that Pharaoh provided the resources, etc. for these, suggesting that his means were far greater than those of the temples, but far less well represented in the documentation as preserved. 
These levies on income were taxes, but the remaining payments and deliveries discussed were taxes only to a very limited extent, because taxation is a system by which a proportion of the total income or wealth is exacted by the government in a system based on private enterprise. As the state - Temples and Pharaoh - was one of the main employers in ancient Egypt, the state was in effect acquiring certain "products" by imposing a kind of corvée labour measured in products rather than time, such as water from the water carriers, fish from the fishermen, etc. It was also collecting a proportion of the grain produced in the fields from the cultivators, but probably according to at least two or three different systems. It was also using the same "fiscal" terms to designate trading income, and objects either purchased or commissioned.

In order to compensate or remunerate or pay for these efforts several systems were likewise being used: (1) it was paying its employees to carry out their jobs (as at Deir el-Medineh), (2) it was acquiring ordered products through exchange, and $\langle 3|$ it was assigning pieces of land to servants of the state, who were entitled to retain the major part of their income, but to render part of the yield to the state; and (4) it was also collecting a larger proportion of the production of the yield from some peasants who were entitled to what remained. This last category probably produced the greater part of the grain consumed by the state administration in wages and rations for its dependents and employees. It will be noted that other members of the society will simply have been expected to contribute their labour (as the lapidary in P. Cairo 58096), 1197 while the scribe will have contributed his labour b:kw in writings, and a small proportion of his yield from the plot assigned to him.

\section{The Temples as Recipients of Income and as Participants in Exchange}

It was pointed out that - given the distribution of silver resources exploited in the ancient Near East - the dependents of the temples could not have acquired silver by mining. It was concluded that the temples could and did acquire precious metals through the exchanges of their traders. It was pointed out that parts of boats identified with temple activity were either being sold or purchased. It was also pointed out that the temples were exchanging honey and clothing at markets. It was likewise pointed out that vessels both certainly and apparently belonging to temples were involved in trading other articles appearing in $P$. Harris, identified in other texts and in P. Harris as inw and $b$ :kw. It was likewise pointed out that the temple dependents were not active full time in order to produce their quotas, and the textual evidence indicated that these quotas could only be understood as representing a fraction of their production. There is thus no reason to believe that the temple dependents can have been generating silver income for the temples except through taxation of commercial activities or through exchange or both. ${ }^{1198}$ The evidence of the commercial activities and taxation is clear, if recognized as such.

1197 Cf. supra, pp. $242 f$

1198 B. Kemp ("Temple and town," in Ucko, Urbanism, pp. 660-661 drew the same conclusions from different evidence), but his argument is marred by the fact that he assumes that the temples were paying taxes to the crown (based on a variant interpretation of the khato-land, etc.), and fails to grasp the intricacies of how the Vizier was 
The implications are that the temples (1) were acquiring silver either $(a)$ as a type of taxrevenue on the activities of temple dependents, or (b) from exchange activities, or (c) both exactions and exchange, and (2) using that silver in order to acquire other products, and to restock their stores, and thus that the relevant paragraphs dealing with the annual htri of šsyt, bikw-rmt might not be the income so much as the total turnover, as some of the items may have been sold to acquire silver, while others may have been purchased with that silver. ${ }^{1199}$

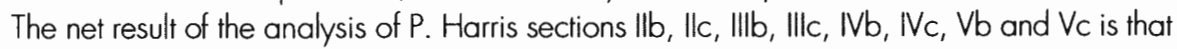
successive Pharaohs supplied dependents and land, etc. to the temples for their own use, and that the temples acquired material from these sources. This material was acquired partially in the form of a tax, but probably also as the assigned activity of the workers in question: miners mined, weavers wove, cultivators cultivated, fowlers fowled, herdsmen herded, boat makers made boats, and traders exchanged.

In several cases we must assume that the workers were remunerated for their efforts, such as the miners, but in the case of the garments and boats, there is fragmentary evidence supporting the proposition that they were actually paid for the work in question. ${ }^{200}$ The income from the holders of small plots (such as in P. Wilbour) suggests that the holders furned over a small proportion of their income from the plots, and kept the remainder, which is taxation or rent (and the opposite of "redistribution"). These small holders probably received plots ex officio to serve as their source of income, effectively relieving the state of the necessity of looking after them - and thus deliberately circumventing the necessity of redistribution. Their payments

responsible for assuring that the temples paid the wages of the Gang at Deir el-Medineh, which was responsible to the King, but actually aiso to the temples, as a particular branch of mortuary temples. Realizing the significance of the resources offered to the temples, he failed to realise the restrictions which sel very firm boundaries on their capacily.

M. Römer ("Der Handel und die Kaufleute im alten Ägypten," SAK 19 [1992]: 276) fails to indicale the capacity in which traders were working for the temples, but does indicate that traders had unusual opportunities to engage in exchange on their own due to their mobility (SAK 19:277). It will probably have been very difficulit to keep tabs on all their activities, and therefore it may be assumed that they were charged with certain obligations to the temples with materials placed at their disposal for that purpose and that they also pursued their own private gain simultaneously, but this is pure speculation.

The evidence of the Giornale text quoted indicates that in contrast to Römer's assumption (SAK 19: 276) the temples were also using precious meials in Egypt, not just abroad. The suggestion that traders were shady characters because of their access to precious metals which were intended to be transformed into statues, etc. (SAK 19: 282) probably exaggerates the extent to which precious metals were an aspect of the religious world. It would be difficult to deny that the Egyptians loved jewelry and obtuse to suggest that they only wore it in the tombs but never in real life. Precious metals and stones were most assuredly a common feature of life in certain classes, and could have been as easily stolen from private homes as from tombs and temples. The fact that payments in precious metals appear in the Turin Tax Lists - supra p. 145 - and O. Gard. 86 - supra pp. 159ff. - and probably in the Inscriptions of Mes and P. Valençay I-supra pp. 136; 139 - all confirm that ordinary people had access to precious metals. McDowell (Jurisdiction, pp. 227ff.) points out that theft was a serious problem even in Deir el-Medineh, where there was little worth stealing. Under the circumstances, traders will have made themselves simultaneously popular and unpopular - in different constituencies - but not merely because of the religious connotations.

1199 The rather bizarre discrepancies in some of the figures in P. Harris / could actually be attributed to book-keeping problems, if certain shipments and deliveries were neglected. As this is entirely speculative, it is not worth elaborating on, but, cf. supra p. $280 \mathrm{nn} .1061$ and 1063.

1200 It is clearly foolish to draw over-arching conclusions from the Giornale boat text, but the meaning of the sheer logic of the situation remains: delivering 82 vessels annually (P. Harris 12b, 12) to the temple of Amun (90 for all the temples) is not the result of taxation, but assigned or contracted work. 
were added to those of the larger temple plots, and to those of the craftsmen and traders, and together these formed the income of the temples. The relevant sections of P. Harris are however therefore not merely a list of things acquired by taxation and by order (in the commercial sense of the word, rather than the military one) but also the lists indicate up to triple entry references to total temple turnover, including both the items exchanged and the products acquired.

Sections IId, IIId, IVd, and Vd list the objects which Pharaoh voluntarily relinquished to the temples. In Ild these are termed inw. Gold, silver, precious stones (carnelian, lapis lazuli, turquoise) and myrrh are the import products par excellence, which Pharaoh acquired from foreign countries, and the ones which are customarily termed the inw from these countries. Garments and fruits are not the type of products one associates with the inw of the foreign countries. The Instructions for the Vizier state explicitly that he was responsible for inw for festival offerings, seemingly of internal revenue. ${ }^{1201}$

\section{Larger and Smaller Temples}

The other sections of P. Harris can be understood in the same fashion, as transfers from Pharaoh to the temples.

In P. Harris, the sections concerning the smaller temples fail to employ the terms $b: k w$, šs $y t$ and htri, where these are found in the corresponding paragraphs of the larger temples $\left(V_{c}\right.$, as opposed to $\mathrm{ll}, \mathrm{Ill}, \mathrm{IVC}$. This is inversely paralleled in the paragraphs of P. Wilbour, where the smaller temples receive $\check{s} m w$, while the larger temples do not label the grain transfers as such. There is a reference to $s m w$ in the Bilgai stele, where the religious institution is small in size. ${ }^{1202}$ The Hermopolis decree of Seti I fails to use any of the conventional vocabulary with regard to temple products. ${ }^{1203}$

This might potentially indicate that there were administrative distinctions between the major temples and the minor temples, and that their income was dealt with differently. Given the evidence however, it is difficult to say more.

Although in the abstract, it is "the bikw of the Two Lands", "1204 "the bikw of Pharaoh", ${ }^{205}$ the "b; kw of the goddess", ${ }^{200} \mathrm{P}$. Harris I repeatedly refers to "their annual b3 kw" $(28,3$ ?), "the ir annual htri" (68b,5), "their inw" $(9,3)$, reminiscent of the Bilgai Stele's "my htri" (vs. 17), "my bikw-rmt(vs. 18), "my annual šmw (vs. 20). It seems clear that the obligation to pay is what belongs to the individuals in question. In the case of the Coastal Defense Officer of the Bilgai Stele, he is responsible for an obligation to pay the works of his dependents. The dollars go on, but the buck stops with him.

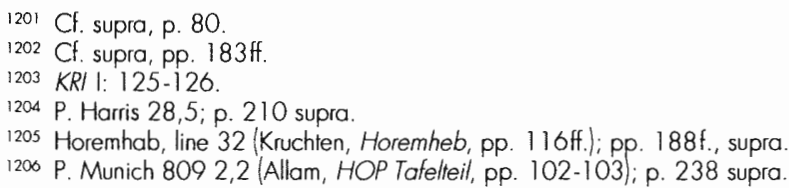


It is entirely possible that the text on the Bilgai stele also preserves an unusual instance of the relationships between small and large temples. Assuming that the Coastal Defence Officer was responsible for an official establishment (the mortuary temple of Siptah?) and a private one (the barque shrine), it would explain his anxiety to demonstrate that he had over-fulfilled his obligations to the official establishment in order to avoid accusations that he had wrongly diverted official resources from those under his official authority to the private establishment, and thus risked the elimination of that private establishment.

This stele not only throws light on the terms with which this study is concerned, but it also throws up two very relevant questions: (1) are any of these figures credible? and (2), if so why did he do it? If our reasoning is correct, then this is the explanation for both questions: yes the figures are correct, and his motivation was to demonstrate his fulfillment of his obligations to the central administration in order to protect his shrine.

On the assumption that there were in fact private religious structures, one is obliged to define the difference between the state religious organizations, and the unofficial organizations. The easiest way to distinguish these is using the categories of the Wilbour and Harris I papyri to distinguish the great cultic centres of Memphis, Thebes and Heliopolis, which it was the obligation of every king to support. Just as private people could erect minor chapels to the gods of their choice, it was also the prerogative of the kings to build temples for Osiris, Hathor, Sobek and any others they may choose, diverting official resources to this purpose. This would be the origin of, e.g., the Nauri stele, for we have the unusual case that the king is diverting "secular government" funds and resources away from the government and to the temple. Under the circumstances, it would be easy for over zealous officials to attempt to recover the lost territories. If this line of reasoning is correct, then it would explain why the Nauri stele was in Nubia, for it would have been difficult to have significantly expanded the resources available to a minor god within the context of Egypt.

\section{The Ancient Egyptian Market Economy}

The evidence of $P$. Louvre E 3226 suggests that during Dynasty XVIII the state organs used grain as a medium of exchange to acquire other goods. ${ }^{207}$ Janssen has suggested that the implications of various texts indicate that by the end of the Ramesside Period, the state grain income had declined to the extent that the state actually turned to the market to acquire grain. ${ }^{1208}$ If this is correct, it confirms that the surface area and yields of fields directly available to the king and temples were not increasing during Dynasty $X X$, as their income

1207 Cf. Megally, Recherches.

1208 Cf. J. J. Janssen, "An Exceptional Event at Deir el-Medina (P. Turin 1879, Verso II)," JARCE 31 (1994): $91-97$. The extraordinary conclusion which emerges from this is that the postulated grain market had actually come into existence. The interpretation is however bold, as the underlying assumption is that the economic chaos led to the actions, and thus amounts to circular argumentation if used as an illustration in this context. More serious is however the assumption that the metal is being taken from the workmen as individuals rather than from the institution of the tomb, as the text would certainly favour the latter rather than the former interpretation. 
would otherwise have been sufficient to assure regular payments to the Gang. ${ }^{1209}$ Grandet recognized that the state did not actually collect grain and then redistribute it, and that it arranged for direct transfers of articles from producers to consumers without the necessity of central storage. Janssen has also identified market exchanges of objects other than grain. All of this suggests that the market was the primary means by which goods were allocated on a large-scale basis.

The raw figures from P. Harris also give further food for thought. Reckoning that temple dependents could conceivably have received 2 khar/month (well below the grain wages of the Gang at Deir el-Medineh), the annual htri of 309'950 khar will have been insufficient to provide 13'000 temple dependents with a low standard of living, and 13'000 is only a small proportion of those supposedly attached to the temples, and a minuscule proportion of the population of ancient Egypt. The figure suggested by $\bigcirc$. Gard. 86 is far greater. Although probably fanciful, taken at face value it suggests that even the production of all the lands in the possession of the temple of Amun in the entire Delta was only five and a half times that amount, which could not possibly account for even 100'000 temple dependents.

The agrarian economic system in Egypt was thus based on taxation and rent in which people were awarded plots in exchange for services, under the condition that they render up part of the surplus to state authorities. In one reference the very justification for issuing grain to an individual was the fact that the request was made by someone who did "not have a field", ${ }^{1210}$ superficially suggesting not only that (1) people normally got their income from their fields, but also that (2) it was usual for private individuals to have fields. ${ }^{1211}$ This suggests that welfare payments were the exception rather than the rule, and this case likewise cannot be taken as evidence for "redistribution" because the person in question is not "producing" anything, and does not lay claim to the payment on the basis of collective production of goods.

Economically and demographically it can be concluded that (a) the annual htri was a mere skimming off of excess production and $(b)$ that this type of income could not possibly have supplied the needs of a "wider redistribution system"1212 based on a "temple-centered economy". ${ }^{1213}$ The over-all quantities for all categories of objects listed in P. Harris clearly demonstrate that this is a great deal of wealth, but it is certainly not enough to finance an entire country. It is thus clear that the temples and the Pharach did not even own a significant portion of the land in ancient Egypt, and that their income from this land was not sufficient to maintain even the most primitive redistributive system. The evidence adduced here should conclusively demonstrate that the redistributive model cannot be supported on the basis of P. Harris I. ${ }^{1214}$

\footnotetext{
1209 This naturally removes the last evidence supporting the contentions that all the land in Egypt belonged to the King, or that the lands not recorded in P. Wilbour beionged to the state (cf. supra pp. $61 \mathrm{n} .118 ; 167$ ).

1210 A. Erman, "Ein Unterstützungsgesuch," ZÄS 38 (1900): 151-152.

1211 This obviously is another argument against $D$. Kessler's conclusions ("Tempelbesitz," $L \ddot{A} V$ : 369 ) that all of the land in Egypt belonged either to the temples or the Crown.

1212 E. Bleiberg, "The King's Privy Purse During the New Kingdom, "JARCE 21 (1984): 156

1213 E. Bleiberg, "The Redistributive Economy in New Kingdom Egypt," JARCE 25 (1988): 157.

1214 For an interpretation of $P$. Harris as representing the illustration of the redistribution system based on reciprocal obligations, cf. Grandet, Papyrus Harris II: 70-76.
} 
In the absence of a functioning redistributive system, the role of the market becomes crucial. Janssen suggests that by the end of Dynasty $X X$, the state was using metal to purchase grain on the market, indicating not only that the redistribution system did not exist, but also that the state was supporting an incipient monetary economy. At the same time, peasants will have been turning to the market to acquire metals in order to fulfill their obligations to the state. Put together, this is a complete reversal of the claims for a redistribution economy. There is thus not only no "redistribution", but the market is the primary means of allocating goods, even for state organs. Ultimately, the use of metal completely eliminated the link between production and consumption.

The logic of the redistribution economy would suggest that one expect an increased concentration of economic power in the hands of the state officials and an increase in the circulation of grain. Such an interpretation would be logical in view of the monuments and texts preserved. The evidence of the role of the state in the market, and the use of metals in this exchange system seems to indicate that the monuments and texts need not be taken at face value, and that a completely different economy then emerges. As state bureaucratic structures tend to grow rather than diminish, it is far more logical to postulate that all earlier developments were based on an original market economy, from which the state initially profited, and finally participated.

The ancient Egyptian economy would thus be a pre-capitalist market economy in an agrarian society in which the state played a significant role not merely as the recipient of income, but as a participant in exchange operations. The New Kingdom state would then be merely the largest single actor, but not the dominating feature of the whole economic landscape. This situation suggests that the economically significant aspects of "redistribution" were the construction projects sponsored by the king, where thousands of masons and labourers might have been employed - and presumably remunerated with grain on occasion. To the extent that they were ordinary tax-paying farmers paid on a regular basis, their "wages" would have been "redistribution" in a strict sense of the term, but economically they would fall within the market-exchange system based on asymmetrical relations with workers accepting wages or compensation offered by a prospective employer.

Except for the prevalent use of the word "redistribution", this would ordinarily be classified as circulation of taxation paid out as wages in economic terms. And were the word not used as an argument in and of itself against the market economy, the redistribution concept would have disappeared long ago. ${ }^{1215}$ It will be noted that precisely those products delivered to the temples in P. Harris I reappear as payments to the workers at Deir el-Madineh in P. Greg. As the workers were state employees they were merely being paid, and not beneficiaries of a redistribution system. While Janssen has cautiously used the word "wages" for the payments made to the Gang at Deir el-Medineh, ${ }^{12 i 6}$ Grandet actually uses the word "wages"

\footnotetext{
1215 Both janssen and Müller-Wollermann have found clear evidence of market, activities, but in each case the mere posited existence of the redistribution system is the explicit reason given for denying the relevance of the market each has discovered; cf. janssen, Markt op de Oever, p. 23; R. Müller-Wollermann, "Warenaustausch im Ägypten des Alten Reiches," JESHO 28 (1985): 165.

1216 Janssen, Prices, pp. 455-493.
} 
for what he assumes was the equivalent of the "redistributed" income which annuls the principle of redistribution according to Polanyi, as his definition of "redistribution" depends upon the absence of "wage" labour. ${ }^{1217}$

It is significant that the Gang at Deir el-Medineh (who made the New Kingdom royal tombs) was the only group of civil servants in ancient Egypt for whom there is evidence of a long term obligation, and yet they do not seem to have been paid regularly. It must therefore be assumed that the state and temple system was not prepared to cope with even small-scale payments on a regular basis for years on end. Insofar as they were paid for services rendered, the term "wages" describes their income, as they were not producing anything collectively. Others however - such as the smdt - were apparently obliged to work without remuneration, and this can be termed corvée labour. If others were obliged to produce objects without remuneration, this can be termed "taxation". If the interpretation of the evidence concerning construction is correct, except for market activities, economically significant "redistribution" did not take place via the temples, and probably not at all. The temples may have channeled some "festival offerings" through to the people, but most of their economically relevant income will have been traded through the market.

Together with widespread private ownership of land and the use of metal in exchange, by both state actors and private individuals, such a system underlines that the market was the basic feature. The significant aspects of the economy were thus "taxation", "remuneration" and "exchange", all of which can be characterized as "circulation", and easily understood in modern economic terms as characteristic of a market economy.

Economically this could be termed a general equilibrium situation - as postulated by Walras in which the prices generated through allocation by means of market exchange were governed by the Jevons's "law of indifference". The economic role of the temples in "redistribution" was probably largely restricted to the circulation of goods through exchange: retailing items which they received as income, exchanging them for other goods which they required. ${ }^{1218}$ This exchange capacity will have been mirrored by an uncertain degree of private enterprise, but the role of middlemen in these transactions will have been limited, while the resources available to the temples may have dwarfed those available to private traders.

The effects on prices in this context are thus quite interesting, for it could be argued that the market might have been seriously impaired by the role of the temples. While the resources available to the temples need not have been any greater than indicated in the lists in P. Harris, it is evident that even the limited quantities listed in P. Harris reveal a decisive ability to influence the market. Furthermore, the temples need not have deliberately

1217 Grandet, Papyrus Harris II: 59. This confirms that Grandet understood the material, but failed to draw the necessary theoretical conclusions.

1218 P. Brooklyn 35. 1453 clearly shows market exchange transactions of this type (Cf. Janssen, Markt op de Oever; V. Condon, "Two Account Papyri of the Late Eighteenth Dynasty," RdE 35 (1984): 57-82). These transactions make it probable that $P$. Leiden 1350 vso.; $P$. Turin $2008+2016$ actually demonstrate that the temple received articles in order to resell them immediately (evidently with the express goal of acquiring profits, cf. Janssen, Ship's Logs, and supra, pp. 222 fff. This conclusion certainly marginalizes the relevance of Grandet's conclusion (Papyrus Harris, pp. 59-60) that redistribution involved administrative instructions directing collection and delivery (cited supra, pp. 93/ff). It effectively indicates that the principal activities were taxation and retailing, as in Genesis (cf. supra, p. 95). 
endeavoured to make a calculated "profit" because the objects they were selling had been acquired without expenditures - as "taxes" - while private entrepreneurs could not afford to pursue exchanges without profits, and thus the temple exchanges might have increased competition, potentially without increasing motivation. Under normal market conditions in the modern world, market type price formation may thus have been inhibited by the fact that the temples acquired merchandise by means of taxation, signifying that cost factors in the modern sense of the word need not have influenced the prices employed by the temples in exchange operations.

Although this inhibition might account for the seemingly anomalous price of papyrus discussed supra (pp. 7 If), it can be argued that the market determined the prices despite this seemingly monopolistic situation. The reason is that in the peculiar nature of the Egyptian economy, precious metals and textiles, etc. were both "money" and "articles", meaning that in exchange operations, the temples will have been circulating both metals and products. This means that if the temples aspired to fix any prices independently of the market, entrepreneurs would immediately have been able to profit from the opportunity for competition: either by investing in metals or textiles, depending upon where the temples were not responding to market values. Therefore the temples could not pursue a monopolistic price policy. This implies that the prices in ancient Egypt correspond not so much to Jevons's "law of indifference" as to Walras's system of tôtonnement. Walras actually postulated that in an ideal situation of equilibrium, entrepreneurs would be unable to make profits and the consumer would win, because competition would reduce profits to costs. ${ }^{1219}$ The role of the temples need not have been great in order to effectively inhibit price competition: the temples need merely to have been stronger than any other individual entrepreneur in order to prevent price fluctuations from injuring the consumer. This implies that the demonstrated price stability corresponded to a "general equilibrium analysis", and that the market ultimately determined prices. Walras wrote:

Thus, in a state of equilibrium in production, entrepreneurs make neither profit nor loss. ${ }^{1220}$

Dominating markets and making generous distributions of festival offerings, other actors would have been unable to compete with the object of making profits in trade. The equilibrium would been supported by state enterprise, and dependent upon it for all facets of economic life. Thus, despite the fact that the state may not have dominated the economy, its position will have assured that it determined economic activity by influencing the market, rather than by decree. Extensive profit-oriented commercial trading was virtually impossible, and priceformation not dictated by competition between entrepreneurs. It is evident that under the circumstances, being attached to a temple or an administrative position promised great advantages. This does not however mean that there were not even greater advantages 
when office was combined with private enterprise. These officials could easily have continued to acquire wealth by private commercial trading: they merely combined the two. ${ }^{1221}$ Viewed thus, not only are Gutgesell's determined economies eliminated for theoretical reasons (since he sought to explain the phenomena without investigating its possible causes), but Polanyi's whole system of categories is rendered irrelevant, for the basic guiding force would still be the exchange system, which was both inhibited and supported by the state economic intervention. As was pointed out at the outset of this study, the Keynesian analysis would suggest that the overall economic system was not sufficiently highly developed to take up the slack when state demand flagged, so that the very weakness of the market without state support demonstrates that the economy was economically dominated by a skewed market. At the same time, we have established that state trading may have played an additional role impairing the development of competitive markets. This may have guaranteed price stability and security but it thus impeded the ability of the market to replace the state, when the latter failed.

Should the logic of compulsory payments in metal for agricultural "tax"-purposes be followed however, the evidence of the temple dependents likewise obliged to render their obligations in metal ${ }^{1222}$ assumes an unexpected importance, as the transformation to a monetarised economy with a comparatively retrograde administrative organization can be assigned a significant role. These two fundamental imbalances - administrative/procedural and economic/financial - probably contributed more to the collapse than a decline in morals.

Thus, the increased role of the temples and the diminished role of Pharaoh meant that neither a free market economy nor a centrally propelled demand stimulus economy could function. At the beginning of Egyptian history an aggressive state investment program had raised demand and nurtured private enterprise. When it faltered two millennia later, this perfectly balanced system stifled and strangled economic growth.

In ancient Egypt there was always a very strict palace economy, in which only small local market-places existed. After the Amarna period, however, there developed a growing trade in Egypt, partly in surpluses of the temples, partly in imports from abroad. This trade was in the hands of the temples or of highly positioned persons and was carried out by foreign, mostly Syrian, employees. In the end, these Syrian merchants sold their merchandise more or less on their own account and directly to the people. As there were too many goods offered compared to the marked scarcity of "money" in the hand(s) of the people, the moral of the people broke down and they tried to obtain "money" by illegal means. ${ }^{1223}$

1221 Cf. the important point made by Kemp /"Old Kingdom, Middle Kingdom and the Second Intermediate Period, ' Trigger, Social History, p. 81) that the mere possession of tittes need not demonstrate that one was not deeply involved in private economic activity. Although Kemp was referring to the Old Kingdom, D. Rathbone (Economic Rationalism, passin) studied the profit-minded private estate management in the Roman period of people who were officially known as Councillors of Alexandria.

1222 As perhaps in the Turin Tax lists and certainly in O. Gardiner 86, supra, pp. 145; 159 ff.

1223 W. Helck, "The Dissolution of the Palace Economy in the Ramesside Period," in Function of the Minoan Palaces, p. 17. 
Although masterly and certainly correct in many details, W. Helck's interpretation of the developments is clearly at variance with this understanding. ${ }^{1224}$ Like M. Römer, Helck assumes that a decline in morals accompanied the increase in trade and was related to the wealth of the temples, and the practice of theft. ${ }^{1225}$ Both models are built on the assumption of a declining redistribution palace economy, and take evidence from the materials available to support an interpretation corresponding to the discrepancy between pre-conceived ideas and the known facts. This approach is not only circular - in finding that the final result is related to their suppositions - but also slightly simplistic.

Not only does this method pre-suppose a transformation where a transformation need not be postulated, but Helck's approach fails to distinguish between the spheres of responsibility implied by the interpretation presented here, which implies a fundamental imbalance between responsibility, authority and capacity. The "Teaching of Ani" seems to support Helck in suggesting that the acquisition and expansion of wealth were not negative, but it does equally assert that to be a scribe was among the most important things. ${ }^{1226}$ The values represented do not seem to vary much from those known earlier, although the sense of responsibility does show a perceptible decline in comparison to the Middle Kingdom. It is difficult to estimate the degree to which temple trading could influence morals, as opposed to the failure of the authorities to assure that the grain surplus increased, i.e., the problem was not the political and economic potency of Karnak, but the political and economic impotence of the king combined with the lack of a legitimate means providing Karnak with the ability to take up the entire royal role, and the failure to realise this. ${ }^{1227}$

The evidence available today indicates that the Third Intermediate Period did not initiate an era of flourishing capitalistic economics, but rather that the temple domination of the economy continued unabated. The overall level of wealth did however drop significantly, or fail to grow. It is only due to the utter ruin of the state economy at the end of Dynasty XX that the market aspects come to the fore, because evidence from other sectors is lacking. This does not mean that these market aspects were not there earlier, and cannot be used to argue an increase in the market sector. The presence of foreign traders can hardly be described as something new, since the evidence indicates that economically active foreigners were significantly involved in Egypt since at least Dynasty XII (and probably contributed significantly

1224 "Dissolution," in Function of the Minoan Palaces, pp. 17-19

1225 M. Römer, "Der Handel und die Kaufleute im alten Ägypten," SAK 19 (1992): 279-281.

1220 Cf. Quack, Ani, pp. 101; 107. Cf. supra, p. 102 n. 274; pp. 133f. If Quack's Ramesside date is correct (Ani, $\mathrm{pp} .6 \mid \mathrm{f}$ ), it could indicate a change in values, but betrays the fundamental production-oriented antagonism based on accumulation and trading rather than production for the acquisition of wealth.

1227 His assumption that the central organization was solely responsible for wholesale import purchasing during Dynasty XVIII is not demonstrated. N. de G. Davies and R. O. Faulkner ("A Syrian Trading Venture to Egypt, "JEA 33 (1947]: 45) wrote: "The butk of the merchandise discharged [... was] doubtless [...] for the granaries of Amun under his control, and possibly also for other high authorities." Their conclusion is possible, but not compelling. This must be set against the much later miscellany text indicating that it was reasonable to suggest that a scribe's ship could come from Syria (P. Anast. IV 3, 10; LEM p. 38,4; Caminos, LEM, p. 138); and the archaeological evidence (cf. Merrillees, Pottery, pp. 173-174). Cf. also E. W. Castle, "Shipping and Trade in Ramesside Egypt,' JESHO 35 (1992): 239-277; and Quack, Ani, p. 101. If the state was not alone responsible for large scale trade before the Amarna period, Helck's argument crumbles (which alone does not demonstrate the veracity of this one, of course). 
to the rise of the Hyksos, for a variety of reasons). It is possible that the role of the state in the market economy increased, and that this leads to the impression that the market is appearing. It is more probable however that state involvement in the market accompanied the overall decline of the state sector, and thus drew the veil away from the market.

A supplementary explanation could be sought proceeding from the inscriptions of Mes and $P$. Valençay I which suggest that even revenues from fields were collected in metal during the New Kingdom, and the implication of a development similar to that introduced under the T'ang and Sung Dynasties in China should be evident. ${ }^{1228}$ Although metal was unquestionably collected during the Old and Middle Kingdoms, exacting taxes on agricultural land in metal may have been new. These two hints are the only indications supporting a metal-based monetarisation of the economy and should not be overdrawn. Combined with Janssen's suggestion that the state was actually using metal to purchase grain, this evidence assumes a completely different significance. The ultimate fall of the Empire and Egypt's failure to recover can be ascribed to multi-fold fundamental economic dislocations, among which the most fundamental will have been state exploitation of the market, combined with the failure to sustain the grain based economy which had produced the Old Kingdom.

The economic implications of this development were that a full-scale grain market was called into existence, where peasants would be competing with state officials to dispose of their grain: the peasants to acquire the metals to pay the taxes, and the officials to acquire desired goods. The existence of the grain market by the end of Dynasty XX would confirm that any previously existing redistribution system had utterly failed.

As demand had previously required that the surplus be at the disposal of the state, the drop in construction projects can either be altributed to (1) the very existence of the grain market, since the incentive to work for grain wages would be limited in a world with a market overflowing with grain; or to (2) the decline in production due to administrative factors. In either case, the economy was destined to decline, with a decreasing supply of precious metals available, and a decreasing incentive to produce a surplus, since bumper crops would merely result in falling prices, and thus higher taxes and lower income. As the prosperity of the earlier period had been dependent upon a system in which over-production had

1228 Cf. pp. 101f.; 136f.; 139 supra. Whether the reference to the šsyt of silver and gold refers to Pharaoh's own income in the Horemhab Decree (supra, p. 189) is less certain, although in this case, the mere presence of the precious metals is significant. It is clear that the acquisition of gold and silver continued despite Horemhab's edict, whatever the original intent of this part of the fragmentary text was. The vague suspicion arises however that Pharaoh started to seek access to the melal wealth of his own citizens rather than that of foreign countries sometime after the accession of Amenophis III, and it is probably this development which is the cause of the symptom of decline identified by Helck in his assumption that private transactions from the time of the Amarna period led to the decline of the economy. The primary difference between the two interpretations would merely be selting the blame clearly on Pharaoh for curtailing private activity, distorting the grain market, and reducing the incentive to produce. For the proportions of gold and silver in Dynasties XVIII and XX, cf. supra, p. 20.

Everything suggests that an economic development in the direction which the rest of Asia followed until the middle of the 18 th century A.D. (cf. Chaudhuri, Asia before Europe) was in the making, but that the crucial situation of an independent market had failed to emerge before the end of the Ramesside period. Strangely enough, it has likewise been claimed that China was on the verge of an industrial revolution in the 12th century A.D. and one wonders what the ultimate role of financial arrangements with low interest rates and increasing supplies of silver had in the European experience after 1500 A.D. 
resulted in increased income, the tables were now turned on the peasants. The only conceivable outlet for excess production under these changed circumstances lay in exports, and a half millennium of decline would ensue before the Mediterranean grain market would be able to take up the slack: the economy could not save itself under the changed circumstances. ${ }^{1229}$

Prior to the emergence of the Mediterranean grain market, however, trade will have been carried out both internationally and on a local scale. On the international scale one could fit the two shipwrecks found off the Turkish coast into a vast web of interlocking markets, as is evident from their cargoes. Both the cargoes and the systems of weights present on the ships indicated that these traders were internationally active. ${ }^{1230}$ It is however interesting to note that it is generally speculated that both ships were victims of bad weather. Both the Cape Gelidonya wreck and the Ulu Burun wreck lie off the Lycian coast, and there are complaints about Lycian pirates in the Amarna letters, indicating that these ships could equally easily have been the victims of foul play. ${ }^{1231}$ Such trading ventures will have been primarily concerned with prestige goods rather than bulk goods, until political security could be established.

One of the arguments in favour of the state adduced above was the security guaranteed by a political organization, and this security was necessarily lacking on the fringes of the Ancient Orient (such as the Lycian coast). Within the territories of the major states, however, security was guaranteed in times of peace. It is evident that the logical conclusions following from the preceding notes are that price stability in ancient Egypt can be associated with Walrasian general equilibrium analysis, and that this type of price stability corresponds very closely to the price systems prevailing among peasant societies. Such systems correspond to the "market-days" and "market-towns" of the peripheral parts of the modern world. In recent years, it has become clear that this was a central element of the world beyond the Mediterranean long before the emergence of the trade fairs which characterized the end of the European Middle Ages. Such fairs were protected by the local political authorities.

1229 It must be repeated that Kemp's postulated "finite limits of the agricultural surplus" ("Old Kingdom, Middle Kingdom and Second Intermediate Period," in Trigger, Social History, p. 176, quoted supra, p. 125) did not really identify the principal difficulty, which was not production, but consumption. As Egypt later exported grain in the Eastern Mediterranean and subsequently became the grain supplier for the Roman Empire, the problem was clearly markets, not production.

It is curious to note that K. Baer ("The Low Price of Land in Ancient Egypt," JARCE I [1962]: 25-45, esp. p. 29) suspected that the low prices in the Third Intermediate Period were due to the political situation, while this explanation would underline the futility of owning land for purely economic reasons. As the political decline is being progressively thrown into doubt, the economic factors assume a greater importance. Baer's date for the "Stèle d'apenage" requires emending, and the units perhaps as well, but the data is still valid for its general relevance (cf. D. A. Warburton, "Keynes'sche Überlegungen zur altägyptischen Wirtschaft," ZÄS 118 [1991]: p. 84 n. 26$)$

1230 Cf. Bass, Gelidonya, pp. 135-142; 163-167; M.H. Gates, "Archaeology in Turkey," AJA 99 (1995): 223225, for the most recent references to the Ulu Burun wreck.

1231 The letters from the King of Alasia mention these, ct. EA $38 \mathrm{ff}$. It would appear entirely possible that the Cape Gelidonya ship was actually trying to flee when it foundered. 
Sir John Hicks erected his entire theory of economic development on the principle that these trade fairs appeared in the Mediterranean world, and that they had not existed elsewhere. ${ }^{1232}$ K. Chaudhuri has however shown that Asian trading activities and towns and cities long preceded their emergence in the Mediterranean. ${ }^{1233}$ Many models have been erected on the basis of excluding Asia and the Ancient Orient from the development of market economics, although it is now evident that the Europeans learnt the principles of market economics from Asia. This reasoning has constantly led to circular logic, which confirms the point of departure. It is more logical to suggest that the temple vessels proceeding along the banks of the Nile were stopping at the ancient Egyptian equivalent of trade fairs, and that these trade fairs were the basic characteristic of the Egyptian exchange economy. ${ }^{1234}$

The Pharaohs and the temples extracted wealth from the land. They used this wealth to build monuments and stimulated the economy in an extraordinary fashion and recorded this in inscriptions. While these inscriptions detail their own activity, and the role of the temples etc., they also imply and explicitly mention and confirm market economic activity, but the evidence has been repeatedly denied, because the preconceptions prevented it from being recognized. There has also been a tendency to compare different types of evidence, without consciously reflecting on whether this was justifiable. ${ }^{1235}$

\section{CONCLUSIONS}

The birth of the ancient Near Eastern Market Economy can probably be assigned the relatively arbitrary date of 2000 B.C. Before this date, the Anatolians were mining tin, and

1232 Hicks, Economic History, pp. 25-41. Sir John actually went so far as to deny that trading-cities could have existed along the coasts of the Indian subcontinent (p. 39), as if unconscious of why the British, French and Portuguese fought for the possession of the subcontinent.

1233 Chaudhuri, Asia Before Europe, passim.

1234 Cf. S. R. Epstein, "Regional fairs, institutional innovation, and economic growth in late medieval Europe," EHR 47 (1994): 459-482, for an analysis of the regional - as opposed to international - aspects of these fairs, and a lengthy bibliography. There is naturally no reason why foreign merchants could not have participated in the Egyptian riverbank markets las in the frequently discussed scene presented by $N$. de $G$. Davies and R. $O$. Faulkner, "A Syrian Trading Venture to Egypt," JEA 33 [1947]: 40-46). I would advocate that this scene is the ideal portrait of the river-bank market, but this is pure speculation.

1235 One could note that Helck's observations took several different details and then drew chronologically far reaching conclusions which reflected little more than circular logic lassuming a redistribution palace economy which then faliered, etc.).

The same phenomenon guided the speculation about the price of papyrus. Caminos and Černy assumed that because it was reused, it must have been expensive. The explanation for the "seeming scarcity" and the seemingly low price is probably easily explained: the administration probably used lots of papyrus for administrative documents which were soon out of date. This papyrus could be used to make cartonnage for coffins, or it could be used to write on. Since there was so much used papyrus around, there was probably little or no motivation to purchase new papyri, except for books of the dead, etc. Thus, papyrus could have been cheap, but widely reused, because of its abundance.

The conclusions and the logic are not all part of one consistent argument - different things are being mixed together, and the result does not necessarily lead to decisive conclusions. The suggestion made here is possible. (There should be little doubt about its relatively low price - accounting for it is another matter.) 
Babylonia was under the thumb of the Redistributive Economy of the Third Dynasty of Ur. After this date, the gold:silver ratio in Egypt changed from 2:1 to 1:2, and the Anatolians stopped mining tin, and the Old Assyrian traders introduced trading profits and fluctuating prices. Prices throughout the ancient world were henceforth denominated ultimately in silver or copper and the "Theory of Comparative Advantage" dictated economic activity in every corner of the ancient Near East. Even if people did not notice the change, it has effected every aspect of their lives ever since. ${ }^{1236}$

In Egypt, economically we have seen that it was demand which was the crucial factor in raising wealth, by creating the surplus and the division of labour which were the prerequisites for the circulation of goods. Politically this surplus was taxation, and economically these goods were circulated through exchange, rations, and wages, but not redistribution. Politically and economically the evidence preserved is heavily weighted in favour of the temples, yet it is evident that the temples were only an adjunct to the centrally steered demand economy. The role that the temples played in the exchange economy implied both stability and justice, but limited the possibility for entrepreneurs to compete with the state, so that entrepreneurial skills were lacking when the state declined. Although the system worked well for everyone while demand and circulation increased, it went badly for everyone when demand and circulation decreased.

The terminology studied in this work suggests that payments directed to the temples can be termed "taxes" and "rents", but that the original objects acquired were re-circulated through a market mechanism, by means of which the temples acquired other objects which they required. It was however established that the Pharaohs kept the temples on a very short leash, maintaining control of the stone and incense essential for cultic activity.

In terms of the overall development through Egyptian history, the economic centres were the royal court and certain powerful families during the Old Kingdom. Throughout Egyptian history, most of the land was in the hands of private land-owners, large and small. Throughout Egyptian history there were private craftsmen and traders working on their own account as well as with the state. The taxation of these land-owners and craftsmen was introduced or formalized during the Archaic period and increased during the early part of the Old Kingdom. This created wealth by increasing demand, sharpening the division of labour, and contributed to a flourishing private economy. The concentration of wealth will however have given the court a central role in exchange, as well as acquisition.

This central role need not however have been over bearing: it need merely have been substantial enough to determine the general level of economic activity. The state exploited

1230 It is perhaps worth noting that the crucial developments leading to this international market economy must be dated to the transition from the Ubaid Period to the Uruk Period, ca. $4500-4000$ B.C. (?). The next decisive change was the international economy at ca. 2000 B.C., and then the global economy since ca. 1571 A.D. It is very curious that the value of silver determined all economic activity between 2000 B.C. and roughly 1700 B.C. At this point European interest rates dropped unexpectedly, precipitously and permanently from c. 30 per cent. to 2.5 - 7 per cent, and the industrial revolution was made possible (because it was now worth borrowing money to manufacture, as opposed to borrowing money in order to make trading profits). 
the possibilities of existing market exchange mechanisms, and was able to maintain a relatively "just" price structure. These prices were however determined by self-interest of the entrepreneurs because of the Walrasian general equilibrium, and not maintained by decree or even deliberately. This implied that when the centrally steered demand economy declined, only those geographical areas with the requisite social structure still intact could reorganize their own miniature imilations of the state economy, which maintain a high level of economic activity, while those more immediately effected by developments were unprepared for the assumption of political responsibility, and their situation declined. The Middle Kingdom endeavoured to resurrect the system at a different level, which led to an imitation of the situation in the Old Kingdom. The Second Intermediate Period was far more complicated than the First, and the repercussions difficult to survey and interpret on an equally global scale, but the resurgence of the New Kingdom introduced the same centrally steered demand economy.

The essential aspect of this central steering was not redistribution, but "collection" and "exchange" of a surplus which effectively increased overall wealth and prosperity. The material beneficiaries of this system were the ostentaciously wealthy occupants of the temples and palaces. Material benefits also accrued to the population at large as the articles acquired through taxation were circulated through the economy in market exchange in order to acquire other goods. The exploitation of the market mechanism benefited all sectors of society, so long as the state's grain surplus was sufficient to stimulate demand and circulation.

During the New Kingdom however, the temples acquired a significance in terms of the legitimacy of the Empire and relations with the Kings that was unparalleled during the Old and Middle Kingdoms. Although politically significant as independent actors, their economic activities were curtailed by a failure to endow them with the equivalent administrative and infrastructural support, so that when the royal family failed to produce the powerful leaders necessary, the temples were unable to fill the gap, being unprepared for the responsibilities which they must have assumed to supplant the Kings. As much of the valuable human resources of the country had been incorporated into the administrative structure of the country in the course of developments during the preceding millennia, the social structure was not as well prepared to assume the responsibilities expected of it, as certain provincial areas had been able to at the close of the Old Kingdom.

The result was that although the $b: k w$-obligations lay heavily on the population, creativity and productive forces had also been supported and developed, but without the social and economic transformations required to free them, so that sociely was unprepared for the slip in central demand with the result that external interference could not be adequately resisted, and decline set in, without any chance of the Crown recovering the position that it had had vis-à-vis the temples at the beginning of the New Kingdom.

An irreversible shift in the balance of economic power had occurred, and the political system was unequal to the task of rectifying it. Economically, the crushing blow was the appearance of a grain market in which the state competed with other members of society. Combined with the introduction of a monetarised system of payments for agricultural taxes, 
this decimated the virtues of using grain and work as the primary elements of state income and expenditure. While this inevitably undermined the state economy, it also diminished the value of private land-ownership. In the period immediately after the Ramesside period, the nmt w w found the obligation to pay taxes a burden which was worth more than the land. As a result, they began to sell their land, cyclically driving its price even further down, and weakening their social position, as they became tenants on land which they had previously owned. ${ }^{1237}$ Thus after the end of the New Kingdom Egyptian sociely was changed, as the roles of the state and the people were fundamentally transformed.

During the Ramesside period the commercial role of the temples had discouraged the development of an independent market based on competition and profit, so that the private sector was economically and socially unprepared and unable to develop freely, without the marketfavoring methods of the temples. The consequence was that politically, the central organizations of the state became a crushing burden rather than a creative factor. The result was that state expenditures overtook income, production plummeted, and the capital of the country was expended, and ruin followed, as Ricardo pointed out would inevitably happen. As the temples had become the guarantors of legitimacy, it was impossible for the ruling family to recover its previous independent economic and political power, and the Egyptian state was condemned to eternal decline.

The whole development indicates that economically the goods exchanged and the nature of the market did not contribute to the development of a high level of exchange, i.e., an economy in which the market mechanism fueled and stimulated an economic take-off leading to production for a market dominated by traders, because (1) at least a large part of the sale and distribution of the limited spectrum of manufactured goods remained in the hands of the producers, even where production was market-oriented and not necessarily motivated by specific orders by clients; (2) a sufficiently large part of the independent commercial trading was in the hands of the central state organizations which impinged on price competition due to the Walrasian equilibrium guaranteed by their behavior; and (3) the saturation of the market with grain failed to enable private investments to prosper without an export economy. The failure of the market to move beyond this low level implied that state-sponsored economic activity - both taxation and trade with articles acquired through taxation - was decisive for the economy, and that the economy rose and fell with the state taxation and investment programs. 
PART V

BibliogRAPHY 



\section{Bibliographical AbBREVIATIONS}

N.B.

This list includes the abbreviations of monographs, periodicals, series and institutions, etc. of immediate bibliographical relevance.

All monographs have been cited in the abbreviated form only. Certain works have been abbreviated with author and title (as, e.g., Assmann, $\ddot{A} H G$, others merely by title (as, e.g., H.O., LRL, etc.).

Only sources cited in abbreviated form in the text are listed here.

Articles in periodicals and collective works cited in the notes are in the following bibliography.

In citing sources in the text the object has been to (1) provide maximum accessibility, while (2) indicating the relevance of the source. The text will thus refer to e.g., O. Gard. 86, while the notes will refer the reader to H.O. 81-82. References such as "LEM, Caminos LEM" or "LRL, Wente $L R L$ " refer to the published text, and the translation. The hope is that the reader will recognize the source quickly.

ÄAT

ÄgAbh

AEO

Ahitur Toponyms

AIPHOS

AJA

Allam Grund und Boden

Allam $\quad H O P$

Allen Book of the Dead

Andrassy Staat

AOS

ARCE

ASAE
Ägyplen und Altes Testament. Wiesbaden.

Ägyptologische Abhandlungen. Wiesbaden.

A. H. Gardiner. Ancient Egyptian Onomastica. 3 vols. Oxford, 1947.

S. Ahituv. Canaanite Toponyms in Ancient Egyptian Documents. Jersusalem, 1984.

Annuaire de l'institut de philologie et d'histoire orientales et slavs. Brussels.

American Journal of Archaeology. Boston.

S. Allam (ed.). Grund und Boden in Allägypten. Tübingen: Untersuchungen zum Rechisleben im alten Ägypten 2, 1994.

S. Allam (ed.). Hieratische Ostraka und Papyri. 2 Parts. Tübingen: Urkunden zum Rechisleben im alten Ägyplen, 1973.

T. G. Allen. The Book of the Dead or Going Forth by Day. Chicago: SAOC 37, 1974.

P. Andrassy. ... Unpublished PhD thesis. Berlin, 1987.

American Oriental Series. New Haven.

American Research Center in Egypt.

Annales du Service des Antiquités de l'Égypte. Cairo. 


\begin{tabular}{|c|c|c|}
\hline Assmann & $\ddot{A} H G$ & J. Assmann. Ägyptische Hymnen und Gebete. Zurich, 1975. \\
\hline Assmann & Ma'at & $\begin{array}{l}\text { J. Assmann. Ma at: Gerechtigkeit und Unsterblichkeit im Alten Ägyplen. Munich, } \\
1990 .\end{array}$ \\
\hline Assmann & Problems & $\begin{array}{l}\text { 1. Assmann, G. Burkard, V. Davies (eds.). Problems and Priorities in Eyptian } \\
\text { Archaeology. London: Studies in Egyptology, } 1987 .\end{array}$ \\
\hline Assmann & Sinngeschichte & Ägypten: eine Sinngeschichte. Darmstadi, 1996. \\
\hline Atzler & Herrschaftsformen & $\begin{array}{l}\text { M. Atzler. Untersuchungen zur Herausbildung von Herrschaftsformen in Ägypten. } \\
\text { Hildesheim: HÄB } 10,1981 \text {. }\end{array}$ \\
\hline AV & & Archäologische Veröffentlichungen of the DAI, Cairo. Mainz. \\
\hline$B A$ & & Biblical Archaeologist. Baltimore. \\
\hline Bakir & Epistolography & A. Bakir. Egyptian Epistolography. Cairo: BdÉ 48, 1970. \\
\hline Ball & Theory & T. Ball. Reappraising Political Theory. Oxford, 1995. \\
\hline Ball, et al. & Political Innovation & $\begin{array}{l}\text { T. Ball, J. Farr, R. L. Hansom (eds.). Political Innovation and Conceptual Change. } \\
\text { Cambridge Universty Press: Ideas in Context, } 1989 .\end{array}$ \\
\hline$B A R$ & & J. H. Breasted. Ancient Records of Egypt. 5 vols. Chicago, 1906-1907. \\
\hline Barry & Theory & N. R. Barry. An Introduction to Modern Political Theory. London, 19953. \\
\hline Bartl & $\begin{array}{l}\text { Zwischen Euphrat } \\
\text { und Tigris }\end{array}$ & $\begin{array}{l}\text { K. Bartl, R. Bernbeck, M. Heinz (eds.). Zwischen Euphrat und Tigrus: Aktuelle } \\
\text { Forschungsprobleme in der vorderasiatischen Archäologie. Hildesheim, } 1995 .\end{array}$ \\
\hline BASOR & & Bulletin of the American Schools of Oriental Research. Baltimore. \\
\hline Bass & Gelidonya & $\begin{array}{l}\text { G. F. Bass, et al. Cape Gelidonya: A Bronze Age Shipwreck. Philadelphia: } \\
\text { Transactions of the American Philosophical Sociely, vol 57/8, 1967. }\end{array}$ \\
\hline $\mathrm{BD}$ & & $\begin{array}{l}\text { Book of the Dead (followed by "Spell" No, cf. Naville Tb.; or Allen, Book of } \\
\text { the Dead or Hornung Tb.). }\end{array}$ \\
\hline $\mathrm{BdE}$ & & Bibliothèque d'Étude. Cairo: IFAO. \\
\hline Beckerath & Chronologie & $\begin{array}{l}\text { J. von Beckerath. Chronologie des ägyptischen neven Reiches. Hildesheim: } \\
\text { НӒB } 39,1994 \text {. }\end{array}$ \\
\hline Bellamy & Theories & $\begin{array}{l}\text { R. Bellamy (ed.). Theories and Concepts of Politics: an Introduction. Manches- } \\
\text { ter, } 1993 .\end{array}$ \\
\hline $\mathrm{BibAe}$ & & Bibliotheca Aegyptica. Brussels. \\
\hline Bierbrier & Papyrus & M. L. Bierbrier (ed.). Papyrus: Structure and Usage. London: BMOP 60, 1986. \\
\hline Bietak & Tell ed-Dab 'all & $\begin{array}{l}\text { M. Bietak. Tell el-Dab a II. Vienna: Österreichische Akademie der } \\
\text { Wissenschaften Denkschriften der Gesamtakademie Band IV Untersuchungen } \\
\text { der Zweigstelle Kairo des Österreichischen Archäologischen Institutes I, } 1975 .\end{array}$ \\
\hline$B I F A O$ & & Bulletin de I'Institut Français d'Archéologie Orientale. Cairo. \\
\hline Bib. Nat & & cf. B.N. \\
\hline $\mathrm{BiOr}$ & & Bibliotheca Orientalis. Leiden. \\
\hline Birch & Facsimile & $\begin{array}{l}\text { S. Birch. Facsimile of an Egyptian Hieratic Papyrus. London, 1876; Wiesbaden } \\
1982^{2} \text {. }\end{array}$ \\
\hline Blaug & Economic History & M. Blaug. Economic History and the History of Economics. New York, 1986. \\
\hline Bloug & Economic Theory & M. Blaug. Economic Theory in Retrospect. Cambridge, $1985^{4}$. \\
\hline BMFA & & Boston Museum of Fine Arts. \\
\hline
\end{tabular}


BMOP

B.N.

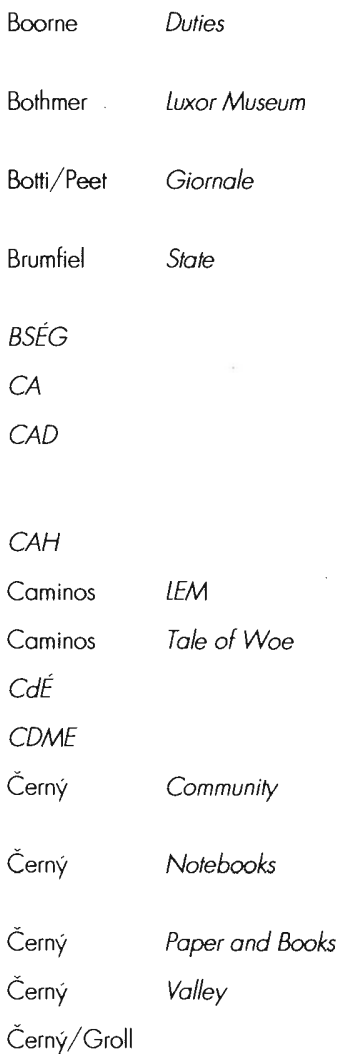

$C G$

Chaudhuri Asia before Europe

Claessen/ Early State
Skalnik
Claessen/ Study of the State
Skalnik
Cohen/

DAI

Davies
British Museum Occasional Papers. London.

Bibliothèque Nationale, Paris (ostraca and papyri in the collection).

G. P. F. van den Boorn. The Duties of the Vizier. London: Studies in Egyptology, 1988.

B. V. Bothmer and J. F. Romano, et al. The Luxor Museum of Ancient Egyptian Art. Catalogue. Mainz: ARCE, 1979.

G. Botti and T. E. Peet. // Giornale della Necropoli di Tebe. Turin: I Papiri leratici del Museo di Torino, 1928.

E. M. Brumfiel led.). The Economic Anthropology of the State. New York, 1994.

Bulletin of the Société d'Égyptologie, Genève. Geneva.

Current Anthropology. Chicago.

L. Oppenheim, et al. (eds.). The Assyrian Dictionary of the Oriental Institute of the University of Chicago. 21 vols. (several still unpublished). Chicago/ Glückstadt, 1964 -

Cambridge Ancient History. Cambridge.

R. A. Caminos, Late Egyptian Miscellanies. Oxford, 1954.

R. A. Caminos. A Tale of Woe. Oxford, 1977.

Chronique d'Égypte. Brussels.

R. O. Faulkner. A Concise Dictionary of Middle Egyptian. Oxford, 1962.

J. Cerny. A Community of Workmen at Thebes in the Ramesside Period. Cairo: BdÉ 50, 1973

J. Černý. Notebooks. The unpublished manuscripts maintained at the Griffith Institute at Oxford University.

J. Černý. Paper and Books in Ancient Egypt. London, 1952.

J. Cerny. The Valley of the Kings. Cairo: BdÉ 61, 1973.

J. Černý and S. 1. Groll. A Late Egyptian Grammar. Rome: Studia Pohl Series Maior 4, 1975.

Catalogue Générale des Antiquités Égyptiennes du Musée du Caire. Numerous vols. Cairo.

K. N. Chaudhuri. Asia before Europe: Economy and Civilisation of the Indian Ocean from the Rise of Islam to 1750. Cambridge, 1990

H. J. M. Claessen and P. Skalnik (eds.). The Early State. The Hague: New Babylon Studies in the Social Sciences 32, 1978.

H. J. M. Claessen and P. Skalnik (eds.). The Study of the State. The Hague: New Babylon Studies in Social Sciences 35, 1981.

R. Cohen and E. R. Service (eds.). Origins of the State: the Anthropology of Political Evolution. Philadelphia, 1978.

1. Creedy (ed.). Foundations of Economic Thought. Oxford, 1990.

Deutsches Archäologisches Institut.

N. de G. Davies. The Rock Tombs of El Amarna. 6 vols. London: Archaeological Survey of Egypt 13-18, 1903-1908. 


\begin{tabular}{|c|c|}
\hline Davies & Rekh-mi-Re- $\bar{e}^{\mathrm{c}}$ \\
\hline \multicolumn{2}{|l|}{$D E$} \\
\hline Decker & Leistung \\
\hline $\begin{array}{l}\text { Deines/ } \\
\text { Westendorf }\end{array}$ & Wörterbuch \\
\hline $\begin{array}{l}\text { Demarée/ } \\
\text { Janssen }\end{array}$ & Gleanings \\
\hline DeVore & Primate Behavio \\
\hline Dittmar & Blumen \\
\hline$D I E$ & \\
\hline Dobb & Capitalism \\
\hline Drenkhahn & Handwerker \\
\hline Drèze & $\begin{array}{l}\text { Unemployment } \\
\text { Equilibria }\end{array}$ \\
\hline
\end{tabular}

EA

$E A$

EHR

Eisenstadt Political Systems

EK

Ellis

Encausse/ Marism and Asia

Schram

$\begin{array}{ll}\text { Endesfelder } & \text { Staat } \\ \text { Erichsen } & \text { Harris }\end{array}$

EU

Faulkner

$C T$

Finley Ancient Economy

Fischer Weligeschichte 3

Frank Capitalism

Frankfort Kingship and the Gods
N. de G. Davies. The Tomb of Rekh-mi-Rée at Thebes. 2 vols. New York: Metropolitan Museum of Art Egyptian Expedition Publications 11, 1943.

Discussions in Egyplology. Oxford.

W. Decker. Die physische Leistung Pharaos. Cologne, 1971.

H. v. Deines and W. Westendorf. Wörterbuch der Medizinischen Texte. 2 parts. Berlin, Grundriss der Medizin der alten Ägypter 7, 1961-1962.

R. J. Demarée and J. J. Janssen (eds.). Gleanings from Deir el-Medina. Leiden: EU 5, 1982.

1. DeVore (ed.). Primale Behavior: Field Studies of Monkeys and Apes. New York, 1965.

J. Dittmar. Blumen und Blumensträuße als Opfergabe im alten Ägypten. Berlin: MÄS 43, 1986.

L. Lesko (ed.). A Dictionary of Late Egyptian. 4 vols. and indices. Berkeley and Providence, $1975 \mathrm{ff}$.

M. Dobb. Studies in the Development of Capitalism. London, 1963.

R. Drenkhahn, Die Handwerker und ihre Tätigkeiten im alten Ägypten. Wiesbaden: ÄgAbh 31, 1970.

J. H. Drèze. Unemployment Equilibria: Essays in Theory, Econometrics and Policy. Cambridge, 1991.

El Amarna. Followed by tomb number.

W. L. Moran. The Amarna Letters. Baltimore, 1992. J. A. Knudtzon. Die El-Amarna-Tafeln. 2 vols. Leipzig, 1915.

Economic History Review. London.

S.N. Eisenstadt. The Polifical Sysiems of Empires: the Rise and Fall of the Historical Bureaucratic Sociefies. New York, 1969.

El Kab. Followed by tomb number.

M. deJ. Ellis. Agriculture and the State in Ancient Mesopotamia: An Introduction to Problems of Land Tenure. Philadelphia, 1976.

H. C. d'Encausse and S. R. Schram (eds.). Marxism and Asia. London, 1969.

Endesfelder. ... Unpublished PhD thesis. Berlin 1980.

W. Erichsen. Papyrus Harris / Hieroglyphische Transkription. Brussels: BibAe 5, 1933.

Egyptologische Uitgaven. Leiden: Nederlands Instituut voor het nabije Oosten.

R.O. Faulkner. The Ancient Egyptian Coffin Texts. 3 vols. Warminster, 19731978.

M. I. Finley, The Ancient Economy. London, $1985^{2}$.

E. Cassin, J. Bottéro and J. Vercoutter (eds.). Die Altorientalische Reiche II: Das Ende des 2. Jahriausends. Frankfurt: Fischer Weltgeschichte 3, 1966.

A. G. Frank. Capitalism and Underdevelopment in Latin America. New York, 1969. (Numerous editions).

H. Frankfort. Kingship and the Gods. Chicago, 1948. 

Fried Political Sociely M. H. Fried. The Evolution of Political Sociely. New York, 1967.
Fs Alp
Fs Fecht
FuB
H. Otten, et al. (eds.). Festschriff für Sedat Alp: Hittite and Other Anatolian and Near Easlern Studies in Honour of Sedat Alp. Ankara, 1992.
J. Osing and G. Dreyer. Form und Mass: Festschrift für Gerhard Fecht. Wiesbaden: ÄAT 12, 1987.
Forschungen und Berichte. Berlin.

Function of the Minoon Palaces

Gamer-Wollert Fische

Gard.

$\begin{array}{ll}\text { Gardiner } & \text { Admonitions } \\ \text { Gardiner } & \text { Grammar } \\ \text { Gardiner } & \text { Hieratic Texts } \\ \text { Gardiner } & \text { Mes } \\ \text { Gardiner } & \text { P. Chester Beattyl } \\ \text { Gardiner } & \text { RAD } \\ \text { Gardiner } & \text { Royal Canon } \\ \text { Gardiner } & \text { Wilbour } \\ \text { Gardner } & \text { Sierling-Dollar } \\ \text { Gasse } & \text { Diplomacy } \\ \text { Gauthier } & \text { Données Nouvelles } \\ & \text { Dict. } \\ \text { Germer } & \text { Flora }\end{array}$

Gibson/Biggs Power

Gillis, et al. Trade and Production

Gledhill State and Society

$G M$

Gödecken Meten

Goedicke Königliche Dokumente
R. Hägg and N. Marinatos (eds.). The Function of the Minoon Palaces. Stockholm: Skrifter utgivna av Svenska Institutet i Athen/Acta Instituti Atheniensis regni Sueciae Series 4 35, 1987.

I. Gamer-Wallert. Fische und Fischkulte im alten Ägypten. Wiesbaden: ÄgAbh 21, 1970.

Gardiner (ostraca from his private collection, published in various places).

A. H. Gardiner. The Admonitions of an Egyptian Sage. Leipzig, 1909.

A. H. Gardiner. Egyptian Grammar. Oxford, $1957^{3}$.

A. H. Gardiner. Egyptian Hieratic Texts. Series 1, Part 1. Leipzig, 1911.

A. H. Gardiner. The Inscription of Mes. Leipzig: Unters. 4/3, 1905.

A. H. Gardiner. The Library of A. Chester Bealty: Description of a Hieratic Papyrus [etc.]. The Chester Beatty Papyri, No. 1. Oxford, 1931.

A. H. Gardiner. Ramesside Administrative Documents. Oxford, 1948.

A. H. Gardiner. The Royal Canon of Turin. Oxford, 1959, $1987^{2}$.

A. H. Gardiner. The Wilbour Papyrus. 3 vols. Oxford, 1948.

R. N. Gardner. Sterling-Dollar Diplomacy. New York, 1969?.

A. Gasse. Données Nouvelles administratives et sacerdotales sur l'organisation du domaine d'Amon XXe-XXle Dynasties. 2 vols. Cairo: BdÉ 104, 1988.

H. Gauthier. Dictionnaire des noms géographiques contenus dans les textes hiéroglyphiques. 7 vols. Cairo, $1925 \mathrm{ff}$.

R. Germer. Flora des pharaonischen Ägyplen. Mainz: DAI Kairo Sonderschriff 14, 1985.

M. Gibson and R. D. Biggs (eds.). The Organization of Power: Aspects of Bureaucrocy in the Ancient Near East. Chicago: SAOC 46, 1987.

Gillis, C., Ch. Risberg and B. Siöberg (eds.). Trade and Production in Premonetary Greece: Aspects of Trade. Jonsered: SMA Pockelbook 134, 1995.

J. Gledhill, B. Bender and M. T. Larsen (eds.). State and Sociely: the Emergence and Development of Social Hierarchy and Political Centralization. London, 1988.

Göttinger Miszellen. Göltingen.

K. B. Gödecken. Eine Betrachtung der Inschriften des Meten im Rahmen der sozialen und rechtichen Stellung von Privatleuten im ägyptischen alten Reich. Wiesbaden: ÄgAbh 29, 1976.

H. Goedicke. Königliche Dokumente aus dem alten Reich. Wiesbaden: ÄgAbh 14, 1967. 


\begin{tabular}{|c|c|c|}
\hline Gordon & inw & $\begin{array}{l}\text { A. Gordon. The Context and Meaning of the Ancient Egyptian Word inw } \\
\text { from the Proto-Dynastic Period to the End of the New Kingdom. Ann Arbor: } \\
\text { University Microfilms International, } 1983 \text {. }\end{array}$ \\
\hline Grandet & Papyrus Harris & P. Grandet. Le Papyrus Harris. 2 vols. Cairo: BdÉ 109, 1994. \\
\hline Griffith & Kahun Papyri & $\begin{array}{l}\text { F. LI. Griffith. The Petrie Papyri: Hieratic Papyri from Kahun and Gurob. } 2 \text { vols. } \\
\text { London, } 1898 .\end{array}$ \\
\hline Guksch & Paheqamen & $\begin{array}{l}\text { H. Guksch. Das Grab des Benja, gen. Paheqamen: Theben Nr. 343. Mainz: } \\
\text { AV7, } 1978 \text {. }\end{array}$ \\
\hline Gulgesell & Datierung & $\begin{array}{l}\text { M. Gutgesell. Die Datierung der Ostraka und Papyri aus Deir el-Medineh und } \\
\text { ihre Interpretation. } 2 \text { vols. Hildesheim: HÄB 18-19, } 1983 \text {. }\end{array}$ \\
\hline$H \ddot{A B}$ & & Hildesheimer Ägyptologische Beiträge. Hildesheim. \\
\hline Harnmond & Cily & M. Hammond. The City in the Ancient World. Cambridge, Mass., 1972. \\
\hline Harmatta & Wirtschaft & $\begin{array}{l}\text { J. Harmatta and G. Komoróczy (eds.). Wirtschaft und Gesellschaft im alten } \\
\text { Vorderasien. Budapest, } 1976 .\end{array}$ \\
\hline Harris & $\begin{array}{l}\text { Lexicographical } \\
\text { Studies }\end{array}$ & $\begin{array}{l}\text { J. R. Harris. Lexicagraphical Studies in Ancient Egyptian Minerals. Berlin: } \\
\text { Deutsche Akademie der Wissenschatten zu Berlin Institut für Orientforschung } \\
\text { Publication 54, 1961. }\end{array}$ \\
\hline (P.) Harris 1 & & q.v. Grandet, Papyrus Harris; Erichsen, Harris; BAR IV: 87ff. \\
\hline Haas & Evolution & J. Haas. The Evolution of the Prehistoric State. New York, 1982. \\
\hline Hammond & City & M. Hammond. The City in the Anceint World. Cambridge, Mass., 1972. \\
\hline $\mathrm{HdO}$ & & Handbuch der Orientalistik. Leiden. \\
\hline Heinen & $\begin{array}{l}\text { Sowjetische } \\
\text { Forschung }\end{array}$ & $\begin{array}{l}\text { H. Heinen (ed.). Die Geschichte des Altertums im Spiegel der sowjetischen } \\
\text { Forschung. Darmstadt, } 1980 .\end{array}$ \\
\hline Helck & Militörführer & $\begin{array}{l}\text { W. Helck. Der Einfluss der Militörführer in der 18. Ägyptischen Dynastie. } \\
\text { Leipzig, Unters. 14, } 1939 .\end{array}$ \\
\hline Helck & Beziehungen & $\begin{array}{l}\text { W. Helck. Die Beziehungen Ägyplens zu Vorderasien im 3. und 2. Jahrtausend } \\
\text { v. Chr. Wiesbaden: ÄgAbh 5, } 1971 .\end{array}$ \\
\hline Helck & Dwi-Hii & W. Helck. Die Lehre des Dwi-Hiji. 2 parts. Wiesbaden: KÄT, 1970. \\
\hline Helck & Materialien & $\begin{array}{l}\text { W. Helck. Materialien zur Wirtschafts-geschichte des Neuen Reiches. } 6 \text { Parts. } \\
\text { Wiesbaden, } 1961 \mathrm{ff} .=\text { Akademie der Wissenschaften und der Literatur; } \\
\text { Abhandlungen der Geistes und Sozialwissen-schaftlichen Klasse, 1960ff. }\end{array}$ \\
\hline Helck & Übersetzung & $\begin{array}{l}\text { W. Helck. Urkunden der 18. Dynastie: Übersetzung zu den Heffen 17-22. } \\
\text { Berlin: Urkunden des Ägyptischen Altertums Deutsch, 1961. }\end{array}$ \\
\hline Helck & Verwaltung & $\begin{array}{l}\text { W. Helck. Zur Verwaltung des Mittleren und Neven Reichs. Leiden: Probleme } \\
\text { der Ägyptologie 3, } 1958 .\end{array}$ \\
\hline Helck & Witschaftsgeschichte & $\begin{array}{l}\text { W. Helck. Wirtschaftsgeschichte des alten Ägypten im 3. und 2. Jahrtausend } \\
\text { vor. Chr. Leiden: HdO 1:1:5, } 1975 \text {. }\end{array}$ \\
\hline Helm & Essays & $\begin{array}{l}\text { J. Helm (ed.). Essays on the Problem of Tribe: Proceedings of the } 1967 \text { Annual } \\
\text { Spring Meeting of the American Ethnological Sociely. Seattle, } 1968 .\end{array}$ \\
\hline Herold & Mind of Napoleon & $\begin{array}{l}\text { J. C. Herold (ed.). The Mind of Napoleon: A Selection from his Written and } \\
\text { Spoken Words. New York, } 1955 .\end{array}$ \\
\hline Hicks & Economic History & J. Hicks. A Theory of Economic History. London, 1973. \\
\hline Hinton & Fanshen & $\begin{array}{l}\text { W. Hinton. Fanshen: A Documentary of Revolution in a Chinese Village. New } \\
\text { York, } 1966 .\end{array}$ \\
\hline
\end{tabular}




$\begin{array}{ll}\text { H. O. } & \\ \text { Hobbes } & \text { Leviathan } \\ \text { Holler } & \text { Arbeitsmarktes } \\ \text { Hollmann } & \text { Politik-lexikon }\end{array}$

Hommages Sauneron

Hornung Amduat

Hornung Einführung

Hornung $T b$.

Hornung Untersuchungen

Hornung/ Skarabäen
Staehelin
HPB
HPE
Hughes
IFAO SDll

Inscriptions of Sinai

Iraq

$\begin{array}{ll}\begin{array}{ll}\text { Jacquet- } \\ \text { Gordon }\end{array} & \text { Noms } \\ \text { Jaeger } & \begin{array}{l}\text { Scarabées } \\ \text { Menkhéperre }\end{array} \\ \text { James } & \text { Pharaoh's People } \\ \text { Janssen } & \text { IRLC }\end{array}$

Janssen Markt op de Oever

Janssen Prices

Janssen Ship's logs

JAOS

JAR

JARCE

JEA

JESHO

Jevons Political Economy
J. Černý and A. H. Gardiner. Hieratic Ostraca. I vol. Oxford, 1957.

T. Hobbes. Leviathan, or The Matter, Forme, \& Power of a Common-wealth, Ecclesiasticall and Civill. London, 1651.

M. J. Holler. Ökonomische Theorie des Arbeitsmarktes. Darmstadt, 1986.

E. Holtmann, H. U. Brinkman and H. Pehle (eds.). Politik-Lexikon. Munich, $1994^{2}$

J. Vercoutter (ed.). Hommages à la mémoire de Serge Sauneron. 2 vols. Cairo: BdÉ 81/82, 1979.

E. Hornung. Das Amduat: Die Schrift des verborgenen Raumes. 3 Parts. Wiesbaden: ÄgAbh 7/13, $1963 \mathrm{ff}$.

E. Hornung. Einführung in die Ägyptologie. Darmstadt, $1993^{4}$.

E. Hornung. Das Totenbuch der Ägypter. Zurich, 1979.

E. Hornung. Untersuchungen zur Chronologie und Geschichte des Neven Reiches. Wiesbaden: ÄgAbh 11, 1964.

E. Hornung and E. Staehelin. Skarabäen und andere Siegelamulette aus Basler Sammlungen. Basle: Ägyptische Denkmäler in der Schweiz 1, 1976.

Hieratische Papyrus aus den königlichen Museen zu Berlin. Leipzig, 1901 ff. History of Political Economy. Durham.

G. Hughes. Saite Demotic land leases. Chicago: SAOC 28, 1952.

Institut Français d'Archéologie Orientale.

A. H. Gardiner, T. E. Peet and J. Černy. The Inscriptions of Sinai. 2 parts. London, 1952/1955.

Iraq. London

H. K. Jacquet-Gordon. Les Noms des Domains Funéraires sous I'ancien empire Egyptien. Cairo, BdÉ 34, 1962.

B. Jaeger. Essai de Classification et Datationdes Scarabées Menkhéperre. Freiburg/Götlingen: OBO SA 2, 1982.

T. G. H. James. Pharaoh's People. London, 1984.

J. J. Janssen. Late Ramesside Letters and Communications. London, Hieratic Papyri in the British Museum 6, 1991.

J. J. Janssen. De Markt op de Oever. Leiden, 1980.

J. J. Janssen. Commodity Prices from the Ramessid Period. Leiden, 1975.

J. J. Janssen. Two Ancient Egyptian Ship's Logs. Leiden: OMRO 42 supplement, 1961.

Journal of the American Oriental Society. New Haven.

Journal of Anthropological Research. Albuquerque.

Journal of the American Research Center in Egypt. Boston.

Journal of Egyptian Archaeology. London.

Journal of the Economic and Social History of the Orient. Leiden.

W. S. Jevons. The Theory of Political Economy. London, 1871. [Edition cited: R. D. C. Black (ed.). Harmondsworth, 1970]. 
JNES

Jones Glossary

JSSEA

JWH

KÄT

Katary land Tenure

Keimer Garrenpflanzen

Kelly

Kemp

Kemp/

Merrillees

Keynes

Keynes

Keynes

Khalidi

Kitchen

Kitchen

Kloft

Kroeling

KRI

KRIN

KRIT

Kruchten Horemheb

KV

$\lfloor\ddot{A}$

Leffwich Price System

LEM
Journal of Near Eastern Studies. Chicago.

D. Jones. A Glossary of Egyptian Nautical Titles and Terms. London: Studies in Egyptology, 1988.

Journal of the Society for the Study of Egyptian Antiquities. Toronto.

Journal of World History. Honolulu.

Kleine Ägyptische Texte. Wiesbaden.

S. L. D. Katary. Land Tenure in the Ramesside Period. London: Studies in Egyptology, 1989.

L. Keimer. Die Gartenpflanzen im alten Ägyplen. Vol. I. Bertin, 1924. Vol. II.

R. Germer (ed.). Mainz: DAI Kairo Sonderschrift 13, 1984.

Critique and Power M. Kelly (ed.). Critique and Power: Recasting the Foucault/Habermas Debate. Cambridge, Mass., 1994.

B. Kemp. Ancient Egypt: Anatomy of a Civilization. London, 1989.

B. J. Kemp and R. S. Merrillees, Minoan Pottery in Second Millennium Egypt. Mainz, 1980.

J. M. Keynes. The Economic Consequences of the Peace. London, 1919

J. M. Keynes. The General Theory of Employment, Interest and Money. London, 1936.

D. Moggridge (ed). Social, Political and Literary Writings. Cambridge: The Collected Writings of John Maynard Keynes Volume XXVIII, 1982.

T. Khalidi (ed.). Land Tenure and Social Transformation in the Middle East. Beirut, 1984.

Pharaoh Triumphant K. A. Kitchen. Pharaoh Triumphant: The Life and Times of Ramesses II. Warminster, 1982.

K. A. Kitchen. The Third Intermediate Period in Egypt (1100-650 B.C.). Warminister, $1986^{2}$.

H. Kloft. Die Wirtschaft der griechisch-römischen Welt: eine Einführung. Darmstadi, 1992.

C. H. Kraeling and R. M. Adams. Cily Invincible. Chicago, 1960.

K. A. Kitchen. Ramesside Inscriptions: Historical and Biographical. 7 vols. Oxford, $1975 \mathrm{ff}$.

K. A. Kitchen. Ramesside Inscriptions: Translated and Annotated: Notes and Comments. Oxford, 1993-

K. A. Kitchen. Ramesside Inscriptions: Translated and Annotated: Translations. Oxford, 1993-

J.-M. Kruchten. Le Décret d'Horemheb. Brussels: Université Libre de Bruxelles Faculte de Philosophie et lettres 72, [1981].

Valley of the Kings (Luxor). Followed by tomb number. (CF. P-M)

W. Helck, E. Otto and W. Westendorff (eds.). Lexikon der Ägyptologie. 7 vols. Wiesbaden: $1975 \mathrm{ff}$.

R. H. Leftwich. The Price System and Resource Allocation. Hinsdale, IL, $1973^{5}$.

A. H. Gardiner. Late-Egyptian Miscellanies. Brussels: BibAe 7, 1937. 
IES

\begin{tabular}{|c|c|}
\hline Lichtheim & Lilerature II \\
\hline Lipinski & State and Temple \\
\hline Lorton & Terminology \\
\hline \multicolumn{2}{|l|}{$L R L$} \\
\hline Lucas-Harris & Materials \\
\hline \multicolumn{2}{|l|}{ MÄS } \\
\hline Moisels & Civilization \\
\hline Marshall & Principles \\
\hline Mason & Peru \\
\hline McDowell & Jurisdiction \\
\hline McDowell & Ostraca \\
\hline McKenna & Price Theory \\
\hline Mcleod & Composite Bows \\
\hline Mcleod & Self Bows \\
\hline MDAIK & \\
\hline Megally & Recherches \\
\hline
\end{tabular}

Mélanges Mokhtar

$\begin{array}{ll}\text { Meier } & \text { Methode } \\ \text { Menger } & \text { Grundsätze } \\ \text { Menu } & \text { Recherches } \\ \text { Menu } & \text { Régime Juridique } \\ \text { Merrillees } & \text { Pottery } \\ \text { Mignon } & \text { Concepts } \\ \text { Möller } & \text { Lesestücke }\end{array}$

A. H. Gardiner. Late-Egyptian Stories. Brussels: BibAe I, 1932.

M. Lichtheim. Ancient Egyptian Literature: A Book of Readings. Volume II: The New Kingdom. Berkeley, 1976.

E. Lipinski (ed.). State and Temple Economy in the Ancient Near East. 2 vols. Leuven: OLA 5\&6, 1979.

D. Lorton. The Juridical Terminology of International Relations in Egyptian Texts through Dyn. XVIII. Boltimore, 1974.

J. Černy. late Ramesside letters. Brussels: BibAe 9, 1939.

A. Lucas and J. R. Harris. Ancient Egyptian Materials and Industries. London, $1962^{4}$.

Münchner Ägyplologische Studien. Berlin.

Ch. K. Maisels. The Emergence of Civilization: From hunting and gathering to agriculture, cities and the state in the Near East. London, 1990.

A. Marshall. Principles of Economics. London, $1920^{8}$.

J. A. Mason. The Ancient Civilizations of Peru. Harmondsworth, 1968.

A. G. McDowell. Jurisdiction in the Workmen's Community of Deir el-Medina. Leiden: EU 5, 1990.

A. G. McDowell. Hieralic Ostraca in the Hunterian Museum Glasgow /The Colin Campbell Ostraca). Oxtord, 1993.

J. P. McKenna. A Handbook of Price Theory. New York, 1972.

W. Mcleod. Composile Bows from the Tomb of Tut 'ankhamün. Oxford: Tut' 'ankhamūn's Tomb Series 3, 1970.

W. Mcleod. Self Bows and other archery tackle from the Tomb of Tut 'ankhamūn. Oxford: Tut 'ankhamūn's Tomb Series 4, 1982.

Mitteilungen des Deutschen archäologischen Instituts Abteilung Kairo. Wiesbaden and Mainz.

M. Megally. Recherches sur l'économie, l'administration et la comprabilité égyptiennes à lo XVIlle Dynastie d'après le Papynus E. 3226 du Louvre. Cairo: BdE 71, 1977.

P. Posener-Kriéger (ed.). Mélanges Gamal Eddin Mokhtar. 2 vols. Cairo, 1985.

Ch. Meier and J. Rüsen (eds.). Historische Methode. = Theorie der Geschichte, Beiträge zur Hislorik, vol. 5. Munich, 1988.

F. A. Hoyek (ed.). Carl Menger: Gesammelle Werke. Vol. I. Tübingen, 1968.

B. Menu. Recherches sur l'histoire juridique, économique et sociale de l'ancienne Égyple. Versailles, 1982.

B. Menu. Le régime juridique des terres et du personnel attaché à la terre dans Papyrus Wilbour. Lille, 1970.

R. S. Merrillees. The Cypriole Bronze Age Pottery found in Egypt. Lund: SMA 18, 1968.

M. R. Mignon. Dictionary of Concepts in Archaeology. Westport, Conn., 1993.

G. Möller. Hieratische Lesestücke für den akedemischen Gebrauch. 3 vols. Leipzig, 1927ff. 


\begin{tabular}{|c|c|c|}
\hline Montet & Géographie & P. Montet. Géographie de l'Égyple Ancienne. 2 parts. Paris, 1957/1961. \\
\hline Morenz & Prestige-Wirtschatt & $\begin{array}{l}\text { 5. Morenz. Prestige-Wintschaft im alten Ägypten. Munich: Boyerische Akademie } \\
\text { der Wissenschaften Philosophisch-Historische Klasse Sitzungsberichte Heft 4, } \\
1969 \text {. }\end{array}$ \\
\hline Müller & Liebespoesie & W. M. Müller, Die Liebespoesie der alten Ägypter. Leipzig, 1899. \\
\hline Müller-Winkler & Objekt-Amulette & $\begin{array}{l}\text { C. Müller-Winkler. Die Ägyptischen Objekt-Amulette. Freiburg/Göttingen: } \\
\text { OBO SA 5,1987. }\end{array}$ \\
\hline $\begin{array}{l}\text { Müller- } \\
\text { Wollermann }\end{array}$ & Krisenfaktoren & $\begin{array}{l}\text { R. Müller-Wollermann. Krisenfaktoren im ägyptischen Staat des ausgehenden } \\
\text { alten Reichs. Tübingen, } 1986 .\end{array}$ \\
\hline Naville & $T b$. & $\begin{array}{l}\text { E. Noville. Das Aegyptische Todienbuch der XVIII. bis XX. Dynastie. } 2 \text { vols. } \\
\text { and Einleitung. Berlin, } 1886 .\end{array}$ \\
\hline Nissen & Grundzüge & $\begin{array}{l}\text { H. J. Nissen. Grundzüge einer Geschichte der Frühzeit des Vorderen Orients. } \\
\text { Darmstadt, } 1983 .\end{array}$ \\
\hline North & Economic History & D. C. North. Structure and Change in Economic History. New York, 1981. \\
\hline O. & & Ostracon. Followed by name of museum or private collection. \\
\hline Obrinsky & Profit Theory & M. Obrinsky. Profit Theory and Capitalism. Oxford, 1983. \\
\hline $\mathrm{OBO}$ & & Orbis Biblicus et Orientalis. Freiburg/Göttingen. \\
\hline OBO SA & & Orbis Biblicus et Orientalis. Series Archaeologica. Freiburg/Göltingen. \\
\hline O. Cairo & & $\begin{array}{l}\text { Ostracon Cairo. } \\
\text { J. Černý. Ostraca Hiératiques. Cairo: CG Nos. 25.501-25832. Cairo, } 1935 . \\
\text { G. Daressy. Ostraca. CG Nos. 25001-25385. Cairo, } 1901 .\end{array}$ \\
\hline O. DeM & & $\begin{array}{l}\text { Ostracon Deir el-Medineh. J. Černý. Ostraca hiératiques non-littéraires de } \\
\text { Deir el-Médineh. Numerous vols. Cairo: Documents des Fouilles de I'IFAO } \\
\text { 3ff., 1935ff. }\end{array}$ \\
\hline OLA & & Orientalia Lovaniensia Analecta. Leuven. \\
\hline$O L P$ & & Orientalia Lovaniensia Periodica. Leuven. \\
\hline O. Michaelides & & H. Goedicke and E. F. Wente. Ostraka Michaelides. Wiesbaden, 1962. \\
\hline OMRO & & Oudheidkundige Mededelingern uit het Rijksmuseum van Oudheden. Leiden. \\
\hline Or. & & Orientalia. N. S. Rome. \\
\hline Osing & Nominalbildung & J. Osing. Die Nominalbildung des Ägyptischen. 2 vols. Mainz, 1976. \\
\hline OH & Preistheorie & A. E. Ott. Grundzüge der Preistheorie. Göltingen, 1968. \\
\hline P. & & Papyrus. Followed by name of museum or private collection. \\
\hline P. Anast. & P. Anastasi & cf. LEM, Bakir, Epistolography, etc. \\
\hline P. Sall. & P. Sallier & cf. LEM, KÄT, etc. \\
\hline $\begin{array}{l}\text { Patterson/ } \\
\text { Gailey }\end{array}$ & Power Relations & $\begin{array}{l}\text { T. C. Patterson and C. W. Gailey (eds.). Power Relations and State } \\
\text { Formation. Washington, D.C., } 1987 .\end{array}$ \\
\hline Peet & Tomb-Robberies & $\begin{array}{l}\text { T. E. Peet. The Great Tomb-Robberies of the Twentieth Egyptian Dynasty. } \\
2 \text { vols. Oxtord, } 1930 .\end{array}$ \\
\hline Peet & Mayer Papyri & $\begin{array}{l}\text { T. E. Peet. The Mayer Papyri A and B: Nos. M. } 11162 \text { and M. } 11186 \text { of the } \\
\text { Free Public Museums, Liverpool. London, } 1920 \text {. }\end{array}$ \\
\hline Petrie & Memphis I & $\begin{array}{l}\text { W. M. F. Petrie. Memphis I. London: British School of Archaeology in } \\
\text { Egypt, 15/Egyptian Research Account 14th year 1908, } 1909 .\end{array}$ \\
\hline
\end{tabular}




\section{P-M}

$\begin{array}{ll}\text { Polanyi } & \text { Livelihood } \\ \text { Polanyi } & \text { Trade and Mark } \\ \text { Polanyi } & \text { Transformation } \\ \text { Postgate } & \text { Taxation } \\ \text { P/R } & \\ \text { Powell } & \text { Labor } \\ \text { Pribram } & \text { Reasoning } \\ \text { Quaegebeur } & \text { Shaï } \\ \text { Quack } & \text { Ani } \\ \text { Quirke } & \text { MKS } \\ \text { Quirke } & \text { Administration }\end{array}$

RAD

Rathbone

Economic Rationalism

Renfrew

Theory

$R d E$

Ricardo Principles

Rider

RLA

Roat

Roccati

Römer

Rostovizeff Hellenistic World

Rostovizeff Roman Empire

Roth Phyles

Rothenberg Temple
B. Porter and R. Moss, et al. Topographical Bibliography of Ancient Egyptian Hieroglyphic Texts, Reliefs, and Paintings. Several volumes, various editions. Oxford, 1927.

K. Polanyi. The Livelihood of Man. Edited by H. W. Pearson. New York, 1977.

K. Polanyi, C. M. Arensberg and H. W. Pearson (eds.). Trade and Market in the Early Empires. New York, 1957.

K. Polanyi. The Great Transformation. Boston, $1957^{2}$.

J. N. Postgate. Taxation and Conscription in the Assyrian Empire. Rome: Studia Pohl: Series Maior 3, 1974.

W. Pleyte and E. Rossi. Papyrus de Turin. 2 vols. Leiden, 1869-1876.

M. A. Powell (ed.). Labor in the Ancient Near East. New Haven: AOS 68, 1987.

K. Pribram. A History of Economic Reasoning. Baltimore, 1983.

J. Quaegebeur. Le dieu égyptien Shaï dans la religion et l'onomastique. Leuven: OLA 2, 1975.

J. F. Quack. Die Lehren des Ani. Freiburg/Göttingen: OBO 141, 1994.

S. Quirke (ed.). Middle Kingdom Studies. Surry: SIA Publishing, 1991.

S. Quirke. The Administration of Egypt in the Late Middle Kingdom. Surrey: SIA Publishing, 1990.

A. H. Gardiner. Ramesside Administrative Documents. Oxford, 1948.

D. Rathbone. Economic Rationalism and Rural Society in third-century A.D. Egypt: The Heroninos archive and the Appianus estate. Cambridge, 1991.

C. Renfrew, M. J. Rowlands and B. A. Segraves (eds.). Theory and Explanation in Archaeology: The Southampton Conference. New York, 1982.

Revue d'Égyptologie. Paris.

D. Ricardo. On the Principles of Political Economy and Taxation. London, 1817 .

C. Rider. An Introduction to Economic History. Cincinnati, 1995.

E. Ebeling, et al. (eds.). Reallexikon der Assyriologie. Berlin, $1928 \mathrm{ff}$.

M. Roaf. Cultural Atlas of Mesopotamia and the Ancient Near East. New York, 1990.

A. Roccati. La Littérature historique sous l'ancien Empire Egyptien. Paris: Littératures Anciennes du Proche-Orient 11, 1982.

M. Römer. Gottes- und Priesterherrschaft in Ägypten am Ende des Neven Reiches. Wiesbaden: ÄAT 21, 1994.

M. Rostovtzeff. The Social and Economic History of the Hellenistic World. 3 vols. Oxford, 1941.

M. Rostovtzeff. The Social and Economic History of the Roman Empire. 2 vols. Oxford, $1957^{2}$.

A. M. Roth. Egyptian Phyles in the Old Kingdom. Chicago: SAOC 48, 1991.

B. Rothenberg. The Egyptian Mining Temple at Timna. London, Researches in the Arabah 1959-1984 1, 1988. 
RT

Sabloff Trade

SAK

Samuelson Economics

SAOC

Sasson Civilizations

SBL

Schoedel listen

Schenkel Bewässerungsrevolution

Schlögl Tatenen

Schneider Kulturwirtschaft

Schulman Rank

Schumpeter Capitalism, elc.

Screpanti/ Economic Thought

Zamagni

Seaton/Political

Claessen Anthropology

Senice Origins

Sethe lesestücke

Shanin Peasants

Silver

Economic Structures

Shorter Oxford English Dictionary

Sieveking Problems

Silverman For His Ka

Simpson literoture

SMA

Smith

v. Soden AHW

Spencer Temple
Recueil de Travaux Relatifs à la Philologie et à l'archéologie égyptiennes et assyrriennes. Paris.

J. A. Sabloff and C. C. Lamberg-Karlovsky (eds.). Ancient Civilization and Trade. Albuquerque, 1975.

Studien zur Altägyplischen Kultur. Hamburg

P. A. Samuelson. and W. D. Nordhaus. Economics. New York, $1985^{12}$.

Studies in Ancient Oriental Civilization. Chicago.

J. Sasson (ed.). Civilizations of the Ancient Near East. 4 vols. New York, 1995.

Sociely for Biblical Literature: Writing from the Ancient World Series. Atlanta

H. D. Schaedel. Die Listen des großen Papyrus Harris. Leipzig: Leipziger Ägyptologische Studien 6, 1936.

W. Schenkel. Die Bewässerungsrevolution im alten Ägyplen. Mainz, 1978.

H. A. Schlögl. Der Gott Tatenen. Freiburg: OBO 29, 1980.

A. Schneider. Die Anfänge der Kultunwitschaft. Essen, 1920. New York, $1979^{2}$.

A. R. Schulman. Military Rank, Titte and Organization in the Egyptian New Kingdom. Berlin: MÄS 6, 1964.

J. A. Schumpeter. Capitalism, Socialism and Democracy. London, 1994 (Numerous editions).

E. Screpanti and S. Zamagni. An Outline of the History of Economic Thought. (D. Field, trans.). Oxford, 1993.

S. L. Seaton and H. J. M. Claessen (eds.). Political Anthropology: The State of the Art. The Hague, 1979.

E. R. Service. Origins of the State and Civilization. New York, 1975.

K. Sethe. Ägyptische lesestücke. leipzig and Hildesheim, 1928ff.

T. Shanin (ed.). Peasants and Peasant Sociefies. Harmondsworth, 1971.

M. Silver. Economic Structures of the Ancient Near East. London, 1985.

W. Little, et al. (eds.). The Shorter Oxford English Dictionary. 2 vols. Oxford, $1973^{3}$.

G. de G. Sieveking, I. H. Longworth and K. E. Wilson (eds.). Problems in Economic and Social Archaeology. London, 1976.

D. P. Silverman (ed.). For His Ka: Essays Offered in Memory of Klaus Baer. Chicago: SAOC 55, 1994.

W. K. Simpson (ed.). The Literature of Ancient Egypt. New Hoven, 1972.

Studies in Mediterraneon Archaeology. Lund.

A. Smith. An Inquiry into the Nature and Causes of the Wealth of Nations. R. H. Campbell, A. S. Skinner and W. B. Todd (eds.). 2 vols. Oxford, 1976. [Original edition, 1776].

W. von Soden. Akkadisches Handwörterbuch. 3 vols. Wiesbaden, 1965ff.

P. Spencer. The Egyptian Temple: A Lexicographical Study. London, 1984 


$\begin{array}{ll}\begin{array}{ll}\text { Spiegelberg } \\ \text { South }\end{array} & \begin{array}{l}\text { Rechnungen } \\ \text { Method }\end{array} \\ \text { Stein } & \text { Early States } \\ \text { Studies } & \text { Griffith } \\ \text { Suret-Canale } & \text { Production } \\ \text { Trigger } & \text { Social History } \\ \text { חT } & \\ \text { Tufnell } & \text { Lachish IV } \\ \text { Turin } & \\ \text { Tylor } & \text { Paheri }\end{array}$

Ucko Urbanism

Ucko/ Domestication
Dimbleby
Unters.

Urk. 1

Urk. IV

$V A$

$\begin{array}{ll}\text { Valbelle } & \text { Ouvriers } \\ \text { Veenhof } & \text { Trade } \\ \text { Ventura } & \text { City } \\ \text { Verhoeven } & \text { Grillen } \\ \text { Vincent } & \text { State } \\ \text { Walker } & \text { British Empire } \\ \text { Wallace } & \text { Taxation in Egypt } \\ & \\ \text { Wallerstein } & \text { World-System } \\ \text { Wallert } & \text { Palmen } \\ \text { Walras } & \text { Economie Politique }\end{array}$

Wb.

Wente letters
W. Spiegelberg. Rechnungen aus der Zeit Setis I. 2 parts. Strassburg, 1896. S. South. Method and Theory in Historical Archaeology. New York, 1977. G. Stein and M. S. Rothman (eds.). Chiefdoms and Early States in the Near East. Madison: Monographs in World Archaeology 18, 1994.

S. R. K. Glanville (ed.). Studies Presented to F. LI. Griffith. London, 1932.

J. Suret-Canale, et al. Sur le "mode de production asiatique". Paris, 1974.

B. G. Trigger, B. J. Kemp, D. O'Connor and A. B. Lloyd. Ancient Egypt: A Social History. Cambridge, 1983.

Theban Tomb. Individual tomb number follows. (CF. P-M)

O. Tufnell, et al. Lachish N: (Tell ed-Duweir) The Bronze Age. London, 1958. Egyptian Museum Turin.

J. J. Tylor and F. U. Griffith. The Tomb of Paheri at El Kab. London: Egypt Exploration Fund 11 th Memoir (bound with E. Naville, Ahnas El Medineh), 1894.

P. Ucko, R. Tringham and G. W. Dimbleby (eds.). Man, settelement and urbanism. London, 1972.

P. Ucko and G. W. Dimbleby (eds.). The domestication and exploitation of Plants and Animals. London, 1969.

K. Sethe and H. Kees (eds.) Untersuchungen zur Geschichte und Altertumskunde Ägyptens. Leipzig.

K. Sethe. Urkunden des alten Reichs. Leipzig, 1933.

K. Sethe and W. Helck. Urkunden der 18. Dynastie. Leipzig and Berlin: Urkunden des Ägyptischen Altertums Vierte Abteilung, $1906 \mathrm{ff}$.

Varia Aegyptiaca. San Antonio.

D. Valbelle. "Les ouvriers de la tombe" Deir el-Médineh à l'époque Ramesside. Cairo: BdÉ 96, 1985.

K. Veenhof. Aspects of Old Assyrian Trade and its Terminology. Leiden, 1972.

R. Ventura. Living in a Cily of the Dead. Freiburg: OBO 69, 1986.

U. Verhoeven. Grillen, Kochen, Backen. Brussels: Rites Égyptiens 4, 1984.

A. Vincent. Theories of the State. Oxford, 1987.

E. Walker. The British Empire. Oxford, $1947^{4}$.

S. L. Wallace. Taxation in Egypt: from Augustus to Diocletion. Princeton, 1938. New York, 1969.

I. Wallerstein. The Modern World-System. 4 vols. New York, 1974 ff.

I. Wallert. Die Palmen im alten Ägypten. Berlin: MÄS 1, 1962.

L. Walras. Eléments d'économie politique pure. Paris, 1952. (= Reprint of fourth edition, 1902).

A. Erman and H. Grapow. Wörterbuch der Aegyptischen Sprache. 5 vols. and References. Berlin, $1926 \mathrm{ff}$.

E. F. Wente. Letters from Ancient Egypt. Atlanta: SBL 1, 1990. 
Bibliographical Abbreviations

\begin{tabular}{|c|c|c|}
\hline Wente & LRL & E. F. Wente. late Ramesside Letters. Chicago: SAOC 33, 1967. \\
\hline WF & & Weekend Financial Times. London. \\
\hline Winstone & Bell & H. V. F. Winstone. Gertrude Bell. London, 1978. \\
\hline Wittfogel & Oriental Despotism & $\begin{array}{l}\text { K. Wittfogel. Oriental Despotism: A Comparative Study of Total Power. New } \\
\text { Haven, 1957. }\end{array}$ \\
\hline Wolf & Kulturgeschichte & W. Wolf. Kulturgeschichte des alten Ägyplen. Stuttgart, 1962. \\
\hline$Z \ddot{S}$ & & Zeitschriff für ägyptische Sprache. Leipzig and Berlin. \\
\hline
\end{tabular}




\section{BIBUOGRAPHY OF ARTICLES CITED}

For the abbreviations of journals and collective works (such as JESHO or Trigger, Social Historyl, cf. the preceding bibliography

AllaM, S.

"Einige Hieratische Ostraka der Papyrussammlung der staatlichen Museen zu Berlin," FuB 22 (1982): $51-61$.

"La vente dans l'Égypte ancienne (particulièrement à l'époque du Nouvel Empire, XVle-Xle siècle avant notre ère)," Revue historique du droit français et étranger 4 ser. 60 (1982): 377-393.

"Trois Lettres d'Affaires," Mélanges Mokhtar I: 19-30.

"msw = Kinder/Volksgruppe/Produkte/Abgaben," SAK 19 (1992): 1-13.

AlT, A.

"Eine syrische Bevölkerungsklasse im ramessidischen Ägypten," ZÄS 75 (1939): 16-20.

BAER, K.

"An Eleventh Dynasty Farmer's Letters," JAOS 83 (1963): 1-19.

"The Low Price of Land in Ancient Egypt," JARCE 1 (1962): 25-45.

BailY, F. G.

"The Peasant View of the Bad Life," in Shanin, Peasants, pp. 299-321

BAINES, J.

"Literacy, social organization, and the archaeological record: the case of early Egypt," in Gledhill, State and Society, pp. 192-214.

"Restricted Knowledge, Hierarchy and Decorum," JARCE 27 (1990): 1-23.

BAKRY, H. S. K.

"The discovery of a temple of Sobk in upper Egypt," MDAIK 27 (1971): 131-146.

BARGuet, $P$.

"Tod: Rapport des Fouilles de la saison février-avril 1950," BIFAO 51 (1952): 81-1 10

BARNES, J.

"Three Hieratic Papyri in the Duke of Northumberland's Collection," JEA 34 (1948): 35-46.

BERNBECK, R.

"Die 'Obed-Zeit: Religiöse Gerontakrien oder Häuptlingstümer," in Bartl, Zwischen Euphrat und Indus, pp. 44 -56.

BICKEL, S.

"Les Domaines funéraires de Thoutmes IV," BSÉG 13 (1989): 23-32.

BIACKMAN, A. M.

"Oracles in Ancient Egypt," JEA 11 (1925): 249-255.

BIEIBERG, E. L.

"Commodity Exchange in the Annals of Thuimose III," JSSEA 11/2 (1981): 107-1 10.

"The King's Privy Purse During the New Kingdom," JARCE 21 (1984): 155-167.

"The Redistributive Economy in New Kingdom Egypt: An Examination of B:kw(f)," JARCE 25 (1988): 157-168.

"The Economy of Ancient Egypt," in Sasson, Civilizations III: 1373-1385.

BOOCHS, W.

"Zur Bedeutung der bskw(t) Leistungen," VA 3 (1987): 207-214

Brewer, A.

"A Minor Post-Ricardian? Marx as an Economist," HPE 27 (1995): 111 -145.

CAMINOS, R.

"Some Comments on the Reuse of Papyrus," in Bierbrier, Papyrus, pp. 43-61.

CASSIN, E.

"Babylonien unter den Kassiten," in Fischer Welfgeschichte 3: 1-101.

Castie, E. W.

"Shipping and Trade in Ramesside Egypt," JESHO 35 (1 992): 239-277. 
Č́rNý, J.

"le Caractère des oushebtis d'après les idées du nouvel empire," BIFAO 41 (1942): 105-133.

"The Will of Naunakhte and the Related Documents," JEA 31 (1945): 29-53.

"An Hieroglyphic Ostracon in the Museum of Fine Arts at Boston," JEA 44 (1958): 23-25.

"Report on Inscriptions," in: Tufnell, lachish IV: 133.

CHRISTOPHE, L.-A.

"La face sud des architraves surmoniant les colonnes 74-80 de la grande salle hypostyle de Karnak," BIFAO 60 (1960): 69-82.

CIVII, M.

"Ur III Bureaucracy: Quantitative Aspects," in Gibson/Biggs, Power, pp. 43-53.

Claessen, H. and P. Skainik

"The Early State: Theories and Hypotheses," in Claessen/Skalnik, Early State, pp. 3-29.

COHEN, R.

"Stale Origins: A Reappraisal," in Claessen/Skalnik, Early State, pp. $31-75$.

CONDON, $\mathrm{V}$.

"Two Account Papyri of the Late Eighteenth Dynasty," RdÉ 35 (1984): 57-82.

Cruz-UriBe, E.

"A Model for the Political Structure of Ancient Egypt," in Silverman, For His Ka, pp. 45-53.

DALTON, $G$.

"Karl Polanyi's Analysis of Long-Distance Trade and His Wider Paradigm," in Sabloff, Trade, pp. 63-132.

Davies, N. de G. and R. O. Faulikner

"A Syrian Trading Venture to Egypt," JEA 33 (1947): 40-46.

DAWSON, W. R.

"An Oracle Papyrus. B.M. 10335," JEA 11 (1925): 247-248.

DIAKONOFF, I. M.

"Slaves, Helots and Serts in Early Antiquity," in Harmatta, Wirtschaft, pp. 45-78.

Dixon, D. M.

"A note on cereals in ancient Egypt," in Ucko/Dimbleby, Domestication, pp. 131-142.

Dooley, P. C.

"Value," in Creedy, Foundations, pp. 124-158.

Eoel, E.

"Zwei Originalbriefe der Königsmutter Tüja in Keilschrift," SAK 1 (1974): 105-146.

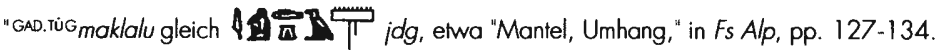

EOGERTON, W. F

"The Nauri Decree of Seti: a Translation and Analysis of the Legal Portion," JNES 6 (1947): 219-230.

"The Strikes in Ramesses III's Twenty-ninth Year," JNES 10 (1951): 137-145.

EICHIER, E.

"Polanyi - Keynes - Warburton," GM 131 (1992): 25-31.

EICHLER, S.

"Untersuchungen zu den Wasserträgern," SAK 17 (1990): 135-175 and 18 (1991): 173-205.

ENDRES, A. M.

"Carl Menger's Theory of Price Formation Reconsidered," HPE 27 (1995): 261-287.

EPSTEIN, S. R.

"Regional fairs, institutional innovation, and economic growth in late medieval Europe," EHR 47(1994): 459-482.

ERMan, A.

"Beiträge zur Kenntnis des ägyptischen Gerichtsverfahrens," ZÄS 17 (1879): 71-83.

"Ein Unterstützungsgesuch," ZÄS 38 (1900): 151-152.

EYRE, C. J.

"An Account Papyrus from Thebes," JEA 66 (1980): 108-119. 
"Work and the Organization of Work in the Old Kingdom," in Powell, Labor, pp. 5-47.

"Work and the Organization of Work in the New Kingdom," in Powell, labor, pp. 167-221.

FAKHRY, A.

"Une staluette du nouvel empire," ASAE 39 (1939): $91-94$

FAUIKNER, R.

"Egyptian Military Organization," JEA 39 (1953): 32-47.

FIYNN, D. O. AND A. GIRÁldez

"Born with a "Silver Spoon": the Origin of World Trade in 1571," JWH6 (1995): 201-221.

FRIED, M. H.

"On the Concepts of 'Tribe' and 'Tribal Society'," in Helm, Essays, pp. 3-20.

"The State and the Chicken and the Egg; or What Came First?", in Cohen/Service, Origins of the State, pp. 35-47.

Gaballa, G. A.

"Three Acephalous Stelae," JEA 63 (1977): 122-126.

GalleY, C. W.

"Culture Wars: Resistance to State Formation," in Patterson/Gailey, Power Relations, p. 35-56.

Gardiner, A. H.

"Four Papyri of the 18th Dynasty from Kahun," ZÄS 43 (1906): 27.47.

"The Stele of Bilgai," ZÄS 50 (1912): 49-57.

"The Geography of the Exodus," JEA 10 (1924): 87-96.

"A lawsuit Arising from the Purchase of Two Slaves," JEA 21 (1935): 140-146.

"A Later Allusion to Akhenaten," JEA 24 (1938): 124.

"The word $m^{\prime} \underline{d}$ ' and its various uses," JEA 26 (1940): 157-158.

"Ramesside Texts Relating to the Taxation and Transport of Corn," JEA 27 (1941): 19-73.

"A Protest Against Unjustified Tax-Demands," RdÉ 6 (1951): $115-134$.

"Some Reflections on the Nauri Decree," JEA 38 (1952): 24-33.

"A Pharaonic Encomium," JEA 41 (1955): 30 and 42 (1956): 8-20.

"The Harem al Miwër," JNES 12 (1953): 145-149.

Gardiner, A. H. and H. I. Bell

"The Name of Lake Moeris," JEA 29 (1943): 37-50.

Gates, M. H.

"Archaeology in Turkey," AJA 99 (1995): 207-255.

Gition, $M$

"La Résiliation d'une fonction religieuse," BIFAO 76 (1976): 65-89.

GLanviLIE, S.

"Records of a Royal Dockyard of the Time of Thutmosis III: Papyrus British Museum 10056," ZÄS 66 (1930): 105-121 and ZAS 68 (1932): 7-41.

GIedHIll, J. AND M. LARSEN

"The Polanyi Paradigm and a Dynamic Analysis of Archaic States" in Renfrew, Theory, pp. 197-229.

GOEDICKE, H.

"Cult-temple and 'State' during the Old Kingdom in Egypt," in Lipinski, State and Temple, pp. 113-131.

"The Title $\left[i m y-r^{c}\right]$ in the Old Kingdom," JEA 46 (1960): 60-64.

GODEIIER, $M$.

"La notion de 'mode de production asiatique' et les schémas marxistes d'évolution des sociétés," in Suret-Canale, Production, pp. 47-100.

GOLDWASSER, O.

"Hieratic Inscriptions from Tel Sera ' in Southern Canaan," Tel Aviv 11 (1984): 77-93.

"The Lachish Hieratic Bowl Once Again," Tel Aviv 9 (1982): 137-138. 
GRIFFITH, F. LL.

"The Abydos Decree of Seti I at Nauri," JEA 13 (1927): 193-208.

GuKsCH, H.

"Das Grab des Benja, gen. Paheqamen: Theben Nr. 343," MDAIK 38 (1982): 195-199.

Gunawardana, R. A. L. H.

"Social Function and Political Power: A Case Study of State Formation in Irrigation Sociely," in Claessen/Skalnik, Study of the State, pp. 133-154.

GUTGESELL, $M$.

"Die Struktur der pharaonischen Wirtschaft - eine Erwiderung," GM 56 (1982): 95-109.

"Die Entstehung des Privateigentums," GM 66 (1983): 67-80.

HABERMAS, J

"Some Questions Concerning the Theory of Power: Foucault Again," in Kelly, Critique and Power, pp. 79-107.

HaLl, K. R. L. AND I. DEVORE

"Baboon Social Behavior," in DeVore, Primate Behavior, pp. 53-110.

HARARI, I

"Nature de la Stèle de donation de fonction du Roi Ahmôsis a la reine Ahmès-Nefertari," ASAE 56 (1959): $139-201$

HARING, B. J. J.

"The Economic Aspects of Royal "Funerary" Temples: A Preliminary Survey," GM 132 (1993): 39-48.

HEICK, W.

"Die Inschrift über die Belohnung des Hohenpriesters 'Imn-ḥtp," MOO 4 (1956): 161-178

"Ramessidische Inschriften aus Karnak," ZÄS 82 (1957): 98-140.

"Ramessidische inschriften II," ZÄS 83 (1958): 27-38.

"Der Papyrus Berlin P. 3047," JARCE 2 (1963): 65-73.

"Eine Briefsammlung aus der Verwaltung des Amuntempels," JARCE 6 (1967): 1 35-151.

"Zum Kult an Königsstatuen," JNES 25 (1966): 32-41.

"Eine Stele Sebekhoteps N. aus Karnak," MDAIK 24 (1969): $194-200$.

"Die große Stele des Vizekönigs St’w aus Wadi es-Sabua," SAK 3 (1975): 85-112.

"The Dissolution of the Palace Economy in the Ramesside Period, " in Function of the Minoan Polaces, pp. 17-19.

"Anmerkungeri zum Turiner Königspapyrus," SAK 19 (1992): 151-216.

"Wege zum Eigentum an Grund und Boden im alten Reich," in Allam, Grund und Boden, pp. 9-13.

HUNt, R. C.

"The Role of Bureaucracy in the Provisioning of Cities: a Framework for Analysis of the Ancient Near East," in Gibson/Biggs, Power, pp. 161- 192.

JANSEN-WINKEIN, K.

"Die Plünderung der Königsgräber des Neuen Reiches," ZÄS 122 (1995): 62-78.

JANSSEN, J. J.

"A Twentieth-Dynasty Account Papyrus," JEA 52 (1966): 81-94.

"Nine letters from the Time of Ramses II," OMRO 4 ) (1960): 31-47.

"Prolegomena to the Study of Egypt's Economic History during the New Kingdom," SAK 3 (1975): 127-185

"The Early State in Ancient Egypt," in Claessen/Skalnik, Early State, pp. 21 3-234.

"The Role of the Temple in the Egyptian Economy during the New Kingdom," in Lipinski, State and Temple II: 505-515

"The Price of Papyrus," DE 9 (1987): 33-35.

"Requisitions from Upper Egyptian temples (P. BM 10401);"JEA 77 (1991): 79-94.

"The Year of the Strikes," BSÉG 16 (1992): 41-49.

"bikw. from Work to Product," SAK 20 (1993): 81-94.

"An Exceptional Event at Deir el-Medina (P. Turin 1879, Verso II)," JARCE 31 (1994): 81-94.

"Debls and Credit in the New Kingdom," JEA 80 (1994): $125-136$. 
JansSEn, J. J. AND P. W. PESTMAN

"Burial and Inheritonce in Ancient Egypt," JESHO 11 (1968): 137-170.

JeLINKOVA-REYMOND, E.

"Recherches sur le role des guardiens des portes (iry- ' 3 ) dans l'administration générale des temples égyptiens," CdÉ 28 (1953): 39-59.

KEMP, B

"Temple and town in ancient Egypt," in Ucko, Urbanism, pp. 657-680.

"Old Kingdom, Middle Kingdom and Second Intermediate Period," in Trigger, Social History, pp. 71-182.

KERBLAY, B.

"Chayanov and the Theory of Peasantry as a Specific Type of Economy," in Shanin, Peasants, pp. 150-160.

KhaZANOV, A.

"Some Theoretical Problems of the Study of the Early State," in Claessen/Skalnik, Early State, pp. 77-92. KITCHEN, K. A

"Prd > Pir = 'Mule' in New Kingdom Egypt?," GM 13 (1974): 17-20.

"The Great Biographical Stela of Setau, Viceroy of Nubia," OLP 6/7 (1975/1976): 295-302.

KOENIG, Y.

"Livraisons d'or et de galène au trésor du temple d'Amon sous la XXe dynastie," Hommages Sauneron I: $185-220$ Korostovcev, M. A.

"Das alte Ägypten," in Heinen, Sowjetische Forschung, pp. 19-45.

KraUSS, R.

"Detailfragen der altàgyptischen Getreidewirtschaft," in Fs Fecht, pp. 266-273.

KRUCHTEN, J.-M.

"L'évolution de la gestion dominiale sous le nouvel empire égyptienne," in: Lipinski State and Temple ll: 517-525.

"Le verbe ḥtr et ses dérivés jusqu'à la fin du nouvel empire," AIPHOS 24 (1980): 39-52

LAPP, J. V.

"Evidence for Artificial Irrigation in Amratian Egypt," JARCE 32 (1995): 197-209.

LARGACHA, A. P.

"Relations Between Egypt and Mesopotamia at the end of the Fourth Millennium," GM 137 (1993): 59-76.

LEGRAIN, G

"Deux stèles trouvés à Karnak," ZÄS 35 (1897): 12-19.

LEVY, T. E. , EY AL.

"New Light on King Narmer and the Protodynastic Egyptian Presence in Canaan," BA 58/1 (1995): 26-35.

LIVERANI, $M$.

"Memorandum on the Approach to Historiographic Texts," Or. 42 (1973): 178-194.

LORTON, D

"What was the pr-nsw and who managed it?," SAK 18 (1991): 291-316.

MASPERO, G.

"Notes sur quelques points de Grammaire et d'Hisłoire," ZÄS 19(1881): $116-131$.

MENU, B

"Quelques Remarques à propos de l'étude comparée de la stèle juridique de Karnak et la stèle' d'AhmèsNefertari," RdÉ 23 (1971): 155-163.

"La 'Stèle' d'Ahmès Nefertary dans son contexte historique ef juridique," BIFAO 77 (1977): 89-100.

"La notion de propriété privée des biens fonciers dans l'Ancien Empire égyptien," in Menu, Recherches, pp. 43-57.

MICHALOWSKI, P.

"Charisma and Control," in Gibson/Biggs, Power, pp. 55-68.

MORONY, $M$

"In a City without Watchdogs, the Fox is the Overseer': Issues and Problems in the Study of Bureaucracy," in Gibson/Biggs, Power, pp. 7-18.

MUELLER, D

"Some Remarks on Wage Rates in the Middle Kingdom," JNES 34 (1 975): 249-263. 
MüLIER, W.

"Ein Terminus des Verwaltungswesens," ZÄS 32 (1894): 131.

"Viehstever," ZÄS 34 (1896): 167-168.

MÜLIER-WOLIERMANN, $R$.

"Bemerkungen zu den sogenannten Tributen," GM 66 (1983): 81-93.

"Ein Tribut an die Methode," GM 77 (1984): 51-55.

"Warenaustausch im Ägypten des alien Reiches," JESHO 28 (1985): 121-168.

"sw. tiw Bauein als Kolonisatoren," VA 3 (1987): 263-267.

"Präliminierungen zur ägyplischen Stadt," ZÄS 118 (1991): 48-54.

MUHLACK, U.

"Von der philologischen zur historischen Methode," in Meier, Methode, pp. 154-180.

NASH, $M$.

"Market and Indian Peasant Economies," in Shanin, Peasants, pp. 161-177.

NEWLANDS, W.

"Rich Treats await at Carnegie's old home," W FT (5/6 August 1995): IX.

NiBBi, A.

"Some Remarks on Ass and Horse in Ancient Egypt and the Absence of the Mule," ZÄS 106 (1979): 148-168.

OAtes, D. and J. OAtes

"Early Irrigation Agriculture in Mesopotamia," in Sieveking, Problems, pp. 109-135.

"Tell Brak: A Stratigraphic Summary, 1976-1993," Iraq 56 (1994): 167-176.

O'CONNOR, D.

"New Kingdom and Third Intermediate Period," in Trigger, Social History, pp. 183-278.

PEET, T. E.

"The Egyptian Words for 'Money', 'Buy' and 'Sell'," in Studies Griffith, pp. 122-127.

PERSHITS, A. I.

"Tribute Relations," in Seaton/Claessen, Political Anthropology, pp. 149-156.

POKARA, $T$.

"China," in Claessen/Skalnik, Early State, pp. 191-212.

POLANY, K.,

"Markeiless Trading in Hammurabi's Time," in Polanyi, Trade and Market, pp. 12-26.

POSENER-KRIÉGER, P.

"Les papyrus d'Abousir et l'économie des anciens temples funéraires de l'ancien empire," in Lipinski, State and Temple I: $133-151$

POSENER-KRIÉGER, P.

"Construire une tombe à l'ouest de Mn-nfr," RdÉ 33 (1981): 47-58.

Postgate, J. N.

"In Search of the First Empires," BASOR 293 (1994): 1-13.

PRICE, D.

"Witffogel's Neglected Hydraulic/Hydroagricultural Distinction", JAR 50 (1994): 187-203.

RENGER, J.

"On Economic Structures in Ancient Mesopotamia," Or. 63 (1994): 157-208.

RÖMER, $M$

"Der Handel und die Kaufleute im alten Ägypten," SAK 19 (1992): 257-284.

Roth, A. M.

"The Organization and Functioning of the Royal Mortuary Cults of the Otd Kingdom in Egypt," in Gibson/Biggs, Power, pp. 133-140.

"The Practical Economics of Tomb-Building in the Old Kingdom," in Silverman, For His Ka, pp. 227-240.

SCHARFF, A.

"Ein Rechnungsbuch des königlichen Hofes aus der 13. Dynastie," ZÄS 57 (1922): 51-68. 
SCHNEIDER, T.

"Zur Elymologie der Bezeichnung "König von Ober- und Unterägypten," ZÄS 120 (1993): 166-181.

SCHULMAN, A.

"Mhr and Mškb, Two Egyptian Military Titles of Semitic Origin," ZÄS 93 (1966): 123-132.

"Catalogue of the Egyptian Finds," in: Rothenberg, Temple, pp. 114-147.

SeIDIMAYER, S.

"Wirtschafliche und gesellschaftliche Entwicklung im Übergang von Alten zum Mittleren Reich," in Assmann, Problems, pp. 175-217.

SJÖBERG, B.

"The Mycenaean Economy: Theoretical Frameworks," in Gillis, et al., Trade and Production, pp. 19-32.

SKINNER, $Q$.

"Language and Political Change," in Ball, et al., Political Innovation, pp. 6-23.

"The State," in Ball, et al., Political Innovation, pp. 90-131.

SMITHER, P.

"A Tax-Assessor's Journal of the Middle Kingdom," JEA 27 (194 1): 74-76.

SPIEgelberg, $W$.

"Varia," RT 15 (1893): 141-145.

"Ein Gerichtsprotokoll aus der Zeit Thutmosis' IV.," ZÄS 63 (1927): 105-115.

TRIGGER, B. G.

"The Rise of Egyptian Civilization," in Trigger, Social History, pp. 1-70.

VOUTSAKI, $S$.

"Value and Exchange in Pre-Monetary Societies: Anthropological Debates and Aegean Archoeology," in Gillis, et al., Trade and Production, pp. 7-17.

WARBURTON, D. A.

"Some Remarks on the Manufacture and Sale of Shabtis," BSÉG 9-10 [1984-85]: 345-355.

"Keynes'sche Überlegungen zur aliägyplischen Wirtschaff," ZÄS 118 (1991): "The Economy of ancient Egypl Revisited Yet Again," GM 146 (1995): 103-111.

WARD, W. A.

"Some Aspects of Private Land Ownership and Inheritance in Ancient Egypt, ca. 2500-1000 B.C.", in Khalidi, land Tenure, pp. 63-77.

WIIKINSON, T.J.

"The Structure and Dynamics of Dry-Farming States in Upper Mesopotamia," CA 35 (1994): 483-520.

WIISON, J.

"Egypt through the New Kingdom: Civilization without Cities," in Kraeling, City Invincible, pp. 124-136.

Wolf, W.

"Papyrus Bologna 1086," ZÄS 65 (1930): 89-97.

WRIGHT, H. T.

"Toward an Explanation of the Origin of the State," in Cohen/Senvice, Origins of the State, pp. 49-68.

YOFFEE, N.

"The Economy of Ancient Western Asia," in Sasson, Civilizations III: 1387-1399.

YOUNG, J.

"Natural Jurisprudence and the Theory of Value in Adam Smith," HPE 27 (1995): 755-773. 

PART VI

INDICES 



\section{Textual References}

Cairo JdÉ $28569 \quad 191$

EA $38 f f$.

Giornale

$1-3$

$1-7$

40

H.O.

17,3

30

45,1

47,2

$58,1,4$

65,2 vs. 2

68,1

71,3

$81-82$

81,14

82,3

114,4

HPB III: 31

KRI I:

4-58

6-32

$16,14-15$

23,3

$41,3-4$

45-58

50,1

50,10

$60-61$

65-66

65-70

$79,11-13$

$81-96$

$90,14-16$

114,4

117,10

$125-126$

197,8

201,5

205, 3
334

175ff., 307

220, 267

$68,120,255,267$

264

103

237

266

149

266

238

29, 143ff., 184, 283.

306

268

283,287

283

264, 265

248

227,250

142

151

228

190,272

167

280

271

228

250

248

271

274

274

227

$280,313,325$

151,227

$212,227,231,248$

227,248
$241-242$

259-261

260,8

263,8

266,9

$299,11-12$

$365 \mathrm{ff}$.

KRI II:

143-146 229

147 , 9 ff 229

$154,10-14 \quad 229$

156,8

$162,12 \quad 229$

$167,7 \quad 229$

171,6

182,11

186,10

197,10

207,13

$245,7-9$

$246,13-15$

$247,4-6$

$253,10-11$

257,11

258-281

260

$260,4-8$

267,$1 ; 3$

268-274

$271,9-11$

283

$285,2-7$

286,16

287,1

289,15

290,1

294,11

294,14

297,16

$317,15-16$

$318,7-8$

326,14

327,6

330,7

332,$8 ; 15$
240, 255. 276

219, 282

221

268

243

243

227, 247

239

229,261

250

250

272

229

274

261

228

228

228

$228,250,261$

250

231

191

251

201

228, 261

228

228

228

250

228

228

250

250

228

228

191

250

250

272 
Textual References

\begin{tabular}{|c|c|c|c|}
\hline (KR/II con'd) & & 178 & 260 \\
\hline 333 & $167,248,250,272,305$ & 259,15 & 228 \\
\hline 416,1 & 250 & $341-343$ & $182 f f ., 258,270,279$ \\
\hline 490,12 & 228 & $343,7-13$ & 285 \\
\hline $514,14-16$ & 229,261 & 368,7 & 251 \\
\hline 603,$2 ; 10$ & 228 & 421 & 239 \\
\hline 608,12 & $228,231,250$ & 421,12 & 238 \\
\hline $671-672$ & 243 & $517-522$ & 296 \\
\hline 705,14 & 247 & 539,3 & 237. \\
\hline $803-806$ & 136 & & \\
\hline \multirow[t]{2}{*}{$894-895$} & 282 & $K R I V:$ & \\
\hline & & 9,3 & 229 \\
\hline KRI III: & & $9,8-9$ & 251 \\
\hline 9,7 & 227 & 27,6 & 229 \\
\hline 16,6 & 247 & 50,12 & 251 \\
\hline 21,9 & 247 & 50,13 & 272 \\
\hline $29,10 f f$. & 264,265 & 65,14 & 229 \\
\hline 31,12 & 265 & 68,10 & 229 \\
\hline $41-43$ & 265 & 93,4 & 229 \\
\hline $45,13-14$ & 264 & 97,$3 ; 9$ & 229 \\
\hline $54-55$ & 247 & 110,7 & 229 \\
\hline $91-94$ & 270,274 & $117,13 f$ & $231,251,272$ \\
\hline 92,9 & 268 & 144,$1 ; 4$ & 229 \\
\hline 136,7 & 247 & $177,13 f$ & 229 \\
\hline $138-140$ & $143 \mathrm{H} ., 283$ & 216,12 & 229 \\
\hline $145-146$ & 264,265 & 218,3 & 229 \\
\hline $146,5 f$ & 268 & 219,16 & 229 \\
\hline $158-161$ & 287 & $221-225$ & 201,274 \\
\hline $160,11 f f$. & $144,278,263$ & 225 & 229 \\
\hline 161 & 265,268 & $225,1-3$ & 248,251 \\
\hline $250-251$ & 206 & 239,12 & 248,251 \\
\hline $254-255$ & 240 & 240,7 & 229 \\
\hline 260,10 & 268 & 241,13 & 248,251 \\
\hline $261-262$ & 283 & 242,2 & 229 \\
\hline 330,2 & 247 & 244,9 & 248,251 \\
\hline 499-504 & 135,239 & 245,11 & 248,251 \\
\hline 509,$1 ; 9$ & 219 & 280,2 & 229 \\
\hline 534,12 & 237 & 284,3 & 272 \\
\hline 542,11 & 237 & 302,14 & 229 \\
\hline 545 & 238 & 317,5 & 229 \\
\hline \multirow[t]{2}{*}{841,14} & 247 & 318,5 & 251 \\
\hline & & 321,2 & 229,251 \\
\hline KRI IV: & & $437-448$ & $152 f f ., 219$ \\
\hline 10,2 & 251 & $437-448$ & 245 \\
\hline $39,10-12$ & 141,285 & 460 & 238 \\
\hline $78-81$ & 283 & 527,6 & 238 \\
\hline 81,2 & 287,144 & 536,14 & 238 \\
\hline $143-144$ & 270 & 610,1 & 238 \\
\hline $164-165$ & 266,238 & & \\
\hline 168 & 219 & & \\
\hline
\end{tabular}




\begin{tabular}{|c|c|c|c|}
\hline KRI VI: & & $102-103$ & $237,242,255,259$ \\
\hline $3-9$ & 226,249 & $175-176$ & 283 \\
\hline 66,$6 ; 7$ & 221 & $190-191$ & 278 \\
\hline $67,2 \mathrm{ff}$ & 221 & $226 f f$. & 270 \\
\hline 67,10 & 269 & $263-265$ & $237,241,267$ \\
\hline 67,11 & 222 & 264,7 & 256 \\
\hline 70 fff & 226 & 265,9 & 212 \\
\hline 120,2 & 238 & 266,8 & 237 \\
\hline $151,1-4$ & 264,266 & $268-273$ & 140 \\
\hline $221-225$ & 273 & $284-285$ & 237 \\
\hline 364,9 & 266 & $292-293$ & 239 \\
\hline 367,7 & 238 & $396,15-16$ & 226 \\
\hline $368,2-3$ & 238 & 455,5 & 264 \\
\hline $395-397$ & 222 & & \\
\hline 399,6 & 238 & LEM & \\
\hline 409,1 & 238 & $5-6$ & $263,276,278,298$ \\
\hline $455-458$ & $186 f ., 258,280,285$ & 38,4 & 332 \\
\hline & 289 & $64-65$ & $133-134,243,278,282$ \\
\hline $517-522$ & $244,255,304$ & & 297 \\
\hline $560-566$ & $175 f f ., 220,267,307$ & 75,14 & 266 \\
\hline 566,4 & 238 & 83: 10 & 134 \\
\hline 571,8 & 200 & 87,16 & 167 \\
\hline 572,10 & 260 & $87-88$ & 135,263 \\
\hline 580,7 & 266 & 89,11 & 213 \\
\hline $581-590$ & 307 & 105 & 170 \\
\hline 582,$1 ; 9 ; 10$ & 219,238 & 111,2 & 191 \\
\hline 583,$1 ; 11$ & 219,238 & 123,1 & 200 \\
\hline $590-594$ & 246,267 & & \\
\hline $590 \mathrm{ff}$. & 255 & LES 68, 1-3 & 233 \\
\hline 603,15 & 239 & & \\
\hline $603-604$ & 239,245 & Lesestücke 69, 1 & 213 \\
\hline $603-608$ & 241 & & \\
\hline $619-624$ & 220,222 & $L R L$ & \\
\hline 624,7 & 245 & $47,3-5$ & 123 \\
\hline 639,15 & 239 & 53 & 239 \\
\hline $650-652$ & 276 & $69-70$ & 170 \\
\hline $653-655$ & 245 & & \\
\hline 653,4 & 238 & Naville, Tb. II: & \\
\hline $653,12-13$ & 239 & 89 & 201 \\
\hline $654,7-8$ & 245 & 325 & 212 \\
\hline $681-684$ & 238,245 & & \\
\hline $682,1,10,11$ & 238,239 & O. Berlin P. & \\
\hline $590 \mathrm{ff}$ & 68 & 1268 & 237 \\
\hline & & 11238 & $264,265,268$ \\
\hline KRI VII: & & 12337 & $265,260,268$ \\
\hline 7,5 & 237 & & \\
\hline $84 f f$. & 238 & O. BM 50722 & 266 \\
\hline $84,8-16$ & 278 & & \\
\hline 85,12 & 278 & O. BMFA 11.1498 & 237 \\
\hline 93,9 & 279 & & \\
\hline
\end{tabular}




\begin{tabular}{|c|c|c|c|}
\hline \multirow{2}{*}{$\begin{array}{l}\text { O. Cairo } \\
25241\end{array}$} & \multicolumn{3}{|c|}{ O. Gard } \\
\hline & 237 & 13 & 264,265 \\
\hline 25271 & 260 & 67 & 237 \\
\hline 25517 & 206 & 86 & $29,143 \mathrm{Hf}, 200,268$, \\
\hline 25536 & 237,239 & & $283,306,331$ \\
\hline 25536 , verso & 219 & 150 & 238 \\
\hline 25588 , ro. & 266 & 227 & 283 \\
\hline 25592,1 & 266 & & \\
\hline 25593 & 238 & O. Mich. 66 & 266. \\
\hline 25597 & 255 & & \\
\hline 25608,2 & 206 & O. Petrie & \\
\hline 25620,1 & 206 & 14 & 103 \\
\hline 25620,4 & 266 & 47 & 283 \\
\hline 25632 & 220 & & \\
\hline 25633 & 238 & O. Toronto A 11 & 265,268 \\
\hline 25678 & 242 & & \\
\hline 25698,1 & 260 & O. Turin 57072,1 & 266 \\
\hline 25698,7 & 266 & & \\
\hline 25722 & 238,239 & P. Amiens & 168 \\
\hline 25726 & 266 & & \\
\hline 25753 & 219 & P. Anast. I 10, 6 & 215 \\
\hline 25763 , ro. 1 & 206 & P. Anast. IV 3,10 & 332 \\
\hline 25810 & 220 & & \\
\hline 25832 & 265 & P. Anast. V 17, 2; 3 & $237,243,255,297,278$ \\
\hline O. Campbell 2, 3 & 239 & P. Anast. VI 42 & 266 \\
\hline O. Cerný 3 & 278 & P. Anast. VIII & 239 \\
\hline O. DeM & & P. Ashmolean 1960. & \\
\hline 45 & 238 & 1283 & 238,266 \\
\hline 46 vso. 10 & 242 & P. B. N. 209 & 243 \\
\hline 92 & 238 & 1.0. & \\
\hline 100 & 265 & P. Berlin $3040 a$ & $144,263,264,278$ \\
\hline 106, vs. 5 & 209 & & 287,291 \\
\hline $108,7-8$ & 267 & & \\
\hline 114 & 264 & P. Berlin 3047 & 136 \\
\hline 139,4 & 307 & & \\
\hline 140 , verso & 307 & P. Berlin 9784, 4 & 171 \\
\hline 142 & 307 & & \\
\hline 143 & 307 & P. Berlin 11239, 2 & 238 \\
\hline 149 & 255 & & \\
\hline 165 & 238 & P. Bib. Nat. 199, 2 & 239 \\
\hline 249 & 220 & & \\
\hline 303 & 237 & P. BM & \\
\hline 306 & 265 & 10335 & 279 \\
\hline $318,9-10$ & 209 & 10401 & $151,288,290,322$ \\
\hline O. Fitzwilliam 1 & 271 & $\begin{array}{l}10373, \text { vso. } 2 \\
10373 \text {, vso. } 6\end{array}$ & $\begin{array}{l}167 \\
143\end{array}$ \\
\hline
\end{tabular}




\begin{tabular}{|c|c|c|c|}
\hline P. Bol. & & $18 b, 7$ & 185 \\
\hline 1086 & $283,284,306$ & 27,12 & 169,278 \\
\hline $1086,21-26$ & $135,144 f ., 184,263$ & 28,3 & $249,254,278$ \\
\hline 1094 6, 3ff. & $263,276,278,298$ & $28,3-5$ & 280 \\
\hline & & 28,5 & $249,273,278$ \\
\hline P. Brooklyn 35. 1453 & $305,329,238,254$ & $32 a, 7$ & 259 \\
\hline & & $32 a, 7-9$ & 280 \\
\hline P. Cairo Jd'́ & & $32 a, 9$ & 273 \\
\hline 52002 & $237,241,237,256,267$ & $32 b, 5$ & 259 \\
\hline 52003 & 237 & $32 b, 6$ & 249 \\
\hline 52002 , vso. 2 & 212 & $32 b, 9$ & 249 \\
\hline & & $32 b, 11$ & 278,280 \\
\hline P. Cairo & & $32 b, 14$ & 251 \\
\hline 58056 & 239,255 & 48,2 & 249 \\
\hline 58057 & $13,240,276$ & 48,6 & 251 \\
\hline 58071,1 & 134 & 48,10 & 273 \\
\hline 58096 & $242,243,255,259$ & $51 b, 3$ & 259 \\
\hline & & $51 b, 10$ & 259 \\
\hline P. EPS & 244 & $51 b, 11$ & 249 \\
\hline & & $52 a, 1$ & 278,280 \\
\hline P. Gard 8 & 238,266 & $52 a, 2$ & 251 \\
\hline & & 59,6 & 169 \\
\hline P. Greg & $152 f f, 219 f f ., 238,245$ & $68 a, 4$ & 273,259 \\
\hline & $267,312,313$ & $68 b, 4-5 ; 8 ; 12$ & 280 \\
\hline & & $68 b, 8$ & 280 \\
\hline P. Gurob & $146 f f ., 221,234,268$ & 69,4 & 259 \\
\hline & $283,288,290,291$ & 69,11 & 278 \\
\hline & & 76,9 & 275 \\
\hline P. Harageh & 173,180 & & \\
\hline P. Harris I & $\begin{array}{l}\text { 194ff., 234f, 249, 303ff., } \\
\text { passim }\end{array}$ & P. IFAO sans & 238,288 \\
\hline 4,4 & 268 & P. Lansing & 170 \\
\hline 4,5 & 251 & 12,4 & 191 \\
\hline $4,4-7,4$ & 268,272 & & \\
\hline $9,4-5$ & 169 & & \\
\hline 11,4 & 260 & P. Leiden I & \\
\hline $12 a, 1$ & 259 & 349 & 206 \\
\hline $12 a, 5$ & 280 & 3503,9 & 167 \\
\hline $12 a, 6-9$ & 273 & 350 verso & $222 f f ., 235,305,239$ \\
\hline $12 b, 2$ & 259 & 350 vso. 4,17 & 269 \\
\hline $12 b, 3$ & $184,249,259,260$ & 368 & 282 \\
\hline $12 b, 6$ & 249,259 & & \\
\hline $12 b, 8$ & 251 & & \\
\hline $12 b, 9$ & $271,278,280$ & P. Louvre E 3226 & $245,255,326$ \\
\hline $13 a, 5-10$ & 273 & & \\
\hline $14 b, 16$ & 280 & P. Mallet & $221,269^{\circ}$ \\
\hline $15 a, 3$ & 185 & & \\
\hline $15 a, 14$ & 185 & P. Mayer A 9, 20 & 167 \\
\hline $18 a, 11$ & 185 & & \\
\hline
\end{tabular}




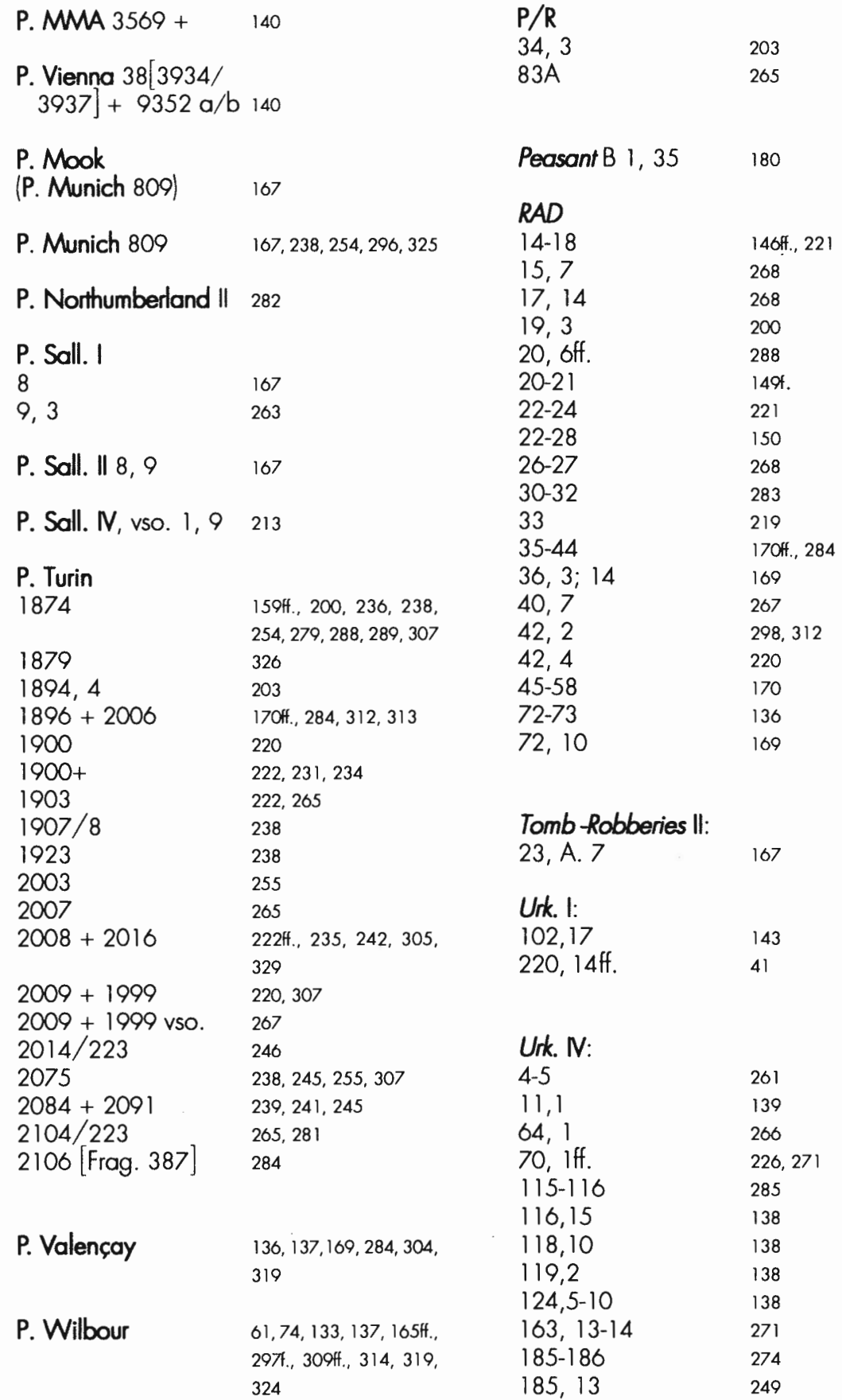




\begin{tabular}{|c|c|}
\hline (Urk. IV con'd) & \\
\hline 186,2 & 249 \\
\hline $195-196$ & 271 \\
\hline 288,13 & 178 \\
\hline 325,13 & 214 \\
\hline 349,10 & 178 \\
\hline 412,4 & 249 \\
\hline 436,6 & 273 \\
\hline 436,13 & 246 \\
\hline 499,4 & 285 \\
\hline 503,8 & 269 \\
\hline $530,11-16$ & $246,269,279$ \\
\hline 536 & 281 \\
\hline 584,10 & 212 \\
\hline $629-634$ & 273 \\
\hline 641,11 & 271 \\
\hline $667,13-14$ & 286 \\
\hline $691,10-13$ & 236 \\
\hline 700,6 & 274 \\
\hline 700,7 & 249 \\
\hline 708, 9ff. & 249 \\
\hline 708,11 & 254 \\
\hline 709,$3 ; 12$ & 286 \\
\hline 712,7 & 236 \\
\hline 734, $2 f f$. & 249,254 \\
\hline 734,10 & 286 \\
\hline 744,7 & 249,274 \\
\hline 745,5 & 271 \\
\hline 746 & 271 \\
\hline $750-751$ & 274 \\
\hline 753,9 & 271 \\
\hline 759 & 247 \\
\hline 925,5 & 190 \\
\hline $931,8-10$ & 269 \\
\hline $973,3-4$ & 246 \\
\hline 1073,3 & 180 \\
\hline $1094,6-10$ & 141,142 \\
\hline $1096,10-16$ & 142 \\
\hline
\end{tabular}

\begin{tabular}{|c|c|}
\hline 1097,16 & 142 \\
\hline $1098,3-10$ & 142 \\
\hline $1099,4-5$ & 142 \\
\hline $1102,11-1103,2$ & 142 \\
\hline $1103-1117$ & $178 f f$. \\
\hline $1111,8 f f$ & 139 \\
\hline 1114 & 269 \\
\hline 1114,$9 ; 13,14$ & 231,264 \\
\hline 1115,$4 ; 12$ & 231,236 \\
\hline 1116,2 & 231 \\
\hline $1119 f f$. & 137 \\
\hline 1124,5 & 137 \\
\hline 1126 & 171 \\
\hline 1127,3 & 137 \\
\hline 1128,3 & 137 \\
\hline 1130,9 & 137 \\
\hline $1131,10-12$ & 137 \\
\hline 1132,6 & 137 \\
\hline 1133,1 & 137 \\
\hline $1134,15-17$ & 137 \\
\hline $1379-1380$ & 269,270 \\
\hline 1379,10 & 226 \\
\hline $1379-1380$ & 246 \\
\hline $1380,1 f f$. & 225 \\
\hline 1390,14 & 191 \\
\hline $1441-1445$ & 139,274 \\
\hline 1442,7 & 249 \\
\hline $1468-1472$ & 225 \\
\hline $1.550,18$ & 212 \\
\hline 1554,11 & 290 \\
\hline 1668,$3 ; 5$ & 249 \\
\hline 1841,16 & 285 \\
\hline 1996,11 & 246 \\
\hline 2011 & 270 \\
\hline 2013,9 & 249 \\
\hline 2144,$10 ; 19$ & 271 \\
\hline 2158,17 & 266 \\
\hline
\end{tabular}




\section{EGYPTIAN WORDS}

\begin{tabular}{|c|c|c|c|}
\hline $3^{c c}$ /speak a foreign & & isw-reeds & 159 \\
\hline language| & 174 & $i t-m-i t$ & 209 \\
\hline $3^{\text {cc }} t$-jars & $203,211,215$ & itn-beam & 176 \\
\hline shht-field & $179,265,286$ & idniniw & 205 \\
\hline sh (fine thing, benefit) & 146 & idg (dress) & 149 \\
\hline sht (goods) & 188 & $-m w$ (weir) & 179 \\
\hline iw (come) & 220,298 & $c_{3-n-s ̌ t}$ /Chief Taxing & \\
\hline iw'-cattle & 208 & Master) & 165 \\
\hline iwfyt-plant & 205 & $3 m$ & 192 \\
\hline ipt (measure of & & 'bw-flowers & 209 \\
\hline capacityl & 20 & 'prw & 200 \\
\hline ipt (shrine) & 184 & ${ }^{\prime} m{ }^{c} m \cdot t$-land & 173 \\
\hline $\operatorname{ipip}(t)$ & 204 & 'nbw-bundles & 208 \\
\hline ipw-cadaster & 167 & p: 'nhww & 259,289 \\
\hline imy-r (overseer) & 174 & 'rryt (hall, gate) & 180 \\
\hline$i m y-r p r-w r$ & 180 & 'h'-fields, -holdings & $135,174,312$ \\
\hline$i m y-r$ pr-hd-n-pr- ${ }^{3}$ & 244 & $h^{c}(w)$ & $147,263 f ., 312 ?$ \\
\hline$i m y-r ~ h t m n$ pa $y m$ & 184 & 'nh-n-nwt & 230 \\
\hline$i m y-r$ sdiwty & 180 & $' g w(t) . f \cap b i{ }^{\prime}$ & \\
\hline imyt-pr-testament & 179,199 & (hoof-of-ore) & $134 f ., 240 \mathrm{Of}$ \\
\hline inyt (brought) & $28,152 f f ., 219 f ., 222$ & 'qut (income) & 178 \\
\hline & $238,282 f, 295,298$ & 'q3y sp sn & 146 \\
\hline & 313 & 'qw-loaves & $148,206 f ., 221,208$ \\
\hline inw (payment) & $28,141,142,148,149$ & $w i \underline{d}-w r(\operatorname{Red}$ Sea) & 214 \\
\hline & $151 \mathrm{ff}, 159,163,166$ & $w^{c} \bar{b}(w) t$. & $67,188,247,271$ \\
\hline & 221 ff., $247 f ., 250$ ff., 259 & $w^{c} b$-priest & 168 \\
\hline & $263,268 \mathrm{ff}, 288 \mathrm{ff}$. & $w b$; (forecourt) & $212 \mathrm{f}$ \\
\hline & $295 \mathrm{ff}, 302,305,322 \mathrm{f}$. & wbriw sd (wounds) & 192 \\
\hline & 325 & $w n d w$-cattle & 160,208 \\
\hline inb (wall, enclosure) & 213 & whyt (harvest) & $190 f ., 285$ \\
\hline inhm (bead) & 242 & $w g$ & 176 \\
\hline inhmn (pomegranate) & 242 & $w \underline{d}$ (palm) & 205 \\
\hline iry- ${ }^{c}$ (porter) & 170 & wdist-amulets & $203 f$ \\
\hline int-fish & 175,307 & wódst & 215 \\
\hline ih (cattle) & 200 & $w d b$ (circulate) & 263 \\
\hline ihwwty (cultivator) & 19 & bir-freighter & $177,216,307$ \\
\hline iht-field & 280 & bih-measure & 200 \\
\hline iht (things) & 307 & bikw (worked) & 207,209 \\
\hline isw (price) & 01 & & \\
\hline
\end{tabular}


bikw (payment)

\section{bikw-rm!}

bi3-breads

bnbn-loaves

brty

bhw

bhrit

bs

bq

bki-plant

p'ypt

$p^{c} t$-loaves

p't-birds

pwtrw (animal tenders) 145

pr (temple)

184

pr-'; (Pharaoh)

$32,67,178$

pr-nsw $(t)$ ("royal

household") $32,67,178,180$

$p r-d t$

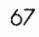

pryw-estates

135

pr-wy-hd (treasaury) 225

prrwt (expenses) 178

p(r)s-breads/cakes 153H., 161, 206

phw /drainage

systems, swamps/ 143

phimy (ends)

143

pšst-work

ptrw (animals)

pdr-sack

$m$ - $\underline{d r}$ (through)

mint-field

$320,323,325,337$

54ff., 206

206

192

229

243

207

205

76

53, 207

209

5

4

$27,28,134,135,139$,

$141,142,152 \mathrm{ff}$, 160ff.

178, 188f., 192f., 194ff.,

$219 \mathrm{f}, 227 \mathrm{ff} ., 237 \mathrm{ff}$.

$258 \mathrm{ff} ., 268 \mathrm{f} ., 27 \mathrm{lff}$.

278ff., 284, 288f., 295ff.,

$304,306,313,316$,

183f., 186f., 194ff., 234

$247,258 \mathrm{ff}, 270,280$,

284, 295ff., 304f., 324f. 


\begin{tabular}{|c|c|c|c|}
\hline$n h(b)$-land & 41,190 & htri (levy, assessment) & $27,28,134,139,140$, \\
\hline$n s w$-ntrw ("king of the & & & $146,147,150,151$ \\
\hline gods") & & & $158,162 f ., 178,180 f$. \\
\hline nswt (royal, kingship) & $32,67,178$ & & $183 f f ., 187,188 f ., 190$, \\
\hline nswtyw & 61,62 & & $193,194 f f ., 221 f f ., 237$, \\
\hline nšdy (lapidary) & 242 & & $246,248 f ., 251,256$, \\
\hline ng:-cattle & 208 & & $258,260,263 \mathrm{ff}, 278 f .$, \\
\hline$n k p t i$-plant & 204 & & $285,295 f ., 304,306$ \\
\hline$n t^{\epsilon}$ (custom) & 274 & & $313,324 f ., 327$ \\
\hline$n d b$ & 208 & hd (money, silver) & $201,246,307$ \\
\hline$r$-prw /mortuary & & $h \underline{d} m-i i^{c}$ & 159 \\
\hline temples) & 152,220 & $h=-(n-), t_{3}$ (khato- & \\
\hline$p_{3}^{\prime} r^{c}-b j k w$ (tomb, site) & $152,237,241$ & land, q.v.l & 264 \\
\hline iwdw-controller & $19,164,191,248,278$ & hw hnt-ih & 201 \\
\hline rmnyt-domains & 135 & hbi-inw & 173,180 \\
\hline rmt-ist (worker) & 279 & p: hnty & $147,150,151,268,279$ \\
\hline rhs-cakes & $206 \mathrm{f}$ & hnmt (jasper) & 204 \\
\hline rhyt & 248 & hr (tomb) & 19,266 \\
\hline rdi (issue, sell) & $222 \mathrm{Ht}, 267$ & hrp /commanded, & \\
\hline rdiw & 207 & administered) & 28 \\
\hline hmn-garments & 202 & brr & 149 \\
\hline his (excess) & 271 & hrš-bundles & 209 \\
\hline hiat (booty, plunder) & $28,141,142,229,251$, & hssbd (lapis lazuli) & 204 \\
\hline & $261 f ., 295$ & $h t_{-}{ }^{c}$, & 208 \\
\hline howt & 159 & his (khar, sack, & \\
\hline hwt (Mansion, temple) & 199 & measure) & 20,144 \\
\hline hmwwt (servants) & 266,313 & hrt (obligation) & 28 \\
\hline hmwt-pr-s; (royal & & hrt-hrw (daily) & 147 \\
\hline craftsmen) & 67 & hrt-rnpt lannual & \\
\hline hmst (session, term) & 178 & obligatory & |) 249 \\
\hline$h n w$-vessels & 207 & $s_{3}^{\prime}-p^{\prime}$ & 149 \\
\hline hnk-measures & 209 & $r \sin$ (to the ground) & 178 \\
\hline 't hankt & 188 & sitw $n$ hnow & 178 \\
\hline hr-s? (arrears) & 283 & $s^{s} b$-cakes & 206 \\
\hline hry-pdt Imilitary & & $s^{i} m$ & 208 \\
\hline officer) & 191 & sw.tjw & 62 \\
\hline hrst (carnelian) & 203 & $s p s n$ & 215 \\
\hline hsb (reckoning) & 136 & spd & 260 \\
\hline hqu't /measure of & & smw (forage) & 188 \\
\hline capacity! & 20 & smdt (serfs) & $20,161,255,257,258 \mathrm{ff} .$, \\
\hline hqq-plant/fruit & 205,208 & & $268,2791,313,320$ \\
\hline htp-basket & 206 & & 329 \\
\hline
\end{tabular}




\begin{tabular}{|c|c|c|c|}
\hline sht-field & 265 & gs-pr (workshop?) & $225 f ., 234,264$ \\
\hline sgnn-oil & 265 & $q m: n m w$ & 212 \\
\hline$s q w$ & 207 & $q^{3} r$-vessel & 250 \\
\hline skny-vessel & $177,201,307$ & qrr-boat & 177,307 \\
\hline sk-flour & 207 & qrh-boat & 209 \\
\hline styw & 170 & $m$ qhqh & 201 \\
\hline sțł (aroura, measure) & 20 & $q d t$ & 200 \\
\hline stt (trap) & 205 & qdt (kite, measure) & 20 \\
\hline sdf (endowment) & 199 & $q d y$-wood & 204 \\
\hline$s \underline{d}$ (inflict) & 192 & $k:($ soul $)$ & $148,151,186,191$ \\
\hline$s \underline{d m}$ (official) & 188,247 & & 210 f., 251,272 \\
\hline$s \underline{d} m$-eye paint & 244 & kiwt (works) & 237,250 \\
\hline$s \underline{d m}-{ }^{c} \breve{s}$ (servant) & 279 (cf. olso $m s d(m) / 1)$ & $k_{3}^{3} r$-vessel & 199, 201, $211 f ., 240 f$. \\
\hline \multirow[t]{7}{*}{ šз̆t } & $27,28,134,183 f ., 186 f$. & k'3r't-boats & 191 \\
\hline & 191, 193, 194ff., 233, & $k b$-jars & 203 \\
\hline & $238,246,249,254$ & kbs-baskets & 207 \\
\hline & 256, 258, 269f., 27וff., & $k f^{c}$ & 188,191 \\
\hline & $278 f f ., 285,288,295 f .$, & krht-bunches & 209 \\
\hline & $304,306,321,324 \mathrm{f}$ & kt (safflower) & 150 \\
\hline & 333 & Iyt-amulets & 204 \\
\hline ššlw & $160 \mathrm{ff}$ & tišps-plant & 204, 207 \\
\hline š’W & $263 f$. & hwW-breads & 153 \\
\hline šsw.t & 144 & tp (district) & 271 \\
\hline šssw (bedouins) & 250 & $t p-\underline{d} r t$ & $27,28,149,151,159$ ff.. \\
\hline š3ki-breads & 153 & & $187,225,254,258 \mathrm{f}$ \\
\hline$\breve{s}: q w$ & 201 & & $279,285,287$ ff., 295 , \\
\hline$\check{s}^{c} y t$-cakes & $148,206 f$. & & 322 \\
\hline šwt (document) & 143 & tpyw-fish & 148,161 \\
\hline šmyt (documentation) & 143 & tpyw & 208 \\
\hline \multirow[t]{5}{*}{ šmw ("harvest-tax") } & $27,28,135,141,161$, & tpt-piece & 176,204 \\
\hline & 172f., 183H., 186f., 191, & trp-geese & 205,208 \\
\hline & $219,234,249,258$ & $\operatorname{th}(b)$ & 41 \\
\hline & $270,276 f ., 282 H ., 295$ & t’3y (basket, sack?) & 207,208 \\
\hline & $306,312,321,325$ & t?:rti-skiff & 201 \\
\hline šmw pš & 166,284 & tmtm-measure & 207 \\
\hline šn ${ }^{c}$-fish & $175,209,307$ & tni (tired) & 190 \\
\hline$\check{s s r} h q^{s}$ st (corn) & 200 & tnfy & 188 \\
\hline šdi (exact) & 179,245 & $t(9) r$-vessel & $242 f$. \\
\hline šdw-plots & 139,179 & trb-vessel & 243 \\
\hline šdyt & $160,164,238$ & $t s$ & $2631 ., 278$ \\
\hline$g^{3} y$-vessel & 206,208 & ts $w$ & 191 \\
\hline grg & 176 & tsw-prt |"sowing ord & $144,263,2287$ \\
\hline
\end{tabular}




\begin{tabular}{|c|c|c|c|}
\hline \multirow{3}{*}{$\begin{array}{l}\text { diiw-cloth } \\
\text { diw (wages) }\end{array}$} & $149,159 f ., 207 f$. & $d^{\prime} y$-barge, ferry & 177,307 \\
\hline & $152 f f ., 189,242,245$ & $d^{2} y / w$-garments & 202,288 \\
\hline & $264 f f ., 313$ & $d^{3} i t$ & 176 \\
\hline$d w$-garments & 202 & $d^{\mathrm{c}} m$-gold & 190,274 \\
\hline$d b n$ (deben, measure) & 20,160 & dph-piece & 176 \\
\hline dnit-baskets & $206 f ., 212$ & $\underline{d} r w$ & 206 \\
\hline$d s$-jars & $153 \mathrm{ff}$. & & \\
\hline
\end{tabular}

\section{Proper Names}

CONVENTIONAL

(cf. also transcribed writings, infra)

Aha
Amenemhat I
Amenophis III
Amenophis IV
Cheops
Dewen
Dier
Hatshepsut
Herihor
Horemhab

Merneptah

Mes

Narmer

Neferirkare

Neshi

Nsy-Khonsu

Pepil

Ptunteamun

Ramesses 1

Ramesses II

Ramesses III

Ramesses IV

296
45
249,333
272
124,126
296
296
269
$18,123,171$
$133,139,188,193$,
$240,247,256,271$,
$281,302,316,325,333$
$213,219,270,283$
$139,302,319,324,333$
296
309
139
315
66
136
$240 f$.
$18,123 f ., 136,148 f .$,
$151,163,184,213$,
$219,228 f ., 242 f ., 248$,
$261,272,274,279$,
283,296
$18,105,140,149,152$,
$158,171,194 f ., 222$,
$229,235,238,248$,
$261,272 f f ., 303 f, 308$,
310,319
$221,303,306$

Ramesses V

Ramesses IX

Ramesses X

Ramesses XI

Scorpion

Seti

Seti I

Seti II

Siptah

Snofru

Tawasret

Thutmosis I

Thutmosis III

Thutmosis IV

Wadj

TRANSCRIBED

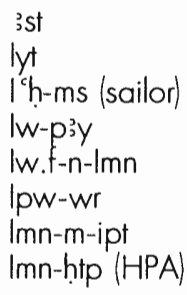

Imn-htp (butler)
$18,165,319$

186f., 238f., 244, 285, 289

238

$18,171,311$

296

149,221

27, 123f., 190ff., 221, 227f., 236, 238, 248, $250,268,271 \mathrm{f}, 274$, $280,302,313,325$

$146 f f, 221$

$152,184,237,258$

124,126

152,184

226

$81,200,212,227,247$, $269,271,273 f ., 286$

212,238

296

267

$242 \mathrm{f}$.

139,261

156

171

26

283

$26,133,186 f, 225,235$, $236,247,258 \mathrm{f} ., 280$, 288ff., $321 \mathrm{f}$.

244 


\begin{tabular}{|c|c|c|c|}
\hline Imn-how & $154 f ., 239$ & Nfr-htp & 238 \\
\hline Intf & 246 & $N f r-k_{3}^{3}-R^{c}-m-p r-I m n$ & 186 \\
\hline s-phty & 153 & Nht-sw & 153 \\
\hline ch-pt & 239 & Nsy-Imn (scribe) & 174 \\
\hline Wnn-nfr (prophet) & 136 & Nsy-Imn (attendant) & 186 \\
\hline Wnn-nfr (stripling) & 154 & Nsy-Imn-m-ipt & 174 \\
\hline Wnn-nfr (treasurer) & 265 & Nsy-Sbk & 170 \\
\hline Bik-n-Imn (fisherman) & 154,156 & $\mathrm{Ndm}$ & 183 \\
\hline Bik-n-wrnr & 153 & $R^{c}-m s$ (vizier) & 264,287 \\
\hline Bik-n-Mwt & $154 \mathrm{f}$ & $R^{c}$-mssw-nht & 244 \\
\hline Bik-n-hnsw & 136 & $\mathrm{Rm}^{\mathrm{c}}$ & 154 \\
\hline$P_{\text {s-ind }}$ & $154 f$. & $R h-m i-R^{c}$ & $81,137,141,171,178$ \\
\hline P3-iry & $240 \mathrm{OF}$. & & 234,290 \\
\hline$P:-y m$ & 154 & $H^{\prime} \mathrm{pi}^{\mathrm{c}_{3}}$ & 239 \\
\hline$P_{3}-W r^{\prime}=3$ & 173 & Hwy (scribe) & 136 \\
\hline$P_{3}-b_{3}-s_{3}$ & $183,270,279$ & Hiwy (workman) & 152 \\
\hline P:-bhnw & 154 & Himy & 156 \\
\hline$P 3-n-I m n$ & 153 & Himy-nfr & $152 f$. \\
\hline P:-nhisy & 143 & Ḧri (vizier) & 239 \\
\hline$P:-n-R n n t$ & 156 & Ḧri (prophet) & 144 \\
\hline$P_{3}$-rn-nfr & 246 & Hri (deputy treasuer) & 265 \\
\hline Pi-hry & $137 \mathrm{f}, 246,285,288$, & Hry (fisherman) & 156 \\
\hline & 306 & Hri (mayor) & 268 \\
\hline$P_{3}-h q^{3}-m n$ & 180,225 & $\mathrm{Hr}-\mathrm{m}-\mathrm{wi} 3$ & 153 \\
\hline Pi-hni & $170 \mathrm{ff}$. & Hq $q^{3}-n h t$ & 118 \\
\hline P:-hrw & 148 & $\dot{H}^{c}-m-w^{3} s t$ & 282 \\
\hline$P_{3}-s_{3}^{3}-n s w$ & 240 & $\mathrm{H}^{\mathrm{c}}-\mathrm{m}-\mathrm{h}{ }^{2}{ }^{\mathrm{s}}$ & 285 \\
\hline $\mathrm{P} ;-\mathrm{Sr}$ (mayor) & 148,287 & $\breve{H}^{c}$-m-tri (woodcutter) & 154 \\
\hline P'-sr (vizier) & 227,247 & $\breve{H}^{c}$-m-tri (fisherman) & 156 \\
\hline$P_{3}-s r$ (scribe) & $152 \mathrm{ft}$. & $\mathrm{H}^{\prime} \mathrm{y}$ (vizier) & $264 f$. \\
\hline$P=-t w-i ?$ & 153 & Hnsw-ms & 170,239 \\
\hline $\mathrm{Pi}^{3} \mathrm{y}$ & $240 f$. & S:-widyt & 153 \\
\hline Pth-m-wi? & 152,155 & Ssh- & 284 \\
\hline$M y_{3}$ & 171 & Sw-n-r (lapidary) & $242 f$. \\
\hline Min-iniwy & 265 & Swnr (overseer) & 282 \\
\hline Min-msw & 139,274 & $\mathrm{Sm}$ & 242 \\
\hline$M n-b p r-R^{c}-s n b$ & 209 & Sn-nfr & 246 \\
\hline Mry-R' & 153 & Sš-siww-nḩt & 148 \\
\hline$M \check{s} 3$ & 240 & Stiow & 270,274 \\
\hline Mtn & $33,43,61 f ., 76$ & Qn-ḥr-hpš.f & 153,157 \\
\hline $\mathrm{Ni}_{3}^{3}$ & 136 & $K_{3}-S_{3}^{3}$ & 153 \\
\hline Nb-phty-Rc & 238 & $\mathrm{Knr}$ & 288 \\
\hline $\mathrm{Nb}-\mathrm{nfr}$ & 264 & $T:-n d m t$ & 246 \\
\hline $\mathrm{Nb}$-nfr (royal scribe) & 268 & Twtw & 270 \\
\hline $\mathrm{Nb}$-ntrw & 151 & Twr & 278 \\
\hline $\mathrm{Nb}-\mathrm{R}^{\bar{c}}$ & 153 & Tnn & 240 \\
\hline$N f_{r}-i r-k_{3}-R^{c}$ & 33 & Dw:-r-nhh & 225,269 \\
\hline Nfr-'sbt & 136 & Dhwity & 246,273 \\
\hline Nfr- bt & 242 & Dhhwty-ms (scribe) & 170 ff., 307,313 \\
\hline Nfr-ḥr & 242 & Dhhwty-ms (herdsman) & $240 \mathrm{fr}$ \\
\hline
\end{tabular}




\section{TOPONYMS}

COnVEntional

(cf. also transcribed writings, infra)

Abu Simbel
Abydos
Afghanistan
Amarna
Aswan
Avaris
Beth Shan
Canaan
Coptos
Crete
Cush

Dakhla
Elephantine
Esna
Gelidonya
Hatti
Heliopolis
Helwan
Hermonthis
Hermopolis
Kadesh
Kanais
Karnak
Lachish
Luxor
Medinet Habu
Megiddo
Memphis

Mitanni

Nahrain

Nubia

Per-Ramessu

Palestine

Phoenicia
124, 190ff., 227, 229,

$248,272,274,313$

235

141

126

124

250

18

$200,269,304$

141

$18,200,214,222,226$,

$235,249,251,265$.

$269,270,274,281,304$

126

151

172

334

$18,251,261 f, 274$

$124,195 \mathrm{ff}, 273,278$,

$280,303 f ., 309,326$

63

182

$280,313,325$

229

228

19, 124, 199, 227f.,

$236,247,248 f ., 261$.

$270,273 f_{.}, 322$

$141,285 f$.

199,228

$124,199,229,246$,

$251,265,321$

286

$190,195 \mathrm{Hf}, 222,228$,

$235,240,243,249$.

$280,303 f,, 326$

18

18

142, 198f., 229, 251, $274,296,326$

139

$69,141,250 f$

198
Punt

20, 141f, 214, 216,

235, 261f., 296, 308

Saqqara

63

$271 \mathrm{f}$.

$68,105 f, 171,308$

$141,199 f ., 214,226 f$.

$235,251,274,286$,

$296,306,308,331$

Thebes

$151,171,178 f ., 194 \mathrm{ff}$.

$228,280,284,303 \mathrm{f}$.

$308,312 f, 326$

Ulu Burun

274,334

250

TRANSCRIBED

Iw-m-itrw $171 \mathrm{ff}$

Iwnw' rqy 182

Iwnw rsy 182

Irty 261

3-ri-k? (?Wadi Allaqi) 216

?

'nh-t’my (Memphis) 186, 197

'gny 172

WiWit 18,249

Wid-wr (Red Sea) 214

Mn-nfr (Memphis) $\quad 145,240$

Mr-wr(t) (Miwr, Gurob) 20, 146ff., 160, 288

Ni-pr-imw 172

nwt rsyt (Thebes) 143, 178f.

T3-nhsy 274

$R_{3}-m^{\prime}-n^{3} \quad 160$

R3-mnn (Lebanon) 249

Rtnw

$18,198,229,249,251$, 274

r-ky-s? (Lachish?) 141,280

r-ty-s? 141,280

hwt-k3-Pth (Memphis) 197, 250

Sb;-n-ly-m-htp $\quad 143$

Qdy 261

Ksks 261

dmi n hwt-k;-Pth

(Memphis) 190 


\section{TOMBS CITED}

EA 8

EK 3

KV 4

П 11

П 99
249,270

137f., 246

171

273

246 $\pi 100$

$\pi 106$

Tा 125

T188

T 343
$137,141,171,234,290$

227, 247

225f., 246

246

$180,225,273$

\section{FOREIGN WORDS}

EGYPTIAN

deben

hin

kite

khar

khato-land

oipe

\section{Accadian}

biltu $(m)$

mashartu $(m)$

nik/qiptu(m)
192

203

204
Aramaic

blt

$m s \breve{k b m}$

192

210

GREEK

$\dot{\alpha} \lambda \lambda \sigma \gamma \lambda \omega \sigma \sigma 05 \quad 174$

aroura

20 (for meaning)

174

212

HEBREW

$b r^{c} t$

192 
ORBIS BIBLICUS ET ORIENTALIS - Lieferbare Titel

Bd. 25/1a MICHAEL LATTKE: Die Oden Salomos in ibrer Bedeutung für Neues Testament und Gnosis. Band Ia. Der syrische Text der Edition in Estrangela Faksimile des griechischen Papyrus Bodmer XI. 68 Seiten. 1980.

Bd. 25/2 MICHAEL LATTKE: Die Oden Salomos in ibrer Bedeutung für Neues Testament und Gnosis. Band II. Vollständige Wortkonkordanz zur handschriftlichen, griechischen, koptischen, lateinischen und syrischen Überlieferung der Oden Salomos. Mit einem Faksimile des Kodex N. XVI-201 Seiten. 1979.

Bd. 25/3 MICHAEL LATTKE: Die Oden Salomos in ihrer Bedeutung für Neues Testament und Gnosis. Band III. XXXIV_478 Seiten. 1986.

Bd. 46 ERIK HORNUNG: Der ägyptische Mythos von der Himmelskuh. Eine Ätiologie des Unvollkommenen. Unter Mitarbeit von Andreas Brodbeck, Hermann Schlögl und Elisabeth Staehelin und mit einem Beitrag von Gerhard Fecht. XII-129 Seiten, 10 Abbildungen. 1991. Zweite ergänzte Auflage.

Bd. 50/1 DOMINIQUE BARTHÉLEMY: Critique textuelle de l'Ancien Testament. 1. Josué, Juges, Ruth, Samuel, Rois, Chroniques, Esdras, Néhémie, Esther. Rapport final du Comité pour l'analyse textuelle de l'Ancien Testament hébreu institué par l'Alliance Biblique Universelle, établi en coopération avec Alexander R. Hulst †, Norbert Lohfink, William D. McHardy, H. Peter Rüger, coéditeur, James A. Sanders, coéditeur. 812 pages. 1982.

Bd. 50/2 DOMINIQUE BARTHÉLEMY: Critique textuelle de l'Ancien Testament. 2. Isaïe, Jérémie, Lamentations. Rapport final du Comité pour l'analyse textuelle de l'Ancien Testament hébreu institué par l'Alliance Biblique Universelle, établi en coopération avec Alexander $\mathrm{R}$. Hulst †, Norbert Lohfink, William D. McHardy, H. Peter Rüger, coéditeur, James A. Sanders, coéditeur. 1112 pages. 1986.

Bd. 50/3 DOMINIQUE BARTHÉLEMY: Critique textuelle de l'Ancien Testament. Tome 3. Ezéchiel, Daniel et les 12 Prophètes. Rapport final du Comité pour l'analyse textuelle de l'Ancien Testament hébreu institué par l'Alliance Biblique Universelle, établi en coopération avec Alexander R. Hulst $\dagger$, Norbert Lohfink, William D. McHardy, H. Peter Rügert $\dagger$, coéditeur, James A. Sanders, coéditeur. 1424 pages. 1992.

Bd. 52 MIRIAM LICHTHEIM: Late Egyptian Wisdom Literature in the International Context. A Study of Demotic Instructions. X-240 pages. 1983.

Bd. 53 URS WINTER: Frau und Göttin. Exegetische und ikonographische Studien zum weiblichen Gottesbild im Alten Israel und in dessen Umwelt. XVIII-928 Seiten, 520 Abbildungen.1987. 2. Auflage. Mit einem Nachwort zur 2. Auflage.

Bd. 54 PAUL MAIBERGER: Topographische und bistorische Untersucbungen zum Sinaiproblem. Worauf beruht die Identifizierung des Ğabal Mūsā mit dem Sinai? 189 Seiten, 13 Tafeln. 1984.

Bd. 55 PETER FREI / KLAUS KOCH: Reichsidee und Reichsorganisation im Perserreich. 352 Seiten, 17 Abbildungen. 1996. Zweite, bearbeitete und erweiterte Auflage.

Bd. 56 HANS-PETER MÜLLER: Vergleich und Metapher im Hohenlied. 59 Seiten. 1984.

Bd. 57 STEPHEN PISANO: Additions or Omissions in the Books of Samuel. The Significant Pluses and Minuses in the Massoretic, LXX and Qumran Texts. XIV-295 pages. 1984.

Bd. 58 ODO CAMPONOVO: Königtum, Königsherrschaft und Reich Gottes in den Frïhjüdischen Schriften. XVI-492 Seiten. 1984. 
Bd. 59 JAMES KARL HOFFMEIER: Sacred in the Vocabulary of Ancient Egypt. The Term DSR, with Special Reference to Dynasties I-XX. XXIV-281 pages, 24 figures. 1985.

Bd. 60 CHRISTIAN HERRMANN: Formen für ägyptische Fayencen. Katalog der Sammlung des Biblischen Instituts der Universität Freiburg Schweiz und einer Privatsammlung. XXVIII-199 Seiten. Mit zahlreichen Abbildungen im Text und 30 Tafeln. 1985.

Bd. 61 HELMUT ENGEL: Die Susanna-Erzäblung. Einleitung, Übersetzung und Kommentar zum Septuaginta-Text und zur Theodition-Bearbeitung. 205 Seiten + Anhang 11 Seiten. 1985.

Bd. 62 ERNST KUTSCH: Die chronologischen Daten des Ezechielbuches. 82 Seiten. 1985.

Bd. 63 MANFRED HUTTER: Altorientalische Vorstellungen von der Unterwelt. Literar- und religions geschichtliche Überlegungen zu «Nergal und Ereškigal». VIII-187 Seiten. 1985.

Bd. 64 HELGA WEIPPERT / KLAUS SEYBOLD / MANFRED WEIPPERT: Beiträge zur prophetischen Bildsprache in Israel und Assyrien. IX-93 Seiten. 1985.

Bd. 65 ABDEL-AZIZ FAHMY SADEK: Contribution à l'étude de l'Amdouat. Les variantes tardives du Livre de l'Amdouat dans les papyrus du Musée du Caire. XVI-400 pages, 175 illustrations. 1985.

Bd. 66 HANS-PETER STÄHLI: Solare Elemente im Jabweglauben des Alten Testamentes. X-60 Seiten. 1985.

Bd. 67 OTHMAR KEEL / SILVIA SCHROER: Studien zu den Stempelsiegeln aus PalästinalIsrael. Band I. 115 Seiten, 103 Abbildungen. 1985.

Bd. 68 WALTER BEYERLIN: Weisheitliche Vergewisserung mit Bezug auf den Zionskult. Studien zum 125. Psalm. 96 Seiten. 1985.

Bd. 69 RAPHAEL VENTURA: Living in a City of the Dead. A Selection of Topographical and Administrative Terms in the Documents of the Theban Necropolis. XII-232 pages.1986.

Bd. 70 CLEMENS LOCHER: Die Ehre einer Frau in Israel. Exegetische und rechtsvergleichende Studien zu Dtn 22, 13-21. XVIII-464 Seiten. 1986.

Bd. 71 HANS-PETER MATHYS: Liebe deinen Näcbsten wie dich selbst. Untersuchungen zum alttestamentlichen Gebot der Nächstenliebe (Lev 19,18). XII-204 Seiten. 1990. 2. verbesserte Auflage.

Bd. 72 FRIEDRICH ABITZ: Ramses III. in den Gräbern seiner Söbne. 156 Seiten, 31 Abbildungen. 1986

Bd. 73 DOMINIQUE BARTHÉLEMY / DAVID W. GOODING/JOHAN LUST/EMANUEL TOV: The Story of David and Goliath. 160 pages. 1986.

Bd. 74 SILVIA SCHROER: In Israel gab es Bilder. Nachrichten von darstellender Kunst im Alten Testament. XVI-553 Seiten, 146 Abbildungen. 1987.

Bd. 75 ALAN R. SCHULMAN: Ceremonial Execution and Public Rewards. Some Historical Scenes on New Kingdom Private Stelae. 296 pages, 41 figures. 1987.

Bd. 76 JOŽE KRAS̆OVEC: La justice (Sdq) de Dieu dans la Bible hébrä̈que et l'interprétation juive et chrétienne. 456 pages. 1988.

Bd. 77 HELMUT UTZSCHNEIDER: Das Heiligtum und das Gesetz. Studien zur Bedeutung der sinaitischen Heiligtumstexte (Ez 25-40; Lev 8-9). XIV-326 Seiten. 1988.

Bd. 78 BERNARD GOSSE: Isaie 13,1-14,23. Dans la tradition littéraire du livre d'Isaie et dans la tradition des oracles contre les nations. 308 pages. 1988.

Bd.79 INKE W. SCHUMACHER: Der Cott Sopdu - Der Herr der Fremdländer. XV1-364 Seiten, 6 Abbildungen. 1988. 
Bd. 80 HELLMUT BRUNNER: Das hörende Herz. Kleine Schriften zur Religions- und Geistes geschichte Ägyptens. Herausgegeben von Wolfgang Röllig. 449 Seiten, 55 Abbildungen. 1988.

Bd. 81 WALTER BEYERLIN: Bleilot, Brecheisen oder was sonst? Revision einer Amos-Vision. 68 Seiten. 1988.

Bd. 82 MANFRED HUT'T'ER: Bebexung, Entsiibnung und Heilung. Das Ritual der Tuunawiya für ein Königspaar aus mitteihethitischer Zeit (KBo XXI 1 - KUB IX 34 - KBo XXI 6). 186 Seiten. 1988.

Bd. 83 RAPHAEL GIVEON: Scarabs from Recent Excavations in Israel. 114 pages with numerous illustrations and 9 plates. 1988.

Bd. 84 MIRIAM LICHTHEIM: Ancient Egyptian Autobiograpbies chiefly of the Middle Kingdom. A Study and an Anthology. 200 pages, 10 pages with illustrations. 1988.

Bd. 85 ECKART OTTO: Rechtsgescbicbte der Redaktionen im Kodex Ešnunna und im "Bundesbuch». Eine redaktionsgeschichtliche und rechtsvergleichende Studie zu altbabylonischen und altisraelitischen Rechtsüberlieferungen. 220 Seiten. 1989.

Bd. 86 ANDRZEJ NIWINSKI: Studies on the Illustrated Theban Funerary Papyri of the 11 th and 10th Centuries B.C. 488 pages, 80 plates. 1989.

Bd. 87 URSULA SEIDL: Die babylonischen Kudurru-Reliefs. Symbole mesopotamischer Gottheiten. 236 Seiten, 33 Tafeln und 2 Tabellen. 1989.

Bd. 88 OTHMAR KEEL / HILDI KEEL-LEU / SILVIA SCHROER: Studien zu den Stempelsiegeln aus Palästina/Israel. Band II. 364 Seiten, 652 Abbildungen. 1989.

Bd. 89 FRIEDRICH ABITZ: Baugeschichte und Dekoration des Grabes Ramses' VI. 202 Seiten, 39 Abbildungen. 1989.

Bd. 90 JOSEPH HENNINGER SVD: Arabica varia. Aufsätze zur Kulturgeschichte Arabiens und seiner Randgebiete. Contributions à l'histoire culturelle de l'Arabie et de ses régions limitrophes. 504 pages. 1989.

Bd. 91 GEORG FISCHER: Jabwe unser Gott. Sprache, Aufbau und Erzähltechnik in der Berufung des Mose (Ex. 3-4). 276 Seiten. 1989.

Bd. 92. MARK A. O'BRIEN: The Deuteronomistic History Hypothesis: A Reassessment. 340 pages. 1989.

Bd. 93 WALTER BEYERLIN: Reflexe der Amosvisionen im Jeremiabuch. 120 Seiten. 1989.

Bd. 94 ENZO CORTESE: Josua 13-21. Ein priesterschriftlicher Abschnitt im deuteronomistischen Geschichtswerk. 136 Seiten. 1990.

Bd. 96 ANDRÉ WIESE: Zum Bild des Königs auf ägyptischen Siegelamuletten. 264 Seiten. Mit zahlreichen Abbildungen im Text und 32 Tafeln. 1990.

Bd.97 WOLFGANG ZWICKEL: Räucherkult und Räuchergeräte. Exegetische und archäologische Studien zum Räucheropfer im Alten Testament. 372 Seiten. Mit zahlreichen Abbildungen im Text. 1990

Bd. 98 AARON SCHART: Mose und Israel im Konflikt. Eine redaktionsgeschichtliche Studie zu den Wüstenerzählungen. 296 Seiten. 1990.

Bd. 99 THOMAS RÖMER: Israels Väter. Untersuchungen zur Väterthematik im Deuteronomium und in der deuteronomistischen Tradition. 664 Seiten. 1990.

Bd. 100 OTHMAR KEEL / MENAKHEM SHUVAL / CHRISTOPH UEHLINGER: Studien $z u$ den Stempelsiegeln aus Palästina / Israel Band III. Die Frühe Eisenzeit. Ein Workshop. XIV-456 Seiten. Mit zahlreichen Abbildungen im Text und 22 Tafeln. 1990.

Bd. 101 CHRISTOPH UEHLINGER: Weltreich und «eine Rede». Eine neue Deutung der sogenannten Turmbauerzählung (Gen 11,1-9). XVI-654 Seiten.1990. 
Bd. 102 BENJAMIN SASS: Studia Alphabetica. On the Origin and Early History of the Northwest Semitic, South Semitic and Greek Alphabets. X-120 pages. 16 pages with illustrations. 2 tables. 1991.

Bd. 103 ADRIAN SCHENKER: Text und Sinn im Alten Testament. Textgeschichtliche und bibeltheologische Studien. VIII-312 pages. 1991.

Bd. 104 DANIEL BODI: The Book of Ezekiel and the Poem of Erra. IV-332 pages. 1991.

Bd. 105 YUICHI OSUMI: Die Kompositionsgeschichte des Bundesbuches Exodus 20,22b-23,33. XII-284 Seiten. 1991.

Bd. 106 RUDOLF WERNER: Kleine Einfübrung ins Hieroglyphen-Luwische. XII-112 Seiten. 1991.

Bd. 107 THOMAS STAUBLI: Das Image der Nomaden im Alten Israel und in der Ikonographie seiner sesshaften Nacbbarn. XII-408 Seiten. 145 Abb. und 3 Falttafeln. 1991.

Bd. 108 MOSHÉ ANBAR: Les tribus amurrites de Mari. VIII-256 pages. 1991.

Bd. 109 GÉRARD J. NORTON / STEPHEN PISANO (eds.): Tradition of the Text. Studies offered to Dominique Barthélemy in Celebration of his 70th Birthday. 336 pages. 1991.

Bd. 110 HILDI KEEL-LEU: Vorderasiatische Stempelsiegel. Die Sammlung des Biblischen Instituts der Universität Freiburg Schweiz. 180 Seiten. 24 Tafeln. 1991.

Bd. 111 NORBERT LOHFINK: Die Väter Israels im Deuteronomium. Mit einer Stellungnahme von Thomas Römer. 152 Seiten. 1991.

Bd. 113 CHARLES MAYSTRE: Les grands prêtres de Ptab de Memphis. XIV-474 pages, 2 planches. 1992.

Bd. 114 THOMAS SCHNEIDER: Asiatische Personennamen in ägyptischen Quellen des Neuen Reiches. 480 Seiten. 1992.

Bd. 115 ECKHARD VON NORDHEIM: Die Selbstbehauptung Israels in der Welt des Alten Orients. Religionsgeschichtlicher Vergleich anhand von Gen 15/22/28, dem Aufenthalt Israels in Ägypten, 2 Sam 7, 1 Kön 19 und Psalm 104. 240 Seiten. 1992.

Bd. 116 DONALD M. MATTHEWS: The Kassite Glyptic of Nippur. 208 pages. 210 figures. 1992.

Bd. 117 FIONA V. RICHARDS: Scarab Seals from a Middle to Late Bronze Age Tomb at Pella in Jordan. XII-152 pages, 16 plates. 1992.

Bd. 118 YOHANAN GOLDMAN: Prophétie et royauté au retour de l'exil. Les origines littéraires de la forme massorétique du livre de Jérémie. XIV-270 pages. 1992.

Bd. 119 THOMAS M. KRAPF: Die Priesterschrift und die vorexilische Zeit. Yehezkel Kaufmanns vernachlässigter Beitrag zur Geschichte der biblischen Religion. XX-364 Seiten. 1992.

Bd. 120 MIRIAM LICHTHEIM: Maat in Egyptian Autobiographies and Related Studies. 236 pages, 8 plates. 1992.

Bd. 121 ULRICH HÜBNER: Spiele und Spielzeug im antiken Palästina. 256 Seiten. 58 Abbildungen. 1992.

Bd. 122 OTHMAR KEEL: Das Recht der Bilder, gesehen zu werden. Drei Fallstudien zur Methode der Interpretation altorientalischer Bilder. 332 Seiten, 286 Abbildungen. 1992. 
Bd. 123 WOLFGANG ZWICKEL (Hrsg.): Biblische Welten. Festschrift für Martin Metzger zu seinem 65. Geburtstag. 268 Seiten, 19 Abbildungen. 1993.

Bd. 125 BENJAMIN SASS / CHRISTOPH UEHLINGER (eds.): Studies in the Iconography of Northwest Semitic Inscribed Seals. Proceedings of a symposium held in Fribourg on April 17-20, 1991. 368 pages, 532 illustrations. 1993.

Bd. 126 RÜDIGER BARTELMUS / THOMAS KRÜGER / HELMUT UTZSCHNEIDER (Hrsg.): Konsequente Traditionsgeschichte. Festschrift für Klaus Baltzer zum 65. Geburtstag. 418 Seiten. 1993.

Bd. 127 ASKOLD I. IVANTCHIK: Les Cimmériens au Proche-Orient. 336 pages. 1993.

Bd. 128 JENS VOSS: Die Menora. Gestalt und Funktion des Leuchters im Tempel zu Jerusalem. 124 Seiten. 1993.

Bd. 129 BERND JANOWSKI / KLAUS KOCH / GERNOT WILHELM (Hrsg.): Religionsgeschichtliche Beziehungen zwischen Kleinasien, Nordsyrien und dem Alten Testament. Internationales Symposion Hamburg 17.-21. März 1990. 572 Seiten. 1993.

Bd. 130 NILI SHUPAK: Where can Wisdom be found? The Sage's Language in the Bible and in Ancient Egyptian Literature. XXXII-516 pages. 1993.

Bd. 131 WALTER BURKERT / FRITZ STOLZ (Hrsg.): Hymnen der Alten Welt im Kulturvergleich. 134 Seiten. 1994.

Bd. 132 HANS-PETER MATHYS: Dichter und Beter. Theologen aus spätalttestamentlicher Zeit. 392 Seiten. 1994.

Bd. 133 REINHARD G. LEHMANN: Friedrich Delitzsch und der Babel-Bibel-Streit. 472 Seiten, 13 Tafeln. 1994.

Bd. 134 SUSANNE BICKEL: La cosmogonie égyptienne avant le Nouvel Empire. 360 pages. 1994.

Bd. 135 OTHMAR KEEL: Studien zu den Stempelsiegeln aus Palästina/Israel. Band IV. Mit Registern zu den Bänden I-IV. XII-340 Seiten mit Abbildungen, 24 Seiten Tafeln. 1994.

Bd. 136 HERMANN-JOSEF STIPP: Das masoretische und alexandrinische Sondergut des Jeremiabuches. Textgeschichtlicher Rang, Eigenarten, Triebkräfte. VII-196 Seiten. 1994.

Bd. 137 PETER ESCHWEILER: Bildzauber im alten Ägypten. Die Verwendung von Bildern und Gegenständen in magischen Handlungen nach den Texten des Mittleren und Neuen Reiches. X-380 Seiten, 28 Seiten Tafeln. 1994.

Bd. 138 CHRISTIAN HERRMANN: Ägyptische Amulette aus Palästinallsrael. Mit einem Ausblick auf ihre Rezeption durch das Alte Testament. XXIV-1000 Seiten, 70 Seiten Bildtafeln. 1994.

Bd. 139 WALTER DIETRICH / MARTIN A. KLOPFENSTEIN (Hrsg.): Ein Gott allein? JHWHVerehrung und biblischer Monotheismus im Kontext der israelitischen und altorientalischen Religionsgeschichte. 616 Seiten. 1994.

Bd. 140 IZAK CORNELIUS: The Iconography of the Canaanite Gods Reshef and Bacal. Late Bronze and Iron Age I Periods (c 1500 - 1000 BCE). XII-326 pages with illustrations, 56 plates. 1994.

Bd. 141 JOACHIM FRIEDRICH QUACK: Die Lebren des Ani. Ein neuägyptischer Weisheitstext in seinem kulturellen Umfeld. X-344 Seiten, 2 Bildtafeln. 1994.

Bd. 142 ORLY GOLDWASSER: From Icon to Metaphor. Studies in the Semiotics of the Hieroglyphs. X-194 pages. 1995. 
Bd. 143 KLAUS BIEBERSTEIN: Josua-Jordan-Jericho. Archäologie, Geschichte und Theologie der Landnahmeerzählungen Josua 1-6. XII-494 Seiten. 1995.

Bd. 144 CHRISTL MAIER: Die «fremde Frau» in Proverbien 1-9. Eine exegetische und sozialgeschichtliche Studie. X II-304 Seiten. 1995.

Bd. 145 HANS ULRICH STEYMANS: Deuteronium 28 und die adê zur Thronfolgeregelung Asarhaddons. Segen und Fluch im Alten Orient und in Israel. XII-436 Seiten. 1995.

Bd. 146 FRIEDRICH ABITZ: Pharao als Gott in den Unterweltsbiichern des Neuen Reiches. VIII-228 Seiten. 1995.

Bd. 147 GILLES ROULIN: Le Livre de la Nuit. Une composition égyptienne de l'au-delà. Ire partie: Traduction et commentaire. XX -420 pages. IIe partie: Copie synoptique. X-169 pages, 21 cartes. 1996.

Bd. 148 MANUEL BACHMANN: Die strukturalistische Artefakt- und Kunstanalyse. Exposition der Grundlagen anhand der vorderorientalischen, ägyptischen und griechischen Kunst. 88 Seiten mit 40 Abbildungen. 1996.

Bd. 149 PIETRO PIFFARETTI: Et de leurs épées ils feront des socs. Analyse littéraire et théologique d'Isaïe 2,1-5. Ca.130 pages. 1996.

Bd. 150 ELISABETH STAEHLIN / BERTRAND AEGER (Hrsg.) Ägypten-Bilder. Akten des «Symposiums zur Ägypten-Rezeption», Augst bei Basel, vom 9.-11. September 1993. Ca. 350 Seiten. 1996.

Bd. 151 DAVID A.WARBURTON: State and Economy in Ancient Egypt. Fiscal Vocabulary of the New Kingdom. 392 pages. 1996.

Bd. 152 FRANÇOIS ROSSIER SM: L'intercession entre les hommes dans la Bible hébraïque. L'intercession entre les hommes aux origines de l'intercession auprès de Dieu. 408 pages. 1996. 


\section{ORBIS BIBLICUS ET ORIENTALIS, SERIES ARCHAEOLOGICA}

Bd. 1 JACQUES BRIEND / JEAN-BAPTISTE HUMBERT (Ed.), Tell Keisan (1971-1976). Une cité phénicienne en Galilée. 392 pages, 142 planches. 1980.

Bd. 2 BERTRAND JAEGER, Essai de classification et datation des scarabées Menkbéperré. 455 pages avec 1007 illustrations, 26 planches avec 443 figures. 1982.

Bd. 3 RAPHAEL GIVEON, Egyptian Scarabs from Western Asia from the Collections of the British Museum. 202 pages, 457 figures. 1985.

Bd.4 SEYYARE EICHLER / MARKUS WÄFLER, Tall al-Hamidiya 1. Vorbericht 1984. 360 Seiten, 104 Tafeln, 4 Seiten Illustrationen, 4 Faltpläne, 1 vierfarbige Tafel. 1985.

Bd. 5 CLAUDIA MÜLLER-WINKLER, Die ägyptischen Objekt-Amulette. Mit Publikation der Sammlung des Biblischen Instituts der Universität Freiburg Schweiz, ehemals Sammlung Fouad S. Matouk. 590 Seiten, 40 Tafeln. 1987.

Bd. 6 SEYYARE EICHLER / MARKUS WÄFLER / DAVID WARBURTON, Tall al-Hamidiya 2. Symposium Recent Excavations in the Upper Khabur Region, 492 Seiten, 20 Seiten Illustrationen, 2 Falttafeln, 1 vierfarbige Tafel. 1990.

Bd. 7 HERMANN A. SCHLÖGL / ANDREAS BRODBECK, Ägyptische Totenfiguren aus öffentlichen und privaten Sammlungen der Schweiz, 356 Seiten mit 1041 Photos. 1990.

Bd. 8 DONALD M. MATTHEWS, Principles of composition in Near Eastern glyptic of the later second millennium B.C., 176 pages, 39 pages with drawings, 14 plates. 1990.

Bd. 9 CLAUDE DOUMET, Sceaux et cylindres orientaux: la collection Chiba. Préface de Pierre Amiet. 220 pages, 24 pages d'illustrations. 1992.

Bd. 10 OTHMAR KEEL, Corpus der Stempelsiegel-Amulette aus Palästina/Israel. Von den Anfängen bis zur Perserzeit. Einleitung. 376 Seiten mit 603 Abbildungen im Text. 1995.

Bd. 11 BEATRICE TEISSIER, Egyptian Iconography on Syro-Palestinian Cylinder Seals of the Middle Bronze Age. XII-224 pages with numerous illustrations, 5 plates. 1996.

Bd. 12 ANDRÉ B. WIESE, Die Anfänge der ägyptischen Stempelsiegel-Amulette. Eine typologische und religionsgeschichtliche Untersuchung zu den «Knopfsiegeln» und verwandten Objekten der 6. bis frühen 12. Dynastie. XXII-366 Seiten mit 1426 Abbildungen. 1996. 


\section{Summary}

Combining philological investigation and theoretical reasoning, this book offers a completely new interpretation of the economic role of the state in ancient Egypt. The first part provides background outlining the relevance of Keynes's General Theory to the ancient Egyptian economy. The central part uses ancient Egyptian texts as the foundation of an analysis of words commonly assumed to relate to taxation during the New Kingdom (c. 1540-1070 B.C.E.). The conclusions summarize the philological results and explore the role of the temples in the ancient Egyptian state during the New Kingdom. The result places ancient Egyptian taxation and state economic activity in an Egyptian economy based on an analysis of primary sources.

The book is thus directed at a broad audience including Egyptologists and all scholars interested in economic history in general and the political development of early antiquity in particular. 